\title{
Nutrients in the Nation's Streams and Groundwater, 1992-2004
}

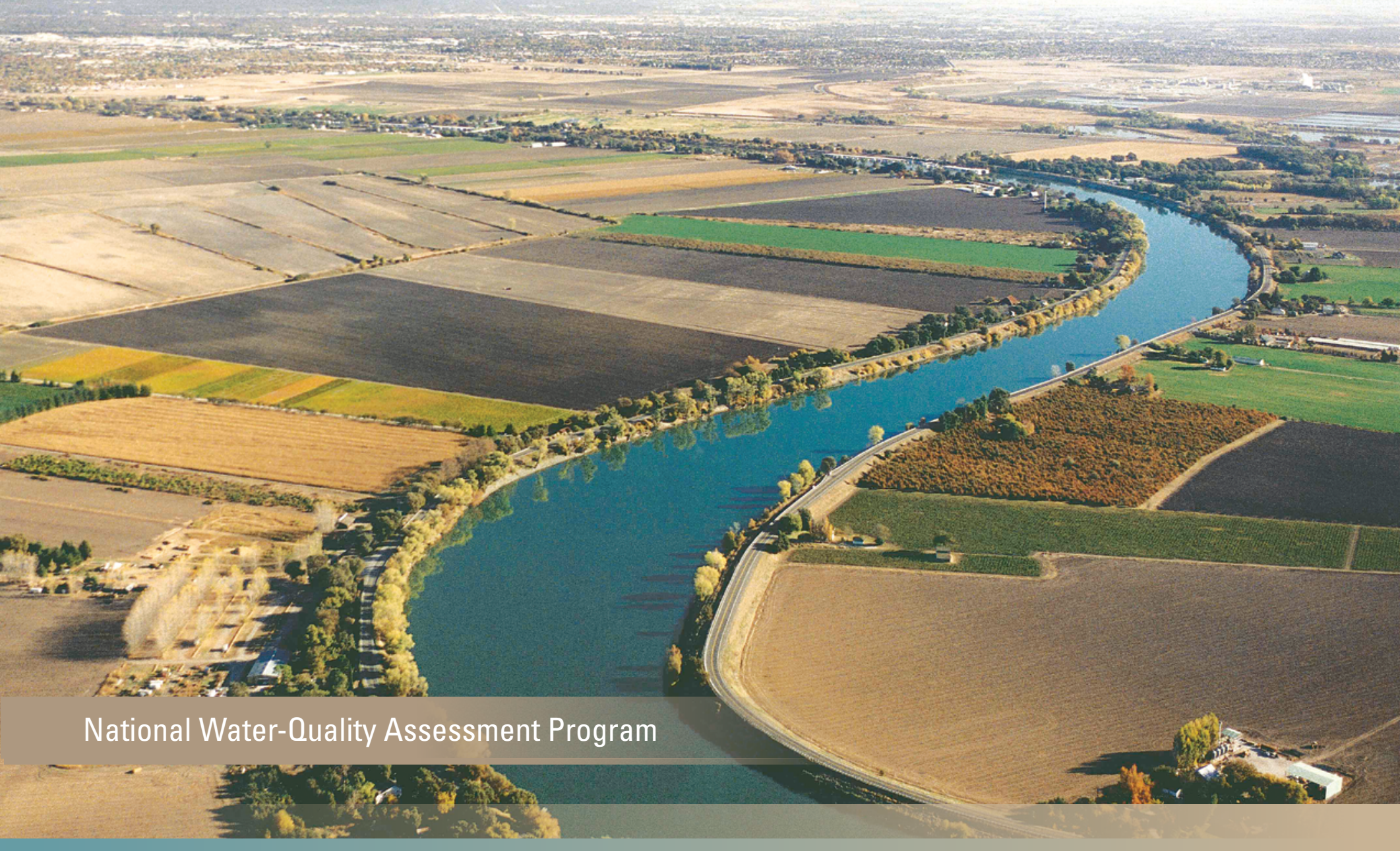

Circular 1350

U.S. Department of the Interior

U.S. Geological Survey 
Cover: Aerial view of the Sacramento River in the Sacramento Valley, California. Photograph taken by Rand Schaal, Ph.D., pilot and photographer. 


\section{The Quality of Our Nation's Water- Nutrients in the Nation's Streams and Ground water, 1992-2004}

By Neil M. Dubrovsky, Karen R. Burow, Gregory M. Clark, Jo Ann M. Gronberg, Pixie A. Hamilton, Kerie J. Hitt, David K. Mueller, Mark D. Munn, Bernard T. Nolan, Larry J. Puckett, Michael G. Rupert,

Terry M. Short, Norman E. Spahr, Lori A. Sprague, and William G. Wilber

National Water-Quality Assessment Program

Circular 1350 


\section{U.S. Department of the Interior KEN SALAZAR, Secretary}

\section{U.S. Geological Survey Marcia K. McNutt, Director}

\section{U.S. Geological Survey, Reston, Virginia: 2010}

For more information on the USGS - the Federal source for science about the Earth, its natural and living resources, natural hazards, and the environment, visit http://www.usgs.gov or call 1-888-ASK-USGS

For an overview of USGS information products, including maps, imagery, and publications, visit http://www.usgs.gov/pubprod

To order this and other USGS information products, visit http://store.usgs.gov

Any use of trade, product, or firm names is for descriptive purposes only and does not imply endorsement by the U.S. Government.

Although this report is in the public domain, permission must be secured from the individual copyright owners to reproduce any copyrighted materials contained within this report.

\section{Suggested reference:}

Dubrovsky, N.M., Burow, K.R., Clark, G.M., Gronberg, J.M., Hamilton P.A., Hitt, K.J., Mueller, D.K., Munn, M.D., Nolan, B.T., Puckett, L.J., Rupert, M.G., Short, T.M., Spahr, N.E., Sprague, L.A., and Wilber, W.G., 2010, The quality of our Nation's waters-Nutrients in the Nation's streams and groundwater, 1992-2004: U.S. Geological Survey Circular 1350, 174 p. Additional information about this study is available at http://water.usgs.gov/nawqa/nutrients/pubs/circ1350

\section{Library of Congress Cataloging-in-Publication Data}

The quality of our Nation's waters : nutrients in the Nation's streams and groundwater, 1992-2004 / by N.M. Dubrovsky, K.R. Burow, G.M. Clark, J.M. Gronberg, P.A. Hamilton, K.J. Hitt, D.K. Mueller, M.D. Munn, B.T. Nolan, L.J. Puckett, M.G. Rupert, T.M. Short, N.E. Spahr, L.A. Sprague, and W.G. Wilber.

p. cm. -- (Circular ; 1350)

ISBN 978-1-4113-2904-1

1. Nutrient pollution of water--United States. 2. Water--Nitrogen content--United States.

3. Water--Phosphorus content--United States. I. Dubrovsky, N. M. II. Geological Survey (U.S.)

III. Title: The quality of our Nation's waters: nutrients in the Nation's streams and groundwater, 1992-2004. IV. Series: U.S. Geological Survey circular ; 1350.

TD427.N87N875 2010

$363.739 ' 0904--d c 22$ 


\section{Foreword}

The U.S. Geological Survey (USGS) is committed to providing the Nation with reliable scientific information that helps to enhance and protect the overall quality of life and that facilitates effective management of water, biological, energy, and mineral resources (http://www. usgs.gov/). Information on the Nation's water resources is critical to ensuring long-term availability of water that is safe for drinking and recreation and is suitable for industry, irrigation, and fish and wildlife. Population growth and increasing demands for water make the availability of that water, now measured in terms of quantity and quality, even more essential to the long-term sustainability of our communities and ecosystems.

The USGS implemented the National Water-Quality Assessment (NAWQA) Program in 1991 to support national, regional, state, and local information needs and decisions related to water-quality management and policy (http://water.usgs.gov/nawqa). The NAWQA Program is designed to answer: What is the quality of our Nation's streams and groundwater? How are conditions changing over time? How do natural features and human activities affect the quality of streams and groundwater, and where are those effects most pronounced? By combining information on water chemistry, physical characteristics, stream habitat, and aquatic life, the NAWQA Program aims to provide science-based insights for current and emerging water issues and priorities. From 1991 to 2001, the NAWQA Program completed interdisciplinary assessments and established a baseline understanding of waterquality conditions in 51 of the Nation's river basins and aquifers, referred to as Study Units (http://water.usgs.gov/nawqa/studyu.html).

National and regional assessments are ongoing in the second decade (2001-2012) of the NAWQA Program as 42 of the 51 Study Units are selectively reassessed. These assessments extend the findings in the Study Units by determining status and trends at sites that have been consistently monitored for more than a decade, and filling critical gaps in characterizing the quality of surface water and groundwater. For example, increased emphasis has been placed on assessing the quality of source water and finished water associated with the Nation's community water systems. During the second decade, NAWQA is addressing five national priority topics that build an understanding of how natural features and human activities affect water quality and establish links between sources of contaminants, the transport of those contaminants through the hydrologic system, and the potential effects of contaminants on humans and aquatic ecosystems. Included are studies of the fate of agricultural chemicals, effects of urbanization on stream ecosystems, bioaccumulation of mercury in stream ecosystems, effects of nutrient enrichment on aquatic ecosystems, and transport of contaminants to public-supply wells. In addition, national syntheses of information on pesticides, volatile organic compounds (VOCs), nutrients, trace elements, and aquatic ecology are continuing.

The USGS aims to disseminate credible, timely, and relevant science information to address practical and effective water-resource management and strategies that protect and restore water quality. We hope this NAWQA publication will provide you with insights and information to meet your needs, and will foster increased citizen awareness and involvement in the protection and restoration of our Nation's waters.

The USGS recognizes that a national assessment by a single program cannot address all water-resource issues of interest. External coordination at all levels is critical for cost-effective management, regulation, and conservation of our Nation's water resources. The NAWQA Program, therefore, depends on advice and information from other agencies — federal, state, regional, interstate, tribal, and local—as well as nongovernmental organizations, industry, academia, and other stakeholder groups. Your assistance and suggestions are greatly appreciated.

Matthew C. Larsen

Associate Director for Water 


\section{The Ouality of Our Nation's Waters}

This report is one of a series of publications, The Quality of Our Nation's Waters, which describes major findings of the NAWQA Program on water-quality issues of regional and national concern. This report presents an assessment of the occurrence and distribution of nutrients in the Nation's streams and groundwater based on water-quality data from about 500 streams and over 5,000 wells collected from 1992 through 2001. Other topics addressed include the relation of nutrient conditions to aquatic life in streams, changes in nutrient conditions from 1988 through 2004, and implications for future changes. Other reports in this series focus on additional waterquality constituents of concern such as pesticides and volatile organic compounds in streams and groundwater, the effects of contaminants and habitat on the condition of aquatic communities in streams, and on the quality of untreated water from private domestic and public supply wells. Each report builds toward a more comprehensive understanding of the quality of regional and national water resources.

The information in this series is intended primarily for those interested or involved in resource management and protection, conservation, regulation, and policymaking at regional and national levels. In addition, the information is relevant to those at a local level who wish to know more about the general quality of streams and groundwater in areas near where they live and how that quality compares with other areas across the Nation.

Donna N. Myers

Chief, Office of Water Quality

U.S. Geological Survey 


\section{Contents}

Chapter 1. National Findings and Their Implications ..................................................... 1

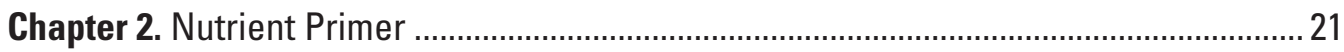

Chapter 3. NAWQA's Approach to Nutrient Assessment .................................................... 41

Chapter 4. Occurrence and Distribution of Nutrients in Streams and Groundwater..........51

Chapter 5. Exchange of Nutrients between Surface Water and Groundwater ................. 85

Chapter 6. Potential for Effects on Human Health .......................................................... 101

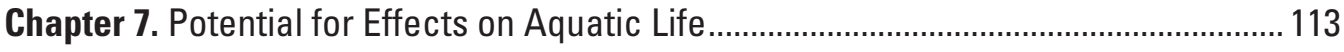

Chapter 8. Changes in Nutrient Concentrations: Past and Predicted............................. 131

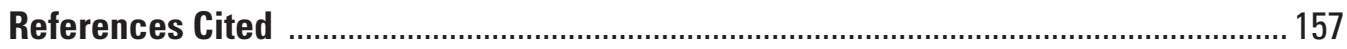

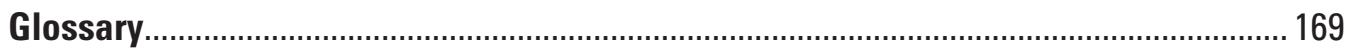

Abbreviations, Acronyms, and Units of Measure …............................................. 174 
This page intentionally left blank. 


\section{Chapter}

\section{National Findings and Their Implications}

\author{
Although the use of artificial \\ fertilizer has supported increasing \\ food production to meet the needs of \\ a growing population, increases in \\ nutrient loadings from agricultural \\ and, to a lesser extent, urban \\ sources have resulted in nutrient \\ concentrations in many streams and \\ parts of aquifers that exceed standards \\ for protection of human health and \\ (or) aquatic life, often by large margins.
}

\section{Do NAWQA findings substantiate national concerns for aquatic and human health?}

National Water-Quality Assessment (NAWQA) findings indicate that nutrient concentrations in streams and groundwater in basins with significant agricultural or urban development are substantially greater than naturally occurring or "background" levels. For example, median concentrations of total nitrogen and phosphorus in agricultural streams are about 6 times greater than background levels. Findings also indicate that concentrations in streams routinely were 2 to 10 times greater than regional nutrient criteria recommended by the U.S. Environmental Protection Agency (USEPA) to protect aquatic life. Such large differences in magnitude suggest that significant reductions in sources of nutrients, as well as greater use of land management strategies to reduce the transport of nutrients to streams, are needed to meet recommended criteria for streams draining areas with significant agricultural and urban development.

Nitrate concentrations above the Federal drinking-water standard — or Maximum Contaminant Level (MCL) — of 10 milligrams per liter (mg/L, as nitrogen) are relatively uncommon in samples from streams used for drinking water or from relatively deep aquifers; the MCL is exceeded, however, in more than 20 percent of shallow (less than 100 feet below the water table) domestic wells in agricultural areas. This finding raises concerns for human health in rural agricultural areas where shallow groundwater is used for domestic supply and may warn of future contamination of deeper groundwater pumped from public-supply wells.

\section{Are levels of nutrients in water increasing or decreasing?}

A decadal assessment of trends in concentrations of nitrogen and phosphorus from about 1993 to 2003 shows minimal changes in those concentrations in the majority of studied streams across the Nation, and more upward than downward trends in concentrations at sites with changes. These findings underscore the need for reductions in nutrient inputs or management strategies that would reduce transport of nutrients to streams. Upward trends were evident among all land uses, including those only minimally affected by agricultural and (or) urban development, which suggests that additional protection of some of our Nation's most pristine streams warrants consideration.

The median of nitrate concentrations in groundwater from 495 wells also increased significantly from 3.2 to $3.4 \mathrm{mg} / \mathrm{L}$ (6 percent) during about the same period, and the proportion of wells with concentrations of nitrate greater than the MCL increased from 16 to 21 percent. Nitrate concentrations in water in deep aquifers are likely to increase during the next decade as shallow groundwater with elevated concentrations moves downward. The potential for future contamination of the deep aquifers requires attention because these aquifers commonly are used for public water supply, and because restoration of groundwater is costly and difficult.

Long-term and consistent monitoring of nutrients, improved accounting of nutrient sources, and improved tracking and modeling of climatic and landscape changes will be essential for distinguishing trends in nutrient concentrations, understanding the causes of those trends, and accurately tracking the effectiveness of strategies implemented to manage nutrients. 


\section{Introduction}

New results-through monitoring and modeling - confirm and expand findings from earlier NAWQA studies.

This report is based on water-quality assessments conducted from 1992 through 2001 in 51 major hydrologic systems across the Nation (referred to as Study Units) by the U.S. Geological Survey's (USGS) National Water-Quality Assessment (NAWQA) Program. The assessments were conducted using a nationally consistent approach in 20 Study Units during 1992-1995; in 16 Study Units during 1996-1998; and in 15 Study Units during 1998-2001. A regional study of groundwater in the High Plains Aquifer continued into 2004, and additional special studies and trends assessments took place during 2002-2004.

Five measures of nitrogen- and phosphorus-containing nutrients are discussed in this report, including nitrate, ammonia, total nitrogen, orthophosphate, and total phosphorus. Samples for analysis of nutrients in water were collected at 499 stream sites throughout the year, including high-flow and low-flow conditions. Most analyses in this report are based on 2 years of monthly data for each site. Sampling at a subset of sites was more intensive during the time of highest runoff and use of agricultural chemicals - generally weekly or twice monthly for a 4- to 9-month period.

Dissolved nutrients were analyzed in water samples from 5,101 wells, including monitoring, domestic, and public-supply wells. Unlike stream monitoring sites, which were sampled multiple times, wells were sampled only once because of the comparatively slow rate of change in most groundwater systems, relative to streams. Data analyses were based on one sample per well.

Sampling sites for streams and groundwater were selected among geographic areas that represent a wide range of physiographic and climatic settings, as well as different land uses associated with a variety of contaminant sources, including agricultural, urban, and natural sources. These broad land-use categories include a multitude of landscape modifications and land-management strategies. Shallow groundwater (generally less than 20 feet below the water table) was sampled in agricultural, urban, and undeveloped areas, whereas deeper groundwater was sampled from wells that tap major aquifers, most of which are affected by a mixture of land uses and are important as potential sources of drinking water.

This analysis of NAWQA results builds upon an initial national assessment of nutrients in streams and groundwater that was based on results from investigations in NAWQA's first 20 Study Units (summarized in the first report of this series, U.S. Geological Survey, 1999). The more extensive data and expanded geographic coverage available for this report reinforce many of the previously reported findings, allow more detailed analyses of each topic, and support new analyses, including: (1) development of statistical models that extend the results from targeted NAWQA studies to areas of the Nation that have not been sampled; (2) evaluation of decadal changes in concentrations of nutrients in streams and groundwater along with modeled estimates for future trends; and (3) comparison of observed and modeled nutrient concentrations in streams to USEPA recommended nutrient criteria.

Findings are summarized for major aspects of the occurrence of nutrients, groundwater and surface water interactions, implications for human and aquatic health, and changes in nutrients over time. Each topic is identified with the chapter in this report in which more detailed results, explanations, and references are provided. Key implications and applications to water-quality management are also summarized for each topic. The NAWQA approach and design are summarized in Chapter 3 , and details on data-analysis methods, as well as all data used in this report, are available at http://water.usgs. gov/nawqa/nutrients/pubs/circ1350. 


\section{Occurrence and Distribution of Nutrients in Streams and Groundwater}

Significantly elevated concentrations of nutrients are widespread in streams and groundwater in areas of substantial agricultural and urban development. Concentrations vary in streams and groundwater across the Nation because of natural features and human activities that affect the sources and transport among different landscapes and during different seasons (Chapter 4).

Concentrations of all five nutrients - nitrate, ammonia, total nitrogen, orthophosphate, and total phosphorus - exceeded background levels at more than 90 percent of 190 streams draining agricultural and urban watersheds. Nitrate concentrations exceeded background levels in 64 percent of 86 shallow aquifer studies sampled in agricultural and urban areas. Concentrations of other nutrients in groundwater were not greater than background levels in most areas; phosphorus tends to be relatively insoluble in water and thus sorbs onto soils and aquifer materials, and the other forms of nitrogen are readily transformed by microbes to nitrate or nitrogen gas.

Concentrations of total nitrogen were higher in agricultural streams than in streams draining urban, mixed land use, or undeveloped areas, with a median concentration of about $4 \mathrm{mg} / \mathrm{L}$, about 6 times greater than background levels (fig. 1-1). The highest concentrations of nitrogen in agricultural streams generally occurred in the Northeast, Midwest, and the Northwest (fig. 1-2), where some of the largest amounts of fertilizer and manure in the Nation are applied to soils.

Agricultural practices influence the transport of nutrients in streams draining large areas of the United States. Such practices include (1) the prevalent use of tile drains and ditches in the Midwest, which help to drain clay-rich soils, facilitating the transport of nutrients to streams; and (2) intensive irrigation and large amounts of irrigation-return flow, such as in the Northwest, which can carry substantial amounts of nutrients to streams. Streams in agricultural areas in the Southeast had relatively lower concentrations of nitrogen than streams in other parts of the
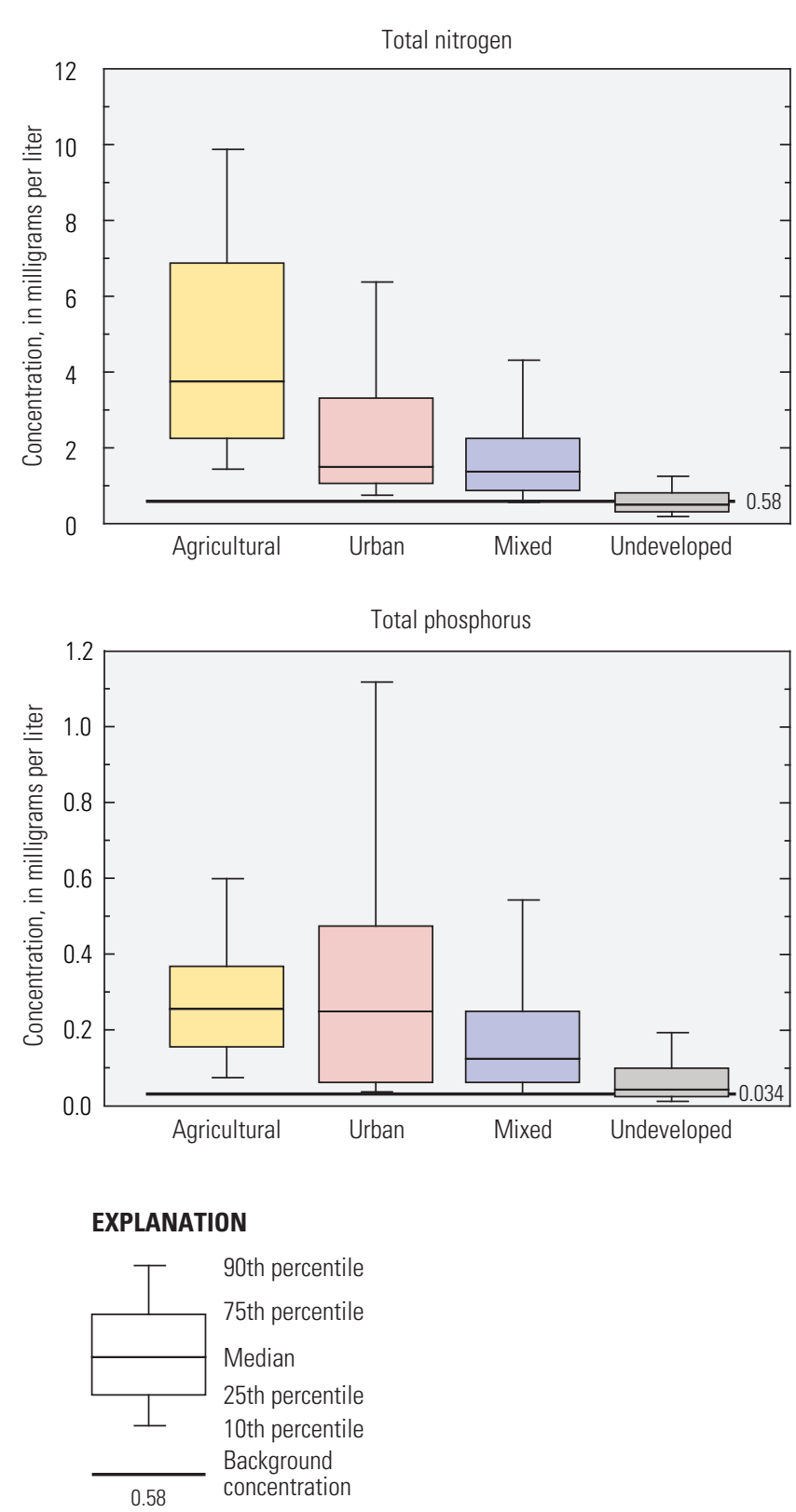

Figure 1-1. Concentrations of total nitrogen were highest in agricultural streams, with a median concentration of about $4 \mathrm{mg} / \mathrm{L}$ (about 6 times greater than background levels), whereas concentrations of total phosphorus were similar in agricultural and urban streams, with a median concentration of about $0.25 \mathrm{mg} / \mathrm{L}$ (also about 6 times greater than background levels).

country, partly because soil and hydrologic characteristics support greater losses of nitrogen through biological uptake and denitrification before overland flow or shallow groundwater reaches streams. 


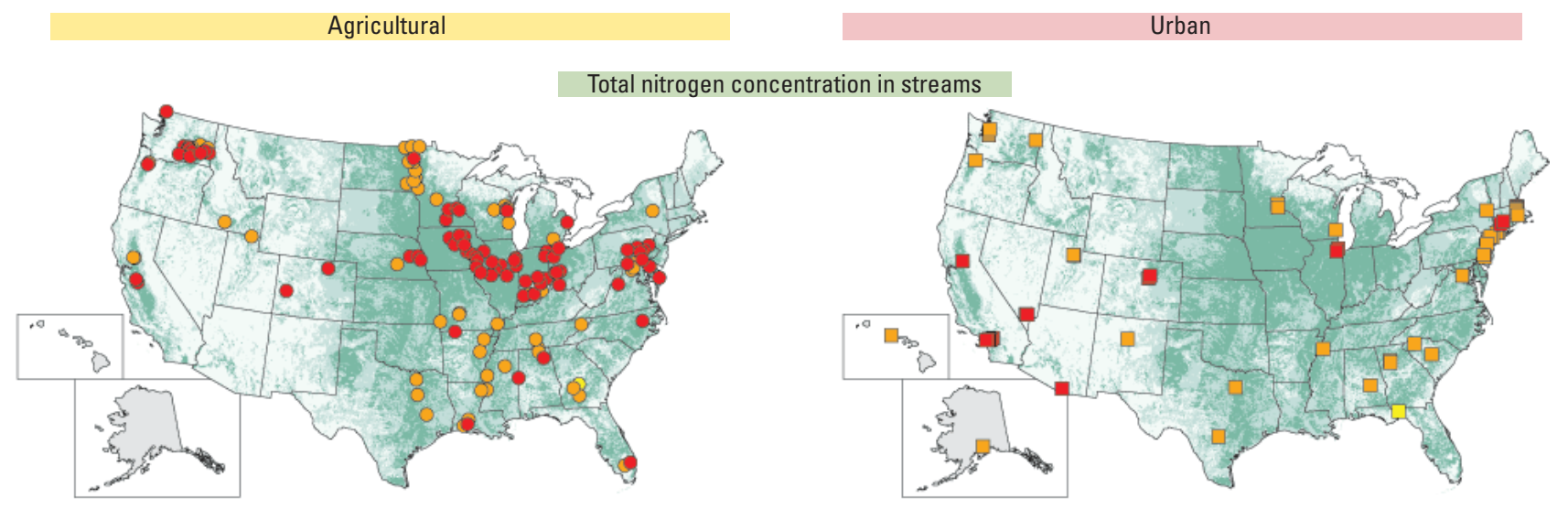

Total phosphorus concentration in streams
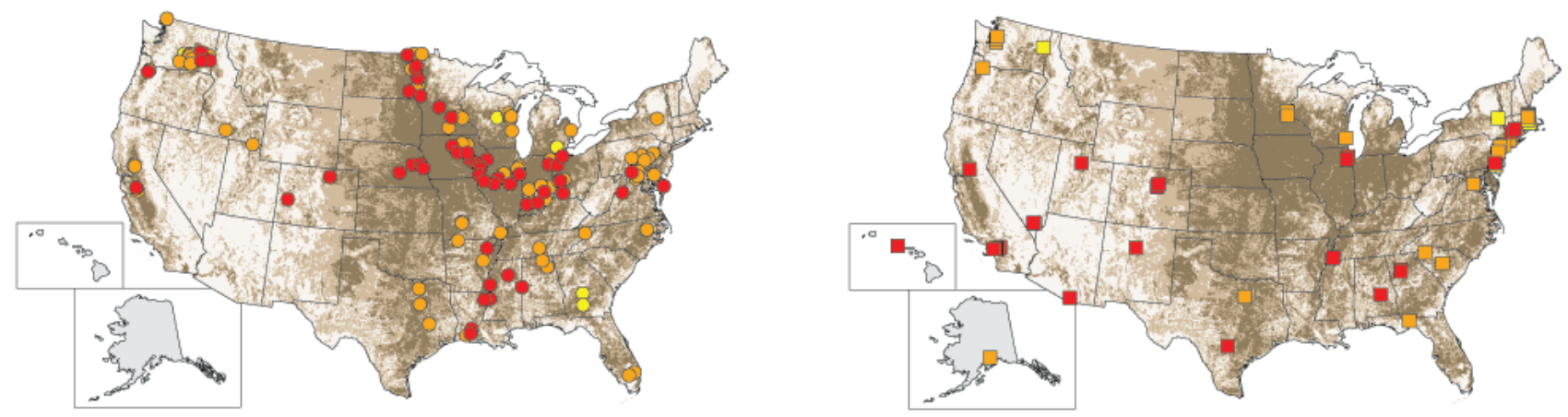

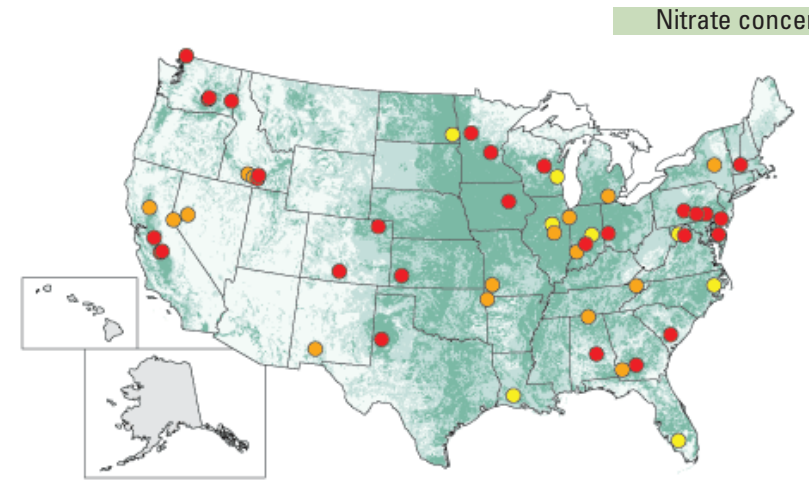

Estimated 1997 nitrogen inputs from fertilizer, manure, and atmosphere, in pounds per square mile $<2,900$ 2,900-15,000

$>15,000$

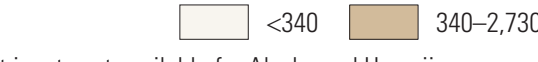

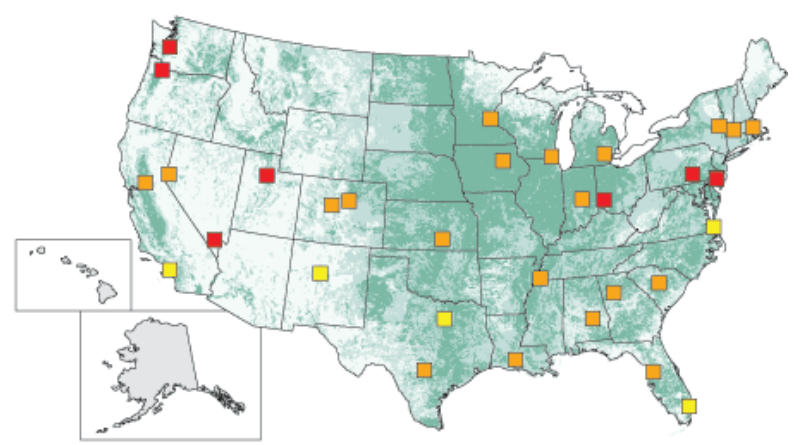

Estimated 1997 phosphorus inputs from fertilizer and manure, in pounds per square mile

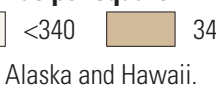

Stream sites or
groundwater studies
by land use
Agricultural $\quad$ Urban
0

$\begin{aligned} & \text { Total nitrogen } \\ & \text { concentration in st } \\ & \text { in milligrams per liter }\end{aligned}$
Low $(<0.66)$
Medium $(0.66-3.17)$
High $(>3.17)$

Total phosphorus concentration in streams, in milligrams per liter

$\operatorname{Low}(<0.05)$

Medium (0.05-0.28)

High $(>0.28)$

\section{Median concentration of nitrate in groundwater, in milligrams per liter as $\mathbf{N}$}

$\operatorname{Low}(<0.08)$

Medium (0.08-2.6)

High (>2.6)

Figure 1-2. Elevated concentrations of nitrogen and phosphorus are associated with some of the highest fertilizer and manure inputs across the Nation. Because tile drains promote transport of nitrogen to streams but inhibit transport to groundwater, high concentrations in groundwater are not as prevalent as in surface water in the upper Midwest. 
Concentrations of total nitrogen in urban streams were lower than those in agricultural streams, with a median concentration less than $2 \mathrm{mg} / \mathrm{L}$ (about 3 times greater than background levels) (fig. 1-1). The highest concentrations in urban streams were scattered across the Nation (fig. 1-2); high concentrations were sometimes associated with upstream wastewater-treatment facilities. In some parts of the country, such as the semiarid West, a large portion of the flow in some streams may be wastewater effluent, particularly during times when natural runoff is low. Atmospheric deposition can account for a significant portion of the nitrogen in streams in some relatively undeveloped watersheds, such as are found in the Northeast.

Concentrations of total phosphorus were highest in streams in both agricultural and urban areas, with a median concentration of about $0.25 \mathrm{mg} / \mathrm{L}$ (about 6 times greater than background levels) (fig. 1-1). High concentrations of phosphorus in agricultural settings are associated with relatively high applications of fertilizer and manure (fig. 1-2). Other urban sources may include treated wastewater effluent and septic-system drainage (in less urbanized settings), as well as runoff from residential lawns, golf courses, and construction sites.

Geographic patterns in the occurrence and distribution of nutrient concentrations are complicated by naturally occurring seasonal fluctuations in climate (such as those that influence streamflow and uptake by aquatic and riparian vegetation) and human factors (such as those related to the application of fertilizer and manure and irrigation). At many sites in the eastern half of the United States, total nitrogen concentrations were highest in the spring when streamflow is highest and fertilizer is applied, whereas total phosphorus concentrations were highest in the summer and autumn when streamflow is lowest and less water is available to dilute effluent from point sources. At other sites, particularly in the upper Midwest, both nitrogen and phosphorus concentrations were highest during high streamflow in the spring. In the western half of the United States, seasonal patterns were less distinct due to the highly variable topography and climate and the ubiquitous presence and effects of dams and canals. The highest concentrations of phosphorus in western streams, particularly in rangeland areas of the interior West, often occurred during the summer (May through July), when snowmelt produces high streamflows and sediment-bound phosphorus is mobilized by erosion. High concentrations of nitrogen often occurred during the winter when streamflow generally is low and less water is available to dilute irrigation return flow and effluent from point sources.
The amounts of nitrogen and phosphorus lost from watersheds to streams - referred to as yields (expressed as mass per unit area) - increased with increasing nutrient inputs regardless of land use. For example, between 5 and 50 percent of the nitrogen input from nonpoint sources was exported out of most (72 percent) watersheds (see dashed red lines, fig. 1-3). Nutrient inputs that are not taken up by plants, immobilized in soil, or volatilized to the atmosphere can be transported to a stream and exported from the watershed. Variability in the amounts of nutrients exported can be explained in part by differences in agricultural practices, and in soils, geology, and hydrology. For example, agricultural lands with tile drains in 5 percent or more of the watershed were 3 times more likely to export more than 25 percent of nitrogen to streams than agricultural lands with fewer tile drains. Less nitrogen was exported from watersheds in the Southeast because of greater amounts of denitrification in the soils and in the shallow groundwater that ultimately discharges to streams. Similarly, less nitrogen was exported from western watersheds because of generally low amounts of precipitation and runoff, as well as the modification of flow systems by irrigation and impoundments. Phosphorus is less soluble than nitrogen and thus, the amount of phosphorus exported was lower than nitrogen at many sites.

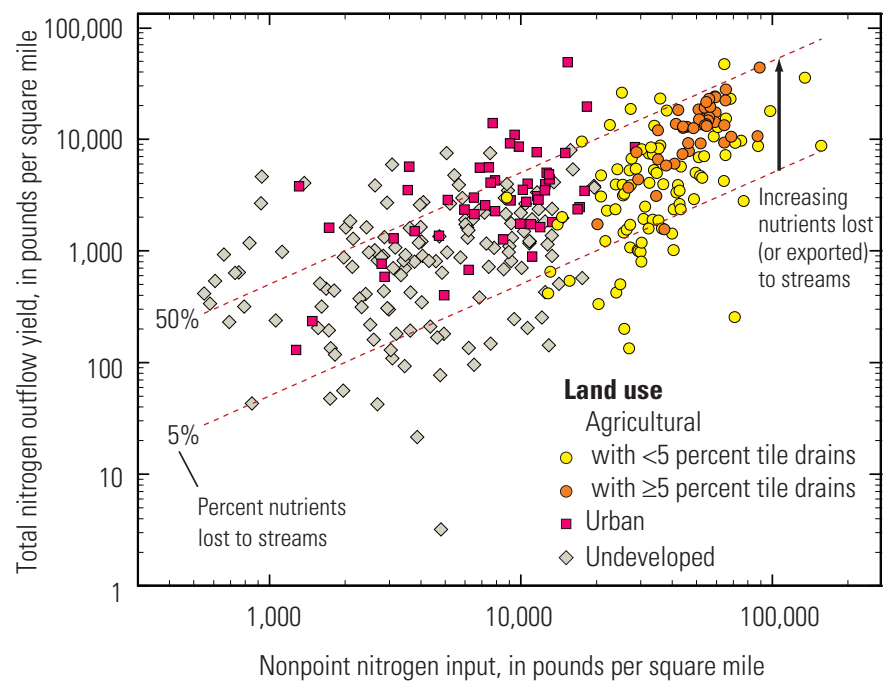

Figure 1-3. The amount of nitrogen exported from watersheds to streams (referred to as yields) increased with increasing nutrient inputs, regardless of land use. Between 5 and 50 percent of the nitrogen input from nonpoint sources was exported out of most (72 percent) watersheds regardless of land use. The proportion of nitrogen input that is exported by a stream as yield is much greater for agricultural streams with tile drains in 5 percent or more of the watershed than for agricultural streams with fewer tile drains. 
The location of the sources of nutrients within a watershed and the characteristics of the stream channel affect the export of nutrients to downstream water bodies, such as the Gulf of Mexico and Chesapeake Bay. Simulations made with a USGS nutrient model that relates instream nutrient loads to the locations of upstream nutrient sources and watershed characteristics that affect nutrient transport provide information on the delivery of nitrogen and phosphorus from 62,000 stream reaches to the Nation's major rivers and estuaries (see Chapter 4 , Using the SPARROW Model to Assess Nutrient Concentrations in Streams). For example, because the amount of biological processing of nitrogen in streams depends on the surface area of the stream bottom (where the organisms live) in relation to the stream's volume, a greater percentage of the nitrogen delivered to large deep rivers is typically exported to downstream water bodies than nitrogen delivered to small streams. Other findings indicate that corn and soybean cultivation are the largest sources of nitrogen annually to the Gulf of Mexico, whereas animal manure on pasture and rangelands and corn and soybean cultivation are the largest contributors of phosphorus.

In groundwater, median concentrations of nitrate were highest $(3.1 \mathrm{mg} / \mathrm{L})$ in shallow wells in agricultural areas, which are associated with relatively large amounts of fertilizer and (or) manure applications. Median concentrations of nitrate were lower in shallow wells in urban areas $(1.4 \mathrm{mg} / \mathrm{L})$.

The lowest concentrations occurred in deep wells beneath a mix of land uses.

Nitrate concentrations in groundwater varied across the Nation. Some of the highest concentrations occurred in the Northeast, Midwest, California, and the Northwest (fig. 1-2). Elevated nitrate concentrations are likely the result of high nitrogen inputs and natural conditions that favor transport. Concentrations of nitrate generally decrease with well depth because (1) recharge of deep, old groundwater most likely occurred when anthropogenic nitrogen inputs were relatively low; (2) the amount of time for microbial processes such as denitrification to take place increases as water moves downward through the aquifer; and (3) deep groundwater is commonly a mixture of water that has moved along flow paths that originate in areas of differing land uses and nitrogen inputs.

The median concentration of nitrate was significantly higher in oxic groundwater (i.e., water with greater than $0.5 \mathrm{mg} / \mathrm{L}$ dissolved oxygen) than in groundwater without dissolved oxygen within each land-use setting, and is strongly dependent on the redox condition (the presence or absence of oxygen) regardless of nitrogen input at the land surface (fig. 1-4). For example, nitrogen inputs in agricultural areas were about the same across the three redox classes, and the median concentration of nitrate was about $5.6 \mathrm{mg} / \mathrm{L}$ in oxic water, but near detection levels in water under reduced conditions. These results show that redox status of an aquifer is a critical factor to consider when assessing vulnerability to nitrate contamination.

Nitrate concentrations are closely associated with groundwater age and geochemical conditions. Groundwater recharged within the last 10 years is typically oxic and has higher nitrate concentrations (median of $1.6 \mathrm{mg} / \mathrm{L}$ ) than old groundwater (median of $0.26 \mathrm{mg} / \mathrm{L}$ ), which generally is deeper and more commonly in a reduced state than young groundwater. Nitrate concentrations greater than $10 \mathrm{mg} / \mathrm{L}$ were rarely detected in groundwater recharged prior to about 1950 .
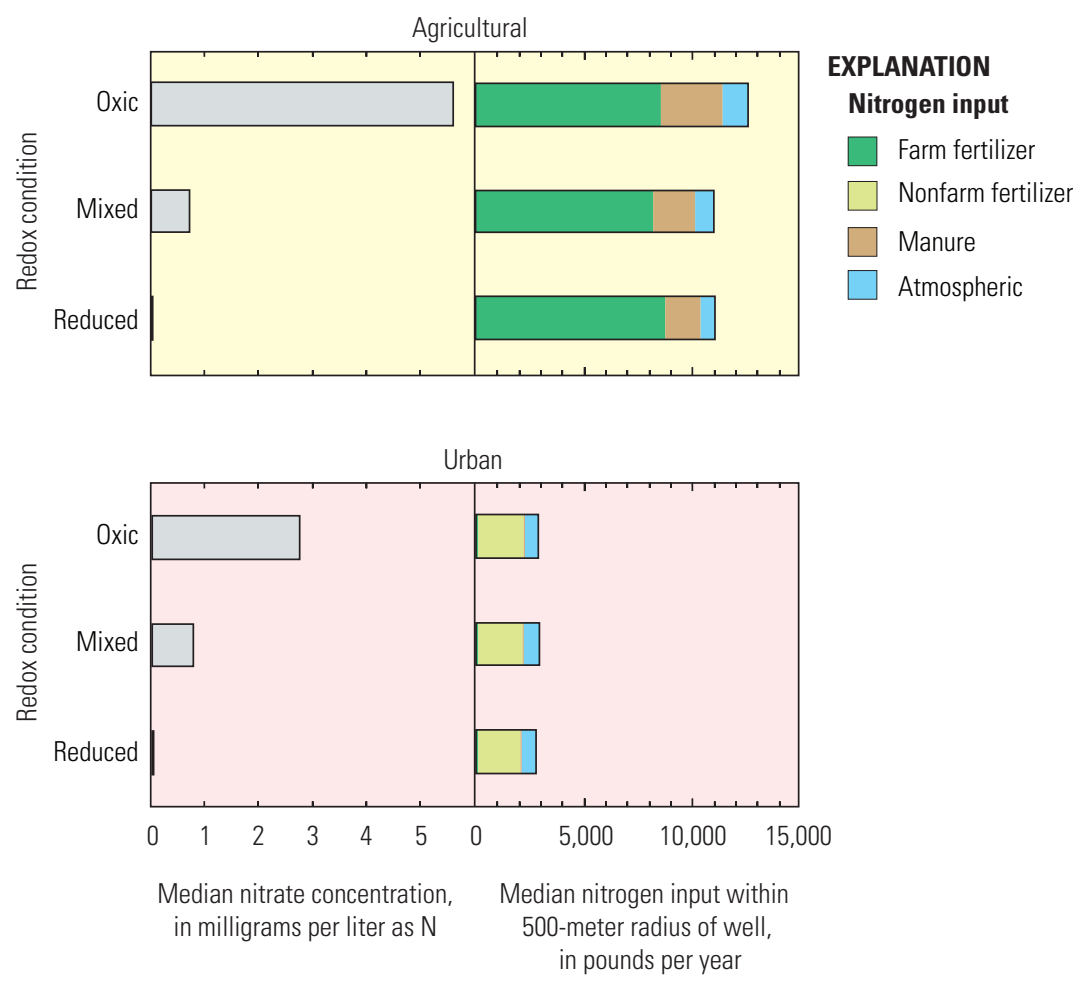

Figure 1-4. Nitrate concentrations were highest in oxic groundwater (i.e., water with greater than $0.5 \mathrm{mg} / \mathrm{L}$ dissolved oxygen) than in groundwater without dissolved oxygen regardless of land use or nitrogen input. 


\section{Implications}

- Nutrient concentrations in streams and groundwater can be anticipated from information about land use and associated fertilizer applications, along with natural features and management practices that influence the amount and timing of nutrient transport over the land and to the groundwater system.

- The major role of groundwater age and geochemical conditions in governing concentrations of nitrate needs to be accounted for in groundwater assessments because these factors can obscure relations between elevated concentrations of nitrate in groundwater and nitrate sources.

- Hydrologic settings in which groundwater is least vulnerable to contamination are often those in which streams may be most vulnerable and vice versa. For example, tile drains may help to protect groundwater from contamination while at the same time increasing nutrient transport to streams.

- The productivity of poorly drained agricultural land has been greatly enhanced by engineering the landscape to promote rapid drainage of the land surface by artificial drains and ditches. The resulting large yields of nitrogen in streams in watersheds with tile drains suggest a need to balance consideration of stream water quality and crop production.

- Because there is less natural attenuation of nutrient yields in large deep rivers than in small streams, nutrient management strategies for the protection of estuaries and other downstream water bodies should pay particular attention to point and nonpoint sources of nutrients that discharge to main stem channels.

\section{Exchange of Nutrients Between Surface Water and Groundwater}

Groundwater can contribute a substantial portion of the total annual load of dissolved nutrients - particularly nitrate - to streams. The relative contribution from groundwater varies in streams across the Nation because of differences in natural features and human activities that affect the interactions across different landscapes and during different seasons (Chapter 5).

Base flow-defined as streamflow conditions following extended periods of minimal precipitation when the source of streamflow primarily is groundwater discharge - contributed more than a third of the total annual load of nitrate in two-thirds of 148 streams studied. These findings are based on data from streams that drain relatively small watersheds (less than 500 square miles), where contributions of nitrate from other sources during base flow are believed to be small or insignificant.

The relative contribution of nitrate from base flow is not uniform across the Nation, but varies geographically in response to base flow sources, as well as to natural features and human activities that can affect transport of groundwater to streams. For example, base flow contributed more than 50 percent of the nitrate load to many streams in northern Alabama through Tennessee, Virginia, Maryland, and Pennsylvania, owing primarily to the relatively permeable and well-drained geologic settings in the Valley and Ridge physiographic province that promote groundwater transport to streams (fig. 1-5). In contrast, base flow contributions generally

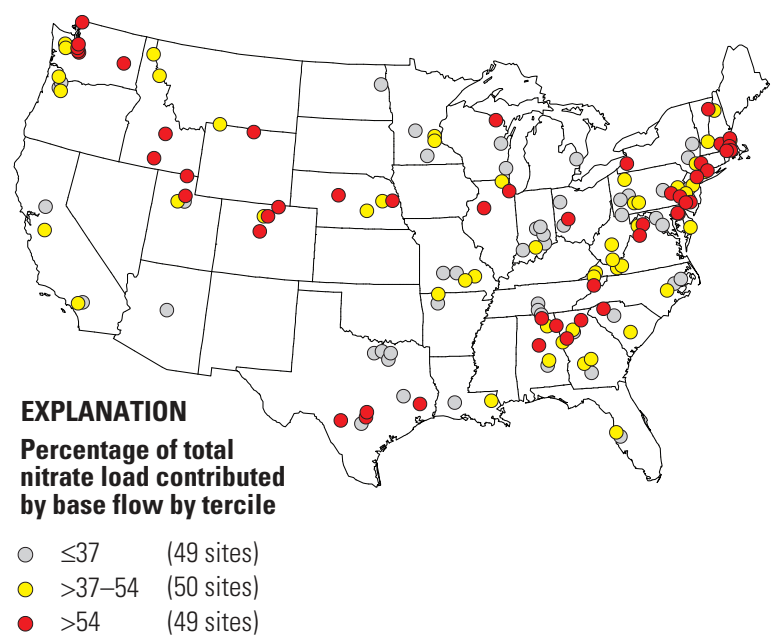

Figure 1-5. Base flow, consisting mostly of groundwater discharge, accounts for more than a third of the total annual load of nitrate in about two-thirds of 148 streams draining watersheds smaller than 500 square miles across the Nation. The magnitude of contribution depends on natural features and human activities that can affect groundwater transport to streams, as well as the potential contribution of other nitrate sources. 
were low (less than or equal to 37 percent) in the Midwest. This is due, in large part, to the use of tile drains and ditches to remove water from poorly drained agricultural lands, which reduces recharge to the groundwater system and enhances runoff to streams.

Findings from a national landscape analysis show an association between base flow which provides substantial contributions of nitrate to streams and the permeability of soils and underlying bedrock. Nitrate loads from base flow were significantly lower (contributing about 27 percent of total stream nitrate load) in streams draining landscapes with impermeable soils and bedrock than in those draining landscapes with permeable soils and (or) bedrock (44 to 47 percent). Permeability affects recharge to the aquifer system and the degree to which groundwater can move through the aquifer to streams.

Natural processes-including physical, chemical, and biological — can affect exchanges of water and its dissolved constituents between aquifers and streams. For example, in the shallow subsurface of riparian zones that contain organic-rich sediments with low dissolved-oxygen concentrations, bacteria convert dissolved nitrate in groundwater to innocuous, gaseous forms of nitrogen through the process of denitrification. Nutrients also can be removed by plants in riparian or buffer zones. The efficacy of these processes depends on the geometry of the local groundwater flow system. For example, in some settings, groundwater can flow along relatively deep flow paths beneath riparian zones such that nitrate in the groundwater is unaffected by the riparian zone and can discharge directly to streams. Findings show that riparian zones are most effective in settings with thin surficial aquifers underlain by a shallow confining layer, with organic-rich soils that extend down to the confining layer. Groundwater in these types of settings tends to flow through biologically reactive parts of the aquifer, which promotes the removal of nitrate.
Nitrate is not the only nutrient that can be contributed to streams through groundwater discharge. Groundwater can contribute significant amounts of phosphorus to streams, particularly where natural sources of phosphorus are present in the aquifer and reduced chemical conditions favor phosphorus transport. Such conditions have been documented in areas as different as the Coastal Plain of North Carolina, and the Tualatin River Basin of Oregon.

\section{Implications}

- Groundwater contributions of nutrients, particularly nitrate, to streams can be important and may merit special attention in settings in which natural features and human activities enhance the connections between groundwater and surface water.

- For streams in which groundwater contributions of nutrients are substantial:

- Crop-management and irrigation practices, which commonly are designed to reduce or slow the movement of overland flow to streams, may have only a limited effect on nutrient loads to streams.

- Improvements in water quality as a result of reductions in nutrient inputs on the land may not be apparent in streams for decades because of the slow rate of groundwater movement from the land surface through the subsurface to streams.

- Full accounting and assessment of groundwater contributions of nutrients to surface water is a critical step in developing management strategies to meet water-quality goals for protection of drinking-water supplies and aquatic life. Specifically,

- Omission of groundwater contributions of nutrients from Total Maximum Daily Loads (TMDLs) calculations can result in errors in the allocation of loads to other sources that need to be controlled, thus limiting the effectiveness of TMDLs for restoring and protecting streams.

- Management practices such as riparian buffer zones can remove nitrate from groundwater discharging to a stream, but the efficacy of the buffer will depend, in part, on the geometry of the local groundwater flow system. 


\section{Potential Significance to Human Health}

Nutrients in streams seldom occurred at concentrations greater than water-quality benchmarks for human health. Concentrations of nitrate greater than the Maximum Contaminant Level (MCL) of $10 \mathrm{mg} / \mathrm{L}$ were more prevalent and widespread in groundwater used for drinking water, including that from domestic and-less frequently-public-supply wells (Chapter 6).

Nitrate was the most frequently detected nutrient in streams at concentrations greater than its human-health benchmark-the USEPA Maximum Contaminant Level (MCL) of $10 \mathrm{mg} / \mathrm{L}$ (the maximum permissible concentration of a contaminant in water that may be delivered to any user of a public water system). Concentrations of nitrate exceeded the MCL in 2 percent of all stream samples, and in at least one sample collected at 10 percent (50 of 499) of streams. Samples from 5 streams had concentrations of nitrite greater than its MCL of $1 \mathrm{mg} / \mathrm{L}$. All of the samples with nitrite exceedances were collected downstream from wastewater-treatment facilities, and none of the streams were used as a source of drinking-water supply. Concentrations of ammonia in streams never exceeded its human-health benchmarkthe USEPA lifetime health advisory of $30 \mathrm{mg} / \mathrm{L}$.

Elevated concentrations of nitrate mostly occurred in streams that drain agricultural watersheds where the use of fertilizers and (or) manure is relatively high. At least one sample from nearly 30 percent of the agricultural streams had a nitrate concentration greater than the MCL, and concentrations greater than the MCL were detected in more than 20 percent of samples from about 11 percent of these streams (fig. 1-6). Concentrations exceeded the MCL at fewer streams draining urban land (about 7 percent), which likely reflects lower use of fertilizers on residential lands. Nitrate concentrations exceeded the MCL in samples from 5 percent of streams draining mixed land-use settings; none of the samples from streams draining undeveloped land had a concentration exceeding the MCL.

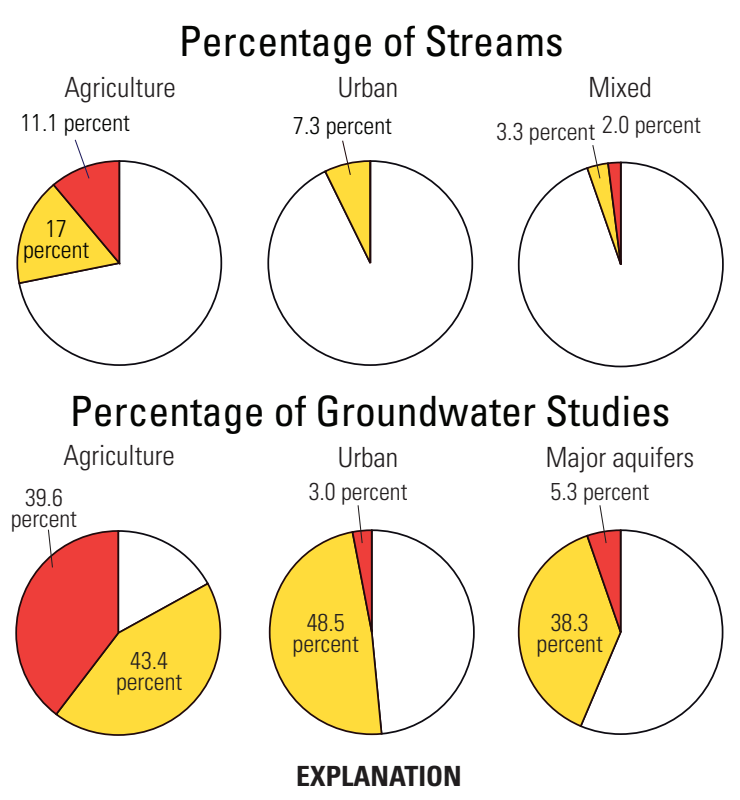

Percentage of samples at each stream site or groundwater study exceeding the nitrate MCL

$$
\begin{aligned}
& \square \text { No exceedance } \\
& \square>0-20 \\
& \square>20
\end{aligned}
$$

Figure 1-6. The Maximum Contaminant Level (MCL) for nitrate in drinking water of 10 milligrams per liter as nitrogen is exceeded far more frequently in streams in agricultural areas than in the other land-use categories. Much larger proportions of groundwater studies have MCL exceedances than do stream sites in all land-use categories.

Most surface-water samples with concentrations of nitrate exceeding the MCL were collected from small streams in the Corn Belt region, which encompasses Illinois, Indiana, Iowa, Nebraska, and Ohio, as well as parts of adjoining States. Fertilizer application rates in the Corn Belt are among the highest in the Nation, and as a result, elevated concentrations of nutrients are widespread in the region's streams and rivers. These elevated concentrations also reflect landscape characteristics and landmanagement practices that promote rapid transport of runoff from fields to streams, including relatively impermeable soils and artificial drainage, such as tile drains. 
For perspective on the relevance of NAWQA findings to surface water used for drinking-water supplies, 12 percent of the Nation's 1,679 public-water supply intakes withdraw water from streams that drain watersheds with predominantly agricultural land. Most (55 percent) of the Nation's water-supply intakes are in watersheds draining undeveloped land, with the remaining intakes in areas of mixed and urban land use (32 and

1 percent, respectively).

Elevated concentrations of nitrate are more prevalent and widespread in groundwater used for drinking water than in streams; concentrations exceeded the MCL in samples from 7 percent of 2,388 domestic wells and in samples from 3 percent of 384 publicsupply wells. In addition, the water from one or more wells sampled in 57 percent of all agricultural, urban and major aquifer studies had concentrations of nitrate exceeding the MCL, compared to 10 percent of all stream sites. The broad distribution of concentrations of nitrate above the MCL is reflected in the large number of groundwater studies in which one or more MCL exceedances were detected: 83 percent of the agricultural studies, 52 percent of urban studies, and 44 percent of major aquifer studies (fig. 1-6). Elevated concentrations of nitrate were detected in groundwater in agricultural and urban areas throughout the United States, but least commonly in the Southeast because of aquifer and soil conditions that promote denitrification of nitrate to other forms, such as nitrogen gas. More than 20 percent of 406 shallow domestic wells located in agricultural areas exceeded the MCL. The proximity to land surface and the level of human activity, including the relatively heavy applications of fertilizers, increase the vulnerability of this resource to nitrate contamination.

The lower frequency of exceedance of the MCL for nitrate in samples from public-supply wells than in domestic wells likely reflects a combination of factors, including (1) greater depths to older and less contaminated groundwater; (2) longer travel times from the surface to the screened interval of the well, allowing degradation and (or) attenuation of contaminants during transport; and (3) the locations of public-supply wells near urban areas, where sources of nitrate are less prevalent than in rural, agricultural areas.

A national statistical model was developed to assess the vulnerability of relatively deep groundwater (more than 164 feet, or 50 meters, below land surface) to nitrate contamination (fig. 1-7). Model simulations predict moderate to severe nitrate contamination in groundwater underlying the High Plains, northern Midwest, and areas of intensive agriculture in the East (such as in eastern Pennsylvania and the Delmarva Peninsula) and the West (such as in the Columbia Plateau in Washington, the San Joaquin Valley in California, and the Snake River Plain in Idaho). Predicted elevated concentrations are associated with nitrogen inputs, such as those from fertilizer and manure; natural soil, landscape, and geologic features that promote rapid transport of groundwater; anthropogenic factors or practices such as irrigation; and the absence of denitrification processes.

The model helps to estimate the number of people who may use wells for drinking water that tap aquifers vulnerable to nitrate contamination. About 15 million people live in areas where nitrate concentrations are predicted to be greater than 1 milligram per liter in wells more than 164 feet below land surface. (Nitrate can occur naturally, but nitrate concentrations greater than 1 milligram per liter are likely to indicate human activities.) Among the potential users, more than 1.2 million people live in areas predicted to have moderate nitrate contamination of groundwater (greater than $5 \mathrm{mg} / \mathrm{L}$ but less than or equal to the MCL of $10 \mathrm{mg} / \mathrm{L}$ ).

Additional well owners may be affected in the future as a result of shallow contaminated groundwater moving downward into the aquifer system. Statistical models suggest, for example, that the number of people exposed to nitrate concentrations greater than the MCL would be 14 percent greater if they obtain their water from shallow wells (33 feet or less) than if they obtain their water from deep wells (164 feet or greater). Because well depth is a proxy for travel time in an aquifer, water-quality conditions at shallow depths serve as an early warning system for possible future conditions. 


\section{Groundwater}

Model for deep groundwater used as drinking water (50-m simulation depth)

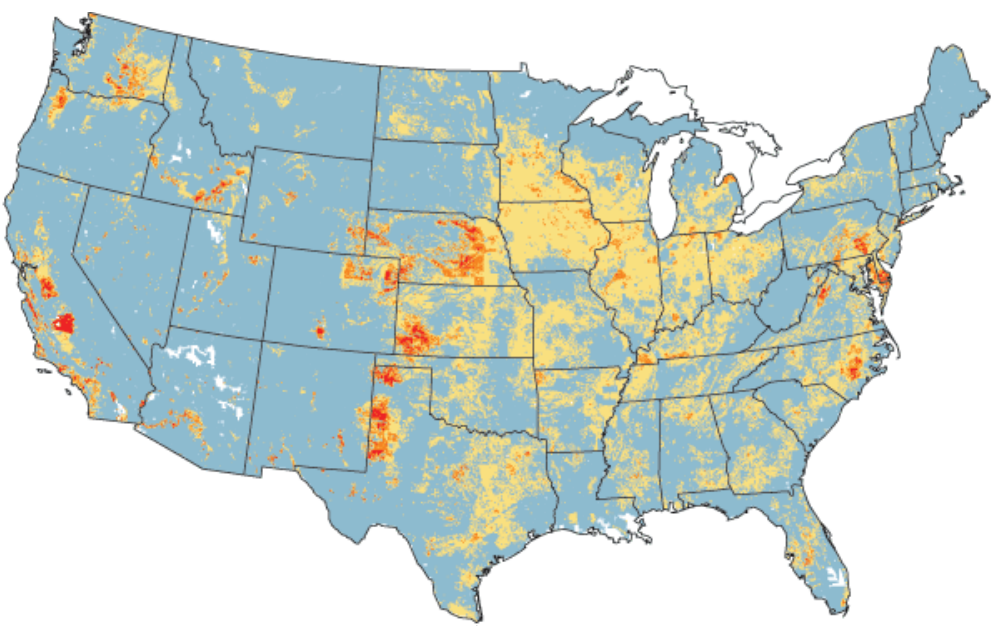

\section{EXPLANATION}

Predicted nitrate concentration, in milligrams per liter as $\mathbf{N}$

$\leq 1$

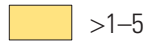

$\square>5-10$

$>10$

Missing data

Figure 1-7. Results of model simulations suggest moderate (shown in yellow and orange) to severe (shown in red) nitrate contamination in relatively deep groundwater (greater than 164 feet or 50 meters below land surface) underlying parts of California, the Northwest, the High Plains, and the East. These areas typically are associated with large nitrogen input; natural soil, landscape, and geologic features that promote rapid transport of groundwater; and a lack of biogeochemical processes that convert nitrate to other forms of nitrogen.

\section{Implications}

- Concentrations of nutrients in streams seldom exceeded humanhealth benchmarks, particularly in undeveloped watersheds. Thus, water utilities that withdraw water from streams in undeveloped or mixed watersheds, which account for 87 percent of the Nation's public-water supply intakes, are unlikely to withdraw water with nitrate concentrations greater than the MCL of $10 \mathrm{mg} / \mathrm{L}$. The likelihood of nitrate concentrations in streams being greater than $10 \mathrm{mg} / \mathrm{L}$ is largest in streams draining agricultural areas, which account for about 12 percent of public-water supply intakes on streams.

- Individuals who obtain their drinking water from shallow domestic wells near existing or former agricultural settings have the highest probability of consuming water with elevated nitrate concentrations. More than 43 million people-about 15 percent of the U.S. population-rely on domestic (privately owned) wells as their source of drinking water. The quality and safety of water from domestic wells are not regulated by the Federal Safe Drinking Water Act nor, in most cases, by State laws. Rather, individual homeowners are responsible for maintaining their domestic well systems and for monitoring water quality. Nitrate, which can persist in groundwater for years and even decades, may be present because of previous land uses and practices, which emphasizes the importance of public education and water-quality testing in areas where land use has changed.

- Even in relatively protected settings, deep aquifers require some level of consideration to support long-term prevention of nitrate contamination. Groundwater at all depths is part of an integrated system and can be vulnerable to future contamination as water moves downward from shallower, contaminated groundwater systems. Future contamination in deep aquifers requires consideration because these aquifers commonly are used as sources of public supply and because restoration of the purity of this relatively inaccessible and slow-moving water is costly and difficult.

- Strategies for managing nutrients require far more information than we can afford to measure directly for all the places and times of interest. Many strategic decisions - such as setting monitoring priorities and implementing management and wellhead protection strategiesinherently depend on predicting the potential effects of nutrients for locations that have never been directly assessed. The continued development of nationalscale predictive models of water quality conditions with quantified reliability is increasingly possible and is a critical step for cost-effective management and protection of water resources. 


\section{Potential Significance to Aquatic Life}

Concentrations of ammonia seldom exceeded levels set to protect aquatic life in streams. Concentrations of nitrogen and phosphorus commonly exceeded recommended regional criteria in selected areas of the United States, particularly in agricultural and urban areas (Chapter 7).

Concentrations of ammonia in streams seldom exceeded recommended USEPA numeric criteria established to protect aquatic life from ammonia toxicity (fig. 1-8). Specifically, concentrations exceeded acute criteria in 33 samples ( 0.14 percent) at 7 streams (1.4 percent), from among about 24,000 samples collected from nearly 500 streams. Concentrations exceeded the chronic criteria in 139 samples from 22 sites. The acute and chronic criteria generally were exceeded in streams in the semiarid West draining watersheds with urban and mixed land uses. For many of these streams, effluent from

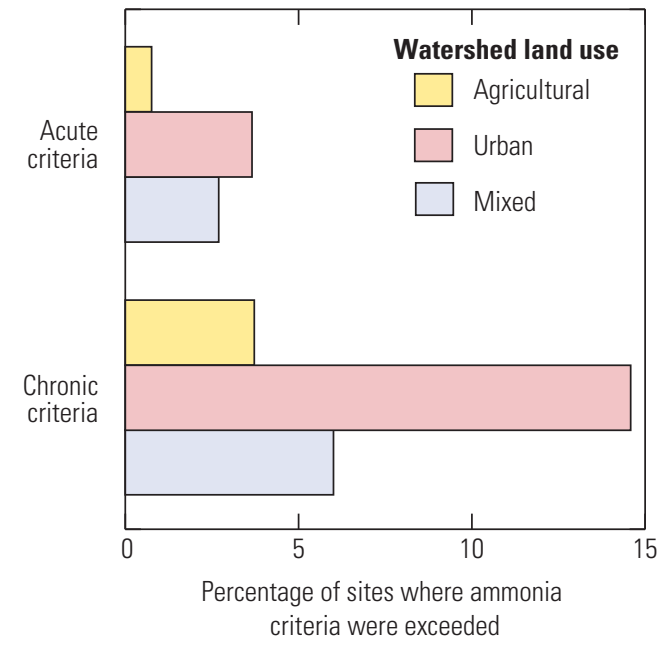

Figure 1-8. Concentrations of ammonia in streams seldom exceeded acute or chronic criteria set to protect aquatic life. Sites at which the criteria were exceeded generally are on streams in the semiarid West that drain areas of urban or mixed land use and are potentially influenced by treated effluent from wastewater-treatment facilities located upstream. wastewater-treatment facilities comprises a significant portion of the streamflow during much of the year. Chronic criteria were exceeded less frequently at agricultural sites (fig. 1-8), despite relatively large fertilizer and manure sources. This finding indicates that ammonia from nonpoint agricultural sources is not reaching or persisting in these streams, but rather is sorbed onto soils, volatilized, converted from the un-ionized form $\left(\mathrm{NH}_{3}\right)$ to nitrate, or taken up by plants.

The USEPA has developed technical guidance and provided recommendations for aquatic life criteria based on estimated reference conditions for nitrogen, phosphorus, chlorophyll $a$, and turbidity in 14 nutrient ecoregions across the Nation. These ecoregions represent areas of similar climate and geology (see Chapter 7 sidebar, The U.S. Environmental Protection Agency's National Nutrient Criteria Program). For comparison and perspective, average background concentrations of nitrogen and phosphorus were estimated for each of the 14 nutrient ecoregions using the USGS SPARROW model. The modeled background concentrations and recommended USEPA criteria generally follow similar patterns within the ecoregions; however, the recommended criteria are more stringent than modeled concentrations in several regions, particularly for phosphorus, suggesting that the recommended criteria may be difficult to attain in some regions (fig. 1-9). Estimation of concentrations indicative of reference conditions is an area of continuing research (Herlihy and Sifneos, 2008).

Median concentrations of nitrogen and phosphorus, measured at 135 agricultural streams, were about 2 to more than 10 times higher than recommended nutrient criteria (fig. 1-9). The relatively large differences suggest that significant reductions in sources of nutrients, as well as reductions in transport through the implementation of land and water management strategies, are needed to meet recommended criteria in these areas. These results span ecoregions throughout the United States, including the Willamette and Central Valleys, the Xeric West, the Mostly Glaciated Dairy Region in the upper Midwest, the Southeastern Temperate Forested Plains and Hills, and the Central and Eastern Forested Uplands. 

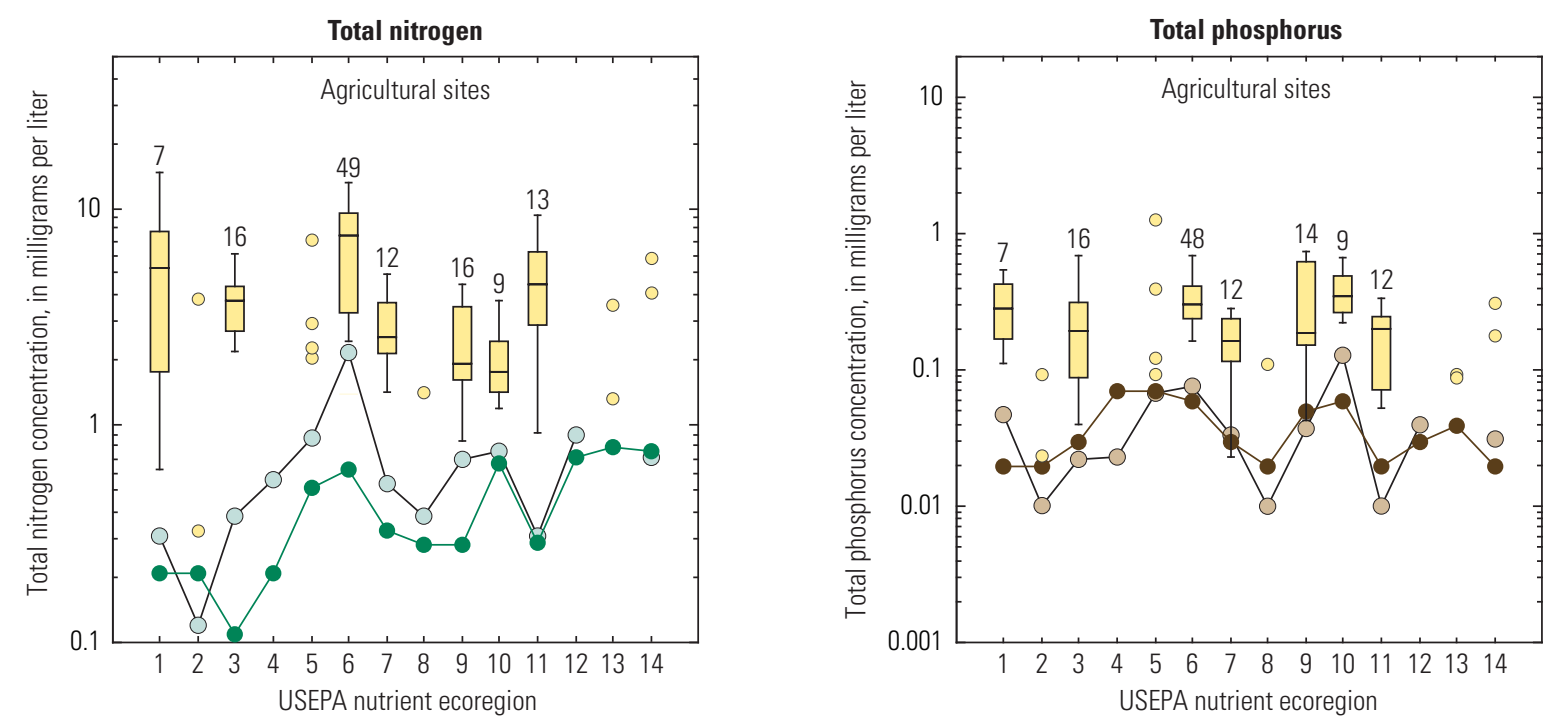

\section{EXPLANATION}

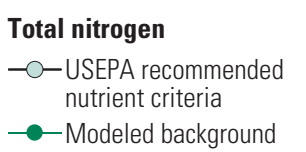
Total phosphorus
- - USEPA recommended nutrient criteria

- Modeled background

Criteria for USEPA nutrient ecoregion 13 are under development.

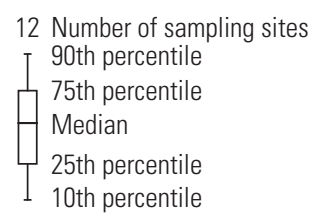

Boxplot shown for ecoregions
with more than 6 sampling sites

Boxplot shown for ecoregions
with more than 6 sampling sites

○ Site value

\section{U.S. Environmental Protection Agency nutrient ecoregions}
1 Willamette and Central Valleys
6 Corn Belt and Northern Great Plains
2 Western Forested Mountains
7 Mostly Glaciated Dairy Region
3 Xeric West
8 Nutrient Poor Largely Glaciated Upper Midwest and Northeast
9 Southeastern Temperate Forested Plains and Hills
4 Great Plains Grass and Shrublands
10 Texas-Louisiana Coastal and Mississippi Alluvial Plains
11 Central and Eastern Forested Uplands
12 Southern Coastal Plain
13 Southern Florida Coastal Plain
14 Eastern Coastal Plain
5 Central Cultivated Great Plains

Figure 1-9. U.S. Environmental Protection Agency (USEPA) recommended nutrient criteria and U.S. Geological Survey modeled estimates for background nutrient concentrations follow similar patterns of variation within the 14 nutrient ecoregions; however, recommended criteria are more stringent than estimates of background concentrations in several regions, particularly for phosphorus, suggesting that the recommended criteria may be difficult to attain in some areas. Median concentrations of nitrogen and phosphorus measured in agricultural streams were from 2 to more than 10 times greater than recommended regional nutrient criteria.

A regression model was developed to estimate the probability of exceeding a specific total nitrogen concentration for any given stream. Simulation results predict widespread exceedance of recommended criteria, suggesting, for example, that there is a greater than 75 percent probability that total nitrogen concentrations would exceed recommended nutrient criteria in 83 percent of stream miles throughout the Nation. This proportion is similar to what would be expected considering how the criteria were designed (U.S. Environmental Protection Agency, 2001, fig. 5). Simulation results also predict that a 25 -percent reduction in fertilizer in the Corn Belt and Northern Great Plains nutrient ecoregion would result in a small (about 2.5 percent) decrease in the number of stream miles expected to exceed the respective recommended nutrient criteria. These findings underscore the challenge of reducing nutrients to levels protective of aquatic life in streams in agricultural areas, and suggest that greater use of land management strategies to reduce the transport of nutrients to streams may be needed to meet recommended criteria. 
Stream ecosystem health can be assessed by determining the biological condition of a stream on the basis of the numbers and types of individuals comprising algal, macroinvertebrate, and fish communities. NAWQA findings suggest that the biological condition of all three communities are increasingly altered with increasing concentrations of nitrogen and phosphorus (fig. 1-10). Changes were most pronounced for algal communities, in which the average biological condition in streams with elevated nutrients (greater than $1.5 \mathrm{mg} / \mathrm{L}$ of nitrogen and $0.075 \mathrm{mg} / \mathrm{L}$ of phosphorus) was about 30 percentage points lower than the algal biological condition in streams with the lowest nutrient concentrations. This finding is consistent with the direct link between nutrient availability and algal growth, whereas the response of higher organisms, such as fish and macroinvertebrates, is indirect, mediated by transfer of energy from aquatic plants and algae via food chains of varying complexity.

NAWQA findings show that the effects of nutrient enrichment on algal biomass (as indicated by chlorophyll $a$ ) are not uniform in streams across the Nation. Regional variations suggest that other factors can influence algal communities, such as streamflow, canopy cover, water temperature, and clarity. A regression model, based on data for 143 sites in 5 different agricultural areas across the United States, showed a weak relation between phosphorus concentrations and algal biomass. Specifically, only 12 percent of the variability in algal growth was explained by concentrations of phosphorus. The relation was even weaker for nitrogen concentrations. Weak relations in some regions also can be explained by elevated nutrient concentrations that are greater than what plants require, so that additional increases in nutrients have little effect on plant biomass. The strength of the relation between nutrient concentrations and algal biomass for individual study areas increased —explaining up to 46 percent of the variability in algal biomass - when stream characteristics, such as water temperature and canopy cover, were included in the analysis.

\section{Implications}

- More stringent ambient water-quality criteria for ammonia have recently been proposed that would be more protective of sensitive species (U.S.

Environmental Protection Agency, 2009), which may result in more streams being out of compliance with respect to ammonia.

- The large differences in magnitude between nitrogen and phosphorus concentrations measured in streams draining areas with significant agricultural and urban development and USEPA recommended nutrient criteria suggest that significant reductions in sources of nutrients, as well as greater use of land and water management strategies to reduce the transport of nutrients to streams, are still needed to meet recommended criteria for these streams.

- The increased sensitivity of algal communities to nutrient enrichment compared to macroinvertebrate and fish communities suggests that algal communities should be considered for stream bioassessments to avoid underestimating the extent of water quality impairment.

- The wide range in biological response to nutrient concentrations supports the need for a regional approach to nutrient criteria and for consideration of factors related to stream habitat and flow characteristics in the development of these criteria.

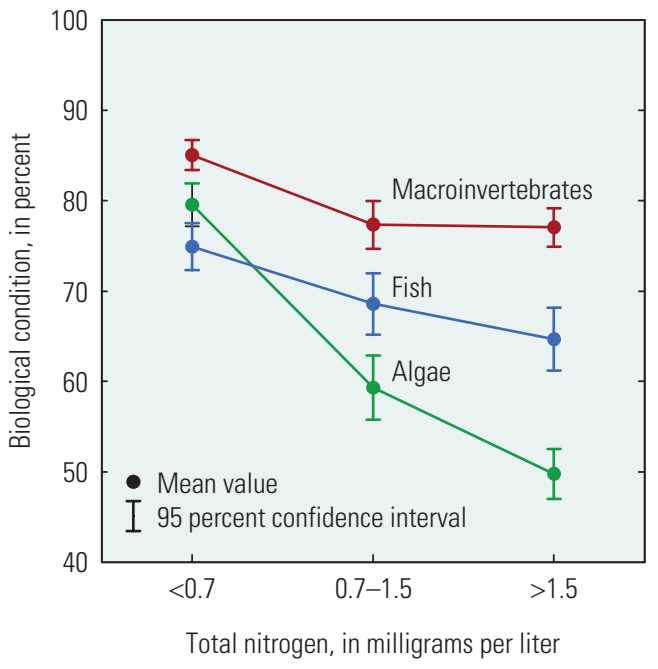

Total nitrogen, in milligrams per liter

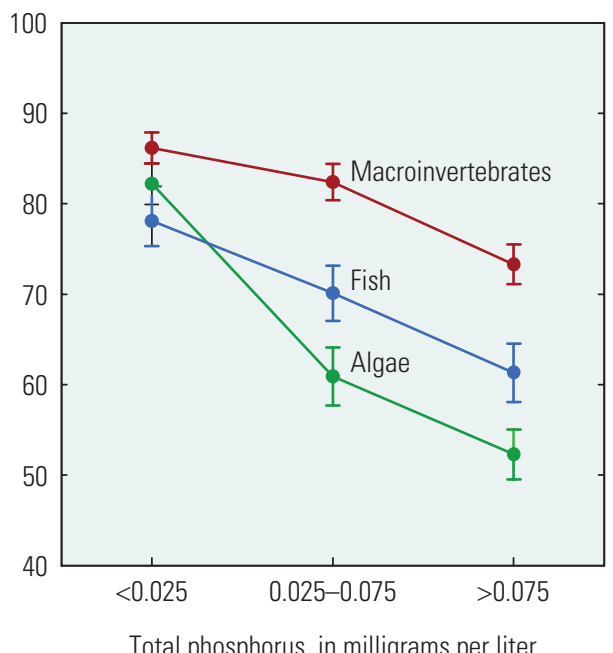

Total phosphorus, in milligrams per liter
Figure 1-10. Biological condition for algal, macroinvertebrate, and fish communities declined with increasing concentrations of nitrogen and phosphorus in streams. Changes were most pronounced for algal communities, in which the average biological condition in streams with the highest nutrients was about 30 percentage points lower than the algal biological condition in streams with the lowest nutrient concentrations. 


\section{Changes in Nutrient Concentrations: Past and Predicted}

Although concentrations of nitrogen and phosphorus in most streams were relatively stable from 1993 to 2003, the number of streams with increasing concentrations outnumbered those with decreasing concentrations. Nitrate concentrations in groundwater also increased over about the same time span (Chapter 8).

NAWQA findings provide a framework for assessing whether nutrient concentrations in streams and groundwater are changing over time and for predicting concentrations in the future. The assessment considers many of the complexities in nutrient occurrence and transport, both in streams, which can respond quickly, even within hours, and in groundwater systems, which can take from years to decades for changes in quality to occur. In addition, nutrient trend assessments in streams are complex because nutrients are influenced by natural variations in precipitation and streamflow, as well as by human activities that affect nutrient sources (such as fertilizer applications) and transport to streams (including implementation of management practices such as conservation tillage or tile drainage). The natural and human factors often occur simultaneously and thus may either counteract or supplement each other. Some of these complexities are removed in the NAWQA analysis by "flow adjusting" measured nutrient concentrations in streams. Flow adjusting concentrations helps to remove variability in concentrations that may be caused by natural changes in precipitation and streamflow, thereby enabling changes caused by human or land-use changes to be better assessed.

The use of nitrogen and phosphorus fertilizers in the United States has increased over the last century and, more specifically, increased 10-fold and 4-fold, respectively, between about 1950 and the early 1980s. There also has been a more than three-fold increase in population in the Nation since 1900. Increases in nitrogen inputs to the environment since 1900 are reflected in the large increases in concentrations of nitrate in streams in areas as disparate as the Blackstone River in urbanized Massachusetts and the San Joaquin River in the agricultural Central Valley of California (fig. 1-11).

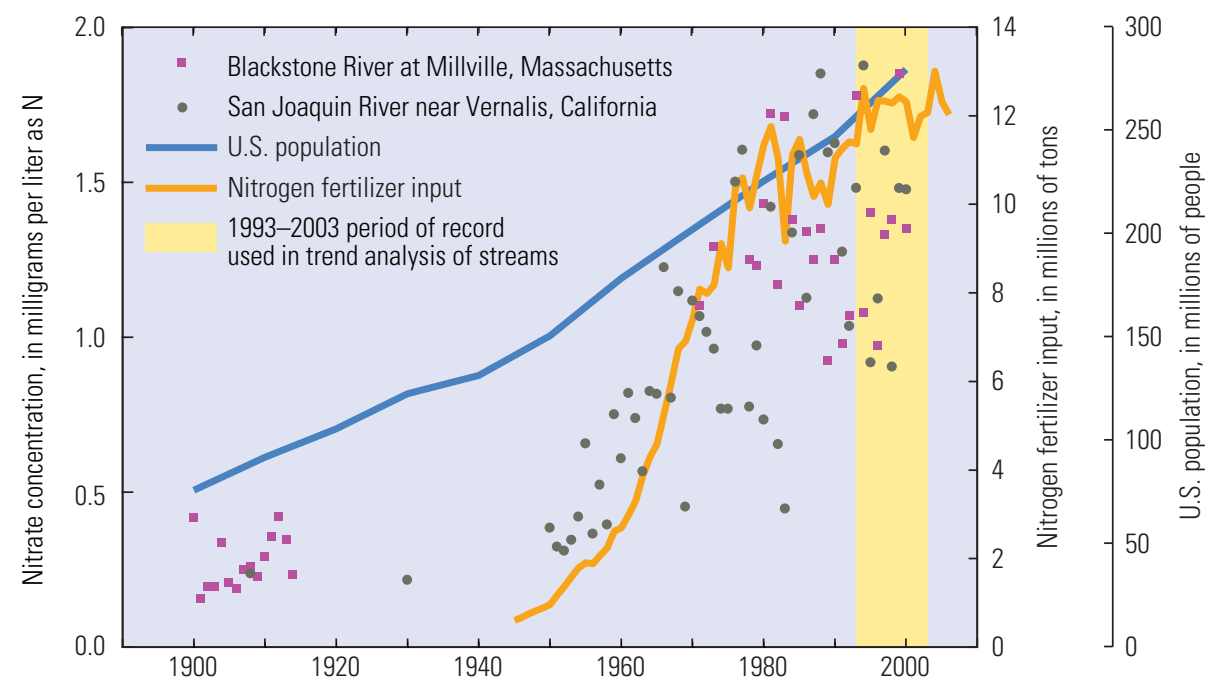

Figure 1-11. The rapid increase in nitrogen inputs to the environment since 1900 is reflected in the large increases in concentrations of nitrate in streams as disparate as the Blackstone River in urbanized Massachusetts and the San Joaquin River in the agricultural Central Valley of California. Since about 1980, application of nitrogen fertilizer has remained relatively stable, as have inputs from manure and nitrogen from atmospheric deposition. The NAWQA assessment reflects changes that may have occurred from 1993 to 2003 (yellow vertical shaded area). 
NAWQA findings reflect periodic measurements of concentrations of phosphorus at 171 stream sites and of concentrations of nitrogen at 137 stream sites from 1993 to 2003 (fig. 1-11, yellow vertical shaded area). This was a period of relatively small changes in nutrient inputs from nonpoint sources that followed larger, sustained increases during much of the 20th century.

No significant flow-adjusted trends were noted at the majority of stream sites for nitrogen (63 percent) or phosphorus (51 percent), suggesting that human and land-use activities contributed minimally to nutrient changes over the decade at these sites. At the remaining sites, there were more upward than downward trends; flow-adjusted concentrations increased at 33 and 21 percent of sites for phosphorus and nitrogen, respectively, and decreased at 16 percent of sites for both nutrients. In some geographic areas and land uses, the flow-adjusted trends were related to changes in sources of nutrients, including fertilizer, manure, and urban sources. For example, at stream sites with greater than 40 percent agricultural land in the basin, increases in manure and fertilizer applications were associated with increasing trends in concentrations of phosphorus.

Geographic patterns in flow-adjusted trends were more obvious for phosphorus than for nitrogen, with upward trends most prevalent in the central and southwestern parts of the United States for phosphorus (fig. 1-12). Increased fertilizer inputs throughout much of the central United States corresponded to widespread increases in phosphorus but not in nitrogen, indicating that the spatial differences between trends in the concentrations of phosphorus and nitrogen may be due to other factors, such as differences in their chemical characteristics. Specifically, some forms of nitrogen are more soluble in water and can move to streams in both surface runoff and groundwater, whereas phosphorus is less soluble in water, tends to attach to soil particles, and thereby preferentially moves to streams in surface runoff. In areas where groundwater contributions to streams are significant, changes in stream nitrogen concentrations can lag changes on the land surface by years or even decades as groundwater moves through the aquifer to streams.

Findings from the flow-adjusted analysis show that human activities contributed to more frequent increases in nutrient concentrations in streams with initial concentrations below the USEPA recommended nutrient criteria than in streams with initial concentrations above the criteria. Nearly 40 and 30 percent of the sites at which concentrations were below the criteria showed upward trends in phosphorus and nitrogen, respectively (fig. 1-13A). Although concentrations at about half of these sites showed no trend, these findings suggest increased risk from human activities on some of our Nation's most pristine streams. Downward trends in nutrient concentrations were more pronounced in streams in which the recommended nutrient criteria were exceeded; the trends in concentrations of phosphorus and nitrogen at nearly 20 percent of these sites were downward (fig. 1-13B).

Overall trends in nutrient concentrations in streams (trends for which concentrations have not been adjusted to remove effects of flow) were upward at fewer sites (24 percent for phosphorus and 11 percent for nitrogen) than flow-adjusted trends noted during 1993 to 2003 (fig. 1-12). This suggests that human-related activities such as those related to increased fertilizer applications did not always result in increased concentrations in streams because they were offset by changes in precipitation and streamflow. The largest difference in flowadjusted versus overall trends in phosphorus concentrations occurred in the Central and Southwestern United States, where drought conditions in the latter part of the study period resulted in reduced surface runoff and streamflow. Concentrations of phosphorus in the streams most likely would have been higher under more normal precipitation and streamflow conditions. The same is true for nitrogen; specifically, differences between upward flow-adjusted trends and overall trends in nitrogen also can be accounted for by downward trends in streamflow at those sites, although these sites are more scattered across the Nation.

The number of downward overall trends was similar to the number of downward flow-adjusted trends in nutrient concentrations from 1993 to 2003 (about 16 percent each for both phosphorus and nitrogen). Streamflow at most of these sites did not change significantly from 1993 to 2003, which suggests that the decreases in nitrogen and phosphorus were often a result of either reduced sources (fertilizers and manure applications and point sources) or improved nutrient management. At sites where initial concentrations were above USEPA's recommended nutrient criteria, concentrations decreased to below the criteria by 2003 in only 2 of 143 streams for nitrogen and 5 of 103 streams for phosphorus. 

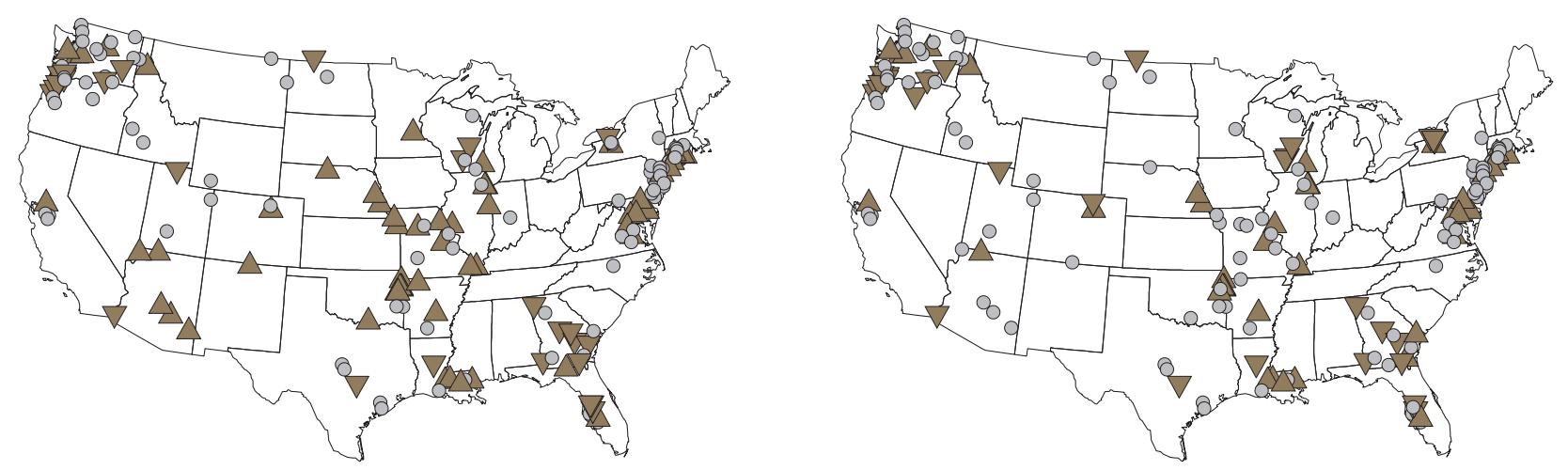

Total nitrogen concentration
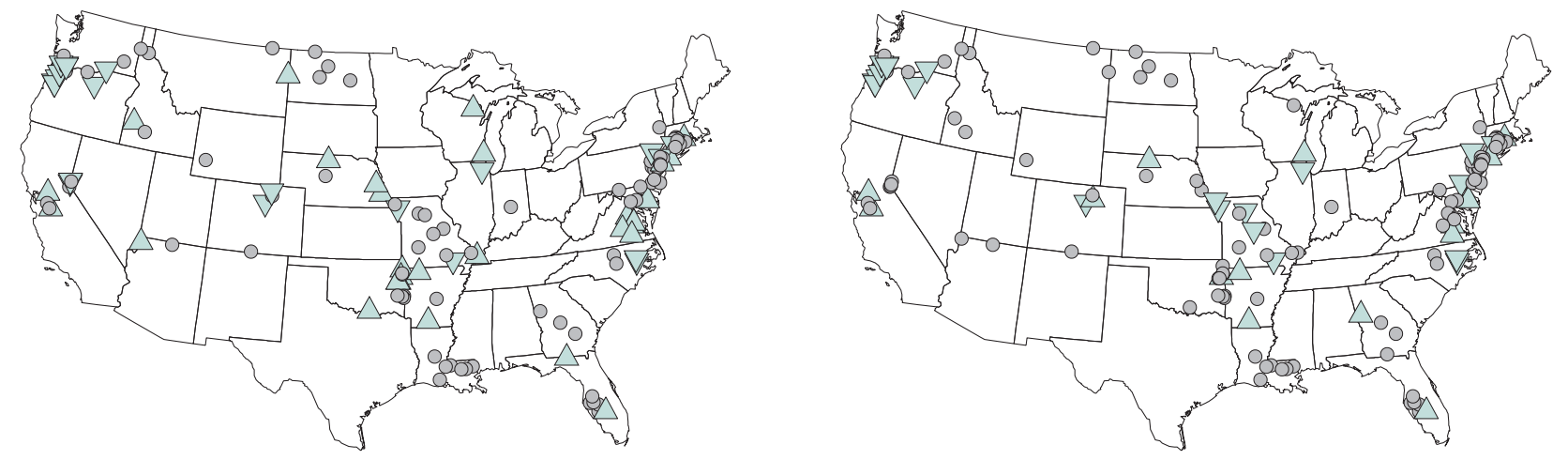

\section{EXPLANATION}

Direction of trend (1993-2003)

$\triangle$ Upward

$\nabla$ Downward

- No significant trend

Figure 1-12. The analysis of flow-adjusted trends indicates that human activities contributed to more increases in nutrient concentrations from 1993 to 2003 (33 and 21 percent for phosphorus and nitrogen, respectively) than decreases (about 16 percent). In the Central and Southwestern United States and parts of the southeast, streamflow decreased at many sites. This resulted in fewer overall trends - which reflect the net effect of all influence on nutrient concentrations in streamsthan flow-adjusted trends. Potential human-related increases in nutrient concentrations at these sites likely were offset by decreases in precipitation and runoff.

The median concentration of nitrate measured in water samples from 495 wells increased from 3.2 to $3.4 \mathrm{mg} / \mathrm{L}$ (6 percent) between the first sampling period of 1988-1995 and the second sampling period of 2001-2004. In shallow groundwater beneath agricultural areas, the median nitrate concentration increased from 4.8 to $5.7 \mathrm{mg} / \mathrm{L}$, whereas in deep groundwater in major aquifers, the median nitrate concentration increased from 1.2 to $1.5 \mathrm{mg} / \mathrm{L}$. The proportion of wells with concentrations of nitrate greater than the USEPA MCL of $10 \mathrm{mg} / \mathrm{L}$ increased from 16 to 21 percent a decade later. 
$\boldsymbol{A}$.

Streams with concentrations in 1993 below USEPA's recommended ecoregional nutrient criteria

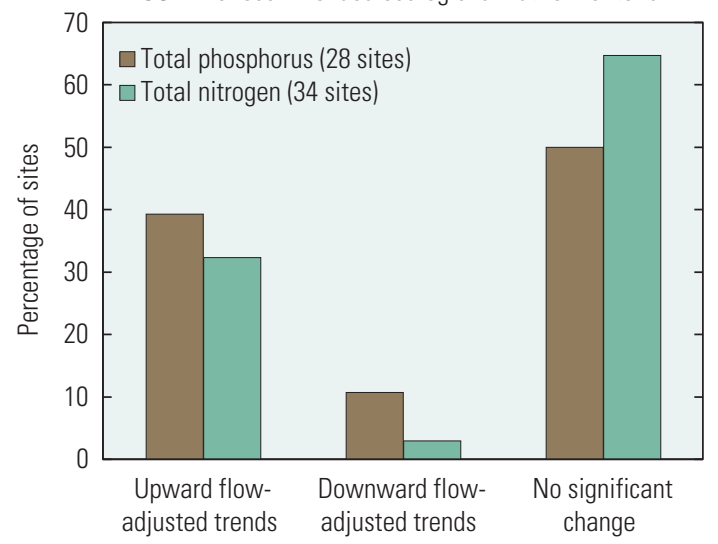

B.

Streams with concentrations in 1993 above USEPA's recommended ecoregional nutrient criteria

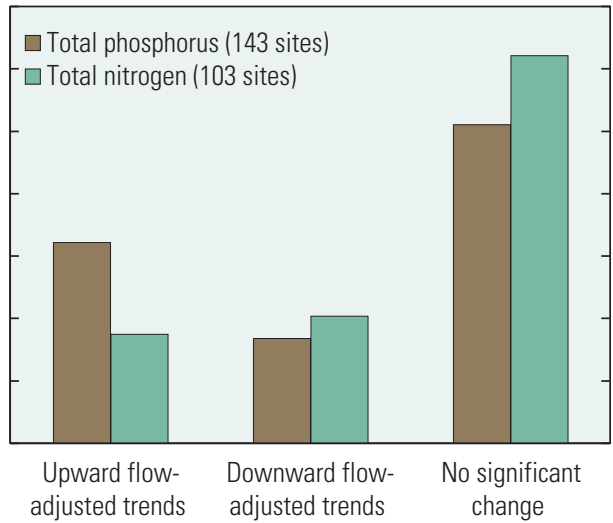

Change between 1993 and 2003

Figure 1-13. Findings from the flow-adjusted analysis show that increasing nutrient concentrations related to human and land-use activities from 1993 to 2003 are more common in streams having nutrient concentrations in 1993 below U.S. Environmental Protection Agency's recommended nutrient criteria than in streams in which those criteria were exceeded. Although concentrations at about one-half of the sites showed no trend, these findings point to increased risk from human activities on some of our Nation's most pristine streams.

Estimates of recharge dates for individual groundwater samples analyzed for nitrate show that concentrations have generally increased since about 1975 (fig. 1-14). Although these samples were collected within a recent and narrow range in time, estimated recharge dates indicate that the time required for the sampled water to travel from the water table to the well intake was in the range of years to decades. Elevated nitrate concentrations appear in shallow groundwater wells as early as the 1950s and 1960s, whereas elevated concentrations in the deep aquifers do not appear until the 1970s. Recharge dates of the sampled groundwater indicate that increases in nitrate concentrations over time are consistent with trends in historical fertilizer use in the United States.

Unlike in many streams, changes in nutrient concentrations in groundwater are probably not associated with current human activities but rather reflect changes in fertilizer applications and land-use practices over time. The lag between what occurs on the land surface and chemical changes in water at a well means that any improvements in water quality that might result from nutrient management practices on the surface may not be apparent for years or decades.

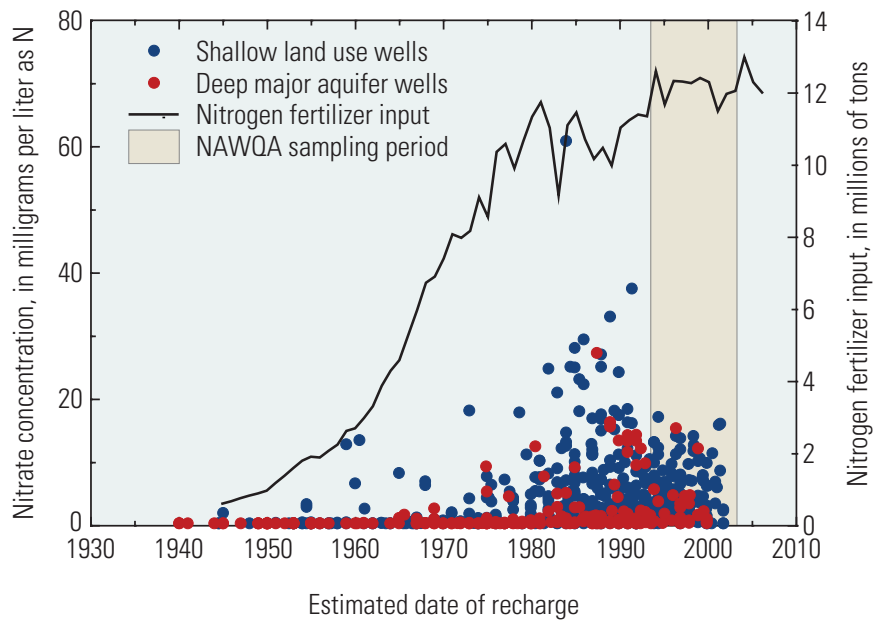

Figure 1-14. Estimates of groundwater recharge dates for individual samples show that nitrate concentrations in groundwater have generally increased since about 1975. Although the samples were collected during a narrow range in time, the range in recharge dates represented by these data spans many decades. 
As a result, in some aquifers, only small changes in nitrate concentrations may be observed from monitoring of relatively deep public-supply wells, whereas larger, more rapid changes in concentration may be observed during the same time period in water from shallow wells.

Redox conditions (the presence or absence of oxygen) in an aquifer influence changes in nitrate in groundwater over time. In aquifers with chemically reduced conditions, changes in nitrate concentrations in the aquifer were very small because of the conversion of nitrate to inert nitrogen gas by bacteria (denitrification). In contrast, changes in nitrate concentration over time in groundwater under oxic conditions can be large because nitrate is stable and persistent under these conditions.

\section{Implications}

- Long-term and consistent monitoring of nutrients in streams and groundwater is essential for distinguishing actual trends from short-term fluctuations and for accurately tracking changes. This is particularly important because nutrient concentrations in streams and groundwater will continue to respond to climatic and landscape changes.

- Upward trends in concentrations of phosphorus and nitrogen in streams were evident among all land uses, including those only minimally affected (as indicated by nutrient concentrations lower than USEPA's recommended nutrient criteria). These findings point to increased risk of impact from human activities on some of our Nation's most pristine streams.

- Understanding the causes of trends in concentrations of nutrients in streams requires an understanding of streamflow and natural and landscape factors, as well as information on changes in land-use and nutrient management activities over time.
- Understanding the causes of trends in concentrations of nitrate in groundwater usually requires estimates of groundwater age, redox conditions, and an understanding of the groundwater flow system because of local and regional complexities in groundwater flow paths.

- Nitrate concentrations in deep oxic aquifers used as a source of water supply are likely to increase during the next decade as shallow groundwater with high concentrations moves deeper into aquifers. These increases will continue to occur for some period of time even if nitrogen inputs on the land surface decrease.

- Improvements in nutrient management practices on the land surface may take years to decades to produce improved groundwater quality because of the slow rate of groundwater flow. Similar time lags also are expected for streams that receive considerable groundwater discharge. 
This page intentionally left blank 


\section{Chapter}

\section{Nutrient Primer}

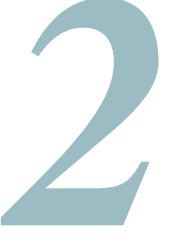

\section{Introduction}

Nutrients - nitrogen and phosphorusare chemical compounds that are essential to life and important for natural plant and animal growth. Efforts to increase food production to meet the demands of a growing global population have greatly increased the use of fertilizers, which have, in turn, increased the occurrence, loads, and concentrations of nutrients in streams and groundwater. Elevated concentrations of nutrients can cause a variety of problems, including degradation of ecosystems, recreational activities, and human health. Many factors affect the transport and concentrations of nutrients in streams and groundwater, including the intensity and distribution of fertilizer use; land management practices and other anthropogenic activities; natural factors, such as soil and aquifer characteristics, and hydrology; and the chemical properties of the nutrient compounds themselves.

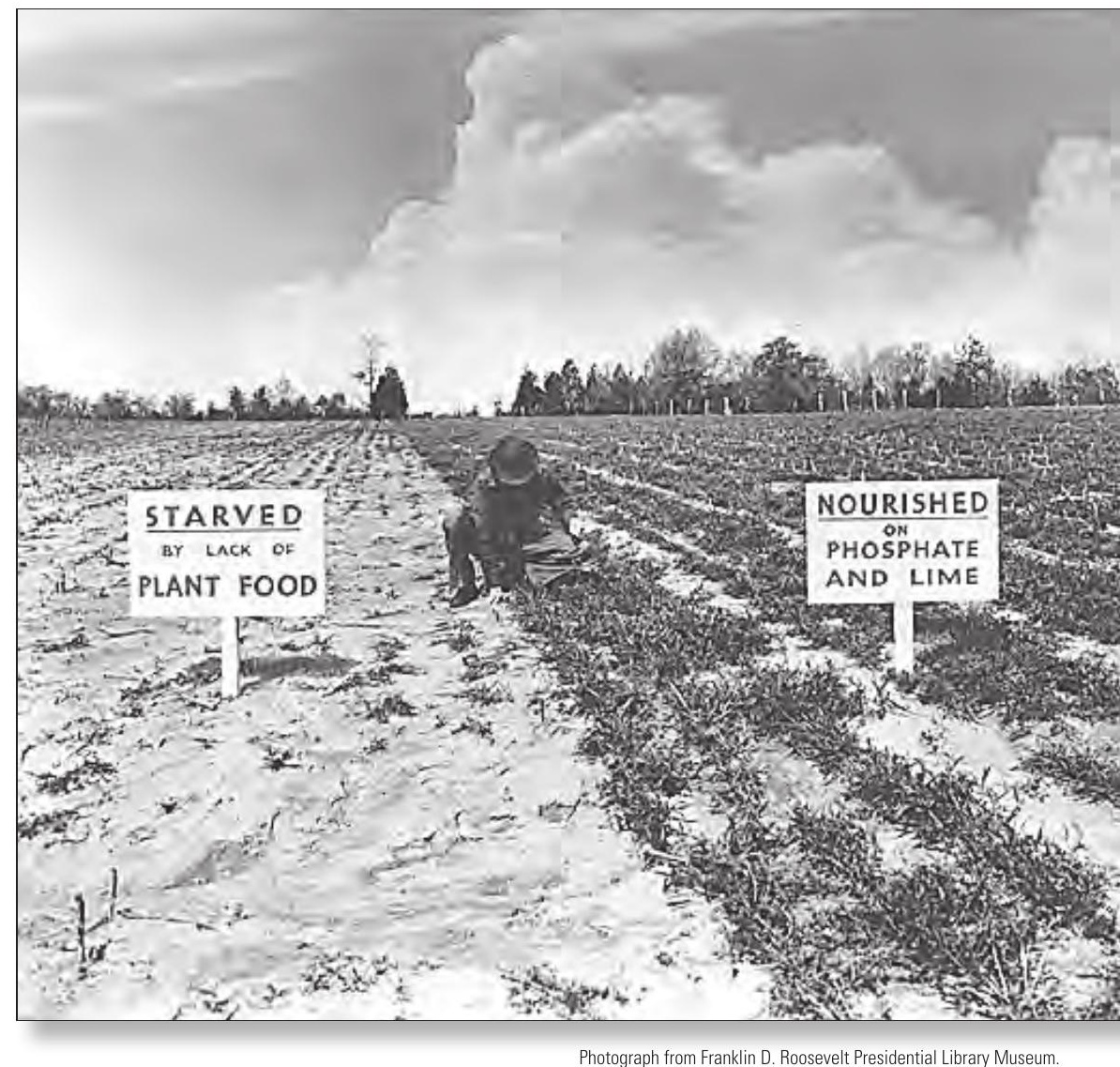




\section{Nutrients and Their Sources}

Nutrients are essential for healthy plant and animal populations and provide a range of benefits, including increased food production for a growing global population. Too many nutrients, however, are not necessarily a good thing, and can have adverse effects on water quality, drinking-water sources, recreation, and aquatic life (see sidebar, Concerns about Elevated Nutrients in Water). For example, excessive nitrate in drinking water can lead to "blue-baby syndrome," in which oxygen levels in the blood become too low, sometimes with fatal results. Elevated concentrations of nitrogen and phosphorus in surface water can cause excessive growth of algae and other nuisance aquatic plants (a condition known as eutrophication). These plants can clog pipes and interfere with recreational activities such as fishing, swimming, and boating. Subsequent decay of algae can result in foul odors and a decrease in the amount of dissolved oxygen in water, also known as hypoxia. Hypoxic conditions, such as those found in the Gulf of Mexico, can harm fish and shellfish that are economically and ecologically important to the Nation. Societal concerns for the quality of our surface waters continue to increase, as many of the Nation's streams and coastal waters do not meet water-quality goals. Data submitted by States in 2004, the most recent reporting date to the U.S. Environmental Protection Agency (USEPA) (2009), indicate that 51 percent of the waters they surveyed are too contaminated for basic uses, such as fishing and swimming, because of their nutrient content.

\section{Concerns about Elevated Nutrients in Water}

The Clean Water Act of 1972 requires that States establish water-quality standards for water bodies, such as lakes and streams, "taking into consideration their use and value for public water supplies, propagation of fish and wildlife, recreational purposes, and agriculture, industrial, and other purposes, and also taking into consideration their use and value for navigation." [Section 303(c)(2)(A)]. Although nitrogen and phosphorus are essential nutrients, elevated concentrations can lead to a variety of direct and indirect impairment of water bodies for many uses, including drinking water, recreation, and aquatic life.

\section{Drinking-Water Supplies and Human Health}

The USEPA has set a standard of $10 \mathrm{mg} / \mathrm{L}$ as $\mathrm{N}$ of nitrate for drinking water to protect against methemoglobinemia, or "blue-baby syndrome," a disorder in which the oxygen-carrying capacity of the blood is compromised. Intake of nitrate and nitrite in drinking water also has been implicated in other human health problems, including specific cancers and reproductive problems, although more research is needed to verify these associations (see Chapter 6 sidebar, Nitrate in Drinking Water: Potential Health Effects; Ward and others, 2005). Indirect effects of nutrient enrichment in surface waters on human health are numerous and complex. For example, algal blooms caused by nutrient enrichment may lead to algal toxins in water supplies (Lopez and others, 2008), an increase in the production of carcinogenic disinfection byproducts during chlorination of drinking water, and the potential for increased disease transmission due to an increase in mosquito populations (Townsend and others, 2003). Objectionable taste and odor are secondary issues related to nutrient-induced algal blooms that, while not a health hazard, are costly for drinking-water managers.

\section{Recreational Uses}

Elevated nutrients can cause algal blooms and over-growth of other aquatic plants, which can cause aesthetic impairment, and interfere with recreational swimming and boating. In Nebraska, for example, the Department of Environmental Quality posts health alerts to warn residents when algal toxins reach levels unfit for recreational activities in specific lakes (Nebraska Department of Environmental Quality, 2009).

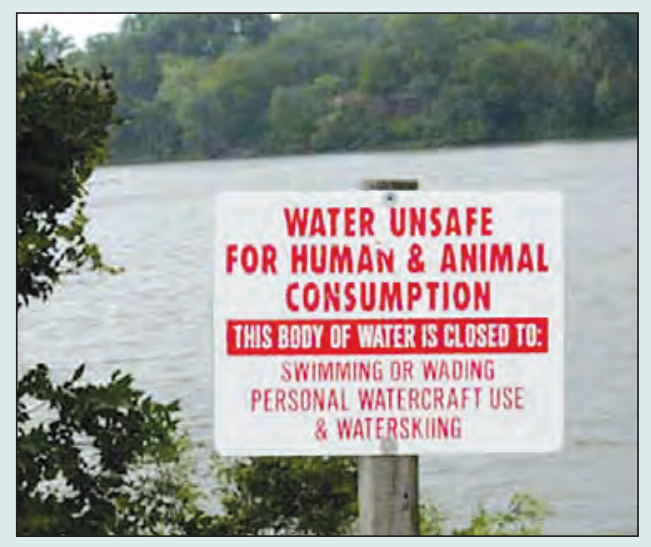

In Nebraska, the Department of alerts to warn residents when algal toxins in lakes reach levels that make them unfit for recreational activities. Photograph courtesy of Tadd Barrow, University of Nebraska, Lincoln. Environmental Quality posts health 


\section{Biological Condition of Freshwaters}

Excessive nutrients and the resulting excessive plant biomass can have negative impacts on aquatic life. Increased plant biomass due to nutrient enrichment can cause a wide range of problems including a reduction in levels of dissolved oxygen (critical for aquatic life), decrease in quality of habitat, decrease in water clarity, enhancement of the growth of invasive species and toxic algae, and overall alteration of biological health (Lopez and others, 2008). Less often, ammonia concentrations reach levels toxic to fish, and national standards have been established for both acute and chronic exposure. In some settings and during different times of year, excessive nutrients can lead to "Harmful Algal Blooms," or HABs, in which the population of algae grows to abnormal levels and either produces toxic compounds and (or) causes severe oxygen depletion associated with the die-off of the algal bloom (Bushaw-Newton and Sellner, 1999; Lopez and others, 2008). HABs are most commonly found in eastern coastal waters and are due primarily to tiny marine organisms called dinoflagellates. Although HABs are less well documented in freshwater, most cases in northern States are associated with blue-green algae (Lopez and others, 2008); however, the golden algae Prymnesium parvum is documented as a producer of a potent toxin to fish in freshwaters in southern States (Lopez and others, 2008).

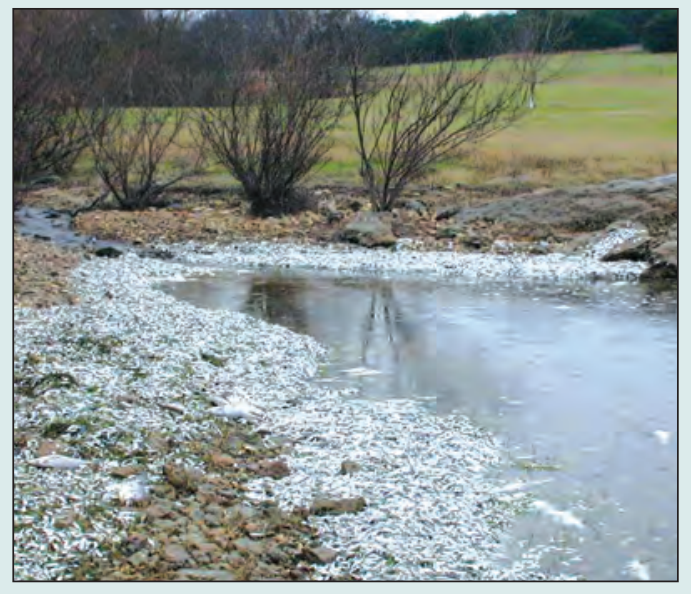

Fish kill associated with a bloom of the golden algae, Prymnesium parvum, on Lake Whitney in Texas forms a silver band of dead fish along the shoreline. Photograph courtesy of Joan Glass, Texas Parks and Wildlife Department, from Lopez and others (2008).

\section{Hypoxia in Coastal Waters and the Great Lakes}

Most recently, HABs have been identified as a major cause of ecological disturbance in large water bodies. The decay of excessive algal biomass can deplete the dissolved oxygen in water, creating a condition called hypoxia (dissolved oxygen less than $2 \mathrm{mg} / \mathrm{L}$ ). This can result in stress or death of near-bottom or bottom-dwelling organisms. Hypoxia in coastal regions that receive excess nutrients from rivers is a serious global problem, and hypoxic conditions plague critical waters in the United States including the Gulf of Mexico near the Mississippi River, the Chesapeake Bay, Puget Sound, and Lake Erie. Development of hypoxic conditions can have consequences for economic activities including fisheries and tourism (fig. 2-1).

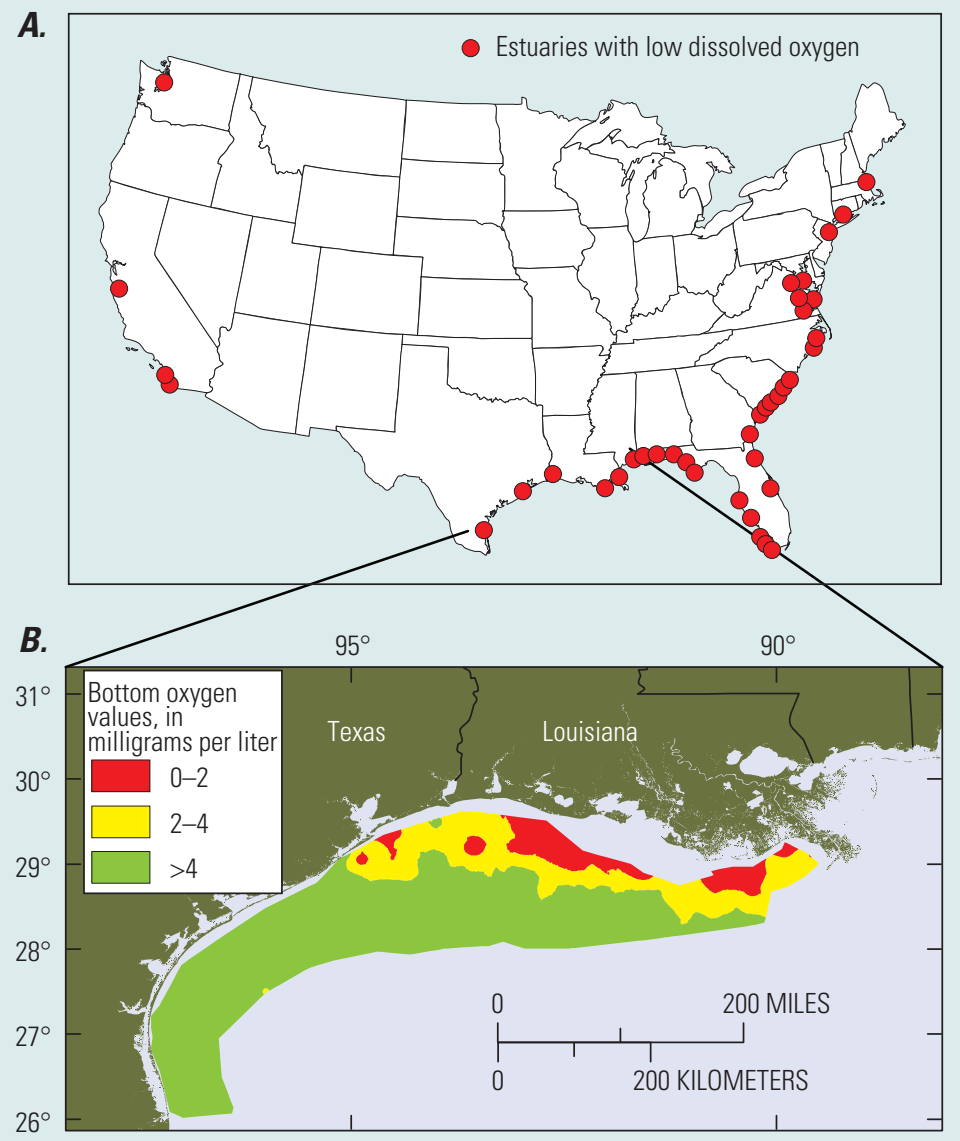

Figure 2-1. Excess nutrients in runoff have resulted in hypoxia-low dissolved oxygen concentrations in water-in estuaries around the country $(A)$, including the Gulf of Mexico $(B)$. ( $A$, modified from National Science and Technology Council Committee on Environmental and Natural Resources, 2003; and B, data from National Oceanic and Atmospheric Administration, 2004.) 


\section{Nutrients Occur in Dissolved and Particulate Forms}

Nutrients occur in several forms, including total nitrogen, nitrate, ammonia, total phosphorus and phosphate (see "Nutrient Forms"). Nitrogen forms available for plant uptake include dissolved inorganic nitrogen (ammonia, nitrate, and nitrite) and organic nitrogen. Nitrate is the primary form of nitrogen dissolved in streams and groundwater. Organic nitrogen, mostly from plant material or organic contaminants, can be dissolved or particulate (bound to sediment or in plant and animal tissue) and can contribute substantially to total nitrogen levels in streams.

The most readily available form of phosphorus for plants is dissolved phosphate, which typically constitutes the majority of the dissolved phosphorus in natural water, and is generally reported as orthophosphate. In addition to dissolved phosphate, total phosphorus includes other forms, such as particulate organic phosphorus, which is mostly from plant material and usually bound to sediment.

\section{Nutrients Occur Naturally but Most are Derived from Human Sources}

Although nitrogen gas constitutes 78 percent of the Earth's atmosphere, most plants and animals cannot utilize it directly, and therefore, they rely on processes that convert nitrogen gas into useable inorganic forms. For example, lightning and nitrogen "fixing" organisms, including legumes, bacteria, and algae, can convert nitrogen gas into biologically useable forms, such as ammonium and nitrate. Phosphorus also occurs naturally, in large part, from phosphate minerals in sediment and rocks.

The natural global nitrogen cycle has been extensively altered through production and application of nitrogen fertilizers, cultivation of nitrogen-fixing crops, animal waste disposal, wastewater and industrial discharges, and combustion of fossil fuels (Galloway and others, 1995; Vitousek and others, 1997). These human alterations have approximately doubled the rate of nitrogen inputs into the terrestrial nitrogen cycle and have greatly increased the transfer of nitrogen from rivers to estuaries and other sensitive receiving waters. Human activities also have profoundly influenced the cycling of phosphorus through the environment, doubling the rate of phosphorus delivery from land to the oceans (Howarth and others, 2000).

The next 50 years will likely see rapid agricultural expansion in response to demand for food and a projected 50-percent increase in global population, which could lead

\section{Nutrient Forms}

Five measures of nitrogen- and phosphorus-containing nutrients are discussed in this report. All forms of nutrients discussed in this report are expressed as concentrations of either nitrogen or phosphorus. For example, a nitrate concentration expressed as 10 milligrams per liter $(\mathrm{mg} / \mathrm{L})$ refers to a nitrate concentration of $10 \mathrm{mg} / \mathrm{L}$ as nitrogen (as N).

- Total nitrogen includes nitrogen in all its formsnitrate, nitrite, ammonia, and organic nitrogen. Nitrite generally is unstable in surface water and contributes little to the total concentration of nitrogen in water. Organic nitrogen (mostly from plant material or organic contaminants) can exist in considerable proportions and contribute substantially to concentrations of total nitrogen in streams.

- Nitrate, a compound of nitrogen and oxygen, is the primary form of nitrogen dissolved in streams and groundwater. In this report, nitrate refers to the sum of nitrate plus nitrite, because nitrite concentrations commonly were negligible.

- Ammonia, a compound of nitrogen and hydrogen, is a dissolved form of nitrogen that is less common than nitrate. As measured by the USGS laboratory, total ammonia includes ammonium ion and un-ionized ammonia. Un-ionized ammonia typically is a minor component of ammonia at acidity levels (or pH levels) commonly observed in streams and groundwater.

- Total phosphorus is usually bound to sediment, and generally includes dissolved phosphates and particulate organic phosphorus (mostly from plant material).

- Phosphates, compounds of phosphorus, oxygen, and hydrogen, typically constitute the majority of the dissolved phosphorus in natural water, and are referred to as orthophosphate. Orthophosphate can be readily assimilated by aquatic plants.

to a 2.5 -fold increase in nitrogen- and phosphorus-driven eutrophication (Tilman and others, 2001). Control of the delivery of these nutrients into the environment is complicated by cycling, in that nitrogen and phosphorus can be reintroduced into a system because of remobilization and biological activity long after nutrient inputs into the system have decreased. 


\section{Human-Related Sources Include Point and Nonpoint Sources of Contamination}

Human-related sources of nutrients can be classified as either point or nonpoint contamination. Point sources, such as those from municipal and industrial discharges and concentrated animal feeding operations, are regulated by laws that place limits on the types and amounts of contaminants that can be released to water. Legislation, starting in 1972 with the Clean Water Act, has resulted in upgrades to wastewater-treatment plants and reductions in industrial sources of nutrients. Although violations still occur, legislation has had a positive influence on limiting the nutrients that enter water systems.

Nonpoint sources of nutrients include applications of commercial fertilizers on agricultural and residential lands, and nutrients from livestock and pet wastes and from septic systems. Atmospheric deposition also is a nonpoint source of nitrogen, which is derived either naturally from chemical reactions (such as through lightning) or from the combustion of fossil fuels, such as in coal-fired power plants, or volatilization of ammonia from fertilizer and manure (U.S. Environmental Protection Agency, 2002). Under some circumstances, nitrogen fixed by leguminous crops or stored in the soil can become a nonpoint source. Nutrients derived from nonpoint sources can be transported to streams in runoff from precipitation or irrigated fields, with inflowing groundwater, or through drainage ditches and subsurface tile-drain systems (hereinafter referred to as tile drains).

Limiting nutrients from nonpoint sources is difficult because these sources are widespread and thus more difficult to identify and quantify than point sources. In fact, nonpoint-source contamination is the leading and most widespread cause of nutrient degradation of water; NAWQA studies estimate that more than 90 percent of nitrogen and phosphorus released to the environment originates from nonpoint sources (Puckett, 1995); the remaining percentages are from point sources.

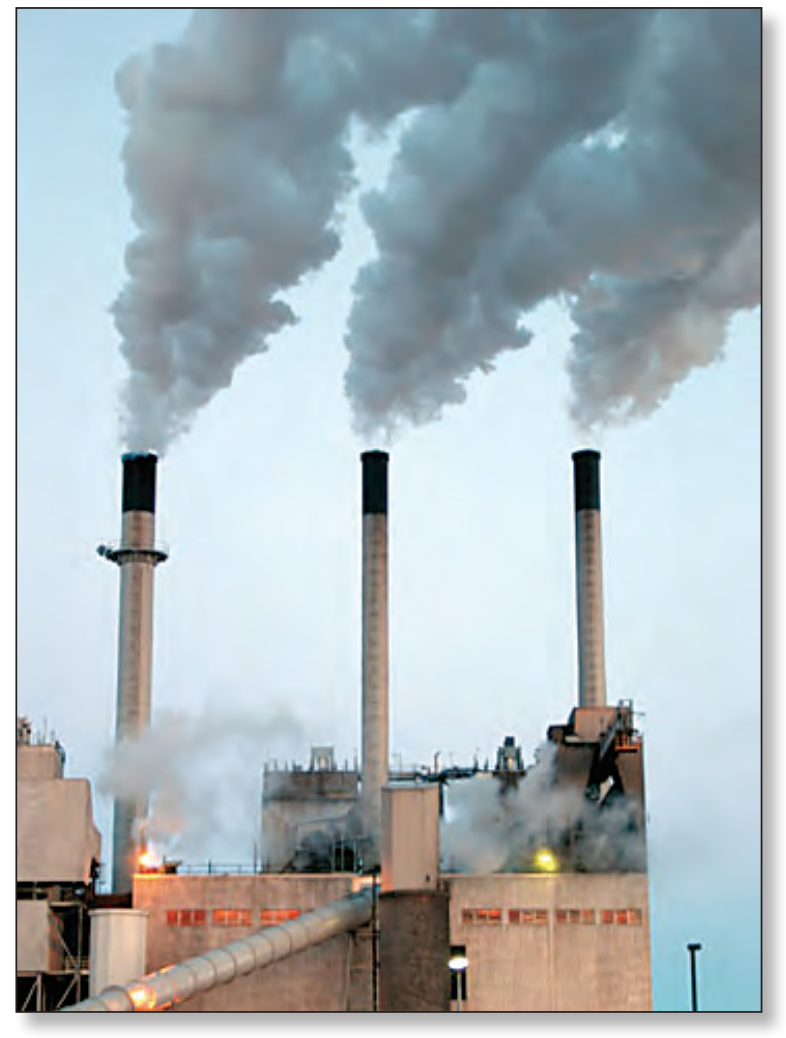

Coal-fired power plants are sources of nitrogen in atmospheric deposition. Photograph by U.S. Geological Survey. 


\section{Nutrient Sources Have Increased Over the Last Century but Have Remained Stable Since about 1980}

The use of nitrogen and phosphorus fertilizers has increased over the last century, by 10 -fold and 4-fold, respectively, between about 1950 and the early 1980s (fig. 2-2). The increase was due, in large part, to increases in areal application rates (the amount of fertilizer applied to each acre for some major crops) and an increase in the acreage of treated land. For example, the areal application rate of nitrogen fertilizer to corn grown in the Midwest increased from 49 to 129 pounds per acre from 1965 to 1980, after which it remained stable (Cassman and others, 2002).

Since about 1980, applications of nitrogen and phosphorus fertilizers have leveled off and have since remained relatively stable (fig. 2-2). This is due in large part to increasing fertilizer costs, growing environmental concerns, and changing agricultural and waste management practices, which have reversed or slowed the pace of increasing use. Nitrogen and phosphorus from manure and nitrogen from the atmosphere also have remained relatively stable since the 1980s (fig. 2-2).

Nationally, commercial fertilizer is the largest single nonpoint source of nutrients. More than 10 million tons of nitrogen and nearly 2 million tons of phosphorus are applied each year as commercial fertilizer (fig. 2-2). Most of the applications are for agricultural purposes, although a small portion, about 2 to 4 percent, of the total nitrogen fertilizer is used in nonagricultural settings such as city parks, golf courses, and residential lawns.

About 6 million tons of nitrogen and nearly 2 million tons of phosphorus are excreted as manure each year. The mass of nitrogen in manure produced by livestock is about one-half as much as that applied in fertilizer and has varied little since data became available in 1982. The mass of phosphorus in manure is about the same as phosphorus applied in fertilizer, and also has varied little since 1982 (fig. 2-2).

A significant proportion of the commercial fertilizer and manure that is applied to crops is taken up by the plants and removed from the fields, and hence does not contribute to environmental problems. Nitrogen uptake efficiencies have increased over the past two decades, and although uptake efficiencies as high as 80 percent in major cereal crops have been attained in controlled research experiments, uptake efficiencies on production farms usually range from 18 to 49 percent (Cassman and others, 2002).

Atmospheric deposition contributes about one-half as much nitrogen as manure does, and less than one-quarter as much nitrogen as does fertilizer application. Specifically, about 2.5 million tons of nitrogen are deposited in the United States each year from the atmosphere (fig. 2-2). Phosphorus generally does not enter the environment with atmospheric deposition.

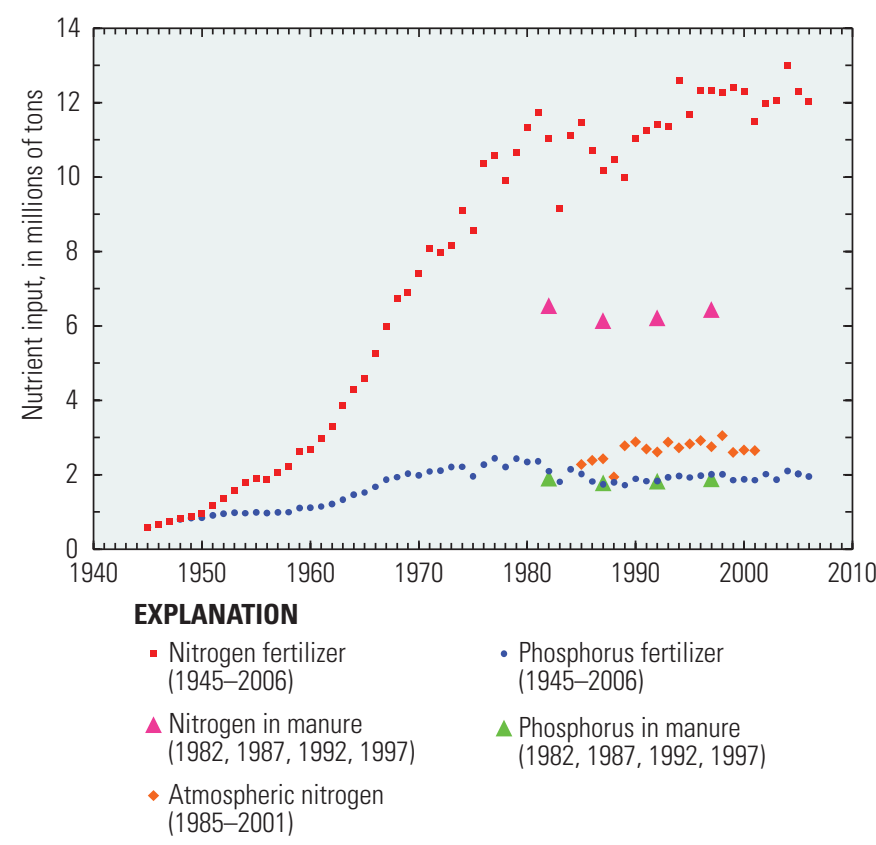

Figure 2-2. The use of nitrogen and phosphorus fertilizers has increased 10-fold and 4-fold, respectively, between about 1950 and the early 1980s. Since about 1980, however, applications of nitrogen and phosphorus fertilizers have leveled off and have remained relatively stable. Nitrogen and phosphorus from manure and nitrogen from the atmosphere also have remained relatively stable since the 1980s. (Modified from Ruddy and others, 2006.)

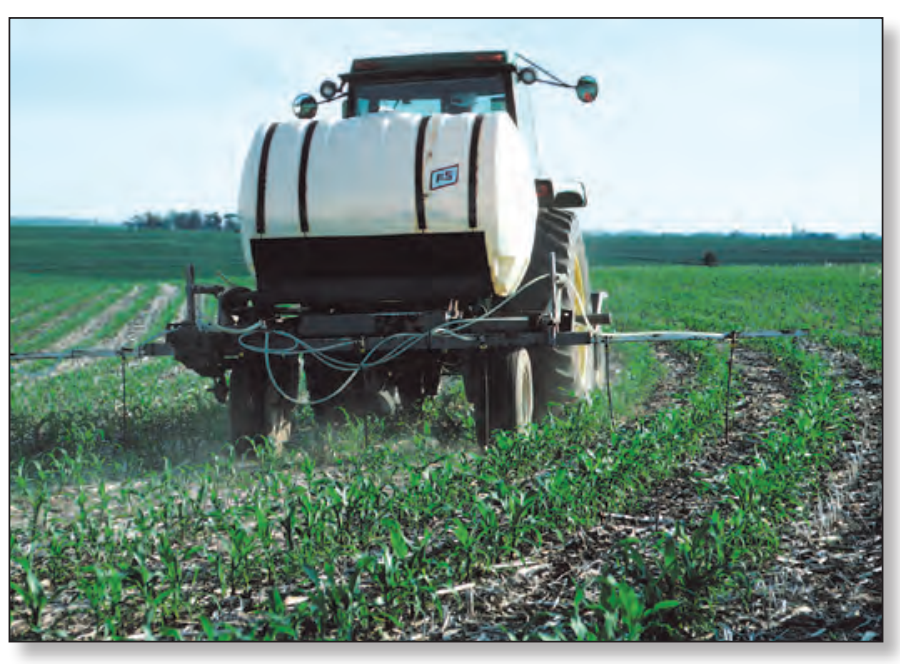

Fertilizer is used extensively in corn and soybean growing areas of lowa. Photograph by Lynn Betts, U.S. Department of Agriculture, Natural Resources Conservation Service. 


\section{Sources of Nutrients by Land Use and Crop Type}

The NAWQA approach to categorizing stream basins results in different sources of nitrogen and phosphorus predominating in streams that represent different land-use categories. Commercial fertilizers constitute more than 60 percent of nitrogen and phosphorus inputs to agricultural basins, and more than 50 percent to urban basins (fig. 2-3). Manure also can be a significant source of nutrients in agricultural watersheds, accounting for about 25 percent and nearly 40 percent, respectively, of nitrogen and phosphorus inputs. Animal manure on pasture and rangelands, and atmospheric deposition, are the largest contributors of nutrients in undeveloped lands.
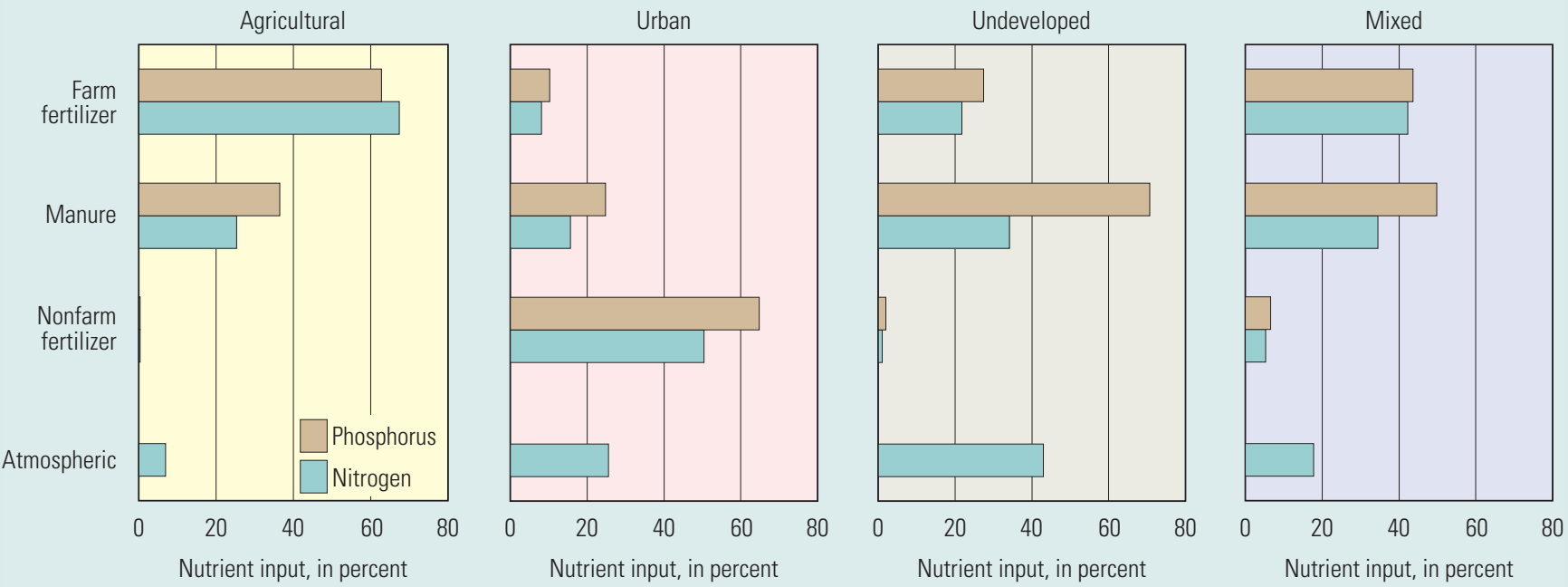

Data on atmospheric phosphorus inputs not available.

Figure 2-3. Different sources of nitrogen and phosphorus predominate in streams that represent different land-use categories. (See table 3-1 for definition of land-use categories.)

In general, the use of commercial fertilizers on agricultural land varies, depending on the type of crop, with the highest areal rates of application on corn (about 130 pounds of nitrogen per acre; fig. 2-4A). Corn also received the largest proportion of nitrogen from commercial fertilizer, representing about 40 percent of the total use in 1997 (fig. 2-4B). In contrast, the areal rate of nitrogen fertilizer application on soybean plants is relatively low (about 30 pounds per acre; fig. 2-4A) because bacteria in the roots of soybean plants are capable of extracting, or "fixing," nitrogen gas from the atmosphere. As a consequence, less than 2 percent of the nitrogen from commercial fertilizer was used on soybean cultivation in 1997 (fig. 2-4B).
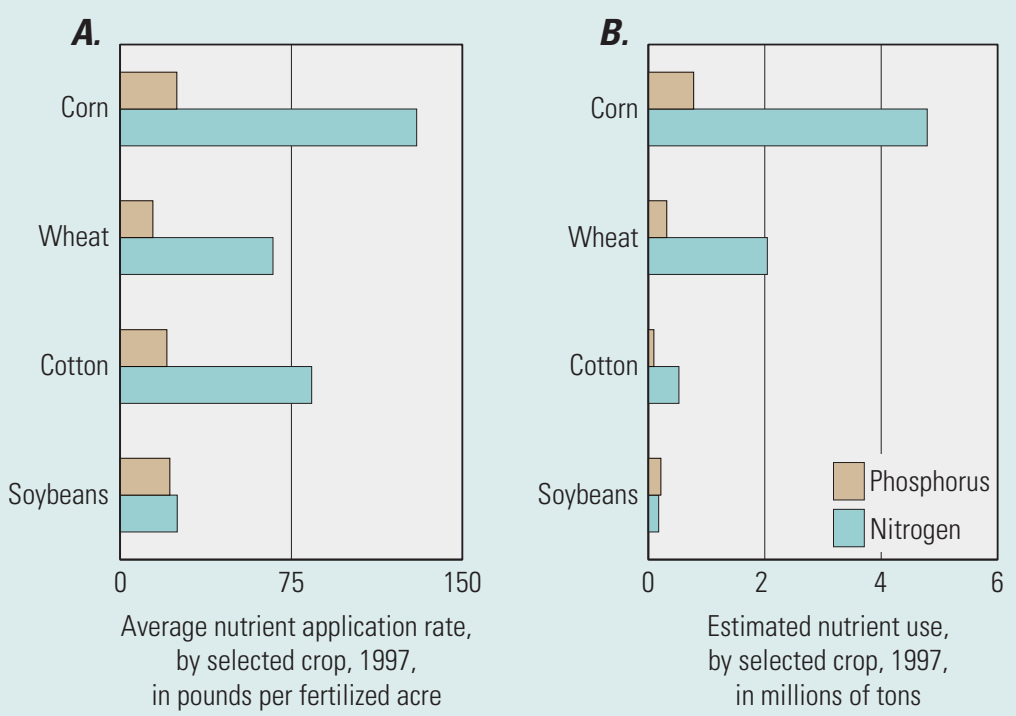

Figure 2-4. Both the areal rate of fertilizer application $(A)$ and the total use $(B)$ vary widely among major crops (U.S. Department of Agriculture, 2006). 
From about 1940 to 1970 , laundry detergent was a major source of phosphorus to the environment. Contributions decreased to almost negligible amounts, however, after the enactment of State bans on the use of phosphate detergent beginning in the 1970s and the voluntary cessation of phosphate use by detergent manufacturers. As a result, the use of phosphorus in detergents decreased from a peak of 220,000 metric tons in 1967 to less than 10,000 metric tons in 1995 (Litke, 1999).

Sources of ammonia also have decreased since the early 1970s when legislation was enacted to improve the treatment of wastewater. The decreased ammonia concentrations achieved through treatment nitrification (or the oxidation of ammonia to nitrate) of wastewater prior to discharge also has increased levels of dissolved oxygen in streams, which can help to improve the health of fish communities. However, because ammonia is converted to nitrate during nitrification, nitrate has increased in some streams downstream from wastewater-treatment plants, such as in the Trinity River, Texas (see Chapter 8 sidebar, Past Changes Resulting from Nutrient Control Measures).

\section{Sources of Nutrients Vary Geographically and by Land Use}

The relative contributions of the different nonpoint nutrient sources vary in different geographic regions of the country (fig. 2-5) and can be explained, in large part, by the distribution of agricultural, urban, and undeveloped land use (see sidebar, Sources of Nutrients by Land Use and Crop Type). The highest rates of farm fertilizer nitrogen application are in the upper Midwest, where an application rate of 40,000 pounds per square mile $\left(\mathrm{lb} / \mathrm{mi}^{2}\right)$ is exceeded over an extensive area from Indiana to Nebraska. Farm fertilizer nitrogen application rates are also high in parts of the irrigated West, such as the Snake River Plain in southern Idaho, California's San Joaquin Valley, parts of Florida, and parts of the east coast.
Some parts of the Southeast and Southern Plains and the extensive western rangelands receive high loads of nitrogen (locally exceeding $40,000 \mathrm{lb} / \mathrm{mi}^{2}$ ) in the form of manure, but such areas of high manure applications are not as extensive as those of high applications of commercial fertilizers. Manure from animals that are restricted to confined feeding operations, such as at dairies or feedlots, is usually stored onsite for later use on adjacent agricultural land; manure from free-ranging livestock is not recovered, but rather is distributed across the grasslands, shrublands, and forests used for grazing.

Nitrogen applications of nonfarm fertilizer, such as that used on lawns in residential areas, generally are restricted to population centers, and rarely exceed $10,000 \mathrm{lb} / \mathrm{mi}^{2}$ outside of densely populated areas (fig. 2-5).

Atmospheric sources of nitrogen are highest in the eastern part of the country, where the deposition rates are highest (fig. 2-5). In general, the rate of atmospheric deposition of nitrogen increases progressively from the west to east. The highest deposition rates of nitrogen occur in a broad band from the upper Midwest through the Northeast. 

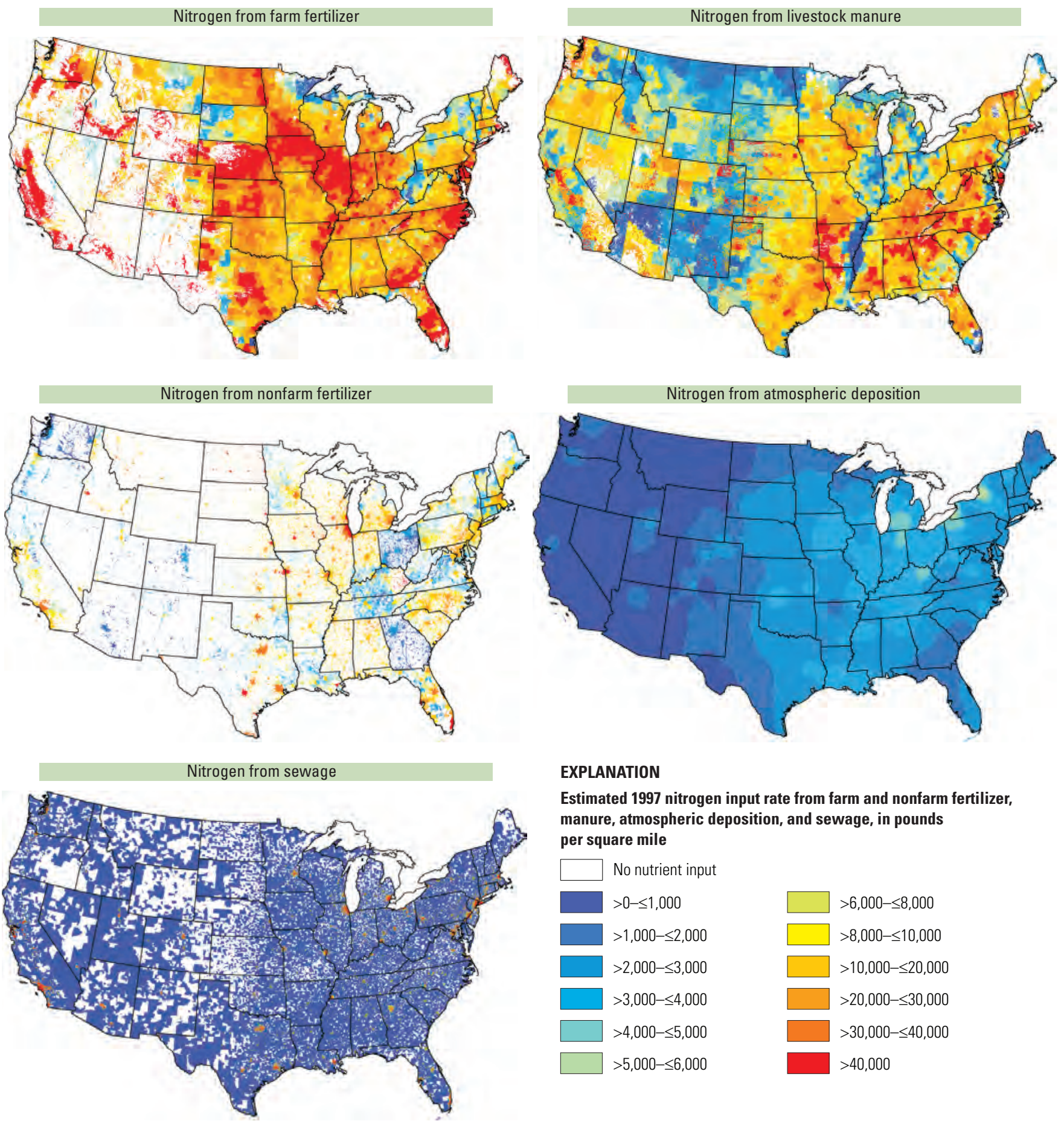

EXPLANATION

Estimated 1997 nitrogen input rate from farm and nonfarm fertilizer, manure, atmospheric deposition, and sewage, in pounds per square mile

\begin{tabular}{|c|c|}
\hline No nutrient input & \\
\hline$>0-\leq 1,000$ & $>6,000-\leq 8,000$ \\
\hline$>1,000-\leq 2,000$ & $>8,000-\leq 10,000$ \\
\hline$>2,000-\leq 3,000$ & $>10,000-\leq 20,000$ \\
\hline$>3,000-\leq 4,000$ & $>20,000-\leq 30,000$ \\
\hline$>4,000-\leq 5,000$ & $>30,000-\leq 40,000$ \\
\hline$>5,000-\leq 6,000$ & $>40,000$ \\
\hline
\end{tabular}

Figure 2-5. The highest rates of commercial fertilizer applications of nitrogen are in agricultural areas of the upper Midwest, and parts of the Great Plains, the Northwest, California, and the southeast Atlantic Coastal Plain. Commercial fertilizers also are a leading source of nutrients in urban areas around the Nation. Manure sources dominate in parts of the South and Southeast and in extensive western rangelands. Atmospheric sources are highest in the eastern part of the country, where the deposition rates are highest, and increase from west to east. 


\section{Different Sources of Nitrogen Predominate in Different Regions of the Country}

Fertilizer is the predominant source of nitrogen in most agricultural areas (fig. 2-6), including in the Midwest and Great Plains (White River Basin, Indiana), the irrigated West (Palouse River Basin, Washington, and the San Joaquin River Basin, California), and in parts of the Southeast. Nutrients from manure, however, can dominate those from commercial fertilizers in some agricultural watersheds with large populations of confined livestock, such as in parts of the East, South, and Southeast (see areas exceeding 40,000 lb/ $\mathrm{mi}^{2}$, fig. 2-5), including in the White River Basin in Arkansas, the Susquehanna River Basin in Pennsylvania, and in the extensive western rangelands (fig. 2-6).
Some urban watersheds receive significant nutrient inputs from wastewater-treatment plants, such as in the South Platte River Basin, Colorado (fig. 2-6). Occasionally, streams are dominated by wastewater effluent from treatment plants; this circumstance is more common in urban areas of the semiarid West, including parts of Arizona, Nevada, and southern California, where wastewater-treatment plant effluent may be the predominant source of water in a stream during dry seasons.

Atmospheric deposition is the largest nonpoint source of nitrogen in undeveloped watersheds in the eastern part of the country where the deposition rates are highest, such as in the Connecticut River Basin, Connecticut (fig. 2-6), and in areas near the Great Lakes and the arid and mountainous West where human development is very sparse.

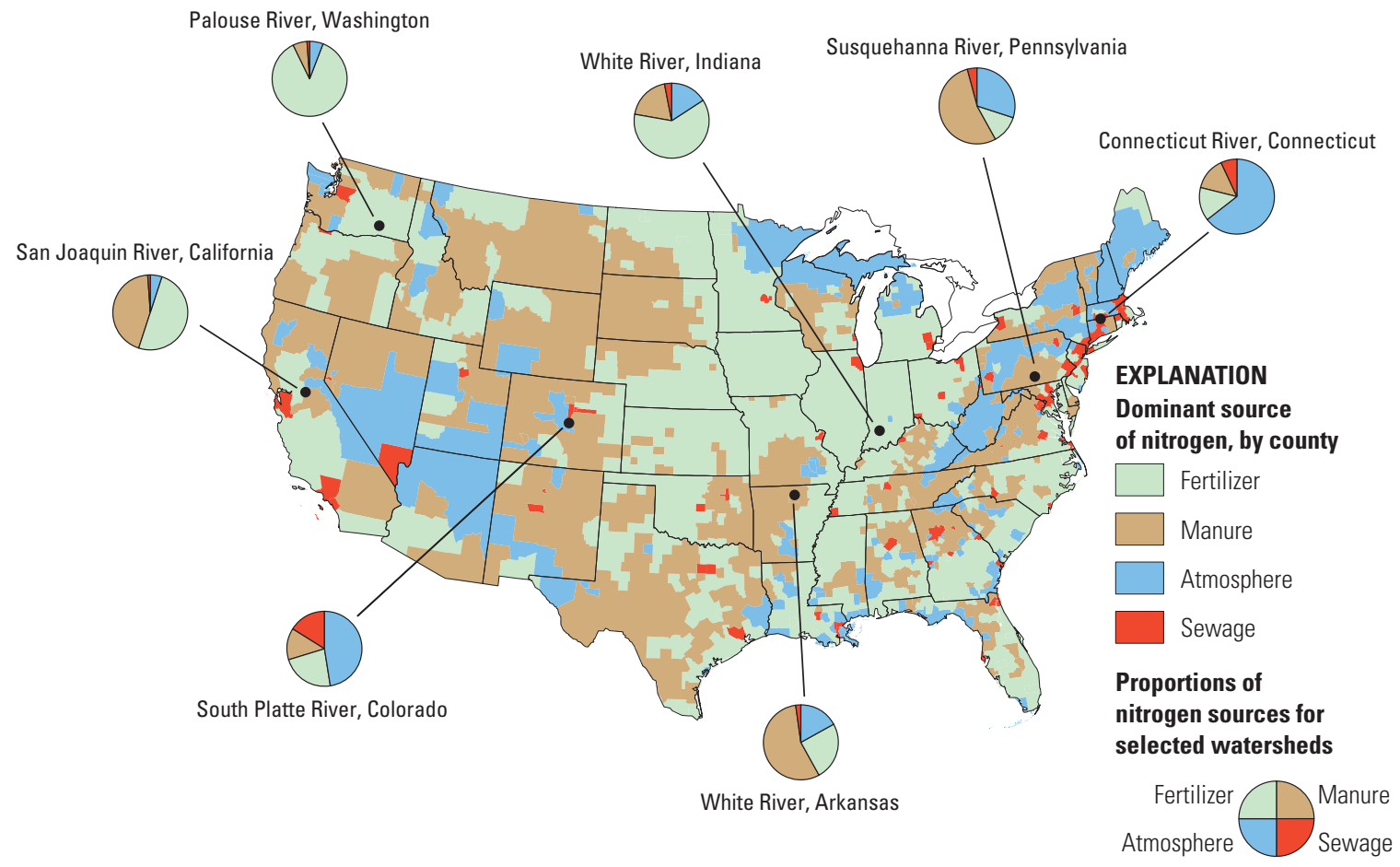

Figure 2-6. Commercial fertilizers are the dominant source of nitrogen in the White River Basin in Indiana, which is typical of their intensive use in the upper Midwestern part of the Nation, and in parts of the Northwest and West, such as in the Palouse River Basin in Washington and the San Joaquin River Basin in California. Commercial nitrogen fertilizers also are the major source of nitrogen in urban basins, and some urban watersheds also have significant nutrient contributions from wastewater-treatment plants, such as in the South Platte River Basin, Colorado. Nutrients from manure can even dominate those from commercial fertilizers in some agricultural watersheds with large populations of confined livestock, such as in the White River Basin in Arkansas and in the Susquehanna River Basin, Pennsylvania, as well as in the extensive western rangelands. Atmospheric contributions of nitrogen are important in the eastern parts of the country, such as in the Connecticut River Basin. 


\section{Nutrient Transport to Streams and Groundwater}

Nutrients released into the environment as diffuse nonpoint sources or as point sources enter streams along with runoff from precipitation, irrigation, or through drainage ditches and tile drains; are transported to groundwater by infiltrating rainfall or irrigation; and are transported to the atmosphere by volatilization either directly from a source or from a contaminated surface-water body (fig. 2-7). Within each of the hydrologic compartments, nutrient concentrations are affected by physical features, such as soils and slope of the land, as well as by biological and geochemical processes that can change the chemical form of the nutrient and (or) transfer it from the water to a solid phase or to the atmosphere. The chemical, physical, and biological processes that influence nutrient transport vary in intensity among different environmental settings.

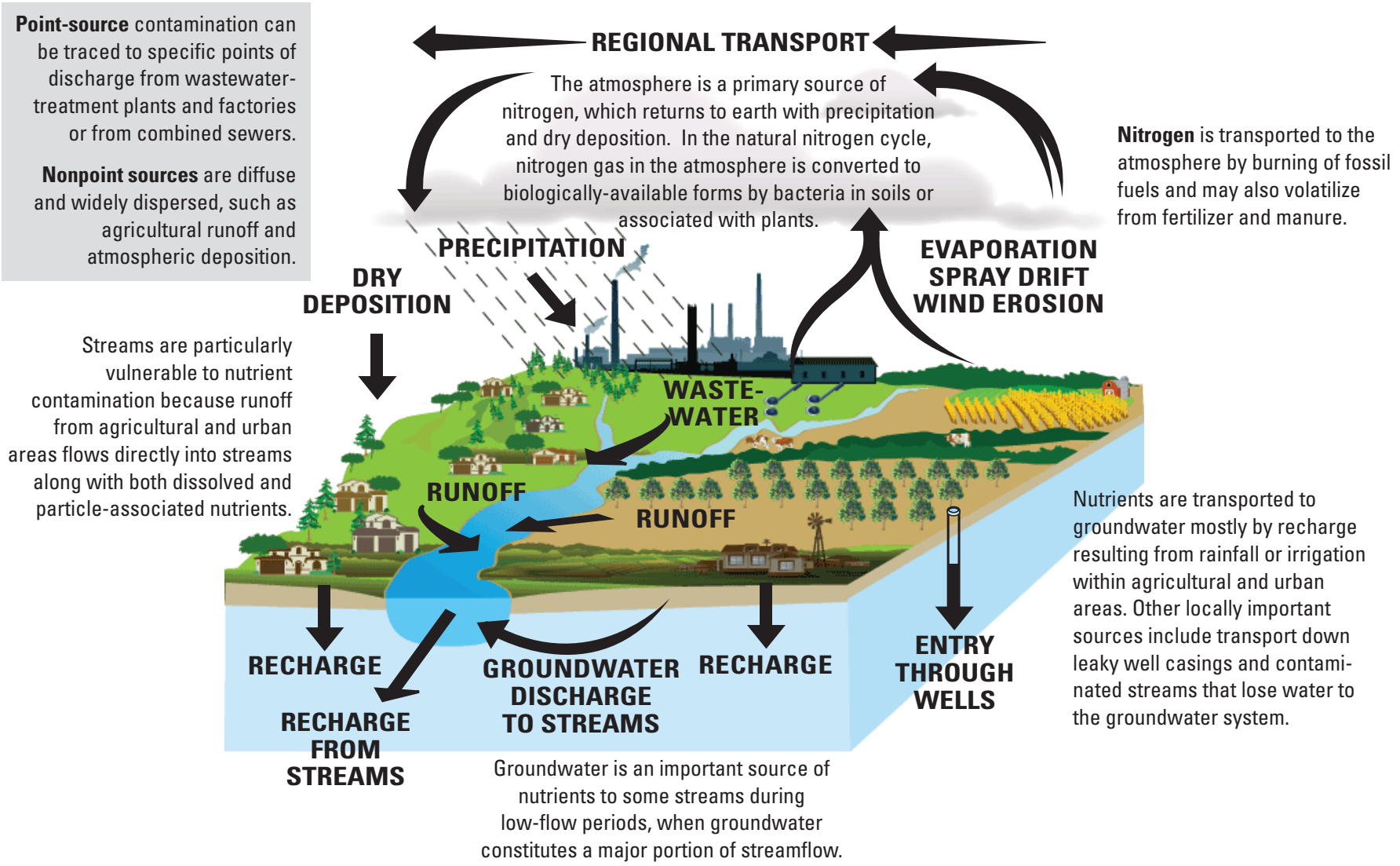

Figure 2-7. Nutrients from nonpoint and point sources are cycled throughout the hydrologic system, but may be affected by different chemical, physical, and biological processes in different parts of the system. (Modified from Majewski and Capel, 1995.) 


\section{Agricultural Best Management Practices}

Agricultural best management practices (BMPs) are designed to minimize the environmental impacts of agriculture while sustaining crop productivity. BMPs reduce nutrient losses to streams through management of nutrient inputs on the land surface and through curtailment of erosion and runoff of nutrients from the land surface to streams. Three common BMPs are conservation tillage, nutrient management plans, and conservation buffers (U.S. Environmental Protection Agency, 2008).

- Conservation tillage-Conventional tillage exposes the soil surface by plowing crop residues into the soil. In contrast, conservation tillage limits tilling while retaining crop residue on the soil surface, thereby increasing infiltration and reducing erosion and runoff to streams.

- Nutrient management plans-Comprehensive nutrient management plans help guide decisions on the placement, rate, timing, form, and method of nutrient application to avoid inputs in excess of crop requirements and to minimize loss to streams, groundwater, or the atmosphere. Nutrient management plans can incorporate a variety of agronomic tests to balance the amount of nutrients currently available in the soil against the amount required for crop production, and to identify the ideal timing for crop growth and irrigation to minimize runoff and leaching.

- Conservation buffers-Conservation buffers are areas of permanent vegetation often planted adjacent to streams, lakes, ponds, and wetlands or along the edges of agricultural fields to help reduce runoff or leaching of nutrients by filtering out nutrients and sediments, enhancing infiltration, and increasing plant uptake. The vegetation in buffers also can provide wind breaks, wildlife habitat, cooler water temperatures, stream-bank stabilization, and improved aesthetics.

BMPs often are included as part of cooperative conservation plans developed through the U.S. Department of Agriculture's (USDA) Farm Service Agency and Natural Resources Conservation Service, other Federal, State, and local agencies, private companies, and individual landowners. Four of the largest national USDA conservation programs are the Conservation Reserve Program (CRP), the Conservation Reserve Enhancement Program (CREP), the Wetlands Reserve Program (WRP), and the Grassland Reserve Program (GRP). These programs are all voluntary. Farmers, ranchers, and other producers enrolled in the CRP plant long-term vegetative covers, such as introduced or native grasses or hardwood trees, to improve water quality, control soil erosion, and enhance wildlife habitat. As of 2008, 34.72 million acres were enrolled in the CRP (U.S. Department of Agriculture, 2008). The CREP, which is part of the CRP, helps producers protect environmentally sensitive land, decrease erosion and runoff, restore wildlife habitat, and safeguard groundwater and surface water through BMPs such as conservation buffers. As of 2008, 1.13 million acres were enrolled in the CREP (U.S. Department of Agriculture, 2008). The WRP provides landowners financial incentives and technical assistance to restore wetland functions while maximizing wildlife habitat benefits. Wetlands reduce downstream flooding, protect drinking water, filter runoff, and provide vital habitat for many wildlife species. As of 2008, 2.0 million acres were enrolled in the WRP (U.S. Department of Agriculture, 2008). The GRP helps landowners restore and enhance grasslands on their property and protects vulnerable grasslands from conversion to crop land, urban land, or other uses. The GRP has enrollments in all 50 States and Puerto Rico (U.S. Department of Agriculture, 2008).

Measuring the cumulative effect of BMPs on water quality in streams across the Nation is a challenging task. In the large watersheds studied by the NAWQA Program, which range from less than 8 square miles to more than 80,000 square miles, BMPs are one of many influences on water quality in streams. Distinguishing the effects of BMPs from the effects of often interrelated changes in land use, source inputs, climate, or other factors can be a difficult task - a task that is further complicated by the lack of comprehensive national-scale data on when and where various BMPs are implemented across the Nation. More comprehensive and detailed data on BMPs could help improve our understanding of the factors affecting nutrient conditions in the Nation's streams and groundwater. Our understanding of the effects of BMPs on agricultural landscapes will be advanced by a multi-scale assessment of the environmental effects of conservation practices and programs being conducted by the USDA's Conservation Effects Assessment Program (U.S. Department of Agriculture, 2010). 


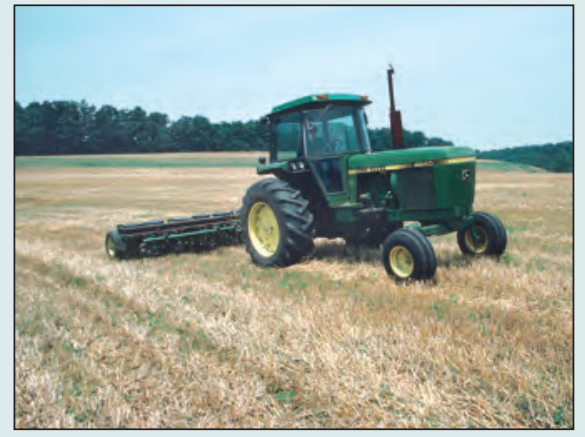

Conservation tillage allows for double-cropping of soybeans in the residue left by winter wheat, yielding two crops during a single growing season and protecting the land from erosion. Photograph by Joseph Larson, U.S. Department of Agriculture, Natural Resources Conservation Service.

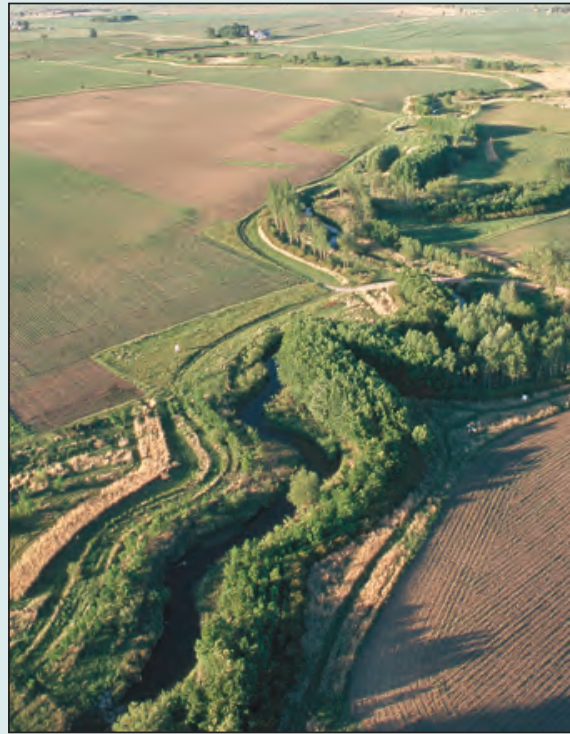

Multiple rows of trees and shrubs, as well as a native grass strip, combine in a riparian conservation buffer to protect Bear Creek in Story County, lowa. The buffer is a nationally designated demonstration area for riparian buffers. Photograph by Lynn Betts, U.S. Department of Agriculture, Natural Resources Conservation Service.
Assessment of the occurrence and transport of nutrients in streams and groundwater, therefore, requires recognition of complicated interconnections among surface water and groundwater systems, atmospheric contributions, and the natural and human factors that can affect transport. Key natural factors, including soil type, geology, and slope of the land, can govern the amount and timing of transport of nutrients to streams and groundwater. Human factors and actions that can affect transport include irrigation, groundwater pumping, the presence of impervious surfaces, artificial subsurface drainage, and best management practices (see sidebar, Agricultural Best Management Practices). The result can be varying concentrations of nutrients in streams and groundwater, even in watersheds that may have similar land-use settings and rates of fertilizer use.

Nutrient transport in water depends on the chemical makeup of the nutrients themselves, which can affect mobility and persistence. Some compounds, such as nitrate, readily dissolve and move with water in both streams and groundwater. Most forms of phosphorus, however, attach to soil particles rather than dissolve; these compounds are transported to streams with eroded soil, particularly during times of high runoff from precipitation or irrigation. Groundwater typically is not vulnerable to contamination by nutrients, such as phosphorus, that attach to soils.

Nutrient transport in water also depends on geochemical conditions of the water, which can affect the persistence of a nutrient. For example, as long as dissolved oxygen is present in groundwater (referred to as oxic conditions) and organic carbon content is low, nitrate generally is stable and hence persistent in groundwater, sometimes for decades (see sidebar, Redox Conditions in Aquifers Affect the Stability of Nitrate in Groundwater). Groundwater inflow to streams, therefore, can be a large source of nitrate in some areas (Bachman and others, 1998; Sprague and others, 2006). If the dissolved oxygen in groundwater is depleted, nitrate becomes unstable and is converted to nontoxic nitrogen gas, a process referred to as "denitrification." 


\section{Streams}

The transport of nutrients to streams is driven by precipitation or irrigation. In large part, it is driven by the timing of the precipitation and associated runoff and drainage relative to fertilizer and manure applications, and controlled by a multitude of natural and human factors that affect runoff and groundwater discharge to streams. Specifically, high rainfall, snowmelt, and (or) excessive irrigation, especially following recent fertilizer applications, can accelerate transport of nutrients to streams. Streams with steep slopes and sparse streamside vegetation to slow runoff and sediment movement generally are vulnerable to nutrients entering their channels. Clayey and compacted soils underlain by poorly drained sediment and (or) nonporous bedrock can create relatively impermeable surfaces for quick runoff, as can extensive urban pavement. Flat areas with tile drains and ditches also can provide quick pathways for runoff to streams. In contrast, some best management practices help to reduce transport of nutrients, particularly those nutrients that bind to soil and sediment, such as phosphorus. Examples of such practices include (1) the use of polyacrylamide, a chemical added to irrigation water to reduce erosion and enhance water infiltration, and (2) conversion from rill irrigation to sprinkler and drip irrigation systems, which use less water and thereby reduce erosion and surface runoff.

The biology and physical habitat of a stream also can affect the transport and occurrence of nutrients in streams. Once nitrogen enters a stream, it cycles in and out of the water as a result of the activities of plants and animals. Production of plant biomass cycles nutrients from the water, while decay of plants and animals cycles nutrients back into the water. As nutrients cycle between the water and biota, they can be eventually lost to the stream either by exchange with the atmosphere (in the case of nitrogen) or by transport downstream. Nitrogen and phosphorus can both limit biological production, with streams in the eastern United States more likely to be phosphorus-limited and streams in the Western United States more likely to be nitrogen-limited.

Three physical habitat factors - light, water temperature, and streamflow - affect the development and growth of algae and aquatic plants, which can thereby affect nutrient uptake and hence the subsequent transport of nutrients in a stream. Overhanging riparian vegetation can block light from reaching the water surface, and suspended sediments can increase turbidity and prevent light from penetrating the water. Growth of algae and aquatic plants is limited by low-light conditions, regardless of nutrient concentrations. Water temperature can regulate the rate at which cells can function and grow, with warmer water temperatures stimulating more rapid plant growth. Streamflow can limit the growth of algae and other

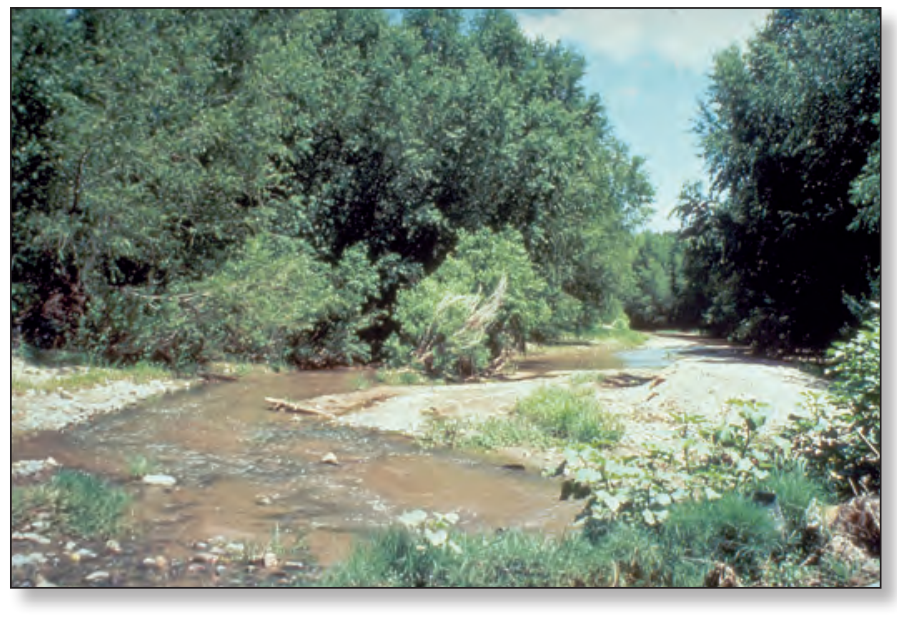

Physical characteristics of streams, such as the amount of shading, influence nutrient transport. Photograph by U.S. Geological Survey.

aquatic plants by limiting nutrient and habitat availability during periods of low flow, or by scouring the bottom of the stream and reducing the abundance of attached vegetation during periods of high flow, such as after a heavy rainfall.

\section{Groundwater}

As with streams, transport of nutrients to groundwater is driven by precipitation or irrigation, which provide sources of water for recharge. Groundwater transport of nutrients is different from that in streams because only dissolved forms of nutrients can move substantial distances in groundwater. Nitrate readily dissolves and moves with water, and is therefore often the dominant nutrient species. Particle bound constituents, like phosphorus, are largely retained by the soil and aquifer materials. In addition, transport of nutrients to and within groundwater systems is much less predictable than transport in streams because flow is considerably slower and more complex than the flow of stream water.

Natural features that accelerate nutrient transport to groundwater generally contrast with those discussed above for streams. Nitrate is readily transported to shallow groundwater in well-drained areas with rapid infiltration and highly permeable subsurface materials. Well-drained and permeable soils that are underlain by sand and gravel or carbonate rock (also referred to as "karst") can enable rapid downward movement of water. Crop-management practices, which commonly are designed to reduce or slow the movement of sediment and nutrients to streams, also can increase infiltration of water and nutrients into the ground. Pumping groundwater can accelerate the flow of water and transport contaminants toward the pumped wells. 


\section{Redox Conditions in Aquifers Affect the Stability of Nitrate in Groundwater}

Under the right conditions, nitrate may be removed from groundwater before it reaches the intake screen of a drinking-water well by a biogeochemical process called denitrification. In aquifers, bacteria are constantly breaking down natural organic carbon compounds to acquire the energy they need to live in much the same way that humans break down the organic carbon compounds in the food we eat. Because carbon is oxidized (by losing an electron) and other reactants are reduced (by gaining an electron), these are known as oxidation-reduction, or "redox" reactions. Less often, an inorganic constituent, such as the reduced form of iron in the minerals pyrite and glauconite, is oxidized. In the first reaction in the sequence, bacteria utilize the oxygen dissolved in groundwater to oxidize the available organic carbon. As long as dissolved oxygen is present in groundwater, nitrate is generally stable and hence persistent. Groundwater containing dissolved oxygen concentrations greater than 0.5 $\mathrm{mg} / \mathrm{L}$ is referred to as "oxic." As oxygen is consumed, groundwater becomes reduced (concentrations of dissolved oxygen less than $0.5 \mathrm{mg} / \mathrm{L}$ ). If dissolved oxygen in groundwater becomes depleted, the bacteria will use nitrate to oxidize the organic carbon in a redox reaction called denitrification. Through denitrification, nitrate $\left(\mathrm{NO}_{3}^{-}\right)$is converted to nitrogen gas $\left(\mathrm{N}_{2}\right)$, which is nontoxic. After nitrate is mostly gone, then bacteria can use organic carbon for other redox reactions such as manganese reduction, iron reduction, sulfate reduction, and reduction of carbon dioxide to methane. As a result of these reactions, nitrate may be removed from the groundwater, only to be replaced by manganese, iron, sulfide, or methane (considered markers of reduced waters). Often these various processes occur in succession as water moves down and through an aquifer, creating a layered or stratified sequence of water chemistry (fig. 2-8).

Otter Tail River, Minnesota

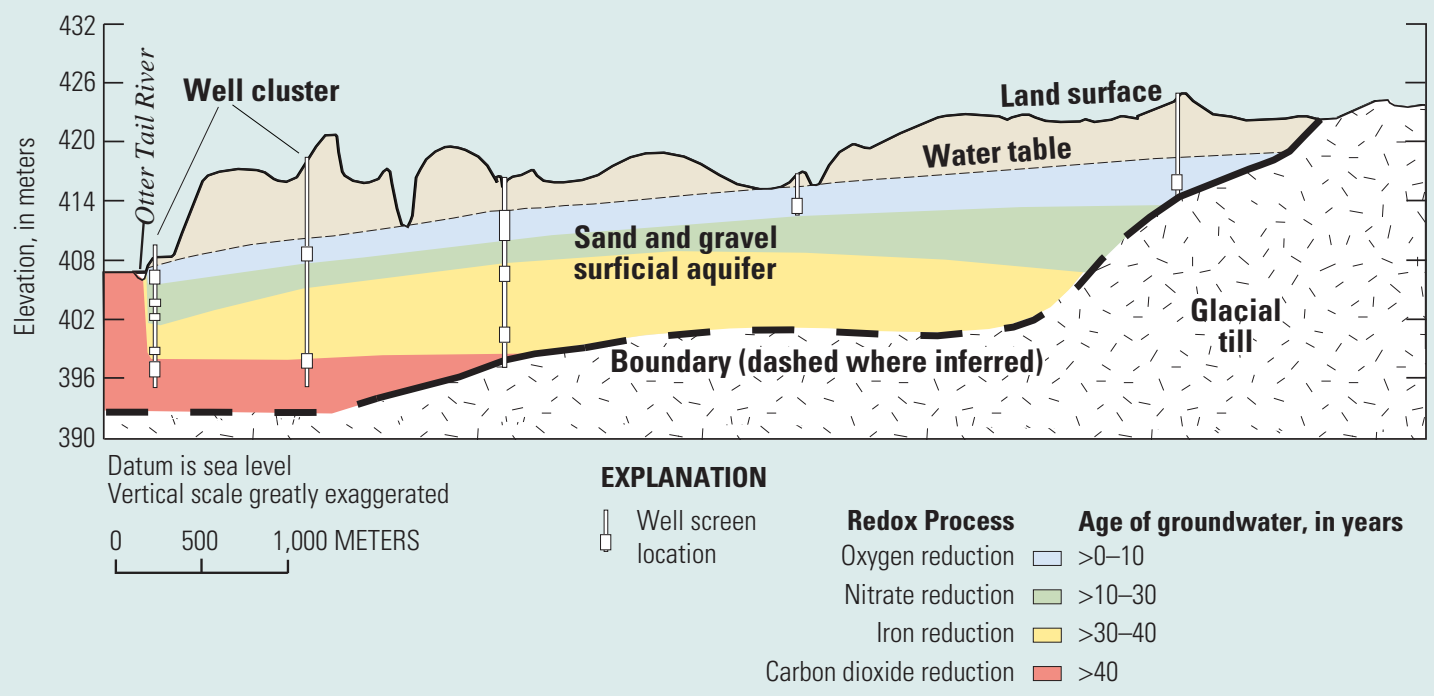

Figure 2-8. Biogeochemical processes can occur in succession as water moves down and through an aquifer, creating a layered or stratified sequence of water chemistry. In the aquifer adjacent to the Otter Tail River, Minnesota, nitrate is removed from the groundwater by denitrification in a zone near the water table. (Modified from Puckett and Cowdery, 2002.) 
Natural processes can significantly reduce nutrient concentrations in groundwater through chemical and biological transformations under the right geochemical, or "redox," conditions (see sidebar, Redox Conditions in Aquifers Affect the Stability of Nitrate in Groundwater). Through denitrification, bacteria can convert nitrate to innocuous, gaseous forms of nitrogen when groundwater passes through organic-rich sediment that is low in dissolved oxygen.

Deep aquifers usually contain water with lower concentrations of nutrients than shallow aquifers because (1) it takes a long time - decades or more, in most cases - for water to move from the land surface to deep aquifers (resulting in long residence times for groundwater and any solutes, like nitrate, it may contain); (2) long travel distances increase the likelihood that nutrients will transform, such as through denitrification, or attach to aquifer materials; (3) protective low-permeability deposits (which inhibit flow and transport) may be present between the land surface and deep aquifers; and (4) mixing of water from complex flow paths over long distances and time periods tends to result in a mixture of landuse influences on the chemical character of deep groundwater, including contributions of nutrients from areas of undeveloped lands where concentrations are generally lower than those from developed lands.

It is important to note that groundwater at all depths is part of an integrated and interconnected hydrologic system and is subject to contamination as water moves downward from the land surface. Future contamination in deep major aquifers could pose serious concerns because these aquifers commonly are sources of private household and public water supplies, and restoration of the purity of this relatively inaccessible and slow-moving water would be costly and difficult.

\section{Transport of Nutrients Varies Seasonally and with Hydrologic Events}

Transport of nutrients to streams and groundwater varies seasonally, in large part following seasonal patterns in human activities. For example, in Granger Drain, Washington, concentrations of nitrate are highest during the non-irrigation season when groundwater is the primary source of water to the stream (fig. 2-9). Concentrations of total phosphorus, however, are highest during the irrigation season, when surface runoff delivers phosphorus-rich sediment to the drain.

The transport of nutrients to streams also can vary in response to changes in precipitation and runoff and streamflow (see sidebar, Effects of Precipitation and $\underline{\text { Climate on Streamflow and Temporal Variability of Nutrient }}$ Concentrations). Increases in precipitation and streamflow in basins in which point-source discharges or nitrate-rich groundwater inflows predominate commonly are accompanied by decreases in nutrient concentrations as a result of greater instream dilution by the relatively clean runoff. The same increase in precipitation and streamflow in basins in which nonpoint sources predominate, however, can increase nutrient concentrations as a result of increased transport by surface runoff. For example, in the Hockanum River, which drains an urban watershed in Connecticut, greater dilution of the relatively constant nutrient input from point sources led to lower total phosphorus concentrations at higher streamflows (fig. 2-10). The opposite pattern occurred in Sugar Creek, which drains an agricultural watershed in Indiana - increased nutrient transport in surface runoff from extensive corn and soybean fields upstream led to higher total phosphorus concentrations at higher streamflows.

The transport of nutrients to streams also can vary seasonally in response to rates at which nutrients are taken out of the water during growth by aquatic organisms ("uptake"). For example, total nitrogen concentrations were lowest in late summer in some agricultural streams due to biological uptake and relatively low rates of fertilizer applications. 


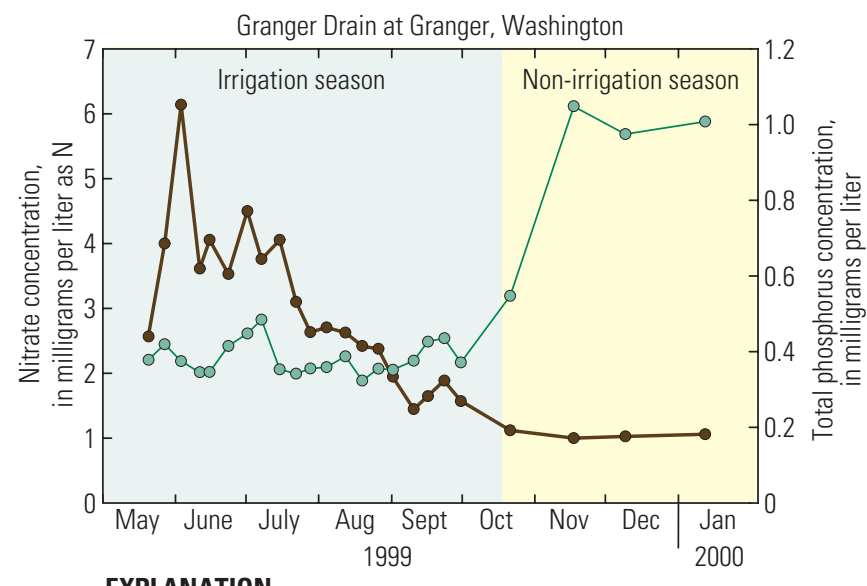

EXPLANATION

-o- Nitrate concentration

$\rightarrow$ - Total phosphorus concentration

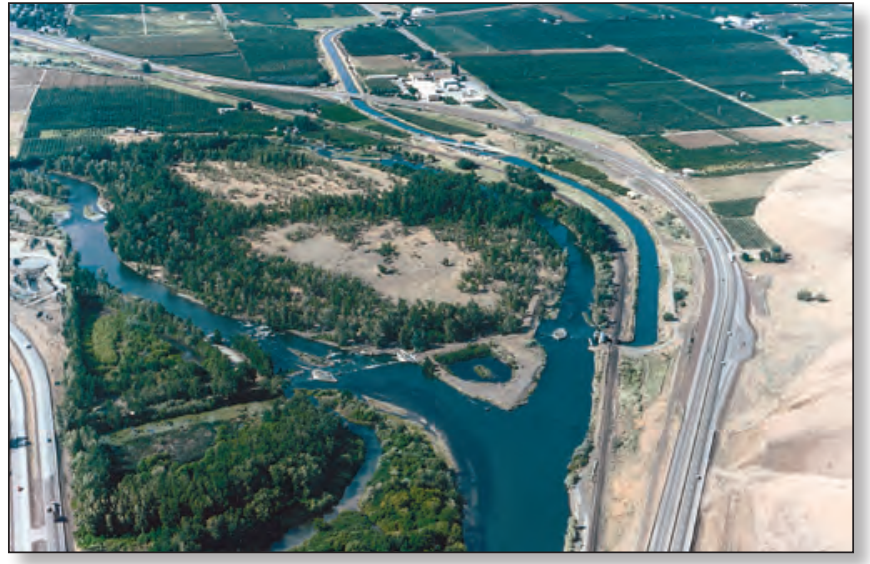

Part of the flow of the Yakima River is diverted to provide irrigation water for crops in Central Washington. Photograph by Henry Ngam, U.S. Geological Survey.

Figure 2-9. Concentrations of nitrate and total phosphorus in Granger Drain, Washington, vary in response to their major transport pathways. Nitrate concentrations are highest during the non-irrigation season, when groundwater is the primary source of water to the stream, whereas total phosphorus concentrations are highest during the irrigation season, when surface runoff transports phosphorus-rich sediment to the stream (Fuhrer and others, 2004).

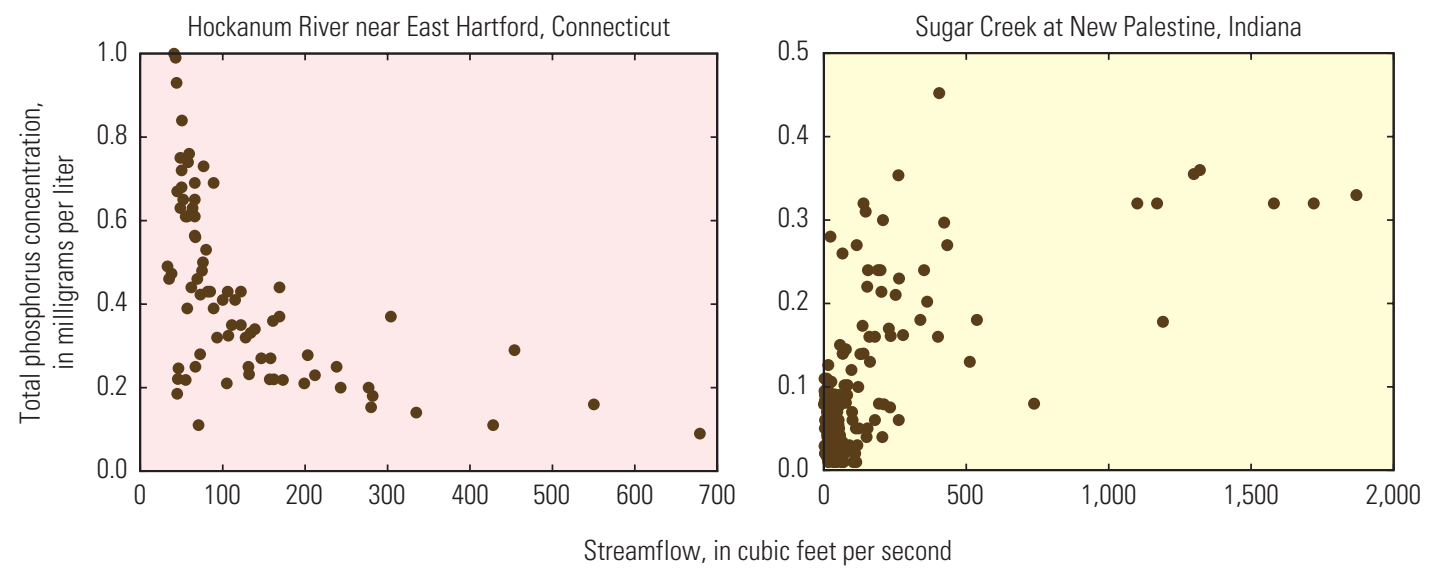

Figure 2-10. Total phosphorus concentrations in the Hockanum River, Connecticut, an urban site with numerous upstream point sources, decreased as streamflow increased because of greater instream dilution. In contrast, total phosphorus concentrations in Sugar Creek, Indiana, increased as streamflow increased as a result of greater surface runoff from extensive fields of corn and soybeans. 


\title{
Effects of Precipitation and Climate on Streamflow and Temporal Variability of Nutrient Concentrations
}

\author{
Michael Dettinger, U.S. Geological Survey
}

Daily, seasonal, and long-term changes in climate can affect streamflow, which in turn affects nutrient variability in streams. Specifically, daily variability in surface temperature, light availability, and precipitation can contribute to short-term (minutes to days) changes in local hydrologic processes such as runoff, snowmelt, and evapotranspiration, that in turn affect streamflow. Seasonal changes (weeks to months) in large-scale weather patterns can bring seasonal dry or wet periods and the start and end of growing seasons. Longer changes (years) are tied to "El Nino" events in the tropical Pacific, which yield a recurring pattern of winter precipitation that favors a wetter-than-normal Southwest and Florida and a drier-than-normal Northwest. The opposite of an El Nino in the tropical Pacific is a "La Nina," which reliably yields wetterthan-normal winters in the Northwest and drier-than-normal winters in the Southwest. Changes that last for decades at a time, such as prolonged droughts, are related to climatic fluctuations over the North Pacific and North Atlantic (fig. 2-11).

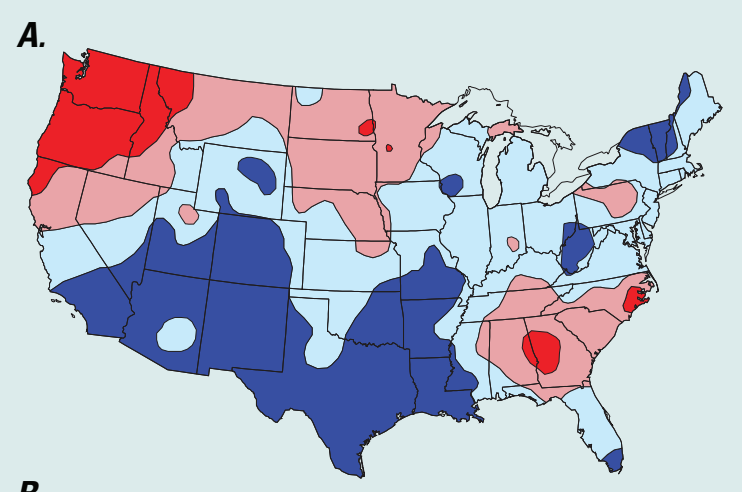

B.

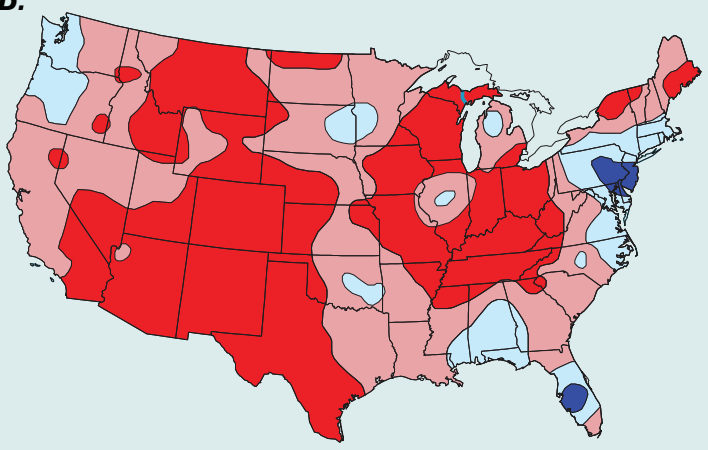

Positive values are shaded red, and negative values are shaded blue. Darker shades indicate stronger correlation ( $>0.4$ or $<-0.4)$.

Figure 2-11. Areas of the conterminous United States where long-term droughts (several years to decades) are positively correlated (red) or negatively correlated (blue) with changes in ocean temperature in the North Pacific $(A)$ and the North Atlantic $(B)$. (Modified from McCabe and others, 2004.) 
Additional multi-decadal streamflow variability may be related to long-term climate change in response to increasing greenhouse-gas concentrations in the global atmosphere, or to naturally occurring variability in winter and spring temperatures and in the form and timing of precipitation. Warming has occurred across the West, upper Midwest, and Northeastern United States, while the Southeast has actually cooled overall. Warmer winters and springs in the Western United States have contributed to widespread hydrologic changes, including trends towards more precipitation as rain rather than as snow, less snowpack overall, earlier greening of vegetation, and earlier snowmelt (fig. 2-12).

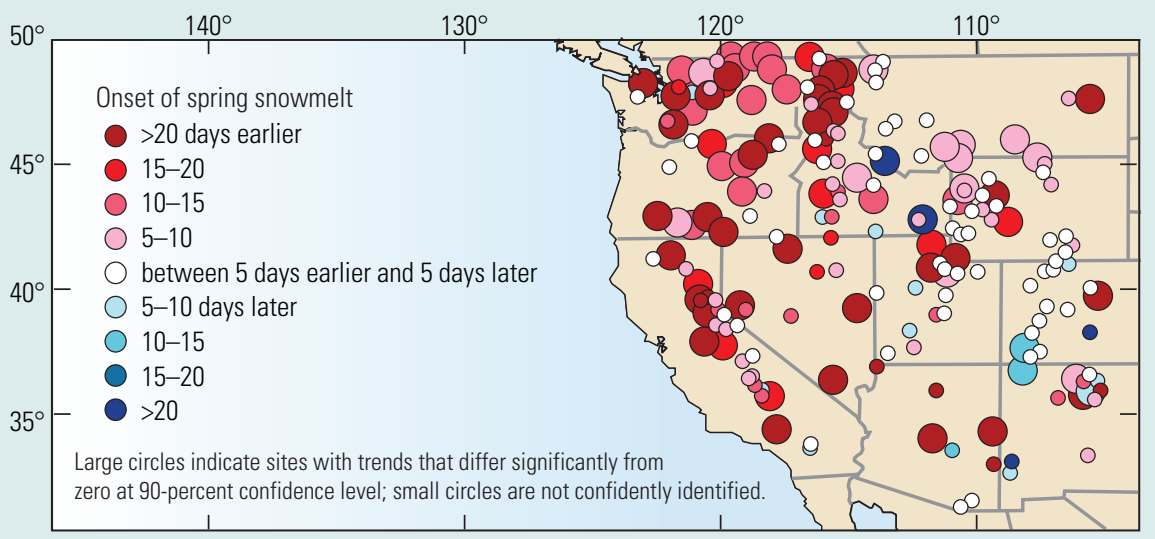

Figure 2-12. Spring snowmelt onset - the date on which snowmelt runoff adds a large initial surge to rivers-occurs a week to almost three weeks earlier now than in the middle of the 20th century in the West (Dettinger, 2005). Changes in the timing of streamflow have implications for agricultural water management and hence nutrient transport.

Nutrient concentrations respond to these short-term and longer-term temporal changes in streamflow. Specifically, nutrient concentrations can change throughout the year and over a 24-hour period in response to changes in light availability, temperature, and in turn, biological productivity (Kent and others, 2005; Peterson and others, 2005). Concentrations in some areas are highest during spring and summer wet periods following fertilizer application. Concentrations in other areas are highest during winter low-flow periods because of groundwater inflow and reduced biological uptake. Finally, annual and decadal changes in precipitation can lead to long-term changes in surface runoff or instream dilution, contributing to long-term changes in nutrient concentrations in streams. 
This page intentionally left blank 


\section{Chapter}

\section{NAWQA's Approach to Nutrient Assessment}

\section{Introduction}

The NAWQA Program's assessment of nutrients during 1992-2004 provides one of the most comprehensive analyses to date of nutrient occurrence in streams and groundwater of the United States. The assessment followed a national study design in which some of the most important hydrologic systems were studied on a rotational schedule using nationally consistent sampling and analytical methods. This approach yields an understanding of water-quality conditions in a national context, while also supporting comparisons and assessments within and among individual watersheds, aquifers, and geographic regions. By systematically relating nutrient occurrence and transport to key factors that control nutrient contamination-such as nutrient use and properties, land use, hydrology, and other environmental features - NAWQA provides information needed for managing nutrients within the Nation's diverse land-use and environmental settings.

\section{National Water-Quality Assessment Study Units}

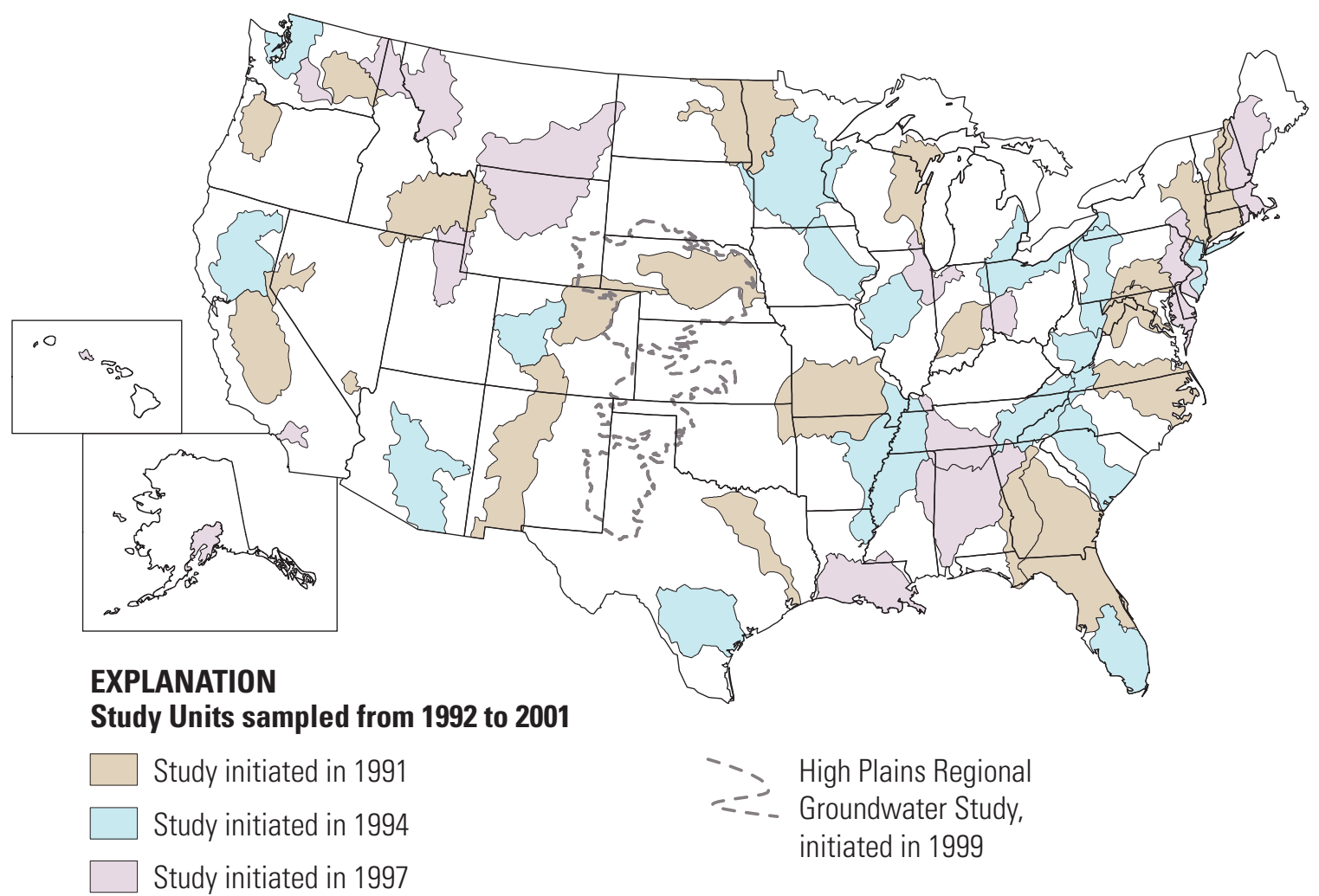




\section{Targeted Sampling Across the Nation's Diverse Land Uses and Environmental Settings}

This report is based primarily on results from NAWQA's first decade of water-quality assessments, which were completed on a rotational schedule from 1992 to 2001 in 51 major hydrologic systems across the country - referred to as Study Units - as well as in the High Plains Regional Groundwater Study, using a nationally consistent study design. Assessments were conducted in 20 Study Units during 1992-1995; in 16 Study Units during 1996-1998; and in 15 Study Units during 19982001. Collectively, the 51 NAWQA Study Units and the High Plains Study cover a substantial portion of the Nation's land area; account for more than 70 percent of total water use and more than 50 percent of the population served by public water supplies and domestic wells; and are representative of the Nation's diverse landscapes, hydrologic systems, ecological resources, and land uses. Water samples were collected from selected streams and aquifers through 2004 to assess the effects of nutrient enrichment on stream ecosystems and to assess trends in nutrient concentrations (Chapters 7 and $\underline{8}$, respectively).

The primary objectives of the NAWQA nutrient assessment were to determine: (1) the occurrence and concentrations of nutrients in streams (ranging from small streams to large rivers) and groundwater; (2) where and when nutrients occur in relation to factors that govern their sources and transport in the hydrologic system; (3) whether any nutrients may be present at concentrations that could affect human health or aquatic life; and (4) how concentrations are changing over time. To address these goals, NAWQA employed a targeted assessment focusing on studies of:

- Streams and shallow groundwater in specific, relatively homogeneous land-use and environmental settings to relate nutrient occurrence to individual types of nonpoint sources; and

- Streams and major aquifers (regionally extensive aquifers that are important groundwater resources for water supply) in areas of mixed land uses to evaluate the integrated effects of multiple sources of nutrients on their occurrence and concentrations.

Details on the sampling design and analytical methods, as well as all data used in this report, are available at: http://water.usgs.gov/nawqa/ nutrients/pubs/circ1350.

For the targeted assessment by land use, streams and shallow groundwater were sampled in agricultural and urban areas, and in undeveloped areas dominated by forest or rangeland. As described in more
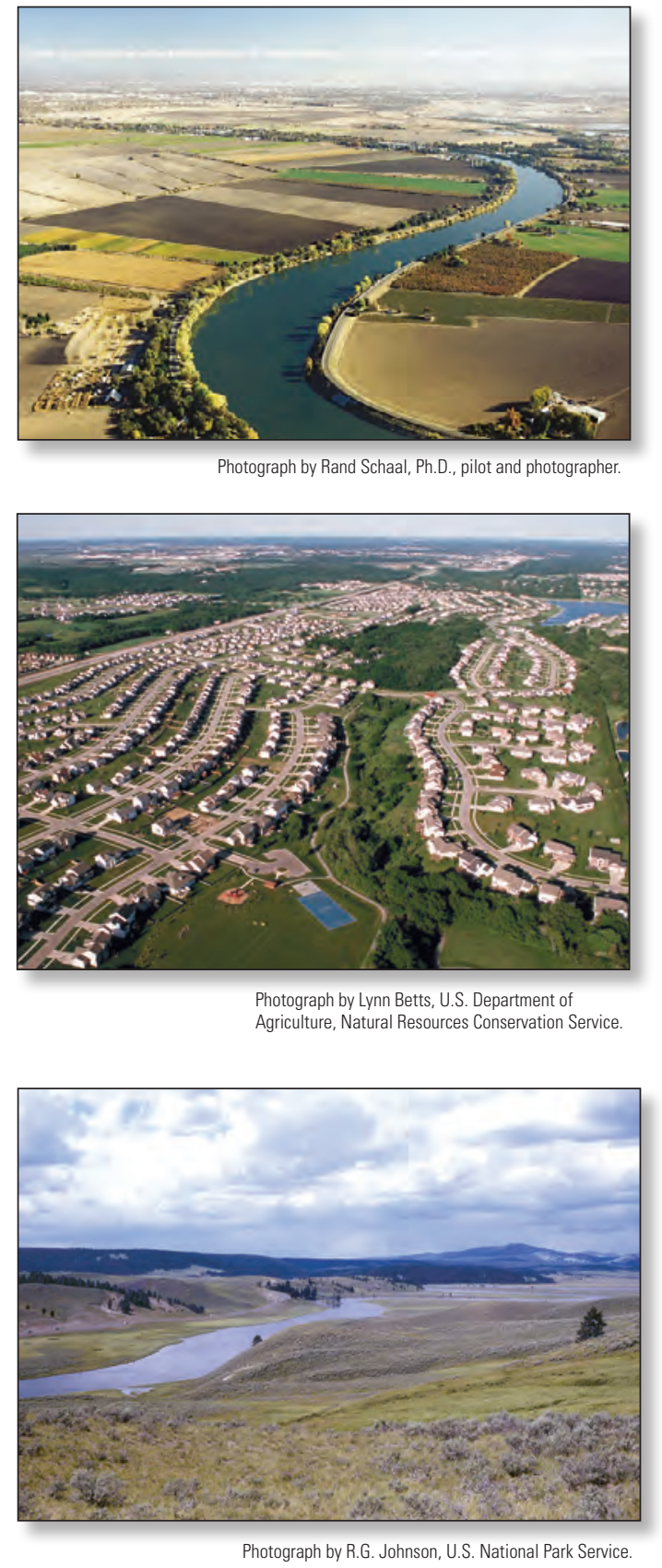

Sampling by NAWQA targeted specific land uses including agricultural (top), urban (middle), and undeveloped (bottom) lands. 
detail below and in the accompanying sidebar, Unique Features of the NAWQA Approach, streams and groundwater were sampled most intensively in agricultural and urban areas because of the importance of assessing nutrient occurrence in areas with the largest manmade nutrient sources. The agricultural areas are diverse in climate, geography, and crop types, and span coastal, desert, and temperate environmental settings. They include, for example, areas dominated by concentrated animal feeding operations in the Midwest; fields of wheat and other grains in the Great Plains; mixed row crops and poultry in the East; and rangeland in the Southwest. The areas sampled in urban settings primarily were residential, typically with low-to-medium population densities (300 to 5,600 people per square mile). Some commercial or industrial areas also were included in the assessments, but point sources and extensive industrial and downtown urban areas generally were not assessed.

\section{Unique Features of the NAWOA Approach}

Water-quality assessments by NAWQA, which is a single program among many local, State, and Federal programs, were not designed to address all of the Nation's water-resource information needs and issues. Listed below are several characteristics and limitations of the NAWQA approach that are important to consider when interpreting the findings on nutrients presented in this report.

- NAWOA assessments collected extensive data to characterize the hydrologic conditions at all stream and groundwater sites in the Study Units. These data are critical for understanding the physical and chemical factors that control transport of nutrients in the environment.

- NAWQA assessments characterized the quality of the available, untreated water resources, and not the quality of drinking water (as would be done by monitoring water from water-treatment plants or from household taps). By focusing on the quality of streams and groundwater in their present condition (ambient water quality), NAWOA studies complement many Federal, State, and local drinking-water monitoring programs.

- NAWQA assessments of nutrients focused primarily on nonpoint sources originating from fertilizer application, manure, and atmospheric deposition in agricultural, urban, and other land-use settings. Some sites-particularly those downstream from major metropolitan areas-also may have been influenced by point sources, such as discharges from wastewater-treatment plants.

- NAWQA assessments targeted specific land-use settings that are most extensive or important to water quality in a wide range of hydrologic and environmental settings across the Nation. This targeted approach gives priority to understanding the most critical factors influencing water quality. Extrapolation of local and regional results to national analyses, however, requires careful definition of each type of water resource and environmental setting for which conclusions are drawn and the use of statistical models to extrapolate results to resources that have not been measured.

- NAWOA assessments did not focus on specific sites with known water-quality problems or narrowly defined issues, but rather on the condition of the total resource, including streams and groundwater in a wide range of hydrologic and land-use settings across the country. 


\section{Sampling Design}

The national sampling design for the NAWQA Program focuses on a characterization of water-quality conditions in streams and groundwater that includes consideration of a broad suite of physical and chemical characteristics of water, streambed sediments, and tissues from aquatic organisms, as well as measures of the condition of the algal, macroinvertebrate, and fish communities. The national assessment of nutrients is based on results from the analysis of 28,466 samples of water from streams, and 5,101 samples of groundwater from the 51 NAWQA Study Units.

\section{Stream Water}

Water samples were collected at 499 stream sites for analysis of nutrients in water (fig. 3-1). The samples were collected from streams throughout the year, including during both high-flow and low-flow periods. Most analyses in this report are based on 2 years of monthly data for each site. Sampling at a subset of sites was more intensive during the time of highest runoff and use of agricultural chemicalsgenerally weekly or twice monthly for a 4- to 9-month period.

Each NAWQA stream site was classified to evaluate the potential land-use influences on the quality of water sampled. The sites were characterized by determining the proportions of each major land use within each stream's contributing watershed. Table 3-1 lists the criteria used to classify stream sites, and figure 3-1 shows the national distribution of these categories for the conterminous United States. Streams classified as "mixed land use" drain mixtures of two or more land-use settings and do not meet the criteria described in table 3-1 for individual agricultural, urban, or undeveloped settings. Land-use classifications were adjusted for a small number of streams that have watersheds with substantial areas that did not contribute streamflow during the study period. Most streams that were classified as agricultural, urban, or undeveloped also commonly have small amounts of other land uses in their watersheds. For example, and of particular importance to findings for nutrients, many streams classified as undeveloped have some agricultural or urban activity in their watersheds.
Table 3-1. Each stream sampled by NAWOA was classified according to the dominant land uses in its watershed.

[Modified from Gilliom and others (2006). The land-use data set used for these classifications was an enhanced version of the USGS 1992 National Land Cover Data (NLCD) (Nakagaki and others, 2007)]

\begin{tabular}{ll}
\hline $\begin{array}{c}\text { Land-use } \\
\text { classification }\end{array}$ & \multicolumn{1}{c}{ Watershed land-use criteria } \\
\hline Agricultural & $>50$ percent agricultural land and \\
& $\leq 5$ percent urban land \\
Urban & $>25$ percent urban land and \\
& $\leq 25$ percent agricultural land \\
Undeveloped & $\leq 5$ percent urban land and \\
& $\leq 25$ percent agricultural land \\
Mixed & All other combinations of urban, \\
& agricultural, and undeveloped land \\
\hline
\end{tabular}

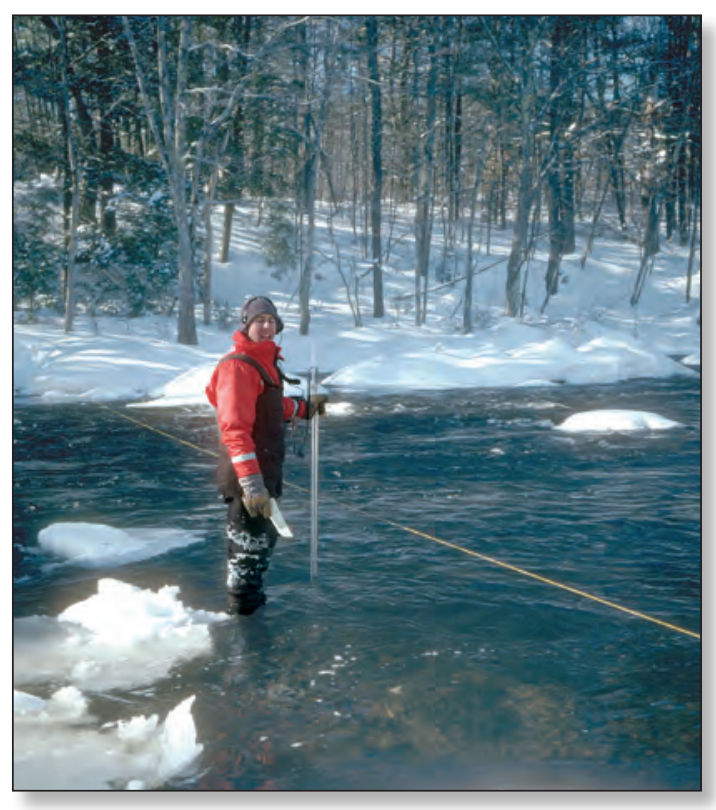

Stream discharge and water-quality samples were collected throughout the year. Photograph by U.S. Geological Survey. 


\section{EXPLANATION}

Land-use classification

$\square$ Agricultural
Urban
$\square$ Undeveloped
Mixed

Nationally consistent data not available for Alaska and Hawaii

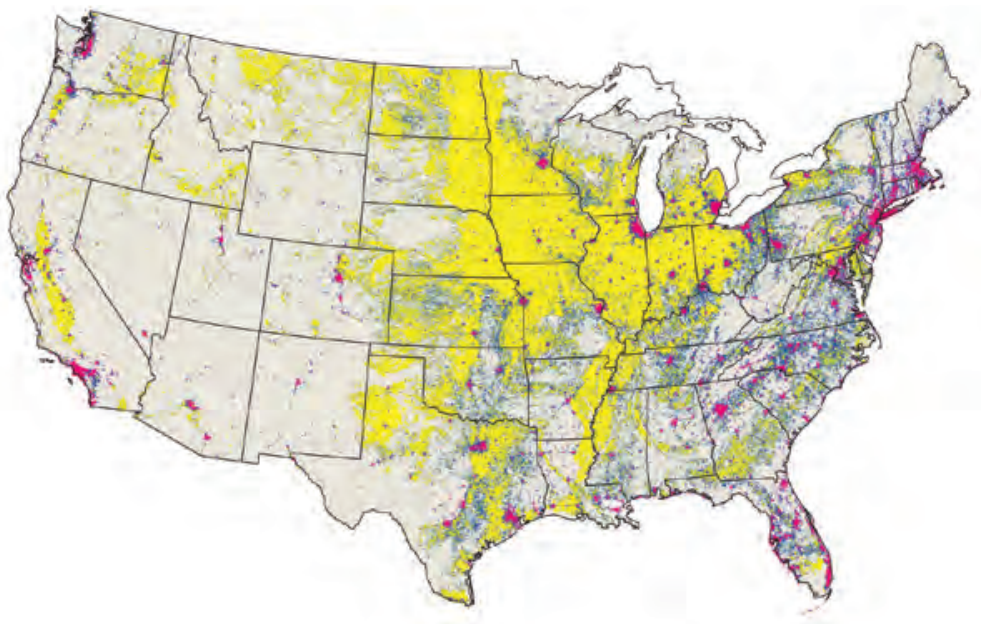

Stream-water sampling sites

Watershed land use

- Agricultural (135 sites)

- Urban (55)

$\diamond$ Undeveloped (159)

- Mixed land use (150)

NAWQA Study Unit

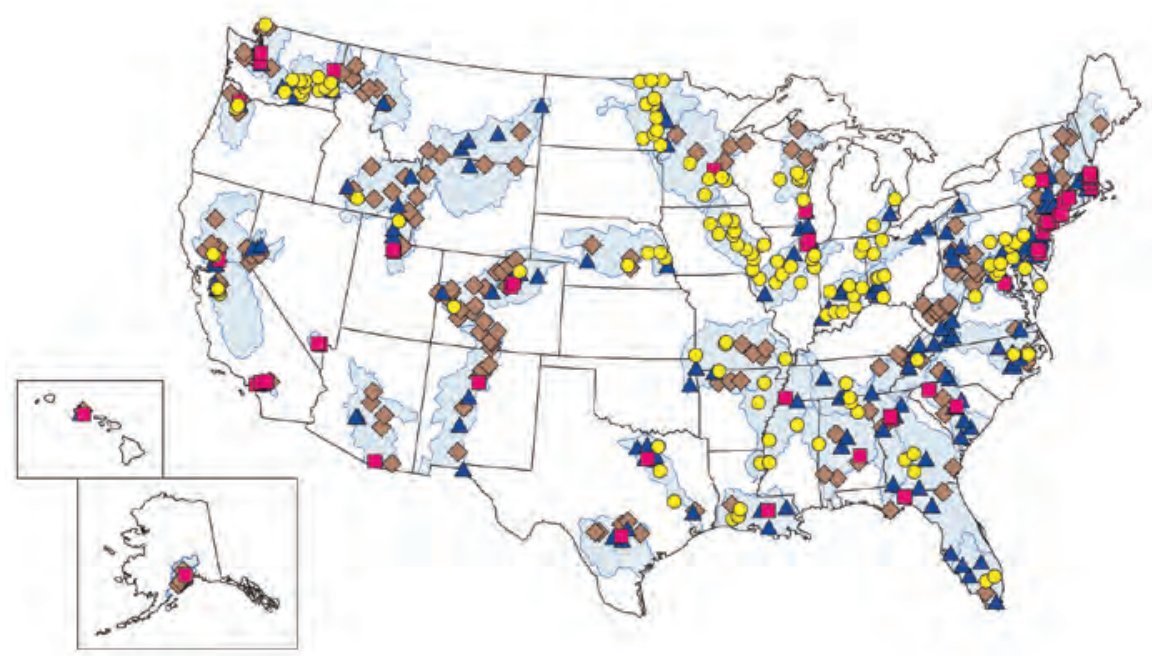

\section{Groundwater studies}

Land-use studies of shallow groundwater

○ Agricultural (53 studies)

- Urban (33)

$\diamond$ Undeveloped (9)

Major aquifer studies

- Mixed land use (94)

NAWQA Study Unit

$\begin{array}{cll}-1 & \text { High Plains Regional } \\ \text { - } & \text { Groundwater Study }\end{array}$
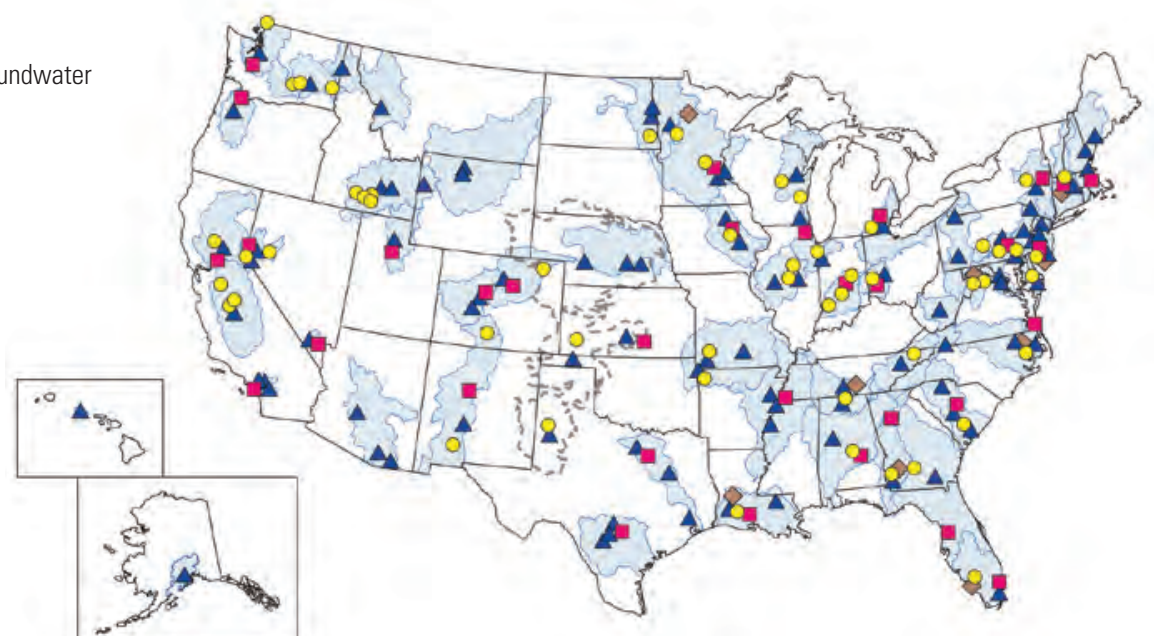

Figure 3-1. Stream sampling sites and groundwater studies in agricultural, urban, and undeveloped areas were distributed across the Nation's diverse environmental settings to evaluate the occurrence of nutrients within areas of specific land uses and in different environmental settings. 
Statistical models that relate nutrient concentrations to streamflow and time were used to compute flow-weighted, mean annual concentrations of ammonia, nitrate, total nitrogen, orthophosphate, and total phosphorus. Use of flow-weighted mean annual values facilitates comparisons among sites and avoids the potential bias to assessment results caused by differences in the number of samples collected at a site, sampling frequency, and varying flow conditions during the period of sampling. Models were developed to estimate nutrient loads and concentrations for each day of the year. The models were calibrated using nutrient concentrations from stream samples and mean-daily streamflow for the date of sampling. These daily values were then used to calculate unbiased summary statistics - including mean annual loads, yields, and flow-weighted concentrations - which were then used to make comparisons among sites.

\section{Groundwater}

NAWQA assessed nutrients in groundwater within specific land-use settings and in major aquifers influenced by a mixture of land uses. Dissolved nutrients were analyzed in water samples from 5,101 wells that were part of 189 land-use and major aquifer study networks (fig. 3-1). Unlike stream monitoring sites, which were sampled multiple times, wells were sampled only once because of the comparatively slow rates of change of water quality in most groundwater systems relative to the rates of change typical of streams. Data analyses were based on one sample per well.

Land-use studies focused on shallow groundwater primarily within agricultural and urban land-use settings, and to a lesser extent in undeveloped areas. Most of the wells sampled that were part of land-use studies were new or existing observation wells or domestic supply wells. Each study involved sampling about 20 to 30 randomly located wells within the targeted land-use area. In most of the wells, samples were collected from depths less than 20 feet below the water table, thus indicating, as directly as possible, the influence of each land use on shallow groundwater quality.

Major aquifer studies involved sampling about 20 to 30 domestic or public-supply wells that withdraw water from aquifers or aquifer systems that are important sources of water supply. Wells that were sampled for these studies were randomly selected throughout the areas underlain by each major aquifer, without regard to land use. Thus, the groundwater sampled for the major aquifer studies reflects the effects of a mixture of different land uses and groundwater ages on water quality, often including water that was recharged long distances from the sampled wells and in a variety of different land-use settings. The nature and extent of each major aquifer sampled for these studies is described in the summary report for the NAWQA Study Unit in which it occurs (see http://water.usgs.gov/nawqa/).

NAWQA also conducted studies that describe the change in water quality along a groundwater flow path from the point of recharge at the land surface to the point of dischargefor example a stream or lake in a natural flow system, or a pumped well. Design of these "flow-system studies" was tailored to the topic being addressed as well as the specific environmental framework at each locale. Examples of topics addressed include transport of constituents to drinking-water wells, and transport of agricultural chemicals in groundwater to streams.

Groundwater sampled during the NAWQA studies was classified into one of three categories of redox condition based on the concentrations of several diagnostic constituents (Jurgens and others, 2009):

- Oxic - groundwater with concentrations of dissolved oxygen greater than $0.5 \mathrm{mg} / \mathrm{L}$.

- Reduced-groundwater with concentrations of dissolved oxygen less than or equal to $0.5 \mathrm{mg} / \mathrm{L}$, and containing chemical markers for iron and manganese reduction.

- Mixed - groundwater with concentrations of dissolved oxygen greater than $0.5 \mathrm{mg} / \mathrm{L}$ and containing chemical markers for iron and manganese reduction.

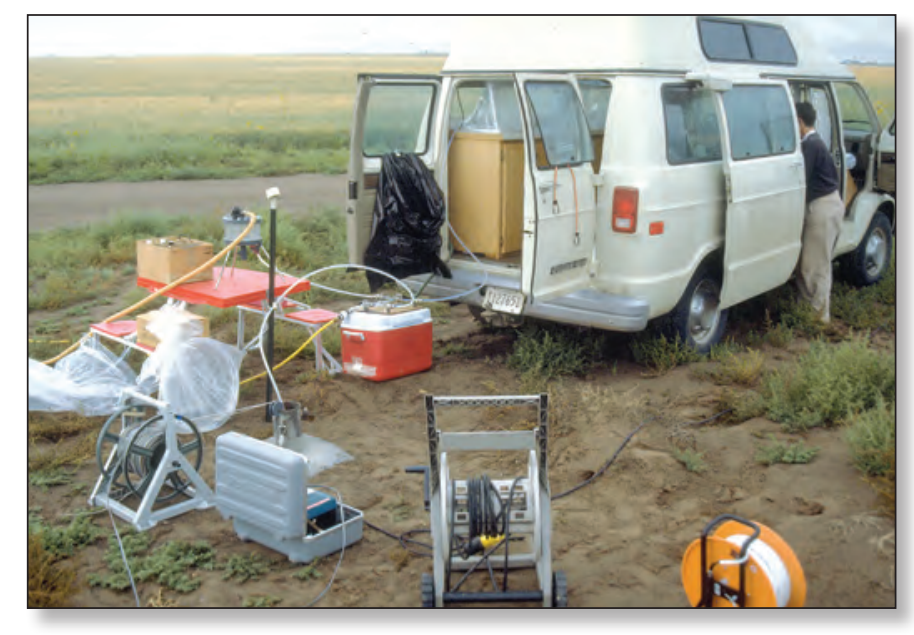

Most of the wells sampled as part of land-use studies were new or existing observation wells. Photograph by U.S. Geological Survey. 


\section{NAWOA Stream-Water Assessment in a National Context}

Consistent with the NAWQA sampling design, which was targeted by land use, the nutrient findings discussed in this report generally are presented by land-use category. Aggregation of NAWQA findings for streams across all land-use categories would not accurately represent all streams in the conterminous United States (fig. 3-2), which were characterized by classifying the watersheds of all stream segments in the USEPA River Reach File (Nolan and others, 2002) using the land-use criteria in table 3-1. For example, nearly 30 percent of the streams sampled by NAWQA were agricultural streams, whereas agricultural streams represent only about 15 percent of all streams in the conterminous United States. Furthermore, as shown in figure 3-2, agricultural streams represent only about 12 percent of all streams with public water-supply intakes. There are 1,679 public water-supply intakes on streams across the Nation for which land use could be characterized. The NAWQA design also over-represented urban streams and under-represented undeveloped streams compared with the national occurrence of streams in these land-use settings (fig. 3-2).

Nutrient concentrations in streams can fluctuate in response to changes in precipitation and streamflow (see Chapter 2, Nutrient Primer), so information on streamflow conditions at the time of sample collection is critical for assessing nutrient conditions. Because of the rotational sampling design used in the NAWQA assessment and because of regional variations in climate, hydrologic conditions during the NAWQA sampling periods were not uniform across all streams. Instead, regional patterns in climate resulted in many eastern streams having normal to above normal flow during

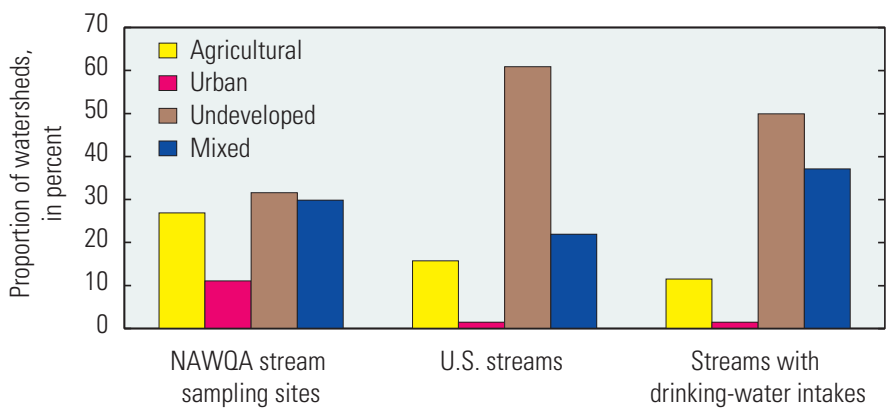

Figure 3-2. The NAWQA design for stream assessments placed greater emphasis on sampling streams that drain agricultural and urban watersheds (as defined in table 3-1), relative to those in undeveloped watersheds. Streams sampled by NAWOA included higher proportions of those classified as agricultural and urbanand lower proportions of those classified as undevelopedcompared with all streams in the conterminous United States and those with drinking-water intakes. (Modified from Gilliom and others, 2006.)

their respective sampling period, whereas flows in western streams were variable, with more having below normal flow during their sampling period (fig. 3-3). Streamflow also varied within the sampling period at many sites. For example, the 3-year sampling period for the Flint River in Alabama, the Great Miami River in Ohio, and the Spokane River in Idaho included both wet and dry periods (fig. 3-3). This hydrologic variability adds complexity to a comparison of sites by geographic region or land use. 


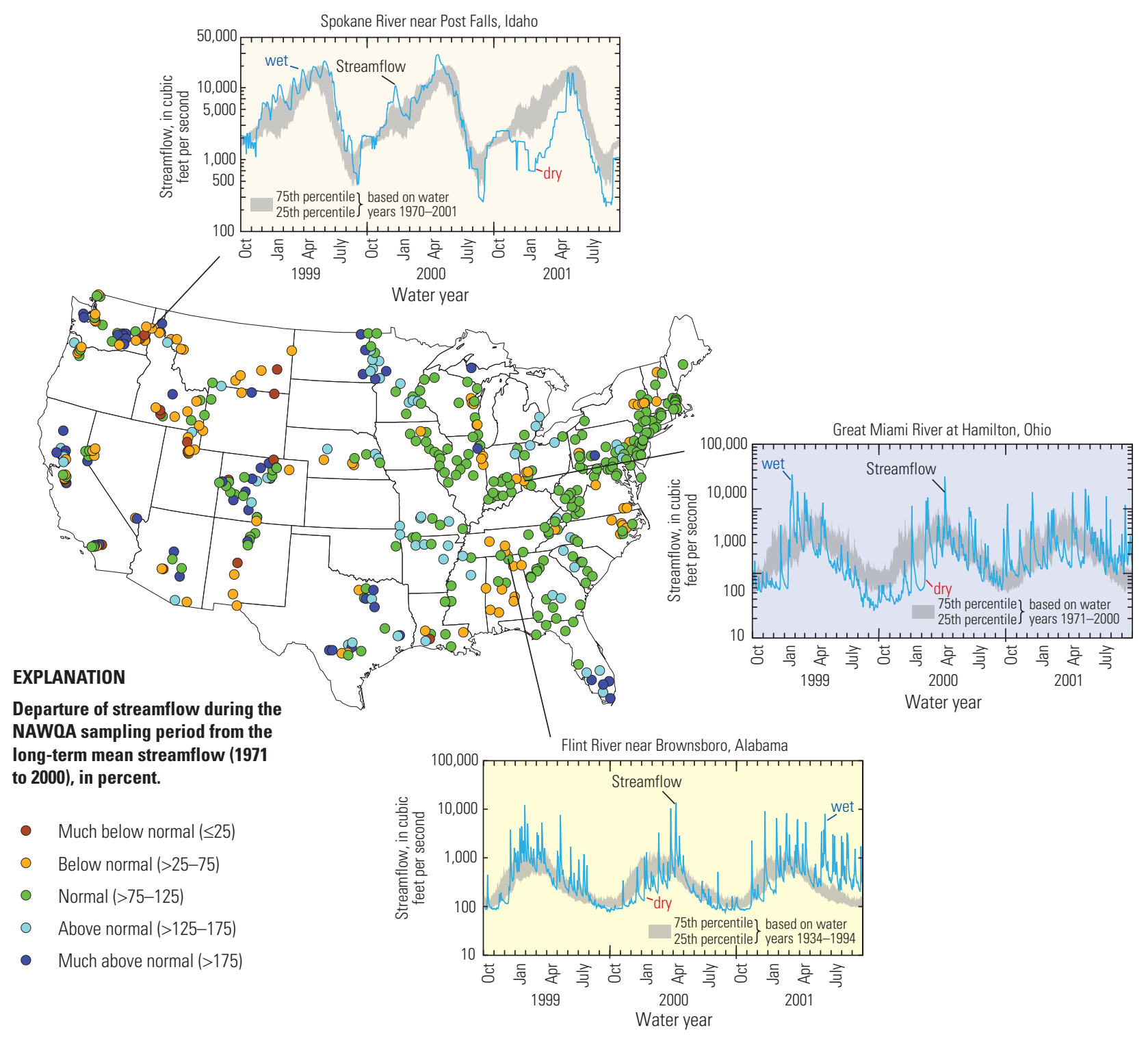

Figure 3-3. Streamflow at many eastern stream sites was normal to above normal during their respective sampling periods, whereas flows at western stream sites were variable, with more being below normal during their sampling period. These contrasts reflect both the rotational sampling design used in the NAWQA assessment and regional variations in climate. Streamflow also varied within the sampling period at many sites; samples from the Flint River in Alabama (Woodside and others, 2004), the Great Miami River in Ohio (Rowe and others, 2004), and the Spokane River in Idaho (Clark and others, 2004) were collected during both wet and dry periods. 


\section{NAWQA Groundwater Assessment in a National Context}

NAWQA findings for groundwater, as for streams, are grouped by land use in this report. NAWQA's targeted sampling design for groundwater over-represented areas with agricultural, urban, and mixed land use, and under-represented undeveloped areas when compared with the national distribution of these land-use settings overlying known groundwater resources (fig. 3-4). Comparisons of land-use distributions for the NAWQA-sampled wells with distributions for the entire Nation were based on NAWQA land-use classifications (as defined in table 3-1) for every square-kilometer area in the conterminous United States. Under-representation of undeveloped areas results from the targeting of agricultural and urban areas by the studies of shallow groundwater, and the scarcity of water-supply wells in areas that have little or no human activity.

\section{Extrapolation to Unsampled Areas}

NAWQA assessments use an integrated approach that includes both monitoring and modeling. Monitoring provides direct observations, often over time, of water-quality properties and characteristics, whereas models are tools that help interpret these observations. Analysis of model simulations can advance understanding of the relation of water quality to human activities and natural processes that affect spatial variations in quality.

Nutrient data collected by NAWQA during its first decade support the development and testing of a wide range of models, particularly statistical models, that are being used to predict nutrient concentrations in streams and groundwater for locations where nutrient concentrations have not been measured. This expansion of water-quality assessments from individual monitoring sites to unstudied locations by use of models for prediction, or spatial extrapolation, is fundamental to extending targeted local and regional studies to a comprehensive national assessment.

NAWQA statistical models establish quantitative linkages between nutrient concentrations measured at sampling sites with the associated explanatory variables that represent sources of nutrients, hydrology, and characteristics of soils, geology, and other factors. The models are built using the explanatory variables that best correlate with, or explain, concentrations of selected nutrients observed in streams and groundwater. Although explanatory variables included in the models are significantly correlated with nutrient concentrations, the specific cause-and-effect relations responsible for the observed correlations are not always clear, and inferences regarding causes should be considered as hypotheses. Models complement the monitoring by helping to estimate the extent of concentrations of concern, or by indicating vulnerable areas that can benefit from enhanced monitoring and protection. The statistical models are constrained to representing areas within the conterminous United States because data on nutrient sources and transport factors are unavailable for Alaska and Hawaii.

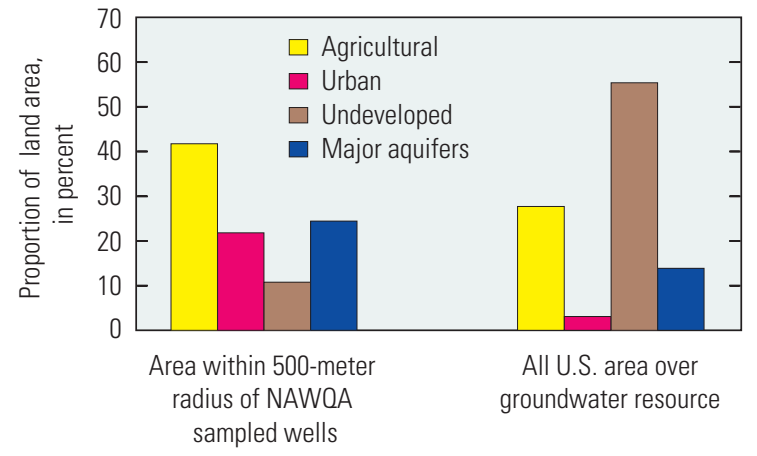

Figure 3-4. NAWQA's targeted sampling design for groundwater emphasized areas with urban, mixed, and agricultural land use - and under-represented undeveloped areas - when compared with the national distribution of land uses. (Modified from Gilliom and others, 2006.)

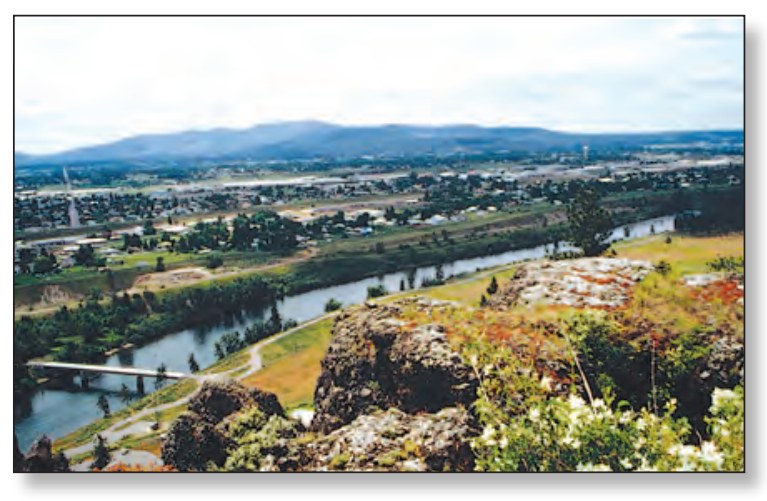

The Spokane River near Spokane, Washington. Photograph by Lan Tornes, U.S. Geological Survey. 


\section{Development of Models for Total Nitrogen Concentrations in Streams}

Models developed to extrapolate total nitrogen concentrations in streams used linear regression statistical techniques to relate flow-weighted, mean annual total nitrogen concentrations at 462 sites to characteristics (explanatory factors) associated with watersheds draining streams in the USEPA River Reach File (Spahr and others, 2010). The models relate total nitrogen concentrations to nitrogen inputs, basin characteristics, and hydrologic factors using data collected from 1992 to 2001. Optimal results were achieved by dividing the sites into two groups based on the percentage of agricultural land use in the upstream watershed: 220 sites referred to as "agricultural" drain watersheds with more than 25 percent of agricultural land use, and 242 sites referred to as "nonagricultural" drain watersheds with less than 25 percent agricultural land use.

The total nitrogen concentration at each site was represented by a flow-weighted, mean annual concentration to represent the movement of nitrogen mass throughout the year. After testing numerous potential explanatory factors, eight were selected for the model of agriculturally influenced sites and four were selected for the model of nonagricultural sites. The regression models were used to extrapolate total nitrogen concentrations to the more than 600,000 miles of streams depicted in the USEPA River Reach File (Nolan and others, 2002). The results of simulations made with both models were merged to produce a national map that shows the predicted mean estimates of the total nitrogen concentration.

\section{Development of the Nonlinear Nitrate Models for Groundwater}

Two models based on nonlinear regression were developed by NAWQA to predict nitrate concentrations in groundwater of the conterminous United States (Nolan and Hitt, 2006). The first model uses data primarily from monitoring wells to predict nitrate contamination of shallow (10 meters, or 33 feet), recently recharged groundwater. The second model uses data from domestic and public-supply wells to predict nitrate contamination in drinking water. The median depth of the drinking-water supply wells was 50 meters (164 feet). The shallow model is intended to maximize correlations with overlying land use, whereas the drinking-water model represents the used resource.

The models for predicting nitrate concentration in groundwater are based on averages of nitrate concentration and other characteristics of NAWQA groundwater studies. The average nitrate concentration of water in the wells sampled in each study was used to smooth local variability, so that the predominant factors that influence nitrate contamination at the national scale would be more readily apparent. The shallow groundwater model was based on data from 97 studies in which most samples were collected from monitoring wells, whereas the drinking-water model was based on data from 111 studies in which all samples were collected from domestic or public-supply wells. Data used to develop the models were collected during 1991-2003 and represent the first full decade of sampling by NAWQA. More than 100 explanatory factors were tested in the models to identify those that most reliably predict nitrate concentrations in groundwater: 16 factors were selected for the shallow groundwater model, and 14 factors were selected for the drinking-water model. Model predictions were made for each square-kilometer area in the conterminous United States for which a complete suite of input data was available, resulting in more than 8 million predictions. Uncertainty analysis was performed with the final models by varying model equations hundreds of times to produce a mean and variance of predictions at each groundwater study location. 


\section{Chapter}

Occurrence and Distribution of Nutrients in Streams and Groundwater

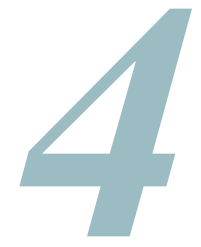

\section{Introduction}

NAWQA's assessment of nutrients in streams and groundwater of the United States includes hydrologic systems representative of the Nation's diverse landscapes, ecological resources, and climatic conditions. The assessment is targeted to specific land-use settings that are important to water quality across the Nation, allowing for characterization of the occurrence and distribution of nutrients in relation to land use and geographic patterns. Results of the assessment also can be used to identify critical factors influencing the occurrence and distribution of nutrients in streams and groundwater, such as anthropogenic (human) nutrient inputs, seasonal variability, and physical and chemical aquifer characteristics.

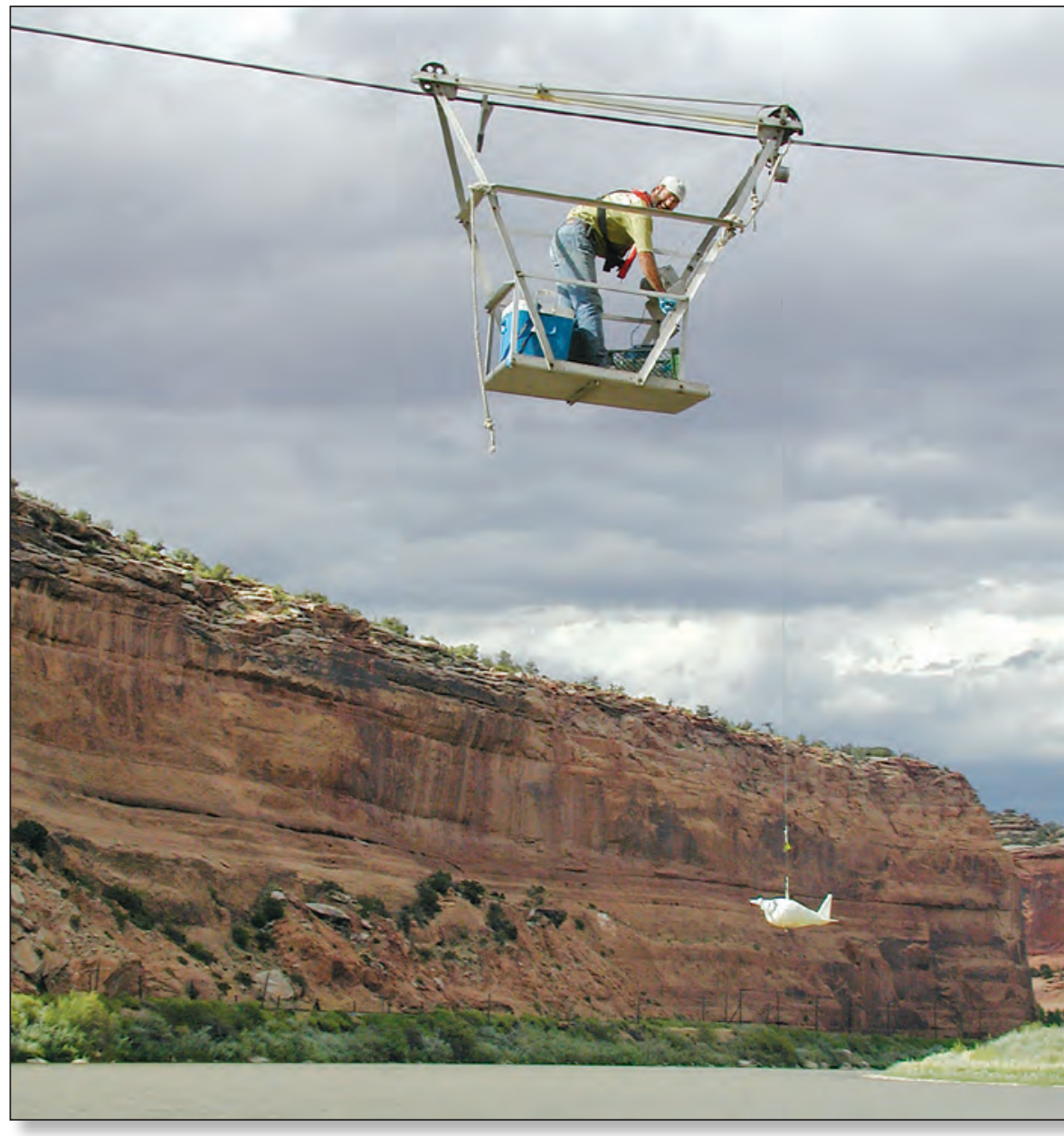

Photograph by Norman Spahr, U.S. Geological Survey. 


\section{Background Conditions}

What would nutrient concentrations be in streams and groundwater if there were no effects of human development? An answer is not readily available for many parts of the Nation because human development is so extensive, and remaining pristine sites, even where present, are often not monitored. To help answer this question, the NAWQA Program collected samples from streams and wells, and gathered complementary data from other programs, in areas with minimal or no development (see sidebar, Estimation of Background Concentrations). These samples reflect nutrients that are present in streams and groundwater as a result of purely natural processes, as well as low-level inputs of nutrients from anthropogenic sources such as atmospheric deposition. Data from these samples were used to estimate what concentrations might be expected under minimally impacted or "background" conditions across the United States.

The nutrient concentrations estimated to represent national background concentrations are listed in table 4-1.
These estimates can be compared with measurements made at other locations to determine whether development has resulted in elevated concentrations. Nutrient concentrations in undeveloped areas may vary considerably among regions of the country, but the number of sites sampled is insufficient to define small-scale variations. The regional variability in background nutrient concentrations is discussed in the context of the development of nutrient criteria protective of aquatic life in Chapter 7.

In areas of substantial agricultural or urban development, nutrient concentrations are likely to be elevated above background levels. Flow-weighted mean annual concentrations for all five nutrient constituents exceeded the background concentrations at 90 percent of 190 NAWQA agricultural and urban stream sites. Median concentrations of nitrate exceeded the groundwater background in 64 percent of 86 shallow aquifer studies sampled by NAWQA in areas underlying agricultural or urban land use; however, concentrations of ammonia and orthophosphate were not greater than background levels in most areas.

Table 4-1. Estimates for national background concentrations of nutrients in streams and groundwater.

[ mg/L, milligrams per liter; -, not applicable]

\begin{tabular}{|c|c|c|c|c|c|c|c|c|c|c|}
\hline \multirow[b]{2}{*}{ Data set } & \multicolumn{2}{|c|}{ Ammonia } & \multicolumn{2}{|c|}{ Nitrate } & \multicolumn{2}{|c|}{ Total Nitrogen } & \multicolumn{2}{|c|}{ Orthophosphate } & \multicolumn{2}{|c|}{ Total Phosphorus } \\
\hline & $\begin{array}{l}\text { Sites or } \\
\text { wells }\end{array}$ & $\begin{array}{c}\text { Concen- } \\
\text { tration } \\
\text { (mg/L) }\end{array}$ & $\begin{array}{c}\text { Sites or } \\
\text { wells }\end{array}$ & $\begin{array}{c}\text { Concen- } \\
\text { tration } \\
\text { (mg/L) }\end{array}$ & $\begin{array}{c}\text { Sites or } \\
\text { wells }\end{array}$ & $\begin{array}{c}\text { Concen- } \\
\text { tration } \\
\text { (mg/L) }\end{array}$ & $\begin{array}{c}\text { Sites or } \\
\text { wells }\end{array}$ & $\begin{array}{c}\text { Concen- } \\
\text { tration } \\
\text { (mg/L) }\end{array}$ & $\begin{array}{l}\text { Sites or } \\
\text { wells }\end{array}$ & $\begin{array}{c}\text { Concen- } \\
\text { tration } \\
\text { (mg/L) }\end{array}$ \\
\hline Streams & 89 & 0.025 & 108 & 0.24 & 88 & 0.58 & 89 & 0.010 & 84 & 0.034 \\
\hline Groundwater & 177 & 0.10 & 419 & 1.0 & - & - & 166 & 0.030 & - & - \\
\hline
\end{tabular}

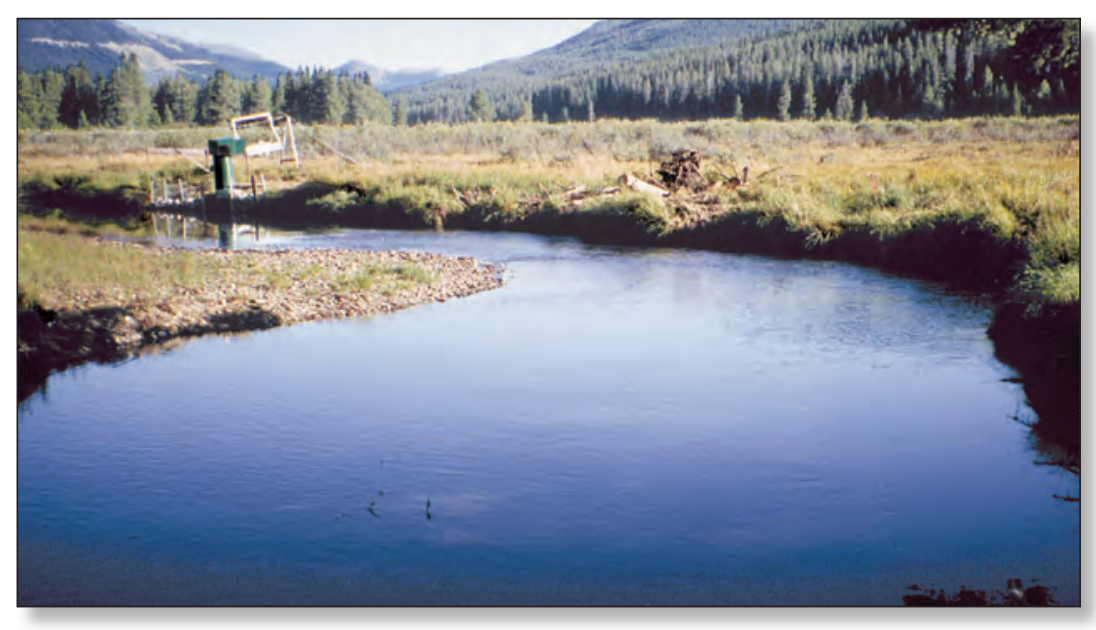

Sites with minimal human impact, such as the Colorado River in Rocky Mountain National Park, were chosen to represent background nutrient conditions. Photograph by J.R. Deacon, U.S. Geological Survey. 


\section{Estimation of Background Concentrations}

Estimates of background concentrations of nutrients in streams were based on data from 110 sites selected on the basis of criteria used by Clark and others (2000) (fig. 4-1).

1. The upstream basin had less than 5 percent urban land and less than 25 percent agricultural land,

2. The site was classified as a reference, forest indicator, or rangeland indicator site by local experts,

3. The basin area was less than $3,000 \mathrm{~km}^{2}\left(1,158 \mathrm{mi}^{2}\right)$,

4. Data were sufficient for estimation of flow-weighted mean annual nutrient concentrations, and

5. If two sites were on the same stream, only the upstream site was included.

Flow-weighted mean annual concentrations (see Chapter 3, NAWQA's Approach to Nutrient Assessment) of the five nutrient constituents at these 110 sites were computed on the basis of several years of samples (see Mueller and Spahr, 2005 , for details). Background concentrations were estimated as the 75th percentile of the flow-weighted means for all sites that had adequate data for each constituent. Selection of the 75th percentile to represent background implies that these concentrations are exceeded at no more than 25 percent of minimally impacted streams.

For groundwater, background concentrations were estimated using data from 419 wells selected on the basis of criteria specified by Nolan and Hitt (2003): 320 "retrospective" wells from the USGS data base, and an additional 99 wells sampled by NAWQA (fig. 4-1). Background concentrations were estimated as the 75th percentile of a single representative sample from each of the 419 wells that had data for the nutrient in question. Only dissolved constituents were included because particulate nitrogen and phosphorus are negligible in groundwater.

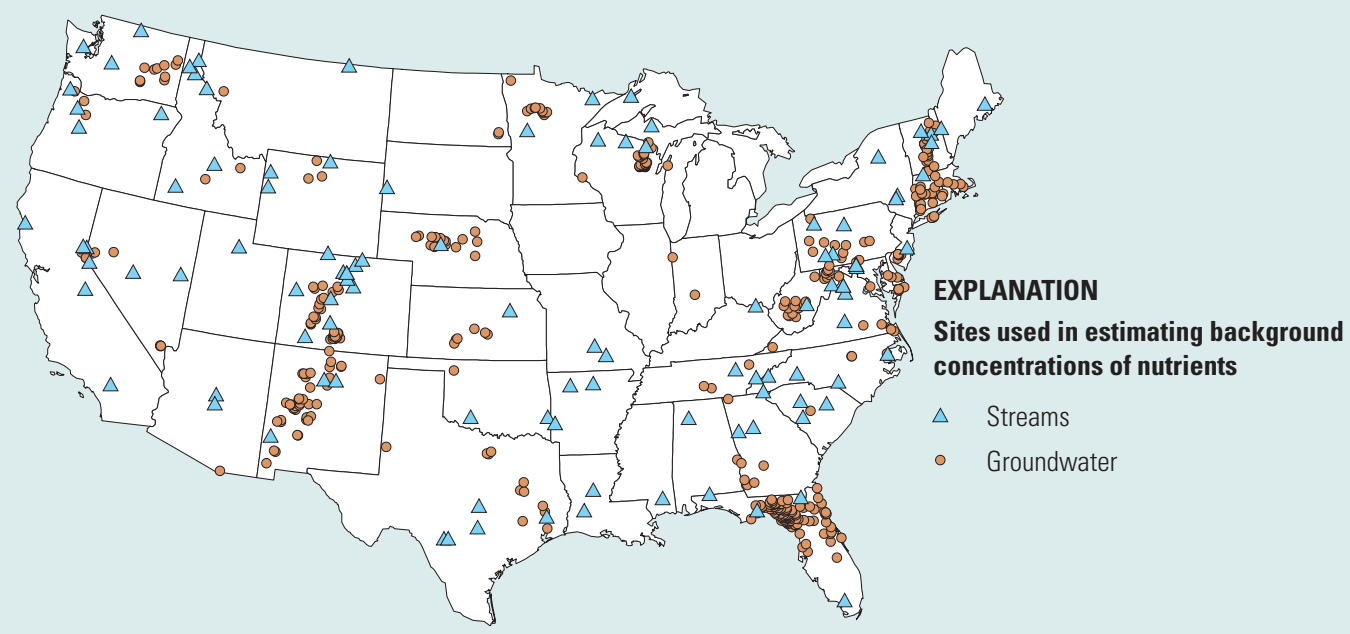

Figure 4-1. Nutrient data from 110 stream sites and 419 wells in relatively undeveloped areas were used to estimate minimally impacted (background) concentrations for the United States. 


\section{Nutrient Concentrations in Streams}

\section{Relations to Land Use}

Variations in the occurrence and distribution of nutrients in streams reflect, in part, differences in land use and associated nutrient sources. Nonpoint inputs, such as those from fertilizers and manure from livestock, are the major sources of nutrients in agricultural areas, whereas both point and nonpoint sources - including wastewater effluent from municipal or industrial facilities; fertilizers applied to lawns, golf courses, and parks; septic systems; and atmospheric deposition - are the major sources in urban areas. In undeveloped areas, nonpoint inputs, such as atmospheric deposition and natural sources released by weathering of rocks and soil, typically are the largest sources. NAWQA sampling sites in watersheds were classified by land use: agricultural, urban, mixed, and undeveloped (see Chapter 3, NAWQA's Approach to Nutrient Assessment, table 3-1). Urban sites were selected to avoid the effects of major wastewater-treatment plants and other point sources, but in some locations this was not feasible.

Median flow-weighted nutrient concentrations for all constituents were higher in streams in developed areas - that is, agricultural, urban, or mixed land-use streams - than in streams in undeveloped areas (fig. 4-2). Concentrations of total nitrogen were higher in agricultural streams than in streams with urban, mixed, or undeveloped land use, with a median concentration of $3.8 \mathrm{mg} / \mathrm{L}$ - about 6 times greater than background levels. Concentrations of total nitrogen in urban streams were lower than those in agricultural settings, with a median concentration of $1.5 \mathrm{mg} / \mathrm{L}$ (about 3 times greater than background levels). Concentrations of total phosphorus were similarly elevated in streams in both agricultural and urban areas, with median concentrations of 0.26 and $0.25 \mathrm{mg} / \mathrm{L}$, respectively-again about 6 times greater than background levels. Concentrations of ammonia and orthophosphate were similar in agricultural, urban, and mixed land-use streams. In urban and mixed land-use streams, the relatively higher concentrations of ammonia, orthophosphate, and total phosphorus compared to concentrations of nitrogen likely were due to the influence of point sources; many of the highest concentrations occurred at sites downstream from wastewatertreatment plants. Although samples from undeveloped streams had lower concentrations of total phosphorus than samples from streams in other land uses, the contrast was not as great as for other nutrients. The likely cause is naturally occurring phosphorus associated with the high suspended-sediment concentration in some undeveloped streams.

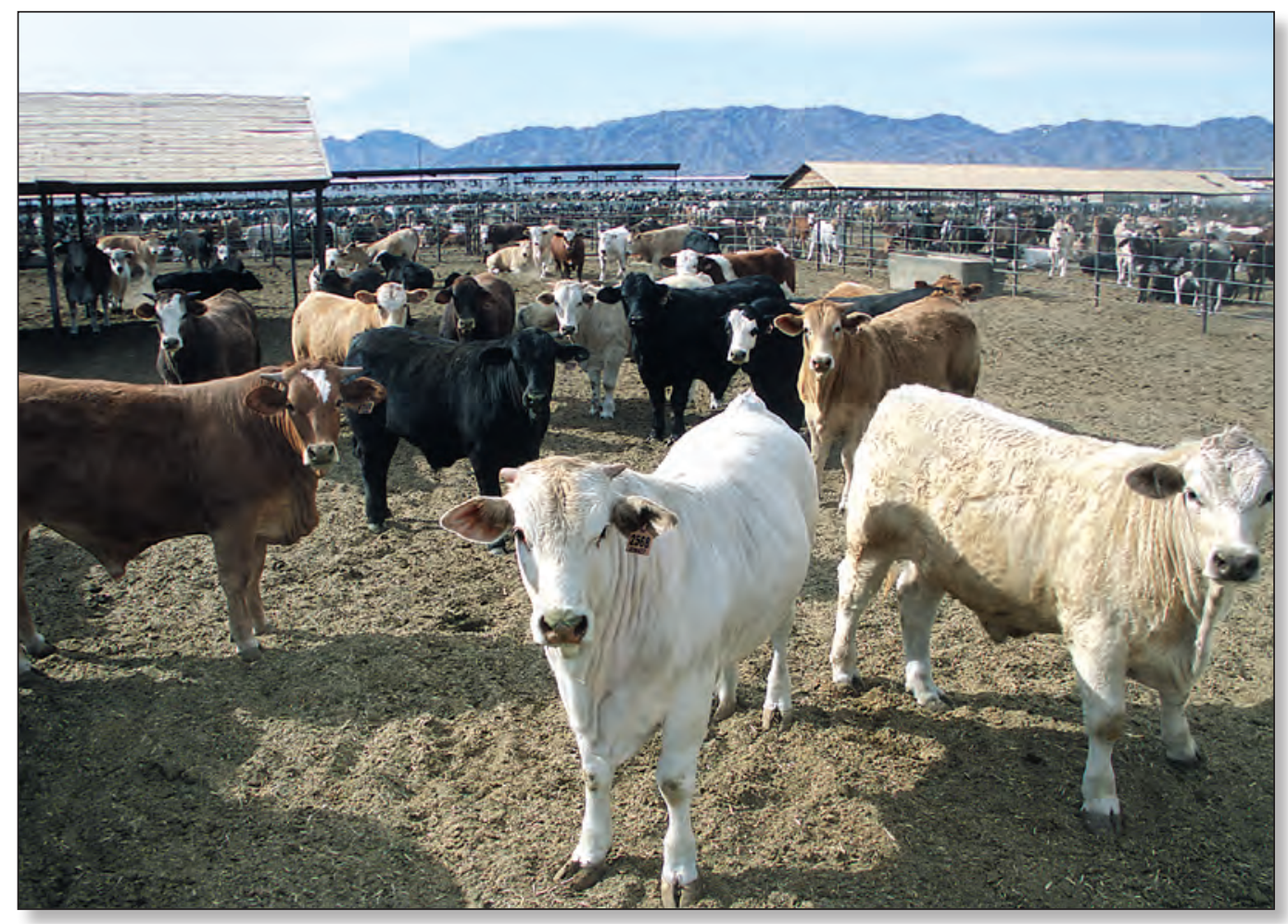

Concentrated animal feeding operations, also referred to as "CAFOs," are potential sources of nutrients to streams and groundwater. Photograph by Jeff Vanuga, U.S. Department of Agriculture, Natural Resources Conservation Service. 

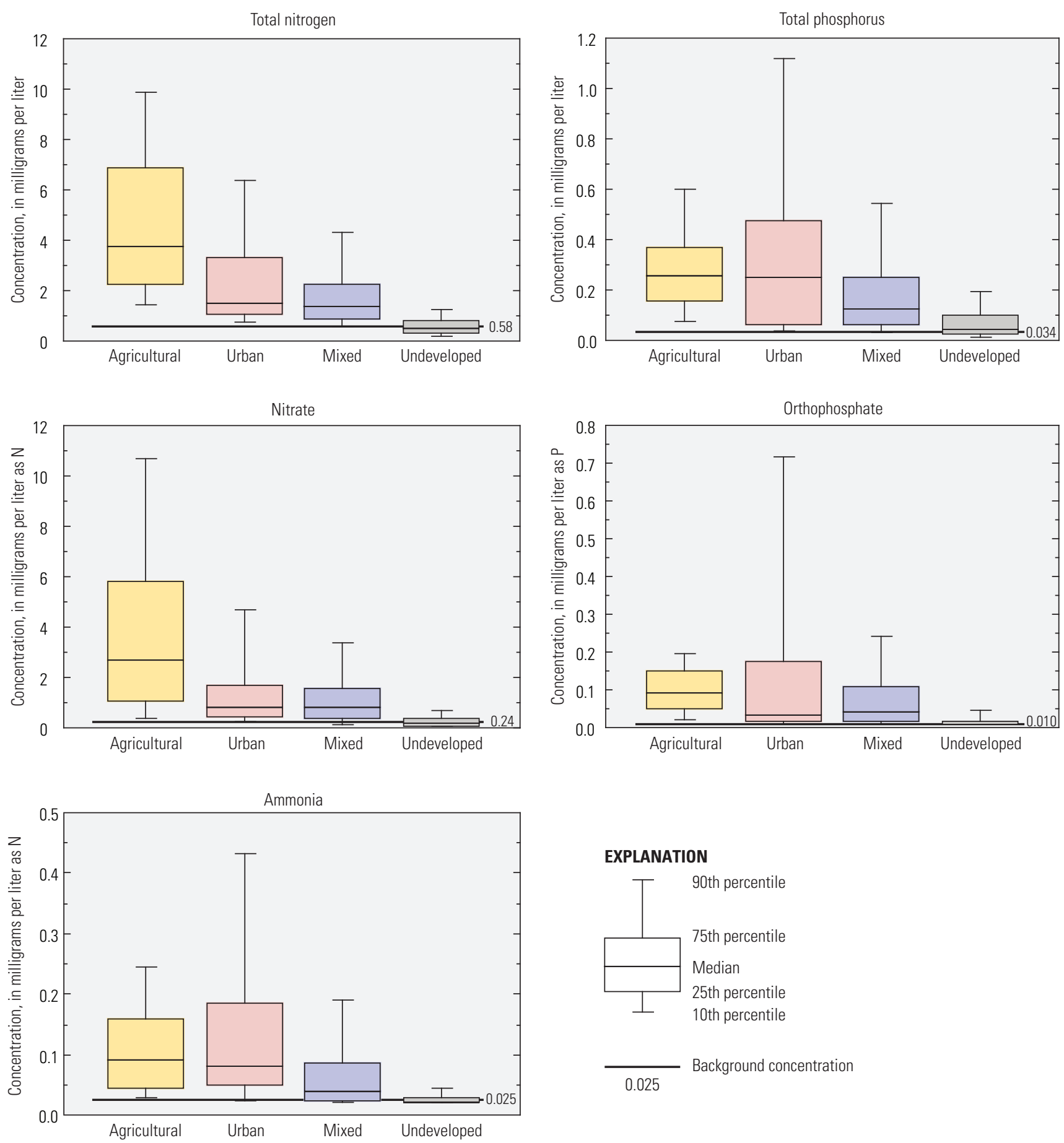

\section{EXPLANATION}

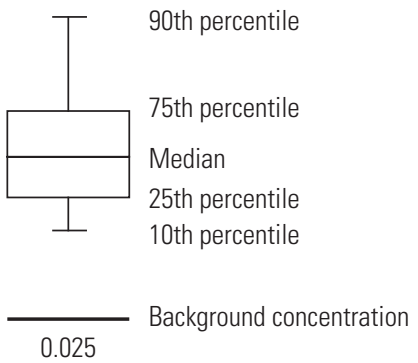

Figure 4-2. In streams, concentrations of total nitrogen and nitrate were higher in agricultural streams than in urban or mixed land-use streams, whereas concentrations of ammonia, orthophosphate, and total phosphorus were similar in agricultural, urban, and mixed land-use streams. 


\section{Geographic Distribution}

The geographic distribution of nutrients in streams reflects regional differences in nutrient sources, hydrologic characteristics of watersheds, and chemical and biological processes that affect specific nutrients. In this section, interactions among these factors are illustrated by comparing the geographic distributions of total nitrogen and total phosphorus in streams. The comparisons are illustrated using a series of national maps showing the relative range (high, medium, or low) of concentrations for sites downstream from specified land uses (fig. 4-4) (see sidebar, Geographic Framework). Sites at which concentrations were within the lowest 25 percent of the data are shown in the "Low" range, sites where concentrations were within the upper 25 percent of the data are shown in the "High" range, and all other sites are shown in the "Medium" range. The background shading on the maps identifies nonpoint-source input rates of nitrogen and phosphorus.

\section{Geographic Framework}

Describing the geographic distribution of nutrients requires a spatial framework with a defined terminology to delineate different areas. For the purposes of this report, the continental United States was divided into eight contiguous areas on the basis of water-resources regions (fig. 4-3). Seaber and others (1987) used the boundaries of major river basins to define 21 water-resources regions. The areas designated on the map below are either single water-resources regions or combinations of regions. These area designations are used in the discussion of geographic distribution of nutrients in streams and groundwater. Alaska and Hawaii are individual regions.

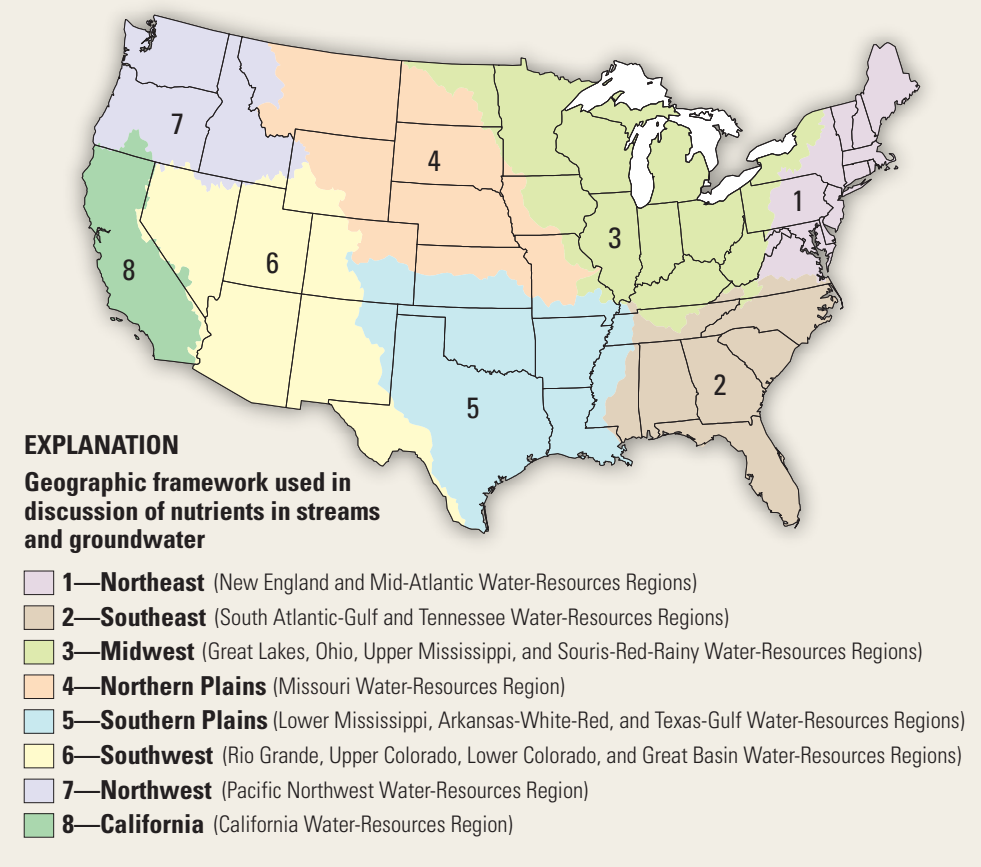

Figure 4-3. For the purposes of this report, the continental United States was divided into eight contiguous areas that are based on water-resources regions. These area designations are used in this report in the discussion of geographic distribution of nutrients in streams and groundwater. 


\section{Streams}
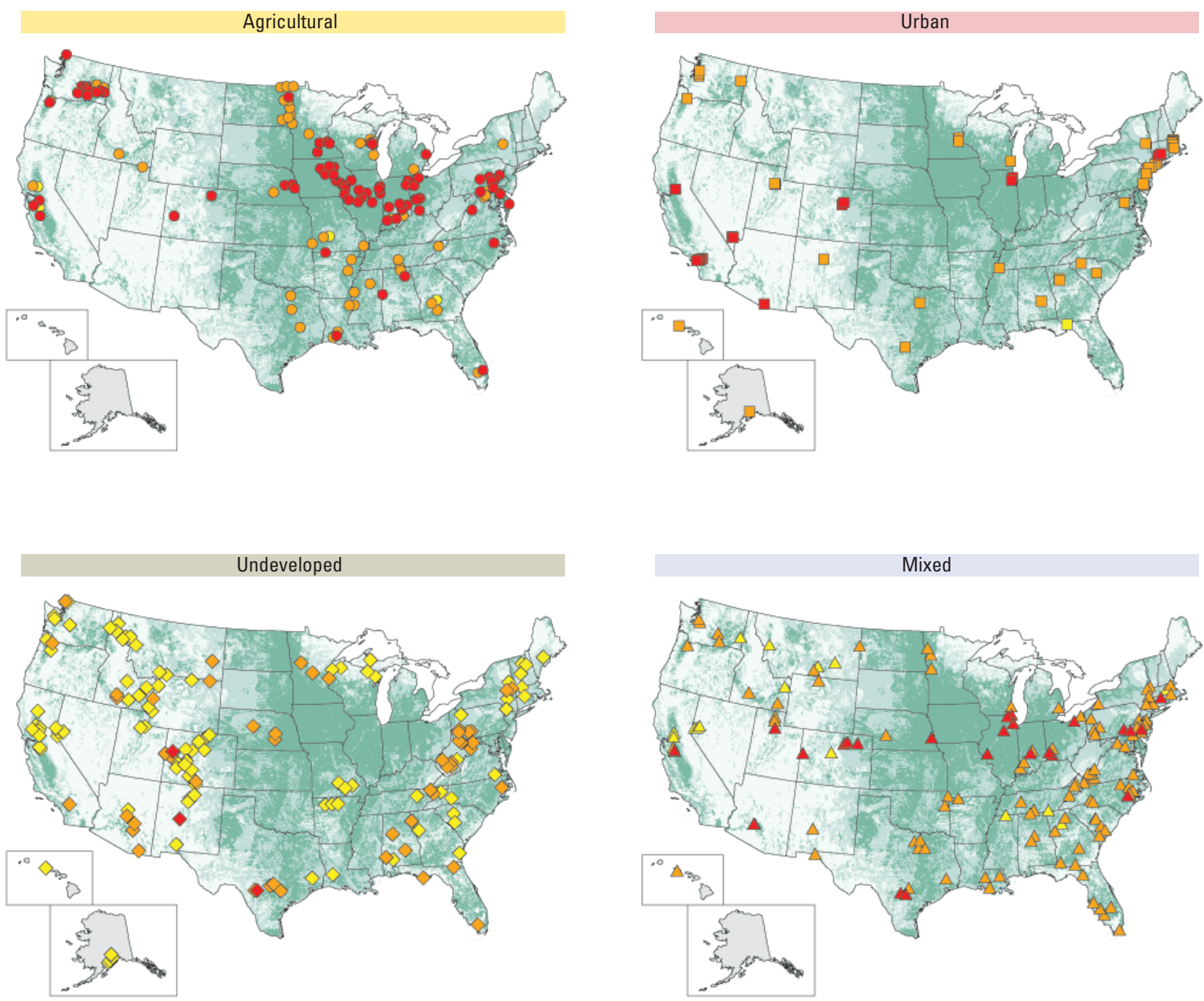

\section{EXPLANATION}

Estimated 1997 nitrogen inputs from fertilizer, manure, and atmosphere, in pounds per square mile

$\square<2,900$
$\square 2,900-15,000$
$\square>15,000$

Data on nitrogen inputs not available for Alaska and Hawaii.

\section{Stream sites, by watershed land use}

$\begin{array}{cccc}\text { Agricultural } & \text { Urban } & \text { Undeveloped } & \text { Mixed } \\ \circ & \square & \diamond & \triangle \\ \odot & \square & \diamond & \triangle \\ \bullet & \square & \diamond & \Delta\end{array}$

Total nitrogen concentration, in milligrams per liter

Low $(<0.66)$

Medium (0.66-3.17)

High $(>3.17)$

Figure 4-4. Concentrations of total nitrogen in agricultural streams were high at sites in areas that receive large annual inputs of nitrogen in the Northeast, Midwest, and Northwest. Total nitrogen concentrations in urban and mixed streams generally were in the medium range, whereas concentrations in undeveloped streams generally were low. 
Concentrations of total nitrogen in agricultural streams were high at most sites in the Northeast, Midwest, and Northwest (fig. 4-4). These sites are in areas that receive large annual inputs of nitrogen in the form of fertilizer, manure, and (in some cases) atmospheric deposition. High concentrations in the Midwest are influenced by the prevalence of tile drains, which facilitate water movement from fields to streams. For example, nitrate concentrations in the Iowa River near Rowan, Iowa, were at their highest while tile drains were flowing, and decreased when flow from tile drains ceased (fig. 4-5). High concentrations at many sites in the Northwest, the Northern Plains, the Southwest, and California might be influenced by large applications of irrigation water. Irrigation return flow can carry substantial amounts of nitrate to streams (fig. 4-6). Most of the medium and low concentrations of total nitrogen in agricultural areas were at sites in the Southeast and Southern Plains, where inputs are more variable. These settings can contain substantial amounts of organic matter, which result in loss of nitrate due to denitrification before it reaches a stream; therefore, concentrations can be relatively low in comparison to inputs (see Chapter 5, Exchange of Nutrients Between Surface Water and Groundwater).
Total nitrogen concentrations downstream from urban areas generally were in the medium range, but sites with high concentrations were scattered from the Northeast through the Southwest and California (fig. 4-4). Many of the sites with high concentrations were downstream from wastewatertreatment plants, which provide an additional nitrogen input. The potential effect of wastewater-treatment plants is especially large in the arid West, where wastewater-treatment plant effluent can be the primary source of the flow in urban streams during parts of the year when precipitation is low.

At sites downstream from relatively undeveloped watersheds, total nitrogen concentrations generally were low (fig. 4-4). Medium-range concentrations in the Northeast and in eastern parts of the Midwest were in areas of greater atmospheric nitrogen deposition. Medium and high concentrations of total nitrogen in the Southwest and western parts of the Northern Plains (fig. 4-4) were detected at sites with greater loads of suspended sediment, which can be a source of organic matter containing particulate nitrogen. This was seen, for example, in the Yellowstone River Basin, where total nitrogen increases along with the concentration of suspended sediment (Peterson and others, 2004) (see sidebar, Contrasts among Undeveloped Watersheds: Forest and Rangeland; fig. 4-7).

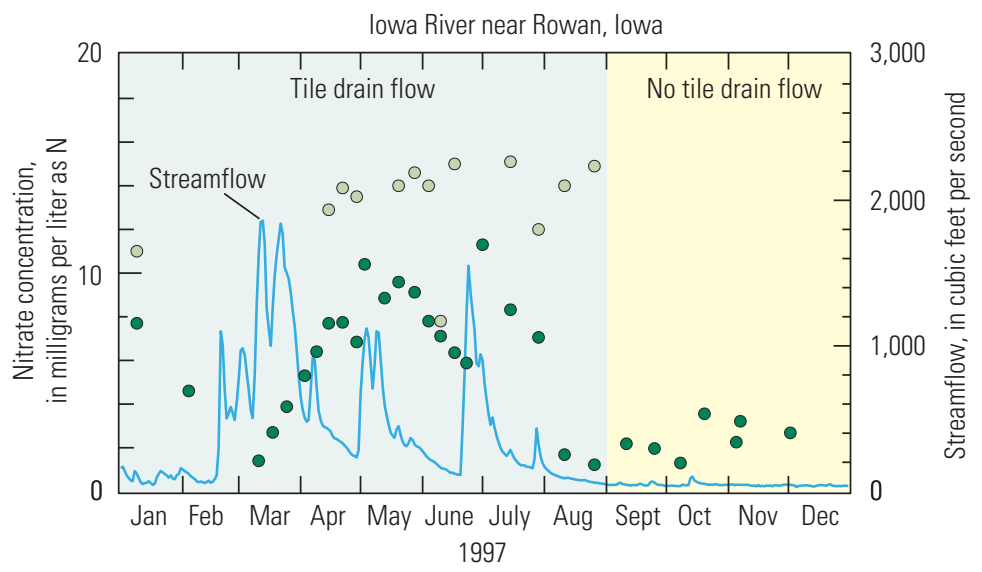

EXPLANATION

- Tile drain nitrate concentration

- lowa River nitrate concentration

Figure 4-5. Tile drains can contribute substantial amounts of nitrate to streams and rivers from agricultural fields. Nitrate concentrations in the lowa River near Rowan, lowa, decreased when flow from tile drains ceased (Kalkhoff and others, 2000). 


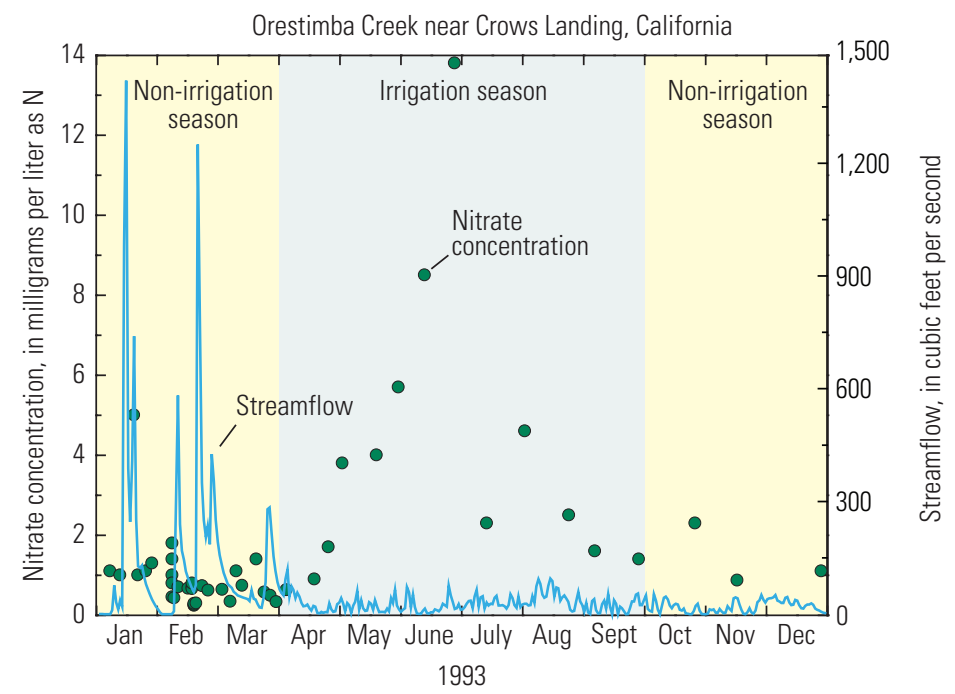

Figure 4-6. In Orestimba Creek, California, irrigation return flow can transport substantial amounts of nitrate to the stream during the spring and summer.

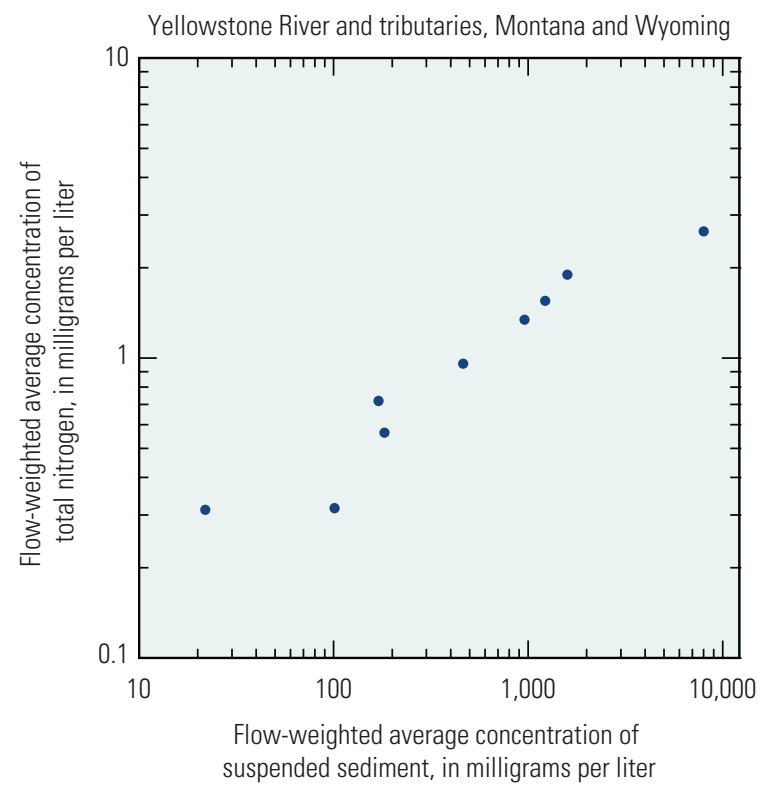

Figure 4-7. Because suspended sediment can be a source of organic matter containing particulate nitrogen, concentrations of total nitrogen were correlated with concentrations of suspended sediment in the Yellowstone River and its tributaries, Montana and Wyoming.

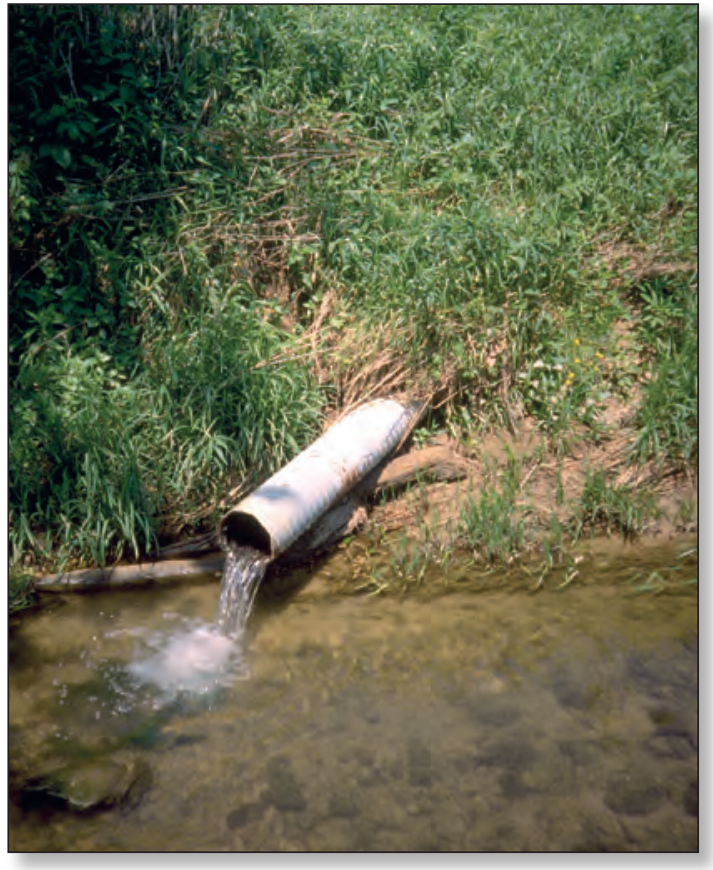

Tile drains buried at shallow depths reduce the water content of poorly drained soils and divert shallow groundwater to nearby streams. Photograph by Jeffrey Martin and Nancy Baker, U.S. Geological Survey.

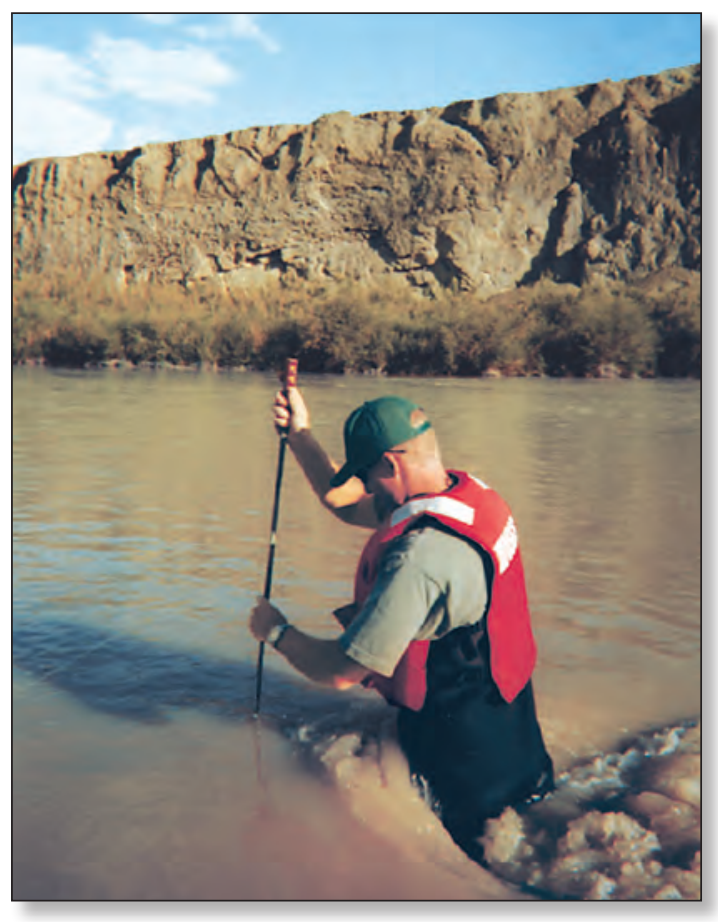

The Bighorn River, Wyoming, displays the high concentration of suspended sediment characteristic of streams that drain rangelands with highly erosive soils. Photograph by Nate Majerus, U.S. Geological Survey. 


\section{Contrasts among Undeveloped Watersheds: Forest and Rangeland}

Water-quality conditions in undeveloped watersheds are related to the same factors that influence natural vegetation types in watersheds and hence were evaluated by sorting the water-quality data according to predominant land cover: forest or rangeland. Comparison of nutrient concentrations in streams shows that total phosphorus is significantly greater in rangeland areas than in forest areas (fig. 4-8). Most of the rangeland sites are in the semiarid and arid western parts of the United States, where phosphorus often occurs naturally in igneous and marine sedimentary rocks (Peterson and others, 2004). Also, because phosphorus tends to attach to soil sediment particles, erosion can transport sediment and attached phosphorus to streams, causing concentrations of total phosphorus in the streams to increase with increasing concentrations of suspended sediment. Rangeland sites are generally in areas where erosion potential is greater, because of slope, soil type, and climate.

Although the concentrations of total nitrogen in streams are not significantly different between forest and rangeland sites throughout the United States (fig. 4-8), total nitrogen in some areas, such as the Yellowstone River Basin, increases along with the amount of rangeland in the upstream watershed because suspended sediment can also be a source of organic matter containing particulate nitrogen. In groundwater, nitrate concentrations are much higher in rangeland areas than in forest areas (fig. 4-8). Studies have shown that naturally high concentrations of nitrate can accumulate in soils and groundwater in semiarid and arid regions (Walvoord and others, 2003).

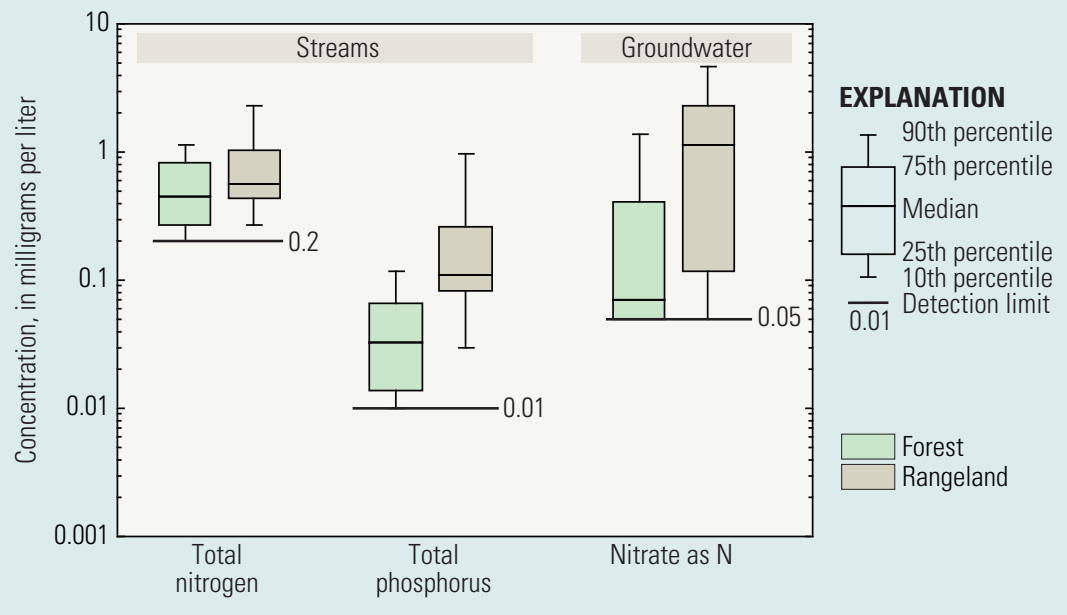

Figure 4-8. Rangeland streams have higher total phosphorus concentrations than streams in forested areas. Rangelands are primarily in the semiarid and arid Western United States, where phosphorus occurs naturally in geologic materials and the erosion potential is high. In groundwater, nitrate concentrations are higher in rangeland areas than in forested areas, most likely because high concentrations of nitrate can accumulate in soils and groundwater in semiarid and arid regions. (Modified from Mueller and Spahr, 2006.)

The geographic distribution of total phosphorus concentrations in streams is similar to that of total nitrogen, with high concentrations found in agricultural streams throughout the country (fig. 4-9). In contrast to the distribution of total nitrogen concentrations, distributions of total phosphorus concentrations were sometimes relatively lower in agricultural streams (more sites in the medium and low ranges, fig. 4-9) and higher in urban streams (more sites in the high and medium ranges, fig. 4-9). In addition, total phosphorus concentrations were relatively higher in streams in undeveloped areas than were total nitrogen concentrations. 


\section{Streams}
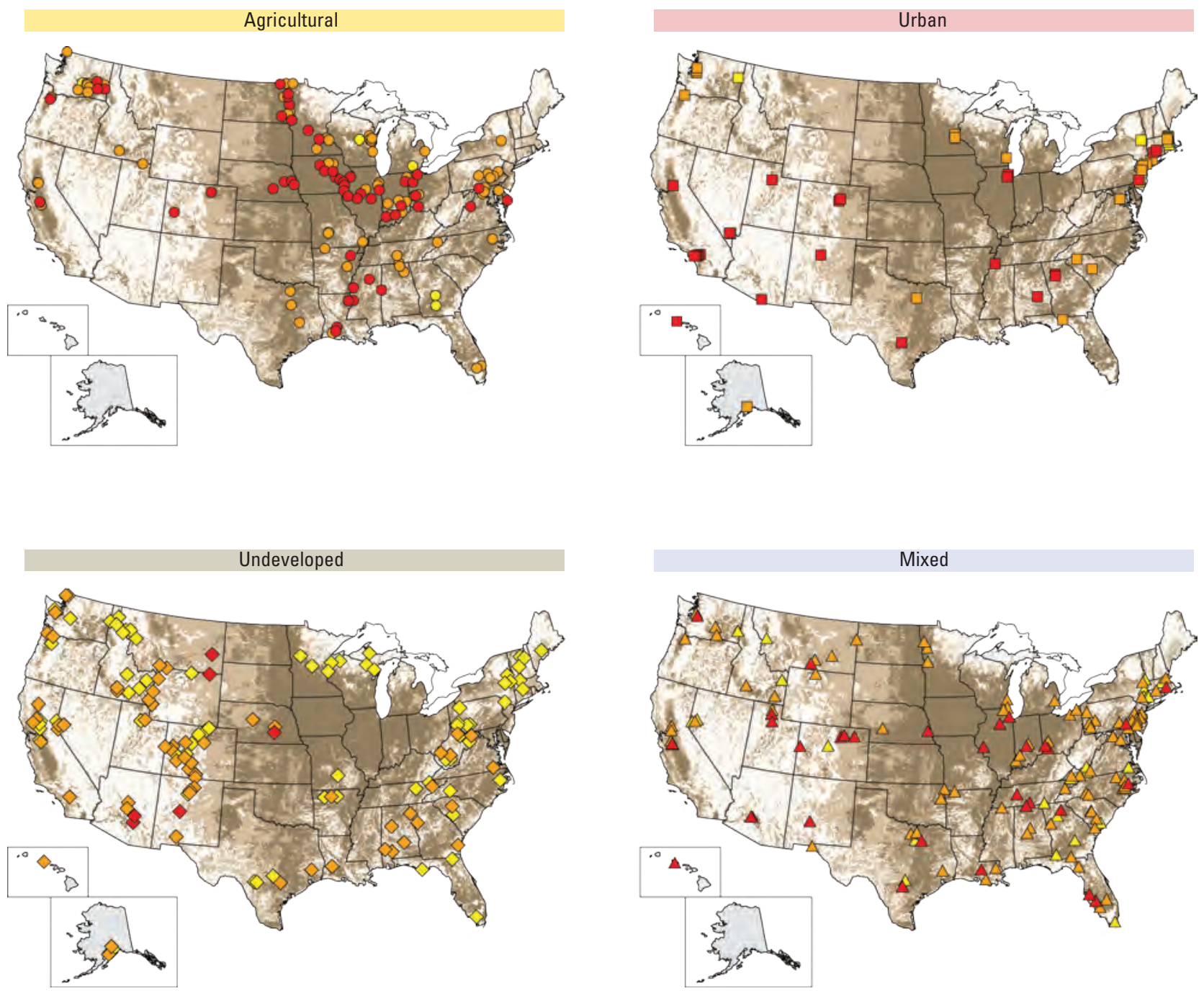

\section{EXPLANATION}

Estimated 1997 phosphorus inputs from fertilizer and manure, in pounds per square mile
$\square<340$
$340-2,730$
$>2,730$

Data on phosphorus inputs not available for Alaska and Hawaii.
Stream sites, by watershed land use

$\begin{array}{cccc}\text { Agricultural } & \text { Urban } & \text { Undeveloped } & \text { Mixed } \\ \circ & \square & \diamond & \triangle \\ \circ & \square & \diamond & \triangle \\ \bullet & \square & \diamond & \Delta\end{array}$

Total phosphorus concentration, in milligrams per liter

$\operatorname{Low}(<0.05)$

Medium (0.05-0.28)

High (>0.28)

Figure 4-9. High concentrations of total phosphorus were found in agricultural and urban streams; however, concentrations of total phosphorus were relatively higher than were total nitrogen concentrations in urban and undeveloped streams. 
Differences between the distributions of total nitrogen and total phosphorus concentrations in streams likely are a result of differences in sources - especially natural sources of phosphorus as well as its relatively high concentrations in wastewater-treatment plant effluent - and differences in the processes that transport nitrogen and phosphorus to streams. For example, water samples from the Trinity River below Dallas, where the streamflow is dominated by effluent from regional wastewater-treatment plants, had higher concentrations of phosphorus than water samples from other streams in the Trinity River Basin, which were affected only by nonpoint sources (Land and others, 1998) (fig. 4-10).

Nonpoint sources of phosphorus in urban areas include runoff from lawns and construction sites.
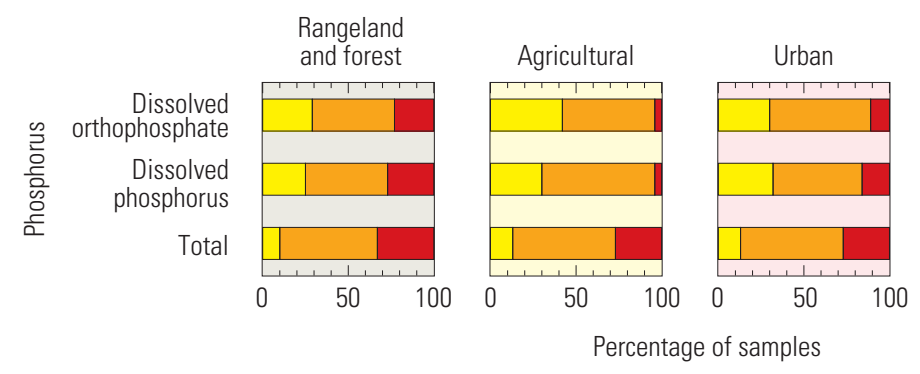

At undeveloped sites, high and medium concentrations of total phosphorus were more common than high and medium concentrations of total nitrogen in the Northern Plains, Southwest, and California (igs. 4-4 and 4-9). Rangeland is the predominant land cover in these areas, whereas forest is the predominant land cover in most other undeveloped areas of the United States. In rangeland areas, phosphorus commonly occurs naturally in geologic materials (fig. 4-11) and erosion potential is high, which contributes to higher total phosphorus concentrations in streams here compared to those in streams in other undeveloped, forested areas (see sidebar, Contrasts among Undeveloped Watersheds: Forest and Rangeland).

Figure 4-10. Samples from the Trinity River below Dallas, where the streamflow is dominated by effluent from regional wastewater-treatment plants, had higher concentrations of phosphorus than samples from other streams in the Trinity River Basin, Texas, which were affected only by nonpoint sources (Land and others, 1998).

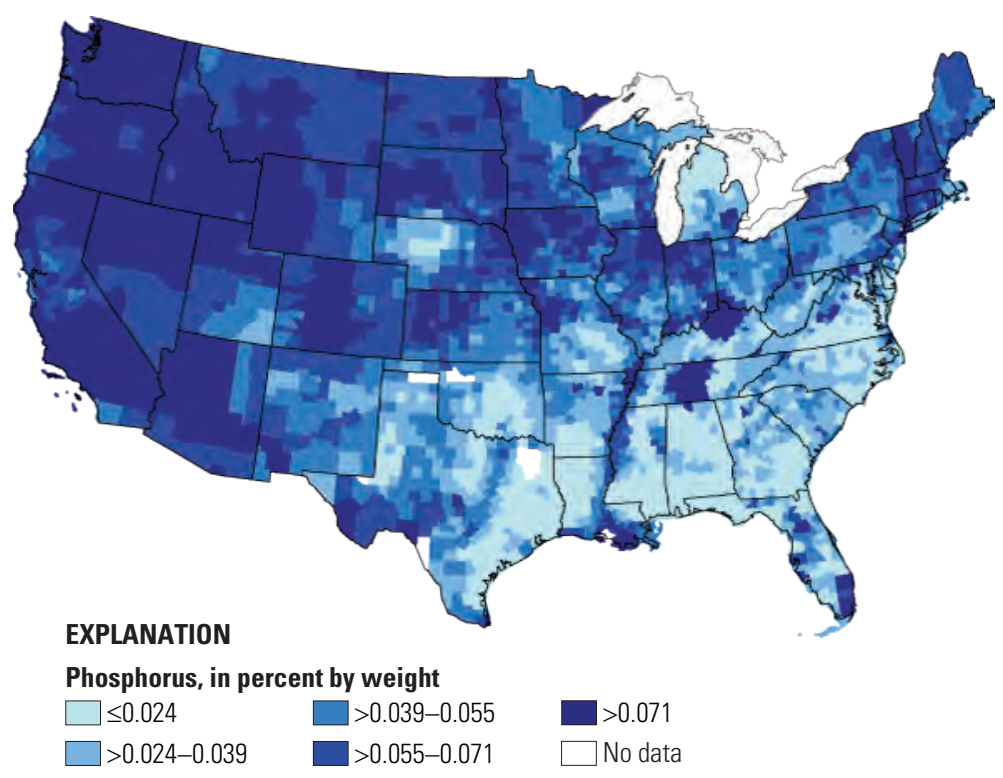

Figure 4-11. Phosphorus is naturally high in some geologic materials in western rangelands, where a high erosion potential may result in the transport of phosphorus-rich sediment to streams. (Data from U.S. Geological Survey, 2009a.) 


\section{Extrapolation of Total Nitrogen Concentrations in Streams to Unsampled Areas}

The results of simulations made with two statistical models - one for agriculturally influenced streams and one for nonagricultural streams - were aggregated to predict the total nitrogen concentrations in streams across the conterminous United States (Spahr and others, 2010) (see Chapter 3, Extrapolation to Unsampled Areas, Development of Models for Total Nitrogen Concentrations in Streams). Model results for streams predict that the highest total nitrogen concentrations should be in areas with the highest nonpoint source nitrogen inputs, such as agricultural areas in the upper Midwest and selected coastal areas of California (fig. 4-12). The lowest concentrations are predicted in the mountainous regions of the West, the Appalachians, and the northern parts of New England. Simulated concentrations for much of the country are less than $5 \mathrm{mg} / \mathrm{L}$ and for major sections are less than $1 \mathrm{mg} / \mathrm{L}$.

The model for agriculturally influenced streams explains more than 70 percent of the variability of total nitrogen concentration. The explanatory factors that represent nitrogen sources in the model include atmospheric nitrogen input, fertilizer nitrogen input, manure nitrogen input, and percentage of undeveloped land in the watershed above the sampling site. Explanatory factors that represent transport to and within streams in the model include percentage of sand in soil, presence of subsurface drains, long-term average percentage Horton overland flow, and mean annual precipitation. Areas with greater nitrogen inputs and subsurface drainage tend to have greater nitrogen concentrations in streams, whereas areas with sandy soils, higher precipitation, and greater undeveloped areas, have lower nitrogen concentrations in streams.

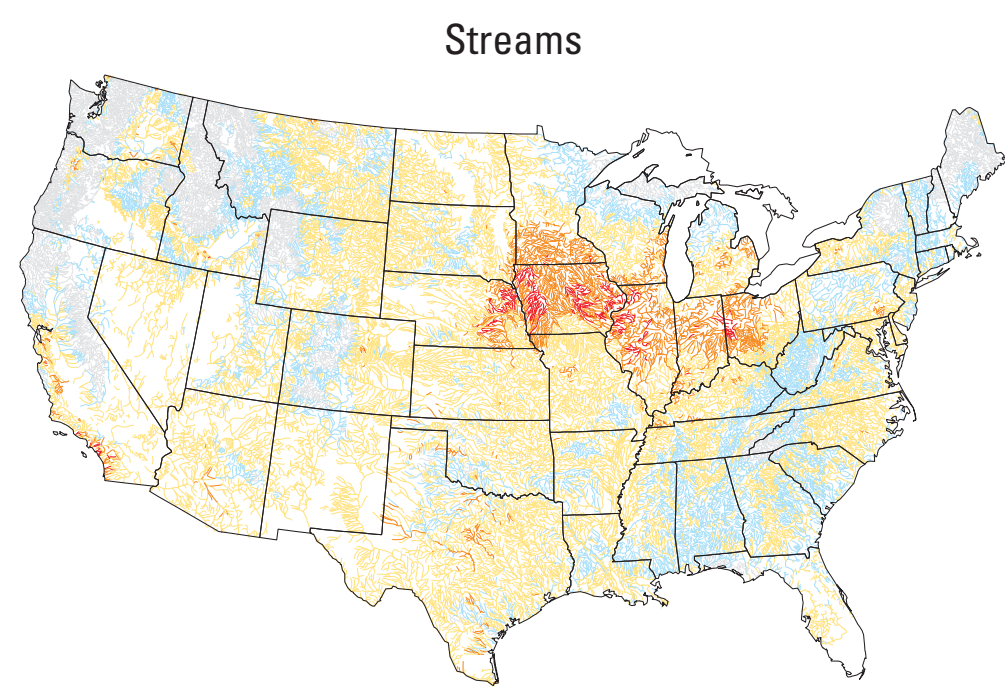

EXPLANATION

Predicted total nitrogen concentration, in milligrams per liter $\leq 0.5$ $>0.5-1$ $>1-5$ $>5-10$ $>10$

Figure 4-12. Model predictions of total nitrogen in streams show the highest concentrations (orange and red) in the upper Midwest. The linear regression models relate the concentrations of total nitrogen at 462 stream sites to several explanatory factors (Spahr and others, 2010).

The model for the nonagricultural streams explained 62 percent of the total nitrogen variability. The explanatory factors that represent nitrogen sources in the model for the nonagricultural sites include a nonpoint source term (representing fertilizer, manure, and atmospheric inputs) and population density; transport factors in the model are mean runoff and base flow index (the ratio of base flow to total flow volume for a given year). In the model, population density acts as a surrogate for nitrogen inputs associated with urban settings that are otherwise unaccounted for, such as point sources. In nonagricultural basins, streams with greater nitrogen inputs and greater population in their watersheds tend to have higher total nitrogen concentrations, whereas streams with greater streamflow and a higher percentage of streamflow derived from groundwater tend to have lower total nitrogen concentrations. 


\section{Nutrient Export in Streams}

When nutrients are input to the land surface from fertilizer application, manure generation, atmospheric deposition, or other sources, they can be taken up by crops and natural vegetation, immobilized in the soil, taken up by aquatic organisms, or, in the case of nitrogen, lost to the atmosphere during denitrification. Any remaining nitrogen or phosphorus is potentially available for export out of the watershed by streams and rivers or by leaching through the soil to groundwater. Nutrients lost (exported or leached) from the watershed can contribute to eutrophication of downstream water bodies and economic losses through reduction in crop yields or expense for additional fertilizer.

The amount of nitrogen and phosphorus lost per unit area (expressed as "per square mile") from watersheds to streams - referred to as the yield - increases with increasing nutrient inputs, regardless of land use (fig. 4-13A). Nitrogen input and yield generally differed among agricultural (median yield 6,518 pounds per square mile), urban (median yield 2,898 pounds per square mile), and undeveloped streams (median yield 904 pounds per square mile). Agricultural streams had the largest yields due to their relatively high

nutrient inputs.

Calculating the ratio of the yield to the input allows an assessment of the proportion of input that is "exported" from a watershed by its stream. Between 5 and 50 percent of the nitrogen input from nonpoint sources was exported out of most (72 percent) watersheds (see dashed red lines, fig. 4-13A). Variability in the amount of nutrient loss can be explained in part by differences in agricultural practices, soils, geology, and hydrology. In the Southeast, a relatively low proportion of nitrogen - usually less than 25 percent of input - is exported at agricultural sites, possibly because of greater amounts of denitrification in shallow groundwater (fig. 4-13B). In the West, a relatively low proportion of nitrogen is exported because of generally low amounts of precipitation and runoff, and possibly highly modified hydrology. In contrast, agricultural sites with tile drains in 5 percent or more of the watershed are about 3 times more likely to export more than 25 percent of the nitrogen input than those in watersheds with fewer tile drains (fig. 4-13B). The median yield of nitrogen from agricultural streams with tile drains also was slightly more than 3 times larger than the median yield for other agricultural streams (fig. 4-13C).

Between 5 and 50 percent of the phosphorus input from nonpoint sources was exported out of 51 percent of watersheds. Apparent phosphorus export is lower than nitrogen export for many sites, possibly reflecting the fact that phosphorus is not as mobile in the aquatic system as nitrogen (fig. 4-13A). Because phosphorus is relatively insoluble, tile drains do not increase phosphorus yields as markedly as they do nitrogen yields (fig. 4-13C).

This comparison assumes that anthropogenic nonpoint-source inputs and stream yield account for all nitrogen and phosphorus movement into and out of these watersheds. These assumptions do not always hold true. For many sites, primarily those in undeveloped and urban areas, apparent export is greater than 50 percent; in some cases, yield even exceeds input. The most likely explanation is that some natural inputs, such as geologic phosphorus or nitrogen fixation, or anthropogenic inputs such as effluent from wastewater-treatment plants, are being underestimated. For other sites, the apparent nutrient export from the watershed is less than 5 percent. At these sites, the proportion of nutrients lost to other mechanisms, such as crop harvesting, incorporation in natural vegetation, and immobilization in the soil, may be greater; or nutrient inputs may be overestimated. 
A.

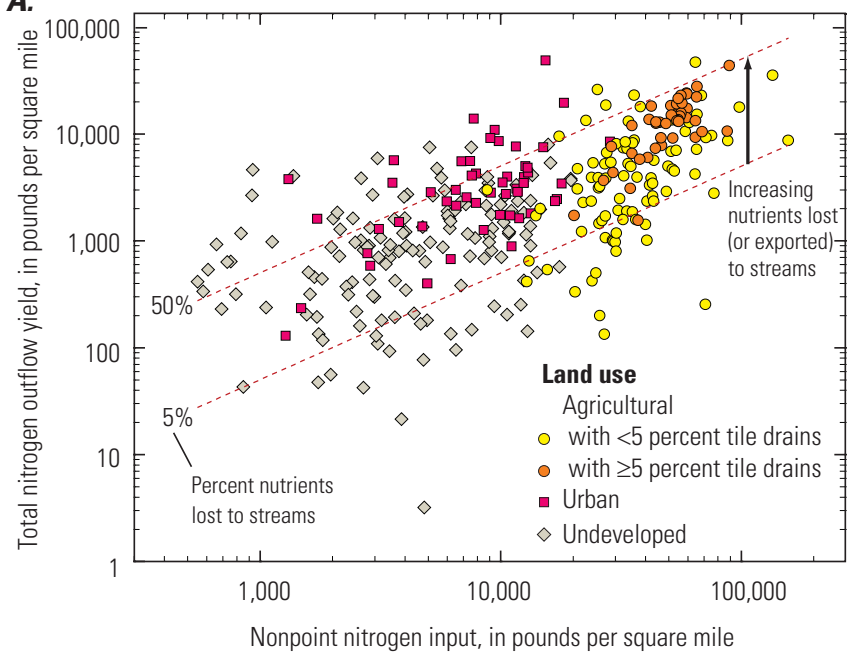

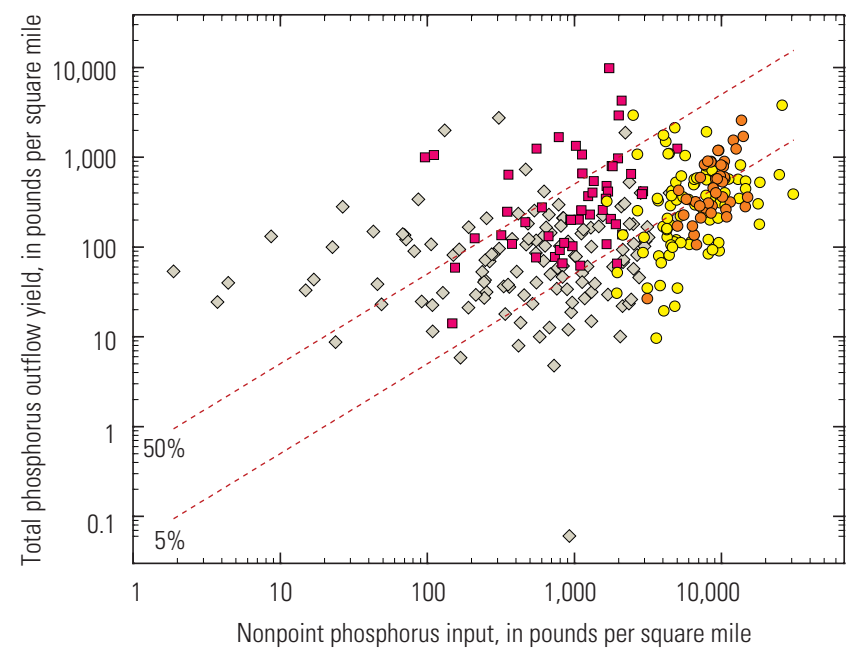

B.

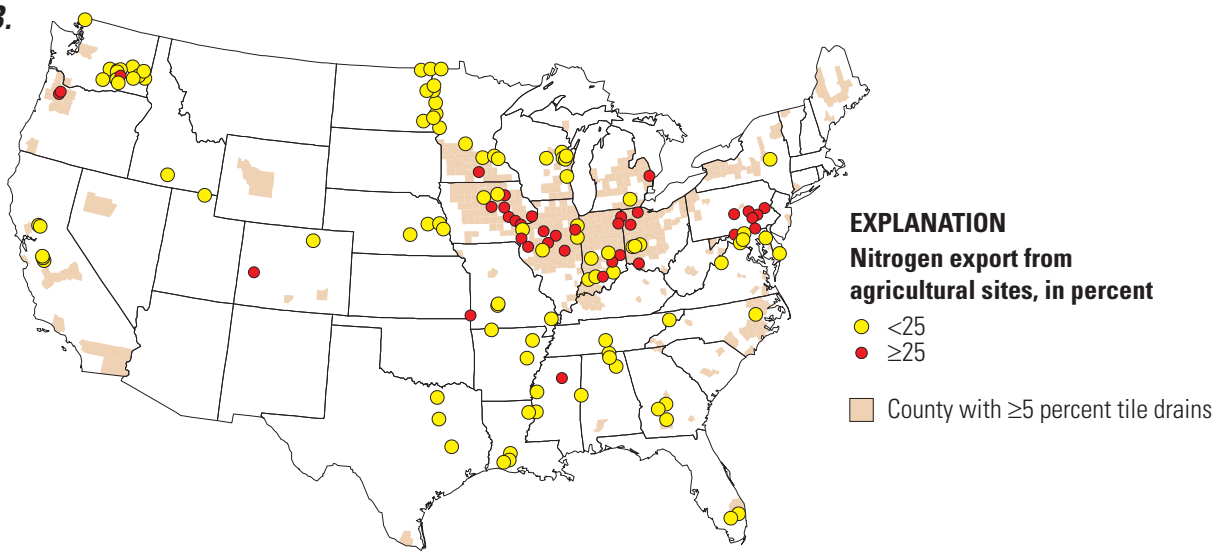

C.

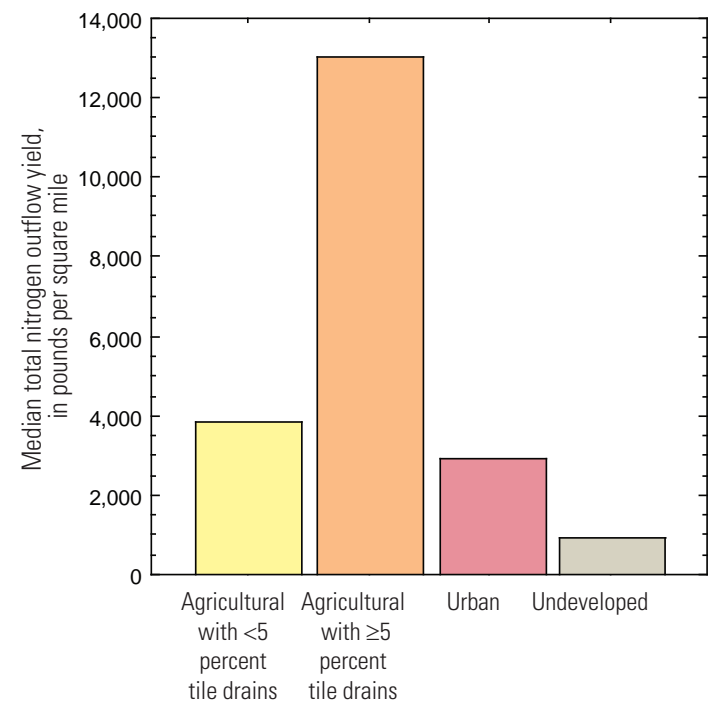

Land use

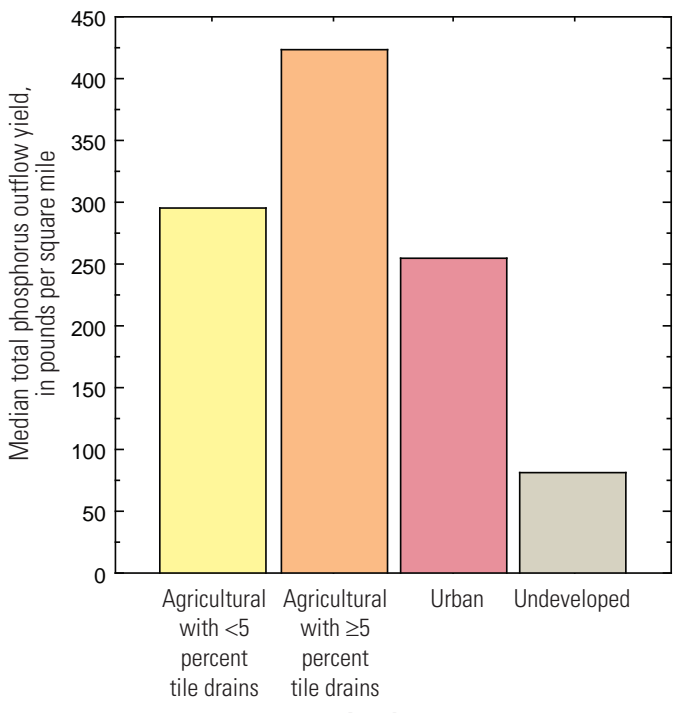

Land use

Figure 4-13. Nutrient yield generally increases with increasing input regardless of land use $(A)$. Both the proportion of nitrogen input that is exported by a stream as yield $(B)$, as well as the amount of yield $(C)$ is much greater for agricultural streams with tile drains in 5 percent or more of the watershed than for agricultural streams with fewer tile drains. Because phosphorus is relatively insoluble, tile drains do not increase phosphorus yields as markedly as nitrogen yields. (Modified from Mueller and Spahr, 2006.) 


\section{Using the SPARROW Model to Assess Nutrient Conditions in Streams}

To extend our assessment to areas that have not been sampled, USGS scientists have developed the statistical model, SPARROW (SPAtially Referenced Regression On Watershed attributes), to relate nutrient concentrations from a large network of monitoring stations to (1) upstream sources, such as fertilizer, manure, wastewater discharges, and the atmosphere; and (2) watershed characteristics affecting transport, including soil permeability, stream size, and streamflow (Smith and others, 1997). These sources and watershed characteristics are spatially referenced to a detailed network of stream reaches that represents pathways of water movement through the modeled region. Because of the spatial referencing, nutrient loss during both surface runoff and instream transport can be evaluated, and loads for each stream reach can be allocated to individual upstream sources and geographic regions. In addition, the statistical basis of the model provides measures of uncertainty for the model and its predictions.

The SPARROW model can be used to address a variety of management issues (Smith and others, 1997). Nutrient concentrations and loads in unmonitored stream reaches can be predicted, thus allowing for identification of specific locations where regulatory standards or criteria are not likely to be met. Nutrients in a given stream reach, estuary, or other receiving water body can be traced to individual sources and locations in the upstream watershed, allowing for targeted management of important nutrient sources and contributing areas. Model inputs can be altered, allowing for simulation of hypothetical conditions, such as changes in nutrient sources associated with proposed nutrient control strategies.

The SPARROW modeling approach has been applied at the national scale to provide estimates of nutrient loads and concentrations in 62,000 stream reaches in the United States and to improve our understanding of the sources, transport, and delivery of nutrients in streams (Smith and others, 1997; Alexander and others, 2008). For example, the rate of nitrogen loss in streams has been found to rapidly decline as water depth and stream size increase, because the amount of biological processing of nitrogen in streams depends on the surface area of the stream bottom (where the organisms live) in relation to the stream's volume (fig. 4-14). Consequently, large deep rivers contribute a larger percentage of their nitrogen to downstream receiving water bodies than small streams (Alexander and others, 2000, 2008). This finding indicates that reductions in nitrogen sources near small streams will have a smaller benefit to receiving water bodies than reductions in nitrogen sources near large rivers. Recently developed national-scale models were used to document key nutrient sources, geographic regions, and transport processes that affected contributions of nitrogen and phosphorus to the northern Gulf of Mexico during 1992 (Alexander and others, 2008). Results from the model revealed the dominance of agricultural nonpoint sources over point sources in the Mississippi River Basin (ig. 4-15). Corn and soybean cultivation

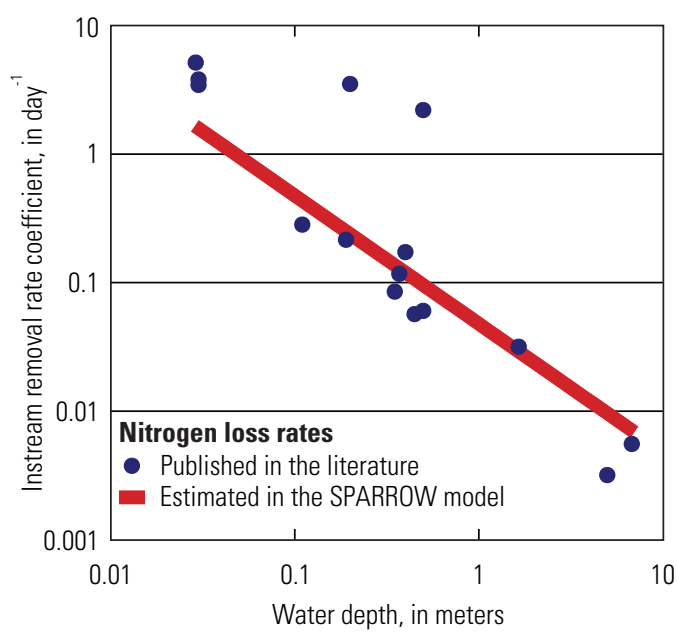

Figure 4-14. The rate of nitrogen loss in streams rapidly declines as water depth and stream size increase; consequently, large rivers contribute a larger percentage of their nitrogen to downstream receiving water bodies than small streams. As a result, reductions in nitrogen sources near small streams will have a smaller benefit to receiving water bodies than reductions in nitrogen sources near large rivers (Alexander and others, 2008).
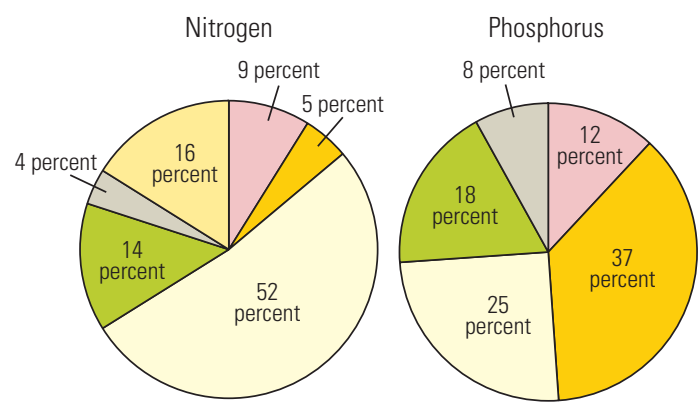

EXPLANATION

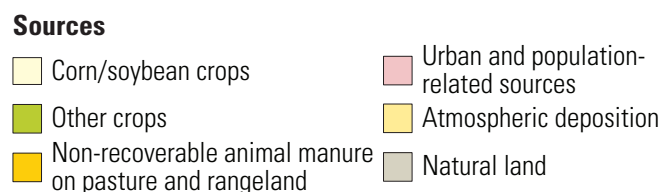

Figure 4-15. Corn and soybean cultivation was the largest contributor of nitrogen to the Gulf, resulting in large part from commercial fertilizer use and manure applications to crops as fertilizer. Corn and soybean cultivation and animal manure on pasture and rangelands were the largest contributors of phosphorus (Alexander and others, 2008). 
was the largest contributor of nitrogen to the Gulf, resulting in large part from commercial fertilizer use and manure applications to crops as fertilizer. Corn and soybean cultivation and animal manure on pasture and rangelands were the largest contributors of phosphorus. Illinois, Iowa, Indiana, Missouri, Arkansas, Kentucky, Tennessee, Ohio, and Mississippi, which together make up only one-third of the 31-State Mississippi River drainage area, were found to contribute more than 75 percent of the nitrogen and phosphorus to the Gulf.

SPARROW models also have been developed for smaller regions to provide a more detailed focus on factors that influence water quality locally but that may not be important everywhere in the country (Preston and others, 2009). Previous regional models for 1992 conditions include those for the Chesapeake Bay watershed (Brakebill and others, 2001), selected North Carolina coastal drainages (McMahon and others, 2003), and the New England region (Moore and others, 2004). In the Chesapeake Bay model, for example, simulation results indicate that only a fraction of the total nitrogen delivered to streams locally in the watershed (fig. 4-16A) was ultimately delivered to the Chesapeake Bay (fig. 4-16B) because of losses in streams during travel to the Bay. The proportion of nitrogen lost during instream travel was greatest for areas farthest from the Bay (fig. 4-16B). New regional models currently are being developed for 2002 conditions in the Northeast, Southeast, Midwest, Northern Plains, Southern Plains, and the Pacific Northwest regions (fig. 4-3). These new SPARROW models are based on updated geospatial data and stream-monitoring records from local, State, and other Federal agencies.
A.

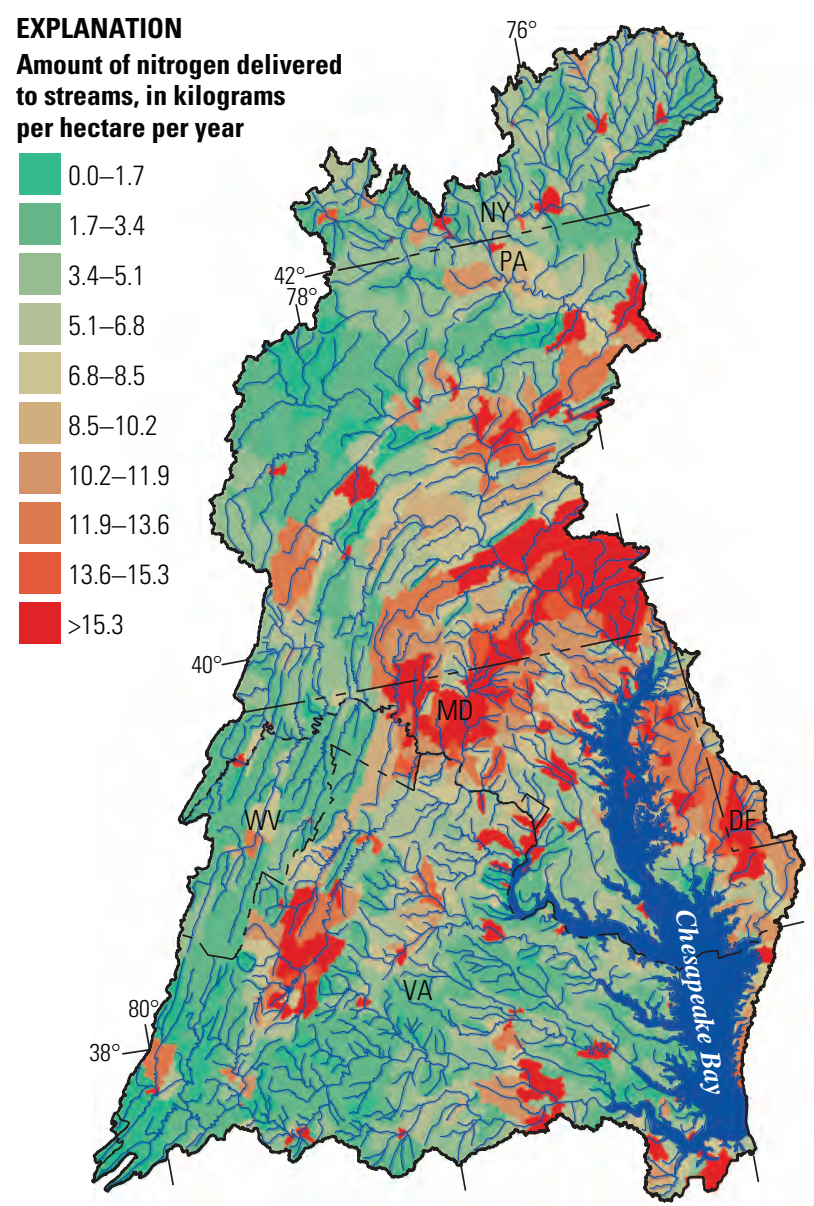

B.

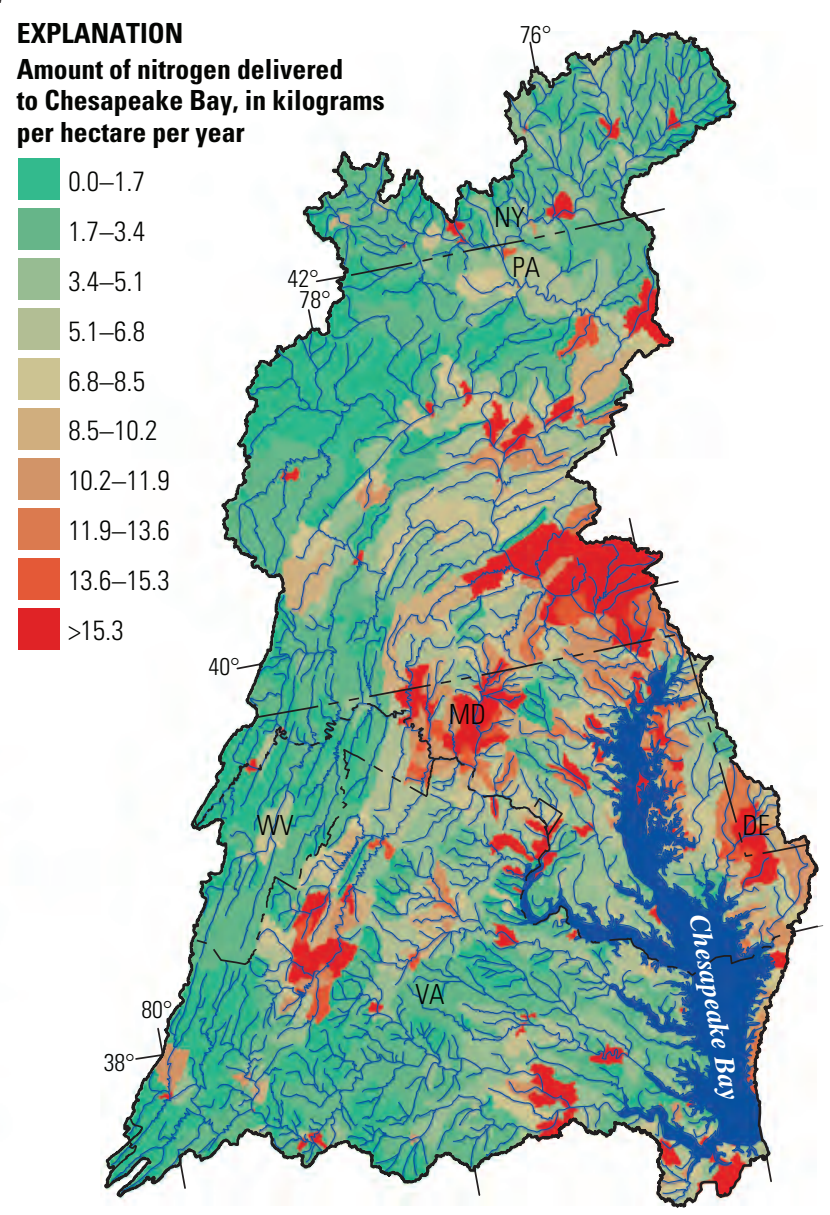

Figure 4-16. Only a fraction of the total nitrogen delivered to streams locally in the Chesapeake Bay watershed $(A)$ is delivered to Chesapeake Bay $(B)$ because of losses in the stream during travel to the Bay. The proportion of nitrogen lost during instream travel was greatest for areas farthest from the Bay. (Data from Brakebill and others, 2001.) 


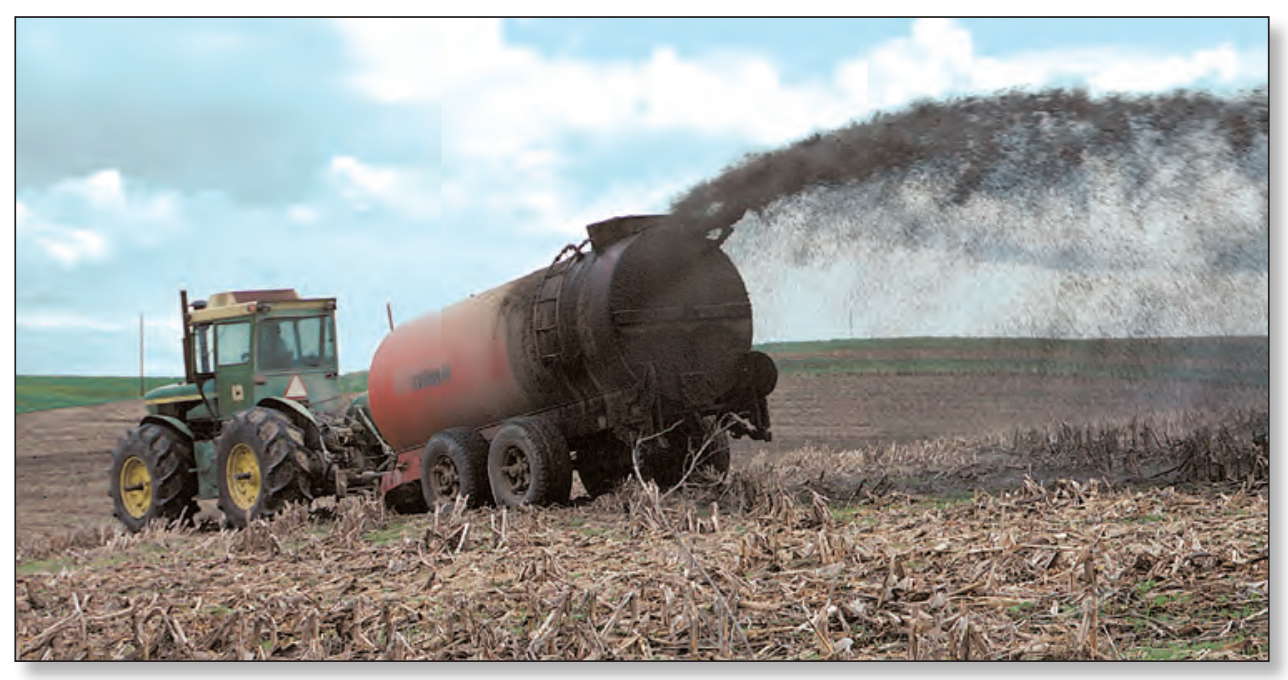

Manure from concentrated animal feeding operations that is used to fertilize crops can be a source of nutrients to nearby streams. Photograph by Tim McCabe, U.S. Department of Agriculture, Natural Resources Conservation Service.

\section{Seasonal Variation of Nutrients in Streams}

Geographic patterns in the occurrence and distribution of nutrient concentrations are complicated by seasonal variations that affect the timing of the highest and lowest nutrient concentrations in streams. Nutrient concentrations vary seasonally in response to natural factors (streamflow and uptake by aquatic organisms) and anthropogenic factors (the type and timing of nutrient sources, such as fertilizer applications, and streamflow alterations, such as diversions and flow augmentation from irrigation return flows).

Evaluation of these seasonal patterns in nutrient concentrations in streams furthers our understanding of factors that contribute to high nutrient concentrations and can, thereby, facilitate design of effective monitoring and management strategies.

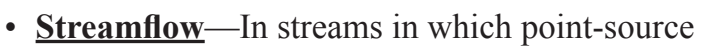
discharge or groundwater inflows predominate, increases in flow driven by increases in precipitation and runoff often lead to a decrease in nutrient concentrations as a result of instream dilution. The same increases in precipitation and consequent flow in streams in which nonpoint sources predominate, however, can cause an increase in nutrient concentrations as a result of the increased surface runoff. Similarly, decreases in streamflow can result in increases in nutrient concentrations where point sources predominate, but decreases in concentrations where nonpoint sources predominate (see Chapter 2. Nutrient Primer). The seasonal pattern of streamflow varies across the United States. In the eastern United States (east of the 100th meridian), streamflows often are highest in the spring and lowest in the autumn, following seasonal precipitation patterns (fig. 4-17A). Seasonal patterns in streamflow in western streams are less distinct because of the highly variable geography and climate, as well as the ubiquitous use of dams and canals to modify streamflow and optimize the use of scarce water resources in this region. Streamflows in some areas of the West are highest in the spring when snowmelt from the mountains makes its way downstream; in other areas, streamflows are highest in the summer during periods of irrigation and when local rainstorms occur (fig. 4-17A). Streamflows often are lowest in the West during the autumn and winter, when little precipitation or snowmelt occurs.

- Timing of nutrient usage -When fertilizers and manure are applied in agricultural and urban areas, nitrogen and phosphorus become available for potential transport to streams. Runoff resulting from precipitation shortly after such applications can transport this nitrogen and phosphorus to streams, thereby increasing instream concentrations. As a result, some of the highest concentrations of nutrients in streams occur immediately after fertilizer and manure application. The timing of fertilizer and manure application is thus a critical factor, and varies across the United States depending on crop type, regional climatic conditions, and fertilizer type.

- Biological activity - Warm water temperatures and abundant sunlight in the summer months create ideal conditions for the growth of algae and aquatic plants. These organisms require nutrients for growth, and nutrient concentrations in streams across the country often decrease in the summer months because of uptake by aquatic organisms. During cooler months, less nutrient uptake occurs because some organisms die, whereas others experience a reduction in metabolism. 
A.

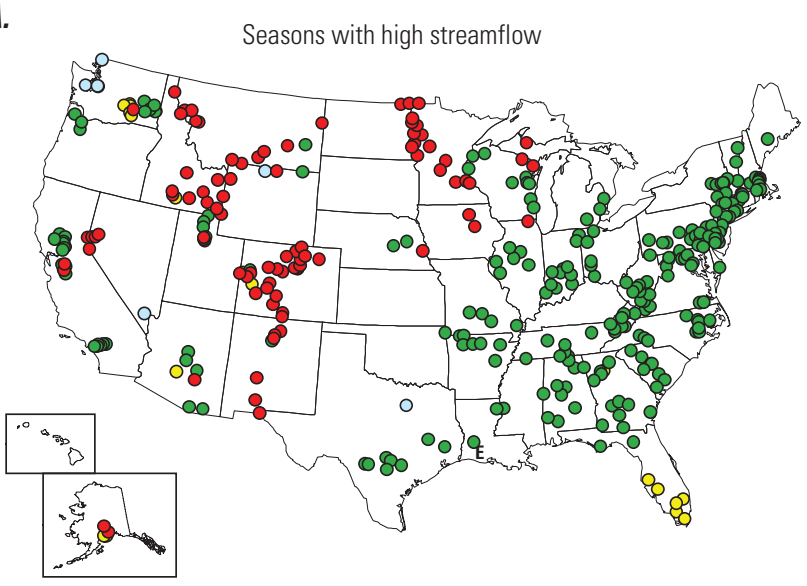

B.

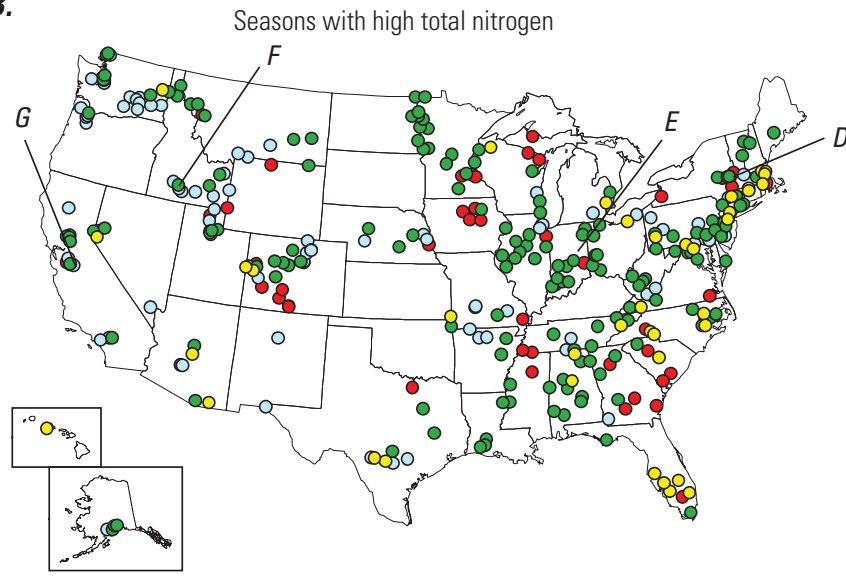

C.

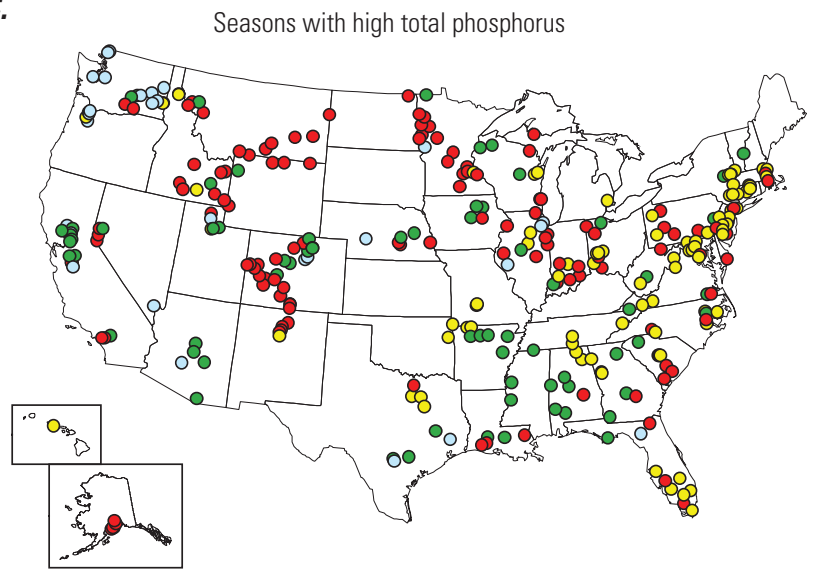

D.

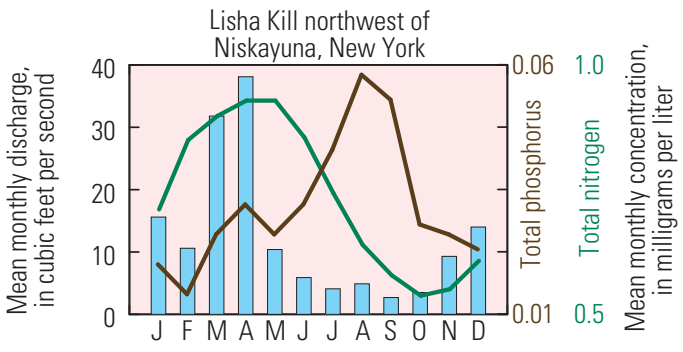

E.

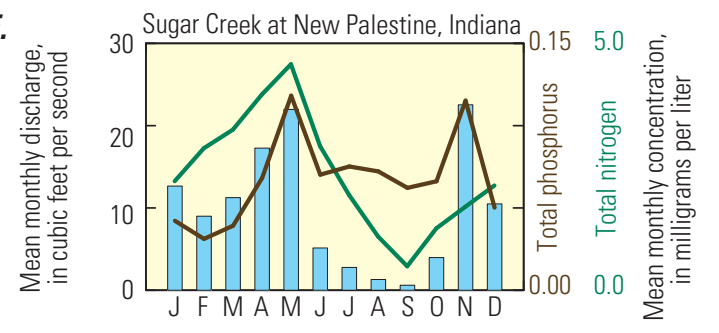

$\boldsymbol{F}$

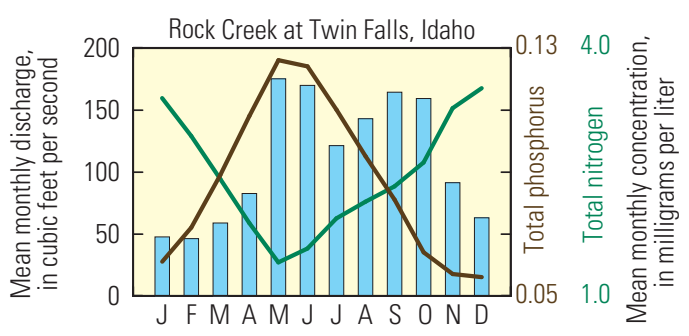

G.

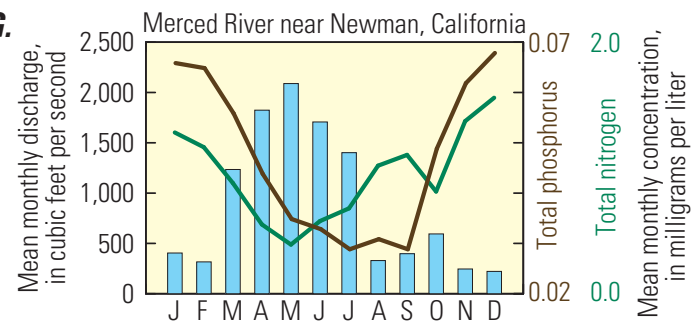

\section{EXPLANATION}

o Winter (November-January)

- Spring (February-April)

- Summer (May-July)

- Autumn (August-October)

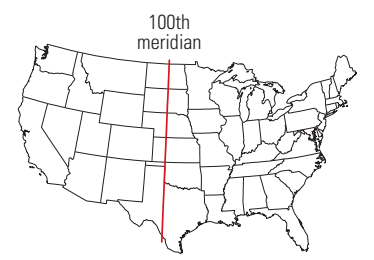

Figure 4-17. The distribution of nutrient concentrations during the year is related to broad regional patterns in streamflow $(A)$. In the eastern United States, many sites have higher nitrogen concentrations in the spring as compared with other seasons of the year $(B)$, whereas phosphorus concentrations generally are higher in the summer and autumn during low streamflow $(C)$. The seasonal pattern in nutrient concentrations in western streams tends to be opposite that in eastern streams: high phosphorus in western streams generally coincides with high summer streamflows $(C)$, whereas high concentrations of nitrogen occur during the winter when streamflow is generally low. Examples of regional patterns are shown in $D$ through $G$. 


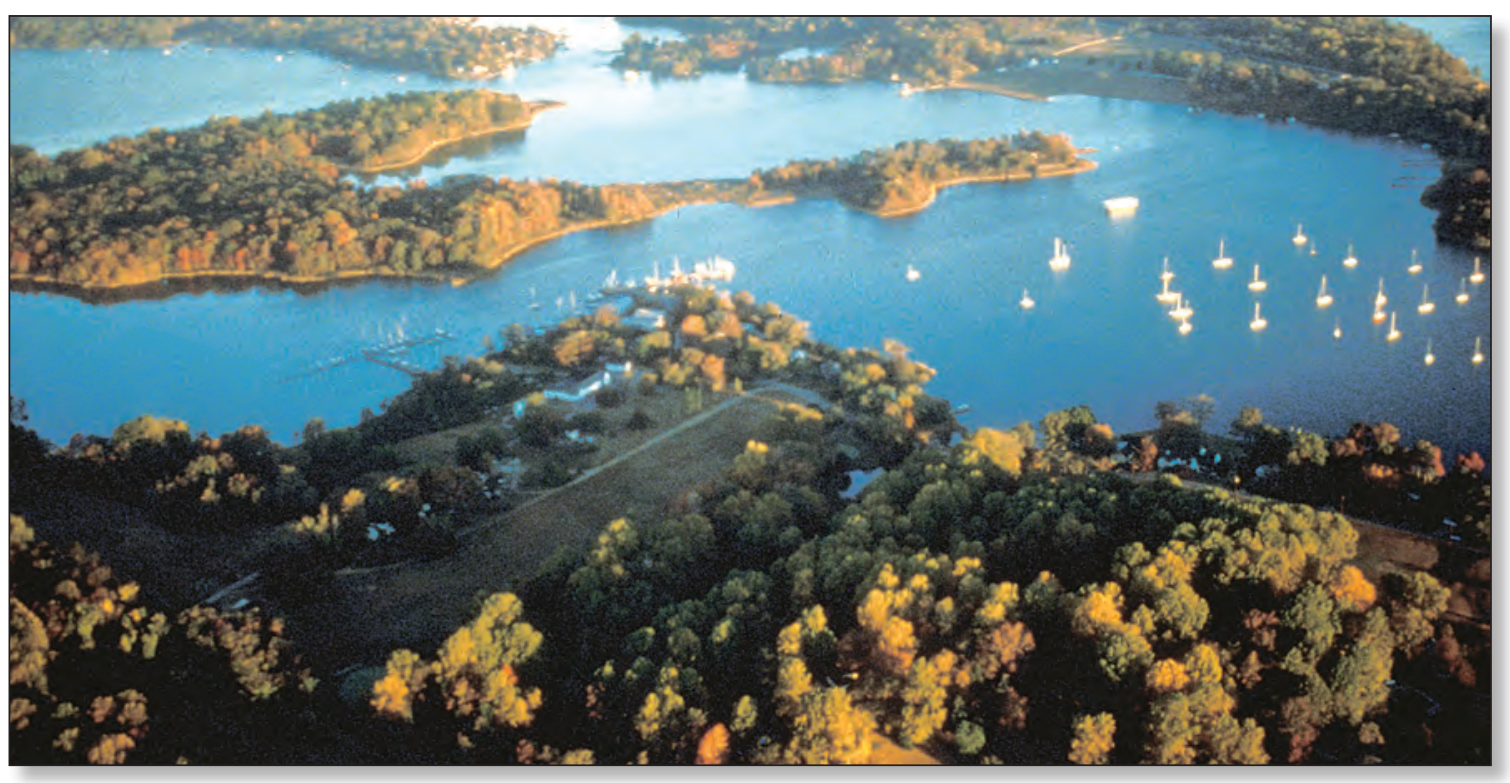

Excess nutrients are the main cause of water-quality impairment in the Chesapeake Bay. Photograph from Chesapeake Bay Program.

The specific seasonal interactions among streamflow, nutrient sources, and biological activity vary regionally and locally (Mueller and Spahr, 2006). Examples of regional patterns are shown in figure 4-17 and are explained as follows:

- In the eastern United States, 63 percent of sites had significantly higher streamflows and 39 percent had significantly higher nitrogen concentrations in the spring as compared with other seasons of the year (figs. 4-17A and 4-17B). Seasonal low streamflows and low nitrogen concentrations occurred during the autumn at 66 and 42 percent of eastern sites, respectively. In contrast to nitrogen, phosphorus concentrations generally were higher in the summer and autumn during low streamflow and lower in the winter and spring when streamflows were high (fig. 4-17C). For example, nitrogen concentrations in Lisha Kill, New York, were high and phosphorus concentrations were low in March and April when streamflow was high (fig. 4-17D). The maximum phosphorus concentrations occurred during periods of low summer streamflow. The association of high nitrogen concentrations with high streamflow suggests transport of nonpoint source nitrogen, such as fertilizer by rainfall runoff, whereas the high phosphorus concentrations during low streamflow indicate point sources, such as wastewater-treatment plants. At an agricultural site in the upper Midwest (Sugar Creek, Indiana), both nitrogen and phosphorus concentrations paralleled the changes in streamflow, suggesting that both nutrients are mobilized from nonpoint sources (fig. 4-17E). Low summer nitrogen concentrations in eutrophic agricultural streams in the Midwest may result in part from uptake of the nitrogen by algae.
- As with streamflow, seasonal patterns in nutrient concentrations in western streams are less distinct than in eastern streams because of hydrologic modifications and the highly variable geography and climate.

The seasonal pattern in nutrient concentrations in western streams tends to be opposite that in eastern streams. The highest concentrations of phosphorus in western streams were most common during the summer when snowmelt produced high streamflows (fig. 4-17C), whereas high concentrations of nitrogen in western streams occurred during the winter when streamflow was generally low (fig. 4-17B). The data for Rock Creek, Idaho (fig. 4-17F), are characteristic of this seasonal pattern, with high concentrations of phosphorus and low concentrations of nitrogen coincident with high spring and summer streamflows. Especially in the semiarid areas of the interior West, high phosphorus concentrations during high streamflow are consistent with mobilization of sediment-bound phosphorus by erosion. High nitrogen concentrations during low streamflow may be derived from irrigation-return flow, point sources, or groundwater discharge to streams - sources that are diluted by spring and summer snowmelt runoff. For example, in the Merced River, California (fig. 4-17G), dam releases of runoff with low nutrient concentrations from the undeveloped Sierra Nevada Mountains dilute the effects of runoff from agricultural land in the San Joaquin Valley during the irrigation season from March to July. Concentrations of both nitrogen and phosphorus increased in the late summer and early winter when reservoir releases were minimal. 


\section{Nutrient Concentrations in Groundwater}

\section{Relations to Land Use}

Nitrate concentrations were significantly different among groundwater samples collected in agricultural, urban, and major aquifer studies (Burow and others, 2010) (fig. 4-18). Concentrations of nitrate were highest in groundwater beneath the agricultural land-use setting, with a median of $3.1 \mathrm{mg} / \mathrm{L}-$ about 3 times the national background concentration of $1.0 \mathrm{mg} / \mathrm{L}$ (table 4-1). Nitrate concentrations were lower in urban areas (median of $1.4 \mathrm{mg} / \mathrm{L}$ ) than in agricultural areas, but were higher in urban areas than in major aquifers. Some of the differences in concentrations between the study types can be explained by differences in the depths of the wells from which samples were collected. Wells sampled in agricultural and urban land-use studies typically are shallow (median well depth, 33 feet), and thus represent mostly
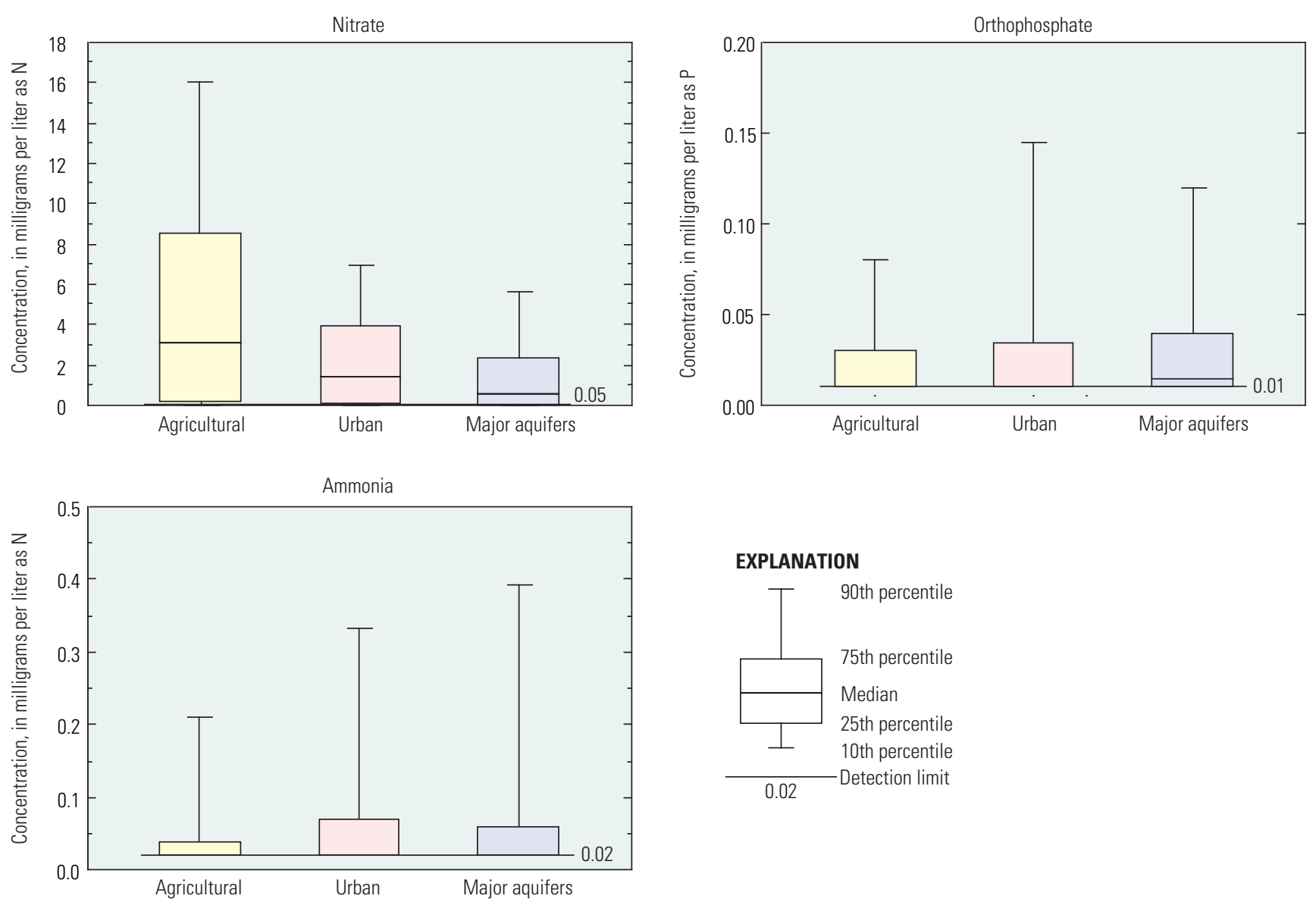

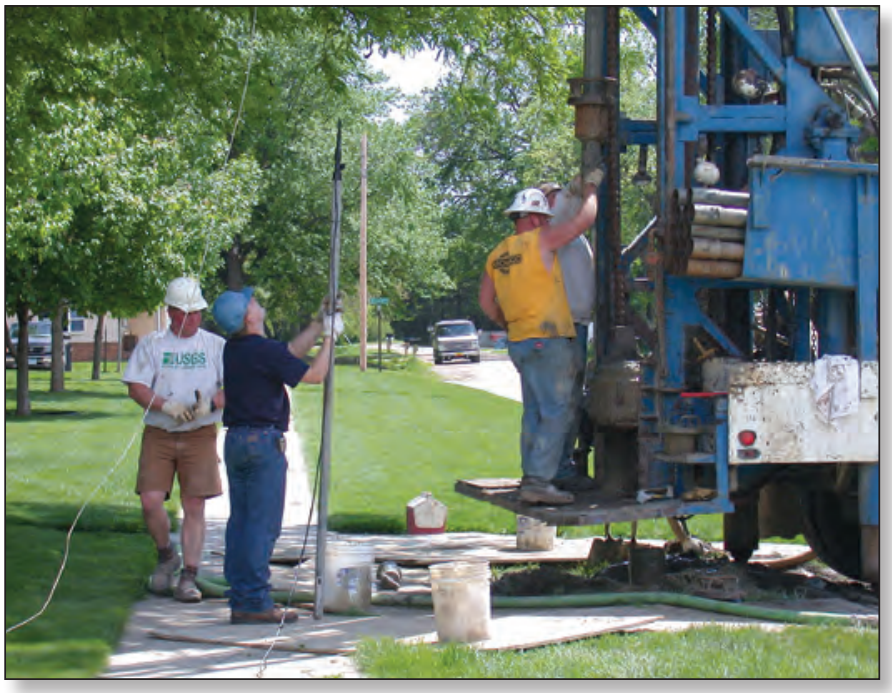

Most wells sampled for agricultural and urban land-use studies were monitoring wells installed by NAWOA. Photograph by U.S. Geological Survey.

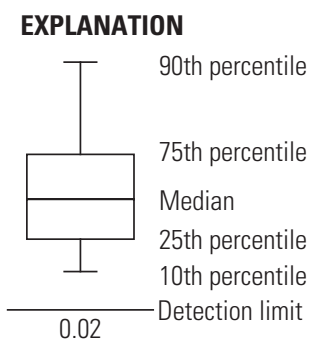

Figure 4-18. Concentrations of nitrate in groundwater were higher in agricultural land-use areas than in urban areas, and were higher in urban areas than in major aquifers. Concentrations of phosphorus and ammonia varied little among land-use categories. 
recently recharged groundwater, whereas wells completed in the major aquifers typically are much deeper (median well depth, 152 feet), and represent older groundwater. Although the highest concentrations of nitrate in groundwater are higher than the highest nitrate concentrations in streams, median concentrations are similar, and the relative differences in concentrations among the different land-use categories are similar.

Concentrations of orthophosphate (hereinafter referred to as dissolved phosphorus) and ammonia were much lower in groundwater than in streams, varied little among land-use categories, and generally were not greater than background levels $(0.03$ and $0.10 \mathrm{mg} / \mathrm{L}$, respectively, table 4-1). Dissolved phosphorus and ammonia are not persistent or mobile enough to affect groundwater concentrations significantly under most conditions.

\section{Geographic Distribution}

Variations in the distribution of nitrate concentrations in groundwater are due to differences in types of sources, physical factors that either favor or inhibit transport of nitrate to groundwater, and chemical factors that result in persistence or removal of nitrate in groundwater over time. Nitrate concentrations are highest in shallow, oxic groundwater that receives high inputs of nitrogen from fertilizer, manure, and atmospheric deposition. Median concentrations of nitrate in shallow groundwater for agricultural land-use studies were higher in many studies in the Northeast, the Midwest, and the Northwest, and in a few studies in the Southeast and California (fig. 4-19). These concentrations were likely the result of high nitrogen inputs and conditions favorable to nitrate transport in groundwater. Median concentrations of nitrate in urban studies were mostly in the medium range; the relatively few studies with concentrations in the low category were distributed across the southern half of the country. Most nitrate concentrations in major aquifers were low or medium, with somewhat higher concentrations in parts of the Northeast, the Northern and Southern Plains, and the Southwest. High concentrations in the Northern and Southern Plains and Southwest could be influenced by irrigation practices, which may accelerate the downward movement of nitrate into groundwater. Sampled wells in the major aquifers of the Northeast are shallower than wells in most of the other major aquifer studies, and thus the samples may represent young groundwater that has moved rapidly through the system. Concentrations generally were low in the major aquifers of the
Midwest and south through the Mississippi Valley to the coast, which can be attributed to a combination of physical and chemical properties that inhibit rapid nitrate transport to these deep aquifers.

The distribution of nitrate concentrations in groundwater (fig. 4-19) contrasts with that of total nitrogen in streams (fig. 4-4). Whereas both agricultural and mixed land-use streams that have total nitrogen concentrations in the highest category are clustered in the upper Midwest, the nitrate concentrations in groundwater in agricultural areas and major aquifer studies do not show this pattern of distribution. The contrast between the spatial distribution of total nitrogen in streams and nitrate in groundwater is a consequence of hydrologic factors that promote rapid and efficient movement of nitrogen to streams yet tend to inhibit the movement of nitrate into groundwater. In the upper Midwest, for example, artificial subsurface drainage and ditches installed to drain dense, clay-rich glacial soils, route runoff and groundwater recharge to streams, while limiting the opportunity for infiltration to the water table.

In contrast to concentrations of phosphorus in streams, dissolved phosphorus concentrations in groundwater generally were low. Eighty-eight percent of the measured concentrations were less than $0.1 \mathrm{mg} / \mathrm{L}$ dissolved phosphorus, although locally some concentrations were as high as $4.3 \mathrm{mg} / \mathrm{L}$.

Phosphorus in groundwater originates from anthropogenic sources, such as fertilizer, manure, and waste effluent, as well as natural geologic sources. Elevated dissolved phosphorus concentrations in groundwater occur throughout the United States, with no definitive spatial pattern. Median concentrations were greater than the background concentration of $0.03 \mathrm{mg} / \mathrm{L}$ in 21 percent of major aquifer studies and 21 percent of agricultural and urban land-use studies. Additionally, dissolved phosphorus concentrations in groundwater showed no correlation to fertilizer and manure use in agricultural areas. This lack of correlation and the similarity of concentrations in both shallow and deep groundwater suggests that natural geologic sources of phosphorus may have a greater influence on concentrations in groundwater than do human-derived sources from activities on the land surface.

The transport of phosphorus in groundwater typically is limited because most phosphorus compounds are not very soluble and tend to precipitate or adsorb to soil particles. Phosphorus can be mobilized under favorable geochemical conditions, however, such as high $\mathrm{pH}$, high organic content, and geochemically reduced conditions. Dissolved phosphorus concentrations were significantly higher in reduced 


\section{Groundwater}
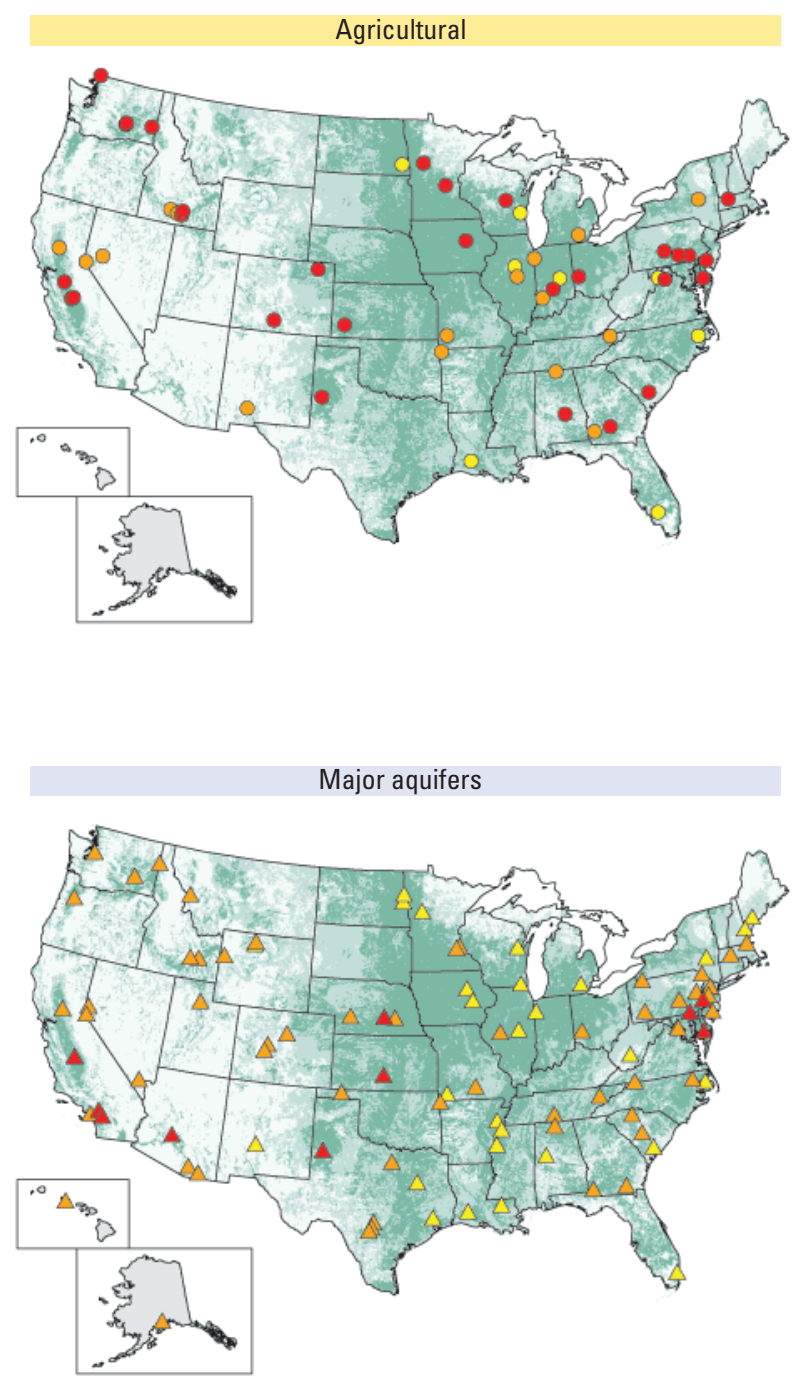

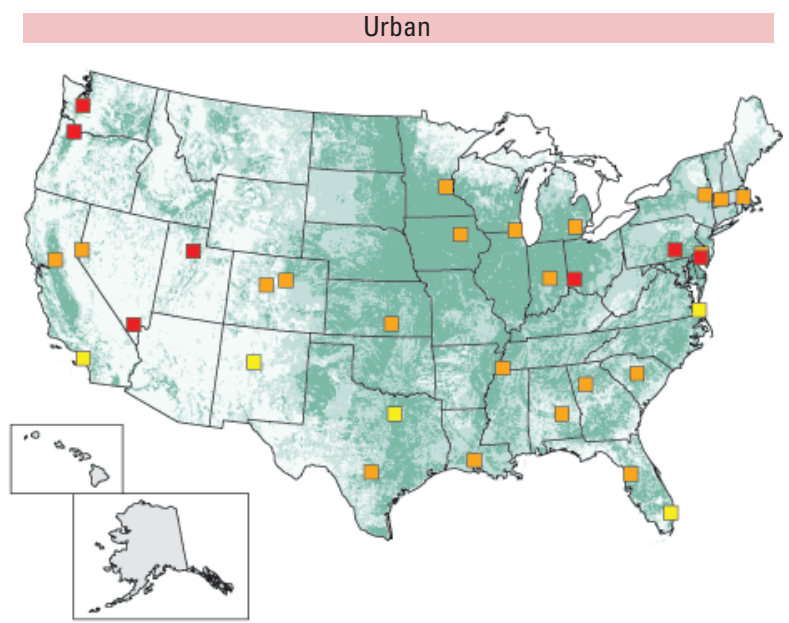

EXPLANATION

Estimated 1997 nitrogen inputs from fertilizer, manure, and atmosphere, in pounds per square mile

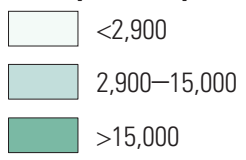

Data on nitrogen inputs not available for Alaska and Hawaii.

$\begin{array}{cccl}\begin{array}{c}\text { Shallow groundwater } \\ \text { studies, by land use }\end{array} & \begin{array}{c}\text { Major } \\ \text { aquifers }\end{array} & \begin{array}{l}\text { Median concentrati } \\ \text { in milligrams per lit }\end{array} \\ \begin{array}{ccc}\text { Agricultural } \quad \text { Urban } \\ \circ\end{array} & \square & \triangle & \operatorname{Low}(<0.08) \\ \circ & \square & \triangle & \text { Medium }(0.08-2.6) \\ \bullet & \square & \Delta & \operatorname{High}(>2.6)\end{array}$

Figure 4-19. High concentrations of nitrate in groundwater in agricultural areas and major aquifer studies are broadly distributed rather than clustered in the upper Midwest, where the nitrogen inputs are high.

groundwater than in oxic groundwater, and concentrations also were higher in groundwater with $\mathrm{pH}$ greater than 7.5. In selected areas with median phosphorus concentrations above background levels, dissolved phosphorus was significantly and positively correlated to $\mathrm{pH}$ and to the concentrations of ammonia, calcium, magnesium, and iron.
Phosphorus is not regulated in drinking water, however, its concentration in groundwater can affect surface-water quality at locations where groundwater inflow contributes significantly to streamflow (see Chapter 5 , Exchange of Nutrients between Surface Water and Groundwater). 


\section{Nitrate Leaching to Groundwater}

Leaching of nonpoint source nitrate to groundwater can pose a threat to drinking water supplies or streams. The amount of nitrate leached to groundwater, represented as the percentage of nonpoint source nitrogen inputs at the land surface that moves beyond the root zone and reaches the aquifer, varies as a function of crop uptake and soil conditions. The percentage of nonpoint source nitrogen leached to groundwater has been estimated in various USGS field studies (fig. 4-20). Although these studies used different methods to estimate the percentage of nitrate leached to groundwater, the estimates generally range from 10 to 50 percent. Leaching fractions are relatively low (less than 20 percent) in areas where tile drains divert percolating groundwater to streams, or where fine-grained sediments impede the vertical movement of water and thus provide more opportunity for denitrification to remove nitrate before the water reaches the aquifer.

Aquifers that underlie areas with high nitrogen inputs to the land surface, combined with coarse-grained soils and rapid rates of vertical movement through the unsaturated zone, are the most vulnerable to nitrate contamination.

Nitrate concentrations measured in oxic shallow groundwater were significantly correlated to estimated nonpoint source nitrogen input within a 500-meter (0.31 mile) radius around each well (fig. 4-21). Although the correlation between median nitrate input and median nitrate concentration is statistically significant, the correlation is weak, indicating that other factors have an important influence on concentrations. For example, concentrations of nitrate in groundwater in the agricultural land-use studies in the Upper Snake River Basin are relatively low despite high nitrogen inputs. In this area, the low background nitrate concentrations (less than $1 \mathrm{mg} / \mathrm{L}$ ), high lateral groundwater flow rates, and dilution by irrigation water from the Snake River result in network medians from about 1 to $4 \mathrm{mg} / \mathrm{L}$. In contrast, the median concentration of nitrate in groundwater in the agricultural land-use study in the Puget Sound Basin is high (about $13 \mathrm{mg} / \mathrm{L}$ ) in spite of low nitrogen input. This study area has one of the highest recharge rates; the sandy aquifer sediments facilitate rapid transport of nitrate to these wells. The nonpoint source nitrogen input in urban landuse study areas is lower than that in agricultural areas, and nitrate concentrations are generally lower in response to this difference in nitrogen inputs. Concentrations of nitrate in groundwater in the Santa Ana Basin, the Great Salt Lake Basins, and South Platte River Basin studies are high relative to the concentrations in other urban land-use studies. The population density in these three study areas is greater than 1,000 people per square kilometer. Population density is significantly correlated with nitrate concentrations within the urban land-use studies, suggesting that the intensity of development of urban land may better reflect nitrogen inputs in urban areas than inputs estimated on the basis of fertilizer and manure applications and atmospheric sources.

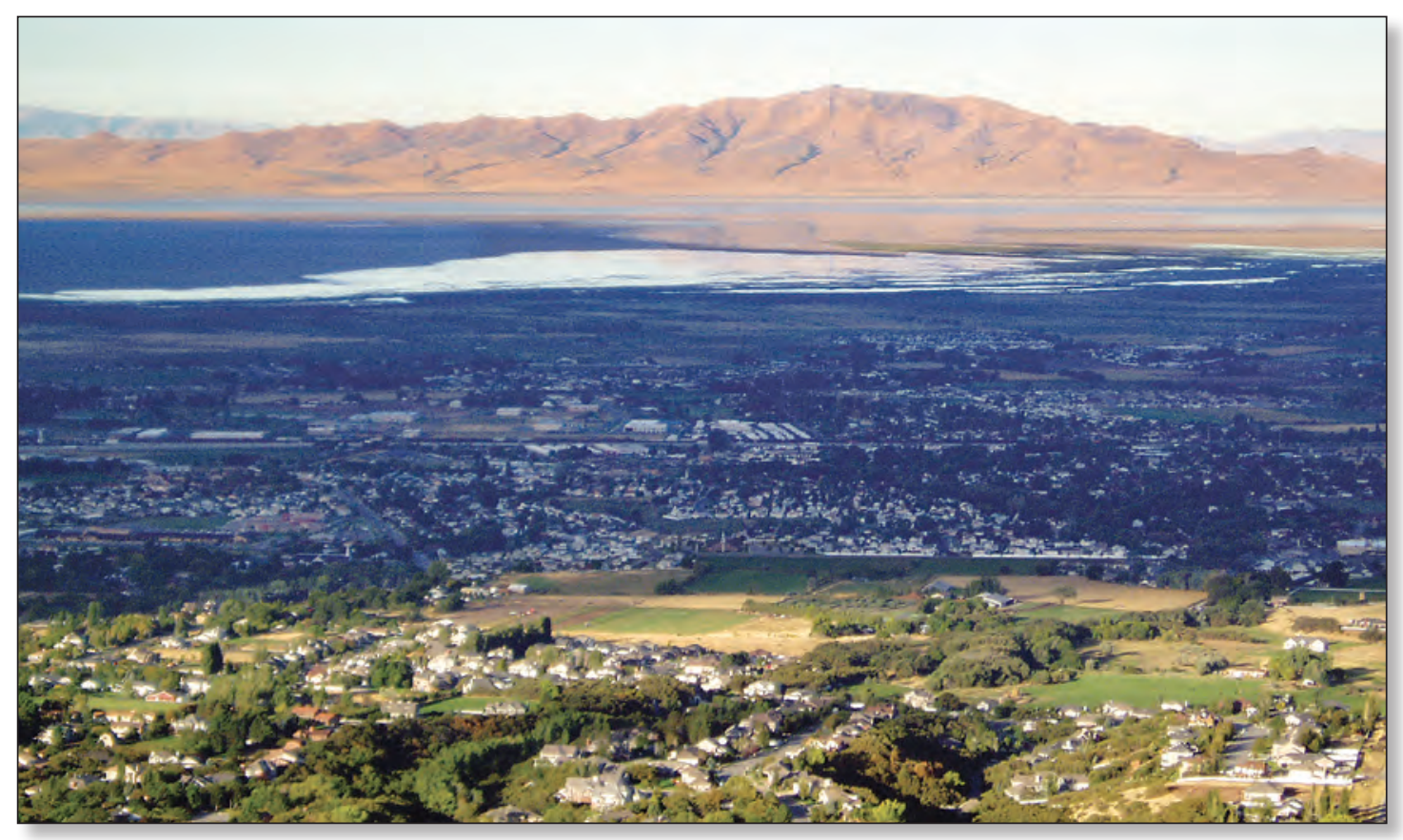

Salt Lake City was among the locations where the quality of shallow groundwater beneath residential urban land was studied. Photograph by Steven Gerner, U.S. Geological Survey. 


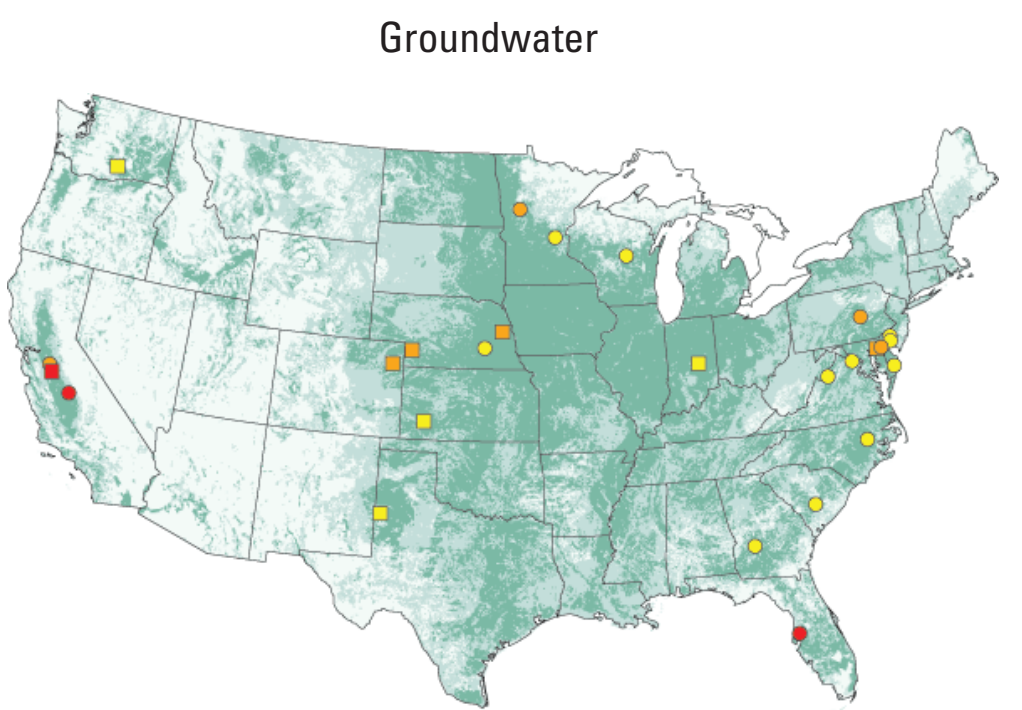

EXPLANATION

Estimated 1997 nitrogen inputs from fertilizer, manure, and atmosphere, in pounds per square mile

$\square 2,900$
$\square, 900-15,000$
$>>15,000$

Figure 4-20. It is estimated that 10 to 50 percent of the nonpoint source nitrogen inputs at the land surface reach the groundwater at the sites where detailed studies were conducted.

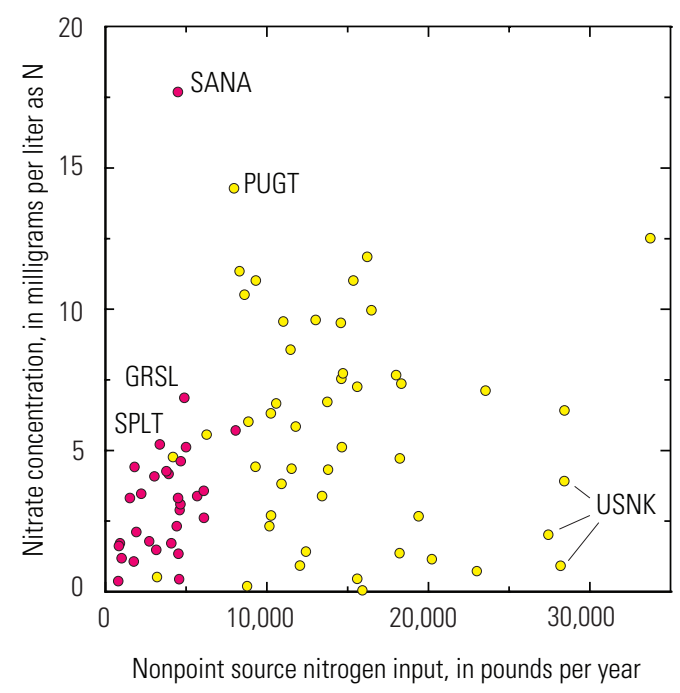

\section{EXPLANATION}

\section{Shallow groundwater study NAWOA Study Unit}

- Agricultural

- Urban

GRSL_Great Salt Lake Basins PUGT_Puget Sound Basin SANA - Santa Ana Basin SPLT—South Platte River Basin USNK—Upper Snake River Basin

Figure 4-21. Although there is a statistically significant correlation between nonpoint source nitrogen inputs and median nitrate concentrations in oxic shallow groundwater, the correlation is weak, indicating that other factors have an important influence on concentrations. 


\section{Geochemical Controls on Nitrate Occurrence in Groundwater}

Redox conditions exert a strong control on nitrate occurrence in groundwater (Burow and others, 2010) (see Chapter 2, Nutrient Primer). When the geochemical environment is oxic, as indicated by the presence of dissolved oxygen greater than $0.5 \mathrm{mg} / \mathrm{L}$ in groundwater, nitrate may persist. When the geochemical environment is reducing, nitrate in groundwater may be removed by denitrification, which yields nitrogen gas. Reducing conditions predominate in areas where large amounts of organic carbon are present in the aquifer and where near-surface water saturation limits the penetration of oxygen gas. Reducing conditions also can evolve because of the progressive depletion of dissolved oxygen by reactions during flow, and hence, groundwater tends to become more "reduced" the longer it resides in the ground. Conditions favorable to reducing conditions are more common in humid, poorly drained areas of the eastern U.S.; oxic conditions favorable for persistence of nitrate are prevalent in the semiarid West (fig. 4-22).

Median nitrate concentrations in groundwater are significantly higher under oxic conditions than under other redox conditions, regardless of the land use (fig. 4-23). In addition, within each land use, nitrate concentrations are strongly dependent on redox condition regardless of nitrogen load. For example, nitrogen input in agricultural areas is similar across the three redox categories, but the median concentration of nitrate is about $5.6 \mathrm{mg} / \mathrm{L}$ in oxic groundwater, and is less than the detection level $(0.05 \mathrm{mg} / \mathrm{L})$ in reduced groundwater. Another striking illustration of the impact of redox condition is that nitrate concentrations are higher in oxic water in shallow urban wells with low nitrogen input, than in agricultural wells with much higher input but reduced water. Similar relations are seen in concentrations of nitrate in wells completed in major aquifers. In addition to potential denitrification in reduced groundwater, in some areas of poorly drained soils tile drains divert infiltrating water to streams, resulting in still less nitrogen load to groundwater.

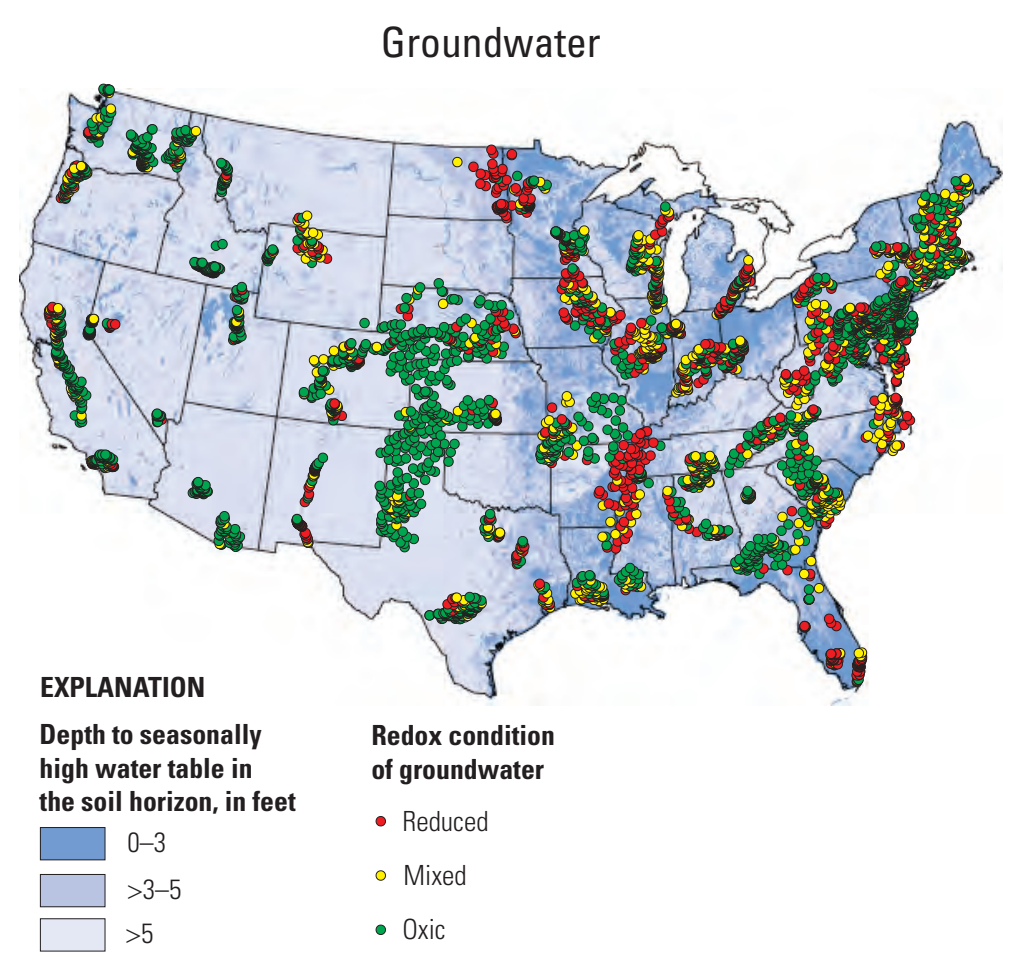

Figure 4-22. Groundwater with reducing conditions (indicated by red dots) is common in the Midwest and eastern United States, where a humid climate and poor drainage lead to saturated soils (indicated by shallow depth to a seasonally high water table). Oxic (oxygen-rich) conditions favorable for persistence of nitrate are prevalent in the semiarid West.

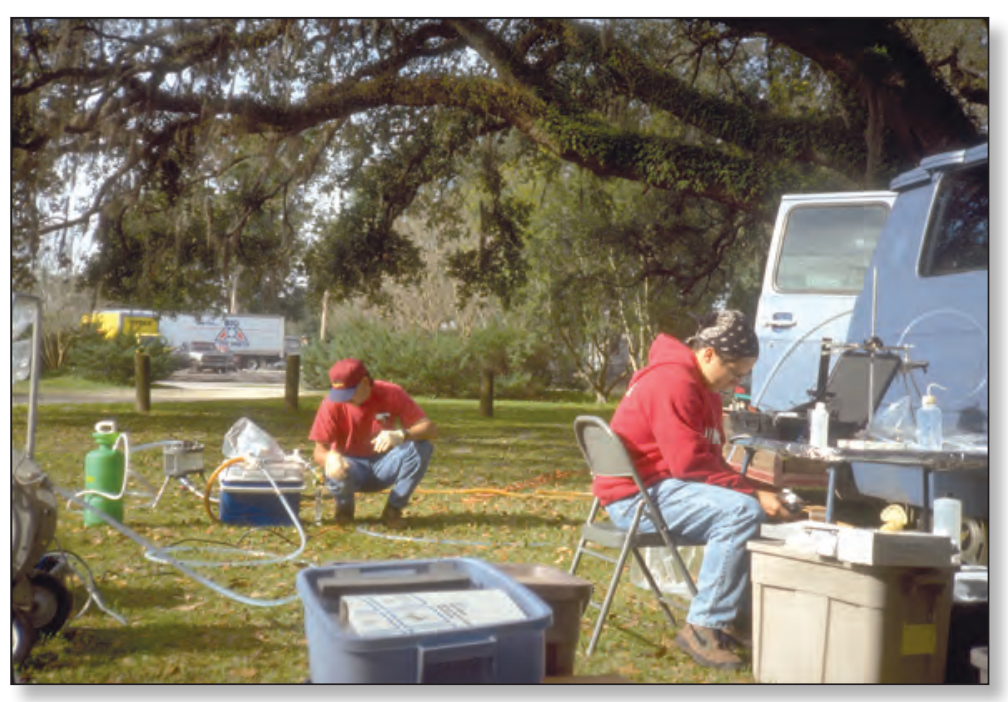

Water-quality characteristics are measured at the site as samples are collected for laboratory analysis. Photograph by U.S. Geological Survey. 

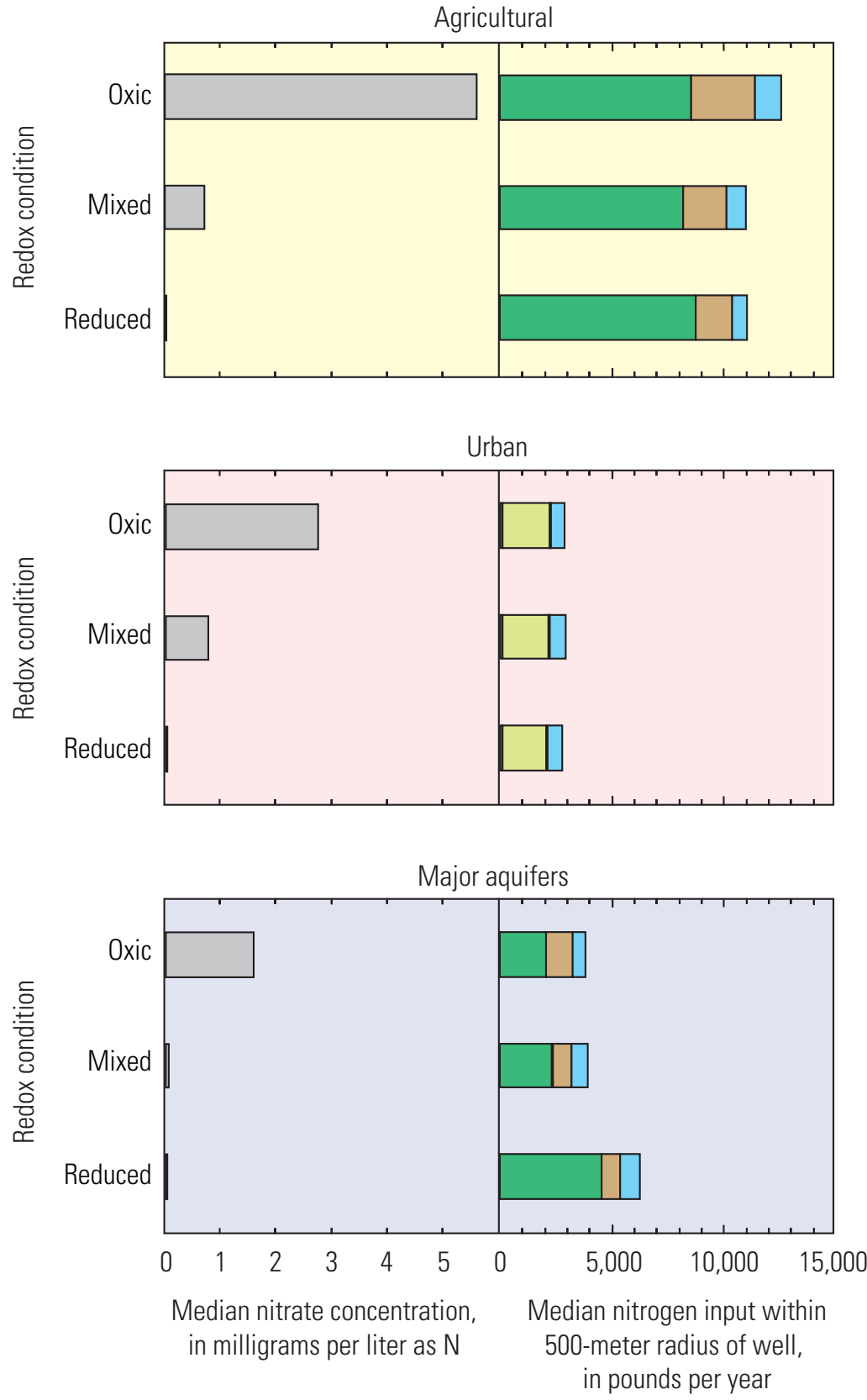

\section{EXPLANATION}

\section{Nitrogen input}

Farm fertilizer

Nonfarm fertilizer
These results show that the redox condition of an aquifer is a critical factor to consider when assessing vulnerability to nitrate contamination. Resource managers could glean critical information on redox condition from data routinely collected on dissolved iron and manganese (which indicate reduced conditions when concentrations are elevated) for assessment of secondary drinking-water standards, or with additional monitoring of dissolved oxygen concentrations.

Figure 4-23. Nitrate concentrations are significantly higher in oxic groundwater regardless of the land use and source of nitrogen. Within each land-use category, nitrate concentration is strongly dependent on redox condition regardless of nitrogen input. (Modified from Burow and others, 2010.) 


\section{Physical Factors: Aquifer and Well Characteristics}

Groundwater age reflects the aggregate effect of all physical factors that control the rate of movement of groundwater in an aquifer - those physical attributes that control the "intrinsic susceptibility" of an aquifer. Water samples collected from a subset of the NAWQA wells were analyzed for tritium, an environmental tracer that indicates whether the bulk of the water was recharged prior to or after 1952 (see sidebar, Groundwater Tracers as Indicators of Groundwater Age). Groundwater with tritium concentrations greater than 2.5 picocuries per liter is assumed to have been recharged after 1952 .

Sorting groundwater samples into two groups - pre- and post-1952 by tritium "age"shows that nitrate concentrations are significantly higher in younger (post-1952) groundwater than in older groundwater (fig. 4-24). Specifically, most of the old groundwater has nitrate concentrations less than the background concentration of $1 \mathrm{mg} / \mathrm{L}$, whereas 59 percent of young groundwater has concentrations greater than $1 \mathrm{mg} / \mathrm{L}$. Groundwater

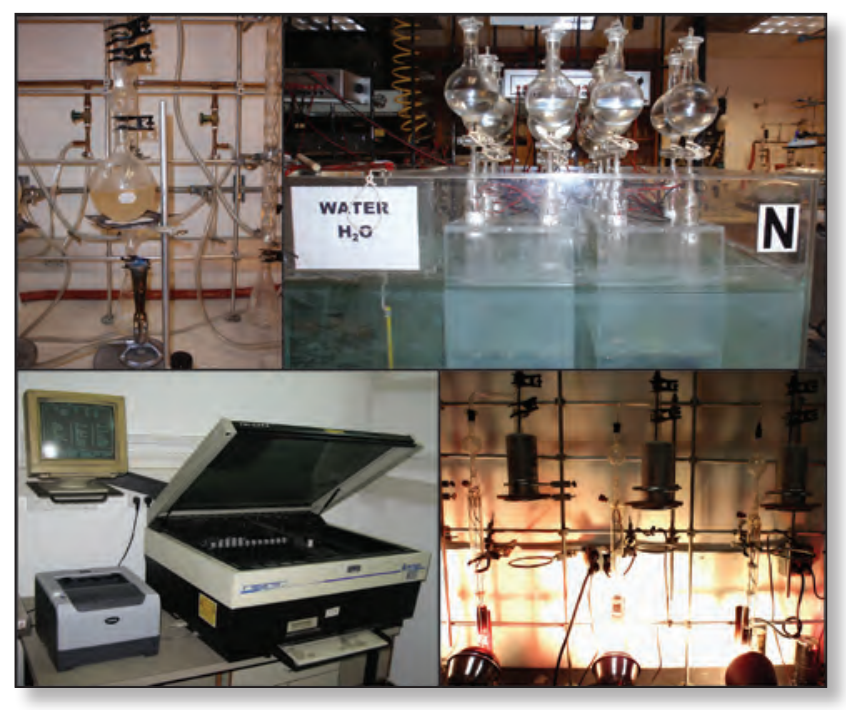

Groundwater samples are analyzed for environmental tracers, such as tritium and chlorofluorocarbons, to determine the time elapsed since recharge. Tritium is analyzed by (clockwise from upper left) distillation, electrolytic enrichment, secondary distillation, and scintillation counting. Photographs by A. Abedini, U.S. Geological Survey.

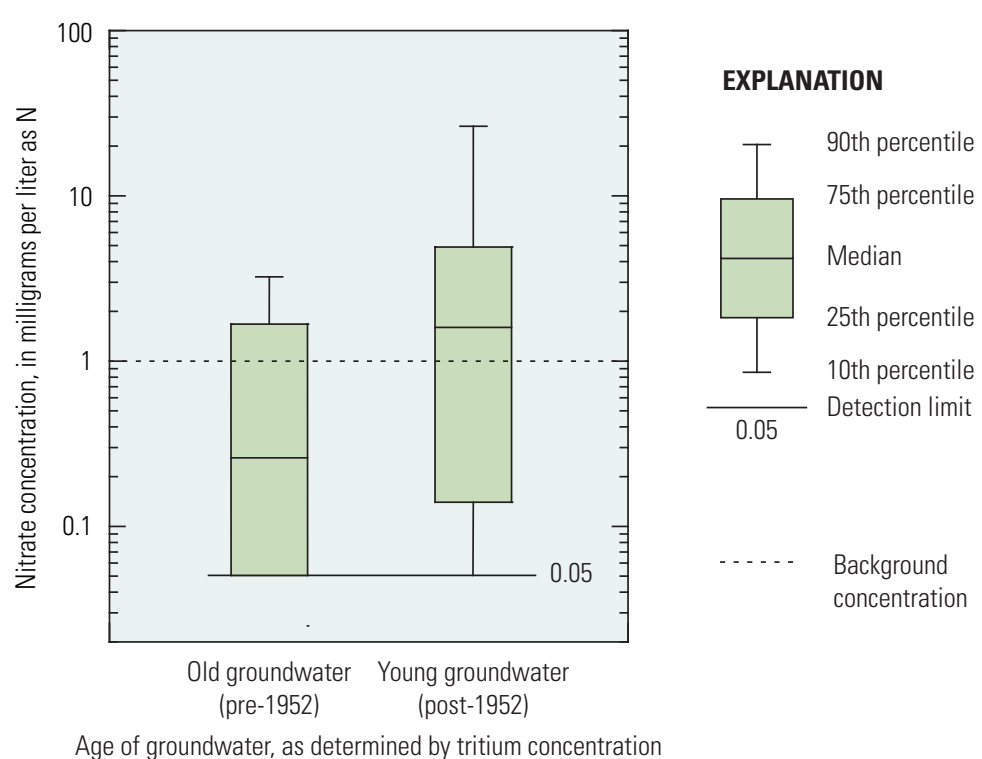

Figure 4-24. Nitrate concentrations are significantly higher in younger groundwater than in older groundwater.

\section{Groundwater Tracers as Indicators of Groundwater Age}

Concentrations of certain anthropogenic chemicals in groundwater can be used to trace the flow of young water (water recharged within the past 50 years) and to determine the time elapsed since recharge (Plummer and Friedman, 1999). Recent human activities have released an array of chemical and isotopic substances to the atmosphere. These atmospheric substances (such as tritium) have been incorporated into the hydrologic cycle and can be found in groundwater recharged within the last 50 years. The age of a groundwater sample is estimated by comparing the concentration of a tracer in the sample with the known history of the change in concentration of the tracer in the atmosphere. Information about the age of groundwater can be used to provide further understanding of nitrate concentrations in wells. For example, low concentrations of nitrate may be found in oxic groundwater with high nitrogen inputs. If the corresponding age of water in the well is greater than about 50 years, then the low nitrate concentration may reflect historically low input of nitrogen (at the time of recharge). Concentrations may increase in the future in this well as groundwater that reflects the currently high inputs reaches the well. 
age is not a definitive control on nitrate concentration, however. For example, areas with young groundwater may have low nitrate concentrations because no nitrate sources are present in their recharge areas, or reducing conditions may have removed any nitrate from the water. Areas with old groundwater also may have high nitrate concentrations, particularly in areas where most of the groundwater moves slowly but fractures or other high-permeability features allow rapid transport of small volumes of high nitrate water to wells (McMahon and others, 2008).

Nitrate concentrations decrease as the depth of a well below the water table increases (fig. 4-25) because of the following contributing factors:

- In general, it takes longer for groundwater to travel to greater depths, and hence, the recharge may have occurred at a time when nitrogen input at the surface was lower.

- Greater depth suggests a longer residence time, which increases the opportunity for denitrification to remove nitrate from water.

- The groundwater flow paths to wells become more complex and intermixed as the well gets deeper. This increase in depth increases the likelihood that the water sampled in a deep well is a complex mixture of water recharged in many different - and possibly distant-land uses with different nitrogen sources (or none at all).

Water from wells completed in confined aquifers had significantly lower concentrations of nitrate than water from unconfined wells (fig. 4-26). Confined aquifers are separated from an overlying unconfined aquifer by fine-grained layers of material that impede downward movement of younger water that may be carrying contaminants from the land surface. Many groundwater protection programs assume that a confined aquifer is not vulnerable to nitrate contamination. But finegrained confining layers may not be completely protective: 25 percent of wells classified as being completed in confined aquifers had concentrations of nitrate above national background levels (1 mg/L), including 2 percent with concentrations above the drinking-water limit of $10 \mathrm{mg} / \mathrm{L}$. In some areas, confining layers are not uniformly extensive, or have preferential flow paths through which water can quickly cross the layers (see sidebar, Protection of Confined Aquifer from Contamination in the High Plains Aquifer).

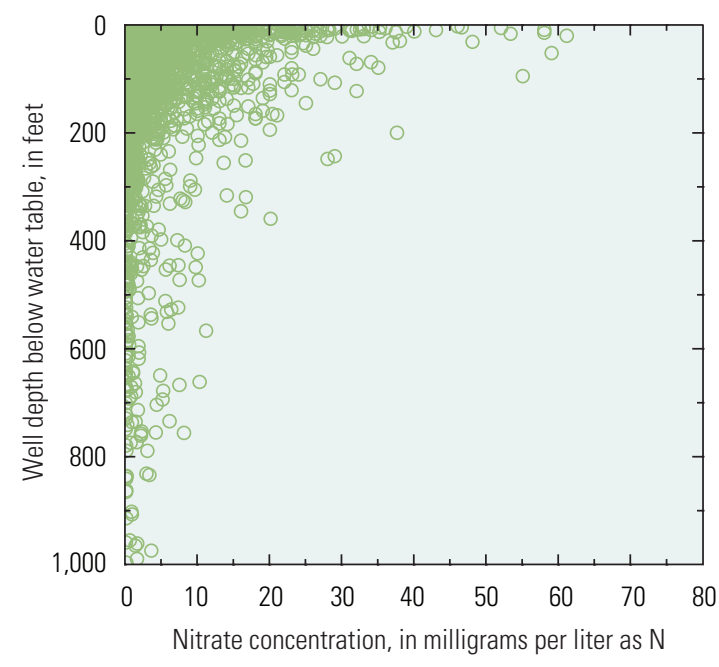

Figure 4-25. A number of factors contribute to a general decrease in nitrate concentrations with increasing depth of a well, including greater mixing and more opportunity for denitrification at greater depths, and greater nitrogen input in recent decades.

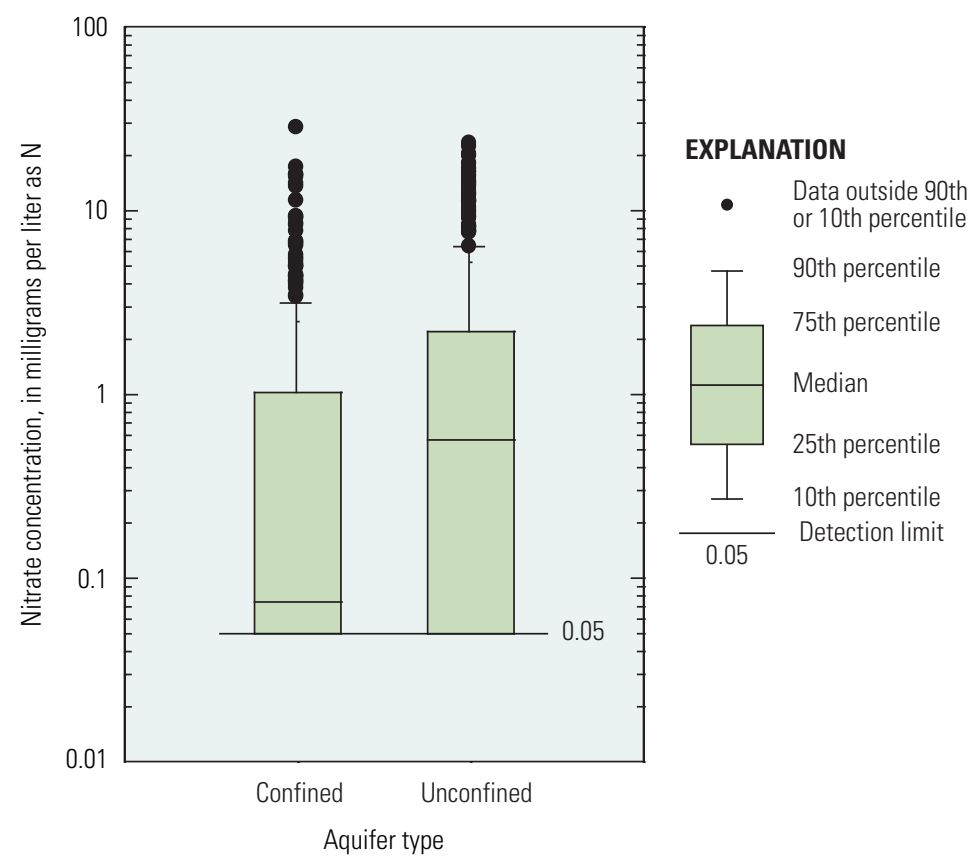

Figure 4-26. Although wells in confined aquifers had lower concentrations of nitrate than did wells in unconfined aquifers, high concentrations - including some that exceeded the Maximum Contaminant Level of 10 milligrams per liter-indicate that confining layers are not always completely protective (Burow and others, 2010). 


\section{Protection of Confined Aquifer from Contamination in the High Plains Aquifer}

Confined aquifers are commonly assumed to be protected from contamination from activities on the land surface because relatively impermeable fine-grained layers impede downward movement of younger groundwater containing contaminants. However, highly contaminated water in unconfined aquifers can move downward or laterally to confined aquifers, particularly if those confined aquifers are heavily used (pumped) or if features exist that allow contaminants to short-circuit through or around the fine-grained layers.

In the northern High Plains aquifer in east-central Nebraska, young contaminated groundwater from the unconfined aquifer is reaching the deeper confined aquifer, where most of the public-supply wells are screened (fig. 4-27) (Landon and others, 2008). The shallow unconfined aquifer beneath both urban and agricultural land has high nitrate concentrations (median concentration of $16 \mathrm{mg} / \mathrm{L}$ ). Water in the confined aquifer generally is old and in a reduced state, so nitrate concentrations generally are low (median concentration of less than $0.06 \mathrm{mg} / \mathrm{L}$ ). However, water from 2 of 11 of the public-supply wells screened exclusively in the confined aquifer had concentrations of nitrate greater than the MCL of $10 \mathrm{mg} / \mathrm{L}$ in at least one sample during the last decade.

On the basis of analysis of chemical tracers, sediment-chemistry data, and simulation modeling, it has been shown that nitrate and other contaminants in the unconfined aquifer have bypassed the highly reducing confining unit by moving through abandoned or inactive well bores to reach the screened intervals of wells completed in the confined aquifer (fig. 4-27) (McMahon and others, 2008; Landon and others, 2008). Movement of nitrate through confining units or along other rapid travel paths has been documented in other areas of the country as well, such as the Floridan aquifer in Florida (Katz and others, 2007). These examples demonstrate that aquifer confinement does not ensure that an aquifer is safe from contamination from activities on the land surface.

High Plains aquifer, Nebraska

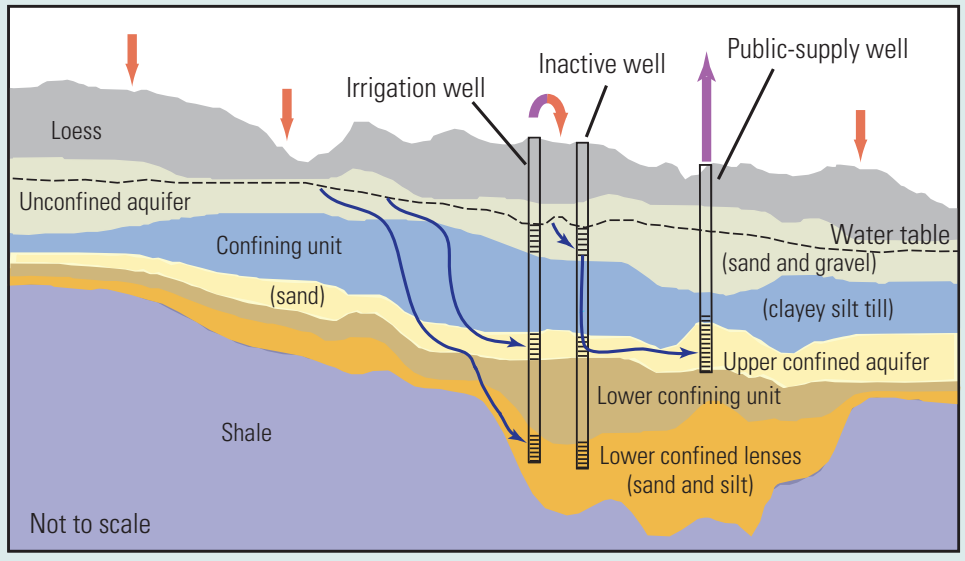

EXPLANATION

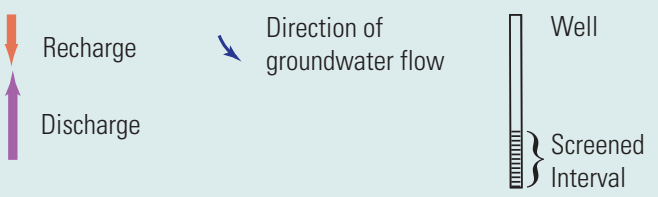

Figure 4-27. Despite the presence of an extensive overlying confining unit, overlying unconfined water containing high nitrate concentrations is reaching drinking water wells in the confined aquifer in parts of the High Plains aquifer. (Modified from Jagucki and others, 2008.) 
Another factor that can influence the vulnerability of groundwater to nitrate contamination is the aquifer lithologythe primary rock type (Miller, 2000; U.S. Geological Survey, 2003; and U.S. Geological Survey, 2009b). Aquifer lithology can influence the speed at which contaminants move through the aquifer. Groundwater studies were grouped into categories on the basis of lithology of the principal aquifer.

The relative vulnerabilities of the principal aquifer settings, as indicated by median nitrate concentration, can be summarized as follows (see fig. 4-28):

- Waters in unconsolidated sand and gravel (non-glacial origin) and in basaltic and other volcanic-rock aquifer lithology groups have relatively high nitrate concentrations regardless of land use. This is consistent with the high permeability of these geologic materials.
- Waters in sandstone and semi-consolidated sand and gravel aquifers consistently have among the lowest nitrate concentrations within each land-use category.

- The relative rank of the nitrate concentrations in water in aquifers in the other four lithology groups varies among the land-use categories. For example, the carbonate rock aquifer lithology group has the highest concentrations of nitrate among the lithology groups in agricultural areas, but among the lowest concentrations in urban and major aquifer networks.

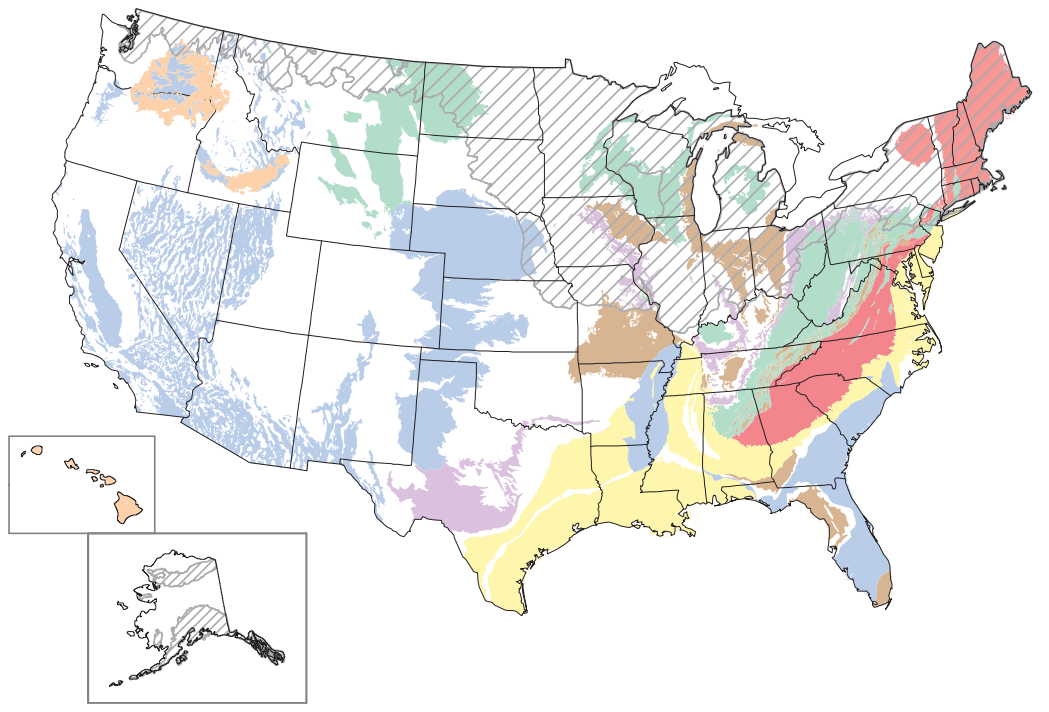

EXPLANATION

Aquifer lithology group

$\square$ Unconsolidated sand and gravel (non-glacial origin)

$\square$ Glacial sand and gravel

$\square$ Semi-consolidated sand and gravel

$\square$ Sandstone

$\square$ Sandstone and carbonate rock

$\square$ Carbonate rock

$\square$ Basaltic and other volcanic rock

$\square$ Crystalline rock
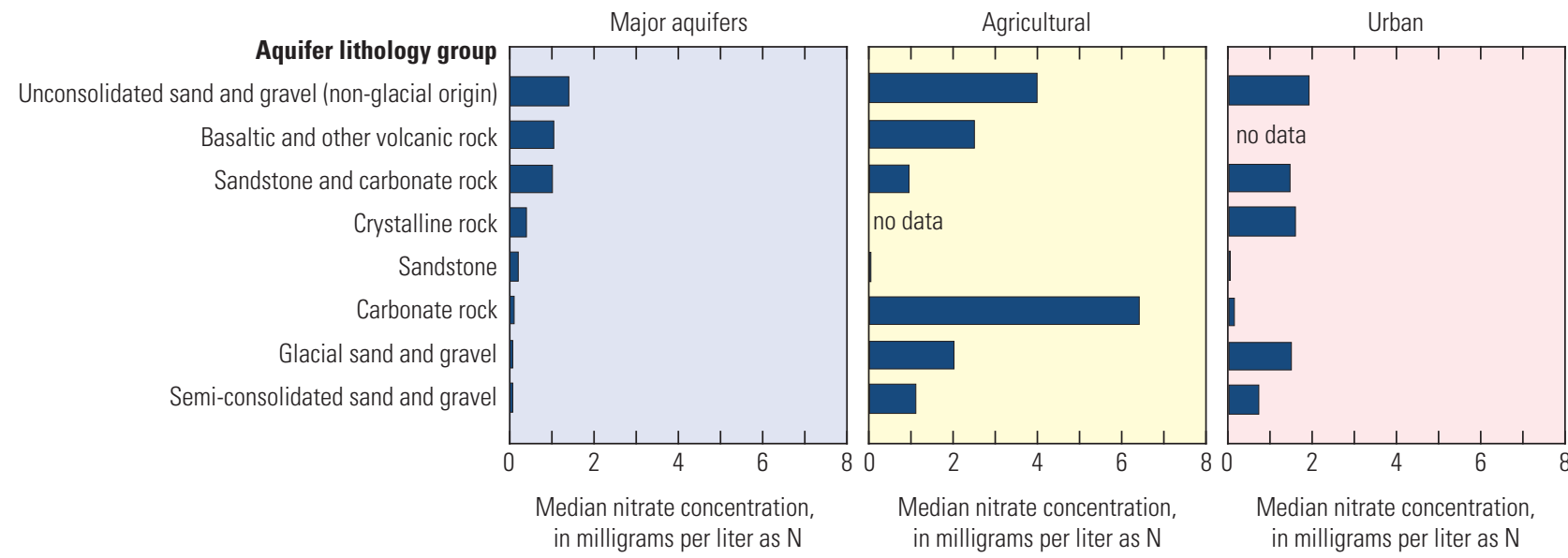

Figure 4-28. Consistent with the high permeability of these lithologies, unconsolidated sand and gravel (non-glacial origin) and basaltic and volcanic-rock aquifer lithology groups contain groundwater with relatively high nitrate concentrations regardless of land use. In contrast, water in sandstone and semi-consolidated sand and gravel aquifers consistently have groundwater with among the lowest nitrate concentrations within each land-use category. 


\section{Integration of Physical and Chemical Factors that Control Nitrate in Groundwater}

The highest nitrate concentrations occurred where both aquifer properties and redox conditions favor nitrate transport and persistence (Burow and others, 2010). Wells were grouped into two age groups (pre- and post-1952, on the basis of tritium activity data) and then split into redox categories to illustrate the relation between groundwater age and redox condition (fig. 4-29). Young water tends to be more oxic, and accounts for most samples with nitrate above background concentrations. In particular, very high nitrate concentrations - greater than $10 \mathrm{mg} / \mathrm{L}$ - are found in only 1.4 percent of old groundwater samples in general, and are nonexistent in old reduced groundwater. These results underscore the vulnerability of groundwater to contamination in areas where both physical and geochemical conditions favor the rapid movement and persistence of nitrate in aquifers.

The highest groundwater nitrate concentrations occur where relatively large nitrogen inputs coincide with physical and chemical factors that favor nitrate transport and persistence. The aquifers most vulnerable to high nitrate concentrations are those with the highest nitrogen inputs, a highly permeable lithology, and oxic conditions (fig. 4-30). The principal aquifer lithologies in which nitrogen inputs were generally high and redox conditions were predominantly oxic, such as the basaltic and volcanic-rock and the unconsolidated sand and gravel (non-glacial origin) aquifers, had the highest nitrate concentrations. In contrast, the sandstone principal aquifer lithology, which generally had low nitrogen inputs and predominantly reduced conditions, had the lowest nitrate concentrations. Because the factors that influence aquifer vulnerability to nitrate contamination are complex and interrelated, statistical models have been used to integrate aquifer vulnerability characteristics over large areas.

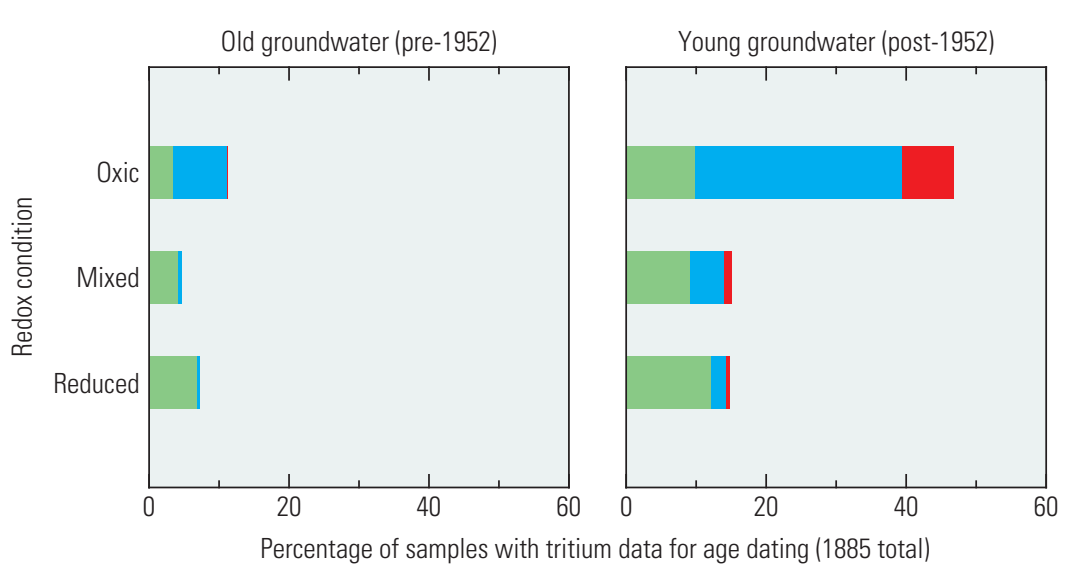

\section{EXPLANATION}

Nitrate concentration, in milligrams per liter as $\mathbf{N}$

$\square \leq 1 \quad \square>1-10 \quad \square>10$

Figure 4-29. The highest nitrate concentrations in groundwater occur where aquifer properties and redox conditions are favorable to nitrate transport and persistence. Nitrate concentrations were highest in young oxic groundwater; in contrast, nitrate concentrations greater than 10 milligrams per liter were rare in old groundwater in general and non-existent in old reduced groundwater (Burow and others, 2010).

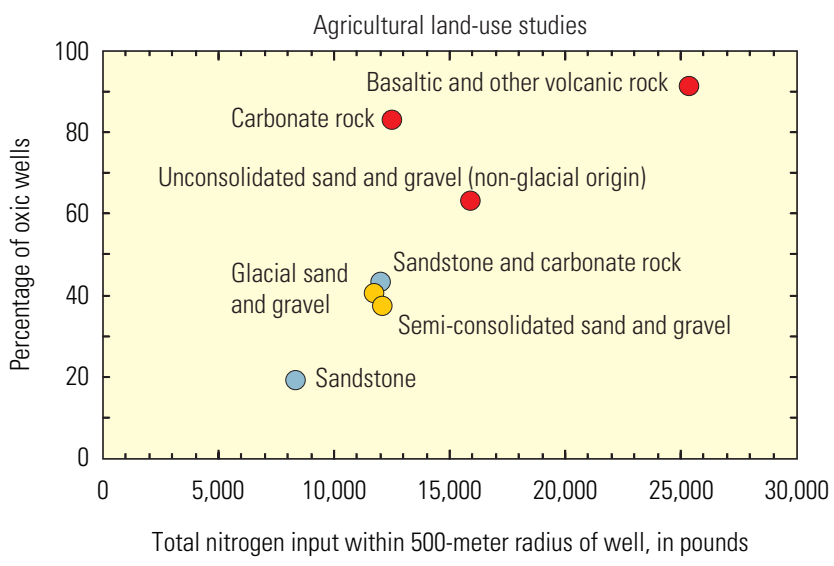

EXPLANATION

Median nitrate concentration, in milligrams per liter as $\mathbf{N}$

$\bigcirc<1 \bigcirc 1-2 \quad \bigcirc>2$

Figure 4-30. The aquifers most vulnerable to high nitrate concentrations are those with the highest nitrogen inputs, oxic conditions, and permeable lithologies, such as basaltic and volcanic-rock aquifers. 


\section{Extrapolation of Nitrate Concentrations in Shallow Groundwater to Unsampled Areas}

A statistical model was developed to predict nitrate concentrations in shallow groundwater (median depth of 10 meters, or 33 feet) based on concentrations measured in samples from wells in 97 studies across the conterminous United States along with selected explanatory factors (Nolan and Hitt, 2006) (see Chapter 3 section, Extrapolation to Unsampled Areas, Development of the Nonlinear Nitrate Models for Groundwater). The model predicts moderate to severe nitrate contamination in the High Plains, northern Midwest, and other areas of intensive agriculture in both the East (eastern Pennsylvania and the Delmarva Peninsula) and the West (the Columbia Plateau in Washington, the San Joaquin Valley in California, and the Snake River Plain in Idaho) (fig. 4-31). The highest nitrate concentrations are predicted in areas with large nitrogen sources, factors that promote rapid transport of nitrogen in groundwater, and a lack of attenuation processes.

The model for shallow groundwater explained about 80 percent of the variation in nitrate concentrations. Factors that represent nitrogen sources include farm fertilizer, manure from confined livestock, and population density, as well as the amount of agricultural land. Factors in the model that represent the rate at which nitrate is transported in groundwater include water input, rock type, the presence of drainage ditches, and percentage of clay. For example, rocks such as limestone in eastern Pennsylvania and basalt in the Columbia Plateau of Washington have features, such as fractures and solution cavities, that promote the transport

\section{Groundwater}

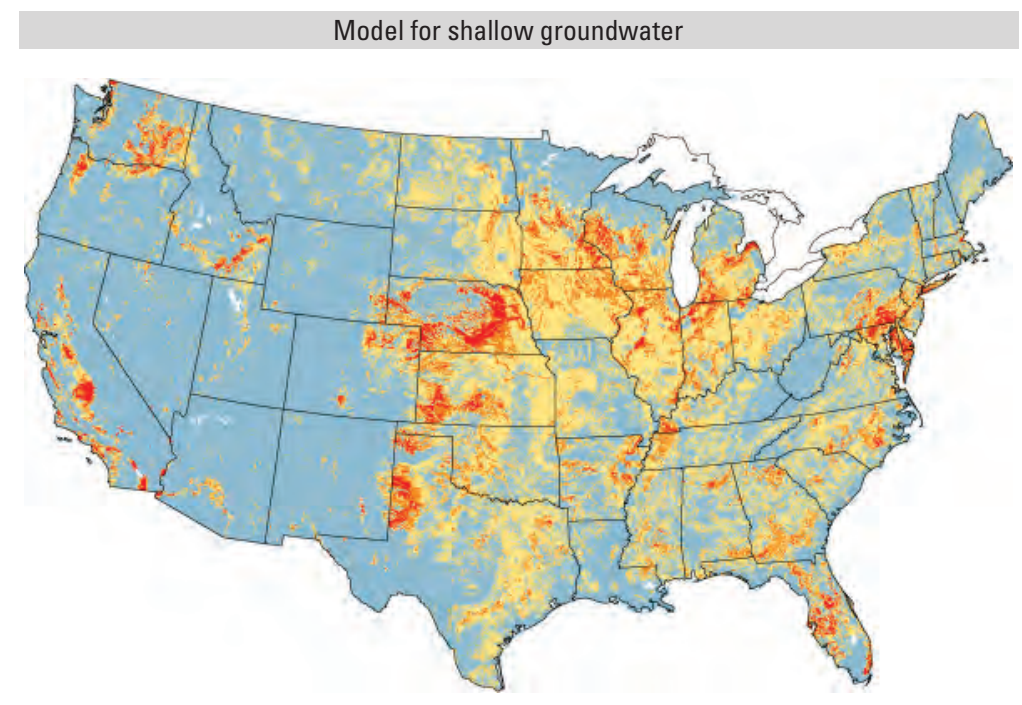

\section{EXPLANATION}

Predicted nitrate concentration, in milligrams per liter

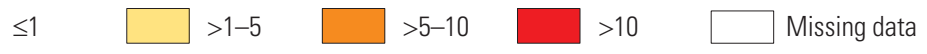

Figure 4-31. The model for shallow groundwater predicts moderate (yellow and orange areas) to severe (red areas) nitrate contamination in areas with large nitrogen sources, factors that promote rapid transport of nitrogen in groundwater, and a lack of attenuation processes (Nolan and Hitt, 2006).

of nitrate in water moving through the aquifer. In contrast, ditches in poorly drained agricultural areas, such as parts of the upper Midwest, divert water to nearby streams, which short-circuits the leaching process. This "diversion" results in low concentrations of nitrate in groundwater despite very large sources of nitrogen on the land surface. Factors that represent nitrate attenuation processes in the model include the presence of wetlands and the extent of soils rich in organic matter. Together, these variables represent the relatively high potential for denitrification in saturated soils with high organic carbon content. 
This page intentionally left blank 


\section{Base Flow Contributions of Nitrate Load to Streams}

The proportion of the nitrate load of a stream contributed by base flow was estimated for 148 relatively small watersheds (each less than 500 square miles) across the Nation (Spahr and others, 2010) (see sidebar, Calculation of the Contribution of Base Flow to the Nitrate Load in Streams). Many streams have a large percentage of their nitrate load contributed by base flow: 66 percent of streams had more than 37 percent of the total nitrate load contributed by base flow (fig. 5-1). Although broad regional patterns are not well defined, small clusters of sites at which similar processes result in similar proportions of nitrate contributions are distinct.

Low to moderate proportions of stream nitrate loadsless than 54 percent of the total load - are contributed by base flow in most streams in the central portion of the country, from the Great Lakes to Texas (fig. 5-1):

- Sites in the Trinity River Basin of eastern Texas typically have less than 37 percent of their nitrate load contributed by base flow. The low base flow proportion at these sites results from periods of very low flow with low nitrate concentrations followed by short duration runoff events with greater nitrate concentrations (Land and others, 1998).

- Sites in the eastern part of the Corn Belt (Indiana and Ohio) have base flow contributions to nitrate in streamflow that commonly are less than 37 percent of total instream nitrate. Relatively low contributions of groundwater to instream nitrate loads result from the use of tile drains in much of the Corn Belt (see sidebar, Hydrologic Modifications Create Seasonal Patterns in Nutrient Concentrations).
Streams with greater than 54 percent of their nitrate load from base flow drain a variety of hydrologic settings and include multiple sources of nitrate (fig. 5-1):

- The Sandhills region of central Nebraska represented by the Dismal River (the red symbol in central Nebraska) is an area with highly permeable soils and bedrock. Very little runoff occurs in this area because precipitation infiltrates directly to groundwater (Frenzel and others, 1998). Streamflow is almost entirely generated by groundwater discharge, resulting in a base flow nitrate load contribution of 97 percent.

- Seven sites in the Valley and Ridge physiographic province, which extends from northern Alabama through Tennessee, Virginia, Maryland, and Pennsylvania, have more than 54 percent of their nitrate load contributed by base flow. Base flow nitrate contribution is more than 70 percent of total instream nitrate for four sites that are underlain by carbonate aquifers. Although hydrologic characteristics vary within the Valley and Ridge carbonate aquifers, they generally are considered unconfined, with karst features including sinkholes, springs, and caverns (Lindsey and others, 2009). The karst and solution features result in aquifers that are highly susceptible to contamination (Hampson and others, 2000) as well as extensive interaction between groundwater and surface water.

- Many sites with snowmelt-dominated hydrology (such as sites in the mountainous areas of Colorado) have high base flow nitrate contributions. Nitrate concentrations at these sites are typically low, but concentrations during base flow periods were routinely greater than those during snowmelt runoff.

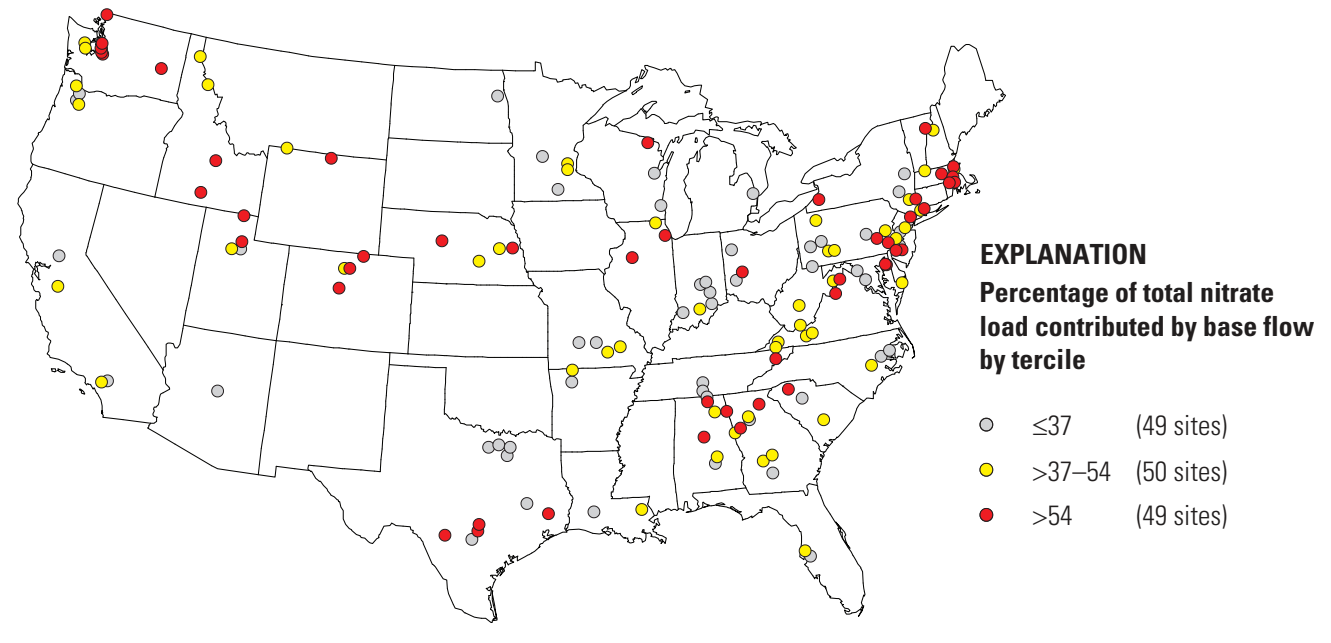

Figure 5-1. Sixty-six percent of the streams evaluated had more than 37 percent of their total nitrate load contributed by base flow. The percentage of total nitrate load contributed to streams by base flow varies greatly depending on the sources of the nitrate and factors that affect its transport in both groundwater and streams. 


\section{Calculation of the Contribution of Base Flow to the Nitrate Load in Streams}

Estimation of the portion of a stream's nitrate load contributed by base flow requires several steps: (1) estimation of the streamflow contributed by base flow, (2) identification of stream samples whose chemistry reflects base flow, and (3) use of the flow and chemical data to calculate annual nitrate loads that are due to base flow. The base flow proportion of streamflow at a subset of NAWQA surface-water sites was estimated using a hydrograph separation method presented by Wahl and Wahl (1988), which is in turn based on methodology developed by the Institute of Hydrology (1980). For example, the blue area in the hydrograph for Clear Creek, Tennessee, is the portion of streamflow attributed to base flow by this method (fig. 5-2). In this case, the base-flow component represents groundwater discharge, because the Clear Creek watershed is small and predominately forested, and is not affected by point sources, return flows, or flow regulation.

Average annual loads (mass per year) of nitrate were determined for base flow and total flow conditions for selected sites sampled during 1990-2006 (Spahr and others, 2010). The period of record for load computations ranged from 1 to 16 years, with an average of 6 years. Briefly, the annual hydrographs were separated into base flow and total flow proportions, resulting in daily total and base flows. Water samples collected at the sites were classified as either base flow or non-base flow samples. A base flow sample was one that was collected on any day when the base flow was 77 percent or more of the total flow. Using the base flow samples and the daily base flow values, base flow nitrate loads were determined using the statistical model LOADEST (Runkel and others, 2004). Total flow loads were determined on the basis of all nitrate concentration values and the total daily streamflow. The ratio of the base flow load to the total flow load represents the portion of nitrate load transported to the stream by base flow. The base flow load was calculated for 148 surface-water sites with watersheds less than 500 square miles in area. (See Spahr and others, 2010, for more details.) Sites suspected to be influenced by wastewater discharges or impoundments were excluded from the analysis.

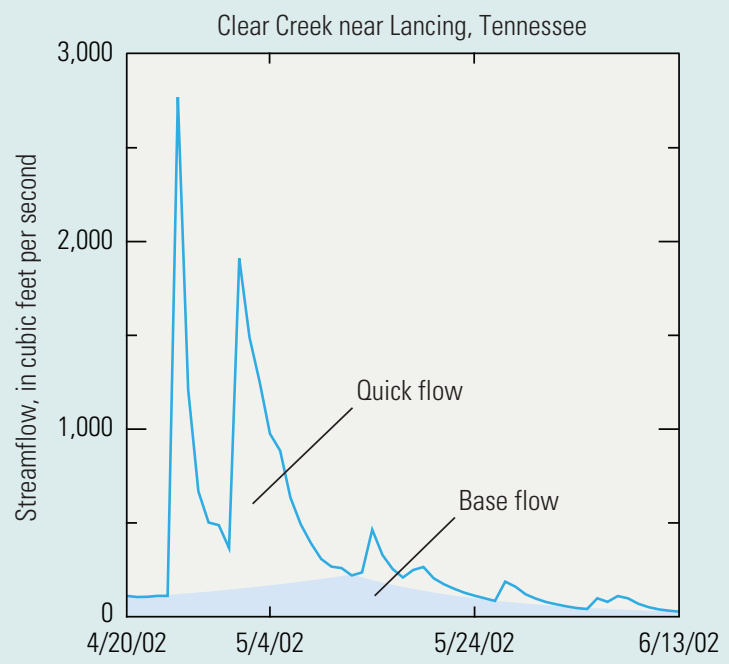

Figure 5-2. This streamflow hydrograph example shows estimated partitioning of total flow into base flow and quick flow components for Clear Creek near Lancing, Tennessee. 


\section{Hydrologic Modifications Create Seasonal Patterns in Nutrient Concentrations}

The seasonal exchange of water between streams and groundwater, and resulting changes in nutrient concentrations, can be radically affected by local man-made modifications of the hydrologic system. In the Central Columbia Plateau of eastern Washington, irrigation wasteways and other surface drains convey low-nitrate irrigation water diverted from the Columbia River during the growing season (April through 0ctober, fig. 5-3). When irrigation ceases and discharge of high-nitrate shallow groundwater becomes the predominant source of streamflow, nitrate concentrations in the stream increase by almost three-fold. The counter-intuitive consequence of this pattern of water management is minimum nitrate concentrations in the stream during the growing - and fertilizer application-season.

In the White River Basin, Indiana, nitrate concentrations of many streams are influenced by the effects of agricultural tile drains. Nitrate-rich shallow groundwater and water percolating through poorly drained soils are intercepted by drains and routed rapidly to streams. Elevated nitrate concentrations are observed in Sugar Creek when tile drains are flowing (fig. 5-4). When drainage ceases, nitrate concentrations decrease to background levels typical of those found in deeper aquifers that contribute water to the streams during these periods (Fenelon, 1998).

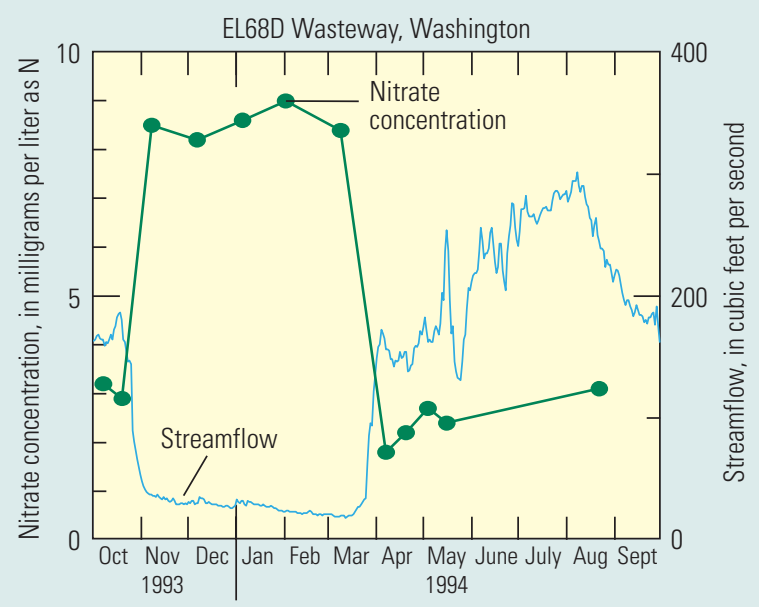

Figure 5-3. Nitrate concentrations in the EL68D Wasteway are low during the growing season, and highest during the winter and early spring, when the main source of streamflow is groundwater discharge with elevated concentrations of nitrate (Williamson and others, 1998).
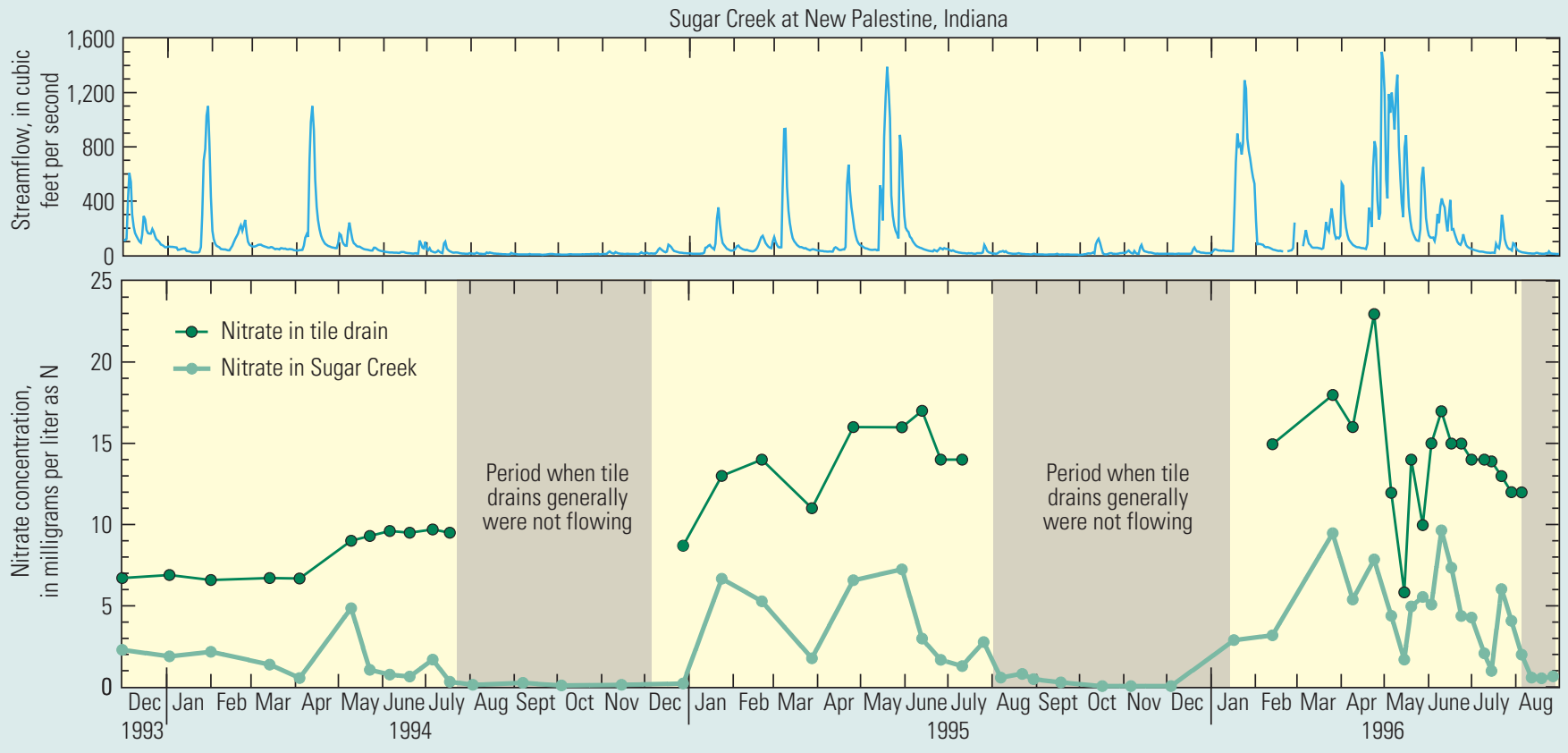

Figure 5-4. In the White River Basin, Indiana, nitrate concentrations of many streams are influenced by agricultural tile drains. Nitraterich shallow groundwater and water percolating through poorly drained soils are intercepted by the drains and routed rapidly to streams. Elevated nitrate concentrations are observed in Sugar Creek when tile drains are flowing. When drainage ceases, nitrate concentrations return to background levels typical of those found in deeper aquifers that contribute water to the streams during these periods (Fenelon, 1998). 


\section{Regional Processes That Affect Base Flow Loads}

Climate, as well as physical characteristics including soils and bedrock permeability and land-surface slope, are among the many factors that affect the mode of transport of nitrate from sources in a landscape to a stream. The influence of contrasting hydrologic landscapes on the sources of nitrate loads in streams was shown by classifying stream sites into one of four landscape categories (Wolock and others, 2004):

1. Landscapes with impermeable soils and impermeable bedrock.

2. Landscapes with impermeable soils and permeable bedrock.

3. Landscapes with permeable soils and impermeable bedrock.

4. Landscapes with permeable soils and permeable bedrock.

This classification of relative bedrock permeability is based on lithologic groups of principal aquifers and bedrock permeability classes. Areas with no principal bedrock aquifer were assigned the lowest permeability class (Wolock and others, 2004). The classification did not consider the shallow aquifers of glacial origin in the Midwest.

\section{EXPLANATION}

Landscape categories

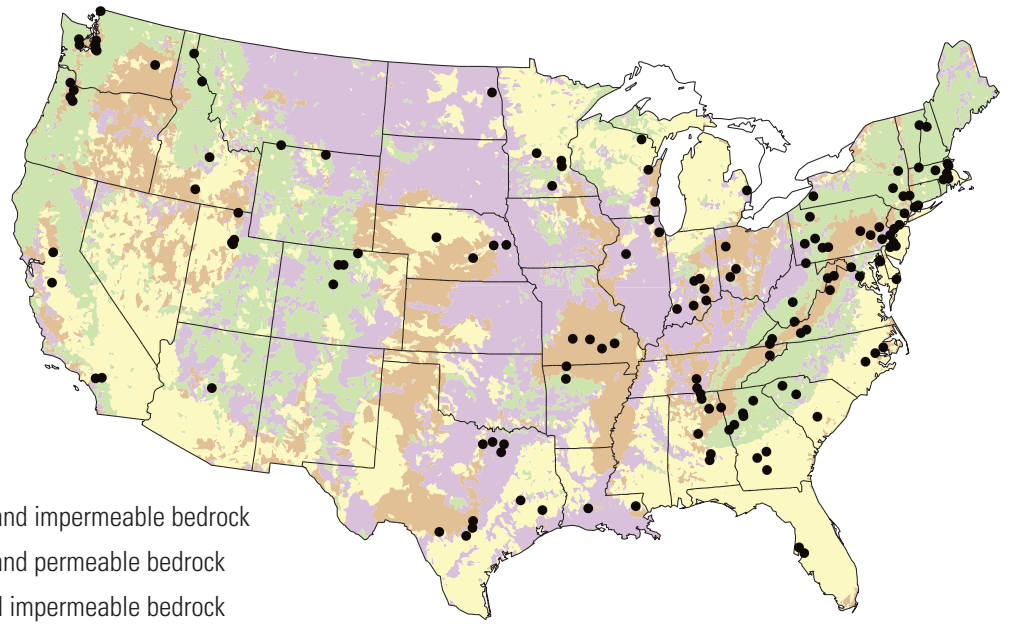

Impermeable soils and permeable bedrock

Permeable soils and impermeable bedrock

- $\quad$ Stream sampling site

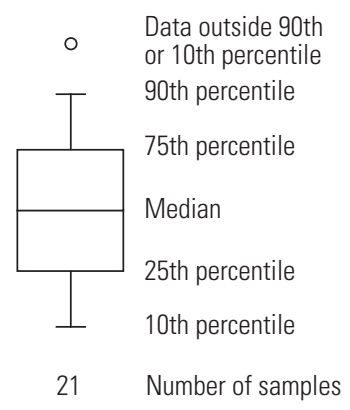

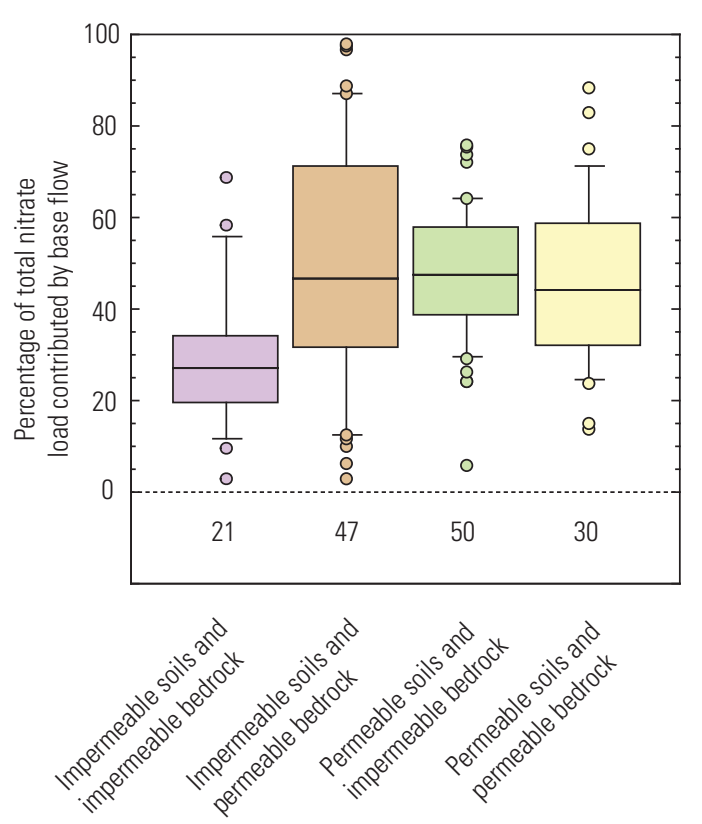

Figure 5-5. The proportion of the total nitrate load in streams attributed to nitrate in base flow was lowest in landscapes where both soils and bedrock are impermeable, and signific antly higher in areas with more permeable soils or bedrock. These impermeable areas could be most responsive to nutrient management practices designed to reduce nutrient transport to streams by runoff. 


\section{The Influence of Groundwater on Nitrogen Delivery to Chesapeake Bay}

Groundwater discharge to stream channels contributes a significant amount of flow and nitrogen to streams in the Chesapeake Bay watershed, and is therefore an important pathway for nitrogen to reach the Bay. Groundwater contributes more than one-half ( 54 percent) of the total annual flow of streams in the Chesapeake Bay watershed, with a range in different streams of 16 to 92 percent. The groundwater nitrate load contributes about one-half (48 percent) of the total annual nitrogen load of streams entering the Bay, with a range of 17 to 80 percent in different streams (Bachman and others, 1998).

The underlying rock type and physiographic province, described by "hydrogeomorphic regions" or HGMRs, influence groundwater contributions to total streamflow (fig. 5-6A). Groundwater contributions to total streamflow are highest in the carbonate rocks of the Valley and Ridge HGMR, where permeable soils and generally low relief promote infiltration, and a high degree of fracturing and solution-enlarged fractures transmit large quantities of water; in the Coastal Plain HGMRs, where well-drained soils and flat topography promote infiltration into shallow aquifers; and in the Piedmont Crystalline and Blue Ridge Crystalline HGMRs, where a permeable mantle of colluvium and regolith generally covers the slopes of hills and acts as a reservoir for groundwater (Bachman and others, 1998). Groundwater contributions to total streamflow are lowest in the Mesozoic Lowland Siliciclastic HGMR, where poorly drained soils and (or) steeper topography favor surface runoff over infiltration, and the bedrock has low fracture connectivity. In the four HGMRs with sufficient numbers of sites and data for statistical analysis, groundwater contributions to the total nitrate load are high in the Piedmont Crystalline HGMR and low in the Appalachian Plateau Siliciclastic HGMR (fig. 5-6B). In general, the highest groundwater nitrate yields are in HGMRs with higher amounts of agricultural land use, while the lowest groundwater nitrate yields are in HGMRs with highest percentages of forested land use (Bachman and others, 1998).

The age of groundwater in shallow aquifers in the Chesapeake Bay watershed ranges from modern (less than 1 year) to more than 50 years, with a median age of 10 years (Lindsey and others, 2003). If nitrate is assumed to move with groundwater, the age of groundwater can be used to estimate the rates of nitrate transport-in this case, nitrate in groundwater may have a transport time of years to decades, with a median transport time of about 10 years. The slow movement of groundwater relative to that of surface water has a significant impact on the total time it takes for nitrogen to move through the watershed and reach the Chesapeake Bay, and thereby creates a lag time between the implementation of management actions and the reduction of nitrogen loads in streams in the Chesapeake Bay watershed (Phillips and Lindsey, 2003).

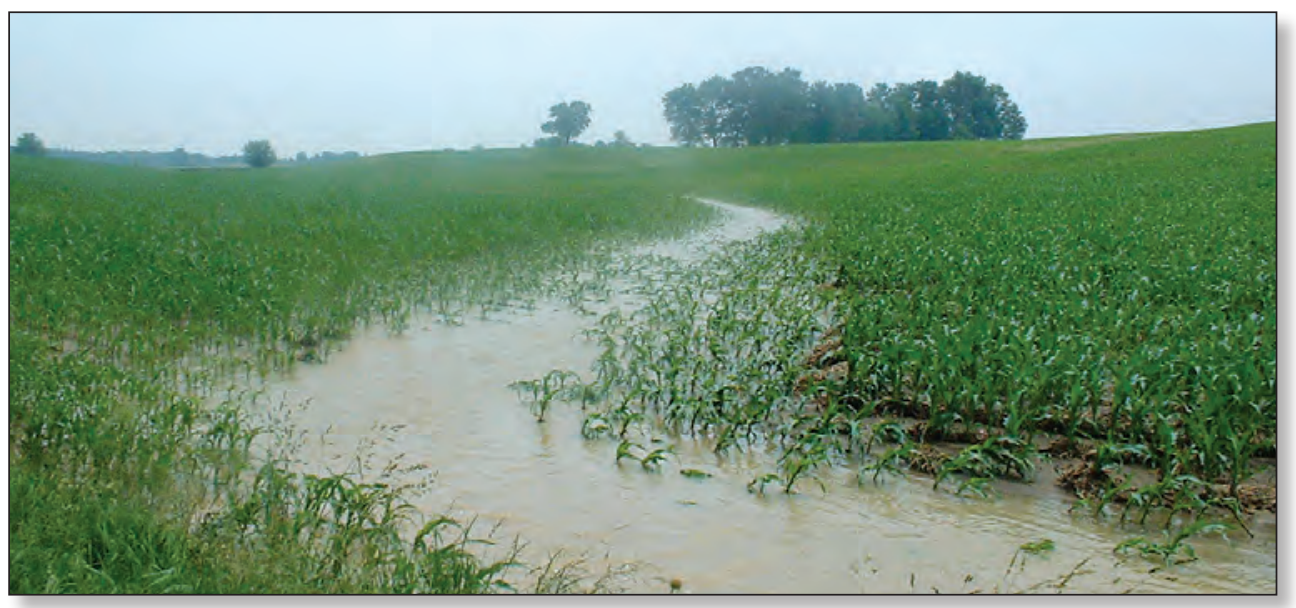

Overland flow is the dominant source of streamflow in landscapes in which both soils and bedrock are impermeable. Photograph by John T. Wilson, U.S. Geological Survey. 
A.

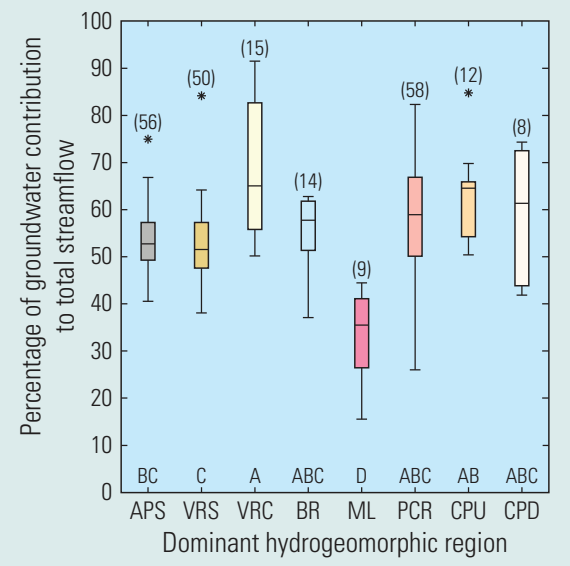

B.

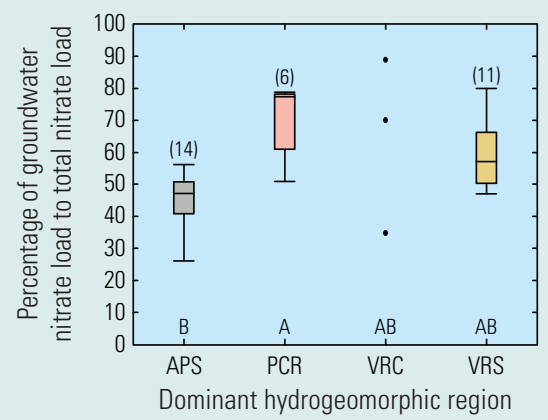

\section{EXPLANATION}

(12) Number of observations

* Outlier data value less than or equal to 3 times and greater than 1.5 times the interquartile range outside the quartile

Tata value less than or equal to 1.5 times the interquartile range outside the quartile

75th percentile

Median

25th percentile

ABC Non-parametric Tukey test (Medians with the same letter are not significantly different.)

\section{Hydrogeomorphic regions}

APC $\square$ Appalachian Plateau Carbonate

APS $\square$ Appalachian Plateau Siliciclastic

VRC $\square$ Valley and Ridge Carbonate

VRS $\square$ Valley and Ridge Siliciclastic

BR $\square$ Blue Ridge Crystalline

ML $\square$ Mesozoic Lowland Siliciclastic

PCA $\square$ Piedmont Carbonate

PCR $\square$ Piedmont Crystalline

CPD $\square$ Coastal Plain Dissected Upland

CPL $\square$ Coastal Plain Lowland

CPU $\square$ Coastal Plain Undissected Upland

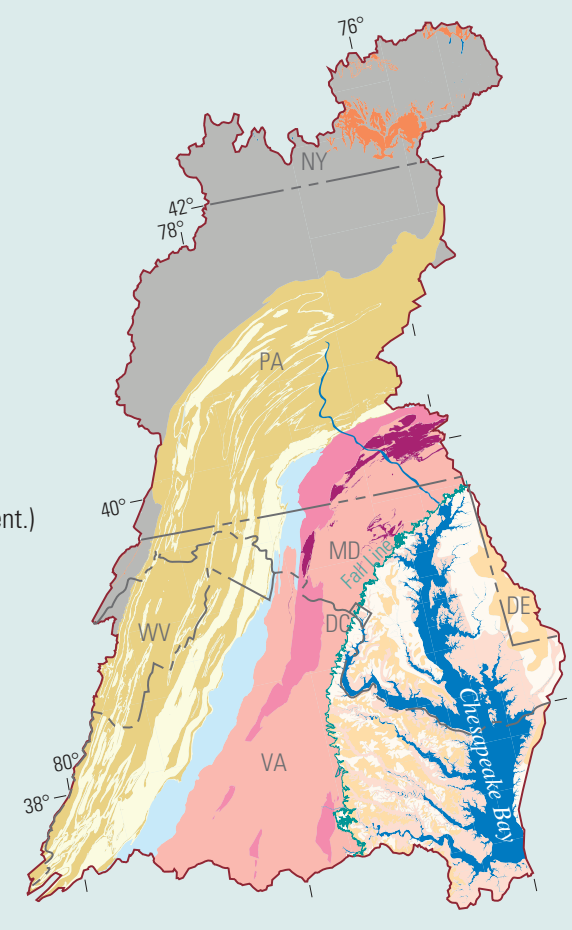

Figure 5-6. Groundwater supplies a significant amount of water and nitrogen to streams in the Chesapeake Bay watershed and is therefore an important pathway for nitrogen to reach the Bay. Groundwater contributions to total streamflow are highest in the carbonate rocks of the Valley and Ridge hydrogeomorphic region (VRC), where permeable soils and generally low relief promote infiltration and solution-enlarged fractures transmit large quantities of water, and are lowest in the Mesozoic Lowland Siliciclastic hydrogeomorphic region (ML), where poorly drained soils and (or) steeper topography favors surface runoff over infiltration, and the bedrock has low fracture connectivity $(A)$. In the four hydrogeomorphic regions with enough sites for statistical analysis, groundwater contributions to the total nitrate load are high in the Piedmont Crystalline hydrogeomorphic region (PCR) and low in the Appalachian Plateau Siliciclastic hydrogeomorphic region (APS) (B). (Modified from Bachman and others, 1998.)

A significantly lower proportion of the nitrate load is derived from base flow at sites in areas with impermeable soils and impermeable bedrock than in the other landscapes, although there is a large amount of variability within each group (ig. 5-5). Landscapes in which both soils and bedrock are impermeable are those in which overland flow is the dominant source of flow in streams. Landscapes with these characteristics are common in the productive agricultural land in the Corn Belt and Great Plains. These areas, as well as similar areas where most of the nitrate load in streams is not delivered by base flow, could be most responsive to nutrient management practices designed to reduce nutrient transport to streams by runoff. Conversely, in areas where a large proportion of the stream nitrate load is derived from base flow, and the base flow is derived primarily from groundwater, changes in nutrient management will have less impact on stream loads until nitrate concentrations in the groundwater reaching the stream decrease. In these areas, slow rates of groundwater flow means that reductions in stream nitrate load could lag behind implementation of management measures for years to decades (see Chapter 8, Changes in Nutrient Concentrations: Past and Predicted). 


\section{Nitrate Concentration in Base Flow and Shallow Groundwater}

The mean annual nitrate concentrations in base flow were compared with the median nitrate concentrations in shallow groundwater samples in the same setting to illustrate the potential effect of the movement of shallow groundwater to streams (Spahr and others, 2010). Nitrate concentrations in groundwater typically were similar to or greater than nitrate concentrations in base flow (fig. 5-7). Areas where the contrast between elevated concentrations of nitrate in groundwater and low concentrations in base flow are greatest are commonly underlain by both permeable soils and permeable bedrockconditions that enhance infiltration of water. Most of these areas also have groundwater that is predominantly oxic - the chemical environment in which nitrate is stable. These characteristicshigh infiltration and oxic conditions - favor nitrate transport and persistence in groundwater. The lack of correspondingly high concentrations in the base flow of the paired surface-water sites may have multiple causes. In some settings, there has not been sufficient time for highnitrate shallow groundwater to migrate to the nearby stream. In these cases, stream nitrate concentrations lag behind those in the shallow groundwater, and concentrations may increase in the future as more high-nitrate groundwater reaches the stream. Alternatively, at some sites, chemical processes may be acting to rapidly remove nitrate as water moves from the aquifer into the stream channel. For example, high denitrification rates in riparian sediments along Fishtrap Creek, Washington, remove nitrate from groundwater before it enters the stream (Tesoriero and others, 2000) (fig. 5-7).

Three sites where surface-water concentrations of nitrate were elevated, yet median groundwater concentrations were low, occur in areas with low infiltration due to impermeable soils and impermeable bedrock (see oval on left side of graph in fig. 5-7).
These sites are in agricultural or mixed landuse areas in the Midwest with large nitrogen input from fertilizer, and with tile drainage systems. In these areas, nitrate concentrations are highly variable in groundwater near the water table (ranging from less than 0.05 to $17 \mathrm{mg} / \mathrm{L}$ ), but consistently less than $0.05 \mathrm{mg} / \mathrm{L}$ in reduced groundwater from greater than 25 feet below the water table. The high nitrate concentrations in the base flow samples at these sites likely represent a blend of shallow high-nitrate groundwater and deeper lownitrate groundwater, whereas low median concentrations for groundwater reflect the greater frequency of samples with low nitrate concentrations. Despite the contribution of some nitrate from groundwater during base flow, at these sites overland flow and tile drainage are the predominant sources of streamflow and nitrate load.

Nitrate concentrations were elevated in both base flow and shallow groundwater in the vicinity of Tulpehocken Creek (fig. 5-7). This site is in an agricultural area of eastern Pennsylvania with highly permeable underlying bedrock (Fischer and others, 2004). Manure from livestock operations is commonly applied to farm fields in this area. Lindsey and others (1998) describe the rapid infiltration of nitrate from fertilizer and manure to groundwater in other agricultural areas of Pennsylvania with similar shallow and highly permeable bedrock. The correspondence between groundwater and base flow nitrate concentrations suggests a fairly rapid - and unattenuated - transport of nitrate in groundwater to this stream.

Although analysis of national-scale data and potential governing processes demonstrate some of the relations between nitrate concentrations in base flow and shallow groundwater, there is a large amount of variability among sites. Site-specific study is often required to completely understand the source of nitrate to a stream during base flow, and in particular, the role of groundwater. 


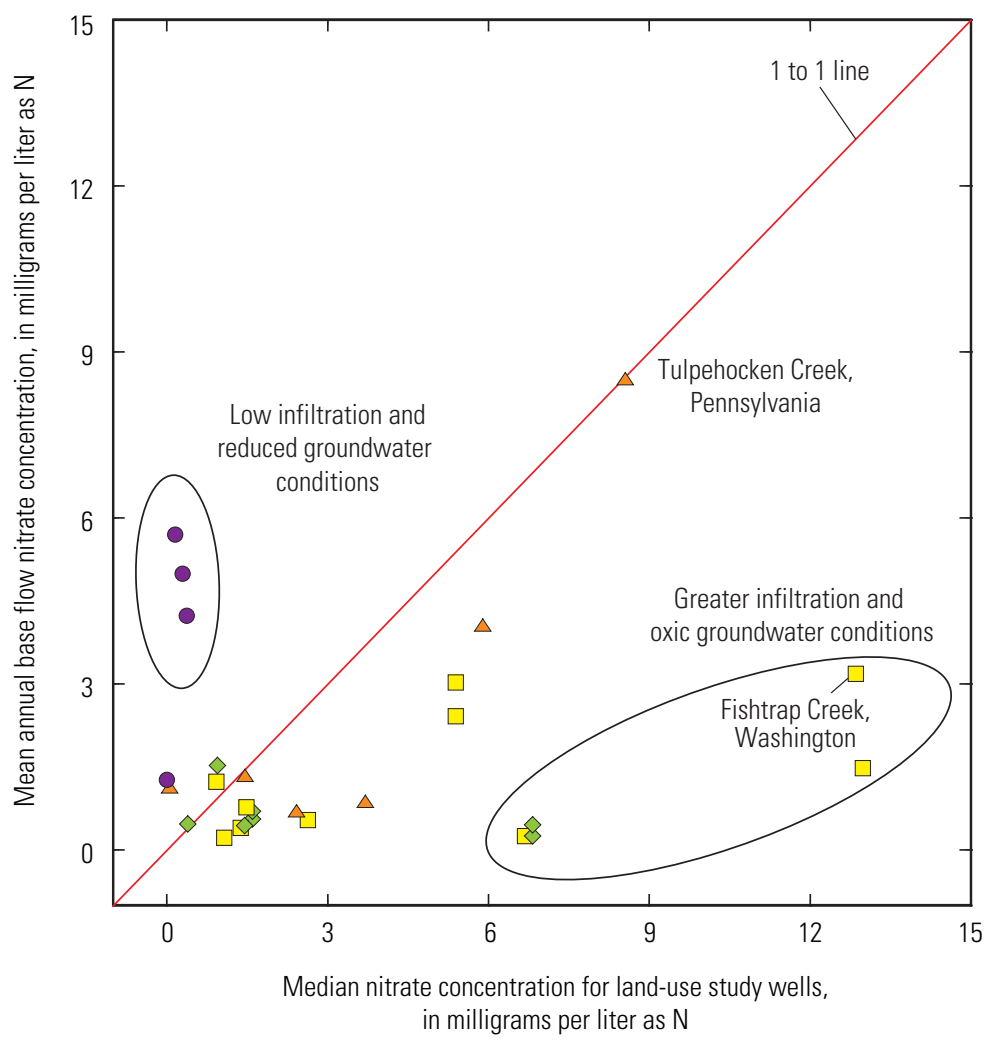

EXPLANATION

Landscape categories

- Impermeable soils and impermeable bedrock

$\triangle \quad$ Impermeable soils and permeable bedrock

$\diamond \quad$ Permeable soils and impermeable bedrock

$\square \quad$ Permeable soils and permeable bedrock

Figure 5-7. Nitrate concentrations in groundwater are often greater than nitrate concentrations in base flow. Sites with particularly high nitrate concentrations in groundwater, but low nitrate concentrations in streams, have characteristics-high infiltration and oxic conditions-that favor nitrate transport and persistence in groundwater. Shallow groundwater with high nitrate concentrations may not have had time to reach these streams and (or) chemical processes may be removing nitrate as water moves from the aquifer into the stream channel. Conversely, sites where nitrate concentrations in groundwater are very low, yet have elevated nitrate concentrations in surface water, occur where overland flow is an important source of streamflow (areas with low infiltration due to impermeable soils), and where there are reduced conditions in groundwater (low dissolved oxygen). 


\section{Nitrate Removal across the Groundwater-Surface-Water Interface}

The capability of streamside riparian zones and streambeds to reduce nitrate concentrations in streams is of considerable interest to agricultural land managers. Nitrate can be removed from nitrate-rich groundwater as it moves through the riparian zone to the stream (fig. 5-8), and nitrate can be removed from stream water that flows through sediments in the streambed. Sediments in both of these environments can contain appreciable amounts of organic carbon and other reactants that support bacterial denitrification. In addition, the vegetation in riparian buffer zones can take up nitrate, an important plant nutrient. These processes have been studied in a variety of land-use and hydrologic settings by intensive instrumentation of this highly dynamic environment (Puckett, 2004; Duff and others, 2008; Puckett and others, 2008).

Denitrification and plant uptake in riparian zones can remove 100 percent of nitrate in discharging groundwater in some environmental settings, but they may be relatively ineffective in others (Puckett, 2004). The removal of nitrate from groundwater is promoted by a combination of hydrogeologic, biological, and biogeochemical processes (table 5-1). Fine-grained sediments and low gradients result in slow flow rates that allow more time for denitrification to take place. If the surficial sediments are primarily silt and clay, however, the fine-grained sediments can form a confining layer that forces groundwater to flow below the biologically active zone and may result in less nitrate removal. Coarse-grained sediments and high groundwater gradients may force groundwater to flow through the riparian zone faster than the biological processes can remove nitrate. In addition, if surface runoff occurs or if shallow groundwater is routed through tile drains and ditches, riparian zones can be bypassed and nitrate-rich water is discharged directly to streams.

Riparian zones appear to be most effective in settings with thin surficial aquifers, underlain by a shallow confining layer, and with organic-rich soils that extend down to the confining layer. This combination of factors forces groundwater to flow through the biologically reactive portions of the aquifer and promotes nitrate removal. For example, in the Albemarle-Pamlico Drainage Basin (fig. 5-9), high concentrations of nitrate are completely removed from groundwater discharging from a surficial aquifer through a narrow zone adjacent to and beneath Middle Swamp, North

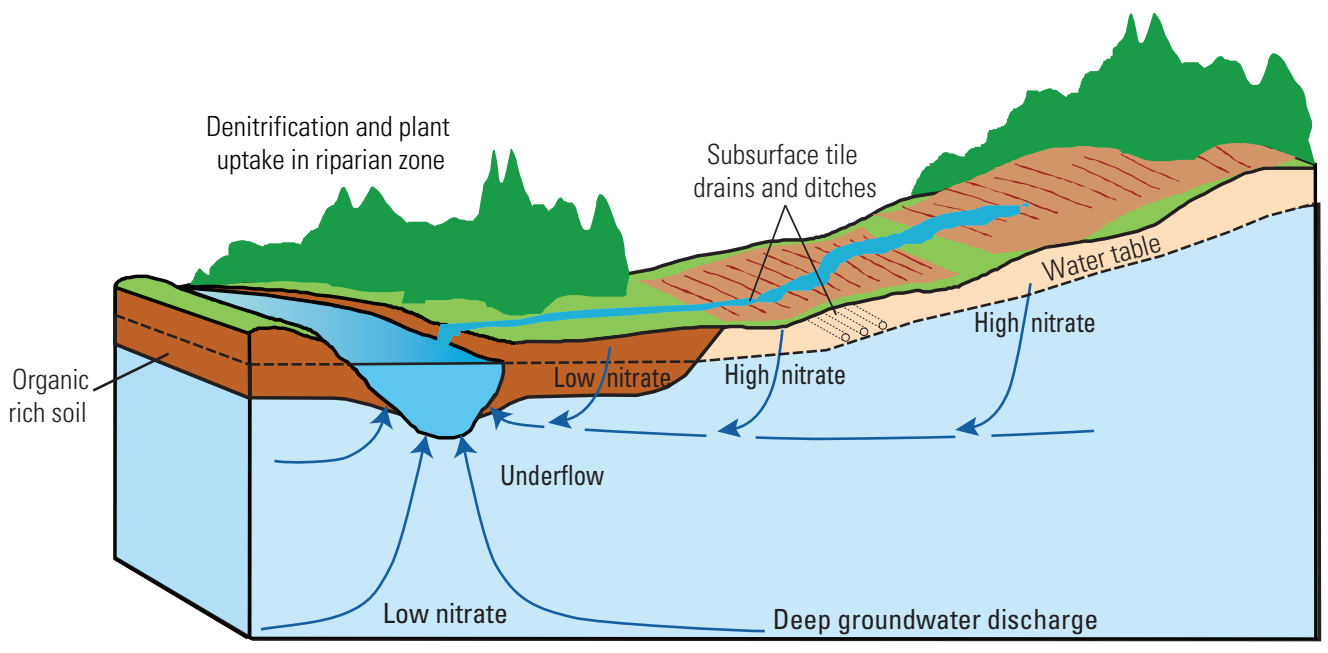

Figure 5-8. Nitrate may be removed from groundwater by various means before it discharges to streams. It may be lost through denitrification in the aquifer if sufficient organic carbon is present, or it may be taken up by plants in the riparian zone. However, nitrate may be delivered directly to streams in water intercepted by tile drains and ditches. In aquifers in which denitrification does not occur, nitrate-rich water may flow beneath the organic-rich, reducing soils of the riparian zone and discharge to streams. This nitrate-rich water may be diluted by nitrate-poor groundwater that recharged through the riparian zone, or by deeper, older groundwater that recharged prior to widespread use of fertilizers. 
Table 5-1. Factors that promote transport or removal of nitrate in riparian zones and streambeds.

\begin{tabular}{|c|c|c|c|}
\hline \multicolumn{2}{|c|}{$\begin{array}{l}\text { Factors and Processes that } \\
\text { Promote Nitrate Transport }\end{array}$} & \multicolumn{2}{|c|}{$\begin{array}{l}\text { Factors and Processes that } \\
\text { Promote Nitrate Removal }\end{array}$} \\
\hline Factors & $\begin{array}{l}\text { Hydrogeologic and } \\
\text { biogeochemical processes }\end{array}$ & Factors & $\begin{array}{l}\text { Hydrogeologic and } \\
\text { biogeochemical processes }\end{array}$ \\
\hline $\begin{array}{l}\text { Well drained soils } \\
\text { Karst terrain }\end{array}$ & $\begin{array}{l}\text { Rapid recharge to the } \\
\text { water table limits nitrate } \\
\text { removal by plant uptake or } \\
\text { denitrification. }\end{array}$ & $\begin{array}{l}\text { Poorly drained soils } \\
\text { - Hydric soils } \\
\text { - Shallow water table }\end{array}$ & $\begin{array}{l}\text { Hydric soils are saturated } \\
\text { (typically, by a shallow water } \\
\text { table) allowing oxygen to become } \\
\text { depleted and denitrifying bacteria } \\
\text { to convert nitrate to nitrogen gas. }\end{array}$ \\
\hline $\begin{array}{l}\text { Oxic groundwater } \\
\text { - Low carbon soils } \\
\text { - Absence of reduced } \\
\text { minerals that support } \\
\text { denitrification }\end{array}$ & $\begin{array}{l}\text { Denitrification does not } \\
\text { occur and nitrate is } \\
\text { transported with minimal } \\
\text { loss. }\end{array}$ & $\begin{array}{l}\text { Low oxygen groundwater } \\
\text { - Carbon-rich soils, aquifer } \\
\text { materials, and streambeds } \\
\text { - Presence of reduced } \\
\text { minerals that support } \\
\text { denitrification }\end{array}$ & $\begin{array}{l}\text { Carbon and reduced minerals } \\
\text { provide the conditions necessary } \\
\text { for bacteria to deplete dissolved } \\
\text { oxygen. Denitrifying bacteria can } \\
\text { then convert nitrate to nitrogen } \\
\text { gas. }\end{array}$ \\
\hline $\begin{array}{l}\text { Short groundwater residence times } \\
\text { - Coarse-grained sediment } \\
\text { - High groundwater gradient } \\
\text { - Tile drains and ditches }\end{array}$ & $\begin{array}{l}\text { Groundwater moves } \\
\text { rapidly through aquifers } \\
\text { and streambeds, limiting } \\
\text { contact time with aquifer } \\
\text { materials that support } \\
\text { denitrification, thus } \\
\text { allowing nitrate to persist } \\
\text { and discharge to surface } \\
\text { waters. Subsurface tile } \\
\text { drains and ditches intercept } \\
\text { shallow groundwater } \\
\text { and shunt it to streams } \\
\text { before it can enter the } \\
\text { groundwater system. }\end{array}$ & $\begin{array}{l}\text { Long residence times } \\
\text { - Fine-grained sediment } \\
\text { - Low groundwater gradient }\end{array}$ & $\begin{array}{l}\text { Groundwater moves slowly } \\
\text { through aquifers and streambeds, } \\
\text { increasing contact time with } \\
\text { aquifer materials that support } \\
\text { denitrification. Even with slow } \\
\text { denitrification rates, long residence } \\
\text { times may allow most nitrate to be } \\
\text { removed. }\end{array}$ \\
\hline
\end{tabular}

Carolina (Tesoriero and others, 2005). Where these conditions do not exist, nitrate-laden groundwater can pass beneath the reactive soil layers of the riparian zone and discharge directly into streams; this outcome was seen in some streams in the Atlantic Coastal Plain including streams in New Jersey (Kauffman and others, 2001), Maryland (Böhlke and Denver,
1995), and South Carolina (Puckett and Hughes, 2005). Sites where high-nitrate water in tile drains and ditches bypasses riparian zones include Cow Castle Creek in South Carolina (Puckett and Hughes, 2005), Plum Tree Branch in North Carolina (Tesoriero and others, 2005), and Leary Weber Ditch in Iowa (Baker and others, 2006). 


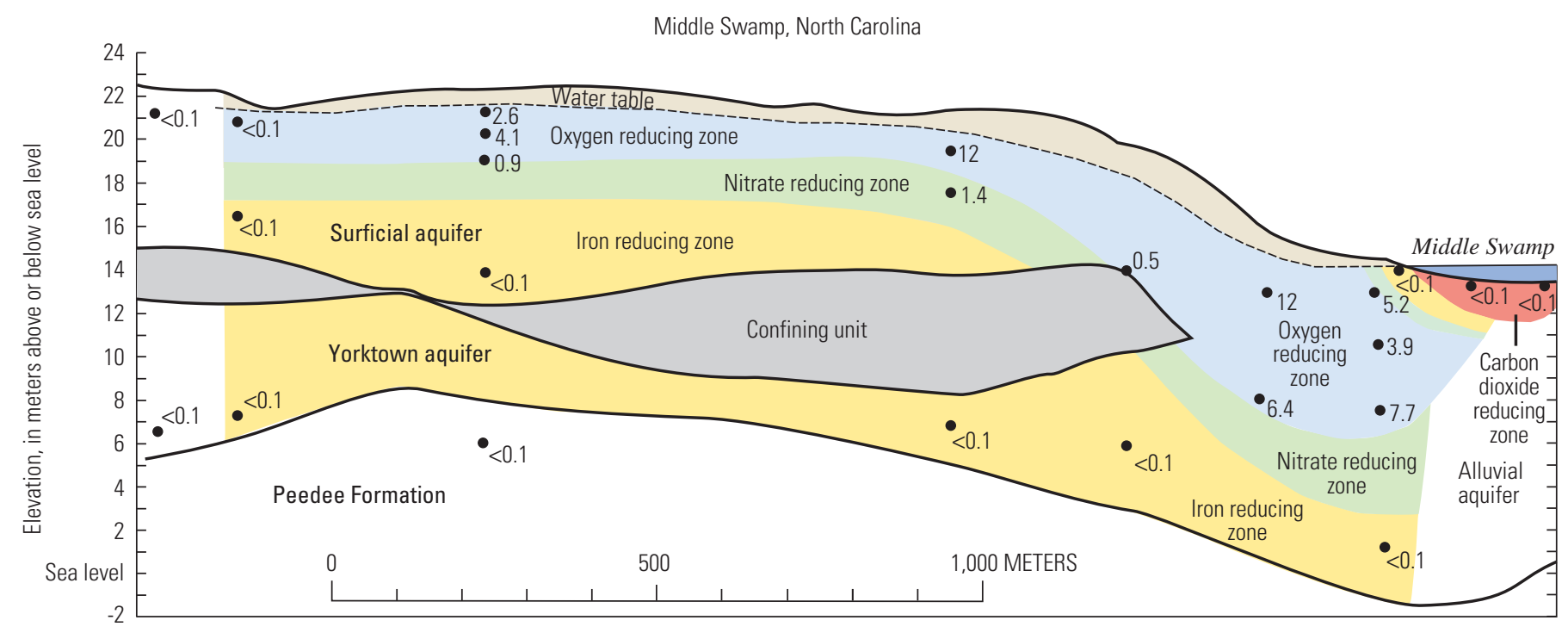

EXPLANATION

- Sampling point

4.1 Nitrate concentration, in milligrams per liter as $\mathrm{N}$

Figure 5-9. Nitrate is removed by natural processes from shallow groundwater in the narrow riparian zone and streambed before it discharges into Middle Swamp in North Carolina. Zones of oxygen reduction, nitrate reduction, iron reduction, and carbon dioxide reduction are shown along with nitrate concentrations at groundwater sampling locations. (Modified from Tesoriero and others, 2005.)

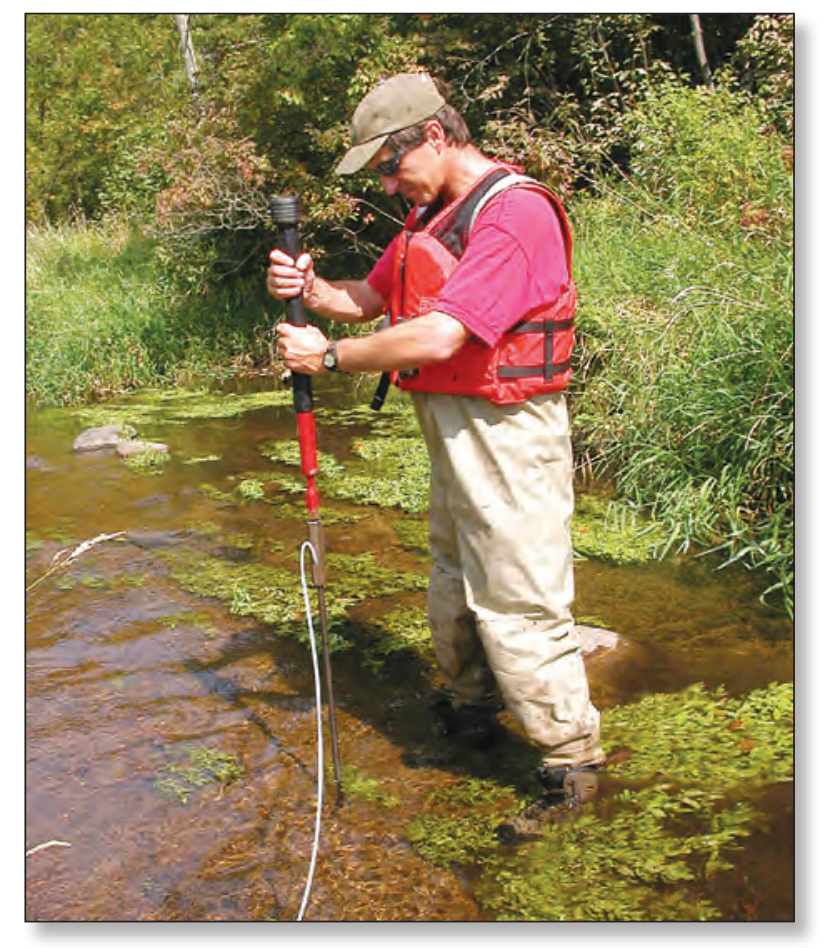

Shallow sampling points were installed in streambeds to assess the chemistry of groundwater discharging to streams. Photograph by U.S. Geological Survey.
Nitrate removal also can take place in an area of active exchange between groundwater and surface water in the streambed known as the hyporheic zone. Numerous hydrogeologic and biogeochemical processes can remove nitrate from stream water that enters the hyporheic zone, as well as from groundwater discharging into the streambed (table 5-1). In the Merced River in California (fig. 5-10), deep groundwater with nitrate concentrations of about $5 \mathrm{mg} / \mathrm{L}$ entered the middle of the streambed. This nitrate was then reduced by denitrification in the hyporheic zone as well as by mixing with lower-nitrate groundwater that flowed in laterally (fig. 5-10) and surface water that entered the hyporheic zone from the stream (Puckett and others, 2008).

Movement of surface water and (or) groundwater into the hyporheic zone is governed by coarse-grained bed materials and the difference in hydraulic head (the sum of elevation head plus pressure head) between surface water and groundwater. For example, if the hydraulic head of groundwater flowing into the hyporheic zone is greater than that of surface water, then the groundwater will dominate in the zone. The hydraulic head differential and streambed material coarseness also control the residence time of water in the hyporheic zone, which can range from a few hours to several weeks, with longer residence times leading to more complete nitrate removal. In addition, the capability of hyporheic zones to remove nitrate from surface water and groundwater may be limited in areas of fine-grained sediments, which limit water movement into the streambed (Puckett and others, 2008). 


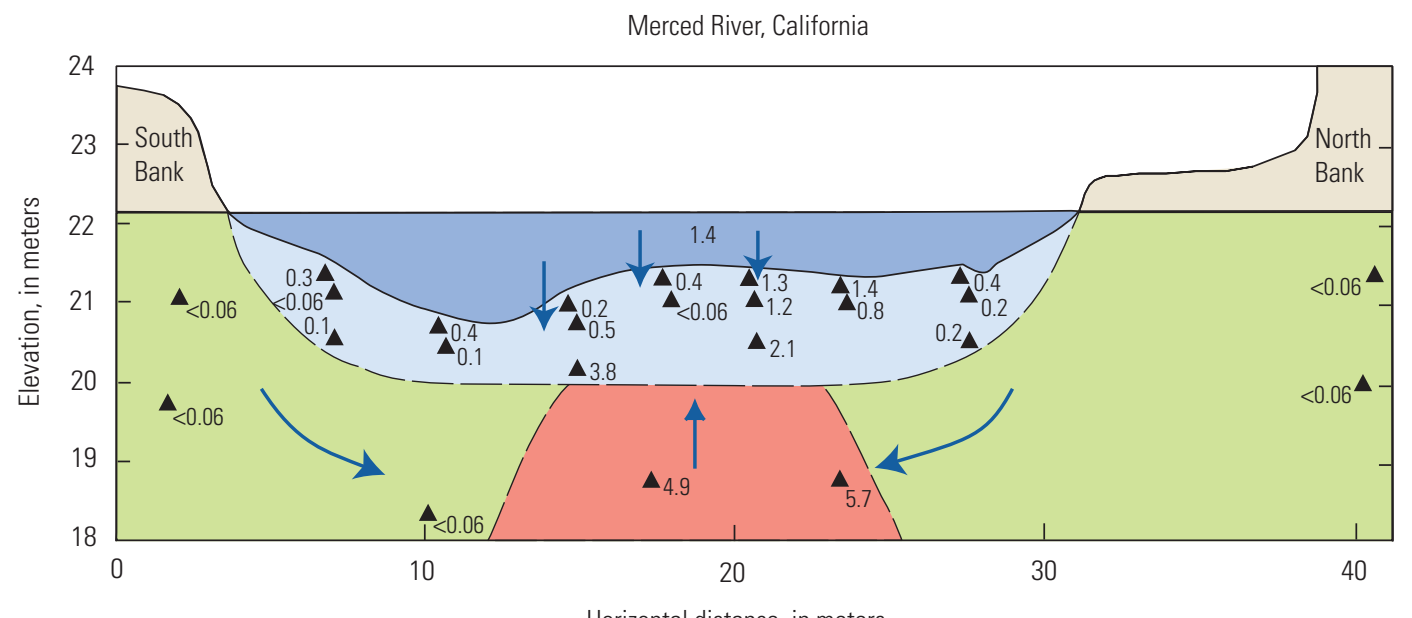

EXPLANATION

$\begin{array}{llll}\square & \text { Merced River } & \boldsymbol{\Delta} & \text { Sampling point } \\ \square & \text { Hyporheic zone } & 2.1 & \text { Nitrate concentration, } \\ \square & \text { High nitrate groundwater } & \text { in milligrams per liter as N } \\ \square \quad \text { Low nitrate groundwater } & \square & \text { Direction of flow }\end{array}$

Figure 5-10. In the Merced River, California, deep groundwater with nitrate concentrations of about 5 milligrams per liter enters the central portion of the streambed. Nitrate concentrations are then reduced as a result of denitrification and dilution by mixing with other groundwater having little or no nitrate, or mixing with stream water that has entered the hyporheic zone.

Under the right conditions, therefore, the hyporheic zone may serve as a "backup" for riparian zones that are inefficient at removing nitrate from groundwater. However, in areas where the rate of groundwater flow exceeds the denitrification rate, nitrate may pass through the hyporheic zone and contribute to stream-water loads. In a study of five sites across the country, it was found that in most low-gradient agricultural streams, little surface water entered the hyporheic zone except during high-flow periods, and thus groundwater discharge dominated in the hyporheic zone (Duff and others, 2008; Essaid and others, 2008; Puckett and others, 2008). These studies also showed that hyporheic processes removed from 45 to 75 percent of groundwater nitrate before it discharged to surface water. Once water was in the streams, however, biological processes removed less than 5 percent of nitrate, minimally reducing downstream loads.

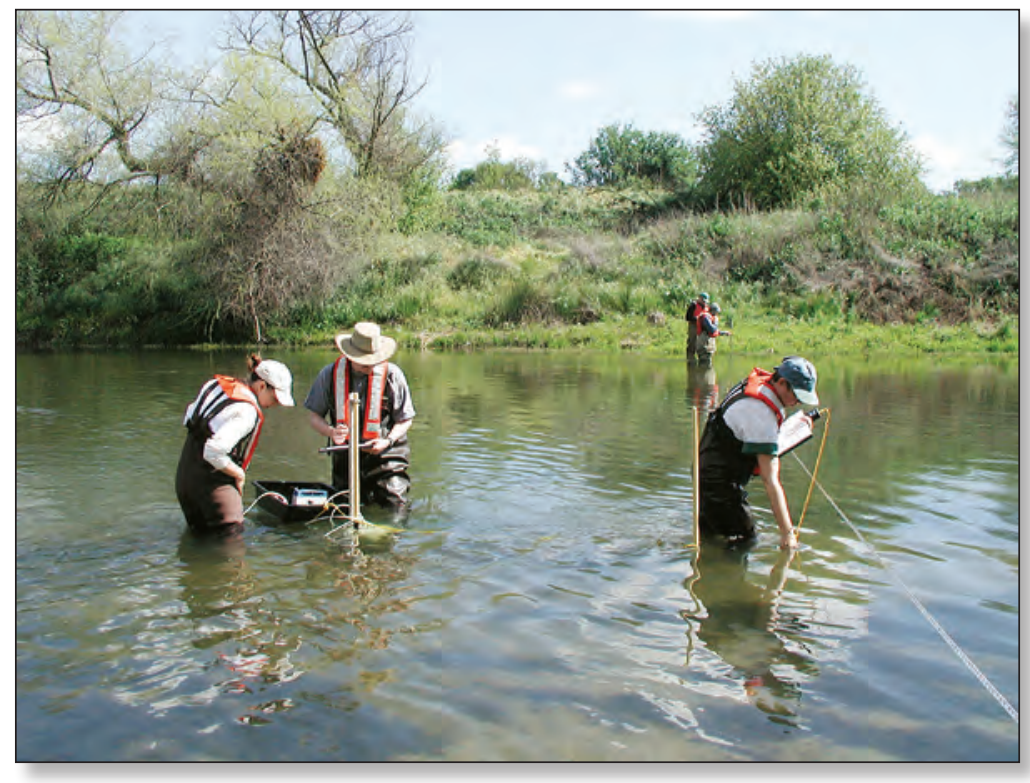

The nitrate load in groundwater discharging to a stream (being measured at left) can make a substantial contribution to the total nitrate load in a stream (being measured at right). Photograph by Joseph Domagalski, U.S. Geological Survey. 


\section{Groundwater Contribution of Phosphorus to Streams}

The generally low concentrations of phosphorus in groundwater suggest that input of phosphorus to streams from groundwater is modest. A detailed analysis of phosphorus transport to five streams in predominantly agricultural watersheds showed that groundwater contributions to the instream phosphorus concentrations usually were minor in these areas (Tesoriero and others, 2009). However, geologic sources of phosphorus in an aquifer, coupled with chemical conditions favorable to phosphorus transport, can result in high groundwater inputs of phosphorus to streams. In the Albemarle-Pamlico Drainage Basin in North Carolina, high phosphorus concentrations in many streams result from discharge of groundwater with naturally high phosphorus concentrations (Spruill and others, 1998). Documenting this natural source of phosphorus has increased the accuracy of Total Maximum Daily Loads (TMDLs) calculated for some North Carolina streams. Analyses of samples collected from 25 sites during low-flow conditions in August and September 1995 indicate that dissolved phosphorus concentrations in groundwater were higher than those in streams at most sites throughout the Coastal Plain (fig. 5-11). The median dissolved phosphorus concentration in groundwater was $0.2 \mathrm{mg} / \mathrm{L}$. Instream concentrations of dissolved phosphorus at 25 sites were significantly correlated to the concentrations in groundwater discharging to the streams, and stream concentrations decreased with increasing streamflow, indicating that groundwater discharge and point sources are the primary sources of dissolved phosphorus in the stream. In some areas, high phosphorus concentrations in groundwater are associated with swampy areas with decomposing organic matter, where groundwater or water in the streambed is geochemically reduced. In other areas, the streams have cut through deeper geologic formations that contain relatively soluble phosphate minerals (Tesoriero and others, 2005).

Similarly, groundwater contributes phosphorus to the Tualatin River, Oregon, during summer low-flow conditions (Kelly and others, 1999). In spite of improvements in wastewater treatment and land management practices in this watershed, the high concentrations of phosphorus contributed from groundwater make it difficult to meet the TMDL. Dissolved phosphorus concentrations ranged from $0.1 \mathrm{mg} / \mathrm{L}$ in shallow groundwater to a maximum of more than $2 \mathrm{mg} / \mathrm{L}$ in deep groundwater. Groundwater discharge accounted for nearly one-fourth of the total phosphorus input to the river. The primary source of high phosphorus in groundwater is the decomposition of organic material at the interface between older valley-fill sediments and overlying catastrophic flood deposits (fig. 5-12). High phosphorus concentrations are contributed to the stream at locations where deep groundwater discharges along long flow paths, or where the river or its major tributaries cut through this interface between the two major geologic strata. 


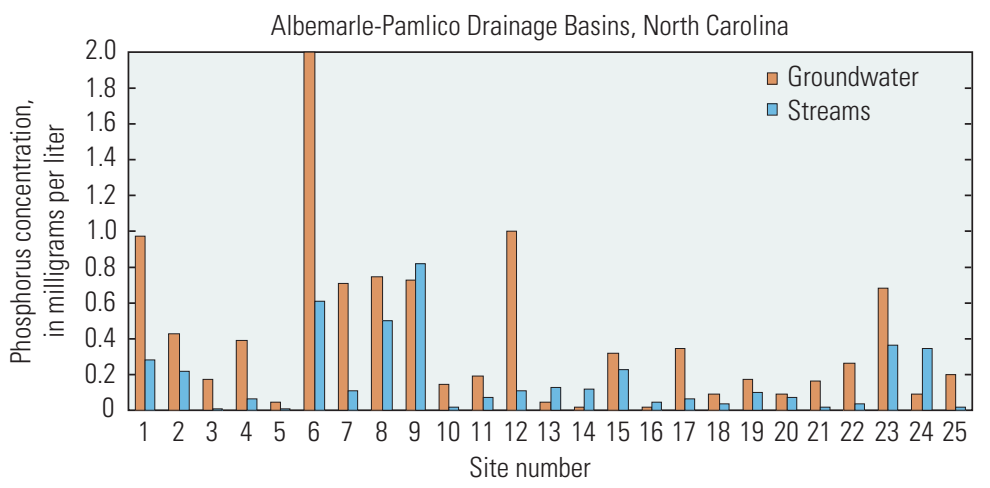

Figure 5-11. Dissolved phosphorus concentrations in groundwater were higher than those in streams at most sites throughout the Coastal Plain in the Albemarle-Pamlico Drainage Basin, North Carolina. Concentrations in streams and groundwater discharging to the streams were significantly correlated, indicating that the groundwater was a significant source of phosphorus to the streams at low flow (Spruill and others, 1998).

Tualatin River, Oregon

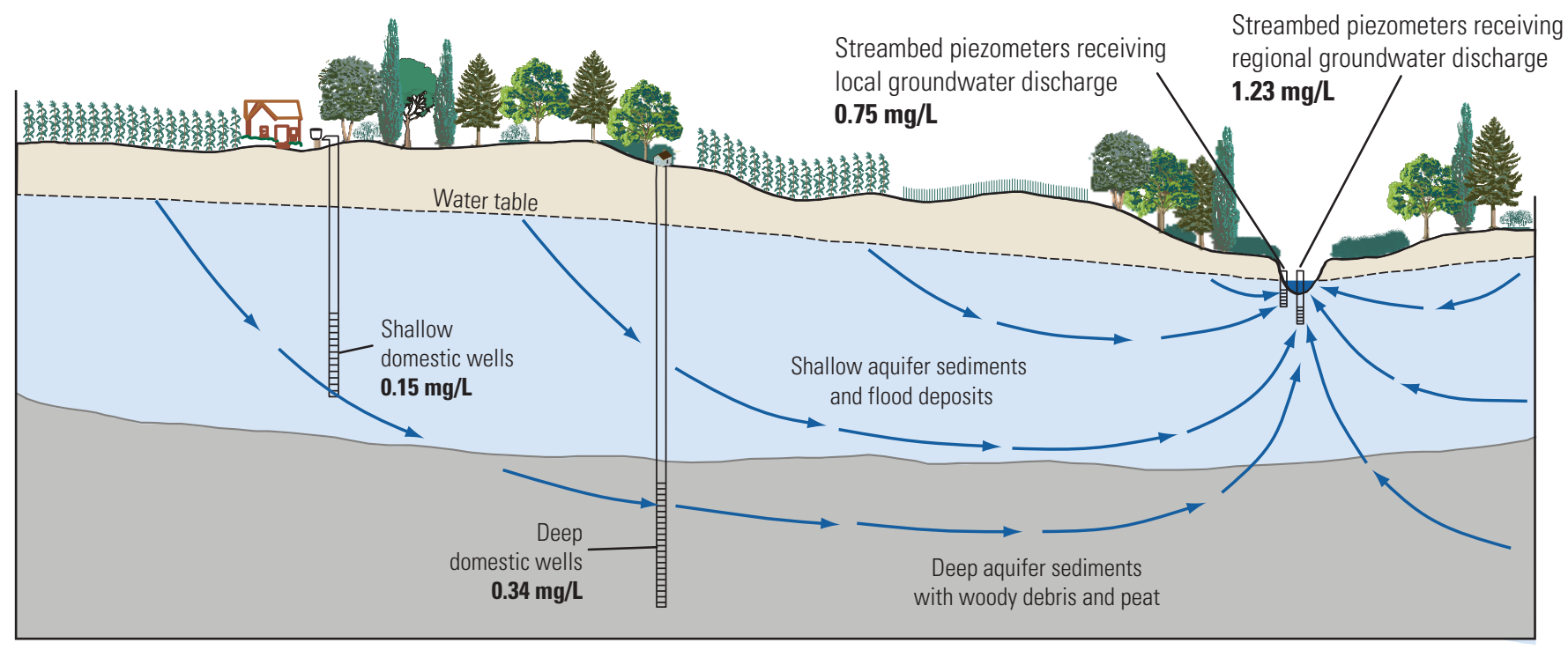

Median total phosphorus concentrations, in milligrams per liter (mg/L), are in bold text.

Figure 5-12. Groundwater contributes phosphorus to the Tualatin River, Oregon, during summer low-flow conditions (Kelly and others, 1999). The primary source of high phosphorus in groundwater is the decomposition of organic material. 
This page intentionally left blank 
Potential for Effects on Human Health

\section{Introduction}

Elevated concentrations of nutrients, particularly nitrate, in drinking water may have both direct and indirect effects on human health. One direct effect of ingestion of high levels of nitrate is methemoglobinemia, a disorder in which the oxygen-carrying capacity of the blood is compromised; the USEPA Maximum Contaminant Level (MCL) of $10 \mathrm{mg} / \mathrm{L}$ of nitrate for drinking water was adopted to protect people, mainly infants, against this problem. High nitrate concentrations in drinking water also have been implicated in other human health problems, including specific cancers and reproductive problems, but more research is needed to corroborate these associations (see sidebar, Nitrate in Drinking Water: Potential Health Effects). The indirect effects of nutrient enrichment of surface waters on human health are many and complex, including algal blooms that release toxins and the enhancement of populations of disease-transmitting insects, such as mosquitoes (Townsend and others, 2003).

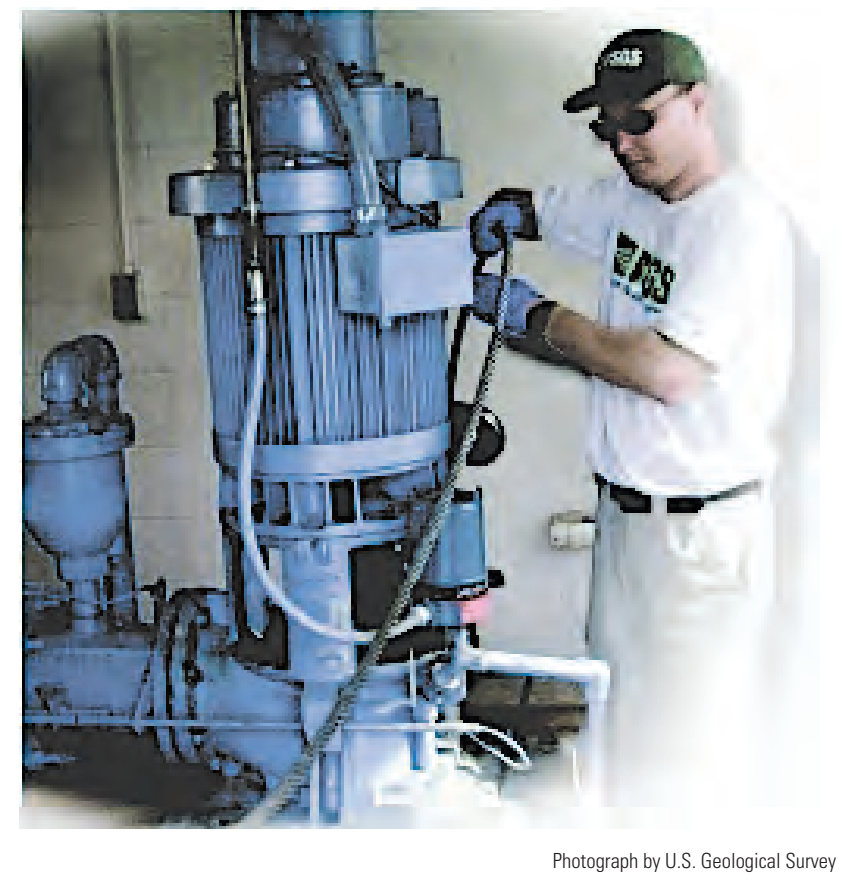




\section{Nitrate in Drinking Water: Potential Health Effects}

Mary H. Ward, Division of Cancer Epidemiology and Genetics, National Cancer Institute, National Institutes of Health, Department of Health and Human Services, Bethesda, MD

Jean D. Brender, Department of Epidemiology and Biostatistics, Texas A\&M Health Science Center, School of Rural Public Health, College Station, TX

Adverse health effects from nitrate in drinking water most likely result from complex interactions among (1) the amount of nitrate ingested, (2) the dietary intake of other constituents that may enhance or inhibit the formation of harmful compounds from ingested nitrate, and (3) medical and (or) genetic conditions that may increase susceptibility (Ward and others, 2005). To date, there have been few well-designed epidemiologic studies on the role of nitrate ingestion in specific chronic diseases. Thus, the results of epidemiologic studies have been varied: although positive associations between nitrate intake and adverse effects have sometimes been found, with the exception of methemoglobinemia, it is difficult for scientists to draw conclusions about human health risk.

Human biomonitoring studies show that ingestion of nitrate via drinking water contributes to the formation of $\mathrm{N}$-nitroso compounds, a class of chemicals that may have ties to cancer, diabetes, and adverse reproductive outcomes. Additional studies that accurately assess drinking-water nitrate exposure are needed to further our understanding of the relation between drinking-water nitrate and health outcomes. This research is particularly relevant for rural users of privately owned wells because these wells are unregulated, and NAWOA studies show elevated nitrate concentrations in shallow groundwater in agricultural areas where rural users reside.

\section{Methemoglobinemia}

The USEPA MCL for nitrate of $10 \mathrm{mg} / \mathrm{L}$ as $\mathrm{N}$ for drinking water was promulgated to protect infants from developing methemoglobinemia, also known as blue baby syndrome. Ingested nitrate is reduced to nitrite, which binds to hemoglobin to form methemoglobin. Too much methemoglobin interferes with the oxygencarrying capacity of the blood, and infants are particularly susceptible to this condition.

A recent assessment of cases of methemoglobinemia associated with well water in the United States found cases occurring at nitrate levels between 20 and $30 \mathrm{mg} / \mathrm{L}$. The concentration of nitrate in drinking water that produces elevated methemoglobin can be affected by several factors including other dietary sources of nitrate, certain medications, and concurrent exposure to enteric bacteria that cause diarrhea. Because fecal bacteria can co-occur with nitrate in domestic wells, a better understanding of the comparative roles of these contaminants as risk factors for methemoglobinemia is needed.

\section{Cancer}

Ingestion of nitrate via drinking water contributes to the formation of $\mathrm{N}$-nitroso compounds in the body — or endogenously — by a process called "endogenous nitrosation." Most N-nitroso compounds are potent animal carcinogens, and several $\mathrm{N}$-nitroso compounds formed endogenously in humans from dietary precursors are considered probable human carcinogens. On the basis of human and animal studies, the International Agency for Research on Cancer (IARC) concluded that "ingested nitrate or nitrite under conditions that result in endogenous formation of $\mathrm{N}$-nitroso compounds is probably carcinogenic to humans."

Most epidemiologic studies of nitrate in drinking water in relation to cancer have been ecologic in design, linking incidence or mortality rates to levels of nitrate in drinking water for large groups of people at the town 
or county level (Cantor and others, 2006). This study design is mostly useful for generating hypotheses about disease risk factors. Studies based on individual exposures are needed to establish cause and effect because of the complex and multi-step process by which ingested nitrate forms potentially carcinogenic $\mathrm{N}$-nitroso compounds. Study designs that assess individual exposure include case-control studies, which compare a group of individuals with a disease or condition with a group who do not have the disease or condition, and cohort studies, which track a select group of people for a period of time.

In the past decade, several individual-based studies have evaluated historical nitrate levels in public-water supplies (largely below $10 \mathrm{mg} / \mathrm{L}$ ) and risk of several cancers. A cohort study of older women in lowa found 2.8-fold and 1.8-fold increases in the risk of bladder and ovarian cancers, respectively, associated with the highest quartile of nitrate exposure (>2.46 mg/L). Significant inverse associations were observed for uterine and rectal cancer and no significant associations were observed for nonHodgkin lymphoma; melanoma; leukemia; and colon, rectal, pancreatic, kidney, and lung cancer. Dietary nitrate intake was not associated with increased risk of any cancer type. A case-control study of nonHodgkin lymphoma in Nebraska showed a significant positive association between the average nitrate level in public-water supplies over about 40 years and risk among men and women; however, subsequent studies of non-Hodgkin lymphoma have found no association. Other recent studies found no association between elevated levels of nitrate in public-drinking-water supplies and stomach cancer or childhood brain cancer; however, the children of one group of women who used private wells during pregnancy had a significantly increased risk of brain cancer.

Some studies evaluated factors that enhance nitrosation, such as low vitamin $C$ intake, to identify a potentially high risk subgroup. For example, although case-control studies of several types of cancer in lowa found no overall association between cancer risk and average nitrate levels in drinking water over almost 30 years, there was a significant increase in the risk of colon cancer among a subgroup with both 10 or more years of exposure above $5 \mathrm{mg} / \mathrm{L}$ of nitrate and factors that increase endogenous nitrosation (low vitamin C or high meat intake). Conversely, a case-control study in Nebraska of adult brain cancer showed no evidence of increased risk among subgroups with lower vitamin $\mathrm{C}$ intake and higher ingestion of nitrate in drinking water.

\section{Adverse Reproductive Outcomes}

Several studies have examined the association between drinking water that contains elevated levels of nitrate and adverse reproductive outcomes, such as spontaneous abortions, stillbirths, premature birth, or intrauterine growth retardation. Results of these studies are inconsistent, possibly indicating that there is no true effect of nitrate in water on reproductive outcomes at the nitrate levels evaluated. Alternatively, the inconsistencies may be due to the different periods over which exposure was assessed, different levels of nitrate in water across studies, or differences in exposure to other co-factors.

Results of studies that evaluated nitrate in drinking water and congenital malformations in offspring also are mixed. Some studies found positive associations between nitrate in drinking water and outcomes, such as neural tube defects. In each of these studies, levels of nitrate in water associated with increased risk of these defects were below the MCL. Two such studies also examined dietary intake of nitrate and nitrite and neural tube defects, and found minimal or no effect on risk. In another study, higher levels of nitrates in food or drinking water during the periconceptional period significantly increased the risk of neural tube defects if women were exposed to nitrosatable drugs. A cohort study in Sweden noted a weakly positive association between maternal prenatal consumption of water with nitrate concentration of $2.0 \mathrm{mg} / \mathrm{L}$ (as nitrate) or greater and congenital heart defects in offspring. 


\section{Streams}

Concentrations of nutrients in the 499 streams routinely sampled by NAWQA during the period 1992-2001 were seldom greater than human-health benchmarks. The USEPA lifetime health advisory for ammonia of $30 \mathrm{mg} / \mathrm{L}$ was not exceeded in any samples, and concentrations of nitrite greater than the Maximum Contaminant Level (MCL) of $1 \mathrm{mg} / \mathrm{L}$ were rare and limited to five sites. The waters at all five sites were heavily impacted by wastewater discharges and were not used as drinking-water sources.

Concentrations of nitrate in streams exceeded the MCL much more frequently than did nitrite, but usually not in streams that would be used as a drinking-water supply. The nitrate MCL was exceeded in about 2 percent of all samples $(566$ of 27,555) distributed among 50 stream sites. Most of the streams with one or more samples with concentrations of nitrate above the MCL are in agricultural areas (fig. 6-1). Twenty-eight percent of the agricultural sites had one or more samples with concentrations above the MCL, and 11 percent of the agricultural sites had concentrations above the MCL in more than 20 percent of the samples. Only 7 percent of urban sites and 5 percent of mixed land use sites had samples with nitrate concentrations above the MCL. The nitrate MCL was not exceeded in any of the 6,728 samples collected at the 159 undeveloped stream sites.

For perspective on the relevance of NAWQA findings to surface water used as a source for drinking-water supplies, 12 percent of the Nation's 1,679 public-water supply intakes withdraw water from streams that drain watersheds with predominantly agricultural land. Most (55 percent) of the Nation's intakes are in watersheds draining undeveloped land, with the remaining (32 and 1 percent) in mixed and urban land use, respectively.

Most streams with nitrate concentrations above the MCL are in the upper Midwest Corn Belt (fig. 6-2). Most of these are small, agricultural streams (median watershed size about 300 square miles), but some larger streams in this region that are used as drinking-water supplies are similarly affected (see sidebar, Nitrate Concentrations Vary Seasonally and are Moderated by Reservoirs in the Midwest). Application rates of commercial fertilizer and (or) manure are high in this region. Sites in the Corn Belt also are often characterized by dense, clay-rich soils and are artificially drained by surface ditches or buried tile drains. The combination of dense soils and artificial drainage promotes rapid transport of runoff and nitrate from farm fields to streams. Most of the concentrations above the nitrate MCL occur during the growing season (May, June, and July) at these sites, consistent with the agricultural origin of the nitrate. Land-use categories for the 15 sites with one or more exceedances that are scattered across the Western United States are more diverse: these sites are almost evenly divided between irrigated agricultural sites and urban or mixed land-use sites with large inputs of wastewater. Only four sites are in the Northeast (all in eastern Pennsylvania) and none are in the Southeast.

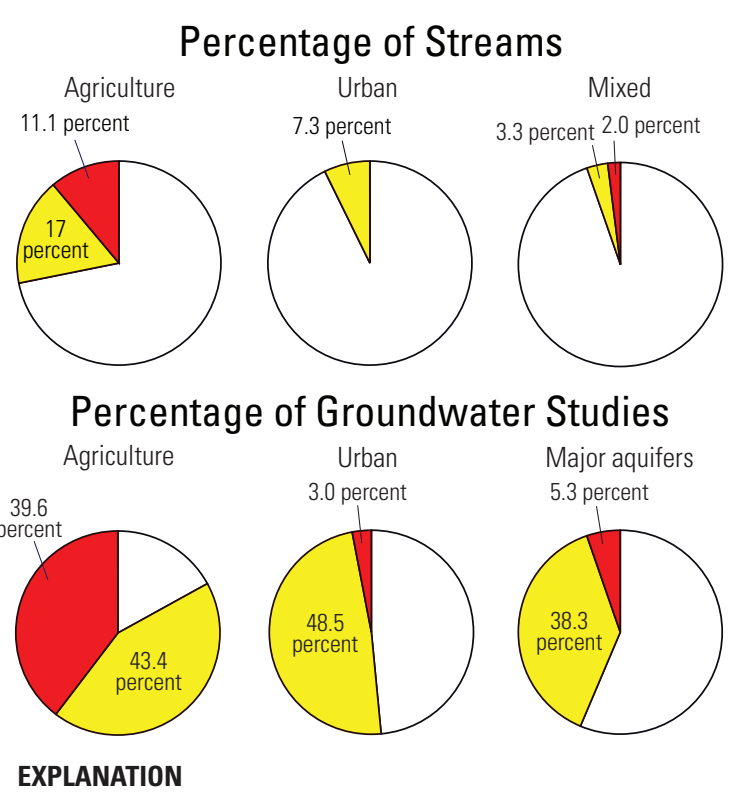

Percentage of samples at each stream site or groundwater study exceeding the nitrate MCL

$\square$ No exceedance

$\square>0-20$

$\square>20$

Figure 6-1. The Maximum Contaminant Level (MCL) for nitrate in drinking water of 10 milligrams per liter as nitrogen is exceeded far more frequently in streams in agricultural areas than in the other land-use categories. Much larger proportions of groundwater studies have MCL exceedances than do stream sites in all land-use categories.

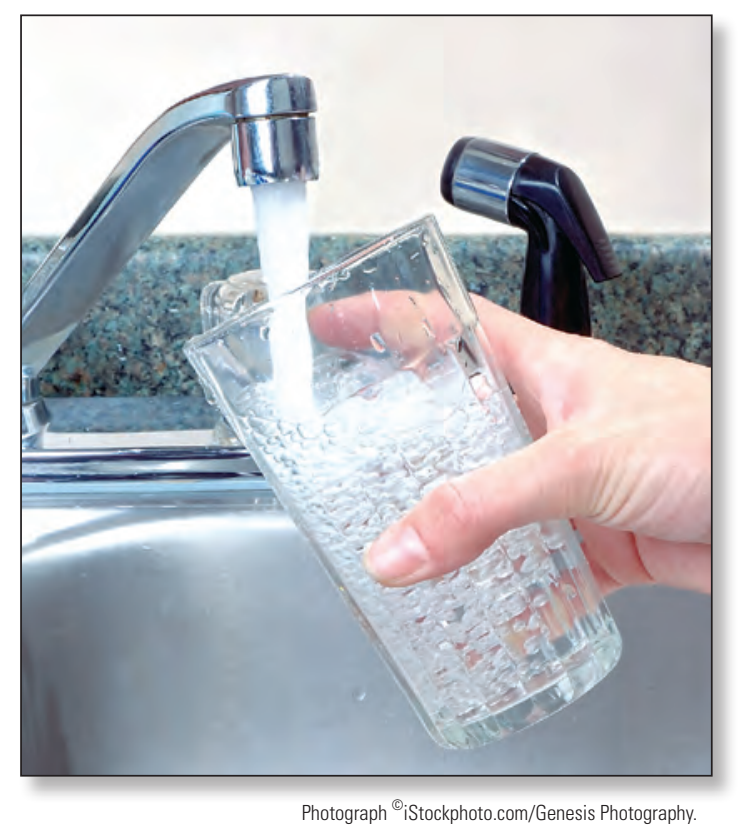



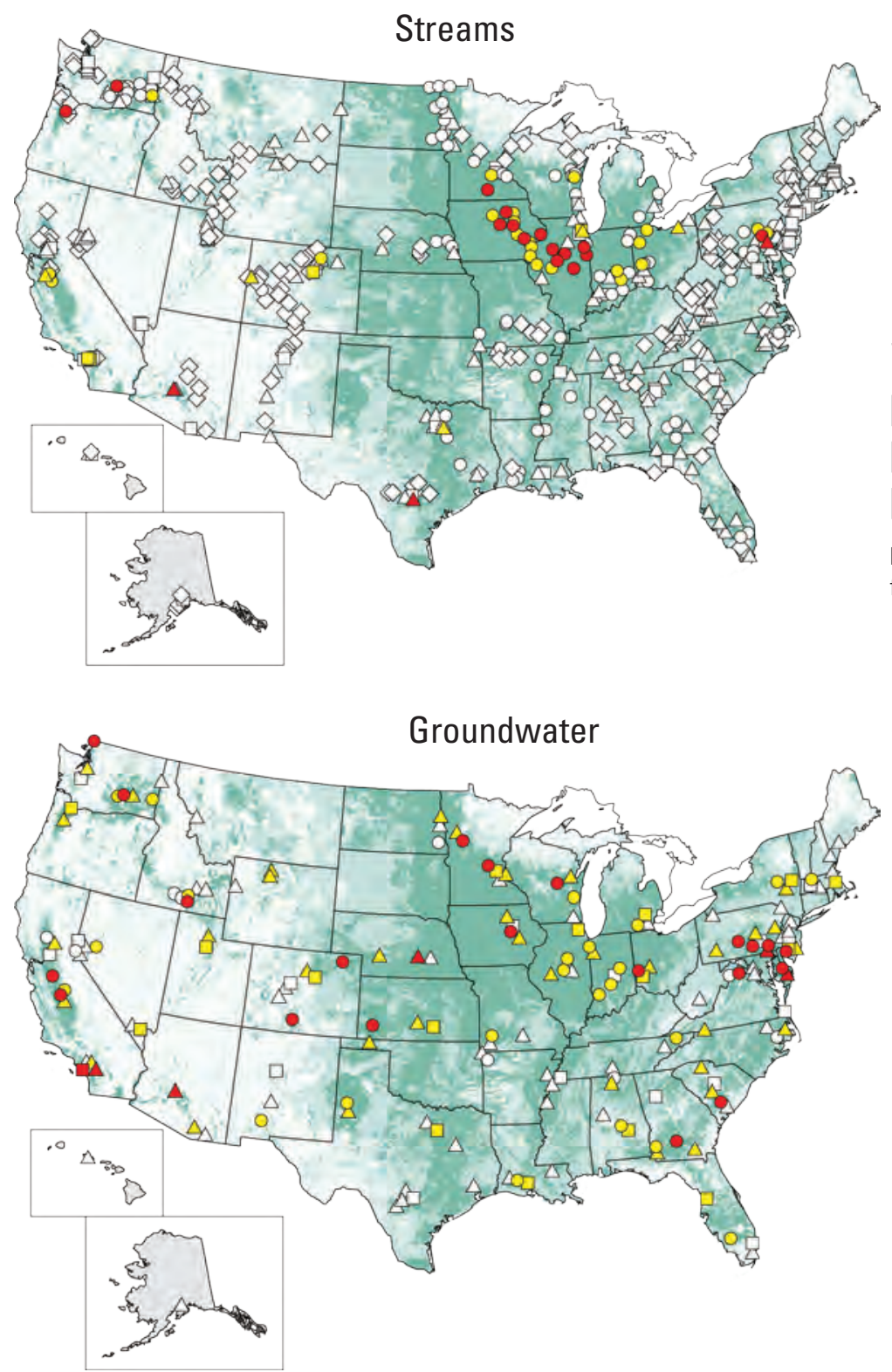

\section{EXPLANATION}

Estimated 1997 nitrogen inputs from fertilizer, manure, and atmosphere, in pounds per square mile

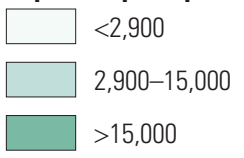

Data on nitrogen inputs not available for Alaska and Hawaii.

Stream sites, by watershed land use Percentage of samples at each stream site

Agricultural Urban Undeveloped Mixed exceeding the nitrate MCL (10 milligrams per liter as $\mathrm{N}$ )

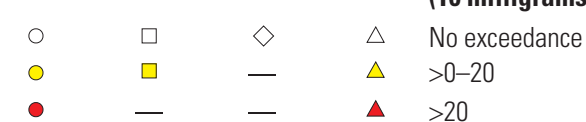

Shallow groundwater studies, by land use

Major aquifers

Agricultural Urban

$\begin{array}{llll}\circ & \square & \triangle & \text { No exceedance } \\ \circ & \square & \triangle & >0-20 \\ \bullet & \square & \Delta & >20\end{array}$

Figure 6-2. Although stream sites with nitrate concentrations above the Maximum Contaminant Level (MCL) for nitrate in drinking water of 10 milligrams per liter are broadly distributed, this standard is most often exceeded in agricultural streams draining basins with dense clay soils and artificial drainage in the Corn Belt States of the upper Midwest. In contrast, the distribution of nitrate concentrations above the MCL in groundwater studies shows no strong spatial pattern. 


\section{Nitrate Concentrations Vary Seasonally and Are Moderated by Reservoirs in the Midwest}

Nitrate concentrations in the Sangamon River in Illinois were more variable upstream of water-supply reservoirs (at Monticello, Illinois) than downstream of the reservoirs (near Oakford, Illinois) (fig. 6-3A). During April through June of 1997 and 1998, concentrations were frequently above the $M C L$ of $10 \mathrm{mg} / \mathrm{L}$ in the Sangamon River at Monticello, 29 miles upstream of Lake Decatur-the drinking-water source for the city of Decatur (fig. 6-3B). When nitrate concentrations exceed the MCL, the city of Decatur either treats the stream water to remove nitrate or mixes the highnitrate surface water with groundwater to dilute the nitrate concentrations. Nitrate concentrations also were highest in the spring in the Sangamon River near Oakford, which is downstream of Lake Decatur and other water-supply reservoirs used by the city of Springfield. Concentrations in samples from the Sangamon River near Oakford, however, seldom reached the nitrate MCL.

From August through November, the above pattern was reversed: concentrations were low at both sites, but the concentrations at the site downstream of the reservoirs were greater than those at the upstream site. Similar concentrations and seasonal patterns occurred in other streams in the corn- and soybean-producing areas of the Midwest (Scribner and others, 1996).

Figure 6-3. Nitrate concentrations in the Sangamon River, Illinois, are affected by reservoirs and other factors. Monticello lies upstream of several multi-purpose reservoirs and the cities of Springfield and Decatur. Oakford lies downstream of the reservoirs $(A)$. The reservoirs are used for water supply, and during spring, they are replenished by river water that exceeds the Maximum Contaminant Level for nitrate. Water leaving the reservoirs usually does not exceed the nitrate standard and has less variability in nitrate concentrations $(B)$.

A.

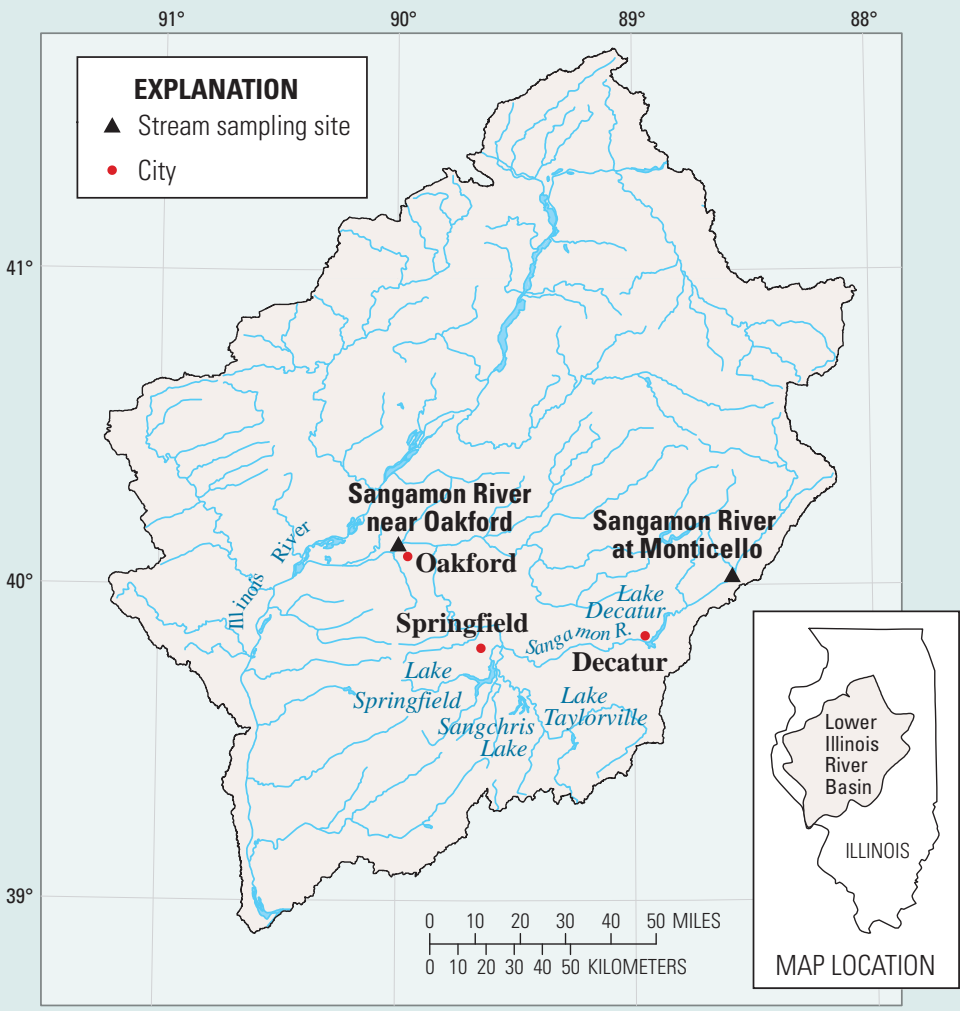

B.

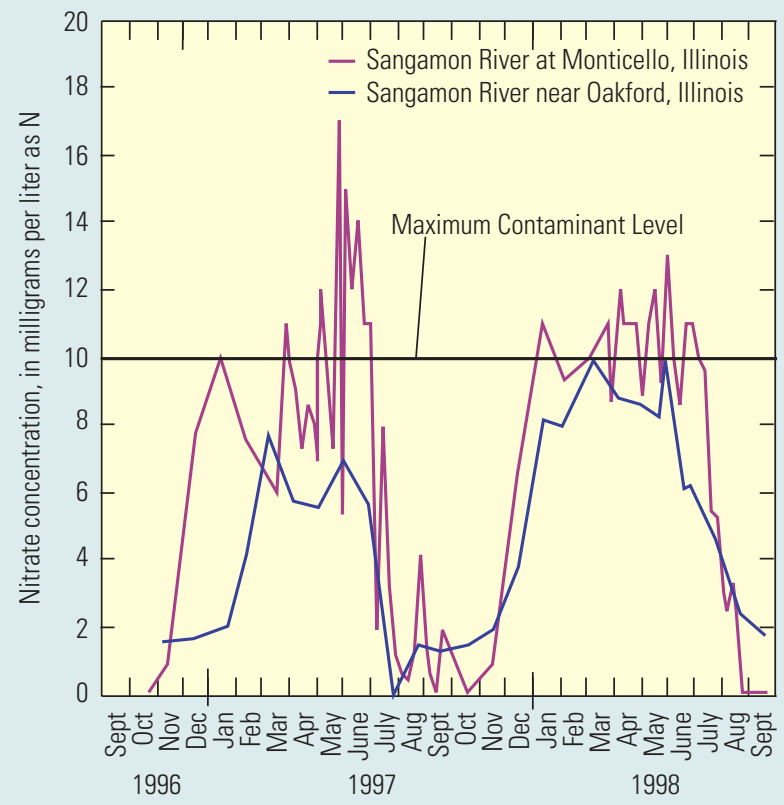




\section{Groundwater}

Concentrations of nitrate greater than the USEPA MCL of $10 \mathrm{mg} / \mathrm{L}$ occur more frequently and are more widespread in groundwater than in streams. About 9 percent of all wells sampled had nitrate concentrations greater than the MCL, compared to 2 percent of all stream samples. Similarly, 57 percent of all agricultural, urban and major aquifer studies had one or more samples with a concentration exceeding the MCL, compared to 10 percent of all stream sites. In addition, a greater proportion of groundwater studies than stream sites had concentrations above the MCL in at least 20 percent of their samples (fig. 6-1). Concentrations exceeding the MCL were much more prevalent in samples from wells in agricultural areas (20 percent) than in samples from either wells in urban areas or in major aquifer wells (table 6-1). The overall rates of exceedance of the MCL in samples from wells in urban areas and major aquifers were similar- 3 and 4 percent, respectively.

Samples from about 7 percent of all domestic wells sampled had nitrate concentrations above the MCL (table 6-1). About 43 million people in the United States obtain water for household use from privately owned (domestic) wells (Hutson and others, 2004). The relatively high rate of exceedance of the MCL for nitrate in shallow domestic wells in agricultural areas is a potential human health concern because the water from these wells generally is used as household supply without treatment. The overall rate of exceedance of the MCL in public-supply wells was only 3 percent. The low rate of exceedance in the public wells reflects the relatively great depth of these wells, and hence, the long travel time of the water from the land surface to the well intakes, as well as measures taken to avoid groundwater with high nitrate concentrations. In contrast to water from domestic wells, source water for public-supply wells that exceeds the MCL is either treated or blended with water having a lower concentration of nitrate to attain the standard prior to being distributed to users. Because of the large number of people potentially affected, the complexity of the problem, and the high cost of treatment, the NAWQA Program is conducting detailed studies of public-supply well vulnerability (see sidebar, NAWQA Study of Public-Supply Well Vulnerability).

The broad distribution of elevated concentrations of nitrate in groundwater is reflected in the high proportion of studies with one or more MCL exceedances: 83 percent of the agricultural studies, 52 percent of urban studies, and 44 percent of major aquifer studies (fig. 6-1). Two subtle spatial patterns in the rate of exceedance of the nitrate MCL in groundwater studies are noteworthy. First, unlike streams, groundwater studies in which concentrations of nitrate exceed the MCL are broadly distributed across the United States (fig. 6-2); in particular, despite the large nitrogen inputs in the upper Midwest Corn Belt, the rates of MCL exceedance in this area are no different from the rates in other agricultural areas of the country. Second, the generally low rate of exceedance of the nitrate MCL in studies across the southeastern portion of the country may be attributed to the prevalence of aquifers with chemically reduced conditions that promote denitrification, and limestone aquifers where rapid flushing results in low nitrate concentrations.

The proportions of public-supply and domestic wells that had nitrate concentrations above the MCL of $10 \mathrm{mg} / \mathrm{L}$ are similar to, but slightly larger than, the results in a previous national study. Results from a USEPA survey of 1,300 wells sampled during 1985-1990 indicate that 1.2 percent of community water system (CWS) wells and 2.4 percent of rural domestic wells produced water that had nitrate concentrations greater than the MCL (U.S. Environmental Protection Agency, 1990). CWS wells are those in piped drinking-water systems that have at least 15 connections or serve at least 25 permanent residents. Rural households were defined as those outside of incorporated or unincorporated areas with a population of 2,500 or more and outside of urban fringe areas as defined by the U.S. Census Bureau.

Table 6-1. Samples from about 7 percent of domestic wells and 3 percent of public-supply wells had nitrate concentrations above the Maximum Contaminant Level (MCL) of 10 milligrams per liter as nitrogen. The rate of exceedance was highest in shallow groundwater under agricultural lands.

\begin{tabular}{|l|c|c|c|c|c|c|c|c|}
\hline \multirow{2}{*}{ Type of groundwater study } & \multicolumn{2}{|c|}{ Public-supply wells } & \multicolumn{2}{|c|}{ Domestic wells } & \multicolumn{2}{c|}{$\begin{array}{c}\text { Monitoring wells } \\
\text { (unused) }\end{array}$} & \multicolumn{2}{|c|}{ Total } \\
\cline { 2 - 10 } & $\begin{array}{c}\text { Number } \\
\text { sampled }\end{array}$ & $\begin{array}{c}\text { Percentage } \\
\text { exceeding } \\
\text { MCL }\end{array}$ & $\begin{array}{c}\text { Number } \\
\text { sampled }\end{array}$ & $\begin{array}{c}\text { Percentage } \\
\text { exceeding } \\
\text { MCL }\end{array}$ & $\begin{array}{c}\text { Number } \\
\text { sampled }\end{array}$ & $\begin{array}{c}\text { Percentage } \\
\text { exceeding } \\
\text { MCL }\end{array}$ & $\begin{array}{c}\text { Number } \\
\text { sampled }\end{array}$ & $\begin{array}{c}\text { Percentage } \\
\text { exceeding } \\
\text { MCL }\end{array}$ \\
\hline Agricultural & 1 & 100 & 406 & 22 & 938 & 20 & 1,345 & 20 \\
\hline Urban & 9 & 0 & 17 & 6 & 781 & 3 & 807 & 3 \\
\hline Major aquifer & 374 & 2 & 1,965 & 4 & 183 & 8 & 2,522 & 4 \\
\hline $\begin{array}{l}\text { Total number, or percent } \\
\text { for lumped studies }\end{array}$ & 384 & 3 & 2,388 & 7 & 1,902 & 12 & 4,674 & 9 \\
\hline
\end{tabular}




\section{NAWOA Study of Public-Supply Well Vulnerability}

The NAWOA Program has implemented an intensive study focused on understanding the factors that affect the vulnerability of public-supply wells to contamination (Eberts and others, 2005). The study findings are intended to help water managers, policy makers, drinking-water suppliers, and scientists to:

- Better understand how and why contamination of public-supply wells occurs and whether water quality may get better or worse over time;

- Assess and predict the vulnerability of groundwater and public-supply wells to contamination, even in unmonitored areas;

- Choose new areas for water-supply wells and develop and prioritize monitoring programs; and

- Evaluate various groundwater pumping, development, and land-management alternatives.

NAWQA findings through 2009 show that important factors that affect public-supply well vulnerability include mixing of water of different ages in wells, "short circuiting," and geochemical conditions in the aquifer. Because subsurface conditions and management practices differ among aquifers and water distribution systems, public-supply wells in different areas of the country are not equally vulnerable to contamination, even where contaminant sources are similar.

Water from public-supply wells is a mixture of water of various ages associated with different land uses and potential sources of contamination from the land surface (fig. 6-4). Wells that draw a notable amount of older water (greater than 50 years) may not fully respond to land-surface activities and sources of contamination for decades. In these types of wells, a decrease in contaminant concentrations can lag years, decades, and even centuries behind clean up and protection efforts due to the mixing of a smaller proportion of young (more contaminated water) with a larger proportion of older water during pumping. In contrast, water quality in public-supply wells that produce predominantly young water (less than 50 years old) can respond relatively quickly (from days to years) to land-use changes near the surface, including source protection efforts.

Under natural conditions, vertical and horizontal movement of groundwater is often slow, and water can take decades to millennia to move through an aquifer system. NAWQA findings, however, show that pumping at public-supply wells in the vicinity of "short circuits" commonly allows water and associated contaminants to move more quickly to the wells than expected. Short circuits can include natural features, such as fractures in glacial till, solution channels in carbonate rock, and sinkholes, as well as human-related factors, such as abandoned or poorly constructed wells.

Geochemical processes within the aquifer can affect contaminant transport and fate. Geochemical processes and conditions can result in contaminants being degraded, adsorbed, volatilized, dispersed, and (or) mobilized as they move in the aquifer. This study has developed a tool to help understand the geochemical conditions in the aquifer and contributing areas to wells, which is critical to determining the transport of contaminants to a public-supply well.

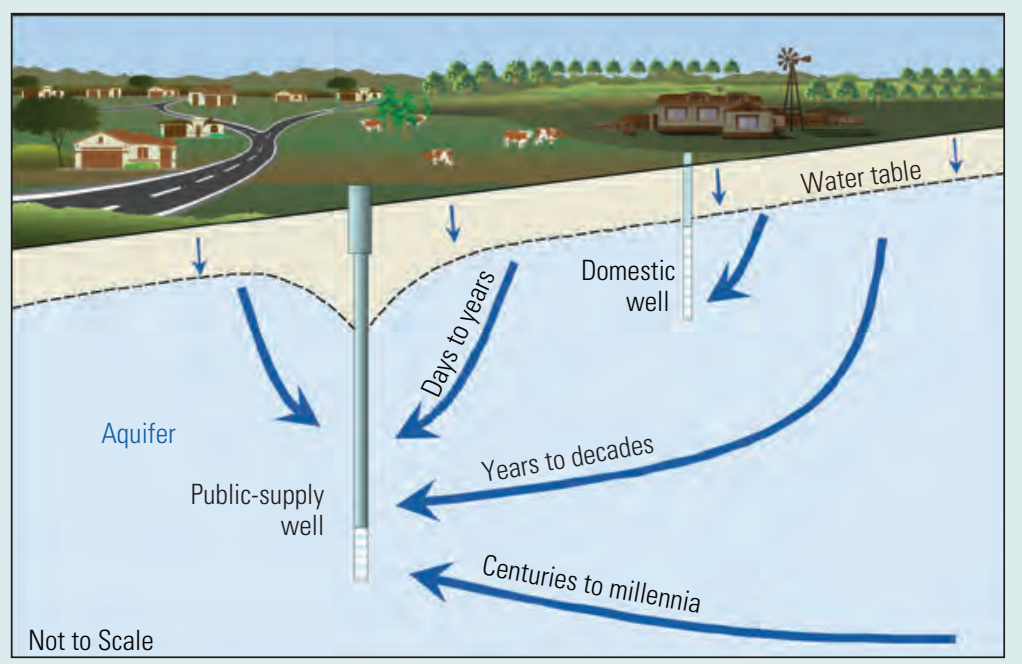

Figure 6-4. Even in urban areas, groundwater reaching public-supply wells is a mixture of water recharged under a variety of land uses, and is a mixture of ages (blue lines on diagram). 
The processes that influence the frequency of exceedance of the nitrate MCL in groundwater studies have already been discussed with respect to nitrate concentrations in general. Nitrate concentrations greater than the MCL are favored by oxic geochemical conditions, and exceedances are rare in chemically reduced groundwater: only 2 percent of samples from wells with reduced groundwater had concentrations above the MCL, whereas 12 percent of samples from wells with oxic groundwater had concentrations above the MCL. Exceedances are similarly infrequent in old groundwater (recharged prior to 1952): only about 1 percent of samples from wells producing old groundwater had concentrations of nitrate above the MCL, whereas about 12 percent of samples from wells with young groundwater had concentrations above the MCL. The much higher rate of exceedance in agricultural areas compared to that in urban areas is due in part to the higher input of nitrogen to the land surface.

The high rate of exceedance of the nitrate MCL in shallow wells in agricultural areas is cause for concern even though the aquifer represented by samples from these wells is not often directly used as a drinking-water source. By design, agricultural land-use study wells sample the shallowest, most recently recharged groundwater at each locale. As such, it is the first water affected by downward movement of contaminants from the land surface. In drinking-water wells (domestic and public-supply wells), the rate of exceedance of the nitrate MCL decreases with increasing depth of the well below the water table (fig. 6-5). This distribution reflects the protective effect of the relatively long time it takes for surface contamination to reach the intakes of drinking-water wells. The long travel time also represents an increased opportunity for removal of nitrate by denitrification or dilution by mixing. In many areas, the shallow groundwater and the deep aquifer zones pumped for domestic and public supply are part of a single, continuous hydrologic flow system. In these areas, downward movement of groundwater containing nitrate at concentrations exceeding the MCL could result in deterioration of drinking-water supplies in the future. Reliable prediction of this potential requires specific hydrologic and geochemical information unique to each locale. Although this level of detail for the entire country is beyond the scope of the NAWQA Program, some case studies examining the migration of nitrate-contaminated groundwater to supply wells have been done, and are described in Chapter 8, Changes in Nutrient Concentrations: Past and Predicted.

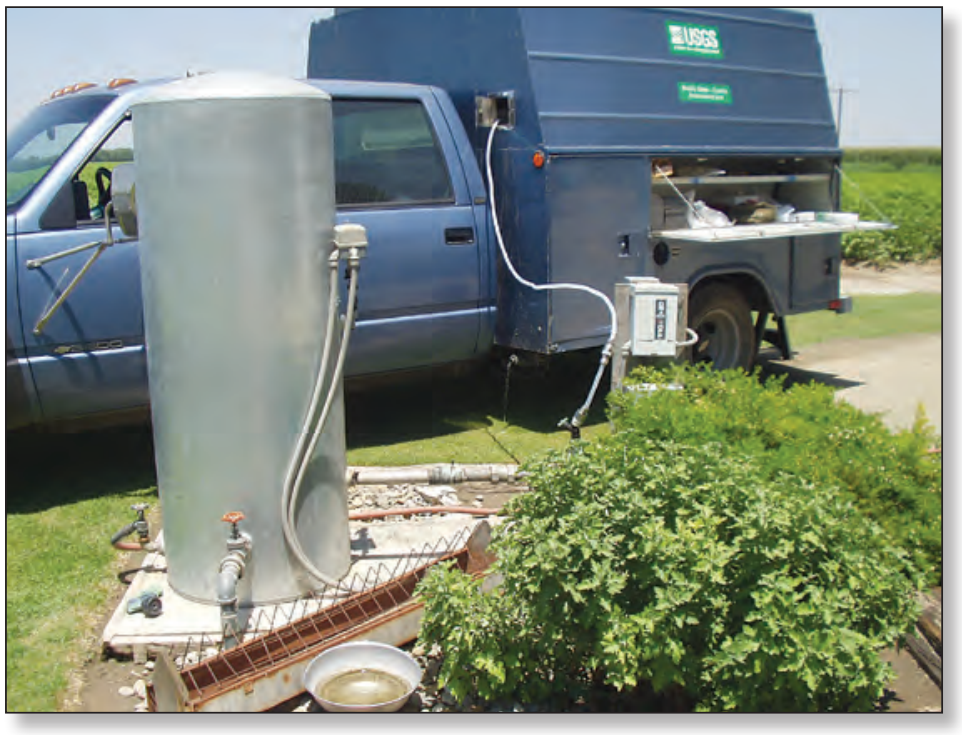

Samples of groundwater were collected from privately owned (domestic) wells; about 43 million people in the United States obtain water for household use from domestic wells. Photograph by U.S. Geological Survey.

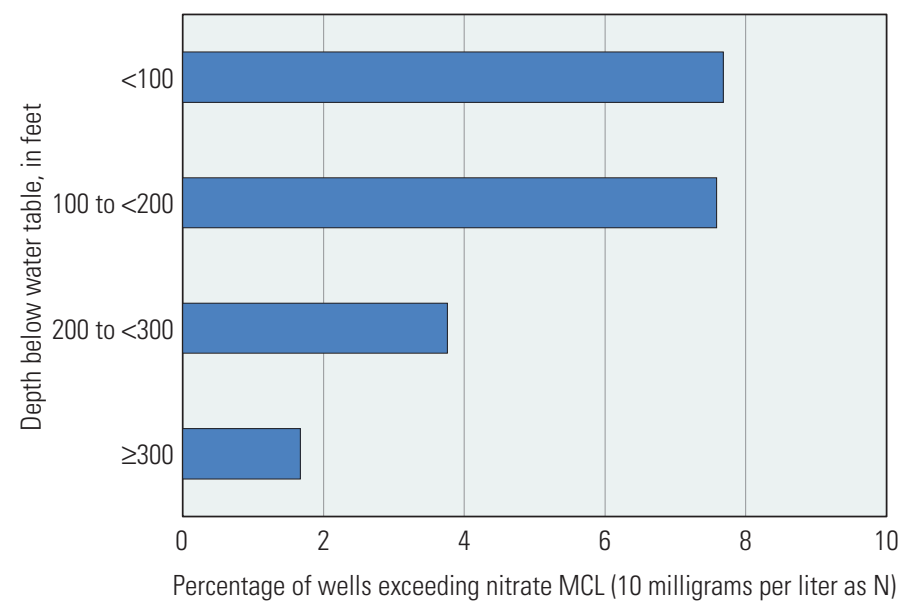

Figure 6-5. In drinking-water wells, the rate of exceedance of the U.S. Environmental Protection Agency Maximum Contaminant Level (MCL) for nitrate of 10 milligrams per liter decreases with increasing depth of the well below the water table. Downward movement of shallow groundwater with nitrate concentrations exceeding the MCL could potentially result in deterioration of drinking-water supplies in the future. 


\section{Extrapolation of Nitrate Concentrations in Drinking Water to Unsampled Areas}

As part of NAWQA's integrated approach to monitoring and prediction, a statistical model was developed to assess the vulnerability of groundwater to nitrate contamination at the national scale (Nolan and Hitt, 2006). The model developed for deep groundwater (median depth of about 50 meters or 164 feet) that is used as drinking water predicts moderate to severe nitrate contamination in the High Plains, the northern Midwest, and other areas of intensive agriculture in both the East (eastern Pennsylvania and the Delmarva Peninsula) and the West (the Columbia Plateau in Washington, the San Joaquin Valley in California, and the Snake River Plain in Idaho) (fig. 6-6). The model predicts the highest nitrate concentrations in areas with large nitrogen sources, factors that promote rapid transport of nitrogen in groundwater, and a lack of attenuation processes.

The model for nitrate in deep groundwater that is used as a drinking-water supply explained about 77 percent of the variation in the nitrate concentrations. Areas that are predicted to have nitrate concentrations greater than $10 \mathrm{mg} / \mathrm{L}$ (red in fig. 6-6) are less extensive than predicted by a similar model for shallow groundwater (see Chapter 4, Occurrence and Distribution of Nutrients in Streams and Groundwater). This is because the drinking-water wells are about 130 feet deeper on average than the shallow wells, and nitrate concentration generally decreases with increasing well depth (fig. 6-5). Greater depth generally represents greater travel time between recharge point and well intake, and greater travel time favors nitrate attenuation. Greater depth also increases the likelihood of the existence of intervening, less permeable layers that restrict the downward migration of water and associated dissolved nitrate. In addition, deeper groundwater is older and may predate recent (1950s to present) increases in nitrogen sources, especially fertilizer, and thus in some cases may have low nitrate concentrations.

\section{Groundwater}

\section{Model for deep groundwater used as drinking water (50-m simulation depth)}

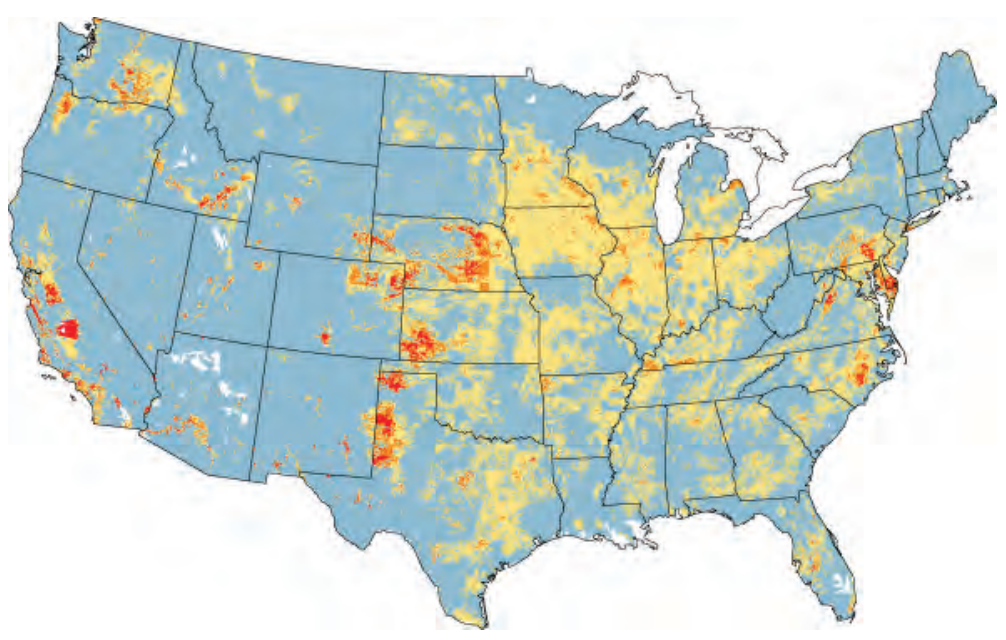

EXPLANATION

Predicted nitrate concentration, in milligrams per liter as $\mathbf{N}$

$\leq 1 \quad \square>1-5 \quad \square>5-10 \quad \square>10 \quad \square$ Missing data

Figure 6-6. Results of model simulations suggest moderate (shown in yellow and orange) to severe (shown in red) nitrate contamination in relatively deep groundwater (164 feet or 50 meters below land surface) underlying parts of California, the Northwest, the High Plains, and the East. These areas typically are associated with large nitrogen input; natural soil, landscape, and geologic features that promote rapid transport of groundwater; and a lack of biogeochemical processes that convert nitrate to other forms of nitrogen.

The model for deep groundwater was used as a basis for estimating the number of users of private wells in contaminated areas. The resulting population counts indicated that almost 15 million people live in areas with predicted nitrate concentrations greater than $1 \mathrm{mg} / \mathrm{L}$ in water from wells that are 164 feet deep. Among these potential users, $1,240,000$ people live in areas predicted to have moderate nitrate contamination of groundwater ( $>5$ to $\leq 10 \mathrm{mg} / \mathrm{L}$ nitrate) (table 6-2). More users may be affected in the future, however, because shallow groundwater with high nitrate concentrations can migrate to greater depths within the aquifer. Because well depth is a proxy for travel time in the aquifer, conditions at shallow depths (33 feet) in essence constitute an early-warning system. Population counts corresponding to predicted nitrate concentrations greater than $1 \mathrm{mg} / \mathrm{L}$ are 3-14 percent greater at a well depth of 33 feet than at 164 feet (table 6-2). 
Table 6-2. The model for deep groundwater was used to predict the number of people using private wells in areas with different nitrate concentrations for two well-depth scenarios. Conditions at shallow depths (33 feet) constitute an early-warning of changes that may occur as shallow groundwater with high nitrate concentrations migrates to greater depths in the aquifer.

[mg/L, milligrams per liter]

\begin{tabular}{lccc}
\hline \multirow{2}{*}{$\begin{array}{c}\text { Predicted nitrate } \\
\text { concentration range }\end{array}$} & \multicolumn{2}{c}{$\begin{array}{c}\text { Population counts for } \\
\text { simulation depth }\end{array}$} & $\begin{array}{c}\text { Percentage } \\
\text { change }\end{array}$ \\
\cline { 2 - 3 } & $\mathbf{1 6 4 \text { feet }}$ & $\mathbf{3 3 \text { feet }}$ & \\
\hline No data & $1,710,000$ & $1,710,000$ & Not applicable \\
\hline $\begin{array}{c}\text { Background: } \\
0 \text { to } \leq 1 \mathrm{mg} / \mathrm{L}\end{array}$ & $20,000,000$ & $19,400,000$ & -3.1 \\
$\begin{array}{c}\text { Elevated: } \\
>1 \text { to } \leq 5 \mathrm{mg} / \mathrm{L}\end{array}$ & $13,000,000$ & $13,300,000$ & +3.1 \\
$\begin{array}{c}\text { Moderate: } \\
>5 \text { to } \leq 10 \mathrm{mg} / \mathrm{L}\end{array}$ & $1,240,000$ & $1,400,000$ & +13.7 \\
\hline $\begin{array}{c}\text { Severe: } \\
>10 \mathrm{mg} / \mathrm{L}\end{array}$ & 467,000 & 528,000 & +13.0 \\
\hline
\end{tabular}

Comparison of the maps of predicted total nitrogen concentrations in streams (see fig. 4-12) and nitrate in groundwater (fig. 6-6) shows a striking contrast in the distribution of areas predicted to have concentrations greater than $10 \mathrm{mg} / \mathrm{L}$ (fig. 6-7). Overlaying simulation results for the two models show that there are only small areas of overlap (red, in fig. 6-7) between areas predicted to have concentrations greater than $10 \mathrm{mg} / \mathrm{L}$ of total nitrogen in streams and areas predicted to have concentrations greater than $10 \mathrm{mg} / \mathrm{L}$ of nitrate in groundwater. The contrast in the maps reflects the contrast in physical and chemical aspects of the landscape that facilitate nitrogen transport to streams or to groundwater. For example, factors that promote rapid infiltration of rainfall into the ground, such as permeable soils, enhance the likelihood for contamination of groundwater; factors that inhibit infiltration and promote runoff, such as impermeable soils and artificial drainage, favor contamination of streams.

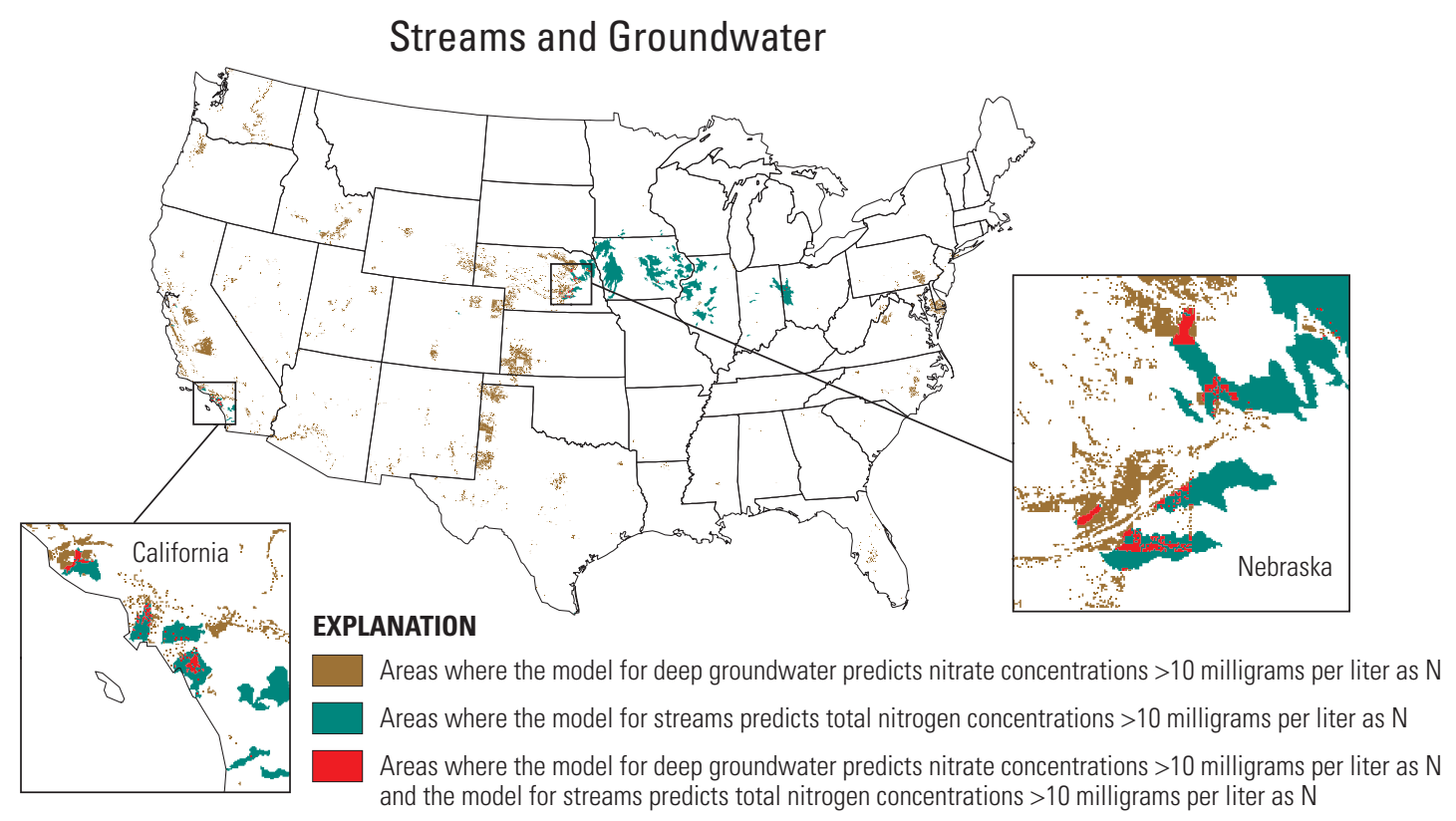

Figure 6-7. The contrast in the areas predicted by the streams model (green) and by the groundwater model (brown) to have total nitrogen (in streams) or nitrate (in groundwater) concentrations greater than 10 milligrams per liter reflects the contrast in physical and chemical aspects of the landscape that facilitate nitrogen transport to streams or to groundwater. 


\section{Co-Occurrence of Organic Contaminants and Nitrate at Concentrations of Concern for Human Health}

Leslie DeSimone, U.S. Geological Survey

Data for 2,167 domestic wells sampled in major aquifers across the United States (DeSimone, 2009) show that the frequency of encountering an organic contaminant-that is, a pesticide or volatile organic compound-at a concentration of greater than one-tenth of an MCL (U.S. Environmental Protection Agency, 2006) or USGS Health-Based Screening Level (HBSL) (Toccalino and Norman, 2006; Toccalino and others, 2006) increases as nitrate concentrations increase (fig. 6-8). The likelihood of encountering a concentration of an organic contaminant that exceeds one-tenth of an MCL or HBSL is about five times greater in samples with nitrate concentrations above the background level of $1 \mathrm{mg} / \mathrm{L}$ than in samples with nitrate concentrations below background levels (see Chapter 4, Background Conditions). Similarly, the frequency of occurrence of an organic contaminant at a concentration above an MCL or HBSL is about four times greater in groundwater with nitrate concentrations above background levels than in groundwater with nitrate concentrations below background levels (see red bars, fig. 6-8). Overall, 84 percent of samples with concentrations of organic compounds greater than MCLs or HBSLs also had nitrate concentrations above background levels. These findings indicate that when concentrations of nitrate are above background levels in a domestic drinking-water supply, additional analysis for organic contaminants should be considered.

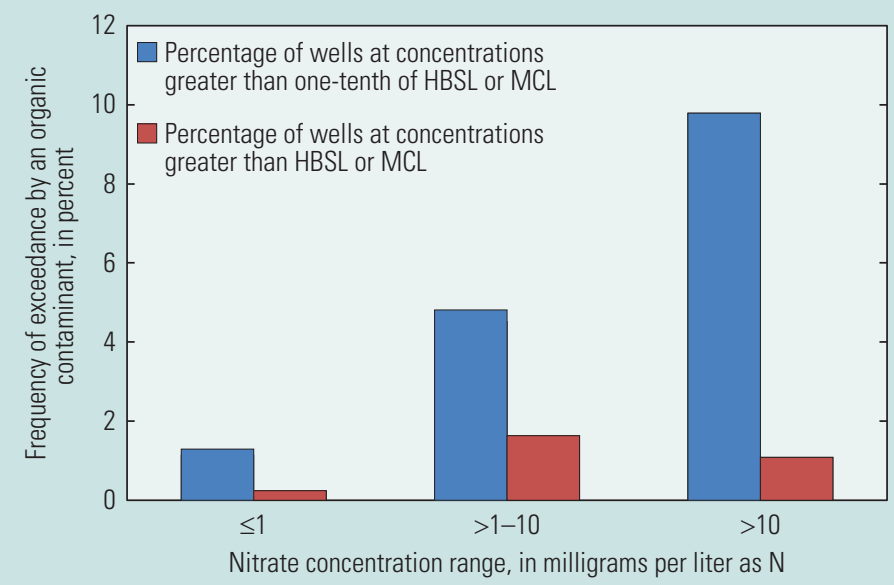

Figure 6-8. The likelihood of detecting an organic contaminant at a concentration of concern for human health is greater in samples with nitrate concentrations above the background level of $1 \mathrm{mg} / \mathrm{L}$ than in samples with nitrate concentrations below background levels. (HBSL, Health-Based Screening Level; MCL, Maximum Contaminant Level.) 


\section{Chapter}

\section{Potential for Effects on Aquatic Life}

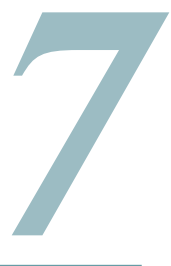

\section{Introduction}

Excessive nutrients and resulting instream plant biomass can have a wide range of impacts on aquatic ecosystems. There is increasing interest in establishing numeric nutrient criteria at scales that reflect the geographic variability in the natural factors affecting instream nutrient conditions. The responses of aquatic biota to nutrient enrichment, and the potential use of biological metrics as measures of water-quality status and biological condition, also are areas of active study. This chapter examines the status of streams with respect to ammonia criteria, geographic variability of background nutrient concentrations, and the response of aquatic biota to varying nutrient levels.

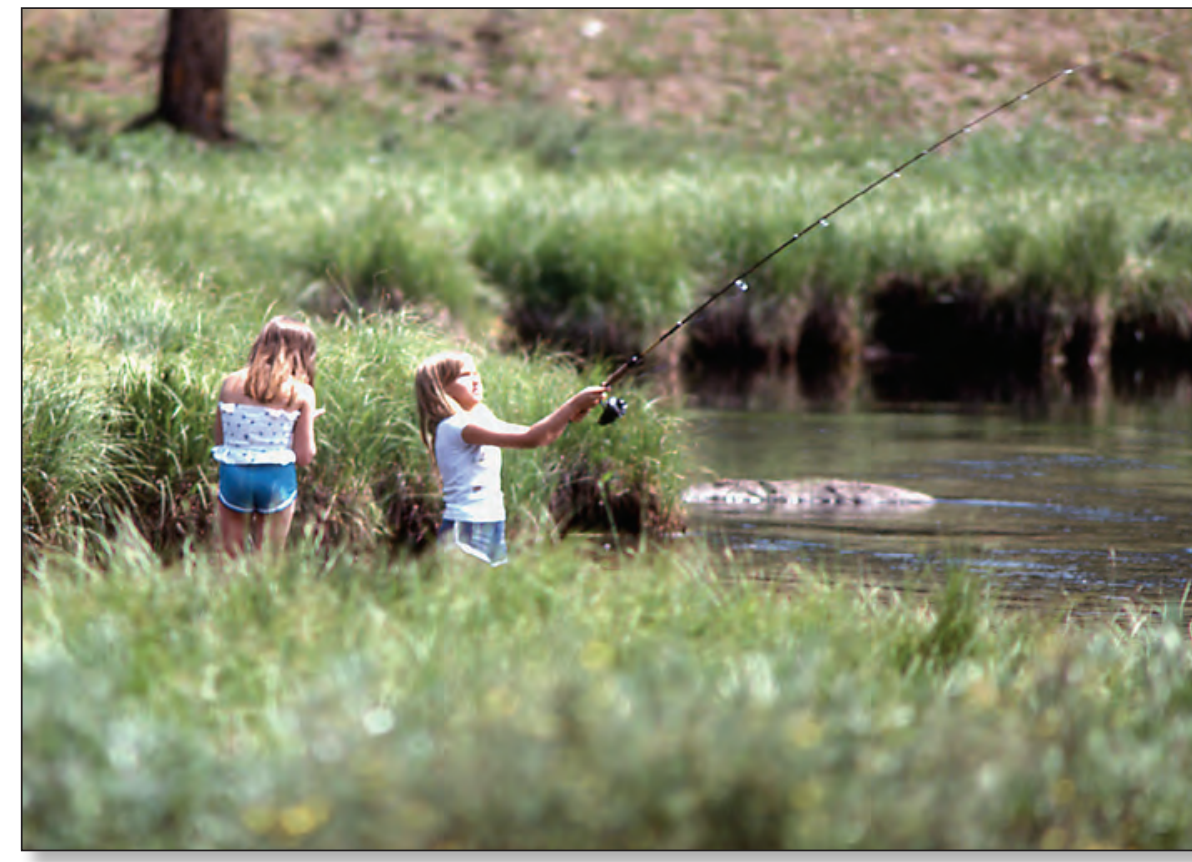

Photograph by William S. Keller, U.S. National Park Service. 


\section{Potential Effects of Ammonia on Aquatic Life}

Ammonia $\left(\mathrm{NH}_{3}\right)$ and its ionized form, ammonium $\left(\mathrm{NH}_{4}^{+}\right)$, occur naturally and are formed during decomposition of proteins, manure wastes, and other nitrogen-containing compounds. Ammonia is an excellent source of nitrogen for plants and is part of most natural and synthetic fertilizer formulations. Ammonia is soluble in water, and water contaminated with fertilizer runoff, animal wastes, or sewage may contain elevated concentrations of ammonia. In well-oxygenated streams, microorganisms may convert ammonia to nitrite and nitrate through a process known as nitrification.
The un-ionized form of ammonia $\left(\mathrm{NH}_{3}\right)$ can be toxic to aquatic plants, invertebrates, and fish at concentrations less than $1 \mathrm{mg} / \mathrm{L}$ (U.S. Environmental Protection Agency, 1999). Concentrations of ammonia in NAWQA samples were compared with aquatic health criteria for both acute and chronic effects using guidelines established by the USEPA for protection of aquatic life (U.S. Environmental Protection Agency, 1999). More stringent ambient water-quality criteria have recently been proposed which would be more protective of sensitive species (U.S. Environmental Protection Agency, 2009a) (see sidebar, Calculation of Potential Ammonia Toxicity).

\section{Calculation of Potential Ammonia Toxicity}

The toxicity of ammonia in water is dependent on the proportion of ammonia present in the un-ionized form. Because the distribution of ammonia between the ionized and un-ionized forms is both $\mathrm{pH}$ and temperature dependent, the $\mathrm{pH}$ and temperature of water samples are required to determine the toxicity of a specific stream environment to organisms. Toxicity increases as $\mathrm{pH}$ increases, and in general, as temperature decreases. Plants are more tolerant of ammonia than animals, and invertebrates are generally more tolerant than fish.

Concentrations in samples from streams were compared with criteria established to prevent both acute and chronic health effects caused by exposure of aquatic organisms to ammonia in water. Acute health effects are those caused by sudden and severe exposure to a toxicant, whereas chronic health effects are those that result from prolonged or repeated exposure over days, months, or years. The acute criteria for ammonia in water range from 1.3 to $49 \mathrm{mg} / \mathrm{L}$ of total ammonia for $\mathrm{pH}$ values of 6.5-9.0 and water temperatures of $0-30^{\circ} \mathrm{C}$. The chronic criteria range from 0.18 to $6.7 \mathrm{mg} / \mathrm{L}$ of total ammonia for the same $\mathrm{pH}$ and water temperature ranges. Effects of chronic exposure generally are evaluated over a 4- to 30-day averaging period (U.S. Environmental Protection Agency, 1999).

The USEPA has proposed new ambient criteria for ammonia that consider toxicological data published since development of the current criteria (beginning in 1985) (U.S. Environmental Protection Agency, 2009a). Although the influence of $\mathrm{pH}$ and temperature on ammonia in the proposed criteria is the same as in the past, the new criteria take into account the presence or absence of freshwater mussels. Freshwater mussels are particularly sensitive to ammonia, and many species are endangered or in decline. For example, laboratory tests show that ammonia concentrations as low as $0.03 \mathrm{mg} / \mathrm{L} \mathrm{can} \mathrm{affect}$ growth rates of freshwater mussels, and at $0.12 \mathrm{mg} / \mathrm{L}$ or greater can be lethal to mussels (Newton and Bartsch, 2007). Adoption of these more stringent criteria may result in more streams being listed as out of compliance with respect to ammonia. 
The concentrations of ammonia at NAWQA stream sites seldom exceeded levels believed to adversely affect aquatic life. Ammonia concentrations in more than 24,000 samples from 499 sites were compared with acute and chronic criteria on the basis of $\mathrm{pH}$ and temperature of the samples. The acute criteria for ammonia were rarely exceeded; only 33 samples ( 0.14 percent) at 7 sites ( 1.4 percent) had concentrations greater than the criteria. Samples that exceeded the acute criteria were split among urban ( 2 sites or 3.6 percent of urban sites), mixed (4 sites or 2.7 percent of mixed sites), and agricultural (1 site or 0.7 percent of agricultural sites) land-use settings (fig. 7-1).

The chronic criteria for ammonia were exceeded in 139 samples ( 0.57 percent) at 22 sites ( 4.4 percent). Sites at which concentrations of ammonia exceeded chronic criteria also were primarily in urban ( 8 sites or 14 percent of urban sites) and mixed ( 9 sites or 6 percent of mixed sites) land use areas; only 10 samples at 5 agricultural sites (3.7 percent of agricultural sites) exceeded the criteria (fig. 7-1). Ninety-one exceedances ( 65 percent) of the chronic criteria occurred at only 4 sites ( 2 urban and 2 mixed land use) in the semiarid West.

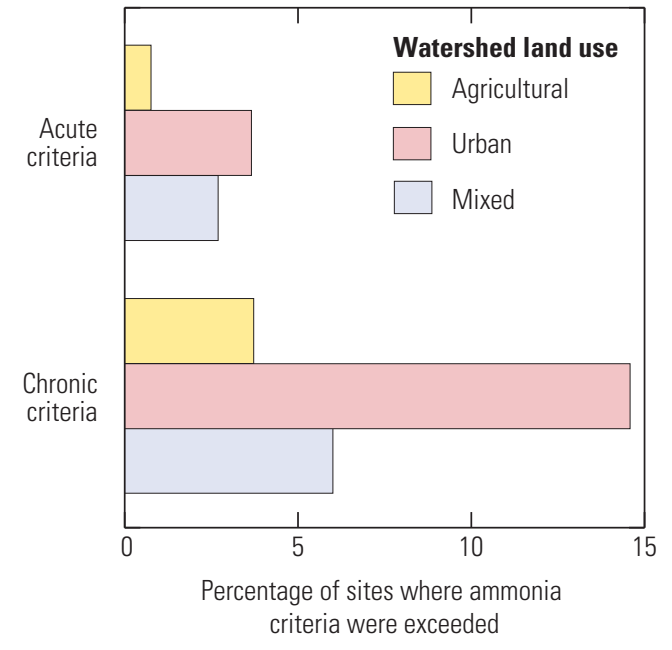

Figure 7-1. Concentrations of ammonia in streams seldom exceeded acute or chronic criteria set to protect aquatic life. Sites at which the criteria were exceeded generally are on streams in the semiarid West that drain large areas of urban or mixed land and are potentially influenced by treated effluent from wastewater-treatment facilities located upstream.

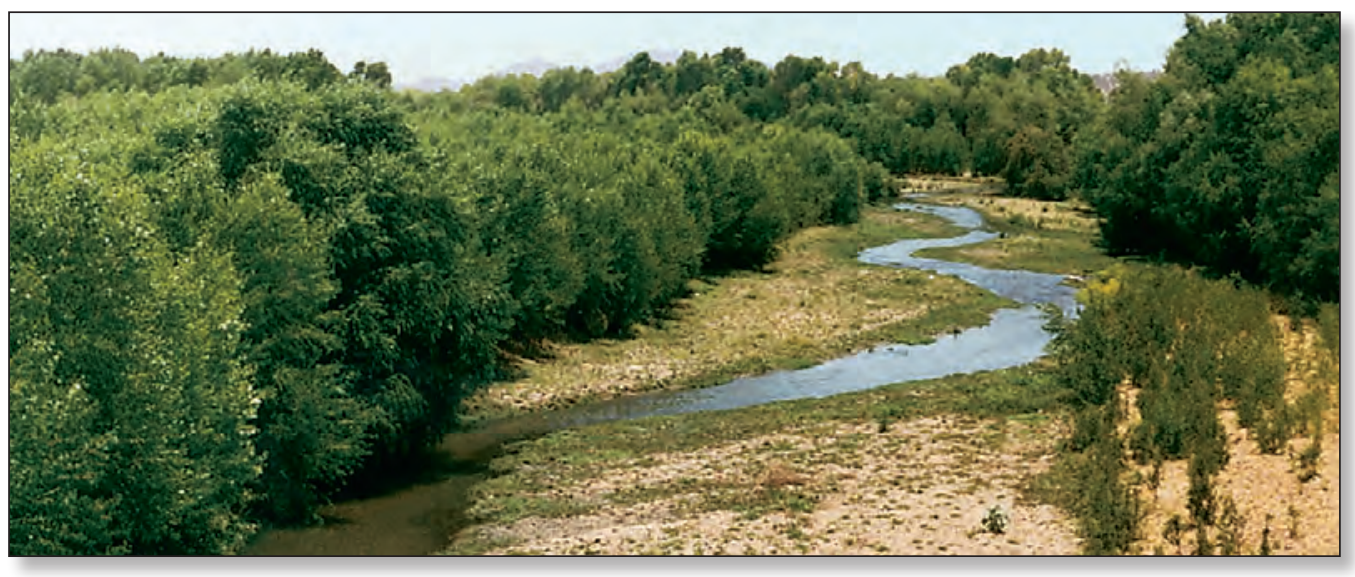

Wastewater-treatment plant effluent provides much of the streamflow in the Santa Cruz River at Tubac, Arizona, during part of the year. Photograph by Gail E. Cordy, U.S. Geological Survey. 
Although concentrations greater than ammonia criteria were infrequent, the sites where criteria were exceeded were predominantly in the Western States (shown by the red and yellow symbols in fig. 7-2). With few exceptions, sites with exceedances generally were in urban and mixed land-use areas. In many cases, treated effluent from wastewater-treatment facilities was known or suspected to be the source of ammonia. NAWQA sampling sites were selected to represent regional-scale, ambient water-quality conditions, and it must be reiterated that when feasible, sites were selected to avoid the effects of major wastewater-treatment plants and other point sources. Thus, these findings generally are not representative of overall stream water-quality conditions where treated effluent is a significant component of streamflow.
Advances in the treatment of wastewater have resulted in decreases in concentrations of ammonia in some streams that receive treated effluent (see Chapter 8 sidebar, Past Changes Resulting from Nutrient Control Measures).

Despite the large inputs of fertilizer and manure, sampling at 135 agricultural sites found only rare exceedances of ammonia criteria. This indicates that ammonia from nonpoint sources is not reaching or persisting in streams at high concentrations. Rather, ammonia in agricultural watersheds is either being sorbed onto soils, volatilized, converted to nitrate through the process of nitrification, and (or) rapidly removed from the water column by aquatic plants.

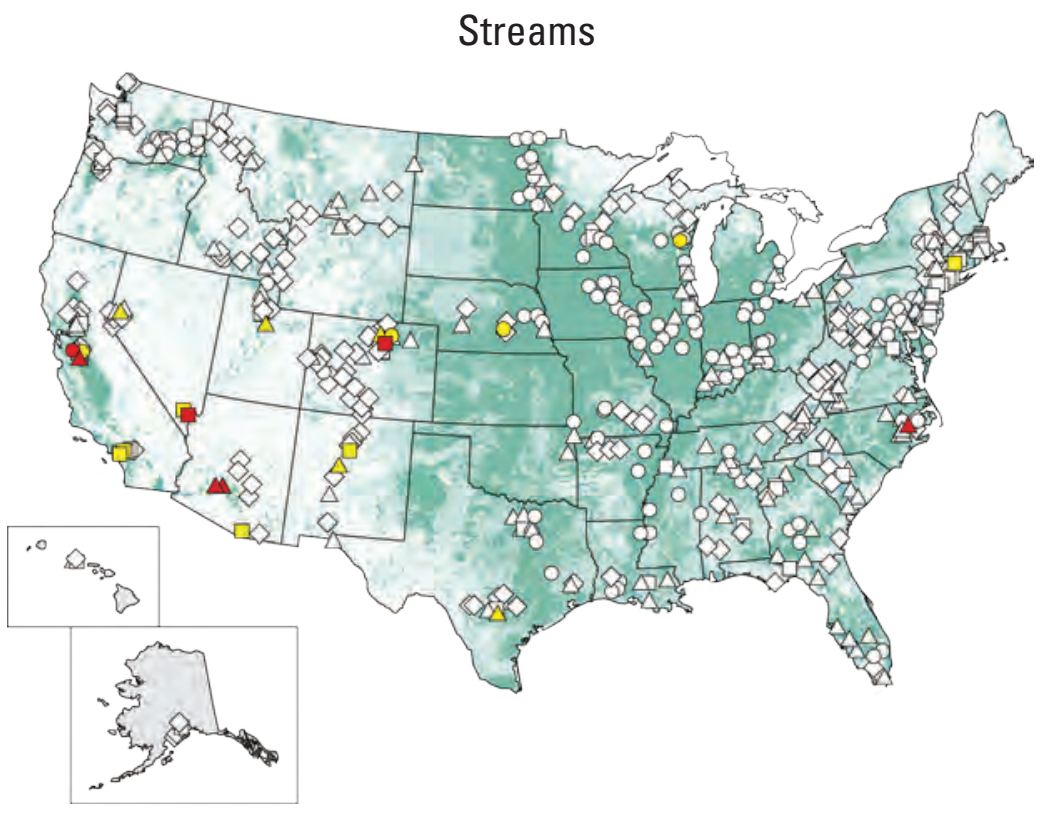

\section{EXPLANATION}

Estimated 1997 nitrogen inputs from fertilizer, manure, and atmosphere, in pounds per square mile

$\square<, 900$
$\square, 900-15,000$
$\square 15,000$

Data on nitrogen inputs not available for Alaska and Hawaii.

\begin{tabular}{cccc}
\multicolumn{3}{c}{ Stream sites, by watershed land use } \\
Agricultural & Urban & Undeveloped & Mixed \\
$\circ$ & $\square$ & $\diamond$ & $\triangle$ \\
$\circ$ & $\square$ & - & $\triangle$ \\
$\bullet$ & $\square$ & - & $\triangle$
\end{tabular}

Type of aquatic health criteria exceeded for ammonia

No exceedance

Chronic criteria exceeded

Acute criteria exceeded

Figure 7-2. Ammonia at concentrations greater than the aquatic life criteria were infrequent, and most such sites were in the Western States. These sites generally are in areas of urban and mixed land use and are either known or suspected to be affected by the discharge of wastewater-treatment plants. 


\section{Changes in Ammonia Sources and Streamflow in Western Basins}

The relation between streamflow and ammonia concentration may reflect whether the ammonia is from a point source or a nonpoint source. Most exceedances of ammonia criteria occurred in western streams in semiarid settings where treated wastewater effluent is likely present. The South Platte River Basin in Colorado and Nebraska is typical of many semiarid western basins with large urban centers. In these basins, treated wastewater effluent is often a major component of streamflow. Concentrations of ammonia in the South Platte River at Henderson, just downstream of the Denver urban center, are an order of magnitude greater than those in the Platte River at Louisville, Nebraska, hundreds of miles downstream. This contrast primarily is a result of the source of ammonia and lack of dilution near Denver. Most of the watershed above the Henderson, Colorado, site is undeveloped, and because of the semiarid climate and upstream diversions, the treated wastewater from the Denver metropolitan area contributes about 69 percent of the streamflow in the South Platte River at this site (Dennehy and others, 1995). Consequently, when streamflow is low in the South Platte River at Henderson, the relative contribution from treated wastewater is high, so that concentrations of ammonia in the river are high (fig. 7-3). When snowmelt runoff from the undeveloped forests at higher elevation in the watershed reaches the streams, flow in the South Platte River at Henderson increases, the relative contributions from treated wastewater decrease, and concentrations of ammonia decrease. In contrast, the watershed of the Platte River at Louisville, Nebraska, is more than 10 times larger than the watershed of the South Platte River at Henderson, and about 83 percent of the Platte River watershed is agricultural land and rangeland. As flow in the Platte River at Louisville increases, concentrations of ammonia also increase (fig. 7-3). Nonpoint sources, primarily fertilizer and manure, are responsible for most of the nitrogen introduced to the watershed upstream of the Platte River at Louisville (Mueller and Spahr, 2005). The increase in ammonia concentrations with flow at the Platte River at Louisville is indicative of a watershed where nutrients primarily are from nonpoint sources and are transported to streams primarily as runoff after their application to the land surface.
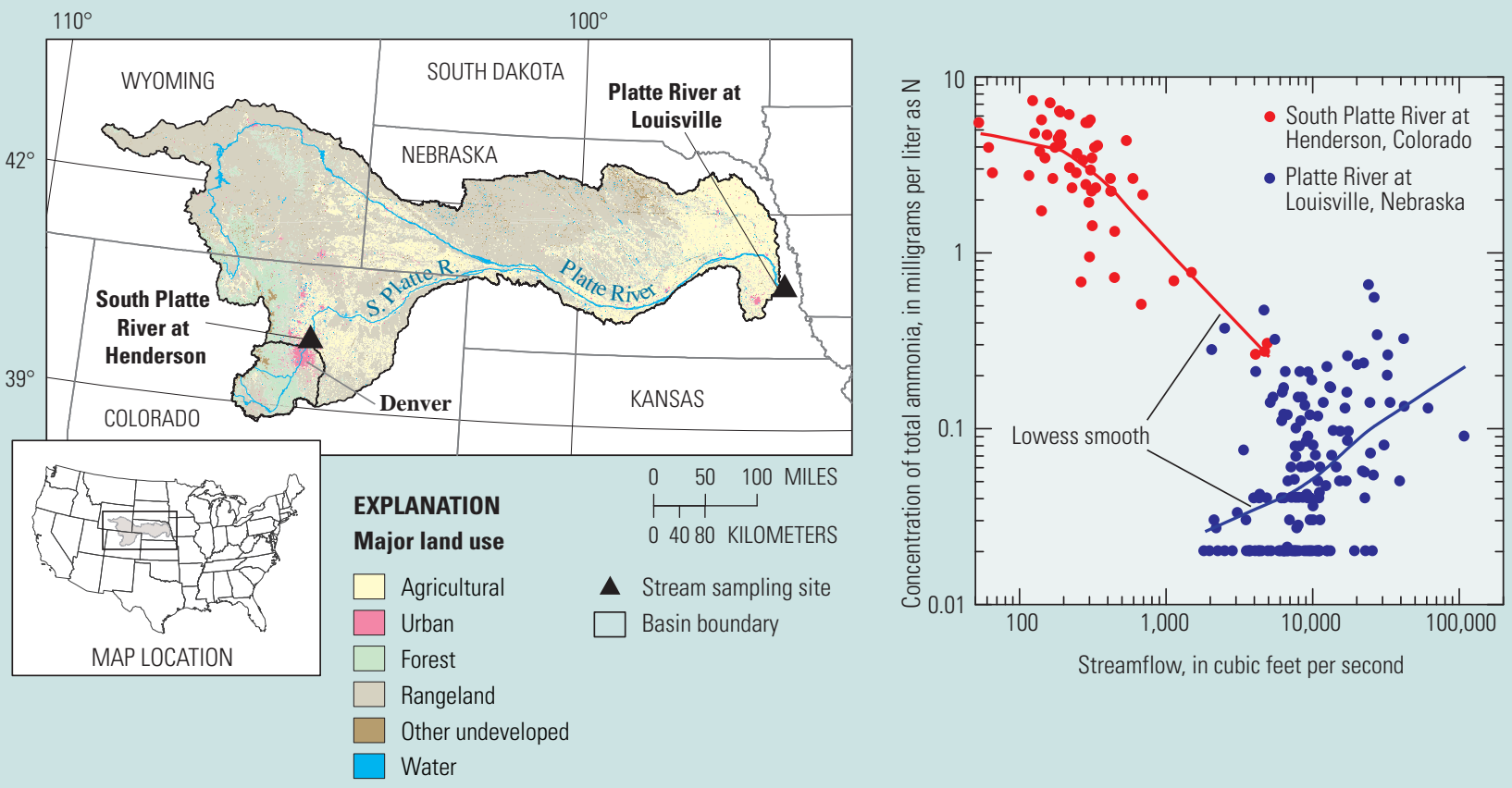

Figure 7-3. The relation between streamflow and ammonia concentration at a site reflects whether the ammonia in a stream is from a point source or a nonpoint source. Discharges of treated wastewater effluent to the South Platte River downstream of Denver, Colorado, result in higher concentrations of ammonia when streamflow is low, and lower concentrations when streamflow is high. The relation between ammonia and streamflow at the Platte River at Louisville, Nebraska, is reversed: ammonia concentrations increase with increasing streamflow, indicating that the ammonia is primarily from nonpoint sources. 


\section{Regional Nutrient Criteria and Background Estimates}

Concentrations of nutrients in minimally impacted streams can be affected by geographic variability of natural conditions, such as geology and climate. Recognizing this variability, the USEPA has developed recommended criteria for total nitrogen and total phosphorus for the protection of aquatic life for 14 nutrient ecoregions (see sidebar, The U.S. Environmental Protection Agency's National Nutrient Criteria Program). These criteria are based on the 25th percentile of data available at the time of criteria development in each ecoregion, and are meant to approximate reference conditions. Current criteria for the 14 ecoregions range from 0.12 to $2.18 \mathrm{mg} / \mathrm{L}$ for total nitrogen and from 0.010 to $0.076^{1} \mathrm{mg} / \mathrm{L}$ for total phosphorus; the criteria also include recommendations for turbidity and chlorophyll $a$ (U.S. Environmental Protection Agency, 2002b).

Smith and others (2003) used the data from Clark and others (2000) to calibrate a simulation model and estimated background concentrations of total nitrogen and total phosphorus for all stream basins in the conterminous United States. From these estimates, they computed the average background concentration for each of the 14 USEPA nutrient ecoregions. These modeled values are compared with the USEPA recommended criteria in figure 7-4. The 75th percentiles of flow-weighted mean concentrations also are shown for the four ecoregions that have at least 10 minimally impacted sites in the data set used for this report.

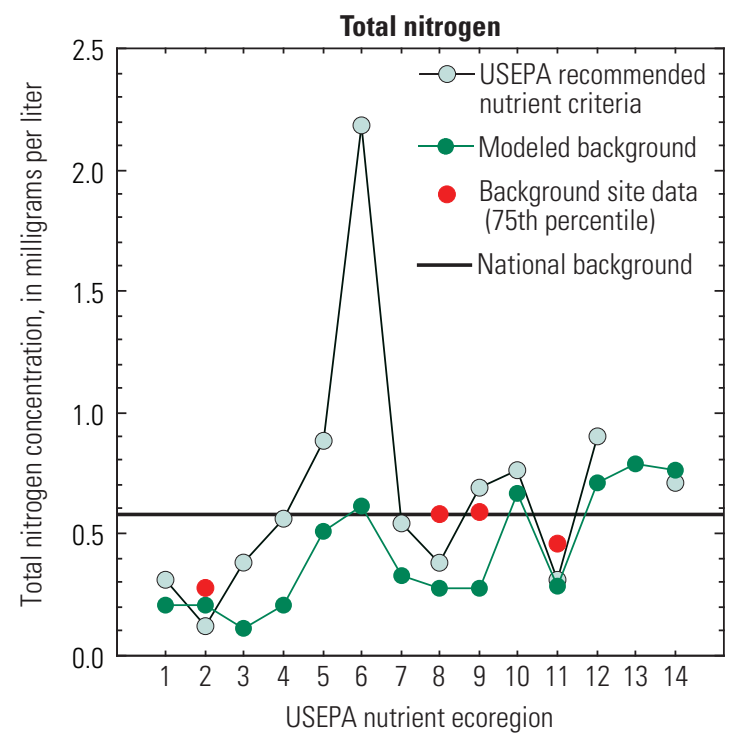

Both the modeled background concentrations and the USEPA recommended nutrient criteria have similar patterns of variation among the nutrient ecoregions (fig. 7-4). Modeled background concentrations represent a condition of no human development and generally are less than the recommended criteria, which represent minimal human impact. However, the recommended criteria are less than modeled background concentrations in several regions, particularly for total phosphorus. Most of the recommended criteria also are somewhat less than regional background concentrations estimated by the 75th percentiles of flow-weighted means for minimally impacted sampling sites. This comparison suggests that it may be difficult to meet the USEPA criteria for phosphorus in streams in developed basins in some nutrient ecoregions, in particular for total phosphorus in streams in basins that have even a modest degree of development, such as those in the Great Plains Grass and Shrublands ecoregion (4).

Other approaches to estimating concentrations indicative of reference conditions are found in the literature, and research is continuing in this area. Herlihy and Sifneos (2008) used data from sites sampled as part of the USEPA's Wadeable Streams Assessment (U.S. Environmental Protection Agency, 2006) to evaluate different approaches to setting regional nutrient criteria. Although the values for total nitrogen were relatively consistent with the USEPA recommended criteria, values for total phosphorus were always greater than the recommended criteria, and were greater by a factor of 3.8 for ecoregion 4 .

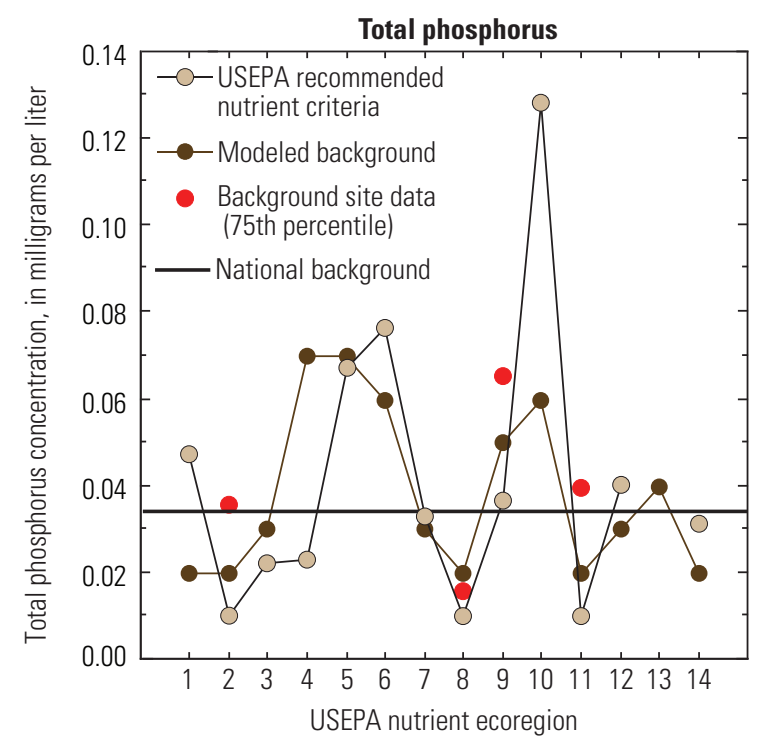

Background site data shown for ecoregions with at least 10 sites. Criteria for USEPA nutrient ecoregion 13 are under development.

Figure 7-4. U.S. Environmental Protection Agency (USEPA) recommended nutrient criteria and U.S. Geological Survey modeled estimates for background nutrient concentrations follow similar patterns of variation within the 14 nutrient ecoregions; however, recommended criteria are more stringent than estimates of background concentrations in several regions, particularly for phosphorus, suggesting that the recommended criteria may be difficult to attain in some areas. (See fig. 7-7 for list of ecoregions.)

\footnotetext{
${ }^{1}$ The value of $0.125 \mathrm{mg} / \mathrm{L}$ for total phosphorus in region 10 is discounted as unreliable by the USEPA.
} 
Concentrations of both total nitrogen and total phosphorus measured in agricultural and urban streams typically are much higher than the recommended ecoregional criteria, as well as the modeled estimates for background concentrations (fig. 7-5A and 7-5B). For example, the median concentration for sites within a specific nutrient ecoregion ranges from about 2 to more than 10 times the

A.

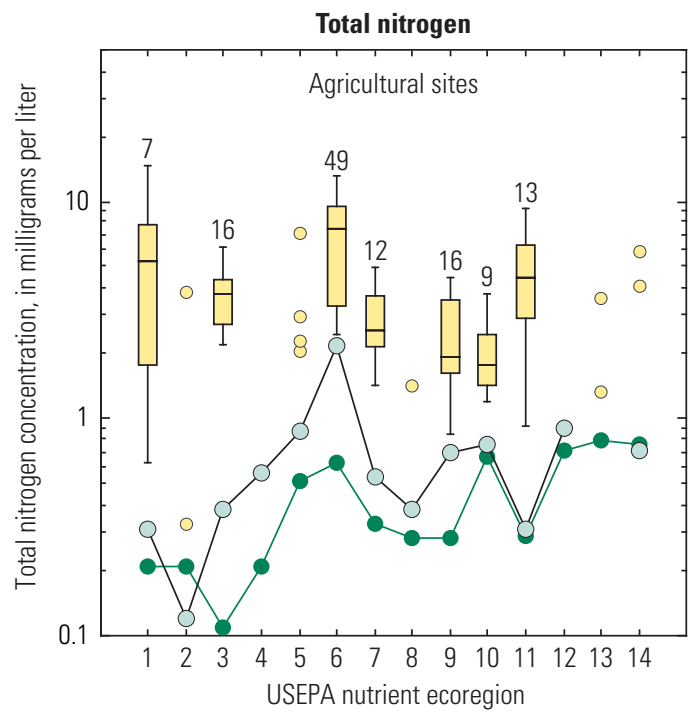

B.

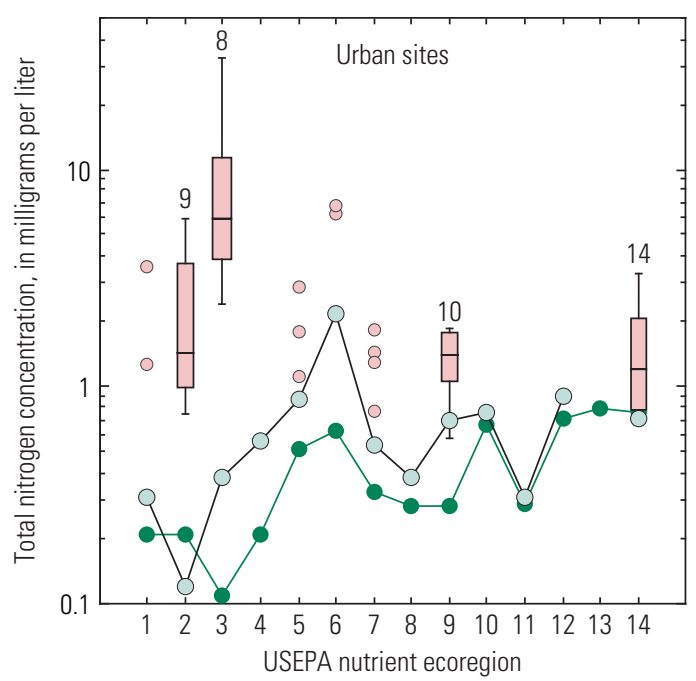

respective ecoregional criterion for both total nitrogen and total phosphorus. The magnitudes of the differences between concentrations measured in agricultural and urban landscapes and recommended criteria show that large reductions in concentration would be necessary if recommended criteria for these areas are to be met.
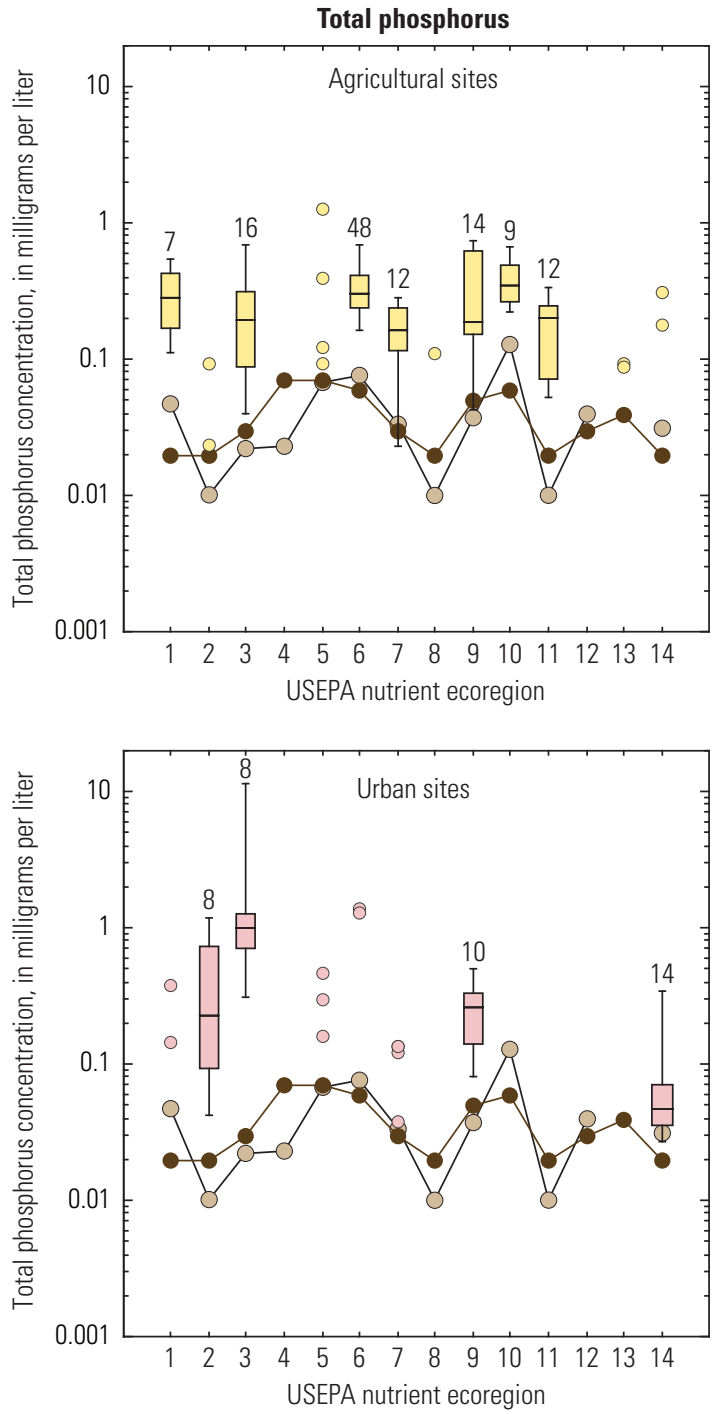

\section{EXPLANATION}

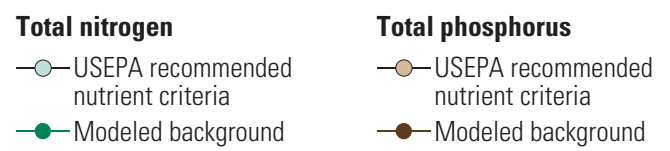

Criteria for USEPA nutrient ecoregion 13 are under development.

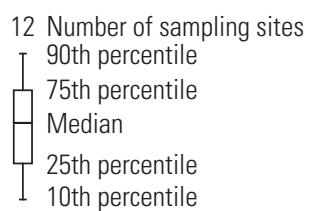

Boxplot shown for ecoregions with more than 6 sampling sites

○ Site value

Figure 7-5. Concentrations of total nitrogen and total phosphorus measured at both agricultural $(A)$ and urban $(B)$ stream sites were from 2 to more than 10 times greater than modeled regional background concentrations and U.S. Environmental Protection Agency (USEPA) recommended nutrient criteria. These comparisons provide a perspective on the magnitude of the challenge necessary to meet the USEPA recommended nutrient criteria for streams in developed basins. (See fig. 7-7 for list of ecoregions.) 


\section{The U.S. Environmental Protection Agency's National Nutrient Criteria Program}

\section{"To restore and maintain the chemical, physical and biological integrity of the Nation's waters" -Clean Water Act Section 101(a)}

Nutrients consistently rank as one of the top five causes of water body impairment for waters surveyed by States, Tribes, and Territories and reported to USEPA. USEPA's current figures indicate that for those waters assessed, nutrients have a combined direct and indirect effect on the impairment of 51 percent of river and stream miles, 52 percent of lake acres, and 58 percent of bay and estuarine square miles (U.S. Environmental Protection Agency, 2009b). The influence of nutrients on streams was further documented in a recent USEPA study that reported that 30 percent of the streams in the United States contained impaired biological communities with nitrogen and phosphorus as the leading causes of impairment (U.S. Environmental Protection Agency, 2006).

To address these issues, the USEPA started the National Nutrient Program as an offshoot of the 1998 Clean Water Action Plan to reduce eutrophication that results from human activity. The USEPA is partnering with States, authorized Tribes, and Territories to identify and adopt appropriate numeric nutrient criteria into State, Tribal, and Territorial water-quality standards and implement those standards in their water-quality programs (fig. 7-6).

USEPA developed recommended criteria for eutrophication causal and response variables for rivers/ streams and lakes/reservoirs. Recommended criteria for rivers/streams were developed for 13 nutrient ecoregions ${ }^{1}$ (fig. 7-7). USEPA also provided technical guidance for developing nutrient criteria for wetlands and for estuarine and coastal marine waters. USEPA provided three options to States and Tribes for adopting nutrient criteria in rivers/streams and lakes/reservoirs:

- Adopt the ecoregional criteria recommendations that USEPA published under section 304(a) of the Clean Water Act;

- Modify the section 304(a) criteria to reflect site-specific conditions; or

- Adopt criteria based on other scientifically defensible methods.

Most States are utilizing the last approach, basing their criteria on the biological responses to nutrients in waters of their State. This approach requires extensive field data, and statistical analysis of those data. USEPA supports the States by funding data gathering efforts and making national experts available to analyze that data, and provides technical assistance as States consider and derive nutrient criteria endpoints. USEPA published a status report in 2008 (U.S. Environmental Protection Agency, 2008) on the progress States are making in adopting recommended nutrient criteria into Water-Quality Standards. This report can be found on the Nitrogen and Phosphorus Pollution Program webpage: http://www.epa.gov/ waterscience/criteria/nutrient/strategy/status.html. In addition to supporting States, Tribes, and Territories in developing numeric nutrient criteria, USEPA also is engaged in the following activities:

- Working with the State of Florida to develop nutrient and biological criteria for both inland and estuarine coastal waters in response to a lawsuit from the Florida Wildlife Federation;

- Developing a document with recommendations for using empirical approaches derived field data to establish nutrient criteria; and

- Working with State and national organizations to assess innovative approaches to reducing nitrogen and phosphorus pollution.

\footnotetext{
${ }^{1}$ Criteria for USEPA nutrient ecoregion 13 are under development.
} 
Geographic scales of nutrient criteria development

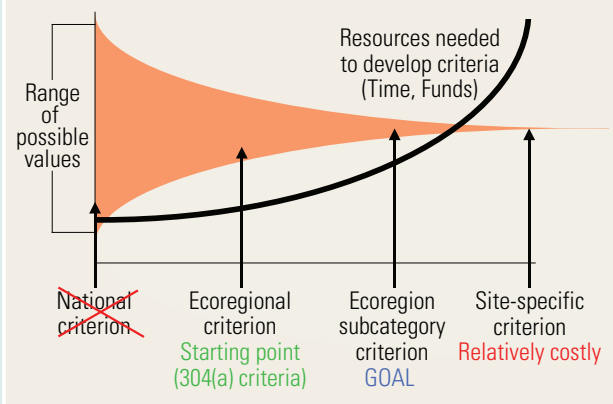

Figure 7-6. In recognition of both the wide range in nutrient concentrations across the Nation, as well as the large amount of resources needed to develop nutrient criteria, the USEPA developed recommended criteria for ecoregions as a starting point for States, Tribes, and Territories to begin developing criteria specific to their conditions.

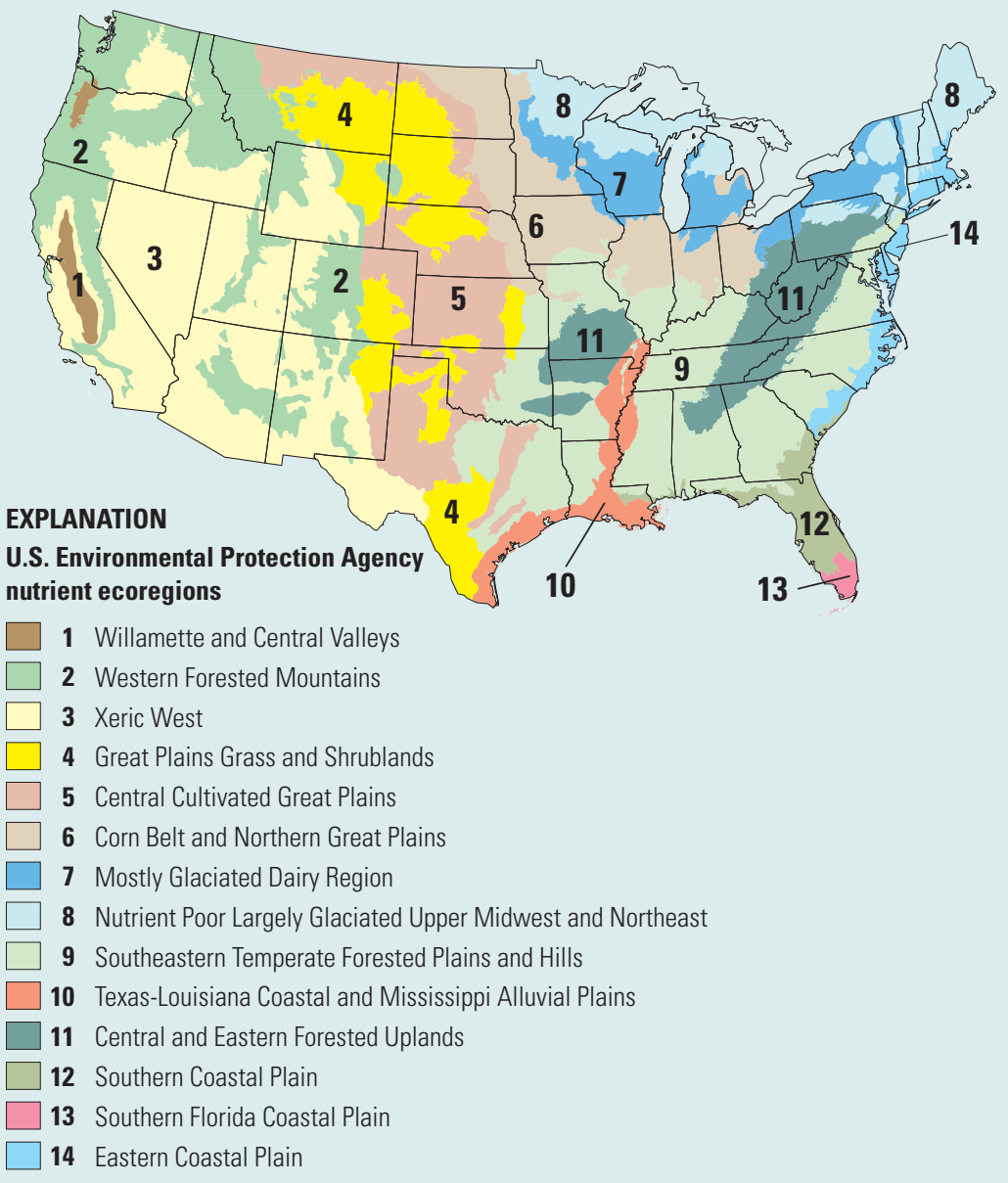

Figure 7-7. The U.S. Environmental Protection Agency has developed recommended nutrient criteria for rivers and streams for 14 ecoregions in the conterminous United States (U.S. Environmental Protection Agency, 2002b). 


\section{Comparison of Nutrient Criteria with Predicted Total Nitrogen in Streams Based on NAWOA data}

A statistical model developed on the basis of NAWQA data for total nitrogen in streams predicts widespread exceedance of the proposed nutrient criteria for total nitrogen concentrations, and only a modest decrease in concentration in response to reduced fertilizer inputs (Spahr and others, 2010) (see Chapter 3, Extrapolation to Unsampled Areas, Development of Models for Total Nitrogen Concentrations in Streams). The model was used to calculate the probability that the flow-weighted average concentration of total nitrogen in a given stream reach is greater than the recommended criteria for that nutrient ecoregion (U.S. Environmental Protection Agency, 2000). The model simulations show that streams in which total nitrogen concentrations have a high probability ( 75 percent or greater) of exceeding the recommended criteria are broadly distributed across the Nation (fig. 7-8A), and constitute 83 percent of all stream miles (fig. 7-8B). This proportion is similar to what would be expected considering how the criteria were designed (U.S. Environmental Protection Agency, 2001, fig. 5). In the Corn Belt and Northern Great Plains (nutrient ecoregion 6), the recommended nitrogen criterion is likely to be exceeded in almost 70 percent of stream miles with a probability of at least 90 percent.
The models also can be used to provide broad regional estimates of how total nitrogen concentrations in streams may change with reductions in nonpoint sources of nitrogen. For example, when nitrogen inputs from fertilizer use were reduced by 25 percent in the Corn Belt and Northern Great Plains nutrient ecoregion, the number of stream miles with a high probability (greater than 90 percent) of exceeding the nutrient criterion decreased by only about 2.5 percent. Although the reduction in fertilizer use resulted in a decrease in the estimated nitrogen concentrations, concentrations in most streams still greatly exceeded the nutrient criterion. Fertilizer inputs are only one potential source of nitrogen to streams, and this exercise did not consider change in other nitrogen sources. Although this scenario does not capture the complex response to a change in nutrient input in a specific stream, it does illustrate the magnitude of the challenge of reducing nutrient impact on streams through source reduction alone. The results suggest that greater use of land management strategies to reduce the transport of nutrients to streams may be needed to meet recommended criteria for streams draining areas with appreciable agricultural and urban development. For example, installation of simple bioreactors to treat tile drainage has been shown to be an effective way to reduce transport of nitrogen to streams (Jaynes and others, 2008). 
A.

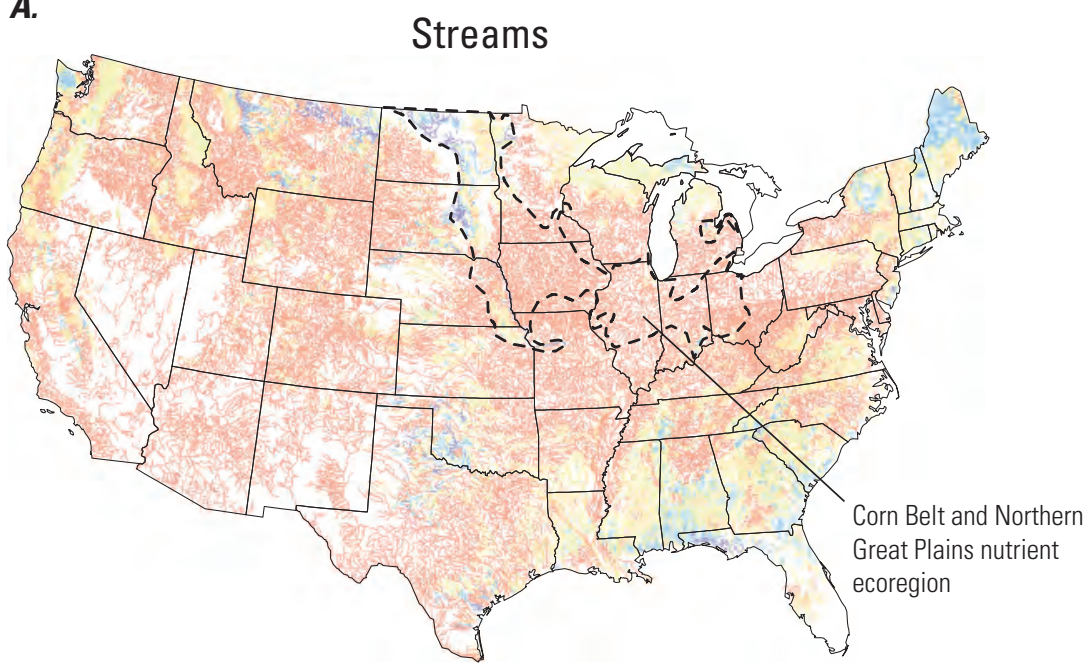

EXPLANATION

Probability that predicted average nitrogen concentration exceeds recommended nutrient criteria for that ecoregion

$\leq 25 \longrightarrow>25-50 \longrightarrow>50-75->75-90 \longrightarrow 90$

B.

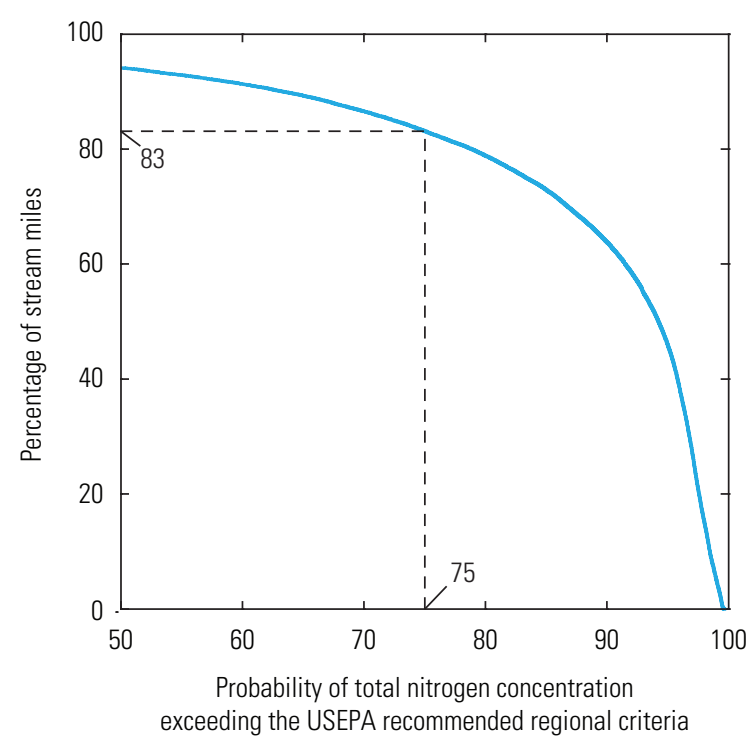

Figure 7-8. Model simulations show that streams in which total nitrogen concentrations have a high probability (75 percent or greater) of exceeding the recommended criteria are broadly distributed across the Nation $(A)$, and constitute 83 percent of all stream miles $(B)$ (Spahr and others, 2010). 


\section{Influence of Elevated Nutrients on Aquatic Life}

Although nutrients, primarily nitrogen and phosphorus, are critical for a healthy ecosystem, excessive levels of nutrients in streams can lead to eutrophic conditions characterized by increased plant growth followed by a decline in oxygen in the water when dead plant material (algae or macrophytes) decomposes. Excessive plant growth can further affect stream health by reducing stream velocity and thereby causing greater deposition of fine sediments along the stream bottom. Increased deposition of fine sediments reduces quality and availability of streambed habitat, often resulting in reduction or loss of bottom-dwelling organisms. Although nutrient enrichment from elevated concentrations of nitrogen and phosphorus is a major contributing factor to stream eutrophication, enrichment effects can vary from one stream to another as a result of differences in patterns of streamflow, amount of riparian shading, water temperature, water clarity, and the extent of groundwater and surface water exchange.

One of the most common approaches to assessing the effects of eutrophication is to use the presence or absence of certain plants and animals as indicators of stream health. These kinds of approaches are referred to as bioassessments, and commonly are used in many Federal and State water-quality programs. Most of these programs are based on assessments of the numbers and kinds of individuals comprising the algal, macroinvertebrate, or fish communities. Data on aquatic organisms add strength to stream-quality assessments because organisms integrate the effects of stream conditions over a period of time ranging from days to years, whereas a measurement of nutrient concentration represents a single point in time. Information about the composition of stream communities can be used to assess the overall health of a stream ecosystem, based on the degree to which biological communities differ from a natural state (see sidebar, Assessment of Biological Condition). Such differences can indicate whether a stream has been influenced by human disturbance or, conversely, how much it has recovered or improved from some previous condition. Calculation of biological condition provides a measure that can be used to compare individual sites or groups of stream sites across different landscapes.

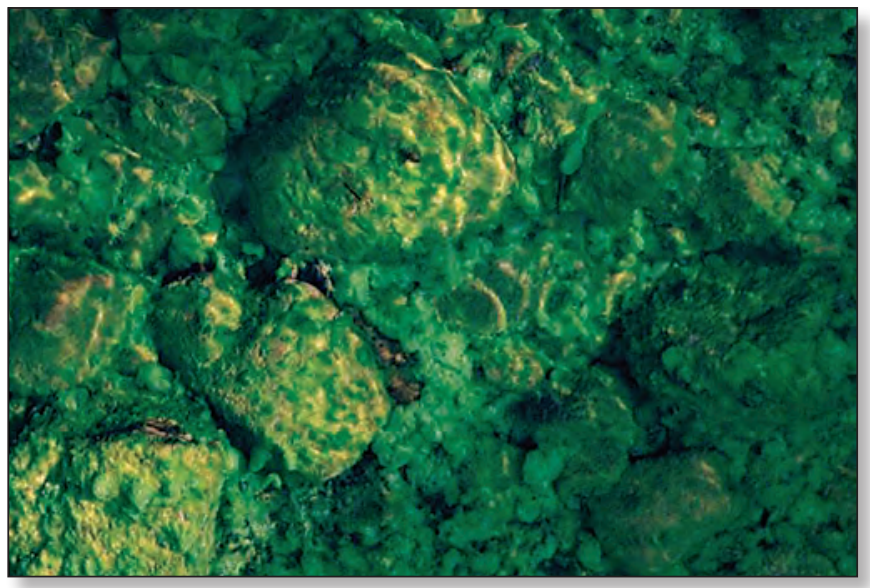

Photograph by Carmen Burton, U.S. Geological Survey.

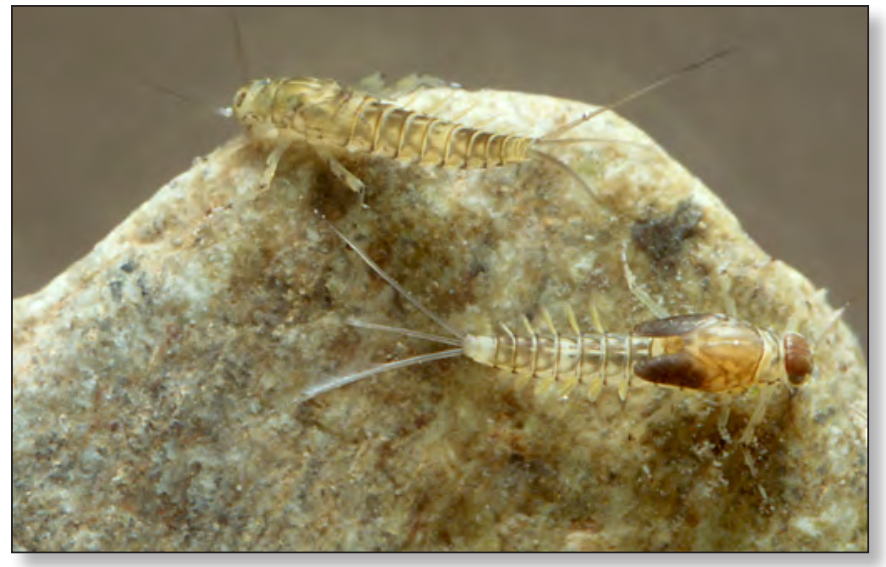

Photograph by Steve Fend, U.S. Geological Survey.

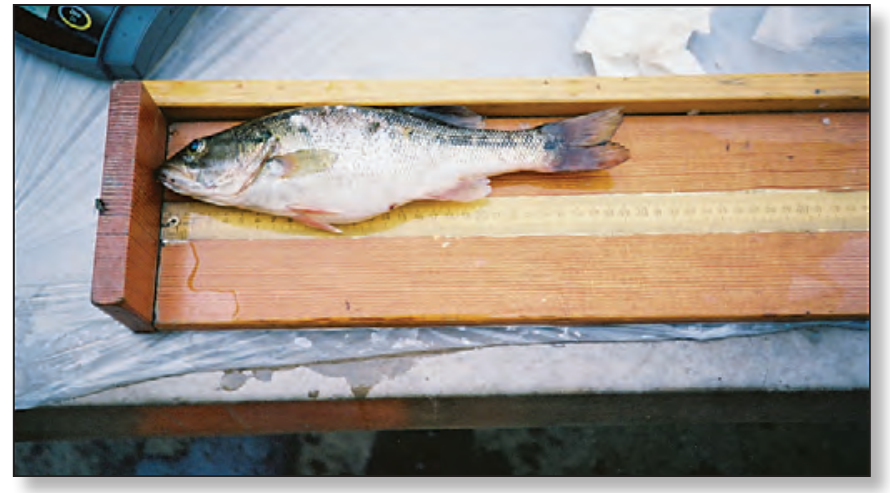

Photograph by Jason May, U.S. Geological Survey.

Some State water-quality programs use assessments of algal, macroinvertebrate, or fish communities. 


\section{Assessment of Biological Condition}

The NAWQA Program used a consistent approach to assess biological condition for algal, macroinvertebrate, and fish communities at about 1,400 stream sites across the Nation. Biological condition was assessed by comparing observed $(0)$ community characteristics (such as the number of taxa) to those expected (E) if the community was minimally disturbed by human activities. The observed condition ( 0 ) is derived from a sample collected at a site, whereas the expected (E) condition is estimated based on data from a set of environmentally similar reference sites. Because natural variation in environmental settings is accounted for in this approach, departures of observed condition from expected condition are likely the result of human activities. The ratio of observed to expected conditions (O/E) can be expressed as a percentage of the reference condition scaled from 0 percent to 100 percent. The lower the percentage, the more altered the biological community, whereas a higher percentage means that the biological community is more similar to reference conditions.

\section{Decreases in Biological Condition Were Associated with Nutrient Enrichment}

Biological condition for algal, macroinvertebrate, and fish communities declined with increasing concentrations of nitrogen and phosphorus in streams (fig. 7-9). Streams were grouped into three categories of nutrient enrichment according to concentration ranges of total nitrogen and total phosphorus based on published nutrient enrichment categories (Dodds and others, 1998). Changes in biological condition corresponding to increasing nutrient concentrations were more pronounced for algal communities than for macroinvertebrate or fish communities. In streams with the highest concentrations of total nitrogen or total phosphorus, average biological condition scores for algal communities were about 30 percentage points lower than algal condition in streams with the lowest nutrient concentrations. In contrast, biological condition scores in streams with the highest nutrient concentrations were about 14 percentage points lower for fish communities and about 10 percentage points lower for macroinvertebrate communities compared to streams with the lowest nutrient concentrations. This finding is consistent with the direct link between nutrient availability and algal growth, whereas the response of higher organisms to nutrients is mostly indirect, mediated by transfer of energy (food resources) from primary producers (aquatic plants and algae) via food chains of various complexity. Algal communities are a useful biological indicator of eutrophication because of their sensitivity to nutrient enrichment (see sidebar, Algae as Indicators of Nutrient Enrichment).
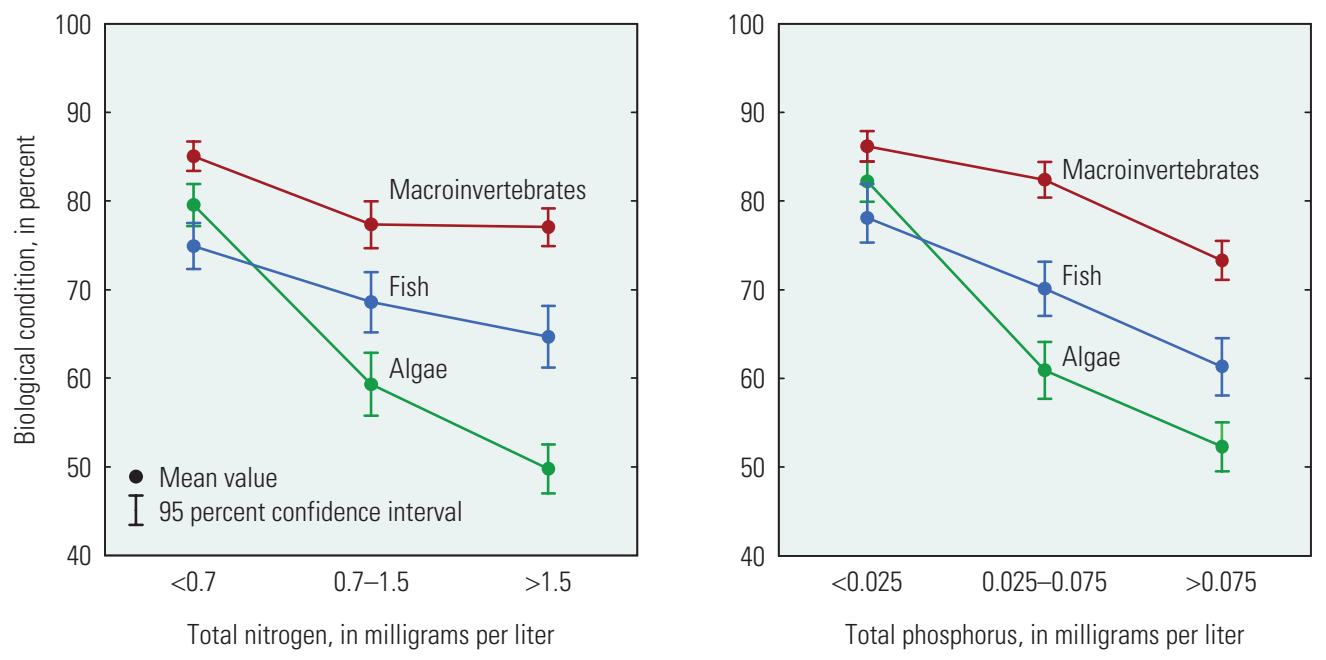

Figure 7-9. Biological condition for algal, macroinvertebrate, and fish communities declined with increasing concentrations of nitrogen and phosphorus in streams. Changes were most pronounced for algal communities, in which the average biological condition in streams with the highest nutrient concentrations was about 30 percentage points lower than the algal biological condition in streams with the lowest nutrient concentrations. 


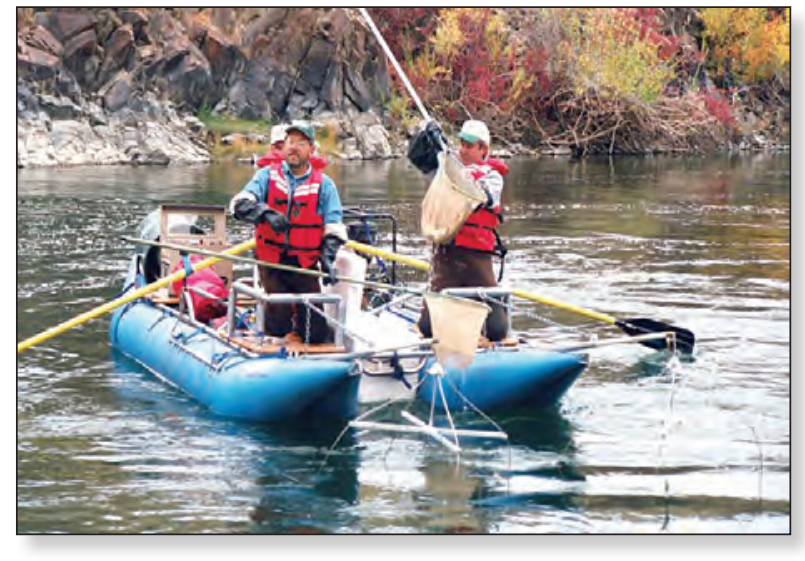

Fish are electroshocked, collected, surveyed, and released back to the stream to determine a census of fish population. Photograph by Terry Maret, U.S. Geological Survey.

\section{Algal Community Condition Was Reduced for Many Streams in Agricultural and Urban Land-Use Settings}

The relatively low median biological condition scores for algal communities in urban and agricultural streams indicated that stream health may be degraded in these land-use settings compared to that in streams in undeveloped areas (fig. 7-10). The median biological condition scores of algal communities in agricultural and urban streams were 33 and 49 percentage points lower, respectively, than the reference condition score. Although the condition of algal communities was significantly reduced in agricultural and urban streams, the wide range of condition scores (indicated by the difference between the tenth and ninetieth percentiles) shows that algal condition was highly variable - that is, streams with high (expected in relatively undisturbed stream environments) as well as low (expected in highly disturbed stream environments) biological condition were found in each of these land-use settings. Algal condition scores generally were lower at urban sites than at agricultural sites, despite significantly higher concentrations of total nitrogen at agricultural sites. This lack of correspondence suggests that other factors, such as habitat, the specific forms of nitrogen or phosphorus present, or the presence of other chemical stressors, also are influencing the condition of algal communities at urban sites.

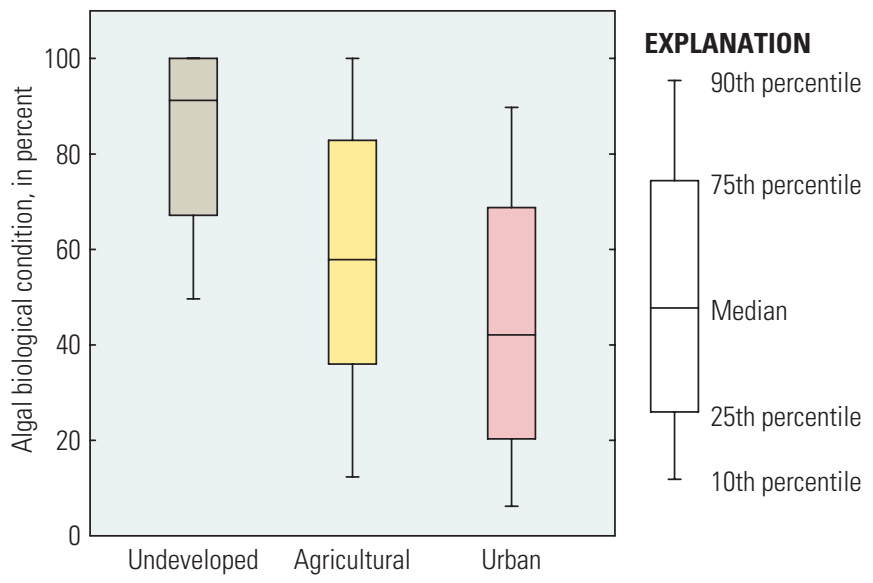

Figure 7-10. The relatively low median biological condition scores for algal communities in urban and agricultural streams indicate that stream health may be degraded in these land-use settings compared to that in undeveloped streams.

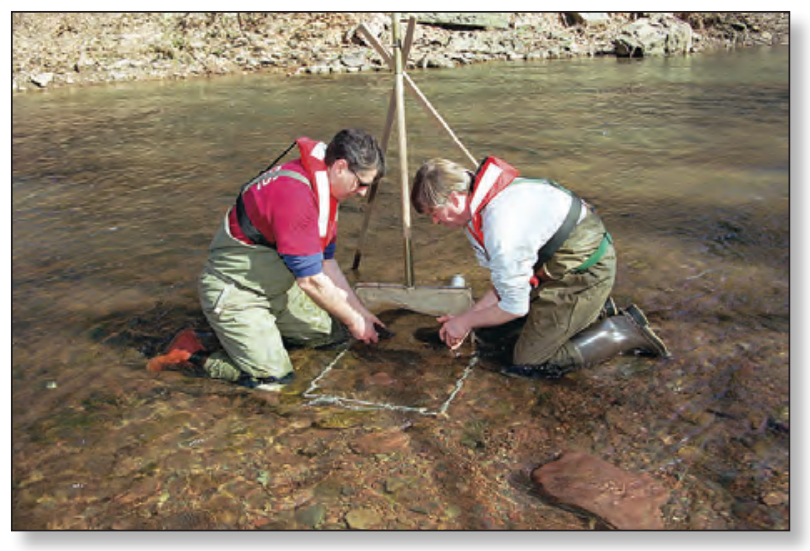

Macroinvertebrates are collected with a Slack sampler. Photograph by Dennis Sun, U.S. Geological Survey. 

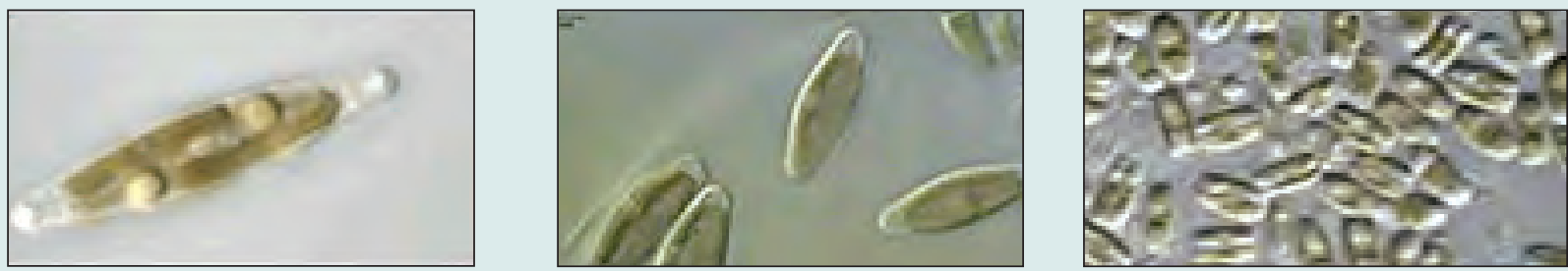

Photographs printed with permission from the Academy of Natural Sciences, Patrick Center for Environmental Research Algae Image Database.

\section{Algae as Indicators of Nutrient Enrichment}

The biological condition of algal communities is an especially effective indicator of human-influenced changes in water and habitat quality because many algal species have specific environmental requirements for growth and development. These requirements — such as food and habitat preferences, reproductive behavior, and lifespan—are all part of each species' life history strategy for survival. Because all algae species have unique combinations of life history strategies and environmental preferences, their presence in a stream indicates a specific - and sometimes narrow-range of environmental conditions. Species occurring in streams in which water and habitat quality are degraded generally are limited to those organisms that are tolerant of existing physical and chemical properties of the stream environment.

As an example, the relative abundance of eutrophic diatoms in algal communities increased as concentrations of nitrogen and phosphorus increased (Porter and others, 2008). Eutrophic diatoms, which are algal species that prefer streams with elevated levels of nutrients, had a higher relative abundance in areas of the country with intensive agriculture, such as the upper Midwest, and in heavily urbanized areas (fig. 7-11). Eutrophic diatoms also were a strong indicator of nutrient enrichment in most - but not all—of the major river basins in the country (Porter and others, 2008). The relative abundance of other algal species may reflect other important environmental conditions, such as the concentration of dissolved oxygen or salinity. Algal indices are increasingly being considered in State and Tribal bioassessment programs (U.S. Environmental Protection Agency, 2002a), as well as in development of nutrient criteria at the State level (Ponader and others, 2005; Belton and others, 2006).

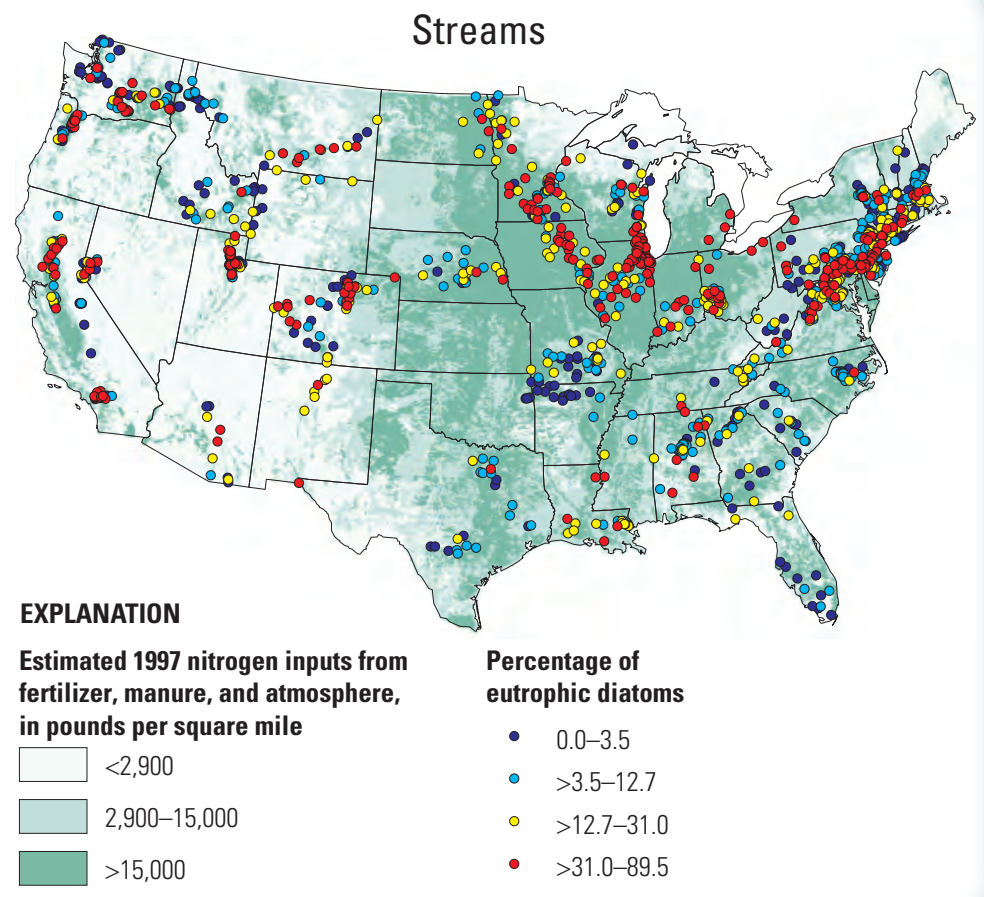

Figure 7-11. Eutrophic diatomsthose that prefer streams with elevated levels of nutrients-have a high relative abundance in areas of the country with intensive agriculture, such as the upper Midwest, and in intensively urbanized areas. (Modified from Porter and others, 2008.) 


\section{Nutrient-Biota Interactions in Agricultural Streams}

In 2001, NAWQA began a study of the effects of nutrient enrichment on stream ecosystems in five areas with extensive agricultural land. The objective of the study was to improve understanding of the interactions of nutrients, habitat, and biological community structure (algal and macroinvertebrate communities) and function (nutrient transformations and metabolism). Currently, the concentrations of nitrogen and phosphorus, along with algal biomass (chlorophyll $a$ ), are used by the USEPA and States for establishing nutrient criteria and for assessing nutrient enrichment in streams. One common approach to establishing nutrient criteria is to develop a statistical model that can predict plant biomass on the basis of specific nutrient concentrations, so that the model can be used to determine a target nutrient concentration for maintaining plant biomass below a specific level. Findings from this study should help State and Federal agencies with the development of nutrient criteria in various subregions of the United States. Although the study is currently (2010) in progress, preliminary findings are presented below. (Details on the study approach are presented in the sidebar, Effects of Nutrient Enrichment on Stream Ecosystems: Study Approach.)

\section{Effects of Nutrient Enrichment on Stream Ecosystems: Study Approach}

To address nutrient-biota interactions in agricultural streams, the NAWQA study on nutrient enrichment sampled 20 to 30 independent, wadeable stream sites distributed along a gradient of nutrient concentrations in each of eight study areas (fig. 7-12). Sites were selected on the basis of geographic data, predicted nutrient loads and measured nutrient concentrations, habitat, and stream size. Data collected during the growing season included nitrogen and phosphorus in water, biological communities (algae and invertebrates), algal chlorophyll $a$, and stream habitat; stream metabolism (primary production and respiration) was collected at approximately one-third of the sites. Geographic Information Systems were used to evaluate riparian and land-use data. More information on study design and findings can be found at http://wa.water.usgs.gov/neet/.

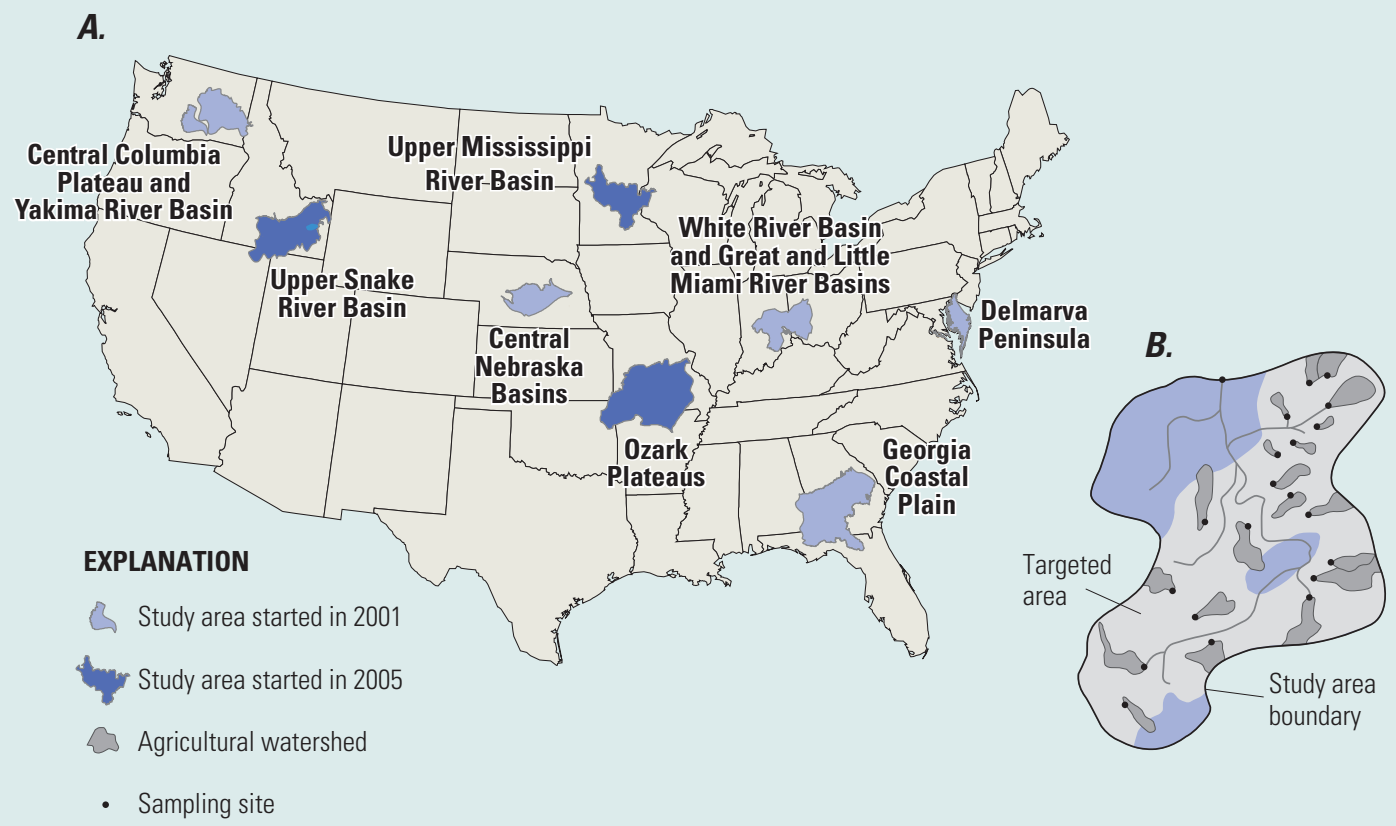

Figure 7-12. The effects of nutrient enrichment on stream ecosystems in agricultural landscapes are being studied in eight geographic areas $(A)$, by sampling 20 to 30 sites in each area along a gradient of nutrient conditions $(B)$. 


\section{Nutrients and Algal Biomass}

Although increases in the concentrations of nitrogen and phosphorus can cause an increase in algal biomass, the relation is often weak, varies geographically, and can be opposite of what one would expect (Munn and others, 2010). Figure 7-13 is a Nutrient-Algal Biomass Conceptual Diagram, developed as part of the NAWQA studies on nutrient enrichment, that describes the hypothetical relation between nutrient concentrations and algal biomass, represented by chlorophyll $a$. There is a general assumption that sites fall along a line that runs from the lower left quadrant, where algal biomass increases as a function of nutrient availability (an oligotrophic stream), to the upper right quadrant, where the nutrient concentrations exceed what algae require (a eutrophic stream) and, therefore, algal biomass becomes limited by other factors, such as habitat. However, sites also can fall into the upper left and lower right quadrants. Sites in the upper left quadrant have algal biomass that accumulates to levels high enough to effectively remove nitrogen and phosphorus from the water column such that their concentrations decrease to lower levels, sometimes even below detection. The implication is that some sites may have concentrations below nitrogen or phosphorus criteria, but still be eutrophic, with high algal biomass and problems similar to those associated with low concentrations of dissolved oxygen. In contrast, sites in the lower right quadrant have elevated nutrient concentrations, but plant growth does not occur because of habitat limitations, for example, reduced light levels due to high concentrations of suspended sediment, or shading by canopy cover. These streams have insufficient solar energy to convert nutrients into algal biomass, and thus nutrients are transported to downstream receiving waters. It is, therefore, critical to consider a mixture of variables when determining whether streams meet nutrient criteria.

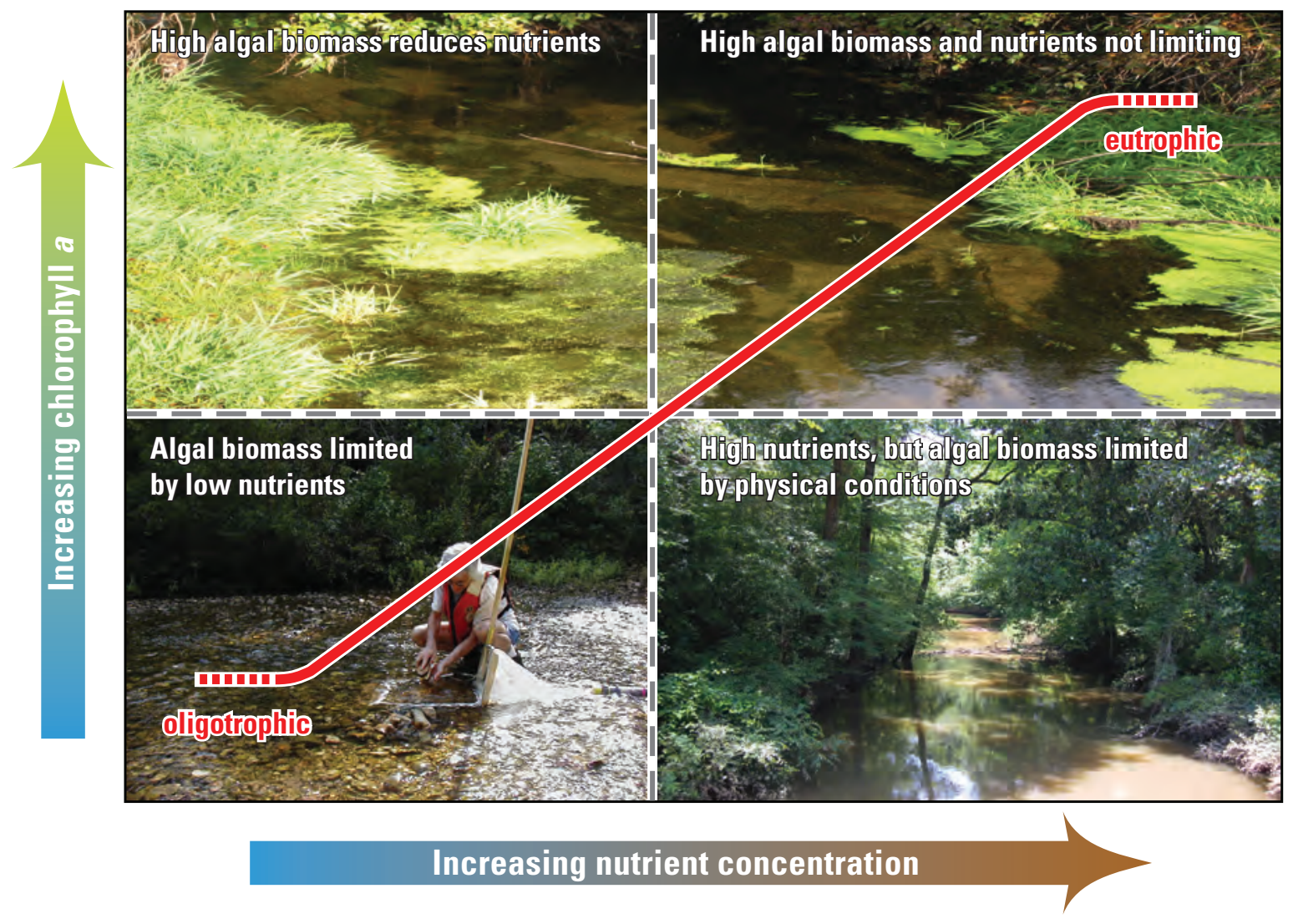

Figure 7-13. This Nutrient-Algal Biomass Conceptual Diagram illustrates the relation between the concentration of nutrients (total nitrogen and total phosphorus) and the resulting algal biomass represented by chlorophyll $a$. The three photographs illustrate the type of streams in each quadrant: the top photograph is Clear Creek near Columbus, Nebraska (taken by M.D. Munn, U.S. Geological Survey), the lower left photograph is North Sylamore Creek near Fifty Six, Arkansas (taken by James Petersen, U.S. Geological Survey), and the lower right photograph is Lime Creek, near Cobb, Georgia (taken by Alan Cressler, U.S. Geological Survey). 
Whereas a positive relation exists between total phosphorus and algal biomass in agricultural streams nationwide, figure 7-14 suggests that the relation is partly driven by aggregating regions with very different relations (Munn and others, 2010). Data from the 143 agricultural sites distributed throughout the five study areas were aggregated to examine the Nutrient-Algal Biomass concept. The regression model developed to determine if benthic algal biomass (chlorophyll $a$ ) on fine-grained sediment could be predicted on the basis of total phosphorus concentration explained only 12 percent of the variability in chlorophyll $a$ (fig. 7-14). The regression model for total nitrogen was not significant.

The lack of a relation between algal biomass and nutrients in some regions indicates that most of the sites within those study areas have nutrient concentrations greater than what the algae require, so that additional increases in nutrients would have minimal effect on algal biomass (the upper right quadrant in fig. 7-13). For example, the lowest concentration of total phosphorus reported for streams in the Central Nebraska study was $0.14 \mathrm{mg} / \mathrm{L}$, which is well above the concentration needed for algal growth. Regression models developed for each study area told divergent stories. Total phosphorus explained 32 percent of the variation in chlorophyll $a$ in the Delmarva Peninsula study area, but the other study areas either did not show a significant relation, or displayed a negative relation (as for the Central Columbia Plateau and Yakima River study area) between total phosphorus and algal biomass that is due to factors other than nutrients. The relative strength of the relation in the Delmarva Peninsula study area is likely due in part to the relatively low-and large range in-phosphorus concentrations.

Regression models were improved by the addition of habitat variables, such as water temperature and canopy cover. For example, the amount of variation in chlorophyll $a$ concentrations explained increased from 12 percent, when nutrients alone were used as input variables, to 32 percent when both nutrients and habitat variables were included. This increase in the amount of variation explained by habitat variables was also found in the Delmarva Peninsula study area, where the amount of variation in chlorophyll $a$ concentrations explained by the statistical model increased from 32 to 46 percent with the addition of a single habitat variable, canopy cover. The wide range in biological response to nutrient levels supports the need for a regional approach to establishing nutrient criteria, but also suggests that specific measures of habitat may need to be part of any criteria and (or) assessment to better understand expectations of changes in management practices meant to reduce nutrient loading to streams.

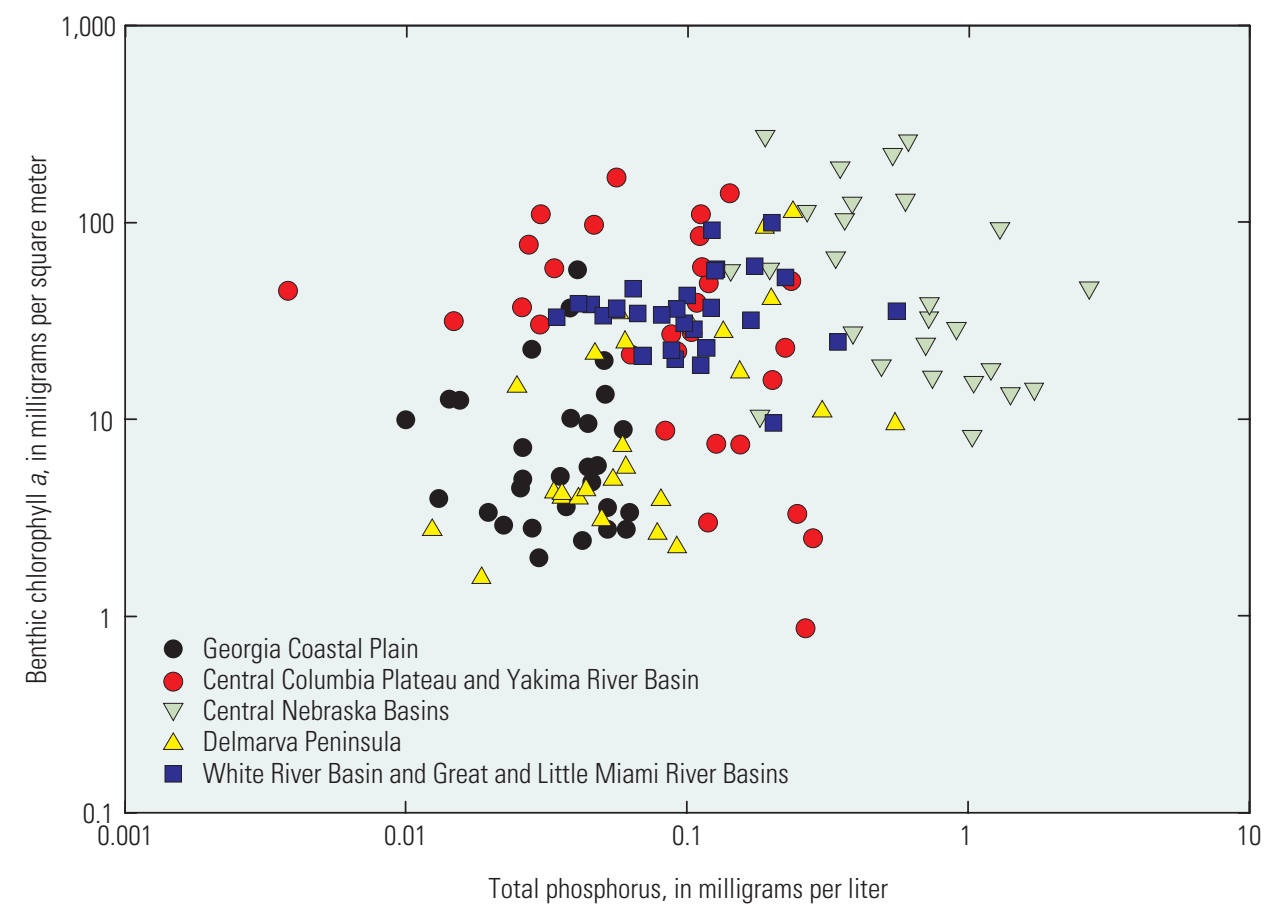

Figure 7-14. Although there is a positive relation between total phosphorus concentration and algal biomass in agricultural streams nationwide, the relation is partly the result of aggregating data for regions with very different relations. (Modified from Munn and others, 2010.) 


\section{Changes in Nutrient Concentrations: Past and Predicted}

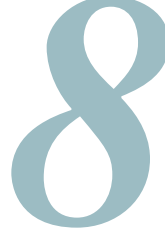

\section{Introduction}

Long-term changes in nutrient concentrations in streams and groundwater are determined by natural climatic changes and human changes in the use and management of agricultural, urban, and industrial sources of nutrients. Detecting changes in nutrient concentrations in streams and in groundwater presents different challenges. In streams, nutrient concentrations can vary widely over a few hours or days, making it difficult to detect smaller sustained changes over several years. In groundwater, the slow flow rates may result in very gradual changes in nutrient concentrations. Both circumstances necessitate longterm monitoring to discern trends in nutrient concentrations. Long-term, consistent monitoring can provide insight into how and why nutrient concentrations are changing over time-insight that is critical for evaluating progress towards waterquality goals, anticipating where action may be necessary to prevent degradation of water resources, and planning effective remediation strategies.

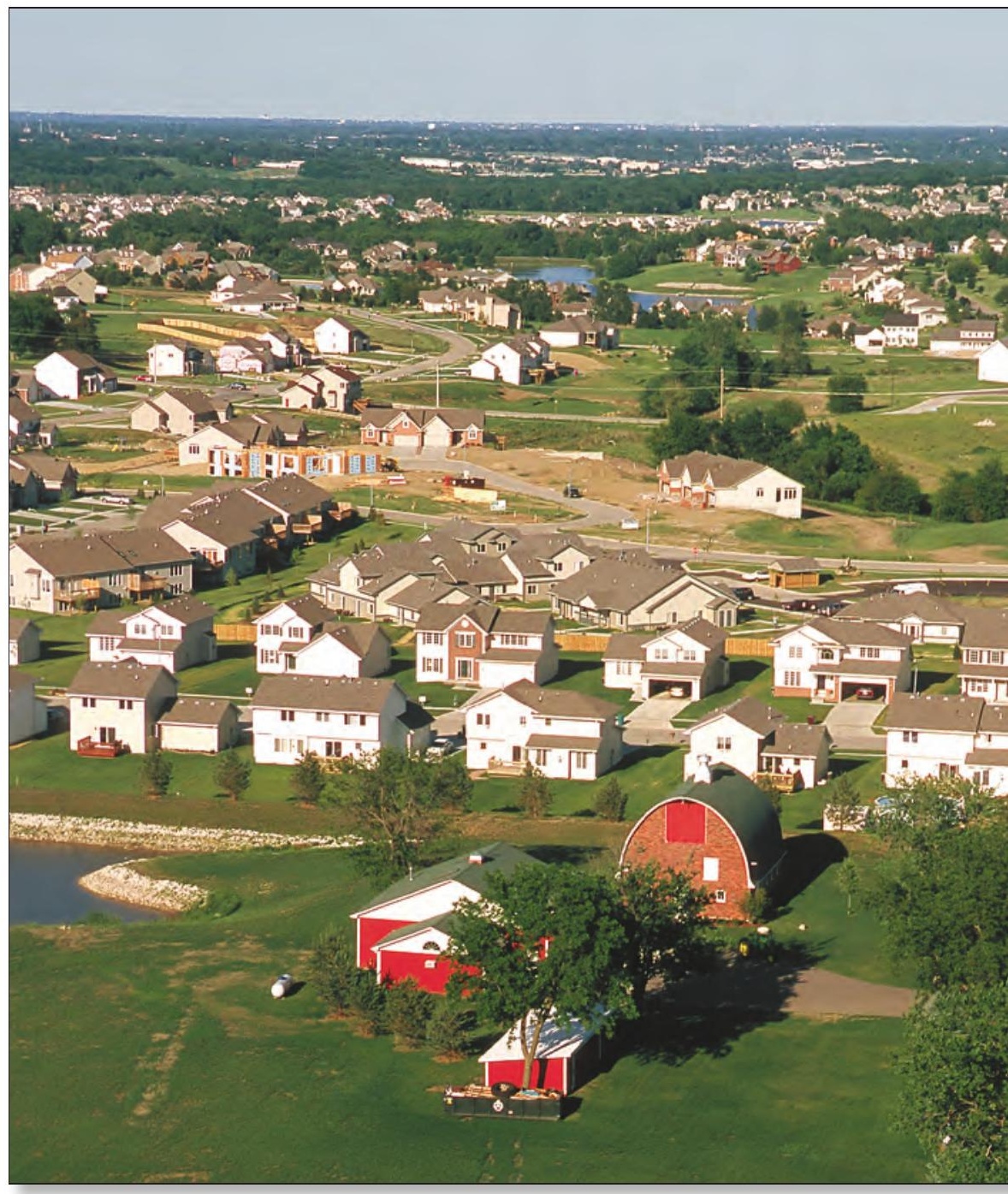

Photograph by Lynn Betts, U.S. Department of Agriculture, Natural Resources Conservation Service. 


\section{Nutrient Trends in Streams}

Nutrient inputs to streams from agricultural and urban sources have increased over the last century (fig. 8-1A). As these inputs increased, nutrient concentrations in streams increased in environmental settings as diverse as the humid urban Northeast and the semiarid agricultural Central Valley of California - as shown through long-term records of the Blackstone River in Massachusetts and the San Joaquin River in California (fig. 8-1B). Within the last two decades, increasing fertilizer costs, growing environmental concerns, and changing agricultural and waste management practices have reversed or slowed the pace of these increases (fig. 8-1A) (see sidebar, Past Changes Resulting from Nutrient Control Measures). NAWQA's assessment of nutrient trends between 1993 and 2003 at 171 stream sites for total phosphorus and 137 stream sites for total nitrogen encompassed only recent changes and consequently does not reflect the changes that occurred earlier in the 20th century.

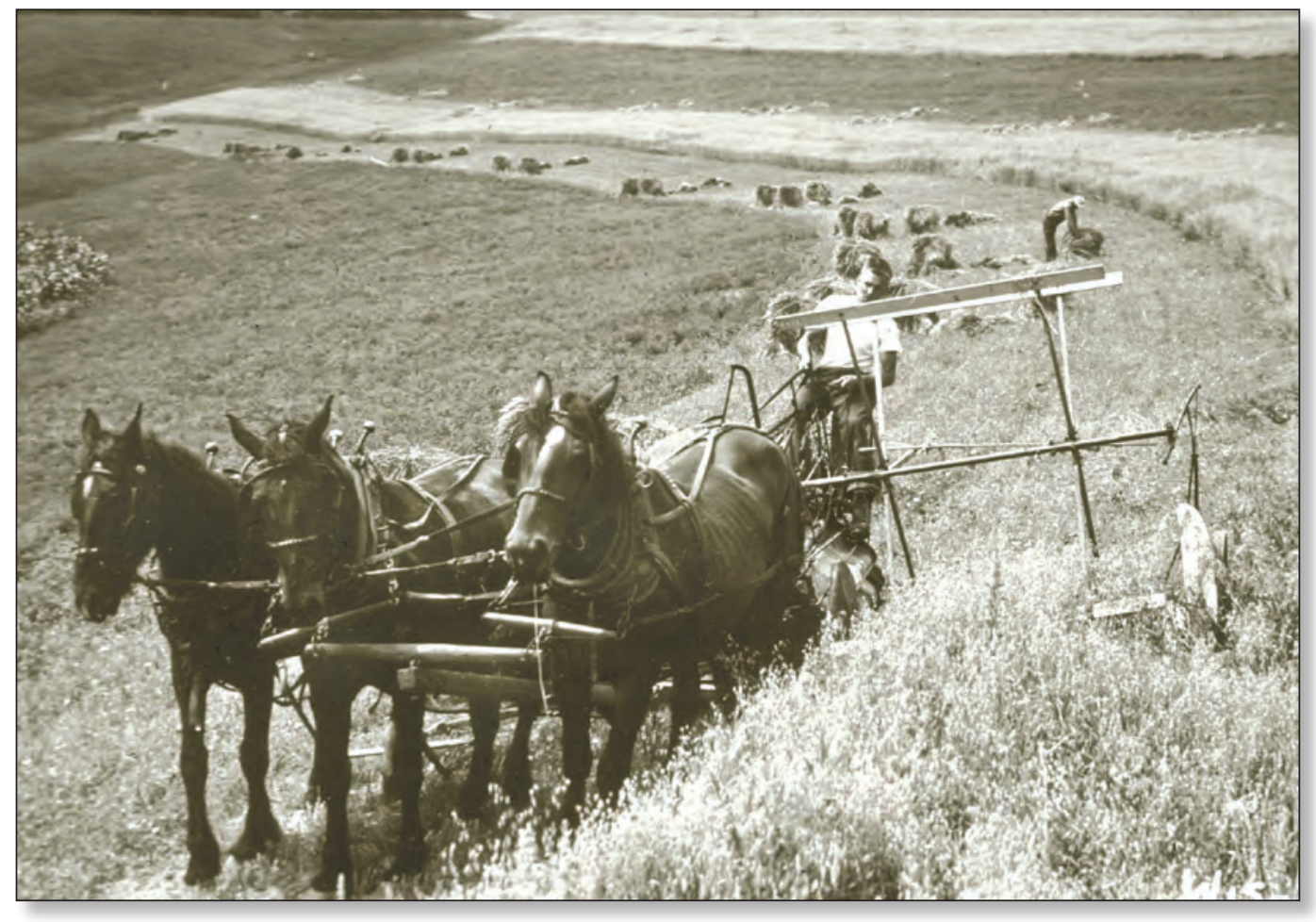

Prior to widespread use of commercial fertilizer, livestock waste was the major source of nutrients for crops on family farms. Photograph by U.S. Department of Agriculture, Natural Resources Conservation Service. 
A.

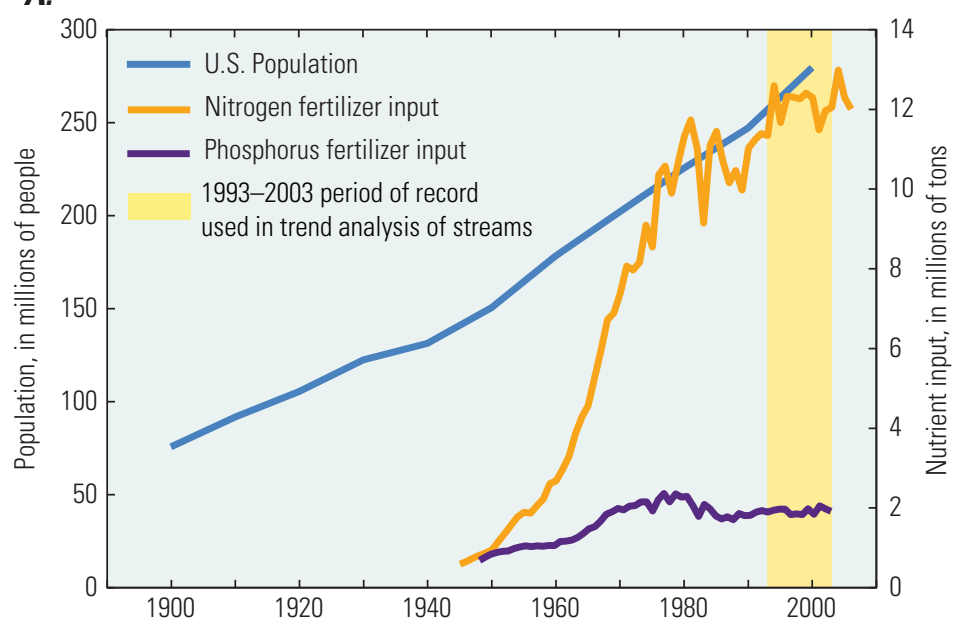

B.

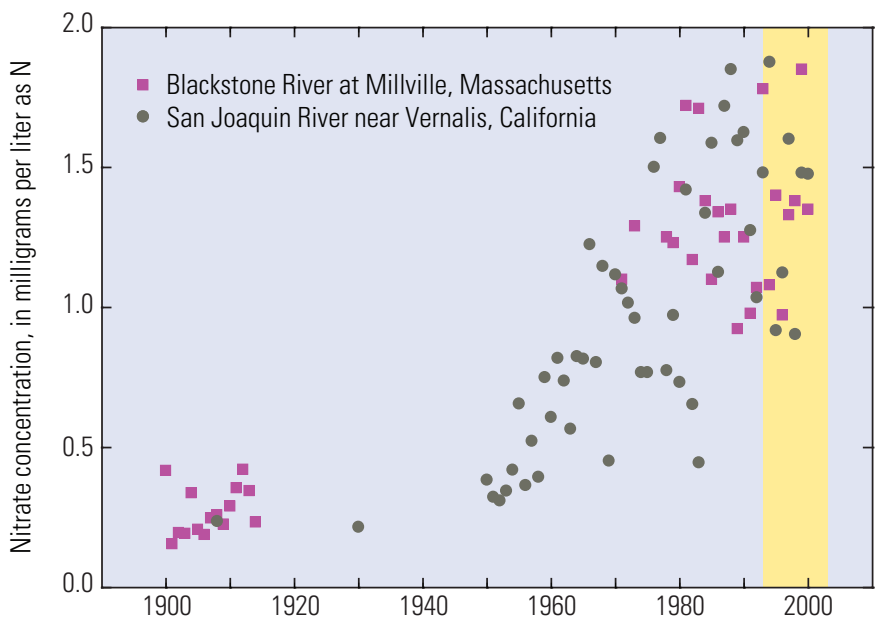

Figure 8-1. Nutrient inputs to streams from agricultural and urban sources have increased over the last century $(A)$. As these inputs increased, nutrient concentrations in streams increased in environmental settings as diverse as the humid urban Northeast and the semiarid agricultural Central Valley of California-as shown through long-term records of the Blackstone River in Massachusetts and the San Joaquin River in California (B). NAWQA's assessment of nutrient trends in streams reflects only changes that may have occurred from 1993 to 2003 (yellow vertical shaded area). 


\section{Past Changes Resulting from Nutrient Control Measures}

Although efforts to control nutrient enrichment have been many and varied, it is often difficult to determine the efficacy of specific management measures because of the lack of suitable data on the degree or spatial extent of the measure, concurrent changes in other sources or factors, or a general lack of nutrient monitoring following the implementation of a measure. But there have been notable success stories in which changes in some aspect of nutrient management resulted in improved water quality.

Phosphate detergent ban-The use of phosphorus in laundry detergents began around 1940 and increased rapidly through 1970 to become a major source of phosphorus to the environment. In 1970, the detergent industry voluntarily agreed to limit phosphate use in manufacturing, and individual States began instituting phosphate detergent bans. As a result, the use of phosphorus in detergents decreased from a peak of 220,000 metric tons in 1967 to less than 10,000 metric tons in 1995 (Litke, 1999). These phosphorus control measures have resulted in decreased phosphorus concentrations in many streams affected by wastewater-treatment plant effluent and septic-system leakage. For example, concentrations of total phosphorus in Contentnea Creek, North Carolina, decreased after 1988 when the State implemented a phosphate detergent ban (Harned, 2003) (fig. 8-2).

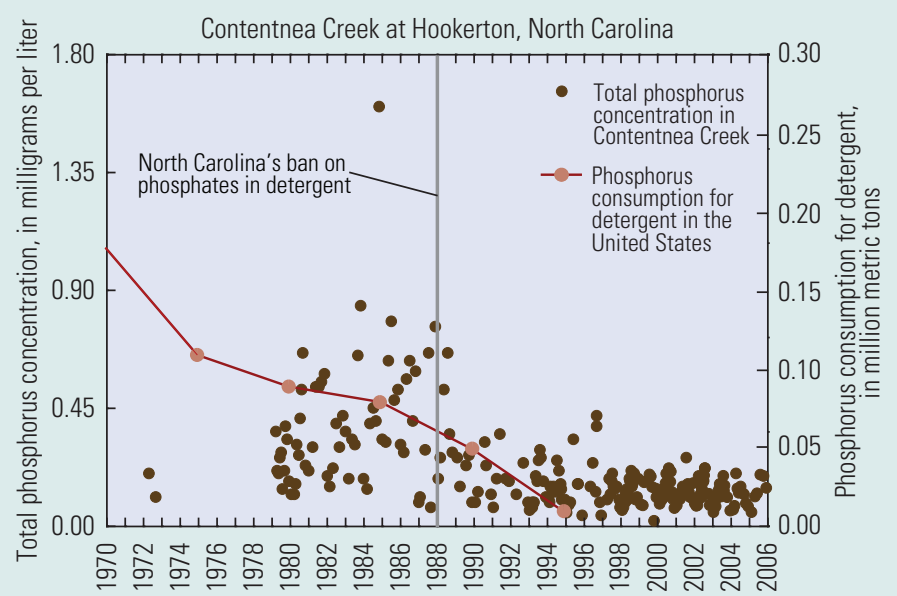

Figure 8-2. North Carolina's 1988 ban on phosphate detergents likely contributed to decreased total phosphorus concentrations in Contentnea Creek, North Carolina. 
Improvements in the treatment of wastewater-During the same period, improvements in the treatment of wastewater resulted in decreased ammonia concentrations in some streams. Decreased ammonia concentrations achieved through nitrification - the oxidation of ammonia to nitrate — of wastewater prior to discharge can lead to increased concentrations of dissolved oxygen in streams, which in turn can improve the health of fish communities. For example, fish were almost nonexistent in the Trinity River below Dallas in the early 1970s (Texas Parks and Wildlife Department, 1974). When ammonia concentrations in the river decreased as a result of upgrades to wastewatertreatment plants after 1980, dissolved oxygen concentrations and the number of fish species in the river increased (Land and others, 1998) (fig. 8-3A). Because ammonia is converted to nitrate during nitrification, however, nitrate concentrations can increase downstream of wastewater-treatment plants, as occurred in the Trinity River (fig. 8-3B).

A.

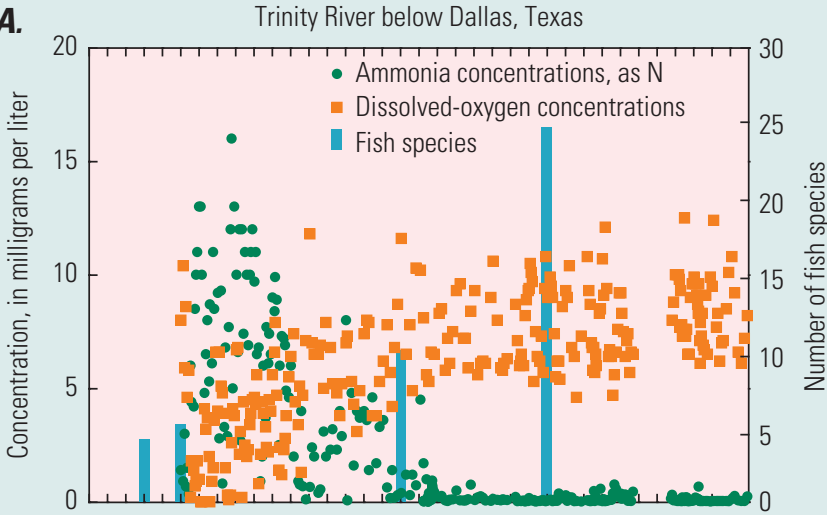

B.

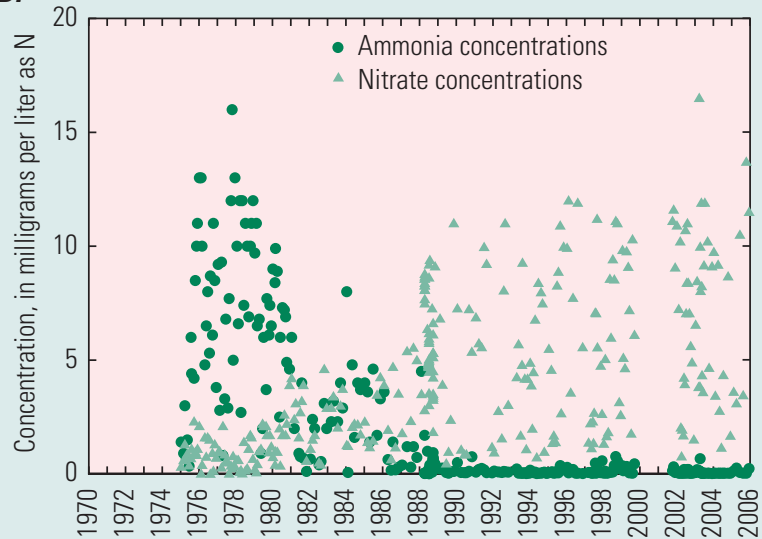

Implementation of agricultural Best Management Practices-Agricultural Best Management Practices (BMPs), such as conservation tillage and drip irrigation, also have improved water quality in some streams. Many BMPs are designed to reduce erosion, and as a result are effective at reducing instream concentrations of nutrients such as phosphorus that bind strongly to eroded sediment. For example, decreased concentrations of total phosphorus between 1997 and 2001 in Granger Drain, Washington, may be related to implementation of BMPs in the basin, including (1) the use of polyacrylamide, a chemical added to irrigation water to reduce erosion and enhance water infiltration, and (2) conversion from rill irrigation to sprinkler and drip irrigation, which use less water and reduce erosion and surface runoff (Fuhrer and others, 2004) (fig. 8-4). Concentrations of nitrate, which does not bind strongly to eroded sediment, did not show a similar decrease.

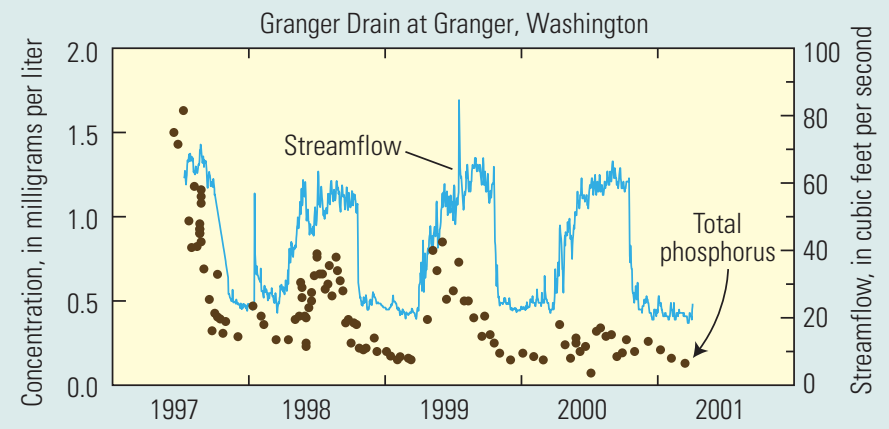

Figure 8-4. Decreases in total phosphorus concentrations in Granger Drain, Washington between 1997 and 2001 may be related to the increased use of agricultural Best Management Practices (BMPs) in the basin (Fuhrer and others, 2004). Data provided by the Roza-Sunnyside Board of Joint Control.

Figure 8-3. Improvements in wastewater treatment have decreased ammonia concentrations, increased dissolved oxygen concentrations, and improved fish communities in the Trinity River below Dallas, Texas (A). Because the ammonia is converted to nitrate during treatment, however, nitrate concentrations in the river have increased $(B)$. Data on fish species modified from Land and others (1998). 
Although the change in the availability of some nutrient sources slowed in the latter part of the 20th century, there were notable national and regional changes between the early 1990s and early 2000s (fig. 8-5). Among these changes:

- Livestock production shifted from a large number of small farms to fewer, larger concentrated animal feeding operations (CAFOs). CAFOs sometimes produce large volumes of manure with more nutrients than can be fully assimilated by crops and pasture on nearby agricultural land (U.S. Environmental Protection Agency, 2004). Shifts in the location and numbers of confined livestock contributed to changes in nutrient inputs from manure, with widespread increases in manure inputs occurring in the central and southeastern United States - particularly in North Carolina, the State with the second largest production of hogs and pigs, and where the number of these animals nearly doubled between 1992 and 1997 and then leveled off between 1997 and 2002 (National Agricultural Statistics Service, 2008) (fig. 8-5A).

- Corn received the largest proportion of nutrients from fertilizer, representing about 40 percent of the total fertilizer use in the United States (U.S. Department of Agriculture, 2008). Changes in nutrient inputs from fertilizer often corresponded to changes in corn acreage and yield, with relatively large increases in acreage occurring in Arkansas, Missouri, Kansas, South Dakota, and North Dakota, and relatively large decreases occurring in North Carolina and Georgia (National Agricultural Statistics Service, 2008) (fig. 8-5B). (Large percentage increases in fertilizer inputs in parts of California, Nevada, and Maine occurred in areas with small amounts of agricultural land and fertilizer inputs; see Chapter 2, fig. 2-2 for estimates of 1997 inputs from fertilizer, manure, and atmospheric deposition). Changes in the acreage of other crops, crop yields, climate, and economic factors such as the price of fertilizer and crops, likely also contributed to changes in fertilizer inputs during this period.

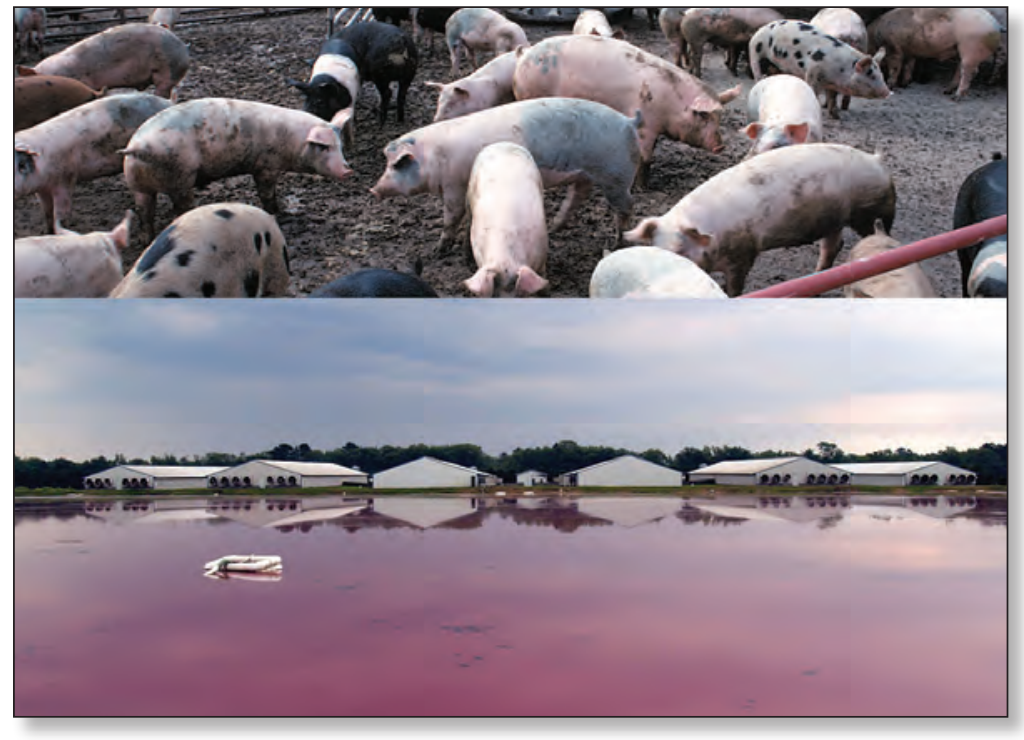

Geographic shifts in the location and numbers of livestock changed the distribution of nutrient inputs in some areas of the country. In North Carolina, the number of hogs and pigs nearly doubled between 1992 and 1997. Photographs by Lynn Betts, U.S. Department of Agriculture, Natural Resources Conservation Service (top), and Steve Reid, North Carolina Division of Water Quality, Raleigh, North Carolina (bottom).

- Nitrogen oxide emissions from vehicles, factories, and other sources throughout the United States decreased 12 percent from 1993 to 2002 - with the largest decreases in the Northeastern and Western States and the smallest decreases in the Rocky Mountains and Great Plains States (U.S. Environmental Protection Agency, 2003). These decreases in emissions largely coincided with widespread stable or decreasing nitrogen inputs from atmospheric deposition from 1993 to 2003 (fig. 8-5C).

- Population growth varied regionally between 1990 and 2000, with greater increases in the West (19.7 percent) and South (17.3 percent) and much lower increases in the Midwest (7.9 percent) and Northeast (5.5 percent) (U.S. Census Bureau, 2001) (fig. 8-5D). For example, the population of Pennsylvania increased by 3.4 percent, from 11.9 million to 12.3 million people, while the population of Nevada increased by 66 percent, from 1.2 million to 2.0 million people. At the county level, the largest decreases in population primarily took place in the Great Plains States, while the largest increases took place in the South and West.

Throughout the United States, nutrient sources changed at different rates and in different directions, making it difficult to determine their effect on nutrient trends in streams. Further complicating this determination, data on many nutrient sources and management practices are of unknown reliability, are inconsistent over time and space, or are not collected at all. 
A.

Change in manure, 1992 to 2002
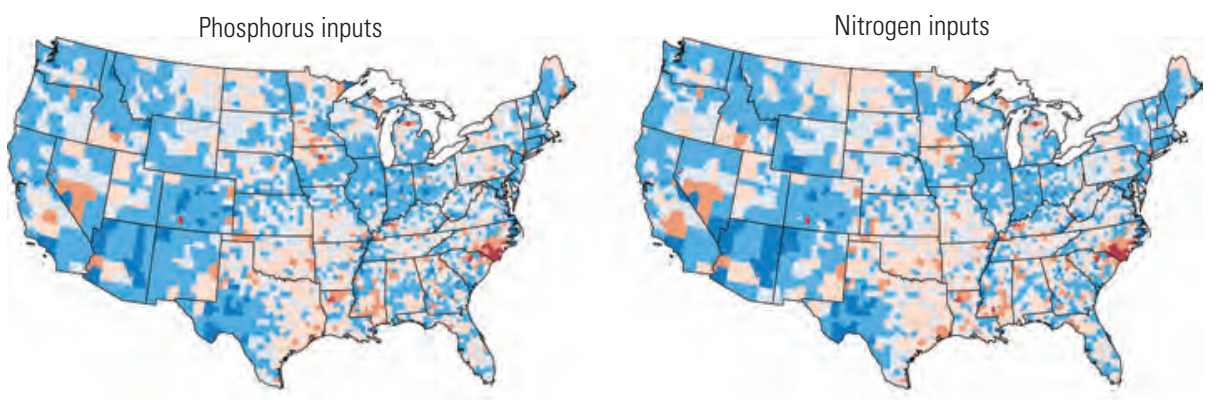

B.
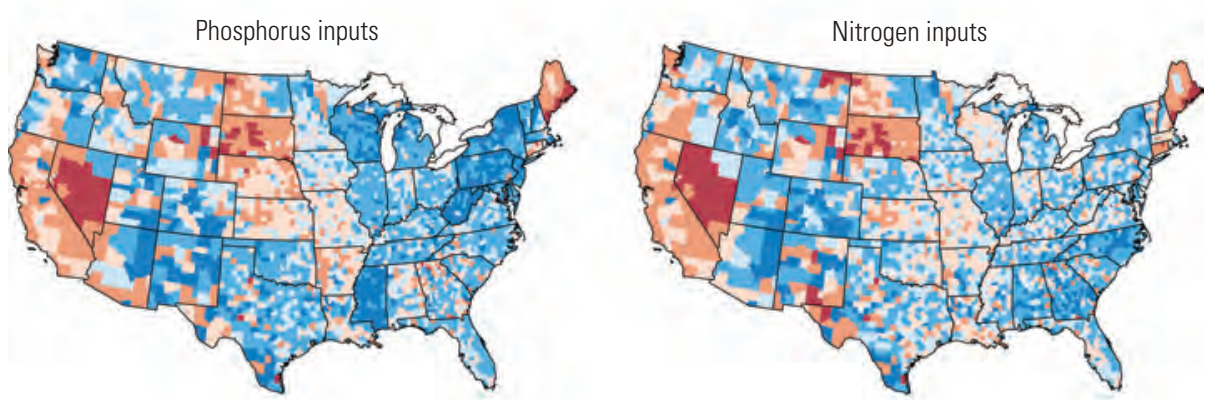

C.

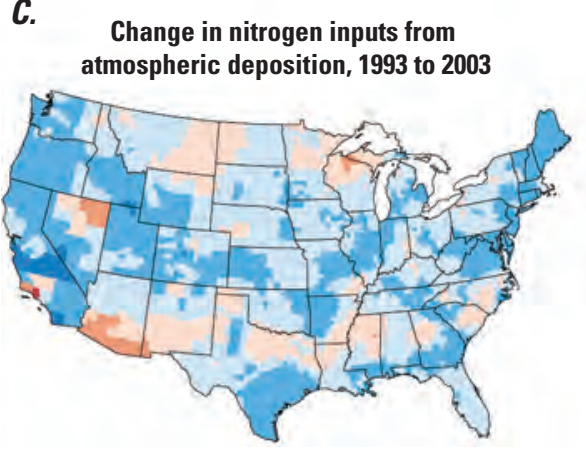

D.

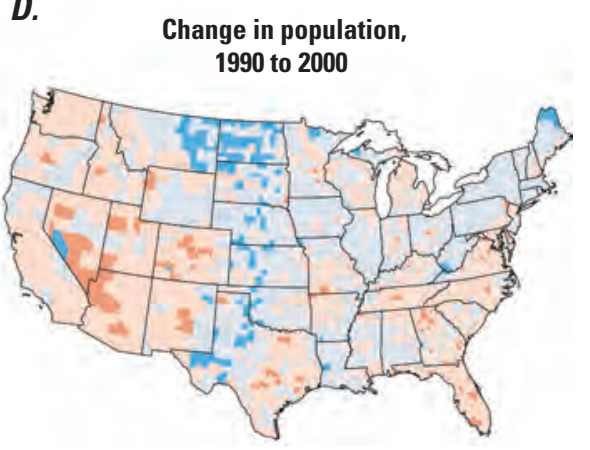

\section{EXPLANATION}

Percent change, by county

$\begin{array}{lll}\square-100--50 & \square>-10-10 & \square>50-200 \\ \square>-50--10 & \square>10-50 & \end{array}$

Figure 8-5. Nutrient sources changed at different rates and in different directions throughout the United States during NAWQA's assessment period, making it difficult to determine their effect on nutrient trends in streams. (See Chapter 2 fig. 2-2 for estimates of 1997 inputs from fertilizer, manure, and atmospheric deposition.) 
Human activities are not the only influence on nutrient concentrations in streams. Natural changes in precipitation and streamflow also can influence concentrations by altering the amount of instream dilution of nutrients and surface runoff carrying nutrients to the stream. At most sites used in the analysis of trends in nutrient concentrations, streamflow did not change significantly from 1993 to 2003 (fig. 8-6). Where changes did occur, the trends were downward at all but two sites. The streamflow decreases occurred primarily at sites in the Central, Southwestern, and parts of the Southeastern United States, often as a result of drought conditions in the latter part of the study period.

Human and natural changes often occur simultaneously, and they can either counteract or supplement each other. For example, nutrient concentrations in a stream may change very little if a decrease in concentration resulting from improvements at a wastewater-treatment plant is offset by decreased instream dilution resulting from a natural decrease in streamflow. In the analysis in the following section on Flow-Adjusted Trends in Concentration, the large amount of variability in nutrient concentrations in streams caused by natural changes in streamflow is removed, allowing trends caused by human changes to be more directly assessed. In the analysis in the following section on Overall Trends in Concentration, the net effects of all simultaneous influences on nutrient concentration are evaluated, allowing for the assessment of concentrations in streams relative to waterquality standards and the condition of aquatic communities. More details on the methods used to evaluate trends in nutrient concentrations in streams are presented in the sidebar, Methods Used to Evaluate Trends in Nutrient Concentrations in Streams.

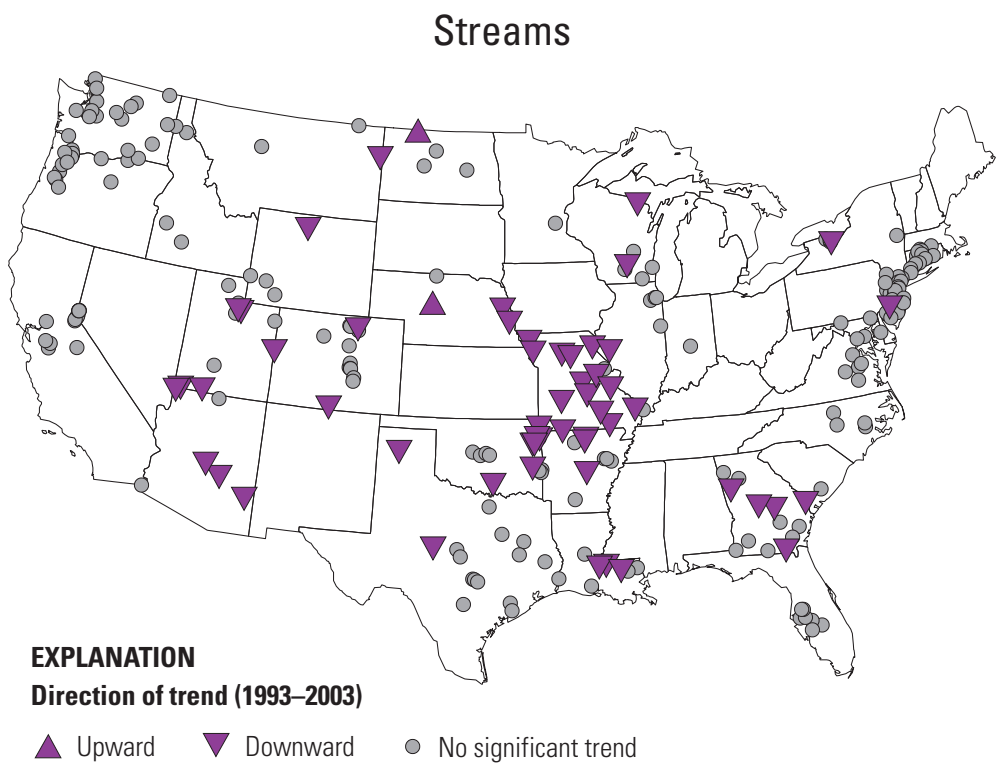

Figure 8-6. At most sites used in the analysis of trends in concentration, streamflow did not change significantly from 1993 to 2003. Where changes did occur, the trends were downward at all but two sites. The streamflow decreases primarily occurred at sites in the Central, Southwestern, and parts of the Southeastern United States, often as a result of drought conditions in the latter part of the study period.

\section{Methods Used to Evaluate Trends in Nutrient Concentrations in Streams}

The analysis of nutrient trends in streams from 1993 to 2003 included data from the USGS's National Water Information System (NWIS) database (collected through the NAWQA Program and in cooperation with other Federal, State, and local agencies) and selected data from the USEPA's Storage and Retrieval (STORET) database. A total of 244 sites were included in the analysis on the basis of the following general criteria: (1) record of nutrient concentrations beginning in 1993 or earlier and ending in 2003 or later; (2) approximately quarterly sampling each year; (3) continuous streamflow record between 1993 and 2003 at that site or a nearby representative site; (4) data gaps no longer than 2 years and only during the middle 6 years of record; (5) representative coverage of samples over the range of the hydrograph to avoid bias toward low or high streamflows; and (6) representative coverage of all seasons to avoid bias towards certain times of year (Sprague and others, 2009).

The statistical procedures used here to evaluate trends assume that the trend is monotonic - that is, the values in the population of observations increase or decrease over time with no substantial reversals in direction. Trend results are reported as the overall change between the beginning and ending dates rather than the year-to-year variation from 1993 to 2003. Shorter duration changes over a few hours, days, or months can cause nutrient concentrations in streams to vary by orders of magnitude. The "noise" caused by frequent short-duration changes can make it difficult to detect the "signal" of a small sustained trend over several years. As a result, some smaller trends in concentration, such as those resulting from the conversion of farmland to suburban areas, may not be detectable until many years have passed. 
The noise, or variability, also can lead to uncertainty in estimating the magnitude of a trend. The amount of uncertainty can be represented as a confidence interval, a range of values that likely includes the true trend magnitude. Confidence intervals are wider for data sets having greater variability (Helsel and Hirsch, 1992). Estimated trend magnitudes are reported here with 95-percent confidence intervals - the interval contains the true trend magnitude with 95-percent confidence. If a 95-percent confidence interval contains both positive and negative values, the trend is considered to be non-significant. If a 95-percent confidence interval contains only positive or only negative values, however, the trend is considered to be significant (upward or downward, respectively), regardless of the interval width.

The magnitude and significance of each trend is sensitive to conditions at the beginning and end of the record. Thus a trend from 1993 to 2003 might be different from a trend during a different period, such as from 1985 to 2003 or from 1993 to 2002 . The use of different periods of record for analysis can lead to different, yet equally valid, trend results for the same site (fig. 8-7). Because the outcome of the trend analysis is sensitive to the period of record, the same period of record (1993 to 2003) was used at all sites to facilitate comparison and summary of trends among sites. NAWQA assessments at some sites did not begin until 1996 or 1998; these sites were not included in the trend analysis unless earlier data were available from another source.

Flow-adjusted trends in concentration were compared with contemporaneous changes in nutrient sources, including atmospheric deposition of nitrogen, phosphorus and nitrogen loading from fertilizer and manure, and population (a surrogate for urban sources of nutrients) to help understand the factors that affect the trends over time. The goal of this analysis was not to explain all factors that affected each trend at individual sites - that was beyond the scope of the study. Rather, the goal was to identify on a broader scale those individual factors that potentially affected trends at groups of related sites. The groups included sites in the Eastern, Central, and Western United States and agricultural, urban, and undeveloped sites. Because the number of sites meeting the NAWQA criteria for agricultural and urban land-use classification (see Chapter 3, NAWQA's Approach to Nutrient Assessment, table 3-1) was too small for statistical analysis, watershed land-use criteria were adjusted to greater than 40 percent agricultural land use (instead of greater than 50 percent) and greater than 10 percent urban land use (instead of greater than 25 percent).
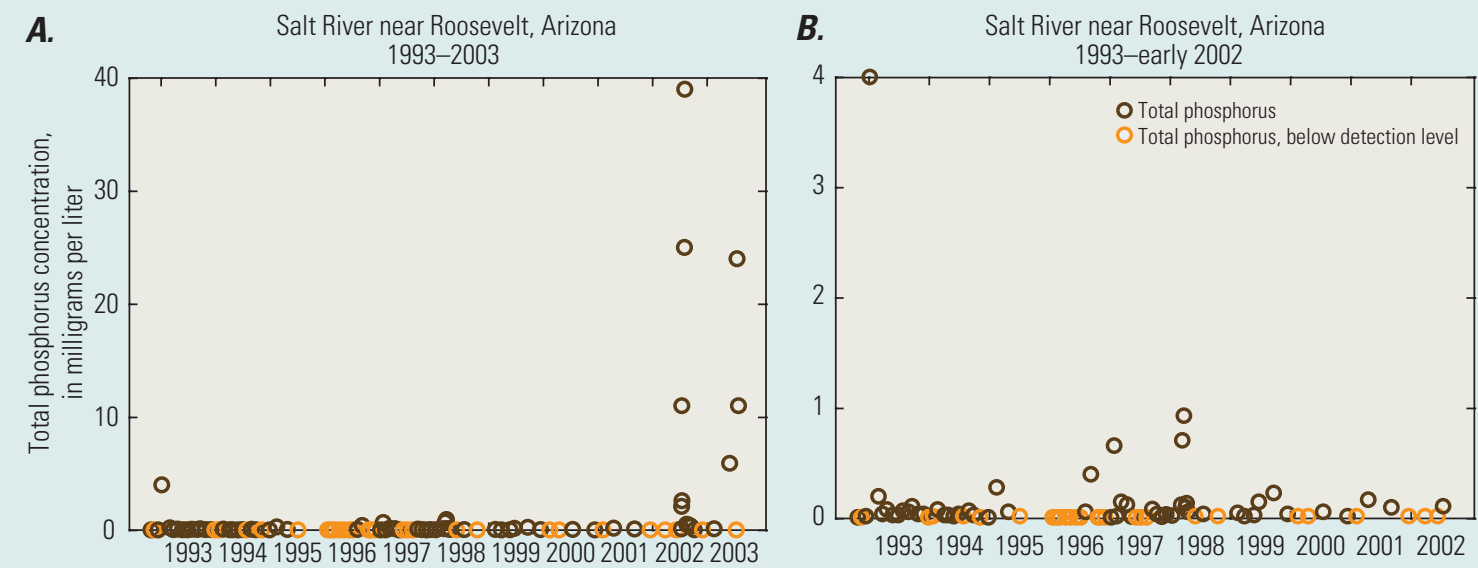

Figure 8-7. The record of total phosphorus concentrations at the Salt River near Roosevelt, Arizona, shows large increases in 2002 and $2003(A)$. These increases likely were due in large part to runoff after the Rodeo-Chediski fire, which burned more than 452 square miles in the Salt River drainage (Arizona Game and Fish Department, 2006). The record of total phosphorus concentrations between 1993 and early 2002 (preburn) shows no evidence of an increase of similar magnitude $(B)$. Flow-adjusted trends during both periods were upward, though the magnitude of the trend was much larger from 1993 to 2003 than from 1993 to 2002. (Note different $y$-axis scales in $A$ and $B$.) 


\section{Flow-Adjusted Trends in Concentration}

Flow-adjusted trends in the concentration of phosphorus and nitrogen from 1993 to 2003 were not significant at the majority of sampling sites nationwide (51 and 63 percent of sites for total phosphorus and total nitrogen, respectively) (Sprague and others, 2009) (fig. 8-8). In the remaining streams, there were more upward than downward flowadjusted trends - trends were upward at 33 and 21 percent of sites for total phosphorus and total nitrogen, respectively, but downward at only 16 percent for both nutrients (fig. 8-8). These findings indicate that human activities such as changes in nutrient inputs or implementation of management practices did not contribute to net changes in nutrient concentrations in most sampled streams. Human activities did, however, contribute to more increases than decreases in the remaining streams, despite relatively stable fertilizer application rates during 1993-2003 (fig. 8-1).

In the Central and Southwestern United States, flowadjusted trends in total phosphorus concentrations generally were upward or nonsignificant (fig. 8-8). Flow-adjusted trends in total nitrogen concentrations generally were downward or nonsignificant in the Northwestern United States.

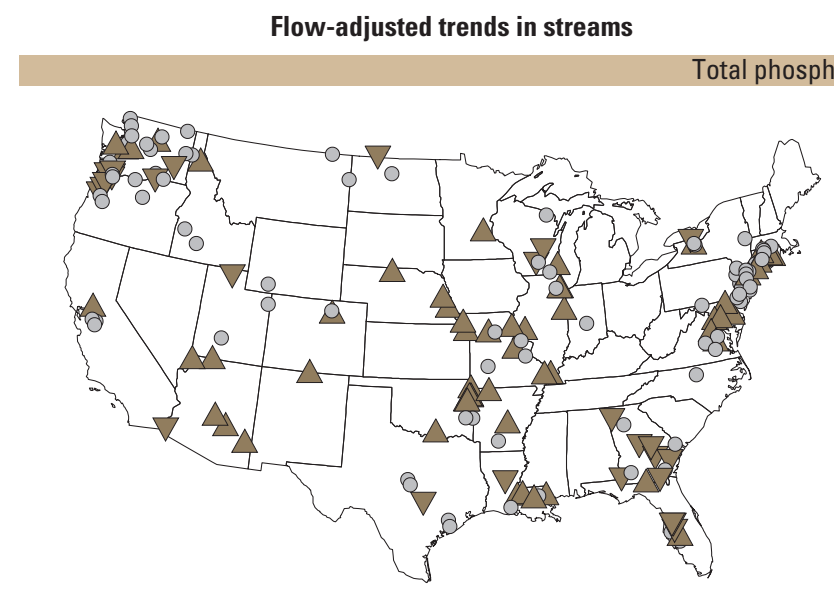

\section{Overall trends in streams}

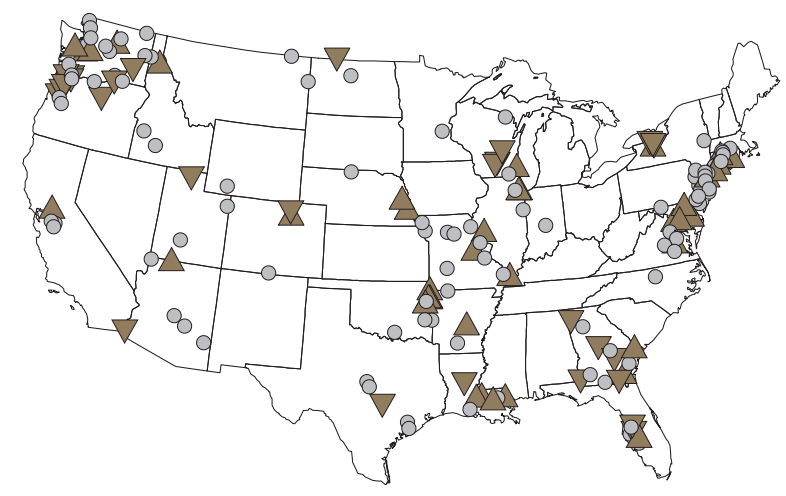

Total nitrogen concentration
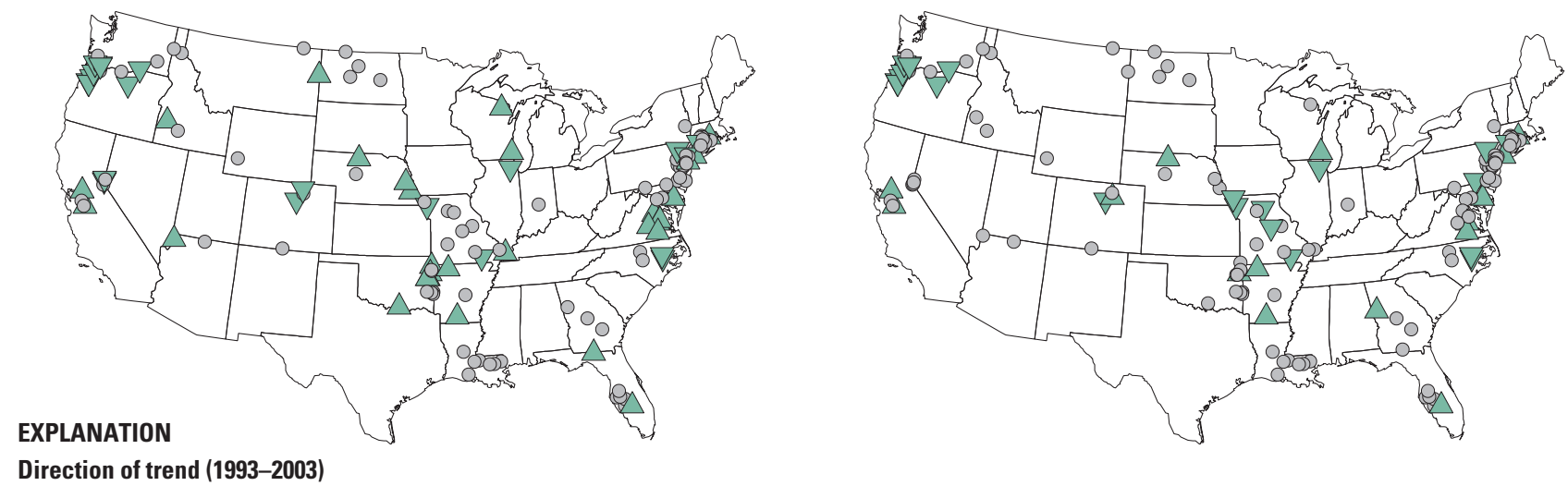

Direction of trend (1993-2003)

$\triangle$ Upward $\nabla$ Downward $\bigcirc$ No significant trend

Figure 8-8. The patterns of flow-adjusted trends in nutrient concentrations indicate that human changes in the use and management of nutrient sources did not contribute to net changes in their concentrations in most sampled streams from 1993 to 2003, and contributed to more increases than decreases in the remaining streams. In Central, Southwestern, and parts of the Southeastern United States, where streamflow decreased at many sites, there were fewer upward overall trends (which reflect the net effect of all simultaneous influences on nutrient concentrations in streams) than upward flow-adjusted trends. Anthropogenic increases in nutrient sources at sites in these areas likely were offset by decreases in precipitation and surface runoff. Without the decrease in surface runoff carrying nutrients to streams, concentrations probably would have been higher than were actually observed. 
Although the trend sites meeting the NAWQA criteria for agricultural and urban land-use classification were small in number and geographically clustered (fig. 8-9), a limited comparison of flow-adjusted trends by land-use category can be made. There were more upward than downward trends in streams in all land-use categories for total phosphorus, particularly in agricultural and mixed land-use streams (fig. 8-9). By comparison, the percentage of upward and downward flow-adjusted trends was comparable for total nitrogen in streams of all land uses except agricultural streams, where no downward flow-adjusted trends were observed. The geographic coverage of these sites was sporadic, however, particularly for urban and agricultural sites. For example, coverage of agricultural areas was limited primarily to parts of the Corn Belt, the Central Valley of California, the Ozark Plateaus, and the Potomac and Columbia River Basins. Data from additional sites would be needed to more fully describe the pattern of trends among land uses.

Flow-adjusted trends in streams by land use Total phosphorus concentration
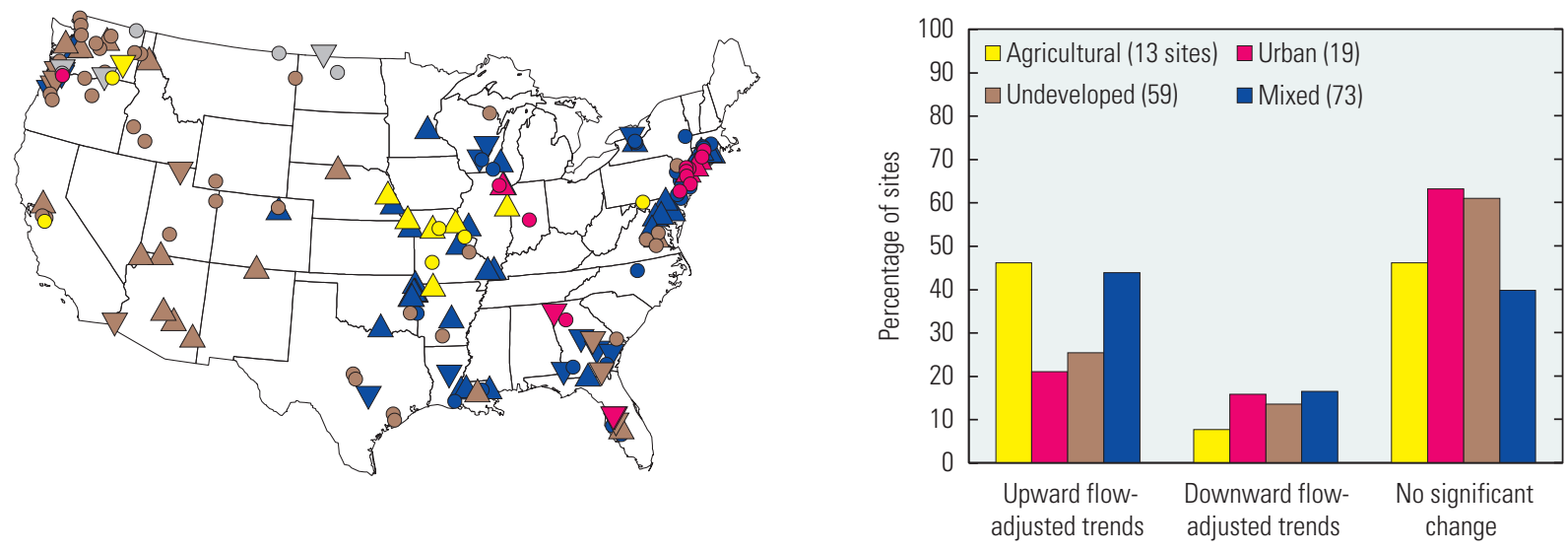

Total nitrogen concentration
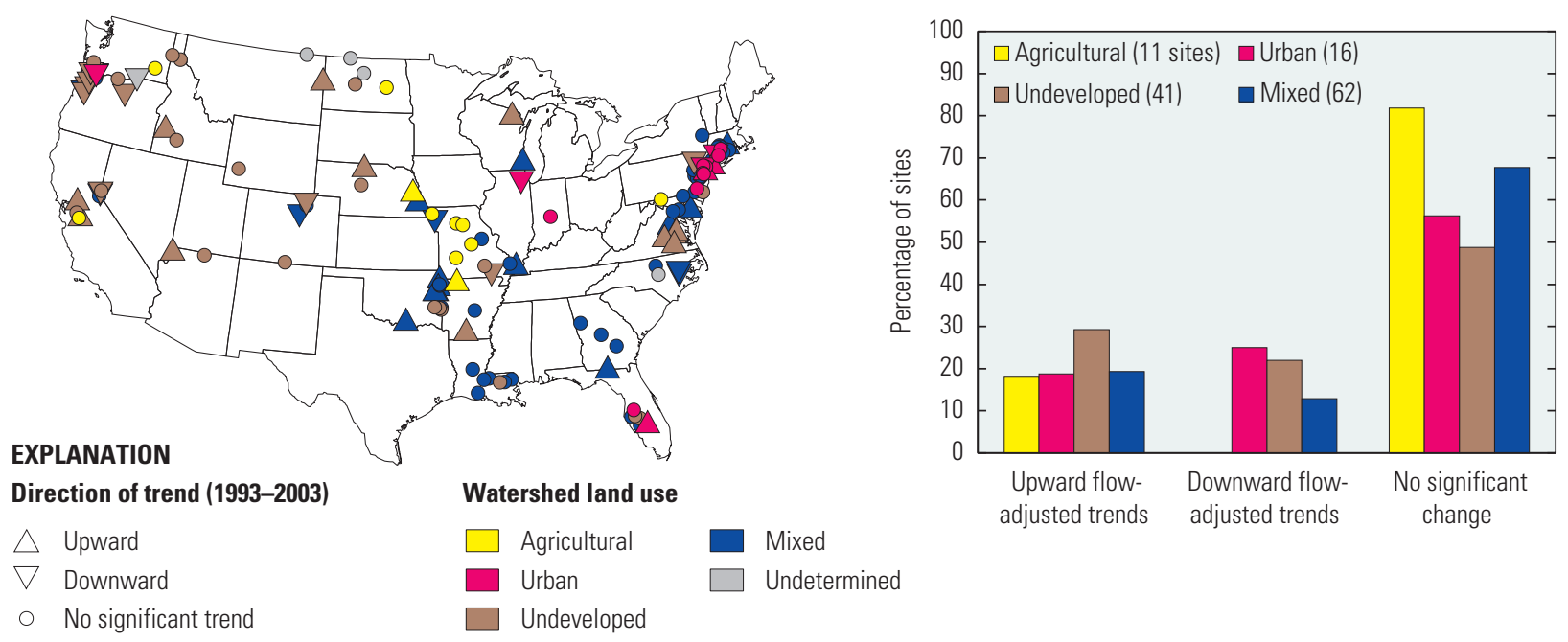

Figure 8-9. There were more upward than downward flow-adjusted trends in streams in all land-use categories for total phosphorus, especially in agricultural and mixed land-use streams. In comparison, the percentages of upward and downward flow-adjusted trends were comparable for total nitrogen in streams of all land uses except agricultural streams, where no downward flow-adjusted trends were observed. 
Flow-adjusted trends were not significant at nearly one-half of the streams that were least affected by nutrient enrichment in 1993 (streams with nutrient concentrations in 1993 below USEPA's recommended ecoregional nutrient criteria), but human activities contributed to more than three times as many increases as decreases in total phosphorus concentrations and more than ten times as many increases as decreases in total nitrogen concentrations at the remainder (fig. 8-10A). More decreases in nutrient concentrations occurred in streams with concentrations that were above USEPA's recommended ecoregional nutrient criteria in 1993, particularly with respect to total nitrogen concentrations (fig. 8-10B) - downward flow-adjusted trends were observed in nearly 20 percent of these more highly affected streams. These findings indicate that while modest gains have been made in nutrient quality in some affected streams, human activities have led to greater nutrient enrichment in some of the Nation's least-affected streams.

In some land-use and specific geographic areas, flow-adjusted trends in phosphorus concentrations were related to changes in major sources of nutrients-fertilizer, manure, and urban sources (represented by population here).

- Agricultural sources-Changes in manure (fig. 8-11A) and fertilizer (fig. 8-11B) inputs were associated with changes in total phosphorus concentrations at sites with greater than 40 percent agricultural land use in the basin.
- Population-Changes in population were associated with changes in total phosphorus concentrations at undeveloped sites and at sites in the Western United States (iggs. 8-11C and $\underline{8-11 D}$ ).

At all sites, there likely were additional factors influencing nutrient trends. Some factors, such as changes in inputs from atmospheric deposition, were not associated with concentration trends in any particular geographic or land-use area, but were likely important at individual stream sites.

Other factors, such as changes in loading from point sources and implementation of nutrient management strategies, could not be evaluated because national-scale, consistently derived data sets for these factors are not currently available.

In general, factors influencing the trends in concentrations were more difficult to identify for total nitrogen than for total phosphorus. Nitrogen is more readily leached through the soil and generally is more mobile in groundwater than phosphorus. Because it may take many years for groundwater to travel from recharge areas to streams, there may be a substantial lag between changes in nitrogen use on the land surface and changes in concentrations in streams. As a result, trends in total nitrogen concentrations in streams that receive nitrogen inputs from groundwater may have been influenced more by changes on the land surface that took place prior to 1993.

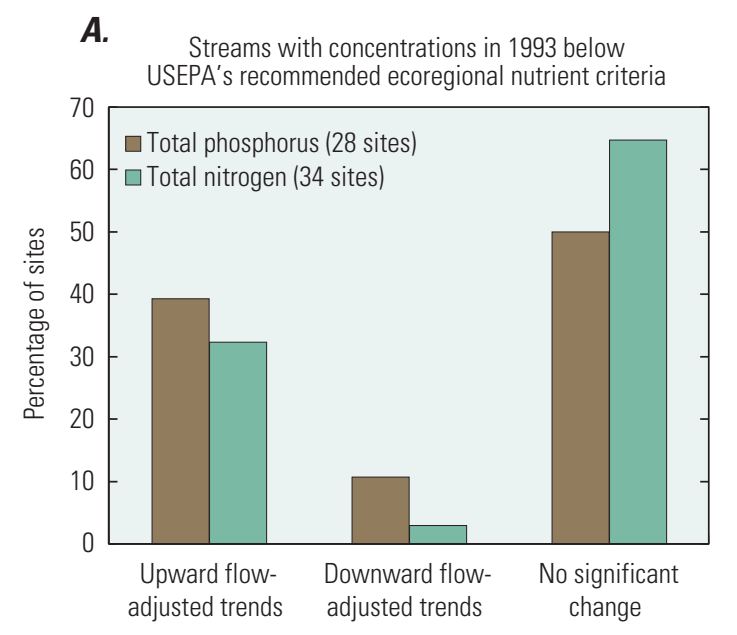

B.

B. Streams with concentrations in 1993 above USEPA's recommended ecoregional nutrient criteria

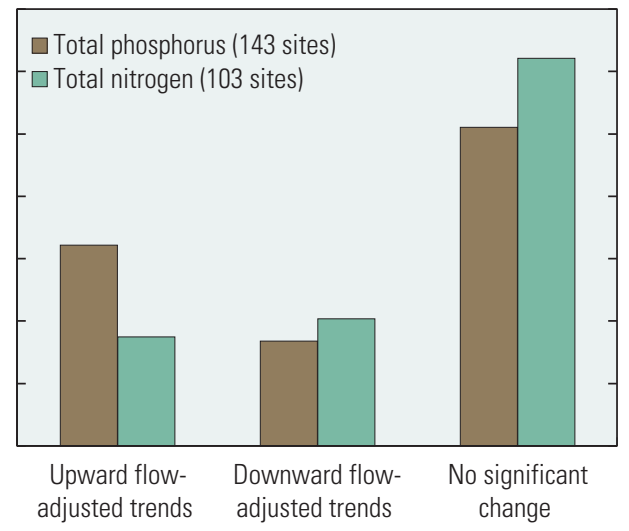

Change between 1993 and 2003

Figure 8-10. In streams with concentrations of nutrients below U.S. Environmental Protection Agency's recommended ecoregional nutrient criteria in 1993, human activities contributed to more increases (upward flow-adjusted trends) than decreases (downward flow-adjusted trends) in concentration ( $A$ ). Decreases in concentrations occurred more frequently in streams with nutrient concentrations above the criteria in $1993(B)$. 
It is important to note that human activities may have had a positive effect even in streams where the flow-adjusted trend was not downward. Often, multiple and possibly counteracting factors are influencing nutrient concentrations in a stream.

One or more factors contributing to decreases in concentration (such as implementation of BMPs) can be offset by additional factors contributing to increases in concentrations (such as increased application of manure or fertilizer), resulting in net increases in or relatively stable concentrations. Without those factors contributing to decreases in concentration, instream concentrations might have been higher.
A.

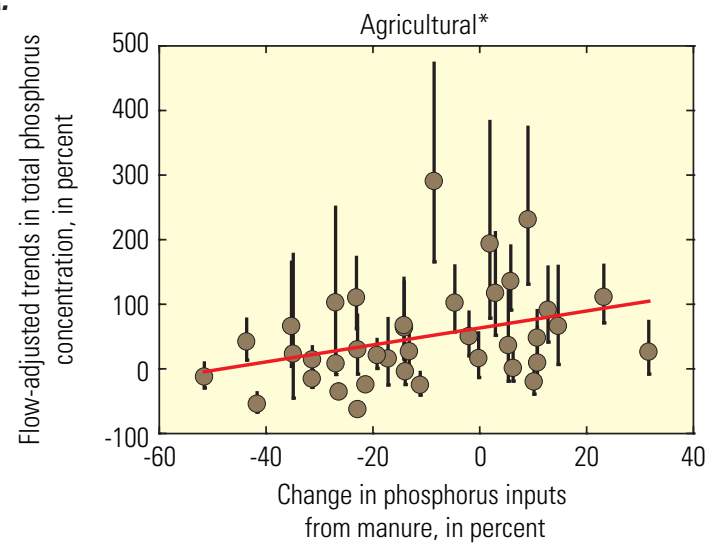

C.

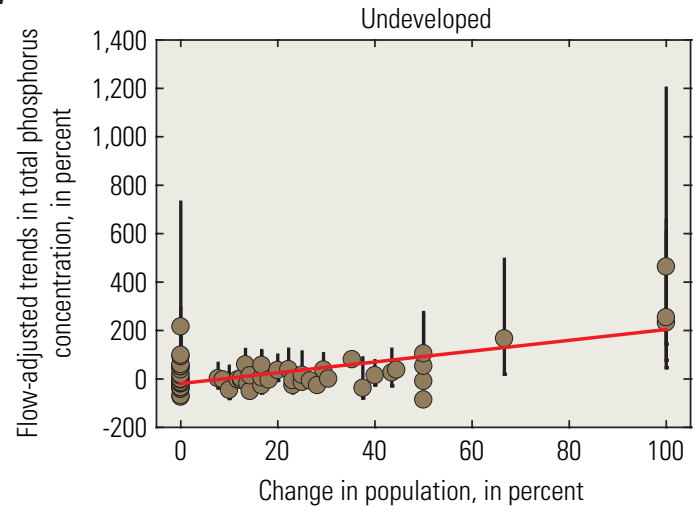

B.

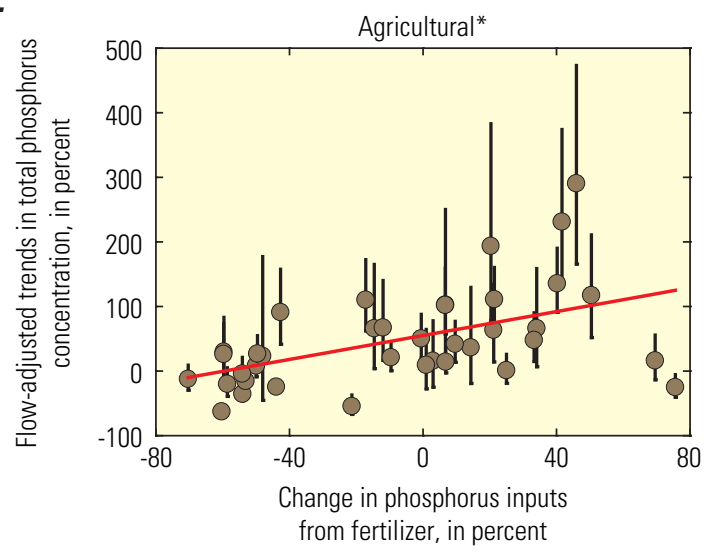

D.

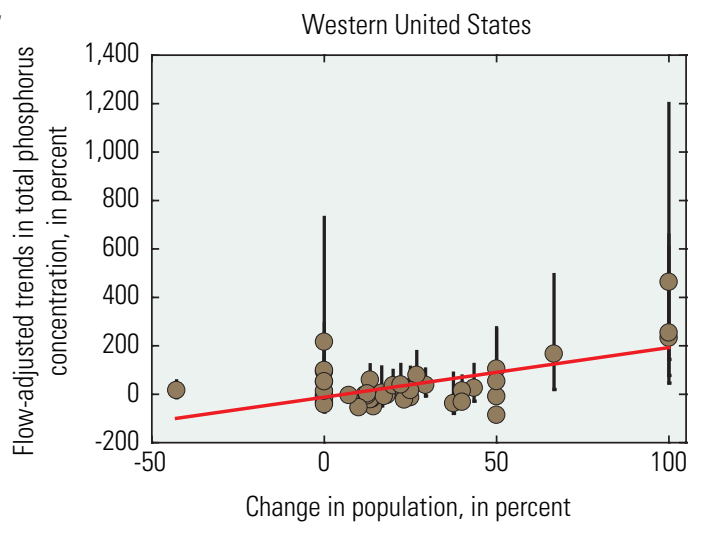

EXPLANATION

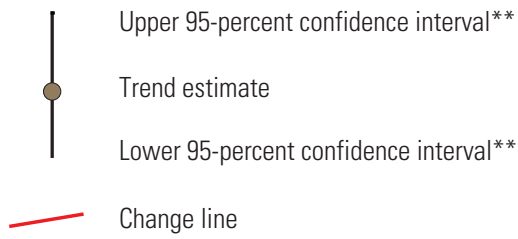

${ }^{*}$ Sites with greater than 40 percent agricultural land use in the basin.

** There is a 95-percent probability that the true trend is between the upper and lower confidence interval (see sidebar, Methods Used to Evaluate Trends in Nutrient Concentrations in Streams).

Figure 8-11. In some geographic and specific land-use areas, flow-adjusted trends in phosphorus concentrations from 1993 to 2003 were related to changes in inputs of major sources of nutrients, including manure at agricultural sites $(A)$, fertilizer at agricultural sites $(B)$, urban sources (represented by population) at undeveloped sites $(C)$, and urban sources at sites in the Western United States $(D)$. Factors associated with flowadjusted trends in nitrogen concentrations were more difficult to identify; because groundwater can take many years to travel to streams, there may be a substantial lag between changes in nitrogen use on the land surface and changes in nitrogen concentrations in streams. 


\section{Overall Trends in Concentration}

There were fewer upward overall trends (reflecting all simultaneous influences on concentrations in streams) than upward flow-adjusted trends (reflecting the influence of human activities; fig. 8-12), indicating that anthropogenic increases in nutrient sources or transport did not always result in increasing concentrations in the stream (Sprague and others, 2009). These differences primarily were in the Central and Southwestern United States for phosphorus and more scattered throughout the Nation for nitrogen, generally at sites where streamflow decreased. At these sites, anthropogenic increases in nutrient sources likely were offset by natural decreases in surface runoff needed to transport the nutrients to the streams. Without the decreases in surface runoff, concentrations in these streams probably would have been higher than were actually observed.

The number of downward overall trends during 1993-2003 was similar to the number of downward flow-adjusted trends in nutrient concentrations - about 16 percent of sites each for both phosphorus and nitrogen. At many sites where both the overall and the flow-adjusted trend were downward, streamflow did not change significantly from 1993 to 2003, which suggests that the decreases in nitrogen and phosphorus concentrations were a result of either reduced sources (fertilizer and manure applications and point sources) or improved nutrient management.

Broad regional patterns were less apparent in overall trends than in flow-adjusted trends (fig. 8-8). Overall trends in total nitrogen concentrations generally were downward or nonsignificant in the Northwestern United States (fig. 8-8).

Upward overall trends were large enough that concentrations generally increased to above USEPA's recommended ecoregional nutrient criteria in 6 of 28 streams (21 percent) with total phosphorus concentrations below the criteria in 1993 and in 6 of 34 streams (18 percent) with total nitrogen concentrations below the criteria in 1993 (fig. 8-13A). At sites at which concentrations increased to above the criteria, the overall trend was similar to the flow-adjusted trend, suggesting that human activities played a large role in the increases. In the majority of these least-impacted streams, however, no significant change occurred (fig. 8-13A) and nutrient quality was maintained.

In comparison, downward overall trends caused concentrations to decrease to below USEPA's recommended ecoregional nutrient criteria in only 2 of 143 streams (1 percent) with total phosphorus concentrations above the recommended criteria in 1993, and in 5 of 103 streams (5 percent) with total nitrogen concentrations above the recommended criteria in 1993 (fig. 8-13B). In six of these

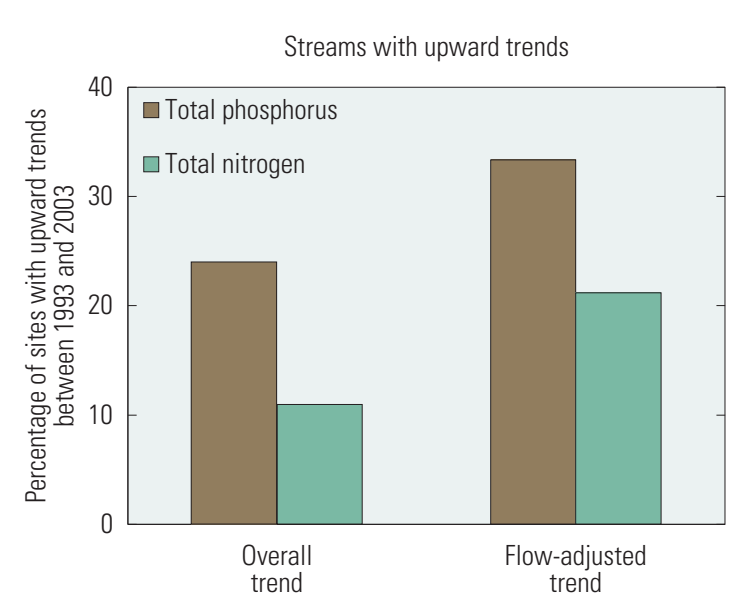

Figure 8-12. There were fewer upward overall trends than upward flow-adjusted trends in nutrient concentrations during 1993-2003, indicating that anthropogenic increases in nutrient sources and (or) transport did not always result in increasing instream concentrations because of the counteracting effects of decreasing surface runoff and streamflow.

seven streams with downward trends, the overall trends were similar to the flow-adjusted trends, suggesting that human activities played a large role in the concentration decreases. In the remaining stream, the overall trend was much larger than the flow-adjusted trend, suggesting that a natural change in streamflow was the primary influence in the concentration decrease. The successes were not limited to streams in which only a small decrease was needed to reach a criterion; they also occurred in more highly affected streams where larger decreases were needed to reach a criterion. Partial progress towards the criteria was made in more streams (sites with downward overall trends, criterion not reached, fig. 8-13B), including some of the most highly affected streams. For example, total nitrogen concentrations in the Neuse River, North Carolina, decreased an estimated 37 percent (95-percent confidence interval of -45 to -27 percent) to approach the recommended total nitrogen criterion of $0.69 \mathrm{mg} / \mathrm{L}$ by 2003 (fig. 8-13C). In most streams, however, the change in concentration was insufficient to reach the criteria (fig. 8-13B) - and in some cases, concentrations increased and nutrient quality declined. For example, total nitrogen concentrations in Flint Creek, Oklahoma, increased an estimated 52 percent (95-percent confidence interval of 33 to 73 percent), thus moving further from the recommended total nitrogen criterion of $0.31 \mathrm{mg} / \mathrm{L}$ by 2003 (fig. 8-13C). 


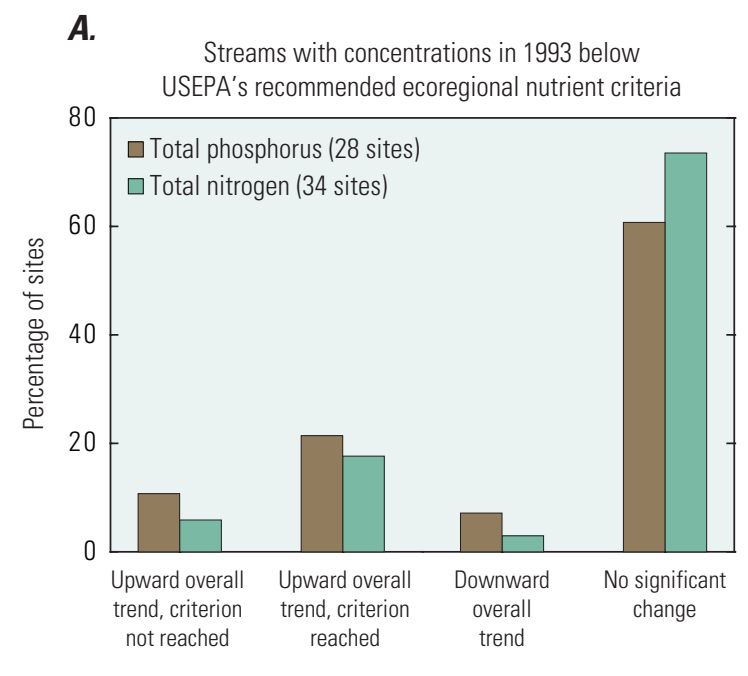

B.

B. Streams with concentrations in 1993 above USEPA's recommended ecoregional nutrient criteria

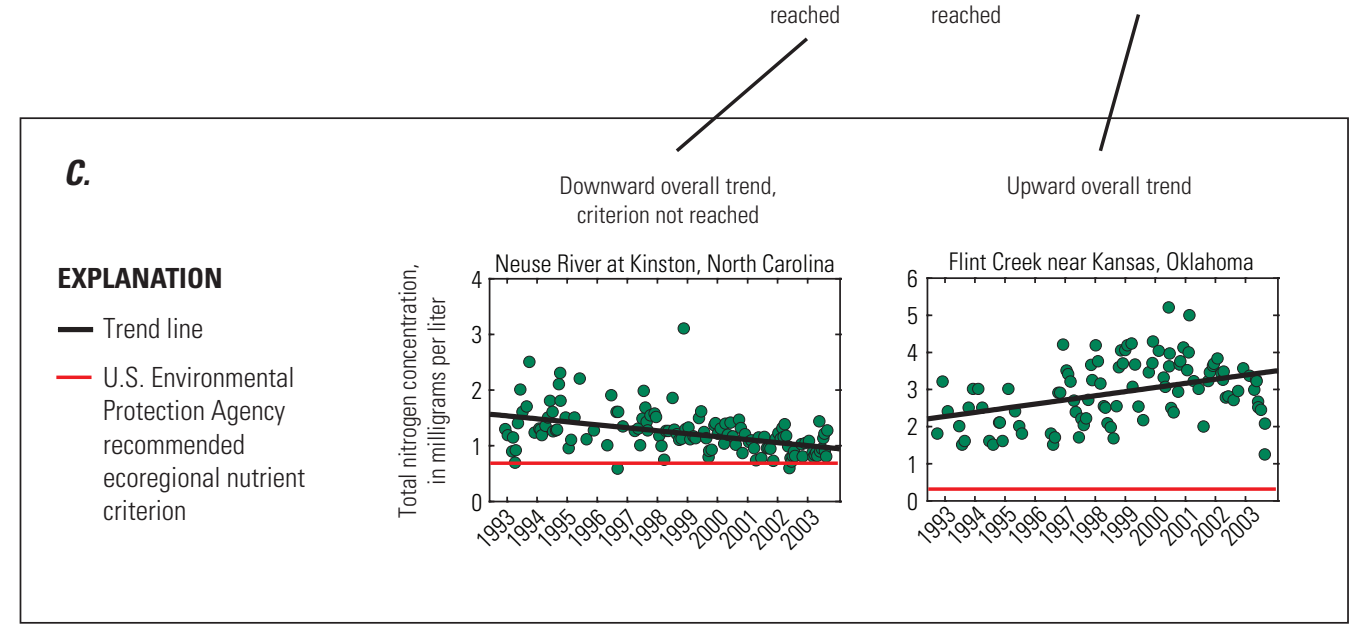

Figure 8-13. Upward overall trends were large enough that concentrations increased to above U.S. Environmental Protection Agency's (USEPA) recommended ecoregional nutrient criteria by 2003 in 21 percent of streams with total phosphorus concentrations below the criteria in 1993 and in 18 percent of streams with total nitrogen concentrations below the criteria in $1993(A)$. By comparison, downward overall trends were large enough that concentrations decreased to below the criteria by 2003 in only 1 percent of streams with total phosphorus concentrations above the criteria in 1993, and in 5 percent of streams with total nitrogen concentrations above the criteria in $1993(B)$. For example, from 1993 to 2003 , total nitrogen concentrations in the Neuse River, North Carolina, decreased to approach the recommended total nitrogen criterion, whereas total nitrogen concentrations in Flint Creek, Oklahoma, increased, moving further from the recommended total nitrogen criterion during the same period $(C)$. 
The trends in nutrient concentrations in U.S. streams between 1993 and 2003 are notably different than those between 1975 and 1994, when more downward trends in nutrient concentrations occurred (Alexander and Smith, 2006). In some U.S. streams, improvements in water quality realized after enactment of the Clean Water Act of 1972 have been offset somewhat by the effects of more recent changes in climate, population, land use, or agricultural and industrial activities. For example, an estimated 60 percent decrease ( 95 -percent confidence interval of -76 to -44 percent) in total phosphorus concentrations between 1972 and 1992 in the Ohio River near Grand Chain, Illinois, was followed by an estimated 61 percent increase (95-percent confidence interval of 17 to 121 percent) in concentrations between 1993 and 2003 (fig. 8-14). In the long term, human activities and climate will inevitably continue to change, affecting stream concentrations. Future nutrient conditions in the Nation's streams will depend on both natural and anthropogenic factors, and consideration of the full range of possible climatic conditions can help in shaping future water-quality management decisions.

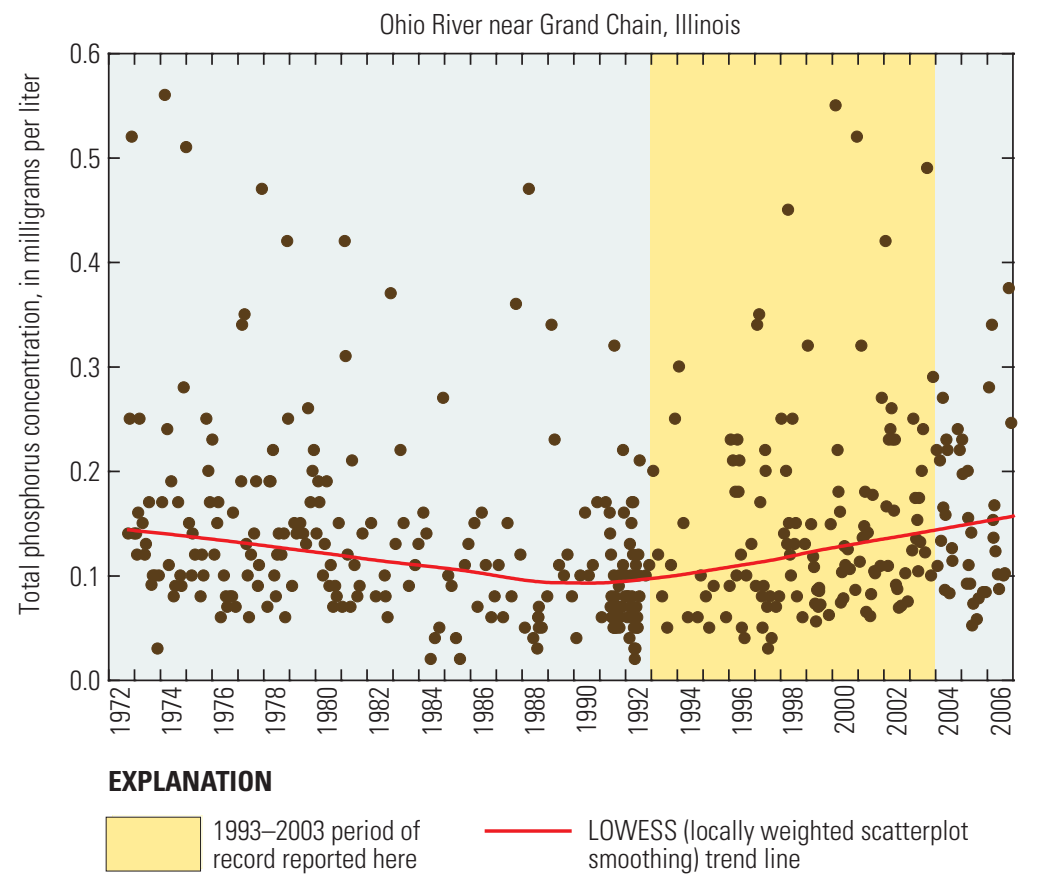

Figure 8-14. In some parts of the United States, improvements in water quality realized after the enactment of the Clean Water Act in 1972 have been offset somewhat by the effects of more recent changes in climate, population, land use, or agricultural and industrial activities. For example, the increase in total phosphorus concentrations between 1993 and 2003 in the Ohio River near Grand Chain, Illinois, followed a sustained decrease that occurred between 1972 and 1992. 


\section{Changes in Nitrate Concentrations in Groundwater}

Nitrate concentrations increased significantly in 495 wells first sampled during 1988-1995, and then resampled during 2001-2004. Median concentration of nitrate across all wells increased significantly from 3.2 to $3.4 \mathrm{mg} / \mathrm{L}$; changes at individual wells were highly variable and ranged from 0 to $33 \mathrm{mg} / \mathrm{L}$. In shallow groundwater beneath agricultural areas, the median concentration of nitrate increased from 4.8 to $5.7 \mathrm{mg} / \mathrm{L}$, whereas in deep groundwater sampled in major aquifer studies, the median concentration increased from 1.2 to
$1.5 \mathrm{mg} / \mathrm{L}$. The proportion of wells with nitrate concentrations greater than the USEPA Maximum Contaminant Level (MCL) was 16 percent at the start of the assessment period and increased to 21 percent of the wells sampled about a decade later. Nearly 90 percent of the wells in which concentrations of nitrate were greater than the MCL were completed in shallow aquifers beneath agricultural land-use study areas. The concentrations of nitrate increased significantly in 7 of the 24 groundwater study areas that were resampled (Rupert, 2008). Nitrate concentrations decreased in only one study area, the Willamette Valley of Oregon (fig. 8-15).

\section{Groundwater}

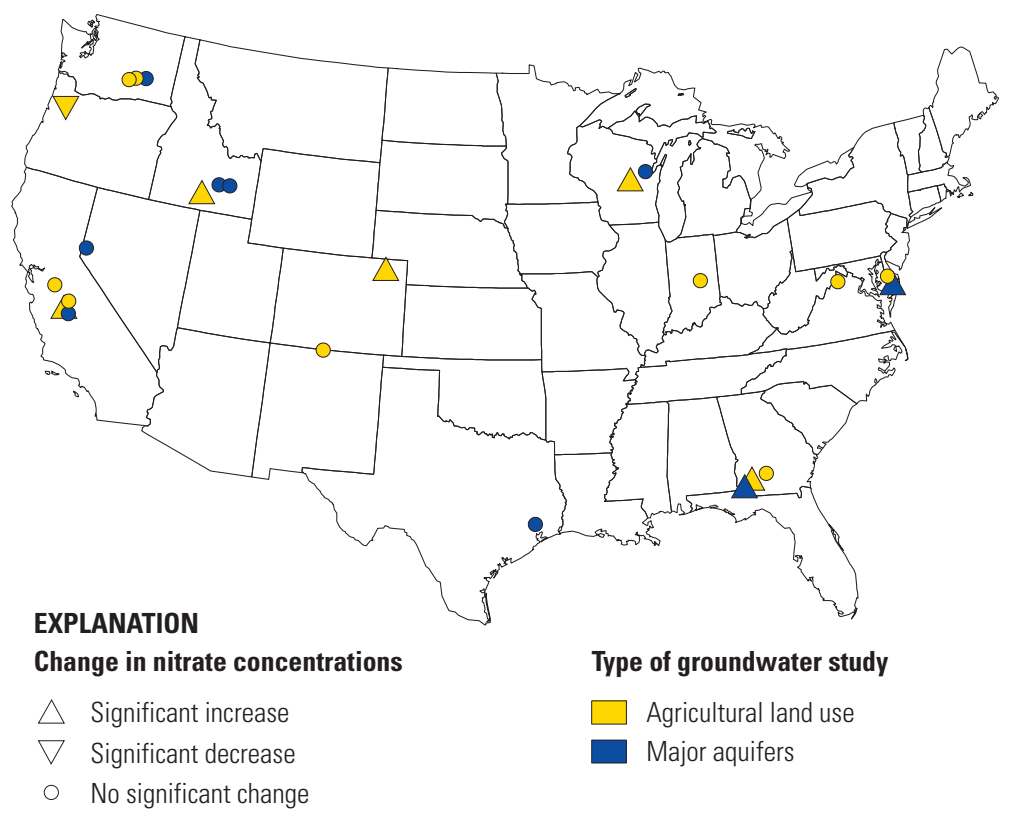

Figure 8-15. Nitrate concentrations increased in 7 of 24 groundwater study areas resampled after about a decade. (Modified from Rupert, 2008.)

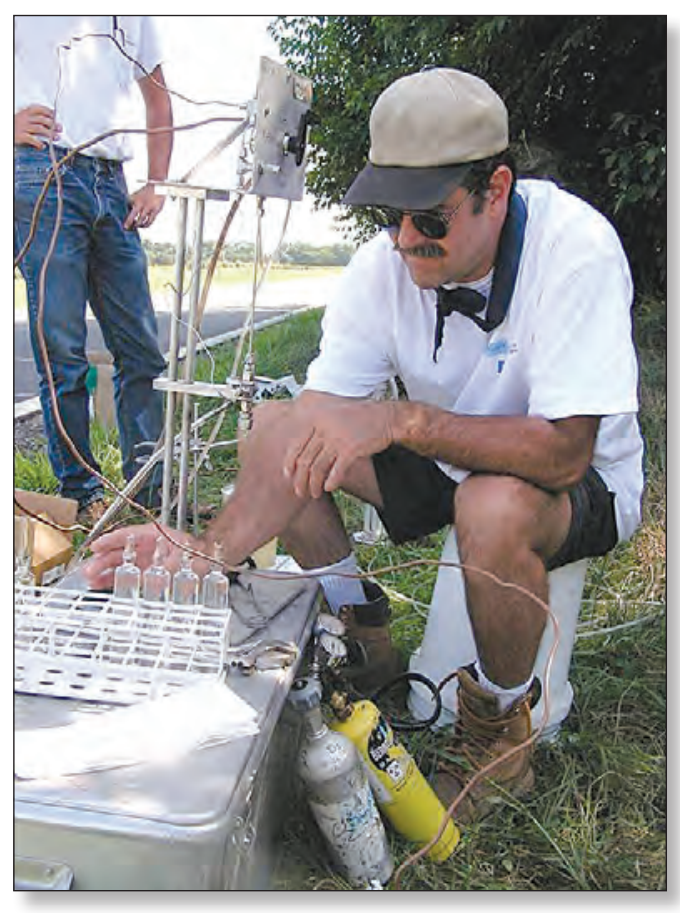

Samples for groundwater are sealed in glass ampoules in the field prior to shipping to the laboratory for determination of the recharge date. Photograph by U.S. Geological Survey. 
Estimates of groundwater recharge dates for individual samples also show that nitrate concentrations generally have increased since about 1975. Data on concentrations of environmental tracers were used to estimate the date that sampled water entered the aquifer (Plummer and Friedman, 1999). Nitrate concentrations plotted at the date the sample was collected (fig. 8-16A) and nitrate concentrations plotted at the date the water recharged the aquifer (fig. 8-16B) provide completely different perspectives of how concentrations vary over time. Although the samples were collected within a very narrow range in time (1993-2003), the recharge dates for these samples span many decades. The recharge dates show that water in samples collected from 1993 to 2003 took from years to decades to travel from the water table to a well intake. The wide range in travel times from recharge areas to the wells reflects the wide range in hydrogeologic conditions across the Nation. The data also show that in addition to increasing over time, elevated concentrations of nitrate appear in the shallow wells (blue symbols) as early as the 1950s and 1960s, whereas elevated concentrations in the deep major aquifer wells (red symbols) do not appear until the 1970s (fig. 8-16B).
The appraisal of the recharge dates of the sampled groundwater shows that increases in nitrate concentrations over time are consistent with trends in historical fertilizer use in the United States. Fertilizer use in the United States increased dramatically starting about 1950 , primarily because of the production of synthetic nitrogen fertilizer. Nitrate concentrations in groundwater increased in response to the increase in the use of nitrogen fertilizer (fig. 8-16B), although the fertilizer use appears to have increased more rapidly in the 1960s and 1970s than did nitrate concentrations in most of the samples collected during this period. Data for domestic and monitoring wells in a regional aquifer in Wisconsin show that an increase in nitrate concentrations in groundwater is strongly correlated to estimates of nitrate input from fertilizer use (Tesoriero and others, 2007) (fig. 8-17). The best fit between fertilizer use and groundwater concentrations assumes that 20 percent of the nitrate in the fertilizer is leached to groundwater.

Nitrate is stable and persistent in oxic water (water in which oxygen is present at concentrations greater than $0.5 \mathrm{mg} / \mathrm{L}$ ), but nitrate concentrations are commonly very low in reduced water because denitrification by bacteria
A.

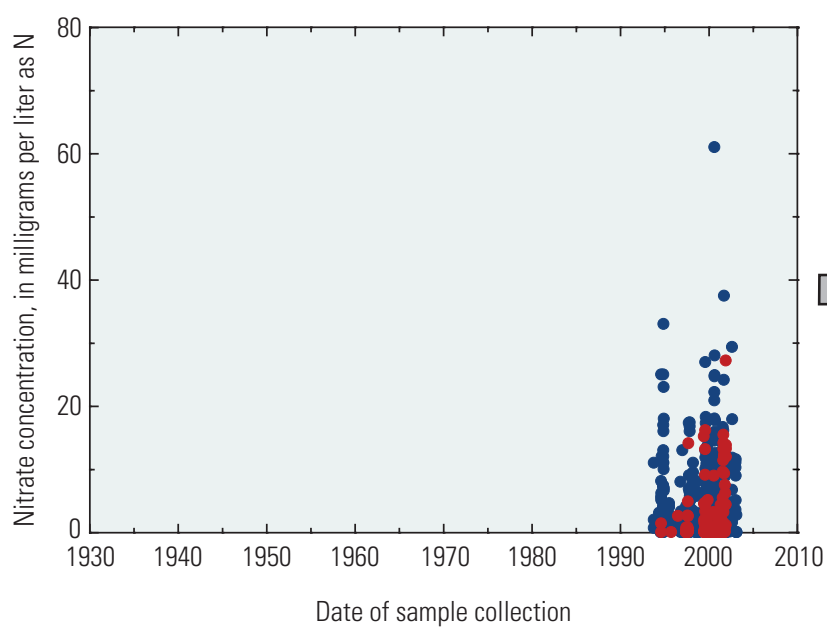

B.

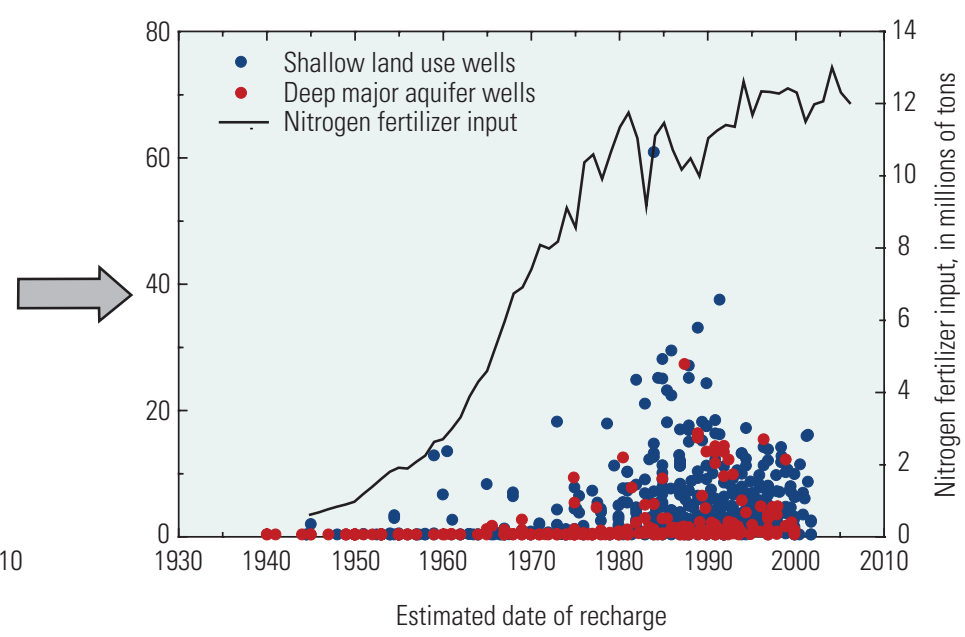

Figure 8-16. Estimates of groundwater recharge dates for individual samples show that nitrate concentrations have generally increased since about 1975. Although the samples were collected during a narrow range in time $(A)$, the recharge dates represented by these data span many decades $(B)$. Comparison between observed concentration of nitrate in groundwater and nitrate loading at the land surface would be difficult without an appraisal of the recharge dates of the sampled groundwater. (Modified from Rupert, 2008.) 
transforms the nitrate to nitrogen gas (see Chapter 2, Nutrient Primer). Changes in nitrate concentrations in groundwater over time can be very large in oxic waters, but changes are typically minimal to negligible in reduced waters because of denitrification (fig. 8-18). In most wells sampled, the redox conditions in the aquifers were stable throughout the sampling period; in a few wells, however, nitrate concentrations increased because of a transition from reduced to oxic conditions. Short-term changes in aquifer redox conditions can occur because of transient conditions, such as changes in the water-table elevation or contaminant loading; long-term changes from reduced to oxic conditions can occur because of depletion of the organic carbon or reduced iron minerals in the aquifer sediments.

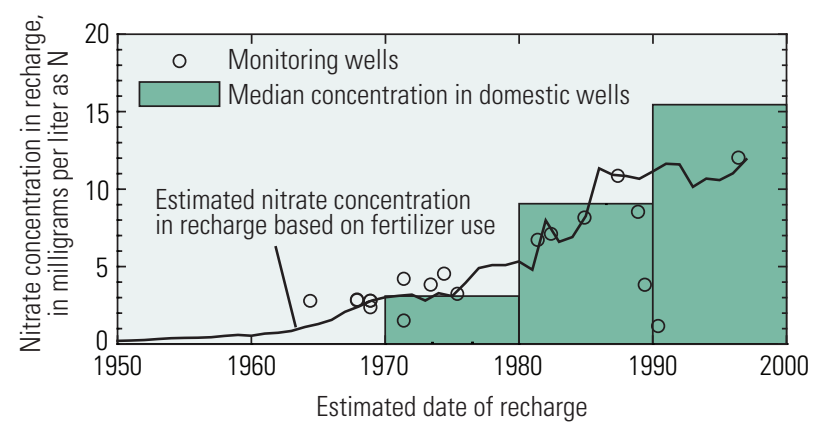

Figure 8-17. An increase in nitrate concentrations in water from domestic and monitoring wells in a regional aquifer in Wisconsin parallels the increase in nitrate in recharge estimated to have resulted from the effects of fertilizer use. (Modified from Tesoriero and others, 2007.)

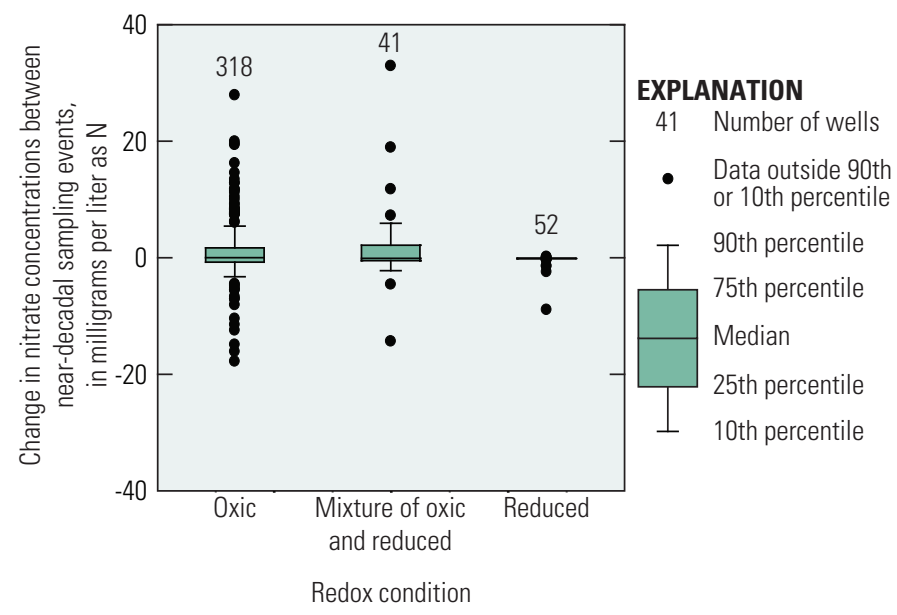

Figure 8-18. Changes in nitrate concentrations are much larger in oxic groundwater than in water under either reduced or mixed redox conditions. Changes in nitrate concentrations in reduced water are negligible because most of the nitrate has been transformed by denitrifying bacteria. (Modified from Rupert, 2008.)

\section{Change Varies by Depth and Well Type}

Changes in nitrate concentrations in wells are dependent on the position of the wells in the aquifer. Nitrate concentrations are typically highest and change most rapidly in the shallow part (that is, the upper part) of an aquifer. Water in the shallow part of the aquifer is young, and it reflects variations in nitrate inputs that may result from recent changes in activities and nutrient management practices at the land surface. Groundwater that lies deeper in the aquifer usually is older and is a composite that averages changing nitrate inputs over time. As a consequence, changes in nitrate concentrations were much greater in shallow groundwater than in deep groundwater (fig. 8-19).

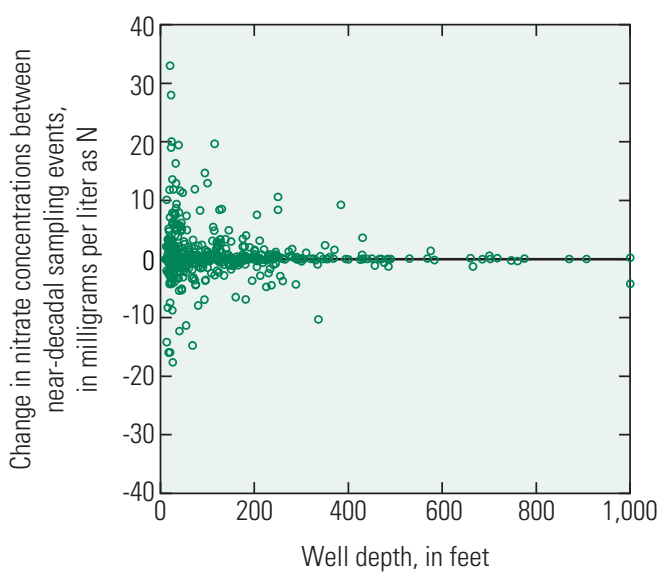

Figure 8-19. Changes in nitrate concentrations were much greater in shallow groundwater than in deep groundwater because the shallow water is younger and reflects the most recent changes in activities and nutrient management practices at the land surface. 
It is important to monitor water quality in various well types in an aquifer because the apparent rate of change in water quality will depend on the type of well, and hence depth interval, sampled. Typically, each type of well-monitoring, domestic supply, or public supply - taps a different depth interval in the aquifer system, so that samples collected from each type of well reflect a different part of the history of nitrogen input in that region. The importance of considering the depth and type of well sampled is illustrated by comparing nitrate concentrations in two contrasting sand and gravel aquifers: the surficial aquifer on the Delmarva Peninsula of Delaware, Maryland, and Virginia (fig. 8-20A), and in the eastern San Joaquin Valley of California (fig. 8-20B). Both areas are intensively and extensively farmed, and nitrogen fertilizer inputs in both increased about 5-fold from 1950 to the 1980s. Water moves at similar rates in both aquifers, but the aquifer on the Delmarva Peninsula is much thinner than the eastern San Joaquin Valley aquifer, and thus the distance that recharge water must travel from the land surface to the well intakes is much shorter. Concentrations of nitrate are most variable and highest near the water table, and concentrations decrease with depth as nitrate is increasingly mixed with older, low nitrate water with increased distance from the water table. The following are important points when comparing nitrate concentrations in groundwater in the Delmarva Peninsula and San Joaquin Valley aquifers:

- In both the Delmarva Peninsula and eastern San Joaquin Valley study areas, concentrations of nitrate were high in water from shallow monitoring wells in agricultural areas (Burow and others, 2008a; Debrewer and others, 2008), with median concentrations above the MCL for nitrate of $10 \mathrm{mg} / \mathrm{L}$ during 2001-2003 (fig. 8-20). During the study period, median nitrate concentrations in oxic groundwater near the water table increased from 8.3 to $12 \mathrm{mg} / \mathrm{L}$ on the Delmarva Peninsula and from 11 to $14 \mathrm{mg} / \mathrm{L}$ in the eastern San Joaquin Valley. The highest concentrations and greatest changes in concentration reflect the short travel time from the land surface to the well.

- The median concentration of nitrate in domestic wells on the Delmarva Peninsula, which are at an intermediate depth, increased significantly from 9 to
$12 \mathrm{mg} / \mathrm{L}$ from 1988 to 2001 (fig. 8-20C). Domestic wells in the eastern San Joaquin Valley are more than 100 feet deeper than those on the Delmarva Peninsula, and nitrate concentrations were lower and increased more slowly, from 6.1 to $7.3 \mathrm{mg} / \mathrm{L}$ from the period 1993-1995 to 2001-2002. Water produced by most of the Delmarva Peninsula wells entered the aquifer within the last decade. In the eastern San Joaquin Valley, however, water tapped by domestic wells was older, likely entering the aquifer more than a decade ago. The concentrations in the San Joaquin wells therefore reflect the lower rate of fertilizer use prior to the 1980s (Spurlock and others, 2000; Burow and others, 2008a).

- The median concentration of nitrate of $5.5 \mathrm{mg} / \mathrm{L}$ in the deepest wells on the Delmarva Peninsula - the public supply wells - was lower than concentrations in the shallower part of the system. Nitrate concentrations in public-supply wells in the eastern San Joaquin Valley were lower than those in the Delmarva Peninsula and increased only slightly, from 3.4 to $3.7 \mathrm{mg} / \mathrm{L}$, from the 1990s to the period 2001-2002 (fig. 8-20C). Concentrations in the public-supply wells in the eastern San Joaquin Valley were also much lower than those in the shallower domestic wells. The average age of groundwater in the Delmarva Peninsula public-supply wells is generally less than 20 years old (Ferrari, 2002), whereas the public-supply wells in the eastern San Joaquin Valley integrate water with ages ranging from several decades to several hundred years (Burow and others, 2008b).

In general, concentrations of nitrate will change more slowly in public-supply wells than in other wells because of their relatively greater depth and because their generally longer intake screens integrate groundwater with a wide range of ages, and hence, nitrate input history. As a result, in some aquifers, concentrations of nitrate in public-supply wells may only change slightly during the same period in which concentrations at shallow depths are increasing rapidly. Nitrate concentrations are likely to increase in public-supply wells during the next decade in oxic parts of these aquifers as the water with high concentrations now being tapped by domestic wells moves deeper into the aquifer. 
A.

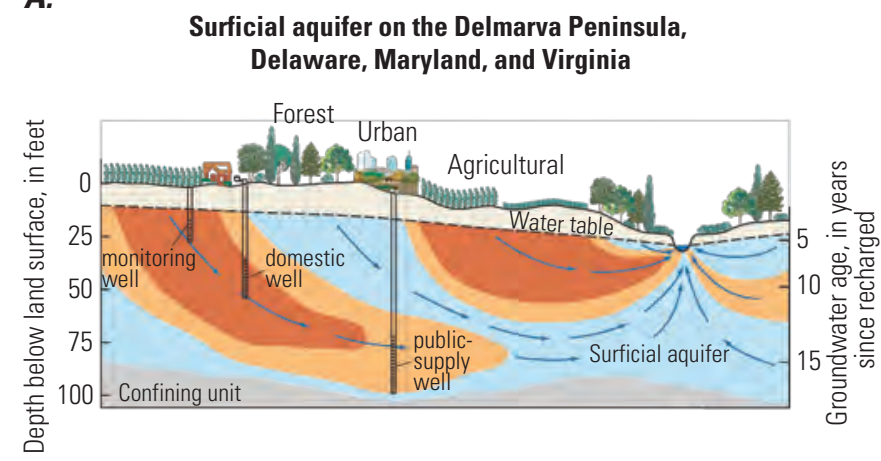

\section{EXPLANATION}

Unsaturated Zone

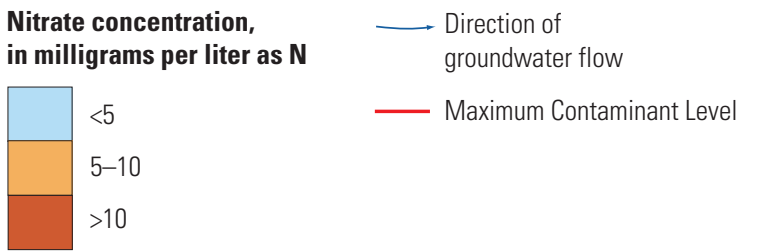

B.

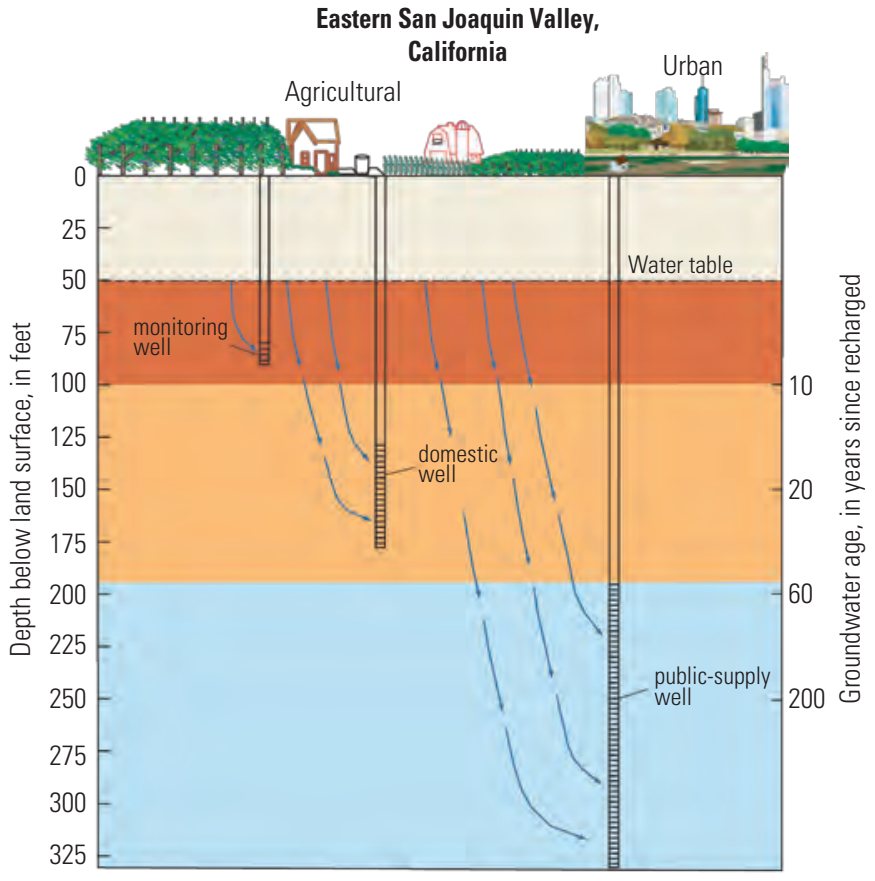

C.

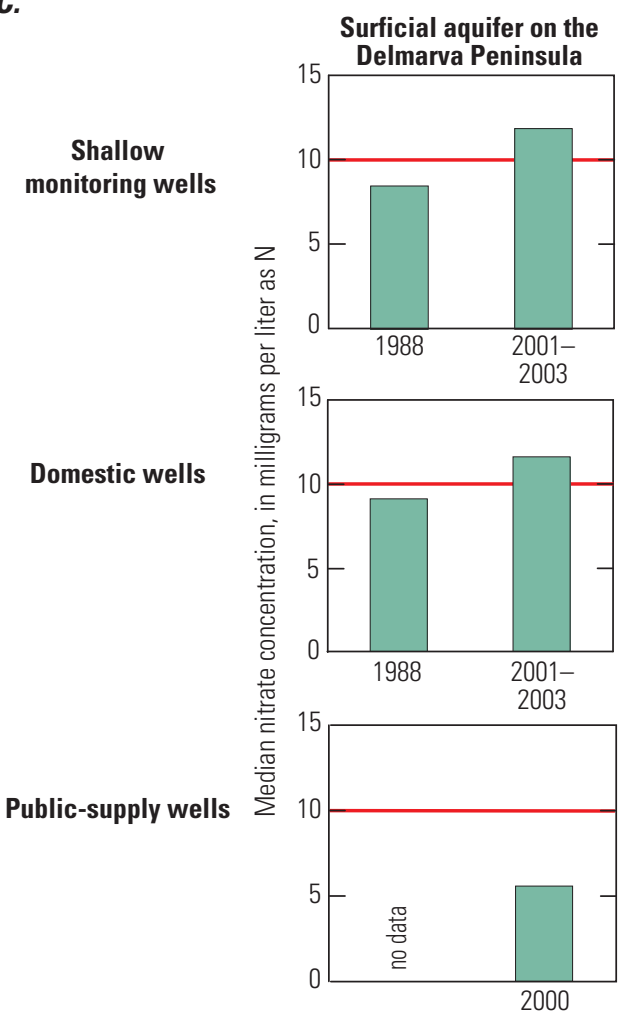

Eastern San Joaquin Valley
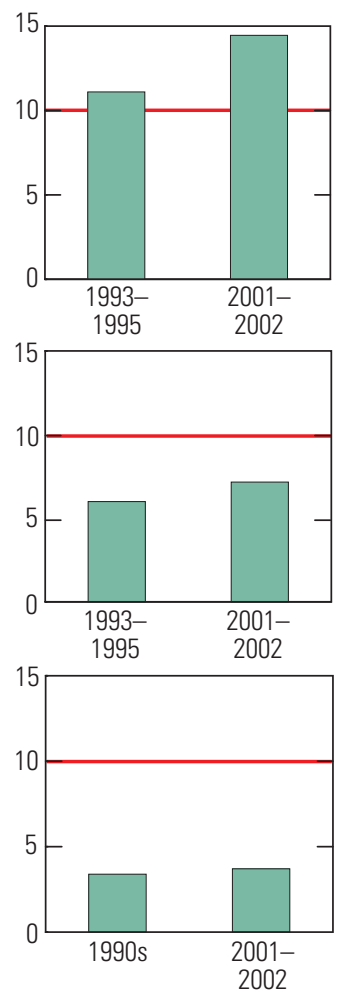

Figure 8-20. It is critical to monitor water quality in various types of wells in an aquifer because the apparent rate of change in chemical characteristics will depend on the type of well, and hence, the depth interval sampled. Median nitrate concentrations in domestic wells increased significantly in both the Delmarva Peninsula $(A)$ and the eastern San Joaquin Valley $(B)$ during the sampling period $(C)$, whereas the change in concentrations from the 1990s to 2001-2002 was insignificant in the relatively deep publicsupply wells in the eastern San Joaquin Valley $(C)$. Concentrations of nitrate exceeded the Maximum Contaminant Level of $10 \mathrm{mg} / \mathrm{L}$ (represented by the red line) in most of the shallow monitoring wells in both areas, as well as in the slightly deeper domestic wells in the Delmarva Peninsula $(C)$. 


\section{Nitrate Contamination in Shallow Groundwater-A Legacy Issue}

Evaluations of NAWQA data for streams and wells during the first decade of the Program show that nutrient concentrations have increased rather than decreased in many study areas, especially in groundwater. In addition, concentrations of nitrate in young, shallow groundwater in agricultural areas are much higher than concentrations in the deep resource usually used for drinking water. These observations, along with the potential for this reservoir of shallow, high-nitrate groundwater to move toward valued water resources, yield two important implications: first, concentrations of nitrate in deep groundwater used as a source of drinking water, and in streams with appreciable groundwater inputs, are likely to continue to increase in many areas of the country under current nutrient management practices; and second, there may be a significant lag time between the implementation of improved nutrient management practices and resulting decreases in nutrient concentrations.

As precipitation and irrigation waters infiltrate the soil, they move vertically downward and usually reach the water table in a matter of weeks to months. Once at the water table, this recharged water enters the groundwater system and flow directions gradually change from near vertical to horizontal until the water nears streams and lakes, where the flow is generally upward. Because groundwater flow rates typically are slow, on the order of a few tens to a few hundreds of feet per year, it can take decades or even centuries for groundwater to move from the most distant recharge areas to the discharge areas at wells, streams, lakes, or the coast. Consequently, most surficial aquifers appear stratified, with younger water near the surface and older water at progressively greater depths, and the aquifer system may contain water that has entered the system at various times over the last $50-100$ years or more (fig. 8-21). During this same period, particularly in the post World War II era, 1945-2004, nitrate use in the United States in the form of commercial fertilizer increased more than 20 -fold, from about 0.6 to about 13 million tons annually. More than 50 percent of the nitrate applied to the land surface may leach to groundwater (Tesoriero and others, 2007), and in oxic aquifers that nitrate can persist indefinitely. NAWQA has sampled groundwater at various depths and distances along flow paths to determine past nitrate inputs and the potential for nitrate to move deeper into aquifers to the intervals at which water-supply wells are screened (Böhlke and Denver, 1995; Puckett and Cowdery, 2002; Puckett and Hughes, 2005; Green and others, 2008; McMahon and others, 2008a; Steele and others, 2008). This approach has allowed NAWQA to examine the potential for groundwater nitrate to discharge to surface waters now and in the future. At selected sites, these data and related findings were used to construct numerical models that can be used to evaluate possible future scenarios.

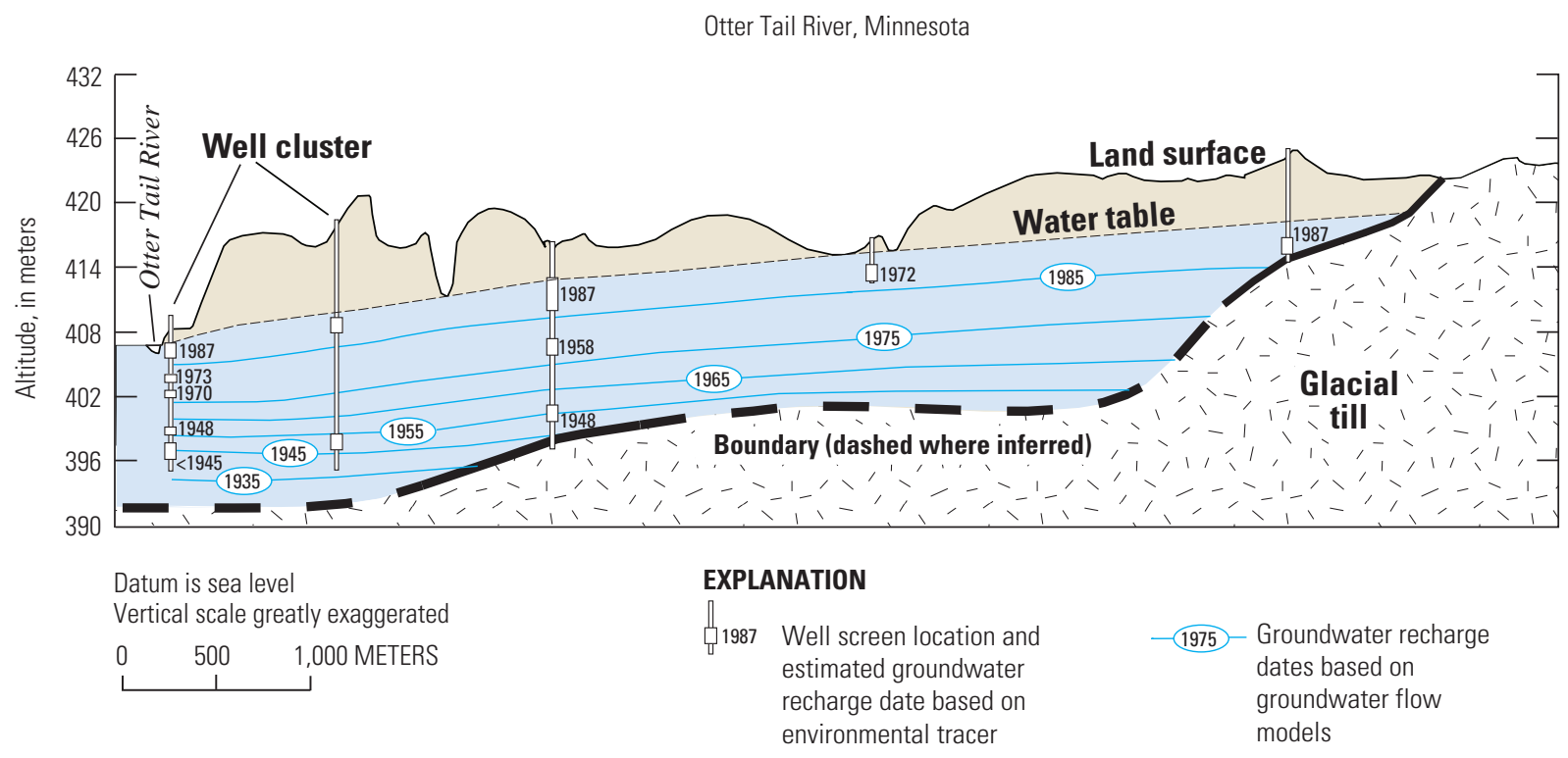

Figure 8-21. Most surficial aquifers appear stratified, with young water near the surface and older water at progressively greater depths. In a glacial outwash aquifer in Minnesota, groundwater recharge dates ranged from 1987 near the water table to 1935 in the deepest and most distal portion of the aquifer. (Modified from Puckett and Cowdery, 2002.) 


\section{Future Changes in Nitrate Transport to Drinking-Water Wells}

Nitrate concentrations generally are higher in wells that are screened in the shallow part of an aquifer than in the deeper parts, especially in agricultural settings. In view of the fact that, on average, 40 percent of the land within a 500 meter radius (1,640 feet) circle around major aquifer wells is agricultural, the fate of the high levels of nitrate in shallow groundwater is an important concern for domestic well owners and public well operators. A consequence of the high nitrate concentrations already present in shallow groundwater is that even if nitrate inputs are decreased, concentrations in deep groundwater are expected to increase as the contaminated young shallow water moves downward.

The impact of the lag time between changes in nitrate inputs at the land surface and consequent changes in nitrate concentrations in groundwater was evaluated for an aquifer near Glassboro, New Jersey, using numerical simulation techniques (Kauffman and others, 2001). Given the concentrations of nitrate in the aquifer in 2000, even with an immediate ban on nitrate inputs, it would take about 30 years to reduce concentrations in public-supply wells below the background level (fig. 8-22). Under a more likely scenario of a gradual reduction in input concentrations to near zero over 50 years, nitrate concentrations in public-supply wells would continue to rise for about 10 years before declining gradually over a period of 50 to 70 years. The lag time between changes in nitrate input at the surface and changes in nitrate concentrations at the well predicted by the model for the aquifer in southern New Jersey is the result of a suite of factors including the hydrogeologic and geochemical conditions of the aquifer.

The lag time between changes in nitrate inputs at the land surface and consequent changes in nitrate concentrations in groundwater from public-supply wells can range from several years to hundreds of years, depending on the hydrogeologic setting and hydrologic conditions within the aquifer. Detailed field studies were used to construct numerical models in four contrasting hydrogeologic settings: a carbonaterock aquifer (the Floridan aquifer system, Tampa, Florida); a thin unconsolidated sand

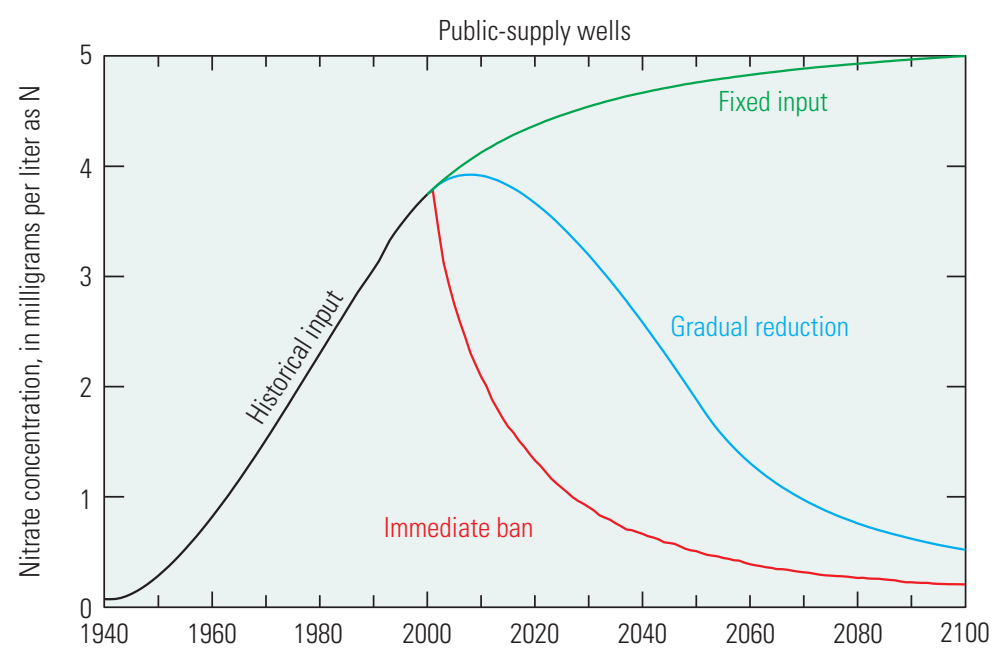

Figure 8-22. At the rate of nitrate input to shallow groundwater in 2000 in this study area in southern New Jersey, concentrations of nitrate in publicsupply wells are predicted to continue to increase in the future. Even if nitrate use is reduced, it may take decades for groundwater concentrations to reach pre-commercial fertilizer levels. (Modified from Kauffman and others, 2001.)

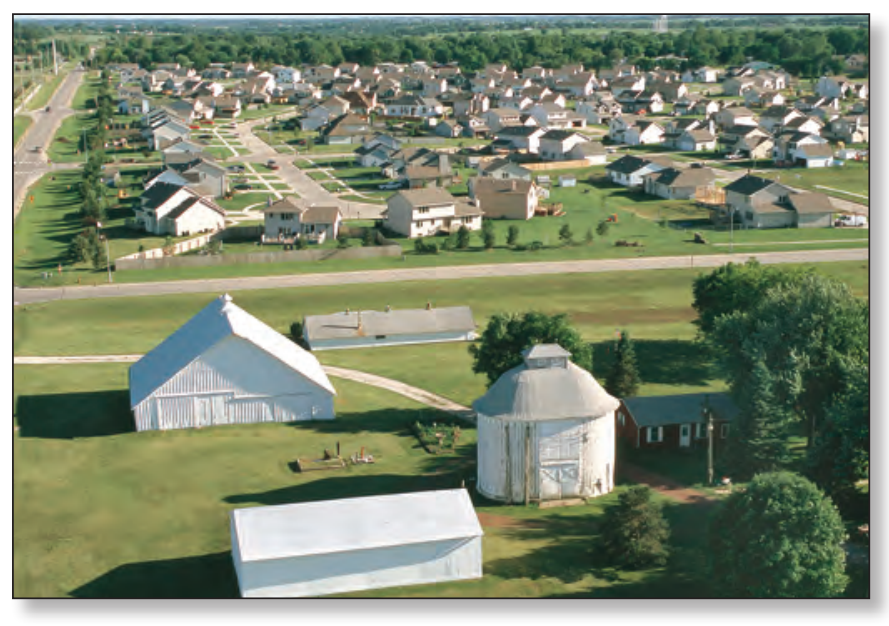

Urban encroachment may result in public supply wells withdrawing groundwater that recharged through agricultural lands. Photograph by Lynn Betts, U.S. Department of Agriculture, Natural Resources Conservation Service.

and gravel aquifer (Glacial aquifer system, Woodbury, Connecticut); and two thick unconsolidated sand and gravel aquifers (the Central Valley aquifer system, Modesto, California, and the High Plains aquifer system, York, Nebraska) (McMahon and others, 2008b). Using the same nitrate input characteristic of historical changes in fertilizer use (Burow and Green, 2008), simulations showed that nitrate concentrations in a public-supply well completed in the thin unconsolidated sand and gravel aquifer responded most rapidly, 
reaching the MCL of $10 \mathrm{mg} / \mathrm{L}$ in less than 10 years after nitrate in recharge reached that level (fig. 8-23A). It took more than a decade for nitrate concentrations in the well in the carbonate-rock aquifer to reach the MCL, whereas the wells in the thick unconsolidated sand and gravel aquifers took more than 60 years to reach concentrations above the MCL. These results illustrate the effects of the physical features of the aquifer systems alone, as denitrification was not accounted for in these simulations.

The nitrate concentrations in the four different hydrogeologic settings also responded differently to simulated urbanization. Simulations were done in which the proportion of agricultural land in the recharge area of the well decreased at a rate of 2 percent annually beginning in the 1970s to represent loss to urban encroachment (McMahon and others, 2008b). Because most of the water reaching the wells in the carbonaterock and thin unconsolidated sand and gravel aquifers is less than 15 years old, simulated concentrations peak and begin to decline after a delay of 6 to 12 years (fig. 8-23B). The response to changes in nitrate inputs in the thick unconsolidated sand and gravel aquifers was much more gradual, and peak concentrations were much lower because a significant proportion of water reaching these wells is old.

Adding denitrification in selected aquifer zones to the models increased lag times slightly in two of the four systems. Removal of nitrate by denitrification may decrease the response of groundwater concentrations to nitrate input in the carbonate-rock aquifer (Crandall and others, 2009), and in the unconsolidated sand and gravel aquifer of the High Plains aquifer system (Clark and others, 2007). The lack of attenuation by denitrification in the unconsolidated sand and gravel aquifers of the Central Valley, California (Burow and others, 2008b), and Woodbury, Connecticut (Starn and Brown, 2007), is attributed to the predominantly oxic conditions and (or) low denitrification rates. In aquifers with chemically more reduced conditions, changes in nitrate input would be buffered by rapid denitrification, and nitrate concentrations in public-supply wells would likely not change. Even in aquifers in which the reactants required for denitrification reactions are in limited supply and the reactions are very slow, long travel times may allow appreciable amounts of nitrate to be removed before the water reaches a well intake. In some aquifers, however, the reactants required for denitrification will gradually be depleted, and nitrate will move deeper into the aquifer and persist longer, creating a greater problem in the future.
A.

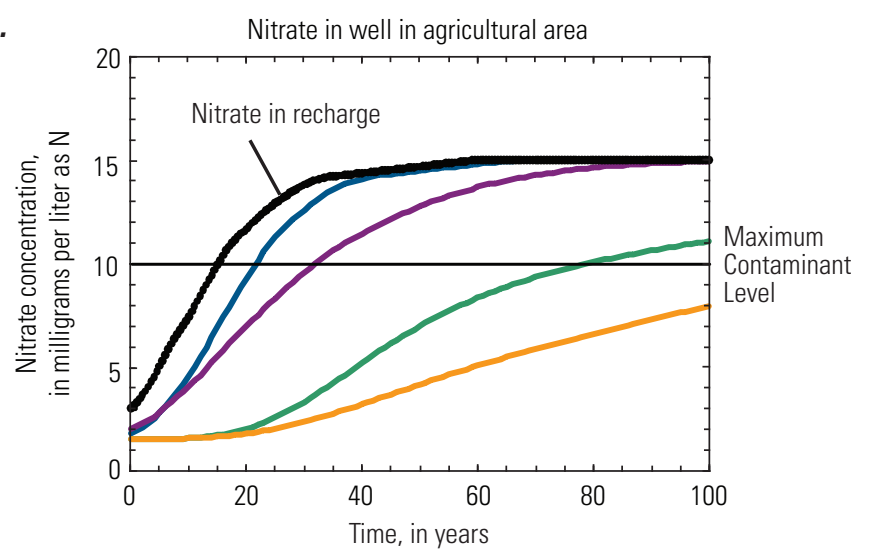

EXPLANATION

Time-series nitrate concentration in well in selected principal aquifers

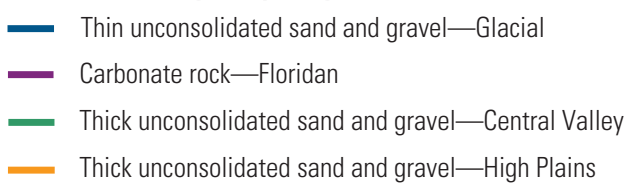

B. Nitrate in well in urban area-2\% annual loss of agricultural land

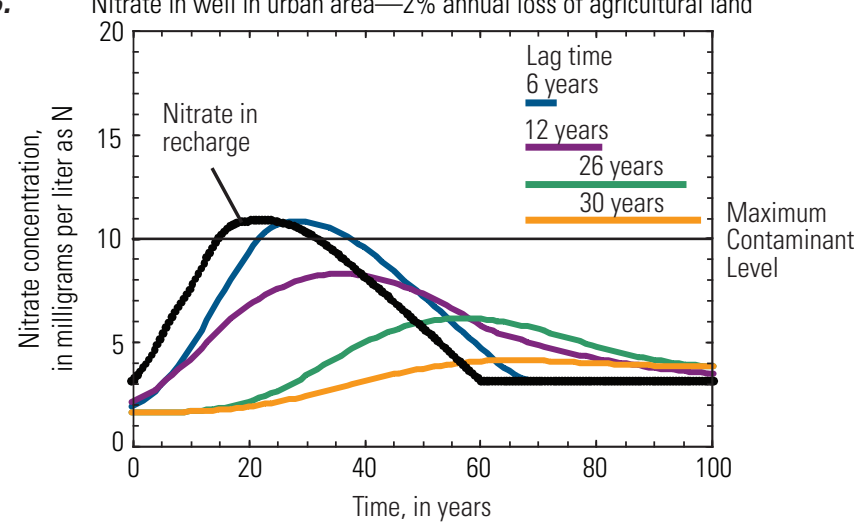

Figure 8-23. Model simulations of the effects of physical features of four aquifer systems on nitrate transport in groundwater show that nitrate concentrations in public-supply wells in carbonate-rock and thin unconsolidated sand and gravel aquifers respond quickly to increases in nitrate input $(A)$ and show a delay of 6 to 12 years before concentrations begin to decline when nitrate input concentrations were decreased due to loss of agricultural land in the recharge area $(B)$. The response to changes in nitrate inputs in deep alluvial aquifers was much more gradual, and peak concentrations were much lower. (Modified from Burow and Green, 2008; and McMahon and others, 2008b.) 


\section{Future Changes in Nitrate in Streams}

The slow rate at which nitrate is transported in groundwater also can result in a considerable lag time between changes in nitrate inputs at the land surface and changes in nitrate concentrations in groundwater discharging to streams. As groundwater reaches streams, the stratified age distribution results in younger water with higher nitrate concentrations discharging along the stream margins and older water containing lower nitrate concentrations discharging towards the center of the stream (fig. 8-24). Consequently, the concentration of nitrate in a stream is a mixture of waters of varying age and nitrate concentration. However, as the older groundwater is replaced by younger water containing higher concentrations of nitrate, the concentration of nitrate in discharging groundwater is projected to become more uniform across the entire width of the stream, and concentrations in the stream will increase.

A numerical model of the aquifer near Glassboro, New Jersey, illustrates the impact of the lag time between changes in nitrate inputs at the land surface and changes in nitrate concentrations in streams (Kauffman and others, 2001). At the current rate of nitrate input, concentrations in streams in this area are predicted to continue to increase in the future (fig. 8-25). Under a scenario of gradual reduction in input nitrate concentrations over 50 years, it may take decades for concentrations in the streams to reach pre-commercial fertilizer levels. Even with an immediate decrease in nitrate input to background levels at the water table, it would take about 30 years to reduce concentrations below background in the streams (fig. 8-25). The actual response of a specific stream to nitrate inputs from groundwater would depend on a large number of factors, including the presence of riparian buffer zones and streambed sediments capable of removing nitrate from the groundwater (see Chapter 5, Exchange of Nutrients between Surface Water and Groundwater).
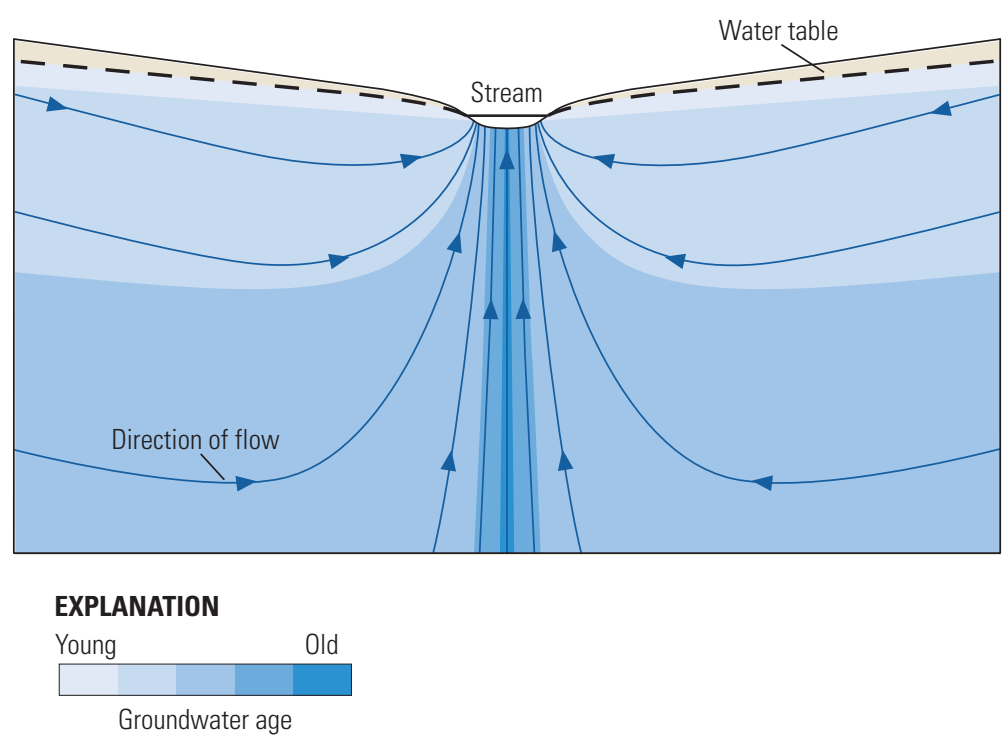

Figure 8-24. When groundwater discharges to a stream, younger waters discharge along the stream margins, and older waters are focused toward the center. Because older groundwater presently contains lower nitrate concentrations than younger groundwater, this creates a pattern of decreasing nitrate concentrations towards the center of the stream. In the future, as groundwater with higher nitrate concentrations replaces older, low-nitrate groundwater, nitrate concentrations will increase in the stream. (Modified from Modica and others, 1998.)

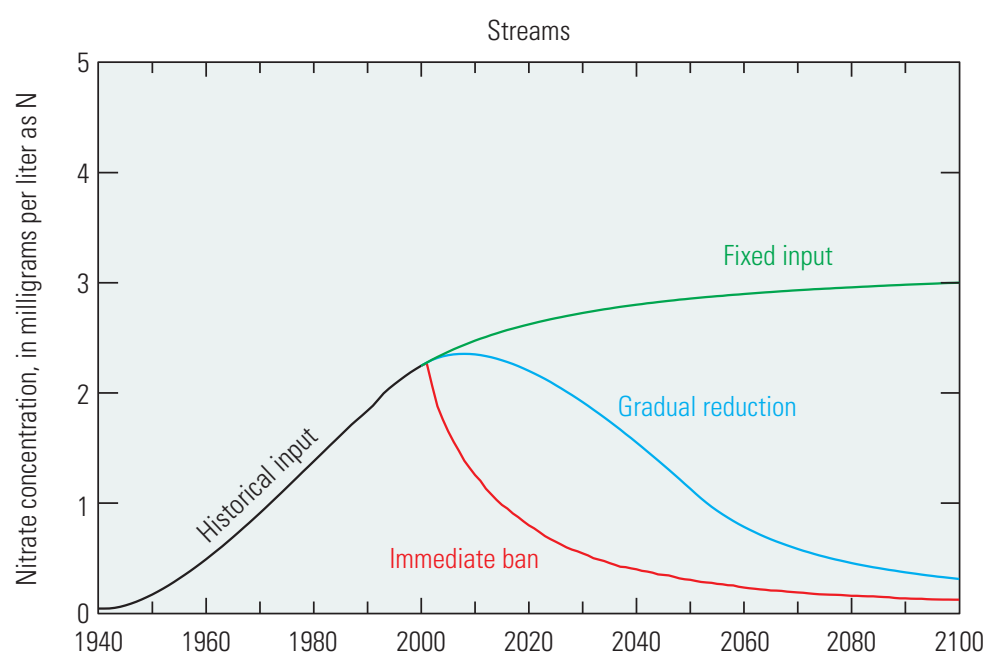

Figure 8-25. Concentrations of nitrate in streams near Glassboro, New Jersey, are predicted to continue to increase in the future at the current rate of nitrate input. Even in areas where nitrate use is now being reduced, it may take decades for concentrations of nitrate in streams to decrease to levels present prior to the use of commercial fertilizers. (Modified from Kauffman and others, 2001.) 
This page intentionally left blank 


\section{References Cited}

\section{Chapter 1:}

Herlihy, A.T., and Sifneos, J.C., 2008, Developing nutrient criteria and classification schemes for wadeable streams in the conterminous US: Journal of the North American Benthological Society, v. 27 , no. 4, p. 932-948, doi:10.1899/08-041.1, accessed June 15, 2010, at http:// www.bioone.org/doi/pdf/10.1899/08-041.1.

U.S. Environmental Protection Agency, 2001, Ambient water quality criteria recommendations: U.S. Environmental Protection Agency, Office of Water, EPA 822-B-01-012, 112 p., accessed June 15, 2010, at http://www.epa.gov/ waterscience/criteria/nutrient/ecoregions/rivers/rivers 1.pdf.

U.S. Environmental Protection Agency, 2009, Draft 2009 update aquatic life ambient water quality criteria for ammonia-Freshwater: U.S. Environmental Protection Agency, Office of Water, Office of Science and Technology, EPA-822-D-09-001, 184 p., accessed June 17, 2010, at http://www.epa.gov/waterscience/criteria/ ammonia/2009update.pdf.

U.S. Geological Survey, 1999, The quality of our Nation's waters-Nutrients and pesticides: U.S. Geological Survey Circular 1225, 82 p. (Also available at http://pubs.usgs.gov/ circ/circ1225/.)

\section{Chapter 2:}

Bachman, L.J., Lindsey, Bruce, Brakebill, John, and Powars, D.S., 1998, Ground-water discharge and base-flow nitrate loads of nontidal streams, and their relation to a hydrogeomorphic classification of the Chesapeake Bay watershed, Middle Atlantic Coast: U.S. Geological Survey Water-Resources Investigations Report 98-4059, $71 \mathrm{p}$. (Also available at http://pubs.usgs.gov/wri/wri98-4059/.)

Bushaw-Newton, K.L., and Sellner, K.G., 1999, Harmful algal blooms, in NOAA's State of the Coast Report, Silver Spring, MD: National Oceanic and Atmospheric Administration, accessed June 17, 2010, at http:// oceanservice.noaa.gov/websites/retiredsites/sotc_pdf/hab.pdf.

Cassman, K.G., Doberman, Achim, and Walters, D.T., 2002, Agroecosystems, nitrogen-use efficiency, and nitrogen management: Ambio, v. 31, no. 2, p. 132-140. http://www. jstor.org/stable/4315226.
Dettinger, M.D., 2005, Changes in streamflow timing in the Western United States in recent decades: U.S. Geological Survey Fact Sheet 2005-3018, 4 p. (Also available at http:// pubs.usgs.gov/fs/2005/3018/.)

Fuhrer, G.J., Morace, J.L., Johnson, H.M., Rinella, J.F., Ebbert, J.C., Embrey, S.S., Waite, I.R., Carpenter, K.D., Wise, D.R., and Hughes, C.A., 2004, Water quality in the Yakima River Basin, Washington, 1999-2000: U.S. Geological Survey Circular 1237, 34 p. (Also available at http://pubs.usgs.gov/circ/2004/1237/.)

Galloway, J.N., Schlesinger, W.H., Levy, Hiram, II, Michaels, Anthony, and Schnoor, J.L., 1995, Nitrogen fixation: Anthropogenic enhancement-environmental response: Global Biogeochemical Cycles, v. 9, no. 2, p. 235-252, accessed June 17, 2010, at http://www.agu.org/journals/gb/ v009/i002/95GB00158/95GB00158.pdf.

Howarth, Robert, Anderson, Donald, Cloern, James, Elfring, Chris, Hopkinson, Charles, Lapointe, Brian, Malone, Tom, Marcus, Nancy, McGlathery, Karen, Sharpley, Andrew, and Walker, Dan, 2000, Nutrient pollution of coastal rivers, bays, and seas: Issues in Ecology, no. 7, accessed June 17, 2010, at http://www.epa.gov/watertrain/pdf/issue7.pdf.

Kent, Robert, Belitz, Kenneth, and Burton, C.A., 2005, Algal productivity and nitrate assimilation in an effluent dominated concrete lined stream: Journal of the American Water Resources Association, v. 41, no. 5, p. 1109-1128.

Litke, D.W., 1999, Review of phosphorus control measures in the United States and their effects on water quality: U.S. Geological Survey Water-Resources Investigations Report 99-4007, 38 p. (Also available at http://pubs.usgs.gov/wri/ wri994007/.)

Lopez, C.B., Jewett, E.B., Dortch, Q., Walton, B.T., and Hudnell, H.K., 2008, Scientific assessment of freshwater harmful algal blooms: Interagency Working Group on Harmful Algal Blooms, Hypoxia and Human Health of the Joint Subcommittee on Ocean Science and Technology, Washington, DC, 65 p., accessed June 17, 2010, at http:// www.whitehouse.gov/sites/default/files/microsites/ostp/ frshh200708.pdf.

Majewski, M.S., and Capel, P.D., 1995, Pesticides in the atmosphere - distribution, trends, and governing factors: Chelsea, Mich., Ann Arbor Press, Pesticides in the Hydrologic System series, v. 1, 214 p. 
McCabe, G.J., Palecki, M.A., and Betancourt, J.L., 2004, Pacific and Atlantic Ocean influences on multidecadal drought frequency in the United States: Proceedings of the National Academy of Sciences of the United States of America, v. 101, no. 12, p. 4136-4141, doi: 10.1073/ pnas.0306738101, accessed June 17, 2010, at http:/www. pnas.org/content/101/12/4136.

National Oceanic and Atmospheric Administration, 2004, National Environmental Satellite, Data, and Information Service, National Oceanographic Data Center, National Coastal Data Development Center, Gulf of Mexico Hypoxia Watch Bottom Dissolved Oxygen Contours for June and July SEAMAP Cruise of 2004, accessed on March 3, 2009, at http://ecowatch.ncddc.noaa.gov/hypoxia/products.

National Science and Technology Council Committee on Environment and Natural Resources, 2003, An assessment of coastal hypoxia and eutrophication in U.S. waters: National Science and Technology Council Committee on Environment and Natural Resources, Washington, D.C., accessed June 17, 2010, at http://oceanservice.noaa.gov/ outreach/pdfs/coastalhypoxia.pdf.

Nebraska Department of Environmental Quality, 2009, Accessing Environmental Alert: accessed June 17, 2010, at http://www.deq.state.ne.us/.

Peterson, D.H., Smith, Richard, Hager, Stephen, Hicke, Jeffrey, Dettinger, M.D., and Huber, King, 2005, River Chemistry as a Monitor of Yosemite Park Mountain Hydroclimates: Eos, Transactions of the American Geophysical Union, v. 86, no. 31, p. 285-288.

Puckett, L.J., 1995, Identifying the major sources of nutrient water pollution: Environmental Science and Technology, v. 29, no. 9, p. 408A-414A, doi: 10.1021/es00009a001, accessed June 17, 2010, at http://pubs.acs.org/doi/ abs/10.1021/es00009a001.

Puckett, L.J., and Cowdery, T.K., 2002, Transport and fate of nitrate in a glacial outwash aquifer in relation to ground-water age, land use practices, and redox processes: Journal of Environmental Quality, v. 31, p.782-796, accessed June 17, 2010, at https://www.agronomy.org/ publications/jeq/abstracts/31/3/782.

Ruddy, B.C., Lorenz, D.L., and Mueller, D.K., 2006, Countylevel estimates of nutrient inputs to the land surface of the conterminous United States, 1982-2001: U.S. Geological Survey Scientific Investigations Report 2006-5012, 17 p. (Also available at http://pubs.usgs.gov/sir/2006/5012/.)
Sprague, L.A., Clark, M.L., Rus, D.L., Zelt, R.B., Flynn, J.L., and Davis, J.V., 2006, Nutrient and suspendedsediment trends in the Missouri River Basin, 1993-2003: U.S. Geological Survey Scientific Investigations Report 2006-5231, 80 p. (Also available at http://pubs.usgs.gov/ $\underline{\text { sir/2006/5231/.) }}$

Tilman, David, Fargione, Joseph, Wolff, Brian, Antonio, C.D., Dobson, Andrew, Howarth, Robert, Schindler, David, Schlesinger, W.H., Simberloff, Daniel, and Swackhamer, Deborah, 2001, Forecasting agriculturally driven global environmental change: Science, v. 292, no. 5515, p. 281-284, accessed June 17, 2010, at http://www. sciencemag.org/cgi/content/full/292/5515/281.

Townsend, A.R., Howarth, R.W., Bazzaz, F.A., Booth, M.S., Cleveland, C.C., Collinge, S.K., Dobson, A.P., Epstein, P.R., Holland, E.A., Keeney, D.R., Mallin, M.A., Rogers, C.A., Wayne, Peter, and Wolfe, A.H., 2003, Human health effects of a changing global nitrogen cycle: Frontiers in Ecology and the Environment, v. 1, no. 5, p. 240-246, doi: 10.1890/1540-9295(2003)001[0240:HHEOAC]2.0.CO;2, accessed June 17, 2010, at http://www.esajournals.org/doi/ abs/10.1890/1540-9295\%282003\%29001\%5B0240\%3AHH EOAC\%5D2.0.CO\%3B2.

U.S. Department of Agriculture, 2006, Economic Research Service, Data Sets, U.S. Fertilizer Use and Price, last updated: September 25, 2006, Downloaded April 30, 2007 http://www.ers.usda.gov/Data/FertilizerUse/.

U.S. Department of Agriculture, 2008, Conservation and Environmental Programs Division (CEPD), FY 2008 Annual Report, 16 p., accessed June 17, 2010, at http:// www.fsa.usda.gov/Internet/FSA File/cepd annual report_2008.pdf.

U.S. Department of Agriculture, 2010, Conservation Effects Assessment Project (CEAP): Natural Resources Conservation Service, accessed June 16, 2010, at http:// www.nrcs.usda.gov/technical/NRI/ceap/.

U.S. Environmental Protection Agency, 2002, NitrogenMultiple and regional impacts: U.S. Environmental Protection Agency Clean Air Markets Division Report EPA430-R-01-006, 38 p., accessed June 17, 2010, at: http:// www.epa.gov/airmarkt/resource/docs/nitrogen.pdf.

U.S. Environmental Protection Agency, 2008, Watershed Academy Web, Agricultural Management Practices for Water Quality Protection, accessed June, 15, 2010, at http:// www.epa.gov/watertrain/agmodule/. 
U.S. Environmental Protection Agency, 2009, National Water Quality Inventory-Report to Congress. 2004 reporting cycle: U.S. Environmental Protection Agency, Office of Water, EPA 841-R-08-001, 37 p., accessed June 17, 2010, at http://www.epa.gov/305b/2004report/2004 305Breport.pdf.

Vitousek, P.M., Aber, J.D., Howarth, R.W., Likens, G.E., Matson, P.A., Schindler, D.W., Schlesinger, W.H., and Tilman, D.G., 1997, Human alteration of the global nitrogen cycle: sources and consequences: Ecological Applications, v. 7, issue 3, p. 737-750, accessed June 17, 2010, at http://www.esajournals.org/doi/abs/10.1890/10510761(1997)007\%5B0737:HAOTGN\%5D2.0.CO\%3B2.

Ward, M.H., deKok, T.M., Levallois, Patrick, Brender, Jean, Gulis, Gabriel, Nolan, B.T., and VanDerslice, James, 2005, Workgroup Report: Drinking-water nitrate and healthRecent finding and research needs: Environmental Health Perspectives, v. 113, no. 11, p. 1607-1614, accessed June 17, 2010, at http://www.pubmedcentral.nih.gov/ articlerender.fcgi? \&artid=1310926.

\section{Chapter 3:}

Clark, G.M., Caldwell, R.R., Maret, T.R., Bowers, C.L., Dutton, D.M., and Beckwith, M.A., 2004, Water quality in the Northern Rockies Intermontane Basins, Idaho, Montana, and Washington, 1999-2001: U.S. Geological Survey Circular 1235, 29 p. (Also available at http://pubs.usgs.gov/ circ/2004/1235/.)

Gilliom, R.J., Barbash, J.E., Crawford, C.G., Hamilton, P.A., Martin, J.D., Nakagaki, N., Nowell, L.H., Scott, J.C., Stackelberg, P.E., Thelin, G.P., and Wolock, D.M., 2006, The quality of our Nation's waters-Pesticides in the Nation's streams and ground water, 1992-2001: U.S. Geological Survey Circular 1291, 172 p. (Also available at http://pubs.usgs.gov/circ/2005/1291/.)

Jurgens, B.C., McMahon, P.B., Chapelle, F.H., and Eberts, S.M., 2009, An Excel ${ }^{\circledR}$ workbook for identifying redox processes in ground water: U.S. Geological Survey OpenFile Report 2009-1004, 8 p. (Also available at http://pubs. usgs.gov/of/2009/1004/.)

Nakagaki, N., Price, C.V., Falcone, J.A., Hitt, K.J., Ruddy, B.C., 2007, Enhanced national land cover data 1992 (NLCDe 92), accessed June 17, 2010, at http://water.usgs. gov/GIS/metadata/usgswrd/XML/nlcde92.xml.

Nolan, J.V., Brakebill, J.W., Alexander, R.B., and Schwarz, G.E., 2002, ERF1_2-Enhanced river reach file 2.0: U.S. Geological Survey Open-File Report 2002-40. (Also available at http://pubs.er.usgs.gov/usgspubs/ofr/ofr0240.)
Nolan, B.T., and Hitt, K.J., 2006, Vulnerability of shallow groundwater and drinking-water wells to nitrate in the United States: Environmental Science and Technology, v. 40, no. 24, p. 7834-7840, doi:10.1021/es060911u, accessed June 17, 2010, at http://water.usgs.gov/nawqa/ nutrients/pubs/est v40 no24/.

Rowe, G.L., Reutter, D.C., Runkle, D.L., Hambrook, J.A., Janosy, S.D., and Hwang, L.H., 2004, Water quality in the Great and Little Miami River Basins, Ohio and Indiana, 1999-2001: U.S. Geological Survey Circular 1229, 40 p. (Also available at $\mathrm{http} / / /$ pubs.usgs.gov/circ/2004/1229/.)

Spahr, N.E., Mueller, D.K., Wolock, D.M., Hitt, K.J., and Gronberg, J.M., 2010, Development and application of regression models for estimating nutrient concentrations in streams of the conterminous United States, 1992-2001: U.S. Geological Survey Scientific Investigations Report 2009-5199, 22 p. (Also available at http://pubs.usgs.gov/ $\underline{\operatorname{sir} / 2009 / 5199 / .)}$

Woodside, M.D., Hoos, A.B., Kingsbury, J.A., Powell, J.R., Knight, R.R., Garrett, J.W., Mitchell, R.L., III, and Robinson, J.A., 2004, Water quality in the Lower Tennessee River Basin, Tennessee, Alabama, Kentucky, Mississippi, and Georgia, 1999-2001: U.S. Geological Survey Circular 1233, 33 p. (Also available at http://pubs.usgs.gov/ circ/2004/1233/.)

\section{Chapter 4:}

Alexander, R.B., Smith, R.A., and Schwarz, G.E., 2000, Effect of stream channel size on the delivery of nitrogen to the Gulf of Mexico: Nature, v. 403, p. 758-761, accessed June 17, 2010, at http://www.nature.com/nature/journal/ v403/n6771/full/403758a0.html.

Alexander, R.B., Smith, R.A., Schwarz, G.E., Boyer, E.W., Nolan, J.V., and Brakebill, J.W., 2008, Differences in phosphorus and nitrogen delivery to the Gulf of Mexico from the Mississippi River Basin: Environmental Science and Technology, v. 42, p. 822-830.

Brakebill, J.W., Preston, S.D., and Martucci, S.K., 2001, Digital data used to relate nutrient inputs to water quality in the Chesapeake Bay watershed, Version 2.0: U.S. Geological Survey Open-File Report 01-251, [variously paged], accessed June 17, 2010, at http://md.water.usgs.gov/ publications/ofr-01-251.

Burow, K.R., Nolan, B.T., Rupert, M.G., and Dubrovsky, N.M., 2010, Nitrate in groundwater of the United States, 1991-2003: Environmental Science and Technology, v. 44, no. 13, p. 4988-4997, doi: 10.1021/es100546y. (Also available at http://pubs.acs.org/doi/abs/10.1021/es100546y.) 
Clark, G.M., Mueller, D.K., and Mast, M.A., 2000, Nutrient concentrations and yields in undeveloped basins of the United States: Journal of American Water Resources Association, v. 36, no. 4, p. 849-860, accessed June 17, 2010, at http://water.usgs.gov/nawqa/nutrients/pubs/awra v36 no4/.

Jagucki, M.L., Landon, M.K., Clark, B.R., and Eberts, S.M., 2008, Assessing the vulnerability of public-supply wells to contamination: High Plains aquifer near York, Nebraska: U.S. Geological Survey Fact Sheet 2008-3025, 6 p. (Also available at http://pubs.usgs.gov/fs/2008/3025/)

Kalkhoff, S.J., Barnes, K.K., Becher, K.D., Savoca, M.E., Schnoebelen, D.J., Sadorf, E.M., Porter, S.D., and Sullivan, D.J., 2000, Water quality in the Eastern Iowa Basins, Iowa and Minnesota, 1996-98: U.S. Geological Survey Circular 1210, 37 p. (Also available at http://pubs.water.usgs.gov/ circ1210/.)

Katz, B.G., Crandall, C.A., Metz, P.A., McBride, W.S., and Berndt, M.P., 2007, Chemical characteristics, water sources and pathways, and age distribution of ground water in the contributing recharge area of a public-supply well near Tampa, Florida, 2002-05: U.S. Geological Survey Scientific Investigations Report 2007-5139, 83 p. (Also available at http://pubs.usgs.gov/sir/2007/5139/.)

Land, L.F., Moring, J.B., Van Metre, P.C., Reutter, D.C., Mahler, B.J., Shipp, A.A., and Ulery, R.L., 1998, Water quality in the Trinity River Basin, Texas, 1992-95: U.S. Geological Survey Circular 1171, 39 p. (Also available at http://pubs.usgs.gov/circ/circ1171/.)

Landon, M.K., Clark, B.R., McMahon, P.B., McGuire, V.L., and Turco, M.J., 2008, Hydrogeology, chemical characteristics, and transport processes in the zone of contribution of a public-supply well in York, Nebraska: U.S. Geological Survey Scientific Investigations Report 2008-5050, 149 p. (Also available at http://pubs.usgs.gov/ $\underline{\operatorname{sir} / 2008 / 5050 / .)}$

McMahon, Gerald, Alexander, R.B., and Qian, Song, 2003, Support of total maximum daily load programs using spatially referenced regression models: American Society of Civil Engineers, Journal of Water Resources Planning and Management, v. 129, p. 315-329, accessed June 17, 2010, at http://ascelibrary.aip.org/getabs/servlet/GetabsServlet?pro $\mathrm{g}=$ normal\&id=JWRMD5000129000004000315000001\&idt ype $=$ cvips\&gifs $=$ Yes.
McMahon, P.B., Böhlke, J.K., Kauffman, L.J., Kipp, K.L., Landon, M.K., Crandall, C.A., Burow, K.R., and Brown, C.J., 2008, Source and transport controls on the movement of nitrate to public supply wells in selected principal aquifers of the United States: Water Resources Research, v. 44, W04401, 17 p., doi:10.1029/2007WR006252, accessed June 17, 2010, at http://www.agu.org/pubs/ crossref/2008/2007WR006252.shtml.

Miller, J.A., 2000, Ground water atlas of the United States: U.S. Geological Survey, Chapters archived online 19901999, accessed April 2, 2010, at http://capp.water.usgs.gov/ gwa/gwa.html.

Moore, R.B., Johnston, C.M., Robinson, K.W., and Deacon, J.R., 2004, Estimation of total nitrogen and phosphorus in New England streams using spatially referenced regression models: U.S. Geological Survey Scientific Investigations Report 2004-5012, 42 p. (Also available at http://pubs.usgs. gov/sir/2004/5012/.)

Mueller, D.K., and Spahr, N.E., 2005, Water-quality, streamflow, and ancillary data for nutrients in streams and rivers across the nation, 1992-2001: U.S. Geological Survey Data Series 152, accessed January 2007, at http:// pubs.usgs.gov/ds/2005/152/.

Mueller, D.K., and Spahr, N.E., 2006, Nutrients in streams and rivers across the Nation-1992-2001: U.S. Geological Survey Scientific Investigations Report 2006-5107, 44 p. (Also available at http://pubs.usgs.gov/sir/2006/5107/.)

Nolan, B.T., and Hitt, K.J., 2003, Nutrients in shallow ground waters beneath relatively undeveloped areas in the conterminous United States: U.S. Geological Survey WaterResources Investigations Report 02-4289, 17 p. (Also available at http://pubs.usgs.gov/wri/wri024289/.)

Nolan, B.T., and Hitt, K.J., 2006, Vulnerability of shallow groundwater and drinking-water wells to nitrate in the United States: Environmental Science and Technology, v. 40, no. 24, p. 7834-7840, doi:10.1021/es060911u, accessed June 17, 2010, at http://water.usgs.gov/nawqa/ nutrients/pubs/est v40_no24/.

Peterson, D.A., Miller, K.A., Bartos, T.T., Clark, M.L., Porter, S.D., and Quinn, T.L., 2004, Water quality in the Yellowstone River Basin, Wyoming, Montana, and North Dakota, 1999-2001: U.S. Geological Survey Circular 1234, 34 p. (Also available at http://pubs.usgs.gov/ circ/2004/1234/.)

Plummer, L.N., and Friedman, L.C., 1999, Tracing and dating young ground water: U.S. Geological Survey Fact Sheet 134-99, 4 p. (Also available at http://pubs.usgs.gov/fs/ FS-134-99/.) 
Preston, S.D., Alexander, R.B., Woodside, M.D., and Hamilton, P.A., 2009, SPARROW MODELINGEnhancing understanding of the Nation's water quality: U.S. Geological Survey Fact Sheet 2009-3019, 6 p. (Also available at http://pubs.usgs.gov/fs/2009/3019/.)

Seaber, P.R., Kapinos, F.P., and Knapp, G.L., 1987, Hydrologic unit maps: U.S. Geological Survey WaterSupply Paper 2294, 63 p. (Also available at http://pubs. usgs.gov/wsp/wsp2294/.)

Smith, R.A., Schwarz, G.E., and Alexander, R.B., 1997, Regional interpretation of water-quality monitoring data: Water Resources Research, v. 33, no. 12, p. 2781-2798, accessed June 17, 2010, at http://water.usgs.gov/nawqa/ sparrow/wrr97/97WR02171.pdf.

Spahr, N.E., Mueller, D.K., Wolock, D.M., Hitt, K.J., and Gronberg, J.M., 2010, Development and application of regression models for estimating nutrient concentrations in streams of the conterminous United States, 1992-2001: U.S. Geological Survey Scientific Investigations Report 2009-5199, 22 p. (Also available at http://pubs.usgs.gov/ $\underline{\text { sir/2009/5199/.) }}$

U.S. Geological Survey, 2003, Principal aquifers of the 48 conterminous United States, Hawaii, Puerto Rico, and the U.S. Virgin Islands: U.S. Geological Survey, accessed April 2. 2010, at http://www.nationalatlas.gov/mld/aquifrp.html.

U.S. Geological Survey, 2009a, National Geochemical Survey, Phosphorus in counties of the conterminous States, accessed June 17, 2010, at http://tin.er.usgs.gov/geochem/doc/ averages/p/usa.html.

U.S. Geological Survey, 2009b, Aquifer basics: U.S. Geological Survey, Office of Ground Water, accessed April 2, 2010, at http://capp.water.usgs.gov/aquiferBasics/ index.html.

Walvoord, M.A., Phillips, F.M., Stonestrom, D.A., Evans, R.D., Hartsough, P.C., Newman, B.D., and Striegl, R.G., 2003, A reservoir of nitrate beneath desert soils: Science, v. 302, no. 5647, p. 1021-1024, accessed on June 17, 2010, at http://www.sciencemag.org/cgi/content/ short/302/5647/1021.

\section{Chapter 5:}

Bachman, L.J., Lindsey, Bruce, Brakebill, John, and Powars, D.S., 1998, Ground-water discharge and base-flow nitrate loads of nontidal streams, and their relation to a hydrogeomorphic classification of the Chesapeake Bay watershed, Middle Atlantic Coast: U.S. Geological Survey Water-Resources Investigations Report 98-4059, $71 \mathrm{p}$. (Also available at http://md.water.usgs.gov/publications/ wrir-98-4059/.)

Baker, N.T., Stone, W.W., Wilson, J.T., and Meyer, M.T., 2006, Occurrence and transport of agricultural chemicals in Leary Weber Ditch Basin, Hancock County, Indiana, 2003-04: U.S. Geological Survey Scientific Investigations Report 2006-5251, 44 p. (Also available at http://pubs.usgs. gov/sir/2006/5251/.)

Böhlke, J.K., and Denver, J.M., 1995, Combined use of groundwater dating, chemical, and isotopic analyses to resolve the history and fate of nitrate contamination in two agricultural watersheds, Atlantic coastal plain, Maryland: Water Resources Research, v. 31, no. 9, p. 2319-2339, doi:10.1029/95WR01584, accessed June 17, 2010, at http:// www.agu.org/journals/ABS/1995/95WR01584.shtml.

Duff, J.H., Tesoriero, A.J., Richardson, W.B., Strauss, E.A., and Munn, M.D., 2008, Whole-stream response to nitrate loading in three streams draining agricultural landscapes: Journal of Environmental Quality, v. 37, p. 1133-1144, doi: 10.2134/jeq2007.0187, accessed June 17, 2010, at at https:// www.agronomy.org/publications/jeq/abstracts/37/3/1133.

Essaid, H.I., Zamora, C.M., McCarthy, K.A., Vogel, J.R., and Wilson, J.T., 2008, Using heat to characterize streambed water flux variabililty in four stream reaches: Journal of Environmental Quality, v. 37, p. 1010-1023, doi: 10.2134/ jeq2006.0448, accessed June 17, 2010, at https://www. agronomy.org/publications/jeq/abstracts/37/3/1010.

Fenelon, J.M., 1998, Water quality in the White River Basin, Indiana, 1992-96: U.S. Geological Survey Circular 1150, 34 p. (Also available at http://pubs.usgs.gov/circ/circ1150/.)

Fischer, J.M., Riva-Murray, Karen, Hickman, R.E., Chichester, D.C., Brightbill, R.A., Romanok, K.M., and Bilger, M.D., 2004, Water quality in the Delaware River Basin, Pennsylvania, New Jersey, New York, and Delaware, 1998-2001: U.S. Geological Survey Circular 1227, 38 p. (Also available at http://pubs.usgs.gov/circ/2004/1227/.)

Frenzel, S.A., Swanson, R.B., Huntzinger, T.L., Stamer, J.K., Emmons, P.J., and Zelt, R.B., 1998, Water quality in the Central Nebraska Basins, Nebraska, 1992-95: U.S. Geological Survey Circular 1163, 33 p. (Also available at http://pubs.usgs.gov/circ/circ1163/.) 
Halford, K.J., and Mayer, G.C., 2000, Problems associated with estimating ground water discharge and recharge from stream-discharge records: Ground Water, v. 38, no. 3, p. 331-342, accessed June 17, 2010, at http://www3. interscience.wiley.com/journal/119034450/abstract.

Hampson, P.S., Treece, M.W. Jr., Johnson, G.C., Ahlstedt, S.A., and Connell, J.F., 2000, Water quality in the Upper Tennessee River Basin, Tennessee, North Carolina, Virginia, and Georgia 1994-98: U.S. Geological Survey Circular 1205, 32 p. (Also available at http://pubs.usgs.gov/circ/ circ1205/.)

Institute of Hydrology, 1980, Low flow studies: Wallingford, Oxon, United Kingdom, Report No. 1, 41 p.

Kauffman, L.J., Baehr, A.L., Ayers, M.A., and Stackelberg, P.E., 2001, Effects of land use and travel time on the distribution of nitrate in the Kirkwood-Cohansey aquifer system in southern New Jersey: U.S. Geological Survey Water-Resources Investigations Report 01-4117, 49 p. (Also available at http://pubs.usgs.gov/wri/wri01-4117/.)

Kelly, V.J., Lynch, D.D., and Rounds, S.A., 1999, Sources and transport of phosphorus and nitrogen during low-flow conditions in the Tualatin River, Oregon, 1991-93: U.S. Geological Survey Water-Supply Paper 2465-C, 94 p. (Also available at http://pubs.er.usgs.gov/pubs/wsp/wsp2465C.)

Land, L.F., Moring, J.B., Van Metre, P.C., Reutter, D.C., Mahler, B.J., Shipp, A.A., and Ulery, R.L., 1998, Water quality in the Trinity River Basin, Texas, 1992-95: U.S. Geological Survey Circular 1171, 39 p. (Also available at http://pubs.usgs.gov/circ/circ1171/.)

Lindsey, B.D., Berndt, M.P., Katz, B.G., Ardis, A.F., and Skach, K.A., 2009, Factors affecting water quality in selected carbonate aquifers in the United States, 1993-2005: U.S. Geological Survey Scientific Investigations Report 2008-5240, 117 p. (Also available at http://pubs.usgs.gov/ $\underline{\operatorname{sir} / 2008 / 5240 / .)}$

Lindsey, B.D., Breen, K.J., Bilger, M.D., and Brightbill, R.A., 1998, Water quality in the Lower Susquehanna River Basin, Pennsylvania and Maryland, 1992-95: U.S. Geological Survey Circular 1168, 38 p. (Also available at http://pubs. usgs.gov/circ/circ1168/.)

Lindsey, B.D., Phillips, S.W., Donnelly, C.A., Speiran, G.K., Plummer, L.N., Böhlke, J.K., Focazio, M.J., and Burton, W.C., 2003, Residence time and nitrate transport in ground water discharging to streams in the Chesapeake Bay Watershed: U.S. Geological Survey Water-Resources Investigations Report 03-4035, 202 p. (Also available at http://pa.water.usgs.gov/reports/wrir03-4035.pdf.)
Phillips, S.W., and Lindsey, B.D., 2003, The influence of ground water on nitrogen delivery to the Chesapeake Bay: U.S. Geological Survey Fact Sheet 091-03, 6 p. (Also available at http://pubs.usgs.gov/fs/2003/fs091-03/.)

Puckett, L.J., 2004, Hydrogeologic controls on the transport and fate of nitrate in ground water beneath riparian buffer zones: Results from thirteen studies across the United States: Water Science and Technology, v. 49, no. 3, p. 47-53, accessed June 17, 2010, at http://water.usgs.gov/ nawqa/nutrients/pubs/wst_v49 no3/wst_v49 no3.pdf.

Puckett, L.J., and Hughes, W.B., 2005, Transport and fate of nitrate and pesticides: Hydrogeology and riparian zone processes: Journal of Environmental Quality, v. 34, no. 6, p. 2278-2292, doi: 10.21.34/jeq2005.0109, accessed June 17, 2010, at https://www.agronomy.org/publications/jeq/ abstracts/34/6/2278.

Puckett, L.J., Zamora, C.M., Essaid, H.I., Wilson, J.T., Johnson, H.M., Brayton, M.J., and Vogel, J.R., 2008, Transport and fate of nitrate at the ground-water/surfacewater interface: Journal of Environmental Quality, v. 37, p. 1034-1050, doi:10.2134/jeq2006.0550, accessed June 17, 2010, at https://www.agronomy.org/publications/jeq/ abstracts/37/3/1034.

Runkel, R.L., Crawford, C.G., and Cohn, T.A., 2004, Load Estimator (LOADEST): A FORTRAN program for estimating constituent loads in streams and rivers: U.S. Geological Survey Techniques and Methods Book 4, Chapter A5, 69 p. (Also available at http://pubs.usgs.gov/ tm/2005/tm4A5/.)

Spahr, N.E., Dubrovsky, N.M., Gronberg, J.M., Franke, O.L., and Wolock, D.M., 2010, Nitrate loads and concentrations in surface-water base flow and shallow groundwater for selected basins in the United States, water years, 19902006: U.S. Geological Survey Scientific Investigations Report 2010-5098, 39 p. (Also available at http://pubs.usgs. gov/sir/2010/5098/.)

Spruill, T.B., Harned, D.A., Ruhl, P.M., Eimers, J.L., McMahon, George, Smith, K.E., Galeone, D.R., and Woodside, M.D., 1998, Water quality in the AlbemarlePamlico Drainage Basin, North Carolina and Virginia, 1992-95: U.S. Geological Survey Circular 1157. (Also available at http://pubs.usgs.gov/circ/circ1157/.)

Tesoriero, A.J., Duff, J.H., Wolock, D.M., Spahr, N.E., and Almendinger, J.E., 2009, Identifying pathways and processes affecting nitrate and orthophosphate inputs to streams in agricultural watersheds: Journal of Environmental Quality, doi: 10.2134/jeq2008.0484, v. 38, p. 1892-1900, accessed June 17, 2010, at https://www. agronomy.org/publications/jeq/abstracts/38/5/1892. 
Tesoriero, A.J., Liebscher, Hugh, and Cox, S.E., 2000, Mechanism and rate of denitrification in an agricultural watershed-Electron and mass balance along groundwater flow paths: Water Resources Research, v. 36, no. 6, p. 1545-1559, accessed June 17, 2010, at http://www.agu. org/journals/wr/v036/i006/2000WR900035/.

Tesoriero, A.J., Spruill, T.B., Mew, H.E., Jr., Farrell, K.M., and Harden, S.L., 2005, Nitrogen transport and transformations in a coastal plain watershed: Influence of geomorphology on flow paths and residence times: Water Resources Research, v. 41, W02008, doi:10.1029/2003WR002953, 15 p., accessed June 17, 2010. at http://nc.water.usgs.gov/reports/abstracts/Tes05Nit.html.

Wahl, K.L., and Wahl, T.L., 1988, Effects of regional groundwater declines on streamflows in the Oklahoma Panhandle, in Proceedings of the Symposium on Water-Use Data for Water Resources Management: Tucson, Arizona, American Water Resources Association, p. 239-249.

Williamson, A.K., Munn, M.D., Ryker, S.J., Wagner, R.J., Ebbert, J.C., and Vanderpool, A.M., 1998, Water quality in the Central Columbia Plateau, Washington and Idaho, 1992-95: U.S. Geological Survey Circular 1144, 34 p. (Also available at http://pubs.usgs.gov/circ/circ1144/.)

Wolock, D.M., Winter, T.C., and McMahon, Gerard, 2004, Delineation and evaluation of hydrologic-landscape regions in the United States using geographic information system tools and multivariate statistical analyses: Environmental Management, v. 34, supplement 1, p. S71-S88, doi:10.1007/ S00267-003-5077-9, accessed June 17, 2010, at http://www. springerlink.com/content/1ljlt2p6nrv7w014/.

\section{Chapter 6:}

Cantor, K.P., Ward, M.H., Moore, L.E., and Lubin, J.H., 2006, Water contaminants, in Schottenfeld, D., and Fraumeni, J.F., Jr., Cancer epidemiology and prevention, 3rd ed., : New York, Oxford University Press, p. 382-404.

DeSimone, L.A., 2009, Quality of water from domestic wells in principal aquifers of the United States, 1991-2004: U.S. Geological Survey Scientific Investigations Report 20085227, 127 p., CD. (Also available at http://pubs.usgs.gov/ sir/2008/5227/.)

Eberts, S.M., Erwin, M.L., and Hamilton, P.A., 2005, Assessing the vulnerability of public-supply wells to contamination from urban, agricultural, and natural sources: U.S. Geological Survey Fact Sheet 2005-3022, 4 p. (Also available at http://pubs.usgs.gov/fs/2005/3022/.)
Hutson, S.S., Barber, N.L., Kenny, J.F., Linsey, K.S., Lumia, D.S., and Maupin, M.A., 2004, Estimated use of water in the United States in 2000: U.S. Geological Survey Circular 1268, 46 p. (Also available at http://pubs.usgs.gov/ circ/2004/circ1268/.)

Nolan, B.T., and Hitt, K.J., 2006, Vulnerability of shallow groundwater and drinking-water wells to nitrate in the United States: Environmental Science and Technology, v. 40, no. 24, p. 7834-7840, doi:10.1021/es060911u, accessed June 17, 2010, at http://water.usgs.gov/nawqa/ nutrients/pubs/est v40 no24/.

Scribner, E.A., Goolsby, D.A., Thurman, E.M., Meyer, M.T., and Battaglin, W.A., 1996, Concentrations of selected herbicides, herbicide metabolites, and nutrients in outflow from selected midwestern reservoirs, April 1992 through September 1993: U.S. Geological Survey Open-File Report 96-393, 128 p. (Also available at http://pubs.er.usgs.gov/ usgspubs/ofr/ofr96393.)

Toccalino, P.L., and Norman, J.E., 2006, Health-based screening levels to evaluate U.S. Geological Survey groundwater quality data: Risk Analysis, v. 26, no. 5, p. 1339 1348, doi: 10.111/j.1539-6924.2006.00805.x, accessed June 17, 2010, at http://infotrek.er.usgs.gov/docs/nawqa_www/ HBSL/reports/Toccalino.Norman.HBSL.RiskAnalysis.pdf.

Toccalino, P.L., Norman, J.E., Booth, N.L., and Zogorski, J.S., 2006, Health-based screening levels - A tool for evaluating what water-quality data may mean to human health: U.S. Geological Survey, National Water-Quality Assessment Program, accessed May 2007, at http://water.usgs.gov/ nawqa/HBSL.

Townsend, A.R., Howarth, R.W., Bazzaz, F.A., Booth, M.S., Cleveland, C.C., Collinge, S.K., Dobson, A.P., Epstein, P.R., Holland, E.A., Keeney, D.R., Mallin, M.A., Wayne, P., and Wolfe, A., 2003, Human health effects of a changing global nitrogen cycle: Frontiers in Ecology and the Environment, v. 1, no. 5, p. 240-246, doi: 10.1890/1540-9295(2003)001[0240:HHEOAC]2.0.CO;2, accessed June 17, 2010, at http://www.esajournals.org/doi/ abs $/ 10.1890 / 1540-9295 \% 282003 \% 29001 \% 5 \mathrm{~B} 0240 \% 3 \mathrm{AHH}$ EOAC \%5D2.0.CO\%3B2.

U.S. Environmental Protection Agency, 1990, National Pesticide Survey, Summary results of EPA's national survey of pesticides in drinking water wells: Office of Water and Office of Pesticides and Toxic Substances, EPA 570990NPS5, 16 p., accessed June 17, 2010, at http:// yosemite.epa.gov/water/owrccatalog.nsf/9da204a4b4406ef8 $\underline{85256 \mathrm{ae} 0007 \mathrm{a} 79 \mathrm{c} 7 / 1 \mathrm{~d} 08 \mathrm{~b} 2 \mathrm{e} 6 \mathrm{be} 76 \mathrm{acdf} 85256 \mathrm{~b} 060072419 \mathrm{e} !}$ OpenDocument 
U.S. Environmental Protection Agency, 2006, 2006 edition of the drinking water standards and health advisories: U.S. Environmental Protection Agency, Office of Water, EPA 822-R-06-013, 18 p.

Ward, M.H., de Kok, T.M., Levallois, Patrick, Brender, Jean, Gulis, Gabriel, Nolan, B.T., and VanDerslice, James, 2005, Drinking-water nitrate and health-Recent findings and research needs: Environmental Health Perspectives, v. 113, no. 11, p. 1607-1614, doi: 10.1289/ehp.8043.

\section{Chapter 7:}

Belton, T.J., Ponader, K.C., and Charles, D.F., 2006, Trophic diatom indices (TDI) and the development of site-specific nutrient criteria: Trenton, New Jersey, New Jersey Department of Environmental Protection, Division of Science Research and Technology, 15 p., accessed June 17, 2010, at http://njedl.rutgers.edu/ftp/PDFs/4676.pdf.

Clark, G.M., Mueller, D.K., and Mast, M.A., 2000, Nutrients concentrations and yields in undeveloped basins of the United States: Journal of the American Water Resources Association, v. 36, no. 4, p. 849-860, doi: 10.1111/j.17521688.2000.tb04311.x, accessed June 17, 2010, at http:// water.usgs.gov/nawqa/nutrients/pubs/awra v36 no4/.

Dennehy, K.F., Litke, D.W., McMahon, P.B., Heiny, J.S., and Tate, C.M., 1995, Water-quality assessment of the South Platte River Basin, Colorado, Nebraska, and WyomingAnalysis of available nutrient, suspended-sediment, and pesticide data, water years 1980-92: U.S. Geological Survey Water-Resources Investigations Report 94-4095, 145 p. (Also available at http://pubs.er.usgs.gov/usgspubs/ wri/wri944095.)

Dodds, W.K., Jones, J.R., and Welch, E.B., 1998, Suggested classification of stream trophic state: Distributions of temperate stream types by chlorophyll, total nitrogen, and phosphorus: Water Research, v. 32, no. 5, p. 1455-1462, doi: 10.1016/S0043-1354(97)00370-9, accessed June 17, 2010, at http://www.ingentaconnect.com/content/els/004313 54/1998/00000032/00000005/art00370.

Herlihy, A.T., and Sifneos, J.C., 2008, Developing nutrient criteria and classification schemes for wadeable streams in the conterminous US: Journal of the North American Benthological Society, v. 27, no. 4, p. 932-948. doi: 10.1899/08-041.1.
Jaynes, D.B., Kaspar, T.C., Moorman, T.B., and Parkin, T.B., 2008, In situ bioreactors and deep drain-pipe installation to reduce nitrate losses in artificially drained fields: Journal of Environmental Quality v. 37, p. 429-436, doi:10.2134/ jeq2007.0279, accessed June 17, 2010, at https://www. agronomy.org/publications/jeq/abstracts/37/2/429.

Mueller, D.K., and Spahr, N.E., 2005, Water-quality, streamflow, and ancillary data for nutrients in streams and rivers across the Nation, 1992-2001: U.S. Geological Survey Data Series 152, accessed January 2007, at http:// pubs.usgs.gov/ds/2005/152/.

Munn, M.D., Frey, Jeffrey, and Tesoriero, Anthony, 2010, The influence of nutrients and physical habitat in regulating algal biomass in agricultural streams: Environmental Management, v. 45, no. 3, p. 603-615, doi: 10.1007/ s00267-010-9435-0, accessed June 17, 2010, at http://www. springerlink.com/content/fk61257070058286/.

Newton, T.J., and Bartsch, M.R., 2007, Lethal and sublethal effects of ammonia to juvenile Lampsilis mussels (UNIONIDAE) in sediment and water-only exposures: Environmental Toxicology and Chemistry, v.. 26, no. 10, p. 2057-2065, doi: 10.1897/06-245R.1, accessed June 17, 2010, at http://www3.interscience.wiley.com/ journal/123274943/abstract.

Ponader, K.C., Charles, D.F., and Belton, T.J., 2005, Diatombased TP and TN inference models and indices for monitoring nutrient enrichment of New Jersey streams: Ecological Indicators, v. 7, p. 79-93, doi: 10.1015/j. ecolind.2005.10.003.

Porter, S.D., Mueller, D.K., Spahr, N.E., Munn, M.D., and Dubrovsky, N.M., 2008, Efficacy of algal metrics for assessing nutrient and organic enrichment in flowing waters: Freshwater Biology, v. 53, no. 5, p. 1036-1054, doi: 10.1111/j.1365-2427.2007.01951.x, accessed June 17, 2010, at http://www3.interscience.wiley.com/journal/119397334/ issue.

Smith, R.A., Alexander, R.B., and Schwarz, G.E., 2003, Natural background concentrations of nutrients in streams and rivers of the conterminous United States: Environmental Science and Technology, v. 37, no. 14, p. 3039-3047, doi: 10.1021/es020663b. (Also available at http://pubs.acs.org/doi/abs/10.1021/es020663b.)

Spahr, N.E., Mueller, D.K., Wolock, D.M., Hitt, K.J., and Gronberg, J.M., 2010, Development and application of regression models for estimating nutrient concentrations in streams of the conterminous United States, 1992-2001: U.S. Geological Survey Scientific Investigations Report 2009-5199, 22 p. (Also available at http://pubs.usgs.gov/ $\underline{\operatorname{sir} / 2009 / 5199 / .)}$ 
U.S. Environmental Protection Agency, 1999, 1999 update of ambient water quality criteria for ammonia: U.S. Environmental Protection Agency, Office of Water, EPA822-R-99-014, accessed June 17, 2010, at http://www.epa. gov/waterscience/criteria/ammonia/99update.pdf.

U.S. Environmental Protection Agency, 2000, Ecoregional nutrient criteria fact sheet, accessed June 17, 2010, at http:// www.epa.gov/waterscience/criteria/nutrient/ecoregions/ factsheet.html.

U.S. Environmental Protection Agency, 2001, Ambient water quality criteria recommendations: U.S. Environmental Protection Agency, Office of Water, EPA 822-B-01-012, 112 p., accessed June 15, 2010, at http://www.epa.gov/ waterscience/criteria/nutrient/ecoregions/rivers/rivers_1.pdf.

U.S. Environmental Protection Agency, 2002a, Summary of biological assessment programs and biocriteria development for States, Tribes, Territories, and Interstate Commissions: Streams and wadeable rivers: U.S. Environmental Protection Agency, Office of Environmental Information and Office of Water, EPA-822-R-02-048, accessed June 17, 2010, at http://www.epa.gov/bioiweb1/html/program summary.html.

U.S. Environmental Protection Agency, 2002b, Summary table for the nutrient criteria documents: U.S. Environmental Protection Agency, Office of Water, 3 p., accessed June 17, 2010, at http://www.epa.gov/waterscience/criteria/nutrient/ ecoregions/files/sumtable.pdf.

U.S. Environmental Protection Agency, 2006, Wadeable streams assessment: A collaborative survey of the Nation's streams: U.S. Environmental Protection Agency, Office of Research and Development and Office of Water, EPA 841B-06-002, 98 p., accessed June 17, 2010, at http://www.epa. gov/owow/streamsurvey/.

U.S. Environmental Protection Agency, 2008, State adoption of numeric nutrient standards 1998-2008: U.S. Environmental Protection Agency, Office of Water, EPA 821-F-08-007, variously paginated, accessed July 30, 2010, at http://www.epa.gov/waterscience/criteria/nutrient/files/ report1998-2008.pdf.

U.S. Environmental Protection Agency, 2009a, Draft 2009 update aquatic life ambient water quality criteria for ammonia: U.S. Environmental Protection Agency, Office of Water, EPA-822-D-99-001, 184 p., accessed June 17, 2010, at http://www.epa.gov/waterscience/criteria/ ammonia/2009update.pdf.

U.S. Environmental Protection Agency, 2009b, An Urgent Call to Action - Report of the State-EPA Nutrient Innovations Task Group, accessed June 17, 2010, at http://www.epa.gov/ waterscience/criteria/nutrient/nitgreport.pdf.

\section{Chapter 8:}

Alexander, R.B., and Smith, R.A., 2006, Trends in the nutrient enrichment of U.S. rivers during the late 20th century and their relation to changes in probable stream trophic conditions: Limnology and Oceanography, v. 51, no. 1, part 2, p. 639-654, accessed June 17, 2010, at http://www. jstor.org/stable/4499617.

Arizona Game and Fish Department, 2006, Did the RodeoChediski fire affect the fish community in the Salt River?, accessed June 17, 2010, at http://www.azgfd.gov/w_c/ research saltriver fire.shtml.

Böhlke, J.K., and Denver, J.M., 1995, Combined use of groundwater dating, chemical, and isotopic analyses to resolve the history and fate of nitrate contamination in two agricultural watersheds, Atlantic coastal plain, Maryland: Water Resources Research, v. 31, no. 9, p. 2319-2339, doi:10.1029/95WR01584, accessed June 17, 2010, at http:// www.agu.org/journals/ABS/1995/95WR01584.shtml.

Burow, K.R., and Green, C.T., 2008, Spatial and temporal trends in nitrate concentration in the eastern San Joaquin Valley regional aquifer and implications for nitrogen fertilizer management: California Plant and Soil Conference: Conservation of Agricultural Resources, February 5-6, 2008, Visalia, California, p. 47-52, accessed June 17, 2010, at http://ucanr.org/sites/calasa/files/320.pdf.

Burow, K.R., Shelton, J.L., and Dubrovsky, N.M., 2008a, Regional nitrate and pesticide trends in ground water in the eastern San Joaquin Valley, California: Journal of Environmental Quality, v. 37, S-249-S-263, doi: 10.2134/jeq2007.0061, accessed June 17, 2010, at https:// www.agronomy.org/publications/jeq/abstracts/37/5 Supplement/S-249.

Burow, K.R., Jurgens, B.J., Kauffman, L.J., Phillips, S.P., Dalgish, B.A., and Shelton, J.L., 2008b, Simulations of ground-water flow and particle pathline analysis in the zone of contribution of a public-supply well in Modesto, eastern San Joaquin Valley, California: U.S. Geological Survey Scientific Investigations Report 2008-5035, 41 p. (Also available at http://pubs.usgs.gov/sir/2008/5035/.)

Clark, B.R., Landon, M.K., Kauffman, L.J., and Hornberger, G.Z., 2007, Simulations of ground-water flow transport, age, and particle tracking near York, Nebraska, for a study of transport of anthropogenic and natural contaminants (TANC) to public-supply wells: U.S. Geological Survey Scientific Investigations Report 2007-5068, 48 p. (Also available at http://pubs.usgs.gov/sir/2007/5068/.) 
Crandall, C.A., Kauffman, L.J., Katz, B.G., Metz, P.A., McBride, S.W., and Berndt, M.P., 2009, Simulations of groundwater flow and particle tracking analysis in the area contributing recharge to a public-supply wells near Tampa, Florida, 2002-05: U.S. Geological Survey Scientific Investigations Report 2008-5231, 53 p. (Also available at http://pubs.usgs.gov/sir/2008/5231/.)

Debrewer, L.M., Ator, S.W., and Denver, J.M., 2008, Temporal trends in nitrate and selected pesticides in midAtlantic ground water: Journal of Environmental Quality, v. 37,S-296-S-308, doi: 10.2134/jeq2007.0664, accessed June 17, 2010, at https://www.agronomy.org/publications/ jeq/abstracts/37/5_Supplement/S-296.

Ferrari, M.J., 2002, Occurrence and distribution of selected contaminants in public drinking-water supplies in the surficial aquifer in Delaware: U.S. Geological Survey OpenFile Report 01-327, 62 p. (Also available at http://pubs. usgs.gov/of/2001/ofr01-327/.)

Fuhrer, G.J., Morace, J.L., Johnson, H.M., Rinella, J.F., Ebbert, J.C., Embrey, S.S., Waite, I.R., Carpenter, K.D., Wise, D.R., and Hughes, C.A., 2004, Water quality in the Yakima River Basin, Washington, 1999-2000: U.S. Geological Survey Circular 1237, 34 p. (Also available at http://pubs.usgs.gov/circ/2004/1237/.)

Green, C. T., Puckett, L.J., Böhlke, J.K., Bekins, B.A., Phillips, S.P., Kauffman, L.J., Denver, J.M., and Johnson, H.M, 2008, Limited occurrence of denitrification in four shallow aquifers in agricultural areas of the United States: Journal of Environmental Quality, v. 37, p. 994-1009, doi: 10.2134/jeq2006.0419, accessed June 17, 2010, at https:// www.agronomy.org/publications/jeq/abstracts/37/3/994.

Harned, D.A, 2003, Water-quality trends in the Neuse River Basin, North Carolina, 1974-2003: Transactions of the American Geophysical Union 2003, Eos, Fall Meeting Supplement, Abstract H41F-1048, v. 84, no. 46, p. F703.

Helsel, D.R., and Hirsch, R.M., 1992, Statistical Methods in Water Resources: New York, Elsevier Publishers, 529 p.

Kauffman, L.J., Baehr, A.L., Ayers, M.A., and Stackelberg, P.E., 2001, Effects of land use and travel time on the distribution of nitrate in the Kirkwood-Cohansey aquifer system in southern New Jersey: U.S. Geological Survey Water-Resources Investigations Report 01-4117, 49 p. (Also available at http://pubs.usgs.gov/wri/wri01-4117/.)

Land, L.F., Moring, J.B., Van Metre, P.C., Reutter, D.C., Mahler, B.J., Shipp, A.A., and Ulery, R.L., 1998, Water quality in the Trinity River Basin, Texas, 1992-95: U.S. Geological Survey Circular 1171, 39 p. (Also available at http://pubs.usgs.gov/circ/circ1171/.)
Litke, D.W., 1999, Review of phosphorus control measures in the United States and their effects on water quality: U.S. Geological Survey Water-Resources Investigations Report 99-4007, 38 p. (Also available at http://pubs.usgs.gov/wri/ wri994007/.)

McMahon, P.B., Böhlke, J.K., Kauffman, L.J., Kipp, K.L., Landon, M.K., Crandall, C.A., Burow, K.R., and Brown, C.J., 2008a, Source and transport controls on the movement of nitrate to public supply wells in selected principal aquifers of the United States: Water Resources Research, v. 44, W04401, 17 p., doi: 10.1029/2007WR006252, accessed June 17, 2010, at http://www.agu.org/pubs/ crossref/2008/2007WR006252.shtml.

McMahon, P.B., Burow, K.R., Kauffman, L.J., Eberts, S.M., Böhlke, J.K., and Gurdak, J.J., 2008b, Simulated response of water quality in public supply wells to land use change: Water Resources Research, v. 44, W00A06, 16 p., doi: 10.1029/2007WR006731, accessed June 17, 2010, at http:// www.agu.org/journals/wr/wr0809/2007WR006731/.

Modica, E., Buxton, H.T., and Plummer, L.N., 1998, Evaluating the source and residence times of groundwater seepage to streams, New Jersey Coastal Plain: Water Resources Research, v. 34, no. 11, p. 2797-2810, accessed June 17, 2010, at http://www.agu.org/pubs/ crossref/1998/98WR02472.shtml.

National Agricultural Statistics Service, 2008, Data and statistics, accessed June 17, 2010, at http://www.nass.usda. gov/Data and Statistics/index.asp.

Plummer, L.N., and Friedman, L.C., 1999, Tracing and dating young ground water: U.S. Geological Survey Fact Sheet 134-99, 4 p. (Also available at http://pubs.usgs.gov/fs/ FS-134-99/.)

Puckett, L.J., and Cowdery, T.K., 2002, Transport and fate of nitrate in a glacial outwash aquifer in relation to ground water age, land use practices, and redox processes: Journal of Environmental Quality, v. 31, no. 3, p. 782-796, accessed June 17, 2010, at https://www.agronomy.org/publications/ jeq/abstracts/31/3/782.

Puckett, L.J., and Hughes, W.B., 2005, Transport and fate of nitrate and pesticides: Hydrogeology and riparian zone processes: Journal of Environmental Quality, v. 34, p. 2278-2292, doi: 10.2134/jeq2005.0109, accessed June 17, 2010, at https://www.agronomy.org/publications/jeq/ abstracts/34/6/2278. 
Rupert, M.G., 2008, Decadal-scale changes of nitrate in ground water of the United States, 1988-2004: Journal of Environmental Quality, v. 37, p. S-240-S-248, doi:10.2134/jeq2007.0055, accessed June 17, 2010, at https://www.agronomy.org/publications/jeq/abstracts/37/5 Supplement/S-240.

Sprague, L.A., Mueller, D.K., Schwarz, G.E., and Lorenz, D.L., 2009, Nutrient trends in streams and rivers of the United States, 1993-2003: U.S. Geological Survey Scientific Investigations Report 2008-5202, 196 p. (Also available at http://pubs.usgs.gov/sir/2008/5202/.)

Spurlock, F.M., Burow, K.R., and Dubrovsky, N.M., 2000, Chlorofluorocarbon dating of herbicide-containing well waters in Fresno and Tulare Counties, California: Journal of Environmental Quality, v. 29, p. 474-483, accessed June 17, 2010, at https://www.agronomy.org/publications/ jeq/abstracts/29/2/JEQ0290020474.

Starn, J.J., and Brown, C.J., 2007, Simulations of groundwater flow and residence time near Woodbury, Connecticut: U.S. Geological Survey Scientific Investigations Report 2007-5210, 56 p. (Also available at http://pubs.usgs.gov/ $\underline{\operatorname{sir} / 2007 / 5210 / .)}$

Steele, G.V., Johnson, H.M., Sandstrom, M.W., Capel, P.D., and Barbash, J.E., 2008, Occurrence and fate of pesticides in four contrasting agricultural settings in the United States: Journal of Environmental Quality, v. 37, p. 11161132, doi:10.2134/jeq2007.0166, accessed on June 17, 2010, at https://www.agronomy.org/publications/jeq/ abstracts/37/3/1116.
Tesoriero, A.J., Saad, D.A., Burow, K.R., Frick, E.A., Puckett, L.J., and Barbash, J.E., 2007, Linking ground-water age and chemistry data along flow paths: Implications for trends and transformations of nitrate and pesticides: Journal of Contaminant Hydrology, v. 94, p. 139-155, doi: 10.1016/j. jconhyd.2007.05.007, accessed June 17, 2010, at http:// or.water.usgs.gov/staff/J Tesoriero/tesoriero et al2007.pdf.

Texas Parks and Wildlife Department, 1974, Trinity River study - a comparison of fish collections and water quality in the Trinity River between Dallas County and Lake Livingston, July 1972 through April 1974: Austin, Tex., Texas Parks and Wildlife Department, Inland Fisheries and Environmental Branches, $47 \mathrm{p}$.

U.S. Census Bureau, 2001, Population change and distribution, 1990 to 2000: U.S. Census Bureau Report C2KBR/01-2, 7 p., accessed June 17, 2010, at http://www. census.gov/prod/2001 pubs/c2kbr01-2.pdf.

U.S. Department of Agriculture, 2008, Data Sets, Fertilizer Use and Price, accessed June 17, 2010, at http://www.ers. usda.gov/Data/FertilizerUse/.

U.S. Environmental Protection Agency, 2003, National air quality and emissions trends report: U.S. Environmental Protection Agency Report EPA 454/R-03-005, 190 p., accessed June 17, 2010, at http://www.epa.gov/air/airtrends/ aqtrnd03/.

U.S. Environmental Protection Agency, 2004, Risk assessment evaluation for concentrated animal feeding operations: U.S. Environmental Protection Agency Report EPA/600/R-04/042, 138 p., accessed June 17, 2010, at http://www.epa.gov/nrmrl/pubs/600r04042/600r04042.pdf. 
This page intentionally left blank 


\section{Glossary}

Agricultural stream A stream draining a watershed with more than 50 percent agricultural land (cropland or pasture) and 5 percent or less of urban land.

Algae Chlorophyll-bearing nonvascular plants, primarily aquatic species that have no true roots, stems, or leaves; most algae are microscopic, but some species can be as large as vascular plants.

Algal bloom Sudden spurts of algal growth, which can affect water quality adversely and indicate potentially hazardous changes in local water chemistry.

Ammonia A compound of nitrogen and hydrogen $\left(\mathrm{NH}_{3}\right)$ that is a common by-product of human and animal waste. Ammonia readily converts to nitrate in soils and streams.

Anoxic Groundwater that has no dissolved oxygen or a very low concentration of dissolved oxygen (that is, less than 0.5 milligram per liter).

Aquatic health guidelines Specific levels of water quality which, if reached or exceeded, may adversely affect aquatic life. These are nonenforceable guidelines issued by a governmental agency or other institution.

Aquifer A water-bearing layer of soil, sand, gravel, or rock that will yield usable quantities of water to a well.

Atmospheric deposition The transfer of substances from the air to the surface of the Earth, either in wet form (rain, fog, snow, dew, frost, hail) or in dry form (gases, aerosols, particles).

Background concentration A concentration of a substance in a particular environment that is indicative of minimal influence by human (anthropogenic) sources.

Base flow Hydrologic regime in streams, following extended periods of minimal precipitation, during which streamflow is derived primarily from groundwater discharge.

Benthic Refers to plants or animals that live on the bottom of lakes, streams, or oceans.
Best management practice (BMP) An agricultural practice that has been determined to be an effective, practical means of preventing or reducing nonpoint source pollution.

Bioassessment Use of organisms to evaluate environmental quality.

Biomass The amount of living matter, in the form of organisms, present in a particular habitat, usually expressed as weight per unit area.

Blue-baby syndrome A condition that can be caused by ingestion of high amounts of nitrate resulting in the blood losing its ability to effectively carry oxygen. It is most common in young infants and certain elderly people. Also called methemoglobinemia.

Carbonate rocks Rocks (such as limestone or dolostone) that are composed primarily of minerals (such as calcite and dolomite) containing the carbonate ion $\left(\mathrm{CO}_{3}{ }^{2-}\right)$.

Chlorophyll A green photosynthetic pigment found in most plants, algae and cyanobacteria.

Confined aquifer An aquifer that is completely filled with water under pressure and that is overlain by material that restricts the movement of water.

Conservation tillage Planting and growing crops with reduced disturbance of the surface soil.

Cubic foot per second ( $\mathrm{ft}^{3} / \mathrm{s}$, or cfs) Rate of water discharge representing a volume of 1 cubic foot passing a given point during 1 second, equivalent to approximately 7.48 gallons per second or 448.8 gallons per minute or 0.02832 cubic meter per second.

Denitrification A process by which oxidized forms of nitrogen such as nitrate $\left(\mathrm{NO}_{3}^{-}\right)$are reduced to form nitrites, nitrogen oxides, ammonia, or free nitrogen, commonly brought about by the action of denitrifying bacteria and usually resulting in the escape of nitrogen to the air. 
Discharge Rate of fluid flow passing a given point at a given moment in time, expressed as volume per unit of time.

Domestic well A privately-owned well that typically serves one home and supplies water for human consumption and other homeowner uses.

Drinking-water standard or guideline A threshold concentration in a public drinkingwater supply, designed to protect human health. As defined here, standards are U.S. Environmental Protection Agency regulations that specify the maximum contamination levels for public water systems required to protect the public welfare; guidelines have no regulatory status and are issued in an advisory capacity. See also MCL, water-quality guidelines, and waterquality standards.

Ecoregion An area of similar climate, landform, soil, potential natural vegetation, hydrology, or other ecologically relevant variables.

Effluent Outflow from a particular source, such as a stream that flows from a lake or liquid waste that flows from a factory or sewage-treatment plant.

Eutrophication The process by which water becomes enriched with plant nutrients, most commonly phosphorus and nitrogen.

Horton overland flow Occurs when the rate of rainfall on a surface exceeds the rate of infiltration and any depression storage has been filled.

Hydraulic head Hydraulic head is an indicator of the total energy available to move groundwater through an aquifer. Hydraulic head is measured by the height to which a column of water will stand above a reference elevation (or "datum"), such as mean sea level.

Hydric soil Soil that formed under conditions of saturation, flooding, or ponding long enough during the growing season to develop anoxic conditions in the upper part of the soil profile.

Hydrograph Graph showing variation of water elevation, velocity, streamflow, or other property of water with respect to time.

Hydrologic system The assemblage of pathways by which water travels as it circulates beneath, at, and above the Earth's surface through various processes such as precipitation, runoff, evaporation, infiltration, transpiration, and groundwater flow.
Hyporheic zone A zone in streambeds in which active exchange of groundwater and surface water can occur and where many biogeochemical processes can remove nitrate and other contaminants.

Hypoxia/Hypoxic waters Waters with dissolved oxygen concentrations of less than 2 parts per million, the level generally accepted as the minimum required for most marine life to survive and reproduce.

Impermeability The incapacity of a rock to transmit fluid.

Intrinsic susceptibility A measure of the ease with which a contaminant in water can enter and move through an aquifer. It is a characteristic of the aquifer and overlying material and hydrologic conditions, and is independent of the chemical characteristics of the contaminant and its sources. See also vulnerability.

Irrigation return flow The part of irrigation water applied to the land surface that is not consumed by evapotranspiration or uptake by plants and that either infiltrates downward to an aquifer or finds its way to a surface-water body.

Karst A type of topography that results from dissolution and collapse of carbonate rocks such as limestone and dolomite, and characterized by closed depressions or sinkholes, caves, and underground drainage.

Land-use study A network of existing or installed shallow wells in an area having a relatively uniform land use. These studies have the goal of relating the quality of shallow groundwater to land use.

Leaching The removal of materials in solution from soil or rock to groundwater; refers to movement of pesticides or nutrients from land surface to groundwater.

Linear regression A statistical method for analyzing and estimating the magnitude of a response variable as a function of one or more explanatory variables.

Lithology The physical character of a rock based on such characteristics as color, structure, mineralogical composition, and grain size.

Macroinvertebrate An animal that is large enough to be seen without magnification and has no backbone or spinal column. 
Macrophyte An aquatic plant growing in or near water that is either emergent, submergent, or floating.

Major aquifer A regionally extensive subsurface geologic formation or group of formations that is used, or has the potential to be used, as a significant groundwater resource.

Major aquifer studies NAWQA investigations involving the sampling of 20 to 30 domestic and (or) public-supply wells that withdraw water from major aquifers.

Maximum contaminant level (MCL) Maximum permissible level of a contaminant in water that is delivered to any user of a public water system. MCLs are enforceable standards established by the U.S. Environmental Protection Agency. See also drinking-water standard.

Mean The average of a set of observations, unless otherwise specified.

Median The middle or central value in a distribution of data ranked in order of magnitude. The median is also known as the 50th percentile.

Mixed-land-use streams Streams draining watersheds in which no single type of land use (agricultural, urban, or undeveloped) predominates. These include all streams not meeting the specific land-use criteria for agricultural, urban, or undeveloped streams.

Nitrate An ion consisting of nitrogen and oxygen $\left(\mathrm{NO}_{3}^{-}\right)$. Nitrate is a plant nutrient and is very mobile in soils.

Nitrite An ion consisting of nitrogen and oxygen $\left(\mathrm{NO}_{2}^{-}\right)$. The nitrite and organic species are unstable in aerated water and generally constitute a small fraction of the dissolved nitrogen species.

Nitrification A microbial process by which reduced nitrogen compounds (primarily ammonia) are sequentially oxidized to nitrite and nitrate.

Nonpoint source A pollution source that cannot be defined as originating from discrete points such as pipe discharge. Areas of fertilizer and pesticide applications, atmospheric deposition, manure generation, and natural inputs from plants and trees are types of nonpoint source pollution.
Nutrient Element or compound essential for animal and plant growth. Common nutrients in fertilizer include nitrogen, phosphorus, and potassium.

Oligotrophic stream Nutrient poor stream with relatively low primary production

Overland flow The flow of rainwater or snowmelt over the land surface toward stream channels. After it enters a stream, it becomes runoff.

Oxic A term used to describe water in which the concentration of dissolved oxygen is greater than or equal to 0.5 milligrams per liter.

Permeability A measure of the relative ease with which a porous medium can transmit a fluid.

Point source A contaminant source at a discrete location such as a discharge pipe, drainage ditch, tunnel, well, concentrated livestock operation, or floating craft.

Principal aquifer A regionally extensive aquifer or aquifer system that has the potential to be used as a source of potable water.

Public-supply well A privately or publicly owned well that provides water for public use to: (1) community water systems, (2) transient noncommunity water systems, such as campgrounds, or (3) non-transient, non-community systems, such as schools.

Recharge Water that infiltrates the ground and reaches the saturated zone.

Redox condition As used in this report, redox condition refers to the geochemical status or position of a groundwater system on a scale between very oxidizing and very reducing.

Reduced Groundwater in which concentrations of dissolved oxygen are less than $0.5 \mathrm{mg} / \mathrm{L}$, and that contains chemical markers for iron (concentrations of iron greater than 100 milligrams per liter) and (or) manganese (concentrations of manganese greater than 50 milligrams per liter) reduction.

Reference site ANAWQA sampling site selected for its relatively undisturbed conditions.

Residence time The amount of time that a constituent, particle, organism, or other entity spends within a given environmental medium. 
Retrospective analysis Review and analysis of existing data in order to address NAWQA objectives, to the extent possible, and to aid in the design of NAWQA studies.

Riparian Areas adjacent to rivers and streams with a high density, diversity, and productivity of plant and animal species relative to nearby uplands.

Saturated zone The region in the subsurface in which all the interstices or voids are filled with water under a pressure exceeding that of the atmosphere.

Simulation model A mathematical model used to predict the combined effects and (or) consequences of one or more processes of interest by reproducing these effects using mathematical relations and (or) numerical techniques, typically through the use of computer programs.

Statistical model A model used to represent the effects of one or more processes of interest by quantitative, probabilistic relations (such as regressions) between one or more explanatory variables and a particular response variable.

Statistical significance The likelihood (commonly expressed as a probability, p) that the result of a statistical test may have occurred solely by chance. Observations associated with $\mathrm{p}$ values of 0.05 or less (a 95 percent or greater confidence level) are typically deemed to be statistically significant, and thus, are unlikely to have occurred solely by chance.

Study Unit A major hydrologic system of the United States in which NAWQA studies are focused. Study Units are geographically defined by a combination of ground- and surface-water features and generally encompass more than 4,000 square miles of land area.

Subsurface tile-drain systems Perforated pipes that are buried to shallow depths in the ground to reduce the water content of poorly drained soils and divert shallow groundwater to nearby streams.

Surface runoff That part of the runoff which travels over the soil surface to the nearest stream channel. It is also defined as that part of the runoff of a drainage basin that has not passed beneath the surface since precipitation.
Taxon (plural taxa) Any identifiable group of taxonomically related organisms.

Tile drain See Subsurface tile-drain systems

Tolerant species Those species that are adaptable to (tolerant of) human alterations to the environment and that often increase in number when human alterations occur.

Total concentration Refers to the concentration of a constituent regardless of its form (dissolved or bound) in a sample.

Total Maximum Daily Load (TMDL) A calculation of the highest amount of a pollutant that a water body can receive and safely meet water quality standards set by the state, territory, or authorized tribe.

Total nitrogen The sum of inorganic nitrogen (nitrate, nitrite, ammonia) and organic nitrogen.

Total phosphorus The sum of inorganic and organic phosphorus.

Unconfined aquifer An aquifer whose upper surface is a water table; an aquifer containing unconfined groundwater.

Undeveloped stream A stream draining a watershed with 25 percent or less of agricultural land and 5 percent or less of urban land.

Unsaturated zone The subsurface region of earth materials above the water table in which the pore spaces may contain a combination of air and water.

Urban stream A stream draining a watershed with more than 5 percent of residential, commercial, transportation, urban recreational areas, and (or) industrial land, and 25 percent or less of agricultural land.

\section{U.S. Environmental Protection Agency recommended ecoregional nutrient} criteria Numerical values for phosphorus and nitrogen concentrations associated with the prevention and assessment of eutrophic conditions. These recommended ecoregional nutrient criteria represent conditions of surface waters that have minimal impacts caused by human activities.

Vulnerability The tendency or likelihood for contaminants to reach a specified position in the groundwater system after introduction at some location above the uppermost aquifer. The vulnerability of a groundwater resource 
to contamination depends on its intrinsic susceptibility as well as the locations and types of sources of naturally occurring and anthropogenic contamination, relative location of wells, and the fate and transport of the contaminant(s).

Water-quality criteria Specific levels of water quality which, if reached, are expected to render a body of water unsuitable for its designated use. Commonly refers to water-quality criteria established by the U.S. Environmental Protection Agency. Water-quality criteria are based on specific levels of pollutants that would make the water harmful if used for drinking, swimming, farming, fish production, or industrial processes.

Water-quality guidelines Specific levels of water quality which, if reached, may adversely affect human health or aquatic life. These are nonenforceable guidelines issued by a governmental agency or other institution.
Water-quality standards State-adopted and U.S. Environmental Protection Agency-approved ambient standards for water bodies. Standards include the use of the water body and the waterquality criteria that must be met to protect the designated use or uses.

Watershed The portion of the surface of the Earth that contributes water to a stream through overland run-off, including tributaries and impoundments.

Water table The point below the land surface where groundwater is first encountered and below which the earth is saturated. Depth to the water table varies widely across the country.

Yield The mass of material or constituent transported by a river in a specified period of time divided by the drainage area of the river basin. 


\section{Abbreviations, Acronyms, and Units of Measure}

$\begin{array}{ll}\text { BMPs } & \text { Best Management Practices } \\ \text { CAFO } & \text { Concentrated animal feeding operation } \\ \text { HBSL } & \text { Health-Based Screening Level } \\ \mathrm{km} & \text { kilometer } \\ \mathrm{L} & \text { liter } \\ \mathrm{Ib} & \text { pound } \\ \mathrm{m} & \text { meter } \\ \mathrm{MCL} & \text { Maximum Contaminant Level } \\ \mathrm{mg} & \text { milligram } \\ \mathrm{mi} & \text { mile } \\ \mathrm{N} & \text { nitrogen } \\ \text { NAWQA } & \text { National Water-Quality Assessment Program (USGS) } \\ \text { SPARROW } & \text { SPAtially Referenced Regression On Watershed attributes } \\ \text { TMDLs } & \text { Total maximum daily loads } \\ \text { USDA } & \text { U.S. Department of Agriculture } \\ \text { USEPA } & \text { U.S. Environmental Protection Agency } \\ \text { USGS } & \text { U.S. Geological Survey } \\ \text { U.S. } & \text { United States }\end{array}$




\section{Acknowledgments}

Special thanks to the following individuals and organizations for their contributions:

NAWQA personnel in study areas across the Nation for their contributions of data and research results.

NAWQA's many partners in the governmental and non-governmental sectors who have helped guide scientific efforts and ensure that NAWQA information meets the needs of local, state, tribal, regional, and national stakeholders.

USGS reviewers:

- Brian G. Katz

- Keith W. Robinson

- Dennis A. Wentz

- Gary L. Rowe, Jr.

External reviewers:

- Susan Holdsworth, USEPA, Office of Wetlands, Oceans, and Watersheds

- Jane Houlihan, Environmental Working Group

- Denise Keehner, USEPA, Office of Wetlands, Oceans, and Watersheds

- Robert L. Kellogg, USDA, Natural Resources Conservation Service

- Jerrell L. Lemunyon, USDA, Natural Resources Conservation Service

- Anne S. Marsh, The Heinz Center

- Jan McGoldrick, PG Environmental, LLC

- Olga Naidenko, Environmental Working Group

- Roberta Parry, Office of Water

- Marc Ribaudo, USDA, Economic Research Service

- Steven H. Wolfe, Florida Department of Environmental Protection

Technical editor:

- Linda Rogers, USGS; Chester Zenone, Editorial Consultant

Technical Illustration:

- Yvonne Roque, USGS

Layout Production:

- Sharon Wahlstrom, USGS

Graphic Design:

- Bill Gibbs, USGS

Publishing support provided by the U.S. Geological Survey

Publishing Network, Sacramento and Tacoma Publishing Service Centers

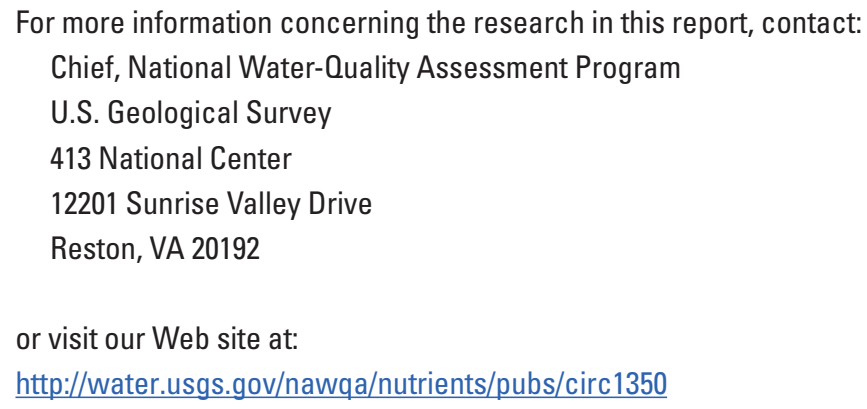


